\title{
Ethics by committee
}

Citation for published version (APA):

Jacobs, N. (2018). Ethics by committee: governing human experimentation in the Netherlands, 19452000. [Doctoral Thesis, Maastricht University]. Maastricht University. https://doi.org/10.26481/dis.20180620jn

Document status and date:

Published: 01/01/2018

DOI:

10.26481/dis.20180620jn

Document Version:

Publisher's PDF, also known as Version of record

\section{Please check the document version of this publication:}

- A submitted manuscript is the version of the article upon submission and before peer-review. There can be important differences between the submitted version and the official published version of record.

People interested in the research are advised to contact the author for the final version of the publication, or visit the DOI to the publisher's website.

- The final author version and the galley proof are versions of the publication after peer review.

- The final published version features the final layout of the paper including the volume, issue and page numbers.

Link to publication

\footnotetext{
General rights rights.

- You may freely distribute the URL identifying the publication in the public portal. please follow below link for the End User Agreement:

www.umlib.nl/taverne-license

Take down policy

If you believe that this document breaches copyright please contact us at:

repository@maastrichtuniversity.nl

providing details and we will investigate your claim.
}

Copyright and moral rights for the publications made accessible in the public portal are retained by the authors and/or other copyright owners and it is a condition of accessing publications that users recognise and abide by the legal requirements associated with these

- Users may download and print one copy of any publication from the public portal for the purpose of private study or research.

- You may not further distribute the material or use it for any profit-making activity or commercial gain

If the publication is distributed under the terms of Article $25 \mathrm{fa}$ of the Dutch Copyright Act, indicated by the "Taverne" license above, 


\section{ETHICS BY COMMITTEE}





\section{ETHICS BY COMMITTEE}

\section{Governing human experimentation in the Netherlands, 1945-200o}

\section{PROEFSCHRIFT}

ter verkrijging van

de graad van doctor aan de Universiteit Maastricht, op gezag van de Rector Magnificus, Prof dr. Rianne M. Letschert volgens het besluit van het College van Decanen, in het openbaar te verdedigen op woensdag 20 juni 2018 om 12.00 uur

door

NOORTJE JACOBS

Geboren op 20 februari 1987

te Gemert 


\section{Promotores}

Prof.dr F.G. Huisman

Prof.dr T.E. Swierstra

\section{Beoordelingscommissie}

Prof.dr E.S. Houwaart (voorzitter)

Prof.dr J.C. Kennedy (Universiteit Utrecht)

Dr. H. Oosterhuis

Dr. L. Stark (Vanderbilt University)

This research was funded by the PhDs in the Humanities Programme of the Netherlands Organisation for Scientific Research (NWO)

The printing was supported financially by Maastricht University and the Netherlands Graduate Research School of Science, Technology and Modern Culture (WTMC)

Printing: GVO Drukkers \& Vormgevers

ISBN: 978-94-6332-366-6

Cover illustration: Fransje Pansters, www.fransjepansters.com 
Voor papa en mama 



\section{- Contents •}

$\begin{array}{ll}\text { Acknowledgements } & \text { ix }\end{array}$

List of Abbreviations $\quad$ xi

Note on Translations $\quad$ xi

$\begin{array}{lr}\text { Introduction } & 1\end{array}$

\section{Part I: Internal Control}

Chapter 1 A moral obligation to medical progress 25

$\begin{array}{ll}\text { Chapter 2 } & \text { A moral need for epistemic filters } \\ \end{array}$

\section{Part II: External Control}

Chapter $3 \cdot$ Medical ethics in a modern society $\quad 97$

$\begin{array}{ll}\text { Chapter } 4 \cdot \text { Experimenting with human beings } & 129\end{array}$

\section{Part III: Expert Control}

$\begin{array}{ll}\text { Chapter } 5 \cdot \text { Public governance in a pluralist society } & 161\end{array}$

Chapter 6 The governing function of ethical experts 197

$\begin{array}{ll}\text { Conclusion } & 233\end{array}$

$\begin{array}{lr}\text { Sources and Literature } & 247\end{array}$

$\begin{array}{ll}\text { Dutch Summary } & 277\end{array}$

Valorisation Addendum $\quad 285$

$\begin{array}{lr}\text { Curriculum Vitae } & 289\end{array}$ 



\section{- Acknowledgements •}

The most rewarding aspect of writing a PhD-thesis, I have found, is the community of which you get to become a part. Even if writing the actual thesis was an at times solitary activity, I have had more support and encouragement in the past few years than I could have fathomed at the start of this project. My first thanks are therefore to my supervisors, Frank Huisman and Tsjalling Swierstra. Frank, even before I became one of your PhD-candidates, you have always stuck out your neck for my academic career. Your careful and at times challenging feedback on all the texts I have sent your way throughout the years, your unwavering belief in my abilities, and our long conversations about life in and outside of academia have been of enormous help to me. I hope we can continue these conversations in the years to come. Tsjalling, even though you were not my daily supervisor, your sharp questions and guidance in helping me think through my arguments sat in the back of my head each time I embarked on writing or revising another chapter. Thank you for all your help and for putting up with my long and often confusing explanations of what I try to do with my work.

I would also like to thank the director of the Utrecht Descartes Centre for the History and Philosophy of the Sciences and the Humanities, Bert Theunissen. Although I suspect he is not particularly fond of elaborate public praise, I could not have finished my thesis without his enduring support. Bert, thank you for all you have done for me in the past years. Thanks also to all the other people I met and learned from through the Descartes Centre. Steven van der Laan, Jesper Oldenburger, Ivan Flis, Fedde Benedictus, Rienk Vermij, Chaokang Tai, and Maaneli Derakhshani made Room 4.07 a joy to work in. Ivan, I think you read and commented on almost all of my writings. They are much better because of it. The many lunch and hallway conversations with Hieke Huistra, David Baneke, Daan Wegener, Guido Bacciagaluppi, and Toine Pieters also made this whole experience much more enjoyable. Hieke, I am only half joking when I say you are a great source of authority. 'What would Hieke do?' is a thought that has often crossed my mind in the past few years. I am indebted to all members of our medical history reading group, Floor Haalboom, Timo Bolt, Nele Beyens, Roland Bertens, Hieke Huistra, and Frank Huisman. Our dinners and conversations have literally provided much food for thought. Thanks also to the team of Isis Journal, and especially to Floris Cohen and Ad Maas, whose guidance and enthusiasm have made me a better historian of science. Pieter Huistra, in the last few months of writing my thesis I had the pleasure of simultaneously working with you on different project-a happy coincidence that has improved the quality of this PhD-thesis.

In Maastricht, I was lucky to teach classes a few years in a row with Geert Somsen, Raf de Bont, Hans Schouwenburg, Simone Schleper, and Thomas Mougey. Our weekly meetings on how to teach history of science taught me much and made the visits to Maastricht something to look forward to. The same goes for Bart Zwegers, Constance Sommerey, Koen Beumer, and Ties van de Werff. My yearly evaluation moments with Kiran Patel and the Graduate School support from Alexandra Supper were valuable in making me think about what type of academic career I want to pursue, and the great questions from Ernst Homburg, who was kind enough to attend two of my presentations, made me reconsider some important elements of my $\mathrm{PhD}$-thesis. 
My work very much benefited from the lively history of science and history of medicine community in the Netherlands. Mart van Lieburg was kind enough to invite me multiple times to the Trefpunt Medische Geschiedenis on Urk and to introduce me to a number of great enthusiasts for the Dutch history of medicine. The biennial Woudschoten conferences were a great place to meet with historians of science and medicine from Belgium and the Netherlands, as were the international conferences organized by the History of Science Society and European Association for the History of Medicine and Health. The conversations that I had at these gatherings with Frans van Lunteren, Heiner Fangerau, Kaat Wils, and Joris Vandendriessche have been greatly important to me. The same goes, if not more, for the biennial $\mathrm{PhD}$-conferences at Rolduc and the Glind, and the cosy dinners and drinks with our Shells and Pebbles editorial team. Jorrit Smit, I thank you in particular for the thoughtful comments you gave me on the introduction of my PhD-thesis. Jeroen Bouterse, I thank you for your thoughtful comments in general. As a member of the Graduate School WTMC I had the pleasure to attend four workshops and two summer schools with inspiring speakers, five supportive coordinators, and numerous PhD-students who were working on great projects and were a lot of fun to be around. I feel lucky I got to be a part of this community, in addition to the more informal Dutch community of PhD-candidates working on the history of science. Many of them have already been mentioned here, but I would fall short if I would not also thank Ingrid Kloosterman, Abel Streefland, Ruben Verwaal, Friso Hoeneveld, Sebastiaan Broere, and Didi van Trijp. Listening to hearing them talk about their work has taught me much about my own.

In the beginning of my PhD-trajectory I was lucky enough to travel to Manchester University for a two-week visit, during which Duncan Wilson took the time to talk with me for hours and hours about the history of bioethics, and the late John Pickstone took me to pubs and for dinners and gave me a great collection of books. I still think fondly of all those conversations and am very proud that Duncan will join me for a workshop organized in honour of my PhD-thesis this June. The same goes for Laura Stark and Nancy Tomes, whom I both greatly admire and who have been kind enough to take up a seat in my defence committee. Thanks to all members of my defence and assessment committees for taking the time to read my work.

Finally, I would like to thank all my friends and family for their love and support. I would run out of pages if I would thank you all personally, although you most certainly deserve it, so I will have to spend a great many more dinners, coffees, and drinks to make it all up to you. Yet, I want to thank Fransje Pansters for her willingness to design the cover of this PhD-thesis, Daphne for reading one of my more technical articles (I still cannot believe you did that), and the Boekenclub for always being there. I dedicate this thesis to my parents. Papa, you are the best reader that any author could hope for, and more importantly, the best person to call at the end of each day when I want to talk about everything and nothing at the same time. Mama, you are the most loving and supportive parent that anyone could wish for. I hope I will be able to be for Hanne what you are to me. Pim, as I am writing this you are preparing me dinner, as you have done for almost every day that I was working on my thesis and getting home late. I can only hope that I get to have countless more morning coffees and evening whiskys with you. You are the best person to never read my work. 


\section{- List of Abbreviations •}

\begin{tabular}{|c|c|}
\hline AVS & $\begin{array}{l}\text { Anti-Vivisectie Stichting } \\
\text { Translation: Antivivisection Foundation }\end{array}$ \\
\hline CCMO & $\begin{array}{l}\text { Centrale Commissie Mensgebonden Onderzoek } \\
\text { Translation: Central Commission on Research Involving Human Subjects }\end{array}$ \\
\hline CME & $\begin{array}{l}\text { Commissie Medische Ethiek } \\
\text { Translation: Committee Medical Ethics }\end{array}$ \\
\hline CMR & Committee for Medical Research \\
\hline FDA & Food and Drug Administration \\
\hline FUNGO & $\begin{array}{l}\text { Stichting voor Fundamenteel Geneeskundig Onderzoek } \\
\text { Translation: Foundation for Fundamental Medical Research }\end{array}$ \\
\hline IRB & Institutional Review Board \\
\hline KEMO & $\begin{array}{l}\text { Kerncommissie Ethiek Medisch Onderzoek } \\
\text { Translation: Core Committee Ethics Medical Research }\end{array}$ \\
\hline KNAW & $\begin{array}{l}\text { Koninklijke Nederlandse Academie van Wetenschappen } \\
\text { Translation: Royal Dutch Academy of the Sciences }\end{array}$ \\
\hline (K)NMG & $\begin{array}{l}\text { (Koninklijke) Nederlandse Maatschappij ter Bevordering van de Geneeskunst } \\
\text { Translation: (Royal) Dutch Society for the Advancement of Medicine }\end{array}$ \\
\hline METC & $\begin{array}{l}\text { Medisch Ethische Toetsingscommissie } \\
\text { Translation: Medical Ethics Review Committee }\end{array}$ \\
\hline NBBV & $\begin{array}{l}\text { Nederlandse Bond ter Bestrijding der Vivisectie } \\
\text { Translation: Dutch Association for Combatting Vivisection }\end{array}$ \\
\hline NHS & National Health Service \\
\hline $\mathrm{NIH}$ & National Institutes of Health \\
\hline NWO & $\begin{array}{l}\text { Nederlandse Organisatie voor Wetenschappelijk Onderzoek } \\
\text { Translation: Netherlands Organisation for Scientific Research }\end{array}$ \\
\hline PHS & Public Health Service \\
\hline RCT & Randomized Controlled Trial \\
\hline TNO & $\begin{array}{l}\text { Nederlandse Organisatie voor Toegepast-Natuurwetenschappelijk Onderzoek } \\
\text { Translation: Netherlands Organisation for Applied Scientific Research }\end{array}$ \\
\hline WHO & World Health Organisation \\
\hline WMA & World Medical Association \\
\hline WMO & $\begin{array}{l}\text { Wet Medisch-Wetenschappelijk Onderzoek met Mensen } \\
\text { Translation: Medical Research Involving Human Subjects Act }\end{array}$ \\
\hline
\end{tabular}

Unless stated otherwise, all translations are my own, including those used in quotations. Due to space limitations, the original Dutch texts have not been provided. For the interested reader, original quotations are available upon request. 

And we all know the saying which is true as well as witty

That a camel is a horse that was designed by a committee

ALLAN SHERMAN $\cdot$ PETER AND THE COMMISSAR $\cdot 1964$ 



\section{- Introduction •}

On February 8, 1980, a short biting letter was published in the Dutch medical weekly Medisch Contact. The epistle, written by a Leiden surgeon, contained over little more than 200 words and opened with an ominous warning:

After years of silence about Him, there he is, God, the Father, with his watchful eye also in the Academic Hospital of Leiden. Finally in the hospital 'for advanced medicine' of the Praesidium Libertatis, while the confessional universities are arduously trying to get rid of Him. His name: CME. ${ }^{1}$

Leiden, the oldest university of the Netherlands (1575), had adopted the motto 'Bastion of Liberty'-Libertatis praesidium-in the late nineteenth century to advertise its status as an independent university where scientific study could progress free from ideological and religious influences. ${ }^{2}$ Yet, by 1980 , Leiden had also become the first Dutch university to allow a mysterious new authority passage into its medical faculty and academic hospital. Who was this 'God, the Father', whose watchful eye now oversaw the activities in the Leiden hospital 'for advanced medicine'? 'He' was the Committee Medical Ethics, installed in 1976 to advise on various issues of ethical concern, but mostly on medical experiments with human beings. It was the first committee of its kind in the Netherlands, but would soon be followed by the instalment of comparable boards throughout the country. By the close of the twentieth century, dozens of watchful eyes were active in Dutch hospitals, general practice clinics, and private research institutes, to oversee the conduct of medical research studies on human subjects. They followed a practice that had taken hold worldwide in the second half of the twentieth century in the governance of human experimentation, and that was historically without precedent. This was the practice of ethics by committee.

Today, when a medical researcher wants to determine the efficacy of a new medicinal product or surgical procedure, she first has to pay an ethics review board like the Leiden CME a visit. Although this visit is usually digital rather than physical, the idea is that the researcher goes and requests her local research ethics committee, as these boards are generically referred to, for official permission to execute the protocol she has designed for a research study involving human subjects. Whether the researcher legally has to await the verdict of this review board depends on the country in which she is located. Nonetheless, in most countries around the world, it has become standard practice not to start a research study on human subjects before a research ethics committee has granted its permission. Plus, once our researcher would try to publish the results of the study, she would be hard pressed to find a respectable journal willing to print her paper without proof that an ethics board had first authorized the ex-

\footnotetext{
${ }^{1}$ M.A. van Dongen, 'Experimenten op Mensen', in Medisch Contact Vol. 35 (1980), p. 170.

${ }^{2}$ For a history of Leiden University, see: Willem Otterspeer, The Bastion of Liberty. Leiden University Today and Yesterday (Leiden: Leiden University Press, 2008).
} 
periment. The same goes for grants from most funding agencies and, depending on the type of research study, for market approval for medicinal products by regulatory agencies like the United States Food and Drug Administration and European Medicines Agency as well. This is true not just for biomedical research but also for behavioural research, and is becoming increasingly common for the social sciences and the humanities. Academics conducting studies involving oral history in the United States, for instance, will be familiar with the routine to first acquire permission for any interviews from an Institutional Review Board-the American version of a research ethics committee. Committees like the Leiden CME, in short, have come to operate as $o b$ ligatory passage points in the twenty-first century infrastructure of science: locus of control that scientists hoping to conduct research involving humans first successfully have to pass through before they can participate in its practice. ${ }^{3}$

Research ethics committees are nowadays such firmly fixed bodies in the oversight of human research studies that it is easy to forget how novel they really are. After all, the scientific use of living human bodies is an age-old practice, going back in recorded history to at least 280 BCE, when Greek physicians Herophilus and Erasistratus were granted permission to vivisect a condemned criminal to observe his inner workings. ${ }^{4}$ From about the seventeenth century onwards, human experiments in science became increasingly popular, and with the rise of academic hospitals and laboratory medicine in the nineteenth century, the practice positively flourished. 5 What is more, the use of humans in experiments was recognized already in the early modern period to constitute a subject of ethical concern and, since the mid-nineteenth century, human experimentation in medicine regularly resulted in social protests and informal moral traditions to seek patients' consent. ${ }^{6}$ Yet, the actual decision to go forward with a human experiment, also when it was expected to have few benefits for the subjects involved, remained the preserve of individual researchers until well into the twentieth century. Until at least the 1960s, hardly any formal checks and balances existed in most countries around the world for the communal oversight of human research.7

\footnotetext{
${ }^{3}$ For 'obligatory passage points', see: M. Callon, 'Elements of a sociology of translation: Domestication of the Scallops and the Fishermen of St. Brieuc Bay', in J. Law (ed.), Power, Action and Belief. A New Sociology of Knowledge (London: Routledge, 1986), pp. 196-223.

${ }^{4}$ See: Anita Guerrini, Experimenting with Humans and Animals. From Galen to Animal Rights (Baltimore: The John Hopkins University Press, 2003).

${ }^{5}$ Charles E. Rosenberg, The Care of Strangers. The Rise of America's Hospital System (New York: Basic Books, 1987); John Harley Warner, The Therapeutic Perspective. Medical Practice, Knowledge, and Identity in America, 1820-1885 (Princeton: Princeton University Press, 1997); Andrew R. Cunningham \& Perry Williams (eds.), The Laboratory Revolution in Medicine (Cambridge: Cambridge University Press, 1992).

${ }^{6}$ Erika Dyck \& Larry Stewart (eds.), The Uses of Humans in Experiment. Perspectives from the $17^{\text {th }}$ to the $20^{\text {th }}$ Century (Leiden: Brill, 2016); Susan E. Lederer, Subjected to Science. Human Experimentation in America Before the Second World War (Baltimore: The John Hopkins University Press, 1995); Martin Pernick, A Calculus of Suffering. Pain, Professionalism, and Anesthesia in Nineteenth Century America (New York: Columbia University Press, 1985); Sydney Halpern, Lesser Harms. The Morality of Risk in Medical Research (Chicago: The University of Chicago Press, 2004); Ronald L. Numbers, 'William Beaumont and the Ethics of Human Experimentation', in Journal of the History of Biology Vol. 12 (1979), pp. 113-135.

${ }^{7}$ One country which did have regulations for the conduct of human experimentation before World War II was Germany. See: Barbara Elkeles, 'The German Debate on Human Experimentation between 1880 and 1914', in Volker Roelcke \& Giovanni Maio (eds.), Twentieth Century Ethics of Human Subjects Research. Historical Perspectives on Values, Practices, and Regulations (Stuttgart: Franz Steiner Ver-
} 
Small wonder, then, that the Leiden surgeon in 1980 invoked the grandeur of 'God, the Father' in his aggrieved letter to Medisch Contact. Suddenly, within a timespan of merely a few decades, a practice that had existed for centuries was brought under the control of official review boards that were to decide if human research studies could proceed. In the Netherlands, dozens of these committees sprang up in the 1980s, and in 1998, Dutch parliament passed the Medical Research Involving Human Subjects Act (WMO), regulating that no medical research studies on humans can take place on Dutch soil without prior permission of a formally recognized Medical Ethics Review Committee (METC) - the Dutch term for research ethics committees. Furthermore, if certain types of studies are at stake, like cell or gene therapy, research with gametes or embryos, or non-therapeutic intervention studies with legally incapacitated individuals, only one Central Committee may give its permission. ${ }^{8}$

In the current Dutch research landscape, in other words, research ethics committees have acquired the hard power of the state to influence scientific research. ${ }^{9}$ They have, as historian of science Laura Stark points out, come to function as "declarative bodies" in science: like a priest who declares the groom and bride to be husband and wife, research ethics committees today are legally empowered "to turn a hypothetical situation (this study may be acceptable) into shared reality (this study is acceptable)", and thus bless certain ways of probing into the world and not others. "In so doing", Stark points out, "they change what is knowable". ${ }^{10}$ Only few control mechanisms in the present-day governance of science can lay claim to this sort of power. But why did research ethics committees spring up in the 1960s and 1970s? And what type of control mechanism were they to meant to be in the governance of human experiments? This PhD-thesis seeks to answer these questions for the Netherlands, with the goal to gain a better understanding of the changing role and position of medicine and medical science in Dutch society in the second half of the twentieth century.

In this period, the professional role of physicians and medical researchers changed radically, both in the Netherlands and internationally. ${ }^{11}$ Whereas they had up until the 1950 enjoyed a high degree of autonomy in deciding what type of interventions were permitted in their research and practice, they were increasingly called upon in the years thereafter to justify and request permission for their conduct in formally arranged settings-such as the research ethics committee. This change in governance was certainly not limited to the conduct of human experiments in medicine, or even

\footnotetext{
lag, 2004), pp. 19-33; Daniel S. Nadav, 'The "Death Dance of Lübeck": Julius Moses and the German Guidelines for Human Experimentation, 1930', in Ibid., pp. 129-135.

${ }^{8}$ Wet van 26 februari 1998, houdende regelen inzake medisch-wetenschappelijk onderzoek met mensen (Wet medisch-wetenschappelijk onderzoek met mensen).

${ }^{9}$ The notion of hard power is typically understood as the power of a government to coerce individuals and institutions to behave in a certain way. It is developed by political scientist Joseph Nye in his work on soft power: the ability to persuade individuals and institutions to behave a certain way. See: Joseph S. Nye, Jr., 'Soft Power', in Foreign Policy No. 80, Twentieth Anniversary (Autumn, 1990), pp. 159171; Joseph S. Nye, Jr., Soft Power. The Means to Success in World Politics (New York: 2004).

${ }^{10}$ L. Stark, Behind Closed Doors. IRBs and the Making of Ethical Research (Chicago, 2012), p. 5.

${ }^{11}$ See: Anne Hardy \& E.M. Tansey, 'Medical enterprise and global response, 1945-2000', in W.F. Bynum et al. (eds.), The Western Medical Tradition. 1800-2000 (Cambridge: Cambridge University Press, 2006), pp. 405-534; James Le Fanu, The Rise and Fall of Modern Medicine (New York: Basic Books, 2012); John Pickstone, 'Production, Community and Consumption. The Political Economy of Twentieth-Century Medicine', in John V. Pickstone \& Roger Cooter (eds.), Medicine in the Twentieth Century (Amsterdam: Harwood Academic Press, 2000), pp. 1-19.
} 
to medical science alone. In a wide variety of professional domains, the latter half of the twentieth century saw the rise of what anthropologists have termed "a culture of accountability", i.e., the realization of oversight regimes designed to subject the performance of professionals to regular inspection and to oblige them to account for their activities in organized settings. ${ }^{12}$ Yet, in the governance of human experimentation, this shift is often argued to have been especially drastic and disruptive-an aberration from the old status quo that was historically without precedent.

And thus, how could it be, the Leiden surgeon charged in 1980, that in times when even the Royal Dutch Association for the Advancement of Medicine admitted to be no longer capable of "adopting in writing generally accepted rules of conduct", a small group of reviewers could be anointed to tell right from wrong within the walls of an academic hospital? Why was it that in an age in which traditional moral authorities were withering away, 'a new God' could be inaugurated to watch over the conduct of medical researchers? And on what grounds exactly were reviewers deemed eligible to take part in the meetings of a research ethics committee? "Are we jubilant when first a philosopher is added to the little club of moderators?”, the surgeon snarled in $\mathrm{Me}$ disch Contact, "Are we then later put at ease when the philosopher turns out to be an ethicist?" Really, what sort of expertise did these scholars possess that granted them a seat at a committee table talking about medical ethics? This PhD-thesis answers the Leiden surgeon, by tracing how research ethics committees emerged as watchful eyes in the Dutch oversight of medical experiments with humans in the second half of the twentieth century, and by exploring what type of control mechanism they became in the public governance of a historically controversial scientific practice.

\section{The importance of careful historical research}

Despite the dominance of research ethics committees in the contemporary biomedical research landscape, their study has not been very popular among medical historians. In a 2009 issue of Medical History, in fact, this lack of scholarship was noted by the British sociologist Adam Hedgecoe, who remarked that he hardly had been able to find any serious historical studies on the origins of research ethics committees that he could use for his work. ${ }^{13}$ As a sociologist, Hedgecoe investigates the present-day practice of ethics review in human research governance: e.g. how committees assess publications, how researchers negotiate trust with reviewers, and how ethics boards function differently depending on their national context. ${ }^{14}$ Still, what he found wanting in

\footnotetext{
${ }^{12}$ Marilyn Strathern (eds.), Audit Cultures. Anthropological studies in accountability, ethics and the academy (London: Routledge, 2000); Michael Powers, The Audit Society. Rituals of Verification (Oxford: Oxford University Press, 1997); Cris Shore \& Susan Wright, 'Governing by numbers. Audit culture, rankings and the new world order', in Social Anthropology Vol. 23 (2015), pp. 22-28.

${ }^{13}$ Adam Hedgecoe, "“A form of Practical Machinery". The Origins of Research Ethics Committees in the UK, 1967-1972', in Medical History Vol. 53 (2009), pp. 331-350, p. 331.

${ }^{14}$ See: A. Hedgecoe, 'Reputational Risk. Academic Freedom and Research Ethics Review', in Sociology (2015), http://dx.doi.org/10.1177/0038038515590756. A. Hedgecoe, 'Trust and Regulatory Organizations. The Role of Local Knowledge and Facework in Research Ethics Review', in Social Studies of Science Vol. 44 (2012), pp. 59-81; A. Hedgecoe, 'Research Ethics Review and the Sociological Research Relationship', in Sociology Vol. 42 (2008), pp. 873-886; A. Hedgecoe, F. Carvalho, P. Lobmayer \& F. Raka, 'Research Ethics Committees in Europe. Implementing the Directive, Respecting Diversity’, in Journal of Medical Ethics Vol. 32 (2006), pp. 483-486.
} 
2009 was "a full explanation for how these bodies developed the way they did"; historical context for why they arose in the 1960s and 1970s. In Medical History, therefore, the sociologist called on historians to carry out a "nuanced, empirically detailed analysis" of the origins and development of research ethics committees. ${ }^{15}$

Since Hedgecoe's 2009 article, two monographs have appeared about the history of United States research ethics committees-called Institutional Review Boards (IRBs). One is by Stark, who traces the invention of the practice of 'ethics by committee' in medical research to the boardrooms of the National Institutes of Health in the early 1950s. ${ }^{16}$ The other is by historian Zachary Schrag, who investigates why federal regulations originally designed for biomedical and behavioural research came to regulate research in the social sciences and humanities as well toward the end of the twentieth century. ${ }^{17}$ Combined, these two books offer detailed insights into the origins and development of research ethics committees in the United States in the second half of the twentieth century. For most other national contexts, however, Hedgecoe's words still apply. For the Netherlands, only a research article by social scientist Patricia Jaspers exists, in addition to a few witness accounts printed in the Festschrifts of those who stood at the cradle of the first Dutch research ethics committees. ${ }^{18}$

Of course, a gap in historical literature is not a problem in and of itself. Nor does a historical perspective automatically help to understand the contemporary practice of ethics by committee. Rather, nuanced historical research is needed, because history itself fulfils a central role in the present-day governance of human experimentation. Take the current Oxford Textbook of Clinical Research Ethics, for instance, published in 2008 to provide 'useful educational materials' for researchers and members of ethics committees. ${ }^{19}$ Of its impressive 73 contributions, the first ten detail case histories of human experimentation. These range from the famous yellow fever experiments by the U.S. army in Cuba in the early twentieth century (when the first written consent forms were supposedly used) to the gruesome experiments on prisoners in the Japanese and Nazi concentration camps during World War II; and from the first randomized controlled trial in 1948 to the exposé of the infamous Tuskegee syphilis study in 1972, when it was revealed that the U.S. Public Health Service had been monitoring the progression of untreated syphilis in impoverished Afro-American men since 1932, even though penicillin had been available as an effective cure for the disease since the 1940 s and other remedies had commonly been used before. ${ }^{20}$ History, in this context,

\footnotetext{
${ }^{15}$ Hedgecoe, “"A form of Practical Machinery”, p. 332.

${ }^{16}$ Stark, Behind Closed Doors.

${ }^{17}$ Zachary M. Schrag, Ethical Imperialism. Institutional Review Boards and the Social Sciences, $1965-$ 2009 (Baltimore: John Hopkins University Press, 2010).

${ }^{18}$ P. Jaspers, 'Controversial Issues in the History of Dutch Research Ethics Governance', in The Journal of Policy History Vol. 23 (2011), pp. 74- 93; F.A. Wolff (ed.), Geneeskunde en Ethiek in Harmonie. Liber Amicorum voor Prof.Dr E.L. Noach bij diens $80^{\text {ste }}$ verjaardag op 21 november 2001 ('sGravenhage: Pasmans Offset Drukkerij BV, 2001); D.P. Engberts, Y.M. Reidsma \& A.R. Wintzen (eds.), Dilemma's getoetst. Liber Amicorum voor prof.dr. H.M. Dupuis en prof.dr. P.Vermeij (Leiden: UFB Universiteit Leiden, 2003).

${ }^{19}$ Ezekiel J. Emanuel et al. (eds.), The Oxford Textbook of Clinical Research Ethics (Oxford: Oxford University Press, 2008).

${ }^{20}$ The 600 men participating in the study -399 of whom had contracted syphilis before its start - were never told they formed an object of study. Instead, the PHS had informed them they had been chosen to receive free health care from the government. See: James Jones, Bad Blood. The Tuskegee Syphilis
} 
is used to teach by example: awareness of key moments in the history of human experimentation is meant to instil researchers and reviewers with a sense of right and wrong about the practice, in the hope of preventing unethical behaviour in the future. The past, in this sense, is used to encircle the present-day governance of human research studies with a number of moral signposts that are to nudge researchers and reviewers in certain directions and to stay clear of others. ${ }^{21}$

In a similar manner, history is also used to justify the existence of strict oversight mechanisms for human experimentation. Against those who complain about the supposedly excessive bureaucracy that ethics review would bring with it (of which there are many), defenders of the status quo can charge that at some point no research ethics committees existed, and look what happened then: the Nazi atrocities happened, Tuskegee happened, not to mention the numerous dubious studies that were regularly conducted on institutionalized groups, such as inmates or psychiatric patients, before the current review system was put in place. History, here, offers a rationalization for the often lamented fact that human experimentation is now surrounded with an elaborate set of formal checks and balances. These would be necessary, because history has proven that researchers just cannot be left to their own devices.

Thirdly, and most importantly in the context of this PhD-thesis, history is regularly brought to bear to frame the political function that research ethics committees have come to fulfil in the public oversight of science. Present-day textbooks and policy reports on research ethics governance, for instance, often begin with a backstory about why research ethics committees emerged in the 1960 s and 1970s, that typically claims that their rise was part of a larger cultural trend in the second half of the twentieth century to bring the professional conduct of medical researchers and practitioners under much needed public control. Thus, in relevant Dutch policy reports it has become commonplace since the 1990 s to narrate how "since the end of the sixties the attention for the social relevance of scientific research increased significantly", resulting in "a more critical attitude with regard to the way in which research data are obtained and the costs that are involved". "In essence", the next lines then read, "this development is a part of society-wide discernible emancipation trend. [...] The realization has grown that dependence obstructs a vocal attitude". ${ }^{22}$ Review committees, the implication is, arose as part of an emancipatory movement to give research subjects a bigger voice in decision-making about human research studies and to enable them to give direction to their own lives. Put this way, history gives body to the idea that research ethics committees first arose to assert democratic control over human experimentation and still exist to hold researchers publicly accountable.

The fact that history fulfils such an important role in the contemporary governance of human experimentation is a crucial reason why histories of this practice need to be subjected to careful scrutiny. After all, depending on the histories that are provided, different signposts, justifications, and frames will be offered for the present-day practice of ethics by committee. For this reason, historians are often wary when they en-

Experiment (New York: Free Press, 1981); Susan M. Reverby, Examining Tuskegee. The Infamous Syphilis Study and its Legacy (Chapel Hill: The University of North Carolina Press, 2009).

${ }^{21}$ The notion of signposts is derived from: Thomas F. Gieryn, Cultural Boundaries of Science. Credibility on the line (London: The University of Chicago Press, 1999).

${ }^{22}$ Tweede Kamer der Staten-Generaal 1991-1992, kamerstuknummer 22588, nr. 3, p. 2. 
counter historical narratives in textbooks and policy reports in which the past offers a neat frame of reference for the correct interpretation of, in this case, the governing role of research ethics committees. As Thomas Kuhn famously argues in The Structure of Scientific Revolutions, history in textbooks functions to initiate students into the paradigm for which that textbook is a pedagogical vehicle, and thus primarily serves to support that paradigm. ${ }^{23}$ According to Patricia Jaspers, the same logic holds true for Dutch policy reports on the regulation of human research studies, which tend to attribute an inevitable historical logic to the rise of research ethics committees in the Netherlands and ignore that "things could have been otherwise". While Jaspers does not use the term Whig history, the implication is clear: historical events are explained in such a way that they "seem to form a progressive path to the future", which is not coincidently the regulatory framework for human experimentation defended in these policy reports. ${ }^{24}$ History tends to be written backwards in such publications, in short, to present the policies they favour as the only logical outcome of past events. If that holds true, then careful historical research is itself an important check on the current system of research ethics governance to ensure that certain historical events and their political implications are not misunderstood-or, worse, misused by calculating political actors to push through their desired policy measures.

\section{Histories of 'outsider' versus 'insider' control}

In her article, Jaspers stresses the need for "a more balanced history of ethics governance", since "a narrow historical view might prohibit a thorough understanding of current ethical review practice". She therefore focuses on controversies in Dutch policy debates about the governance of human experimentation in the second half of the twentieth century, to make clear that the outcome of these debates was not inevitable. Careful historical analysis, Jaspers argues, proves that other choices could have been made and recovers paths not taken, which may offer valuable input for current policy debates on human experimentation. Still, despite this emphasis on historical contingency, her narrative does not deviate substantially from those offered in most Dutch policy documents to explain why research ethics committees first arose in the 1970 s in the Netherlands-Jaspers similarly argues that their rise should be understood "as part of this effort to break the monopoly of doctors on medical decisions". Although Dutch physicians had traditionally enjoyed much professional autonomy, the narrative goes, they lost the "unquestioned authority that had allowed them to make all the decisions about medical research and practice" in the 1960 s due to unrest over practices like abortion and euthanasia, and new medical technologies. Hence, by the early 1970s, "it was no longer assumed that physicians in science always do good. No, the professional community and lay persons should judge about that”. ${ }^{25}$

\footnotetext{
${ }^{23}$ Thomas S. Kuhn, The Structure of Scientific Revolutions (4th ed.) (Chicago: University of Chicago Press, 1962/2012), p.137. See also: Marga Vicedo, 'Introduction: The Secret Lives of Textbooks', in Isis Vol. 103 (2012), pp. 83-87; Kathryn M. Olesko, 'Science Pedagogy as a Category of Historical Analysis: Past, Present, and Future', in Science \& Education Vol. 15 (2006), pp. 863-880.

${ }^{24}$ Jaspers, 'Controversial Issues', p. 75.

${ }^{25}$ The quotes in this paragraph are from: Ibid., pp. 79-80. The last quote is a translation of Jaspers from a lecture given by the first chairman of the Leiden CME in 1999: E.L. Noach, "Verschuivende normen in de Medische Ethiek", Lecture HOVO Courses 1989-99, University of Leiden, p. 3.
} 
This historical frame of growing outsider involvement with the practice of medicine in the 1960 s and 1970 s has for a long time been popular to explain the rise of research ethics committees internationally, most notably the United States. Yet it is also a narrative structure which has been subject to growing criticism in the last fifteen years or so, for the same reason why Jaspers is critical of the use of history in policy: it would read history backwards in an attempt to legitimize the current position of another form of external involvement with the practice of medicine, i.e., the field of bioethics. Historians of bioethics often claim that the installation of research ethics committees in many countries during the 1960 s and 1970 s was one of the first material effects of a broad social movement that emerged in the second half of the twentieth century in response to public concerns over the unchecked powers of physicians and researchers over patients and research subjects, and that would coalesce in the 1960 s as this new field of academic reflection and social action. In his 1991 classic Strangers at the Bedside, for instance, historian David Rothman outlines how the traditional authority of the physician at the bedside was replaced during this decade by formal mechanisms of collective decision-making due to a widespread loss of trust in the self-regulatory capacities of the American medical profession. After the mid-1960s, in reaction to a number of exposés of unethical human experiments, an array of "medical outsiders" joined forces to bring medical research and practice under public control. After all, "when one could no longer assume that the physician shared the same set of values as the patient, it seemed vital to devise and implement new mechanisms, preferably formal or even rigid, to further patients' particular wishes". ${ }^{26}$ The first of these new mechanisms "was an entirely new system of governance for human experimentation": i.e. federal regulations requiring the practice of ethics by committee. ${ }^{27}$

Others, such as bioethicist and historian of medical ethics Robert Baker, similarly claim that the field emerged in the United States as a result of a laissez-faire attitude towards ethical issues in the ranks of the American medical profession in this period, particularly in the oversight of human experimentation. In effect, when new medical technologies and human research scandals confronted the wider American public in the 1960 s and 1970s, this "vacuum of authoritative moral leadership created a need for action in the public sphere". ${ }^{28}$ And thus the field of bioethics emerged as an alternative voice of moral authority "to meet this need, to fill that space left empty by organized medicine". ${ }^{29}$ Also ethicist Albert Jonsen, one of the founding fathers of the American bioethics movement, argues in his book The Birth of Bioethics that the field emerged as part of the civil rights movements of the 1960s and 1970s to rally against traditional authorities and power relations..$^{30}$ Medicine had come to be considered an institute of social control, with medical ethics a tool to privilege the interests of an

\footnotetext{
${ }^{26}$ David J. Rothman, Strangers at the Bedside. A History of How Law and Bioethics Transformed Medical Decision Making ( $3^{\text {rd }}$ ed.) (New Brunswick: AldineTransaction, 1991/2003), p. 11.

${ }^{27}$ Ibid., p. 10.

${ }^{28}$ Robert Baker, Before Bioethics. A History of American Medical Ethics from the Colonial Period to the Bioethics Revolution (Oxford: Oxford University Press, 2013), pp. 316-317.

${ }^{29}$ Ibid., p. 317.

${ }^{30}$ Albert R. Jonsen, The Birth of Bioethics (Oxford: Oxford University Press, 1998). See also: Peter Singer, 'Introduction', in Peter Singer (ed.), Applied Ethics (Oxford: Oxford University Press, 1986), pp. 1-9; Robert Baker, 'From Metaethicist to Bioethicist', in Cambridge Quarterly of Health Ethics Vol. 11 (2002), pp. 369-379.
} 
elite social class. Hence, the set-up of a nationwide IRB-system in the early 1970 s was a historic moment for the American bioethics field, as it meant a "transformation of the debate on the ethics of experimentation from a private argument within the world of medicine into broad, public discourse". ${ }^{11}$ After all, in a democratic society, even (or especially) medical ethics could be nothing else than a sub-domain of a nation's moral code that was accessible to all citizens. As the ethicist Robert Veatch puts it in his own participatory account of 'the birth of bioethics' in the United States:

I suddenly saw that explicitly in the text of the [Hippocratic] Oath would-be physicians pledged they would not reveal the precepts of the profession to anyone outside the group. [...] Nothing could be in greater conflict with the ways of knowing morality in the secular world where reason, empirical observation, or metaphorical social contract involving all reasonable people provided a basis for knowing the moral norms". ${ }^{2}$

Still, despite its evident popularity, this historical frame that bioethics and research ethics committees emerged as "part of this effort to break the monopoly of doctors on medical decisions" has received a fair amount of scholarly criticism in the last fifteen years or so. Already in 1991, sociologist Charles Bosk remarked somewhat sceptically in review of Strangers at the Bedside that "there is reason to believe that the changes that have taken place have done more to protect hospitals from liability than to actually change practice". ${ }^{33}$ Likewise, in her 2000 book Bioethics in America, historian Tina Stevens claims that the field did not win institutional legitimacy because it gave outsiders a mouthpiece, but "because it had proved far less threatening to existing social arrangements than the changes demanded by more radical, and more popular, social critics of the sixties". 34 Putting forward a somewhat different argument, sociologist John Evans suggests in his 2012 book The History and Future of Bioethics that the field flourished in the late twentieth century because it "met the needs of the bureaucratic state" in a secularizing political climate: i.e. instead of traditionally thick approaches to morality in theology, bioethics offered thin principles of morality (autonomy, beneficence, justice) that could easily be translated into liberal policies and regulations focused on patients' rights. ${ }^{35}$ In various reviews of books of Rothman and Baker, historian Roger Cooter even charges that "bioethics has a history of opportunism" because it served to secure the professional interests of "clapped-out philosophy departments" in the 1970 s. ${ }^{36}$ Public concerns over medicine became a timely source

\footnotetext{
${ }^{31}$ Jonsen, The Birth of Bioethics, p. 157.

${ }^{32}$ See also: Robert M. Veatch, 'The Birth of Bioethics; Autobiographical Reflections of a Patient Person', in Cambridge Quarterly of Health Ethics Vol. 11 (2002), pp. 344-352, p. 344. See also: Stephen Toulmin, 'How Medicine Saved the Life of Ethics', in Perspectives in Biology and Medicine Vol. 25 (1982), pp. 726-750.

${ }^{33}$ Review by Charles L. Bosk in Contemporary Sociology Vol. 20 (1991), pp. 831-833, p. 832.

${ }^{34}$ M.L.T. Stevens, Bioethics in America: Origins and Cultural Politics (Baltimore: John Hopkins University Press, 2000), p. x.

${ }^{35}$ John H. Evans, The History and Future of Bioethics. A Sociological Review (Oxford: Oxford University Press, 2012), p. 75. See also: John H. Evans, 'A Sociological Account of the Growth of Principalism', in Hastings Center Report Vol. 30 (2000), p. 31-38.

${ }^{36}$ Roger Cooter, 'Inside the Whale: Bioethics in History and Discourse', in Social History of Medicine Vol. 23 (2010), pp. 662-673, p. 665, p. 662. See also: Roger Cooter, 'The Resistible Rise of Medical
} 
of funding for struggling humanities scholars, who willingly helped to legitimize medical research and practice by protecting it from social critiques that reached beyond the importance of informed consent in medical decision-making.

In her 2012 book Behind Closed Doors, Stark applies this counter-narrative to the emergence of Institutional Review Boards as well. The model of group review for the evaluation of human experiments, she argues, was "invented, justified, and expanded less by 'outsiders' like bioethicists and activists than by the researchers themselves". ${ }^{37}$ Stark traces the origin of communal review of human research studies to the National Institutes of Health in 1953, when a hospital opened on their premises in Bethesda, Maryland, in which research studies with healthy human subjects took place. While scientific experiments had in the past often been conducted on institutionalized populations like prisoners, orphans, and the mentally ill, the routine hospitalization of healthy citizens, by a government agency no less, was a new development in the United States in the 1950s. Ethics review, Stark argues, was invented to manage this practice. Clinical directors met regularly to discuss study protocols, a procedure that allowed them to deal with issues like study design or the interaction between researchers and subjects. In this context, the communal review of protocols came to function as a new method for making moral decisions in research, but also as a technique for solving legal problems. Meetings served to determine if all studies proceeded according to official guidelines, and whether any patients displayed alarming behaviour that had to be dealt with before it might escalate. Moreover, when widespread public unrest followed the Tuskegee-exposé in 1972, ethics review "helped researchers to manage a legal crisis that threatened their share of the federal budget and the reputation of medical researchers". In short, Stark concludes, the histories of bioethics and IRBs should be read as "two parallel stories with one common cause: medical researchers' concerns over their legal liability in clinical studies and clinical care". $3^{8}$

This shift of historical frame, from an emphasis on outsiders to insiders, and from democratic control to legal protection and political legitimization, does not limit itself to the United States alone. Historian Duncan Wilson, for example, states in his recent book The making of British bioethics that the origins of research ethics committees in the United Kingdom have little to do with a supposed "backlash against professional society" in the 1960s, and should be disentangled from the rise of bioethics as an outsider critique on medicine. 39 Instead, their rise served as an enduring form of "club regulation": a form of self-regulation by members of the medical profession for members of the medical profession that ignored calls for lay involvement in the oversight of human research studies. $4^{\circ}$ Wilson follows Hedgecoe in this analysis, who equally argues that research ethics committees did not emerge in the United Kingdom due to calls for public control over human experimentation, but because of changing grant policies by the U.S. Public Health Service in 1967, requiring ethics review for all study

Ethics', in Social History of Medicine Vol. 8 (1995), pp. 275-288; Roger Cooter, 'The Ethical Body', in Medicine in the Twentieth Century, pp. 451-467.

${ }^{37}$ Stark, Behind Closed Doors, p. 8.

${ }^{38}$ Ibid., p. 162.

${ }^{39}$ Duncan Wilson, The making of British bioethics (Manchester: Manchester University Press, 2014); Harold Perkin, The Rise of Professional Society. England since 1800 (London: Routledge, 1990).

${ }^{40}$ Ibid. Adapted from: Michael Moran, The British Regulatory State. High Modernism and HyperInnovation (Oxford: Oxford University Press, 2003). 
protocols that it would decide to fund. While that does not negate that this policy was very much developed in response to growing concern over the practice of human experimentation in the United States, Hedgecoe claims it would be a mistake to think of this development as growing outsider control over medical research in Great Britain. For also when the British Ministry of Health became involved in the nationwide setup of research ethics committees in the late 1960s, the idea was actively preserved that ethics review had to function as a form of self-regulation. In other words, the rise of the practice of ethics by committee as a control mechanism for human experimentation should be understood as a continued form of club regulation, not as a new inclusive method for ensuring democratic control over medical science. ${ }^{41}$

\section{A cultural history of changing political control}

At stake in these histories is an assessment and positioning of the political function that research ethics committees fulfil in the governance of research studies involving human subjects. According to Rothman et al., research ethics committees emerged as a tool of external control over the conduct of individual medical researchers, i.e., an instrument to take the medical profession out of its social isolation and to subject it to "a nation's moral code" approved and applied by all citizens, including ethicists, laypeople, and even "society-representatives" (see chapter 4). According to authors such as Stark and Hedgecoe, however, this historically unwarranted emphasis on outsider control belies the emergence of research ethics committees as a tool of internal control over the conduct of individual medical researchers, i.e., an instrument that had to be yielded by medical researchers and practitioners; that preserved the idea that the medical profession constituted a separate social class subject to its own mores and traditions; and that ultimately served to ward off all too invasive outsider control by serving "as a technique of promoting research and preventing lawsuits". ${ }^{42}$ Which origin story is accepted as authoritative matters, for depending on the reasons behind the establishment of past research ethics committees, their current function in the governance of human subjects research is viewed in a different light. Likewise, also this PhD-thesis argues that, despite the dominant historical narrative that research ethics committees first emerged in the Netherlands "to break the monopoly of doctors on medical decisions", their rise originally served to give 'elite' physicians more internal control over human research, to intensify its conduct in the Netherlands, and to protect this scientific practice from all too critical societal voices.

At the same time, however, despite their young age, it would be incomplete to limit the history of research ethics committees to their origins, and to present a narrative of political control frozen in time. Public concerns over the professional autonomy of medical researchers did influence the development of Dutch thinking about the political functioning of research ethics committees in the second half of the twentieth century, and certainly changed the way they were originally conceived of in the 1950 s and 1960s. Especially in the 1970 s and 1980s, decades in which calls for democratic

\footnotetext{
${ }^{41}$ See also: Jenny Hazelgrove, 'British Research Ethics after the Second World War. The Controversy at the British Postgraduate Medical School, Hammersmith Hospital', in Twentieth Century Ethics of Human Subjects Research, pp. 181-197.

${ }^{42}$ Stark, Behind Closed Doors, p. 8.
} 
oversight over medicine reached a peak in the Netherlands, the notion that research ethics committees were needed to increase external control over human experimentation arose alongside the original idea of ethics by committee as an instrument of internal control. The next chapters therefore chart both governance ideals as they were proposed in the Netherlands in the latter half of the twentieth century, and study how tensions between them were eventually resolved in Dutch political circles tasked with the regulation of human subjects research. In all chapters, the reasons advocating one form of governance over another take centre stage, with the goal to tease out underlying cultural conceptions of the appropriate role and position of medicine and medical science in Dutch society, and how these changed through time.

With this approach, this PhD-thesis hopes to move away from the strong juxtaposition between outsiders and insiders in the realization of research ethics committees, and to focus instead on the political functions that the practice of ethics by committee historically has been imagined to fulfil in the governance of human experimentation. For while the ebb and flow of specific interest groups is an important question in the history of research ethics governance, the sizable attention to the position of relevant historical actors tends to direct attention away from the fact that, irrespective of who was at the helm, the success of research ethics committees in the second half of the twentieth century entailed a monumental change in the governance of human experimentation, and of the sciences more generally. What we need to understand, therefore, is not so much whether outsiders or insiders were responsible for this profound shift in governance, but rather, as Wilson has argued for the history of bioethics, "the mechanisms that underpin the emergence of [research ethics committees] in specific times and places". 43 What problems was the practice of ethics by committee perceived to solve, and by whom? What solutions did it present for the governance of human experimentation, and for whom? And, crucially, how did this linkage of problems and solutions change through time? Also, what underlying cultural conceptions of the role of medicine and medical science in society gave rise to the first Dutch research ethics committees, and how did growing concerns about the autonomy of the Dutch medical profession influence these conceptions? And, finally, how did these configurations frame the ethical concerns at stake in human experimentation, and who or what benefited from the policy solutions that were eventually chosen?

Of course, this type of historical questions does not preclude attention to the role of outsiders or insiders in the governance of human experimentation, nor to their political interests. As sociologist Joseph Gusfield already pointed out in his canonical 1981 book The Culture of Public Problems, "human problems do not spring up, full-blown and announced, into the consciousness of bystanders". 44 It involves work for an issue to be recognized as a problem in need of public governance and, even then, it matters a great deal who is appointed to come up with appropriate policy solutions. Why do governments allow laboratory animals to be bred for scientific research, for instance, while this would be considered absolutely deplorable for humans? It is not that animal rights' activists have never rallied fiercely against such practices. Yet, such groups

\footnotetext{
${ }^{43}$ Ibid., p. 6. [Research ethics committees] replaces [bioethics]. See also: Nikolas Rose, The Politics of Life Itself (Princeton: Princeton University Press, 2007); Cooter, 'Inside the Whale'.

${ }^{44}$ Joseph R. Gusfield, The Culture of Public Problems: Drinking-Driving and the Symbolic Order (London, 1981), p. 3.
} 
have never been fully successful in convincing others, and particularly those in power, to consider the issue to be equally problematic. Instead, those in favour of animal experimentation have by and large been able to maintain that it is a scientific practice that should not only be allowed by law but should be advanced with streams of public funds as well. Likewise, this PhD-thesis will establish that those in favour of human experimentation have by and large been able to insulate the practice from more radical social critiques due to their privileged seats at Dutch policy tables.

However, of primary interest is not that lobbyists were insiders or outsiders to the medical research establishment, but how they made sense of and gave direction to the issues at stake in the governance of human experimentation. Hence, the main goal of this $\mathrm{PhD}$-thesis is to re-collect the dominant notions that once gave form to the Dutch practice of ethics by committee in the governance of human experimentation; to trace how these notions changed in conjunction with changing cultural conceptions of the place of medicine and medical science in Dutch society; and to hold up these reflections as a mirror for the present-day governance of human subjects research. "At root", Cooter argues in 2010, "the history of bioethics is not about medicine and morality at all, nor about the activity of bioethicists, but rather, is a reconfiguration of what it is to be human". With this often used expression in medical historiography, Cooter points out that historians should study how the notion of patients' rights came to be celebrated as a capstone of ethical and legal decision-making in the latter half of the twentieth century, rather than to focus on whether "the authority of doctors was displaced by the would-be authority of (laity-minded) bioethicists".45 It presents an approach to history that is not so much interested in that "things could be otherwise", although it certainly does not deny this. However, it serves to recover what went into the configuration of the practice of ethics by committee as it did and, as such, make explicit which cultural conceptions of the role of (medical) science in society underlie the governance of human subjects research in the Netherlands today.

\section{The Netherlands as a reference culture}

Of course, research ethics committees may have arisen for very different reasons in the Netherlands than in the United States or United Kingdom. Judging from existing Dutch texts on the ethics of human experimentation, however, it is easy to forget that the Netherlands might have its own history of research ethics governance. Textbooks for Dutch medical students, for example, tend to follow the same genealogy, starting with the Nazi concentration camp experiments and the 1947 Nuremberg Code, a set of now world famous principles for human experimentation that were promulgated as part of the verdict of the Doctors' Trial against 23 physicians accused of conducting experiments on prisoners in the Nazi concentration camps. ${ }^{46}$ Then, they move on to the 1964 Helsinki Declaration of the World Medical Association (WMA), another set of principles for human research studies that is now often called the cornerstone doc-

\footnotetext{
${ }^{45}$ Cooter, 'Inside the Whale', p. 669.

${ }^{46}$ George J. Annas \& Michael A. Grodin (eds.), The Nazi Doctors and the Nuremberg Code. Human Rights in Human Experimentation (Oxford, 1992); Paul Weindling, 'The Origins of Informed Consent: The International Scientific Commission on Medical War Crimes, and the Nuremberg Code', in Bulletin of the History of Medicine Vol.75, No.1 (Spring, 2001), pp. 37-71.
} 
ument of human research ethics worldwide. ${ }^{47}$ Subsequently, the seminal 1966 article 'Ethics and Clinical Research' in the New England Journal of Medicine by the anaesthesiologist Henry K. Beecher is mentioned, which lists twenty-two research studies that had then recently appeared, and which Beecher believed to be flagrantly unethical. $4^{8}$ This 'roll of dishonour', as it came to be called, includes examples of withholding known treatments, of failure to obtain any form of consent, of conducting dangerous physiological experiments, of administering virulent strings of hepatitis to intellectually disabled children, and of injecting live cancer cells into elderly patients of the Jewish Chronic Disease Hospital. To this, the 1967 book Human Guinea Pigs by British physician Maurice Pappworth is often added, listing numerous questionable experiments conducted on hospital patients, orphans, inmates, and other confined populations in the United Kingdom in this period. 49 The 1972 exposé of the Tuskegee syphilis study typically concludes such segments, whereafter it is concluded that, today, stringent legislation for human research studies exists worldwide..$^{\circ}$

Such a placeless genealogy ignores, however, that these exposés hardly played any role of significance in the establishment of the first research ethics committees in the Netherlands. While Dutch news did report on scandals like Tuskegee and the exposés of 'Mister Pappworth', none of these ever led to much action from the Dutch government. It also neglects that the Netherlands itself was not free from research scandals. In the 1960 s and 1970s, multiple dubious human research studies were reported on, such as for instance experimental tests with a flu vaccine by pharmaceutical company Philips-Duphar in a Dutch psychiatric clinic in 1966 (see chapter 3). But although the responsible Dutch statespersons usually did issue a formal reply condemning these studies, they did not lead to much government action before the early 1980 . Hence, the famous research scandals that are typically invoked to explain the rise of research ethics committees in a country such as the United States cannot account for their emergence in a country such as the Netherlands. This is one of the main reasons why Wilson stresses the need for attention to national context. The singular focus on the United States overlooks how specific factors shape what is taken as ethical or problematic in different times and places, which Wilson suspects to be an important cause of the at times heated polemics over the past and present-day institutional function of bioethics: i.e. by reducing its history either to a need for action in the public sphere or to a strategy to protect the interests of scientists and physicians, one ignores that "bioethics is a multi-sited and interdisciplinary set of activities" which cannot be traced back to a single historical event (Tuskegee) or figure (Beecher). ${ }^{1}$

\footnotetext{
${ }^{47}$ Andreas Frewer \& Ulf Schmidt (eds.), History and Theory of Human Experimentation. The Declaration of Helsinki and Modern Medical Ethics (Frankfurt, 2007).

${ }^{48}$ Henry K. Beecher, 'Ethics and Clinical Research', in New England Journal of Medicine Vol. 74 (1966), pp. 1354-1360.

${ }^{49}$ Maurice H. Pappworth, Human Guinea Pigs. Experiments on Man (London: Routledge \& Kegal Paul, 1967). Also: Maurice H. Pappworth, 'Human Guinea Pigs: A Warning', in Twentieth Century Vol. 171 (1962-1963), pp. 66-75.

${ }^{50}$ See, for example: H.A.M.J. ten Have, R.H.J. ter Meulen \& E. van Leeuwen, Medisch Ethiek (Houten: Bohn Stafleu van Loghum, 2003). Stark calls this the 'critical event narrative'. See: Laura J. M. Stark, 'Morality in Science. How Research is Evaluated in the Age of Human Subjects Regulation', $\mathrm{PhD}$ Thesis, Princeton University, 2006, p. 32.

${ }^{51}$ Wilson, The making of British bioethics, p. 50. See also: David Reubi, 'The Will to Modernize. A Genealogy of Biomedical Research Ethics in Singapore', in International Political Sociology Vol. 4
} 
The same holds true for the practice of ethics by committee. The history of research ethics committees in the Netherlands has a distinct trajectory from those of the United States and Great Britain, outlined above in broad strokes. While both countries did serve as key "reference cultures" in Dutch newspapers and policy reports to frame the issues under discussion, the concerns for which ethics by committee was envisioned as a policy solution were significantly different..$^{2}$ Unethical human experimentation, for example, was for a long time taken to be a foreign problem, an epidemic that had not touched upon Dutch shores. Nor was the early Dutch 'bioethics' movement much concerned with human experimentation. The first monograph by a Dutch ethicist on the ethics of medical experiments with humans, for instance, was not published until 1985, when most Dutch research ethics committees were already up and running. 53 Instead, as will become clear, those who pushed most ardently for more mechanisms of collective control in Dutch research ethics governance for a long time were 'elite' medical researchers, who were frustrated that their government seemed to care little for the safety of human subjects (in addition to, not coincidently, the swift progress of biomedical science and clinical experimentation in the Netherlands).

Internationally, the history of Dutch research ethics governance in this $\mathrm{PhD}$-thesis may serve two purposes. First, given its study of the changing conception of the practice of ethics by committee in the second half of the twentieth century and its accompanying focus on changing cultural notions of the position of medicine and medical science in Dutch society, it may provide useful starting points to further develop histories of research ethics committees in other national contexts. According to historian Zachary Schrag, for instance, still more historical attention is needed for the changing function of ethics review in the United States in the years since it left the board rooms of the National Institutes of Health. Contemporary IRBs bare a family resemblance to their distant past, Schrag argues, but in many ways "the differences are as striking as the similarities". 54 Second, mapping the history of Dutch research ethics governance can help to tax the exemplary function that Dutch medical ethics, for good or for bad, fulfils internationally, due in large part to Dutch legislation for euthanasia and physician-assisted suicide (which permits the practice if certain criteria of due care have been met). 55 In Baker's work on the history of bioethics, for instance, the Netherlands functions as a reference culture for his thesis that bioethics arose in the United States due to a vacuum of moral leadership among American physicians. Thus, the laissezfaire attitude of the American medical profession to moral issues is contrasted to the attitudes of the Dutch medical profession, which Baker claims to have retained jurisdiction over medical ethics, both in the past and the present: "The Royal Dutch Medi-

(2010), pp. 142-158; Duncan Wilson, 'What Can History Do for Bioethics', in Bioethics Vol. 27 (2013), pp. 215-223.

${ }^{52}$ For 'reference culture' see: Joris van Eijnatten, 'Beyond Diversity. The Steady State of Reference Cultures', in International Journal for History, Culture and Modernity Vol. 3 (2015), pp. 1-8.

${ }^{53}$ Inez de Beaufort, Ethiek en medische experimenten met mensen (Assen: Van Gorcum, 1985).

${ }^{54}$ Zachary M. Schrag, 'Review: Behind Closed Doors: IRBs and the Making of Ethical Research by Laura Stark', in American Journal of Sociology Vol. 118 (2012), pp. 494-496, p. 496.

${ }^{55}$ See: James Kennedy, Een weloverwogen dood. Euthanasie in Nederland (Amsterdam: Uitgeverij Bert Bakker, 2002); John Griffiths, Alex Bood \& Heleen Weyers, Euthanasia and Law in the Netherlands (Amsterdam: Amsterdam University Press, 1998); Hans Krabbendam \& H.-M.T.D. ten Napel, Regulating Morality. A Comparison of the Role of the States in Mastering the Mores in the Netherlands and the United States (Apeldoorn: 2000). 
cal Association (founded in 1849) was able to negotiate physician-initiated euthanasia practices with Dutch legal authorities without involving 'bioethicists' in any major decision". ${ }^{6}$ In histories he has written on the governance of human experimentation after World War II, Baker makes similar use of the Netherlands, which he argues was one of the first countries in the world to actively enforce the 1947 Nuremberg Code. 57 In this same fashion, he and other historians have claimed that the Netherlands was one of the first countries to try to install "local research councils (later to be called institutional review boards, or IRBs)", and that the Dutch delegation to the WMA first put the ethics of human experimentation on the agenda of the international organization, which eventually resulted in the 1964 Declaration of Helsinki. $5^{8}$

It is true that, relatively speaking, an early awareness existed in the Netherlands about the need for more oversight in the practice of human experimentation. As chapter 1 will show, already in 1949 Dutch doctors voiced concerns that the recently established WMA did not have enough attention for the ethics of human experimentation and, in 1955, the country's national Health Council advised the Dutch government to establish a national advisory board that could aid researchers in conducting clinical trials (a recommendation that has led some historians to claim that the Dutch were among the first to realize research ethics committees). Still, despite these 'early' activities, it would take until the close of the twentieth century until Dutch parliament passed the WMO, long after many other countries had realized legislation regulating human experimentation. This was not for lack of trying. From the 1950 s onwards, the Dutch government requested reports from official advisory bodies on at least six occasions to help decide whether legislation for human experimentation was desirable, and what this legal framework should look like. In Dutch parliament, the matter was discussed throughout the 1980 s and 1990 s and politicians complained regularly that the realization of an appropriate legal system for research ethics governance was long overdue. In the same period, both medical insiders and outsiders frequently ventilated frustrations about the inability of the Dutch government to realize proper legislation in journals such as Medisch Contact. "The Netherlands is becoming an international testing ground for all sorts of experimental research", commentators would write, "a Freistaat for experiments [...] which are refused elsewhere". 59

Hence, due to a reluctant government, conversations over the ideal governance of human experimentation spanned a period of more than 40 years in the Netherlands, revealing clear shifts in the conceptualization of the research ethics committee and its appropriate function in the governance of medical research and practice. Where Stark argues that the practice of ethics by committee in the United States already in the 1960 s became an "entrenched, routine way of doing things" that required "less justifi-

\footnotetext{
${ }^{56}$ Baker, Before Bioethics, p. 278.

${ }^{57}$ Robert Baker, 'Transcultural Medical Ethics and Human Rights', in Ulrich Tröhler \& Stella ReiterTheil (eds.), Ethics Codes in Medicine. Foundations and achievements of codification since 1947 (Aldershot, 1998), pp. 312-331.

${ }^{58}$ Ibid., p. 320. See also: Ulrich Tröhler, 'The Long Road of Moral Concern: Doctors' Ethos and Statute Law Relating to Human Research in Europe', in History and Theory of Human Experimentation, pp. 27-54, p. 34; Susan E. Lederer, 'Research Without Borders: The Origins of the Declaration of Helsinki', in History and Theory of Human Experimentation, pp. 145-164.

${ }^{59}$ H.D.C. Roscam Abbing, 'Genetische experimenten met mensen. Wetgever quo vadis?', in Medisch Contact Vol. 41 (1986), pp. 533-535, p. 533.
} 
cation and explanation over time", in the Netherlands it remained an active subject of deliberation in expert advisory committees, parliamentary hearings, and discussion pages of scientific journals and mainstream newspapers until the late twentieth century. ${ }^{60}$ For decades, the original blueprint for the practice of ethics by committee was tweaked and twisted in these outlets, until most parties involved deemed it ready to be cast into law. Consequently, an impressive paper trail has been left behind on the shelves of the Dutch National Archive and in the proceedings of Dutch parliament. These sources will be combined with a variety of published materials, including pamphlets, newspapers, journal articles, private correspondence, and broadcasts, to map in detail how the notion of ethics by committee travelled from the first Dutch policy report on the subject in 1955 to the eventual passing of the WMO in 1998.

\section{What and what not to expect}

The following chapters make clear that this journey did not follow a straight path. Between 1955 and 1998, the original Dutch blueprint for ethics review changed substantially in conjunction with changing cultural conceptions of the role and position of medicine and medical science in Dutch society. Chapters 1 and 2 map the original notion of ethics review by committee as a form of internal control over the practice of human experimentation. Chapter 1 first provides an overview of the longer history of human experimentation, the growing importance of this practice to medical decisionmaking in the nineteenth and early twentieth century, and the impact that World War II and the Nazi concentration camp experiments had on human research practices in the Netherlands. Subsequently, it investigates the incentives behind the development of the first Dutch policy report on research ethics governance of 1955 and its provisional notion of the practice of ethics by committee. Chapter 2 examines the next two policy reports that were developed by the Dutch Health Council between 1968 and 1981 in response to parliamentary questions about the permissibility of a new form of human experimentation in medicine: the randomized controlled trial. The medical researchers behind these reports were convinced that legal measures were needed to bring this practice under control. However, these researchers were concerned not just about the rights and safety of human research subjects. The conduct of randomized controlled trials also had to be protected, they argued, and the Dutch government had a moral responsibility to heighten both the quality and quantity of this scientific practice. Ethics review had to ensure that this upsurge would be realized.

Chapters 3 and 4 map the sudden enfolding of this original notion of ethics review into a movement pushing for more external control over medical research and practice towards the end of the 1970s. Chapter 3 first traces the emergence of this movement in the 1960s and 1970s. Although the Royal Dutch Society for the Advancement of Medicine had proudly announced after World War II that the longstanding moral traditions of Dutch physicians had played a vital role in their resistance against the Nazi occupation, this proud independent identity crumbled in the decades thereafter. By 1970, the pages of Medisch Contact were filled with concern about a Dutch crisis of medical ethics, unease was voiced in Dutch parliament about the seeming inability

$\overline{{ }^{60} \text { Stark, Behind Closed Doors, p. } 133 .}$ 
of the organized Dutch medical profession to regulate the conduct of its members, while an amalgam of social movements started advocating a need to codify patients' rights. Chapter 4 traces how the rights of research subjects, which initially received minor attention in this changing cultural climate, became a central part of this discourse toward the end of the 1970s, in response to a number of unexpected research scandals. This outcry resulted in a policy advice on the governance of human experimentation in the Netherlands from the Central Council for Public Health, which recommended the Dutch government in 1982 to include "society-representatives" in the oversight of human experimentation, as "seclusion and mystery have to make way for openness and transparency" in a modern democratic society. ${ }^{61}$

Chapters 5 and 6, finally, study the sixteen years between the publication of this latter policy report and the 1998 WMO. In 1983, the Dutch government announced it fully agreed with the Central Council for Public Health and would develop appropriate legislation soon. Yet in the years thereafter, successive cabinets found reasons to postpone the realization of a human research bill-inertia that gave rise to much frustration in the Netherlands. Chapter 5 shows that lack of political action did not prevent a plethora of Dutch research ethics committees to spring up in the 1980 s. It did, however, ensure that the Dutch government had little influence on the way in which these practically came to manifest themselves. Consequently, when Dutch parliament in 1997 could for the first time deliberate on a bill for medical research involving human subjects, it was debating a practice of ethics by committee that had already congealed around the ideas of those who had started to push in the 1980s for more expert control over human experimentation in the Netherlands. Chapter 6 investigates the policy solution that the so-called Purple administration eventually devised to mediate between the two ideals of expert and democratic governance in the public oversight of human research studies. It was a solution, chapter 6 argues, dependent on a specific configuration of ethical expertise that had emerged in the second half of the twentieth century in reaction to "the waning of traditional moral authority"-and that indeed favoured the new health or bio-ethics profession in the Netherlands. However, it was not a solution that was particularly congenial to ethicists or medical researchers above all else. Rather, it was a solution which enabled the Dutch government to claim, on the one hand, that it did not neglect the regulation of ethically contentious issues in fields of science, technology, and health, while, on the other, that it also did not unduly interfere with the beliefs of people in a pluralist society.

Since this PhD-thesis focuses on policy debates about the governance of human experimentation in the Netherlands, the day-to-day dealings and decisions of the more than hundred Dutch research ethics committees that have existed since the 1970 s receive only minor attention in the following pages. Instead, the emphasis lies with the language of political discourse in which their role and function has been imagined and not with their actual historical or current practice. ${ }^{62}$ For this reason, this $\mathrm{PhD}$ -

\footnotetext{
${ }^{61}$ Centrale Raad voor de Volksgezondheid, Deeladvies inzake medische experimenten ('s-Gravenhage: Staatsuitgeverij, 1982), p. 7, p. 15.

${ }^{62}$ Other scholars have conducted such research. Already in 1975, Bradford H. Gray published a book about the daily practice of United States institutional review boards, an ethnographic approach which has since been repeated by other scholars, for the United States and for other countries as well. See: Bradford H. Gray, Human Subjects in Medical Experimentation. A Sociological Study of the Conduct and Regulation of Clinical Research (New York: Wiley-Interscience, 1975). See also: Maureen H.
} 
thesis focuses on 'committees thinking about committees', i.e., the numerous advisory bodies that have been requested since the 1950 s by the Dutch government to write reports on the topic and the two 'committees' ideally elected once every four years to represent the interests and concerns of Dutch citizens-the House of Representatives and the Senate (in Dutch called Tweede Kamer and Eerste Kamer). ${ }^{63}$

According to sociologist Sheila Jasanoff, expert advisory committees are important resources for scholars interested in the boundary work that goes into framing contentious issues as problems in need of public action. ${ }^{64}$ Outside of the limelight that dominates parliamentary deliberations, they often establish the parameters within which subsequent policy discussions will be held. Relevant policy documents have therefore formed a central point of departure for identifying the source material on which this PhD-thesis rests. Drawing on these reports and the detailed minutes that have been preserved of committee meetings, additional sources such as the documentation materials used by committee members have been collected. In addition, as these bodies regularly drew on developments in scientific practice and public discourse, relevant academic journals and popular newspapers have been studied to gain a better picture of the changing cultural climate in which policy deliberations took place. All issues of the journal Medisch Contact (1945-present) have been studied, for instance, as have other relevant medical, philosophical, and legal journals. Such sources are often included in the upcoming pages, albeit within margins. Discussions that hardly had an effect on the development of relevant policies, even if they were of high concern to those involved, receive only minor attention in the upcoming chapters.

The following pages also do not address the role of research ethics committees in non-medical research contexts. Of course, depending on the definition given to concepts such as experiment and research, the scope of a law regulating human research studies may differ widely. In fact, as this $\mathrm{PhD}$-thesis will show, a big part of the policy discussions about the appropriate oversight of human experimentation was dedicated to deciding what precisely constitutes an experiment and how it differs from regular clinical interventions. In his 2010 book Ethical Imperialism, Schrag similarly shows how in the United States the legal definition of 'research' has over the years come to include most studies with human beings in the social sciences as well, a process that has gone hand in hand with a reconfiguration of the notion of 'science' in these scholarly fields. ${ }^{65}$ Nonetheless, also Schrag emphasizes that U.S. federal policies for human

Fitzgerald, 'Punctuated Equilibrium, Moral Panics and the Ethics Review Process', in Journal of Academic Ethics Vol. 2 (2005), pp. 315-338; Jan Jaeger, 'An Ethnographic Analysis of Institutional Review Board Decision-Making', Ph.D. diss., University of Pennsylvania (2006); Hedgecoe, 'Research ethics review'; L. Abbott \& C. Grady, 'A systematic review of the empirical literature evaluating IRBs: what we know and what we still need to learn', in Journal of Empirical Research on Human Research Ethics Vol. 6 (2011), pp. 3-19; Stark, Behind Closed Doors; Robert L. Klitzman, The Ethics Police? The Struggle to Make Human Research Safe (Oxford: Oxford University Press, 2015). For those specifically interested in the present-day functioning of Dutch research ethics committees, see: Patricia Jaspers, Rob Houtepen \& Klasien Horstman, 'Ethical review: Standardizing procedures and local shaping of ethical review practices', in Social Science \& Medicine Vol. 98 (2013), pp. 311-318.

${ }^{63}$ This PhD-thesis uses the English wording for these two Chambers.

${ }^{64}$ Sheila Jasanoff, The Fifth Branch. Science Advisers as Policymakers (Cambridge: Harvard University Press, 1990). Also: Sheila Jasanoff, Designs on Nature. Science and Democracy in Europe and the United States (Princeton: Princeton University Press, 2005).

${ }^{65}$ Schrag, Ethical Imperialism. See also: Charles L. Bosk \& Raymond De Vries, 'Bureaucracies of Mass Deception. Institutional Review Boards and the Ethics of Ethnographic Research', in Annals of 
experimentation were originally designed for the biomedical and behavioural sciences, and only later transposed to the social sciences and humanities. Likewise, in the Netherlands, policy deliberations mostly revolved exclusively around medical experimentation, and the 1998 WMO only speaks of medical-scientific research, leaving it up to the administrative body responsible for the execution of the law to decide which types of other research studies fall within its scope. ${ }^{66}$ This PhD-thesis therefore primarily focuses on the role of research ethics committees in the governance of medical research involving human subjects, and only includes other scientific fields when they presented an issue of concern in the sources under investigation.

Finally, this PhD-thesis does not provide a definition of the term governance. Although it is admittedly an elusive term that cannot be translated into all languages, it is a widely recognized concept to consider acts of organizing, managing and ruling, by a variety of entities and actors, through formal and informal channels, in a multitude of spheres. Governance, almighty Wikipedia says (as does Governance: A very short introduction), refers to "all of processes of governing, whether undertaken by a government, market or network, whether over a family, tribe, formal or informal organization of territory and whether through the laws, norms, power or language". ${ }^{67}$ Bruno Latour refers to concepts like governance as part of a scholar's infra-language: "They don't designate what is being mapped, but how it is possible to map anything from such a territory. They are part of the equipment on the geographer's desk to allow him to project shapes on a sheet of paper". ${ }^{68}$ And thus, in the upcoming pages, the term is equipped to bring into view two fundamental shifts in 'governing' human experimentation that this $\mathrm{PhD}$-thesis wants to capture: (1) the transition of the locus of ethical decision-making from individual researchers to select groups of reviewers in the oversight of human research studies, and (2) from a tradition of self-governance in medical science to one of strict public control-as it occurred in the second half of the twentieth century, in a small country called the Netherlands.

\footnotetext{
the American Academy of Political and Social Sciences Vol. 595 (2004), pp. 249-263; Kevin D. Haggerty, 'Ethics Creep: Governing Social Science Research in the Name of Ethics', in Qualitative Sociology Vol. 27 (2004), pp. 391-414; Will C. van den Hoonaard, The Seduction of Ethics. Transforming the Social Sciences (Toronto: University of Toronto Press, 2011).

${ }^{66}$ Ethics review of humanities studies remains uncommon in the Netherlands. Only in the last five years have ethics committees for these research studies started to pop up in response to changing funding policies at the EU-level and changing publishing policies of international academic journals.

${ }^{67}$ As Wikipedia also says: "Governance is a very general concept that can refer to all manner of entities”. Derived from https://en.wikipedia.org/wiki/Governance on June 2, 2016; Mark Bevir, Governance. A Very Short Introduction (Oxford: Oxford University Press, 2012), p. 1.

${ }^{68}$ Bruno Latour, Reassembling the Social. An Introduction to Actor-Network-Theory (Oxford: Oxford University Press, 2005), p. 174.
} 




\section{PART I}

\section{INTERNAL CONTROL}

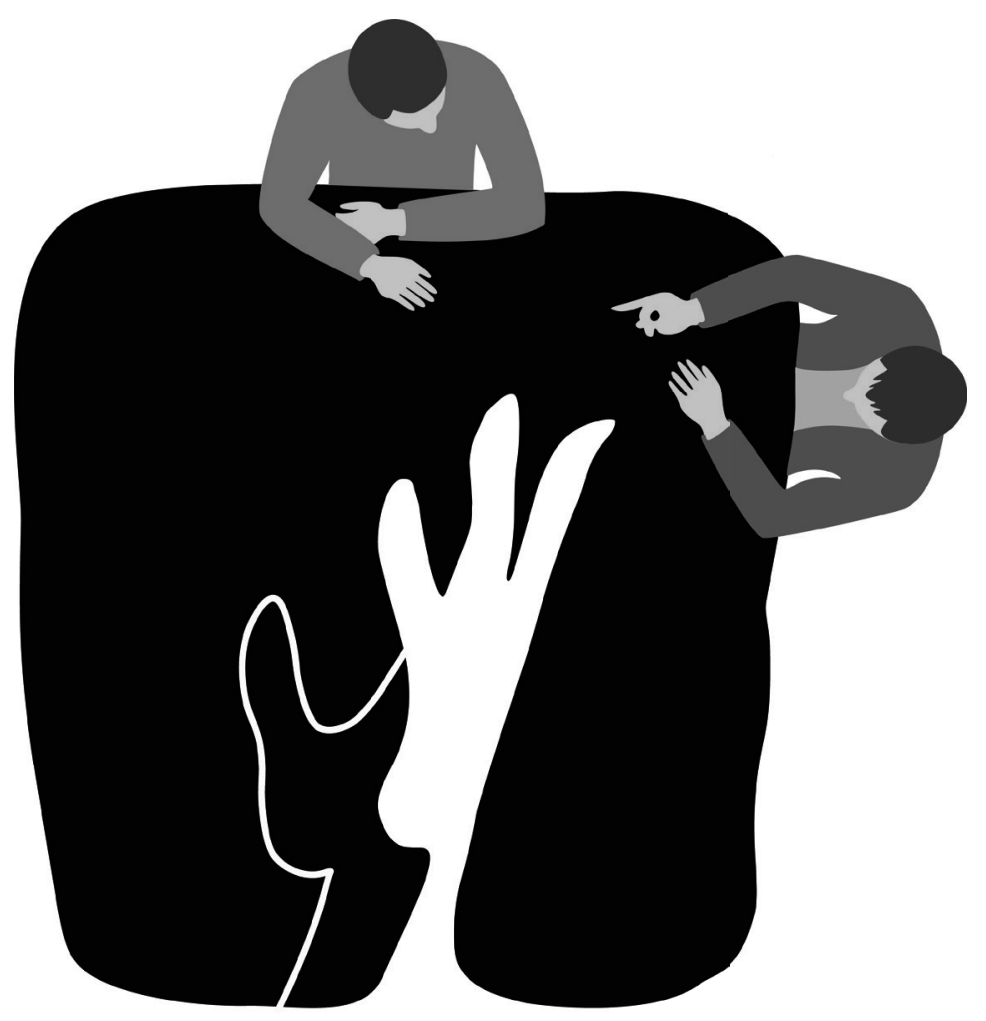





\section{- Chapter 1 . a moral obligation to medical progress}

“Both modern medications and modern medical practice carry risks. Hippocrates' old theorem can therefore in this modern day and age no longer be maintained in its entirety". ${ }^{1}$ In 1954, Dutch internist Job Pannekoek laid this firm conclusion on the table of the committee 'tests upon human beings' of the Health Council of the Netherlands. Only a few months earlier, this ad hoc committee-consisting of sixteen eminent physicians-had been installed on government request to study the permissibility of human experimentation. For two years, this group gathered every few months to discuss under what circumstances this practice was acceptable in the Netherlands and which measures needed to be taken to keep it under control. Pannekoek and colleagues were worried about some of the experiments conducted in Dutch hospitals and expressed deep concern about stories that reached them from countries like the United States. Yet, they also felt that the existing medical ethics no longer befitted physicians who committed themselves to 'the practice of modern medicine': Primum non nocere, the old Hippocratic theorem to 'first, do no harm', could no longer be maintained by physicians who had an array of medicines and tools at their disposal to do good, and who carried a responsibility to benefit as many patients as possible. Hence, a new ethical framework was needed-to do justice to the position that science had acquired in the practice of medicine. Modern medicine required modern medical ethics.

This chapter explores the incentives behind the establishment of the Dutch Health Council committee 'tests upon human beings' in 1953. In 1955, its conclusions about the appropriate governance of human experimentation in the Netherlands were published as a twelve-page policy advice to the Dutch government, which contained fourteen guidelines for medical tests with humans and recommended to install a national advisory board to guide this practice. ${ }^{2}$ According to some historians, it was one of the first times that the need for institutional oversight over human experimentation was recognized in national policy circles. ${ }^{3}$ Still, why did a national advisory body to the Dutch government formulate ethical guidelines for the conduct of medical tests upon human subjects in the 1950s, a decade when only few precedents existed internationally to suggest that the state rather than the medical profession was responsible for the governance of this practice? Why did it decide that the existing medical ethics had become obsolete for its governance in the mid-twentieth century? And what sort of oversight role did the Health Council imagine for a national advisory board in guiding the conduct of human experimentation in the Netherlands?

\footnotetext{
${ }^{1}$ Dutch National Archive (hereafter: NL-HaNA), Gezondheidsraad 2.15.33, 548, Minutes committee 'tests upon human beings' [proeven op mensen], 11 March 1954, p. 2.

${ }^{2}$ Advies van de voorzitter [J. Wester] van de Gezondheidsraad d.d. 10 oktober 1955, uitgebracht aan de Minister van Sociale Zaken en Volksgezondheid betreffende proeven op mensen.

${ }^{3}$ Baker, 'Transcultural Medical Ethics and Human Rights', pp. 312-331; Tröhler, 'The Long Road of Moral Concern: Doctors' Ethos and Statute Law Relating to Human Research in Europe', pp. 27-54.
} 
To answer these questions, this chapter traces how and by whom human experimentation was turned into a matter of public concern in the Netherlands in the first decade after World War II. In this period, revelations of the Nazi concentration camp experiments provoked radically different responses among different social groups in the Netherlands. Leaders of the medical profession vowed to never again let the corrupting influences of political ideology and government bureaucracy take a hold over medicine. Others, however, found definitive proof in the concentration camp experiments of the dangers of 'modern medicine' and its reductionist perspective on human (and animal) life. As a result, debates over the governance of human experimentation in the immediate post-war period came to revolve in the Netherlands both around the societal standing and epistemic authority of 'modern medicine'. And consequently, when the Dutch Health Council in 1955 published a report on 'tests upon human beings', it attempted not just to lay down the groundworks for the future governance of human experimentation in the Netherlands, but also to enforce a definitive statement about its rightful position in mainstream medicine and 'modern society'. This chapter explores what this statement was-and who was responsible for it.

As a background to these post-war developments and by way of introduction to the history of human experimentation more generally, section I of this chapter first explains why the conduct of medical experiments on human beings became increasingly common in the modern period. Section II shows how, in relation to this development, opposition arose to 'modern medical science' and its use of animal and human experimentation in this period, a development that in the early twentieth century gave rise to the first requests to the Dutch government to bring the conduct of human experimentation under public control. Sections III and IV detail how World War II influenced these debates in the Netherlands during the 1940s and 1950s, and how ongoing complaints about "the horrors of modern medicine" led to the installation of no less than three Health Council committees between 1947 and 1953 to advise the Dutch government on how best to handle this phenomenon. The last of these three was the committee 'tests upon human beings'. Section V, finally, explains the organization of this committee and shows which function its 1955 report was meant to serve in ongoing Dutch debates on the rightful societal position of 'modern medicine'.

\section{The growing importance of human experimentation}

Human experimentation is an age-old practice, but it has not always been a central part of medical research and practice. Of course, as every new medicinal product and surgical procedure once had to be tried out on a human patient for the first time, it is possible to argue that medical experiments on humans are as old as medicine itself. 4 But experiments whereby an intervention on the human body is undertaken not primarily to benefit the health of the individual under investigation but to obtain generalizable scientific insights started to gain in popularity only during the Renaissance. In first instance, these experiments (or, to use the correct historical term, demonstra-

\footnotetext{
${ }^{4}$ Gert H. Brieger, 'Human Experimentation. I. History', in Warren T. Reich (ed.), Encyclopedia of Bioethics Vol. 2 (New York: The Free Press, 1978), pp. 684-692; Susan E. Lederer, 'The Ethics of Experimenting on Human Beings', in Robert B. Baker \& Laurence B. McCullough (eds.) The Cambridge World History of Medical Ethics (Cambridge: Cambridge University Press, 2009), pp. 558-565.
} 
tions) were mostly conducted on human corpses by anatomists in search of the structure of the human body. ${ }^{5}$ However, by the seventeenth century experiments with living human bodies grew popular as well. According to historians Erika Dyck and Larry Stewart, the ethos of experiment set forth by the first learned societies from the 1650 s onwards turned the human body into just another object that was to be manipulated, probed, and inspected to reveal intimate truths about nature. ${ }^{6}$

Many of these early experiments were conducted on the bodies of experimenters themselves. The philosophers of the Royal Society of London, the oldest learned society in existence (1660), often willingly offered their bodies for the study of physical phenomena. Simon Schaffer describes how natural philosophers zealously "blinded themselves with sunlight, gassed themselves into states of ecstasy and insensibility, and electrified their limbs into paralysis or spasm".7 Physicians used their own bodies to demonstrate the safety and efficacy of new medications. Their willingness to test a drug on themselves (or their children) before giving it to a patient was a sign they had trust in their remedies and did not hesitate to sacrifice themselves for their patients. ${ }^{8}$ In the famous medical marketplace of the early modern period, at which university educated physicians competed with surgeons, apothecaries, and quacks for customers, the willingness 'to go first' had a distinct commercial advantage. ${ }^{9}$

But philosophers and physicians experimented on others as well. In the eighteenth century, experiments with new machineries like the Voltaic pile or apparatus for producing factitious airs became parlour games and drew in crowds of volunteers quite willing to participate as research subjects in popular demonstrations. ${ }^{10}$ Many medical experiments were conducted on those who could not be considered volunteers. Londa Schiebinger describes how charity patients in England in the eighteenth century were likely to be subjected to all sorts of experimental treatments. Physicians used them to test cures and dosages until they deemed these ready to prescribe to paying patients. Prominent physicians in France and Germany promoted experimenting on prisoners and to submit them to extreme trials and surgeries for "the sake of humanity". ${ }^{11}$ Individuals confined in closed institutions like workhouses, orphanages, and prisons were particularly vulnerable to human experimentation. ${ }^{12}$ Horded together and dependent

\footnotetext{
${ }^{5}$ Guerrini, Experimenting with Humans and Animals; A.-H. Maehle \& U. Tröhler, 'Animal Experimentation from Antiquity to the End of the Eighteenth Century. Attitudes and Arguments', in Nicolaas A. Rupke (ed.), Vivisection in Historical Perspective (London: Croom Helm, 1987), pp. 14-47.

${ }^{6}$ Dyck \& Stewart, The Uses of Humans in Experiment. Dyck and Stewart draw on Michael Foucault, The Order of Things. An archaeology of the human sciences (New York: Routledge, 1970).

${ }^{7}$ Simon Schaffer, 'Self Evidence', in Critical Inquiry Vol. 18 (1992), pp. 327-362, p. 329.

${ }^{8}$ Lawrence Altman, Who Goes First. The Story of Self-Experimentation in Medicine (New York: Random House, 1986); Londa Schiebinger, 'Human Experimentation in the Eighteenth Century. Natural Boundaries and Valid Testing', in Lorraine Daston \& Fernando Vidal, The Moral Authority of Nature (Chicago: The University of Chicago Press, 2003), pp. 384-408.

${ }^{9}$ Andrew Wear, 'The Discourses of Practitioners in Sixteenth- and Seventeenth Century Europe', in The Cambridge World History of Medical Ethics, pp. 379-390.

${ }^{10}$ Paola Bertucci, 'Shocking Subjects. Human Experiments and the Material Culture of Medical Electricity in Eighteenth-Century England', in The Uses of Humans, pp. 111-138; Larry Stewart, 'Pneumatic Chemistry, Self-Experimentation and the Burden of Revolution, 1780-1805', in Ibid., pp. 139-169.

${ }^{11}$ Schiebinger, 'Human Experimentation in the Eighteenth Century', p. 394.

${ }^{12}$ Slaves, one of the most vulnerable populations of the early modern period, were a notable exception to this rule. Mostly, their bodies were deemed too economically valuable by their owners to be used for scientific experimentation. See: Londa Schiebinger, 'Medical Experimentation and Race in the Eighteenth-century Atlantic World', in Social History of Medicine Vol. 26 (2013), pp. 364-382.
} 
on the grace of others, they were often taken as "readily available material". It did not help in this regard that 'the institutionalized' often came from vulnerable classes that were appraised as 'lesser citizens': the poor, deviant, and mad. ${ }^{13}$

In the (late) modern period, systematic medical experimentation with human beings intensified. There are various reasons for this development. First, changes in the understanding of medical science itself played an important role. Already in the seventeenth and eighteenth century, a medical doctrine advantageous to the comparison of human bodies had developed. Doctors gradually abandoned the Galenic conception that illness depended on unique combinations of bodily constitution, age, gender, and environment. Instead, a tradition of medical empiricism arose, in which diseases rather than patients became the central category of analysis and disease specific treatments were developed that could be administered across patients to constant effect. ${ }^{14}$ As a result, the human body became a vessel for disease and thus comparable, which, in turn, stimulated statistical approaches to medical efficacy. Physicians started to collect cases with the aim to increase observations of single instances before publishing their findings. ${ }^{15}$ In the nineteenth century, this approach became an important validation and impetus for human experimentation. In the 1830 s, Parisian physician Pierre Louis (1787-1872) famously developed the 'numerical method' to medical practice, using calculus and probability theory to measure the risk and benefits of clinical procedures. ${ }^{16}$ This numerical approach subjected individual experience to systematic comparison. Central was not whether medicines worked for one patient, but whether they produced significant effects on a population level. To establish this, repeated experimental tests were needed on higher numbers of patients.

In addition, after the mid-nineteenth century, the growing popularity of the theory that miniscule organisms (germs) cause diseases had the effect that medical practice increasingly modelled itself after scientific practice. ${ }^{17}$ In and around hospitals, laboratories were built to examine fluid and tissue samples, to isolate 'microorganisms', and to study disease aetiology by means of animal and possibly even human experiments. In his 1865 Introduction to the Study of Experimental Medicine, the famous French

\footnotetext{
${ }^{13}$ Anita Guerrini, 'The Human Experimental Subject', in Bernard Lightman (ed.), A Companion to the History of Science (West Sussex: John Wiley \& Sons Ltd, 2016), pp. 126-138.

${ }^{14}$ Harold J. Cook, 'Practical Medicine and the British Armed Forces after the "Glorious Revolution", in Medical History Vol. 34 (1990), pp. 1-26; Andreas-Holger Maehle, Drugs on Trial. Experimental Pharmacology and Therapeutic Innovation in the Eighteenth Century (Amsterdam: Rodopi, 1999); Charles E. Rosenberg, 'The Tyranny of Diagnosis. Specific Entities and Individual Experience', in Milbank Quarterly Vol. 80 (2002), pp. 267-260.

${ }^{15}$ Ulrich Tröhler, "To Improve the Evidence of Medicine". Arithmetic Observation in Clinical Medicine in the Eighteenth and Early Nineteenth Century', in History and Philosophy of the Life Sciences, Vol. 10 Supplement (1988), pp. 31-40; Andrea Rusnock, 'The Weight of Evidence and the Burden of Authority. Case Histories, Medical Statistics and Smallpox Inoculation', in Clio Medica Vol. 29 (1995), pp. 289-315.

${ }^{16}$ John Rosser Matthews, Quantification and the Quest for Medical Certainty (Princeton: Princeton University Press, 1995); Theodore M. Porter, The Rise of Statistical Thinking, 1820-1900 (Princeton: Princeton University Press, 1986).

${ }^{17}$ Cunningham \& Williams, The Laboratory Revolution in Medicine; Ilana Löwy, 'The Experimental Body', in Medicine in the $20^{\text {th }}$ Century, pp. 435-449.
} 
physiologist Claude Bernard (1813-1878) explained: "So, among the experiments that may be tried on man, those that can only harm are forbidden, those that are innocent are permissible, and those that may do good are obligatory". ${ }^{18}$ Hence, under the right circumstances, human experiments could even be a moral obligation for physicians. ${ }^{19}$ Even though few of these experiments produced any distinct therapeutic advances for most of the nineteenth century, this faith that greater knowledge of disease would eventually reap its rewards was rarely doubted. Bernard, for one, was fully confident that 'modern experimental medicine' would eventually conquer all diseases. "We cure it always without any exception", he declared in the Introduction, "when we place ourselves in the known experimental conditions for reaching this goal". ${ }^{20}$

This experimental tradition was facilitated in the nineteenth century by the rise of modern research hospitals. Already since the eighteenth century, hospitals had grown in both size and number throughout Europe. ${ }^{21}$ Under influence of the Age of Enlightenment, the authority of physicians within hospitals grew as well, a development that coincided with and stimulated human experimentation. After all, hospital walls contained a reservoir of patients that could be compared for experimental purposes. ${ }^{22}$ In the early nineteenth century, the idea that hospitals were teaching and research centres as much as they were service institutes gained prominence. Emphasis in the hospitals lay on diagnosis, not cure. Based on new theoretical insights in physiology, students were trained in new diagnostic techniques to recognize which parts of the diseased body were failing. After patients passed away, autopsies served to confirm these findings. In many cases, interventions served to demonstrate scientific insights and skill as much or even more than that they served to provide care. In this process, hospital patients effectively came to function as research subjects. ${ }^{23}$

In this period, still, hospital patients were often from the lower classes of society. Affluent patients preferred to be taken care of in their own homes, far away from the noise and filth of hospital wards. Towards the end of the nineteenth century, however, the growth of laboratory medicine in combination with the invention of invasive new medical technologies like stomach tubes and x-rays ensured that also well-to-do patients were increasingly taken care of in hospitals-where these technologies were more readily available. As a result, physicians' careers grew less dependent on their patients' preferences and more on the approval of hospital boards and medical peers. With that, their professional needs and interests changed too. Whereas the patronage of wealthy patients had been an important means to advance a medical career in the early modern period, allegiance to the experimental tradition in medicine became one

\footnotetext{
${ }^{18}$ Claude Bernard, An Introduction to the Study of Experimental Medicine (1865; trans. 1927; reprint, New York: Dover, 1957), p. 102.

${ }^{19}$ Numbers, 'William Beaumont and the Ethics of Human Experimentation', p. 134.

${ }^{20}$ Bernard, An Introduction to the Study of Experimental Medicine, p. 214.

${ }^{21}$ Guenther B. Risse, Mending Bodies, Saving Souls. A History of Hospitals (Oxford: Oxford University Press, 1999).

${ }^{22}$ William Bynum, 'Reflections on the History of Human Experimentation', in Stuart F. Spicker et al. (eds.), The Use of Human Beings in Research. With Special Reference to Clinical Trials (Dordrecht: Kluwer Academic Publishers, 1988), pp. 29-46; Michel Foucault, The Birth of the Clinic. Trans.: A.M. Sheridan-Smith (London: Tavistock Publications, 1973).

${ }^{23}$ The classic text on the rise of the Paris hospital system remains: Erwin H. Ackerknecht, Medicine at the Paris Hospital, 1794-1848 (Baltimore: John Hopkins University Press, 1967).
} 
in the (late) modern hospital setting. ${ }^{24}$ Experimenting with humans, if successful and above moral suspicion, could greatly boost a curriculum vitae.

A final, more remote, factor contributing to the intensification of experiments with human beings in the nineteenth century is the fact that the social power of physicians grew. In this period, states increasingly started to take an interest in public health. A healthy population could have distinct economic and military advantages and, more generally, was taken to be a sign of national superiority. ${ }^{25}$ To organize and streamline medical practice, therefore, states enacted licensing laws to regulate who got to practice medicine, with what diplomas, and under what conditions. Physicians were enlisted to act as state officers and carry out health care programmes. These developments resulted in a more hierarchical organization of national health care systems. ${ }^{26}$ In 1865 , for instance, the Dutch government passed legislation that made it illegal to see patients without the right medical license, officially creating a "doctors' monopoly". ${ }^{27}$ In turn, this contributed to a more corporate identity of the medical profession. In 1849, the Dutch Society for the Advancement of Medicine (NMG) was created to represent the interests of all orthodox physicians in the Netherlands, a development that took place in many other countries as well in the mid-nineteenth century. ${ }^{28}$ Such professional societies stimulated a rhetoric of communal responsibility: doctors did not just carry a responsibility to individual patients, they had a duty to take care of the body politic of a nation as a whole. In the late nineteenth and twentieth century, this utilitarian logic served to justify human experiments. After all, if physicians were responsible for "the wellbeing of the greatest number of people", perhaps some risks could be taken with a few patients if these could benefit the many.

Of course, the relevance and extent of these changes for the practice of human experimentation differed per region. The use of medical statistics, for instance, originated in England in the eighteenth century and was brought to fruition in Paris in the nineteenth century. ${ }^{29}$ Similarly, in the early nineteenth century, doctors from all over Europe and the United States flocked to Paris to watch their French colleagues make rounds and use the newest instruments in their bedside diagnoses. $3^{30}$ With the rise of 'laboratory medicine' in the mid-nineteenth century, Germany took over this leading international position, whereas in the twentieth century the United States increasingly assumed international leadership in the medical sciences. ${ }^{31}$ In the Netherlands, the pace of change was on average slower. Throughout the nineteenth century, promi-

\footnotetext{
${ }^{24}$ Mary E. Fissell, 'The Medical Marketplace, the Patient, and the Absence of Medical Ethics in Early Modern Europe and North America', in The Cambridge World History of Medical Ethics, pp. 533-539; Warner, The Therapeutic Perspective; Annet Mooij, 'Roddels, Ruzie, Achterklap. Veranderende omgangsvormen in de medische beroepsgroep', in Gewina Vol. 21 (1998), pp. 30-37.

${ }^{25}$ Roger Cooter, 'Medicine and Modernity', in Mark Jackson (ed.), The Oxford Handbook of the History of Medicine (Oxford: Oxford University Press, 2011), pp. 100-116.

${ }^{26}$ Fissell, 'The Medical Marketplace'.

${ }^{27}$ M.J. van Lieburg, 'De tweede geneeskundige stand (1818-1865). Een bijdrage tot de geschiedenis van het medisch beroep in Nederland', Tijdschrift voor Geschiedenis Vol. 96 (1983), pp. 433-453.

${ }^{28}$ Henri Festen, 125 jaar geneeskunst en maatschappij (Utrecht: Koninklijke Nederlandsche Maatschappij tot Bevordering der Geneeskunst, 1974).

${ }^{29}$ Tröhler, "“To Improve the Evidence of Medicine"”; Rusnock, 'The Weight of Evidence'.

${ }^{30}$ See: John Harley Warner, Against the Spirit of System. The French Impulse in Nineteenth-Century American Medicine (Princeton: Princeton University Press, 1998).

${ }^{31}$ Cunningham \& Williams, The Laboratory Revolution in Medicine; W.F. Bynum et al., The Western Medical Tradition, 1800-2000 (Cambridge: Cambridge University Press, 2006).
} 
nent physicians expressed frustration at the fact that the national Dutch government seemed unwilling to invest similar sums of money in the nation's hospital system or education programmes as their counterparts in France and Germany did. ${ }^{2}$ Likewise, to keep up with the latest insights in their field, students travelled to cities like Paris to receive medical training they felt was unavailable in the Netherlands. Until far into the twentieth century, such feelings of frustration would last. Systematic human experimentation was not possible in the Netherlands, the feeling was, because it lacked the infrastructure to bring together the know-how of academia, the "patient material" in hospitals, and the financial means of industry (also see chapter 2).

Yet, also in the Netherlands, medical research and practice underwent substantial changes in the nineteenth century, which stimulated systematic human experimentation. Around the 1850 s, the statistical method grew popular, the hospital system underwent significant revisions, and diagnostic laboratories were established. 33 The idea that poor hospital patients mainly served as "research material" became a trope in the Netherlands in this period. ${ }^{34}$ And by the turn of the century, members of Dutch parliament even started to wonder if measures had to be taken to bring the practice under public control, as reports reached them, especially from countries east of the border, of all sorts of ungodly activities taking place in medical laboratories. Members of the Dutch medical profession vehemently opposed such accusations-In the Netherlands, doctors knew and respected the boundaries of human experimentation. Nonetheless, within the ranks of the NMG too, some started to argue in the early twentieth century for additional safeguards to keep the practice within bounds.

\section{Moral traditions and social concerns}

Sometimes, the history of human experimentation prior to the advent of research ethics committees in the second half of the twentieth century is presented as one that could proceed in any shape or form without public or professional scrutiny. Historical research has shown, however, that already in the early modern period the practice of human experimentation attracted moral discussion. Dyck and Stewart, who have analysed the use of humans in early modern science experiments, claim that "trials upon the ill-informed, the desperate, and the unreliable raised clear and serious alarm in the minds of the experimenters" in the early modern period. ${ }^{35}$ Similarly, historians who have investigated experimental blood transfusions in the seventeenth century,

\footnotetext{
${ }^{32}$ Annet Mooij, De polsslag van de stad. 350 jaar academische geneeskunde in Amsterdam (Amsterdam: Uitgeverij De Arbeiderspers, 1999).

${ }^{33}$ Eduard Simon Houwaart, De hygiënisten. Artsen, staat en volksgezondheid in Nederland, 1840-1890 (Groningen: Historische Uitgeverij Groningen, 1991); Klasien Horstman \& Gerard de Vries, 'Experimenten met mensen. De constitutie van een medisch-wetenschappelijke praktijk en een ethisch probleem (Nederland, 1870-1915)', in Kennis en Methode Vol. 1 (1989), pp. 62-83; H. Beukers, 'Een nieuwe werkplaats in de geneeskunde. De opkomst van laboratoria in de geneeskundige faculteiten', in Tijdschrift voor de Geschiedenis van de Geneeskunde, Natuurkunde, Wiskunde en Techniek Vol. 9 (1986), pp. 266-277; M.J. van Lieburg, 'De ontwikkeling van het klinisch-diagnostisch laboratorium in Nederland tot omstreeks 1925', in Tijdschrift voor de Geschiedenis van de Geneeskunde, Natuurkunde, Wiskunde en Techniek Vol. 9 (1986), pp. 278-318.

${ }^{34}$ Mooij, De polsslag van de stad, p. 270; Annemieke Klein, Verlangen naar verbetering. 375 jaar academische geneeskunde in Utrecht (Amsterdam: Boom, 2010), p. 116.

35 'Introduction', in The Uses of Humans, pp. 1-27, p. 14.
} 
and smallpox inoculations in the eighteenth century, have shown that these practices at the time engendered heated disputes among physicians and philosophers about their ethical permissibility. ${ }^{36}$ "The point is not that this was a matter of a drastic morality", Dyck and Stewart explain, "but rather that the issue was then fairly acknowledged and well considered". ${ }^{37}$ Indeed, in his book Drugs on Trial on eighteenth century pharmaceutical drug trials, also Andreas-Holger Maehle argues that awareness existed that patients in these experiments served as research subjects. In clinical lectures, physicians emphasized the need for caution; experimenters were to proceed "as if one experimented on one's friends or on oneself". ${ }^{38}$ In addition, most physicians either served themselves as subjects or demanded that their patients were to benefit from participation. Nor did they typically hide the dangers of participation.

In the nineteenth century, fledgling medical professions in Europe and the United States developed more pronounced views on the permissibility of human experimentation. In her 2004 book Lesser Harms, Sydney Halpern argues that they developed moral traditions for handling the risks associated with untested remedies and surgical procedures. 39 These traditions, she emphasizes, were largely informal and uncodified: few formal mechanisms (legislation, state inspections) existed to prevent or repress excesses by individual researchers. Nonetheless, many physicians treated these traditions as if they were self-evident, nor did they shy away from shaming colleagues whom they believed to have transgressed the boundaries of the permissible in human experimentation. In the late nineteenth century, for instance, Louis Pasteur (18221895) sparked international debate amongst physicians when he inoculated the nineyear-old boy Joseph Meister-who had been badly bitten by a rabid dog-with a rabies vaccine that he had recently developed.40 Disagreement existed whether this experimental intervention had been justified. Had Pasteur conducted enough prior tests on animals, for instance, before moving on to humans? If not, many considered that the French scientist had violated a clear moral boundary.

Other imperatives, Halpern shows, were the practice of prior self-experimentation and the "logic of lesser harms", which stipulates that an intervention is only justified when the benefits are likely to outweigh the risks. Following Martin Pernick, Halpern traces this logic to the growing influence of statistical reasoning in medical practice in the mid-nineteenth century. Louis' numerical method, Pernick argues, introduced "a calculus of suffering" to medicine. Judicious physicians were expected to leave behind medical theories and traditions and instead establish the safety and efficacy of medical interventions solely by counting. ${ }^{41}$ The introduction of anaesthesia in American surgical practice in 1846, for instance, was justified using this calculus of suffering.

\footnotetext{
${ }^{36}$ See also: Simon Schaffer, 'Regeneration. The Body of Natural Philosophers in Restoration England', in C. Lawrence \& S. Shapin (eds.), Science Incarnate. Historical Embodiments of Natural Knowledge (Chicago: University Of Chicago Press, 1998), pp. 83-120; Peter Moore, Blood and Justice. The seventeenth-century Parisian doctor who made blood transfusion history (London: John Wiley, 2003).

37 'Introduction', in The Uses of Humans, p. 15.

${ }^{38}$ Maehle, Drugs on Trial, p. 103. Maehle does point out that dangerous trials did take place in the eighteenth century, not only with patients but also with healthy research subjects who typically found themselves in a dependent position to the experimenting physician - as their house pupil for instance.

${ }^{39}$ Halpern, Lesser Harms.

${ }^{40}$ Also: Gerald L. Geison, 'Pasteur's Work on Rabies. Reexamining the Ethical Issues', in Hastings Center Report Vol. 8 (1978), pp. 26-33.

${ }^{41}$ Pernick, A Calculus of Suffering.
} 
Anaesthesia was not without risk. Patients could and did die from this purposefully induced deep sleep and strong opposition existed among surgeons and physicians to the use of a procedure that could kill patients. However, proponents collected numerical evidence to prove that surgeries without anaesthetics killed a larger percentage of patients than surgeries with anaesthetics. ${ }^{42}$ Hence, on a population level, the calculus of suffering pointed in favour of anaesthesia. Although it was clear that some patients would never wake up due to the use of anaesthetics, more could be saved if the technology was used. According to Halpern, this utilitarian logic was increasingly used in the early twentieth century to justify experiments without a direct benefit for participating research subjects. Risks taken with individuals could be balanced "by the expectation of a contribution to the greater social good".43

In addition to the development of moral traditions within medical professions, the nineteenth century also saw growing social opposition to human experiments. In conjunction with the growing popularity of experimental medicine in this period, efforts to restrict scientific experimentation in medical practice grew stronger as well. Many of these attempts revolved around the practice of animal experimentation rather than human experimentation. Nonetheless, by the end of the nineteenth century, also the use of humans in medical research increasingly became a topic of concern for organizations dedicated to the prevention and abolition of animal research-typically called 'antivivisectionist societies'. Vivisection is a term that became popular in English and Germanic languages in the eighteenth century to denote the cutting of living bodies for scientific study. ${ }^{44}$ By the late nineteenth century, it was often used interchangeably with experimentation. When American researchers spoke of human vivisection, for instance, they referred to tests undertaken on human beings not for the benefit of the humans involved but to increase scientific understanding. ${ }^{45}$ In the Netherlands, 'vivisectie' mostly referred to animal experimentation, but could imply human experimentation as well. Until the 1960 s, it remained a commonly used term to reference invasive scientific experiments with living beings (mostly mammals).

A fairly extensive body of literature exists that details the history of antivivisection movements in the second half of the nineteenth and early twentieth century. These histories show that these movements have distinctly national components. The first organized antivivisectionist groups originated in England during the 1870s, a country where the opposition to animal experimentation historically has been strong (this, in contrast to France, that had a strong tradition in experimental medicine in the nineteenth century, but experienced far less social opposition). ${ }^{46}$ Historians have also shown, however, that antivivisection societies were founded around roughly the same time in most parts of Europe and the United States and that debates about merits and

\footnotetext{
${ }^{42}$ See also: Martin S. Pernick, 'The Calculus of Suffering in Nineteenth-Century Surgery', in The Hastings Center Report Vol. 13 (1983), pp. 26-36.

${ }^{43}$ Halpern, Lesser Harms, p. 5.

${ }^{44}$ Maehle \& Tröhler, 'Animal Experimentation from Antiquity', p. 14.

${ }^{45}$ Lederer, Subjected to Science, p. xiv.

${ }^{46}$ Richard D. French, Antivivisection and Medical Science in Victorian Society (Princeton: Princeton University Press, 1975); N. Rupke, 'Introduction', in Vivisection in Historical Perspective, pp. 1-13.
} 
dangers of vivisection were strikingly similar. 47 In the Netherlands, for instance, the English antivivisection movement was an important source of inspiration for the opponents of animal experimentation. In 1890, the Nederlandsche Bond ter Bestrijding der Vivisectie (Dutch Association for Combatting Vivisection, NBBV) was established with support of both English and German antivivisectionists. ${ }^{48}$

Of course, important differences existed among and within national antivivisection movements. Yet, on average, antivivisectionists expressed a few typical objections to animal experimentation. First of all, they argued it to be a cruel practice on par with other forms of animal violence. Early antivivisection societies were therefore often linked to animal protection groups. Secondly, they typically argued that torture inflicted on animals in the name of science blunted the minds and senses of scientists to the extent that they would inflict cruelty on humans as well. Once researchers had grown accustomed to causing suffering in animals, little would stop them from doing the same to children or the elderly. Hence, animal experimentation was nothing but a slippery slope towards human experimentation. Thirdly, for many antivivisectionists, a charge against vivisection included a charge against 'the corrupting effects of modern medicine'. The experimental tradition, they argued, had reduced the traditional healing art to a cold mechanistic science that prioritized scientific knowledge above patient care and that ignored everything not made out of matter. The germ theory of disease, for instance, had reduced illness to single deterministic causes and neglected the crucial influence of environment and psyche. Likewise, the bewildering array of medical specialties that had sprung up in the nineteenth century was argued to have fuelled a harmful reductionist perspective on life. This subdivision ignored that living beings were more than the sum of their parts who could only be understood in relation to the world around them. Felix Ortt, for instance, a founding father of the Dutch antivivisection movement, believed an inconceivable order to exist in the world that operated on and through everything-from the electron, molecule and cell, to the organism, society and state. Vivisectionists literally cut the connection to this ordering principle and would thus never be able to produce any true knowledge. 49

Historians have often argued that the late nineteenth century debate over vivisection was, in fact, a debate over the cultural authority of modern medicine and science. Vivisectionists represented the "priorities and aspirations of science", Nicolaas Rupke argues, "and scientists defended the practice, even if they had no direct contact with it". ${ }^{\circ}$ In contrast, those who opposed the practice did so because they "saw their cultural influence waning as that of science grew". ${ }^{51}$ Antivivisectionists were typically members of the aristocracy, clergy and judiciary, who feared to lose their traditional authority to the new classes of scientists and doctors. Marxist historian Jan Romein

\footnotetext{
${ }^{47}$ Ibid. See especially the contributions of: Guarnieri, 'Moritz Schiff (1823-96). Experimental Physiology and Noble Sentiment in Florence', pp. 105-124; Tröhler \& Maehle, 'Anti-vivisection in Nineteenth-century Germany and Switzerland. Motives and Methods', pp. 149-187; Bromander, 'The Vivisection Debate in Sweden in the 1880s', pp. 214-235; Lederer, 'The Controversy over Animal Experimentation in America, 1880-1914', pp. 326-258.

${ }^{48}$ Amanda Kluveld, Reis door de hel der onschuldigen. De expressieve politiek van de Nederlandse anti-vivisectionisten, 1890-1940 (Amsterdam: Amsterdam University Press, 2000), p. 49, p. 51.

${ }^{49}$ Amanda Kluveld, 'Felix Ortt. De kleine geloven als brug tussen wetenschap en geloof", in De Negentiende Eeuw Vol. 25 (2001), pp. 137-146.

${ }^{50}$ Rupke, 'Introduction', p. 8.

${ }^{51}$ Ibid., p. 8 .
} 
describes antivivisectionism as one of the various petites religions that gained popularity in the nineteenth century, a category in which he includes practices like magnetism, homeopathy, Buddhism, Christian-anarchism, and theosophy..$^{52}$ All found their support among members of the bourgeoisie, who rallied against the demystified and materialistic existence of the modern industrialised world in which distant scientific understanding had come to dictate the general pace of life. 53

Other historians take issue with this representation of the antivivisectionists. Susan Lederer, for instance, criticizes the equation of antivivisectionism to anti-science sentiments for the context of the United States in the early twentieth century. This dichotomy, she argues, fails to capture the multiple and fluid meanings that medical science itself embodied during this period. ${ }^{54}$ Likewise, in her history of Dutch antivivisectionism, Amanda Kluveld points out that antivivisectionists did not so much denounce 'modern science', but rather offered an alternative integration of elements of science, religion, and philosophy to the by then established scientific order. ${ }^{55}$ Ortt, for one, drew on Maxwell's laws of thermodynamics in his ideas of an all-ordering principle. Still, both historians agree that antivivisectionists did position their perspectives as an alternative to 'the evils of modern science'. In turn, they were typically denounced by their opponents as a mindless group of quacks.

The practice of human experimentation fulfilled a specific role in these tugs of war. On the one hand, for many antivivisectionists, animal and human experiments were intimately related. Not unjustly, the impression existed that vulnerable social groups were more likely to fall victim to the vivisector's knife than the well-to-do. Orphans, mental patients, prisoners-for antivivisectionists they were all powerless individuals in dire need of protection. As such, they were not so different from animals. A difference in degree existed, but not in kind. Yet, at the same time, antivivisectionists often instrumentally drew on cases of unethical human experiments to lobby for legislation restricting animal vivisection. In Dutch parliament in 1903, for instance, a member of the Anti-Revolutionary Party (ARP) warned Prime Minister Abraham Kuyper against the dangers of human experiments to convince him that animal vivisection had to be brought under legal control:

And, above all, Mister Chairman, a statutory regulation of vivisection would be necessary for the upcoming generation of professors and doctors, so that we can entrust to them with confidence the weak, the poor, amongst us. It is for the sake of them that I called vivisection a harrowing national distress. ${ }^{6}$

He did not want to suggest that unethical experiments took place in Dutch hospitals, but it was well known that in "clinics abroad" the most terrible tests had been taken

\footnotetext{
${ }^{52}$ Jan Romein, Op het breukvlak van twee eeuwen 2nd Ed. (Amsterdam: Em. Querido's Uitgeverij, 1976), pp. 631-651.

${ }^{53}$ For a clear exposition of Romein's understanding of the petites religions in the context of Dutch medical history around the turn of the twentieth century, see: Frank Huisman \& Henk te Velde, 'Op zoek naar nieuwe vormen in wetenschap en politiek. De 'medische' kleine geloven', in De Negentiende Eeuw Vol. 25 (2001), pp. 129-136.

${ }^{54}$ Lederer, Subjected to Science.

${ }^{55}$ Kluveld, Reis door de hel der onschuldigen.

${ }^{56}$ Handelingen Tweede Kamer 1903-1904, 12 december 1903, pp. 865-866.
} 
on humans. Rumour went that even "children and chaste maidens" had deliberately been infected with syphilis for its scientific study! That was why legislation for animal vivisection was needed now in the Netherlands, before also the minds and senses of Dutch vivisectors had become so blunted that they would be unable to refrain themselves in conducting this type of godless practices on humans.

Hence, due to the vocal and well-organized social opposition to animal vivisection, the practice of human experimentation started to gain in attention in Dutch political circles around the turn of the twentieth century. Still, no political party actually called upon the Dutch government to take measures against the conduct of experiments on human beings as such. The antivivisectionist framework emphasized a need to bring the suffering of weak members of society to an end. As humans on average were more capable to defend themselves than animals, their plight took a backseat in the battle against "the dark sides of modern experimental medicine".

Parliamentary discussions of human vivisection did have the effect that members of the Dutch medical profession started to pronounce more explicit views on its appropriate governance around the turn of the twentieth century. In 1904, for instance, Editor of the Dutch Journal of Medicine Hendrik Burger reacted shocked to the insinuation by a member of Dutch parliament that dubious human experiments might take place at the hands of Dutch doctors. Half of his reaction served to dismiss such unfounded accusations. Admittedly, in countries like Germany abuse had taken place, but little proof existed that Dutch physicians were equally guilty of unethical medical experiments on humans. Half of his reaction, however, also served to remind readers of the Dutch Journal of Medicine that "tests upon human beings which only satisfy our medical curiosity and that do not meet the distinct medical grounds of a specific case deserve absolute disapproval". ${ }^{57}$ Physicians who wanted to conduct medical experiments could only use their own bodies for doing so.

Burger also urged his readers to be vigilant. It was the duty of every physician to speak up when he suspected another colleague to cross the line. To suit the action to the word, he therefore proceeded to scold a member of the Dutch medical profession who had recently stated he was willing to give a homeopath access to his patients just to prove that the homeopathic doctrines were unfounded. If one was sure a therapy had no effect, Burger wrote sternly, it was deeply unethical to expose patients to such haughty experiments. This editorial comment led to a heated dispute in the Journal whether this naming and shaming was proper etiquette. Yet, Burger considered it his duty as an editor to condemn unethical research studies..$^{8}$ Failure to do so, he stated, would undermine the public's trust in the Dutch medical profession.

\footnotetext{
${ }^{57}$ H. Burger, 'Proefnemingen op menschen', in Nederlandsch Tijdschrift voor Geneeskunde (1904), Part I, pp. 317-320, p. 318.

${ }^{58}$ W. Koster, 'Nog eens proefnemingen op menschen', in Nederlandsch Tijdschrift voor Geneeskunde (1904), Part I, pp. 378-379; H. Burger, 'Nog eens proefnemingen op menschen', in Ibid., pp. 379-380; J.C. Kindermann, 'Proefnemingen op menschen', in Ibid., pp. 414-415; H. Burger, 'Proefnemingen op menschen', in Ibid., pp. 415-416; W. Koster, 'De bewijsvoering van Dr. Burger', in Ibid., pp. 463-465; H. Burger, 'De bewijsvoering van Dr. Burger', in Ibid., pp. 466-467; M.A. Brants, 'Proefnemingen op menschen', in Ibid., pp. 520-522; H. Burger, 'Proefnemingen op menschen', in Ibid., pp. 522-524.
} 
Physicians like Burger with influential positions in the Dutch medical profession frequently used their authority to moralize the practice of medicine in the early twentieth century. They did so, because they were convinced that medicine primarily had to be governed with processes of internal control. Until the rise of the patients' rights movement in the 1970 s (see chapter 3), it was common in the Dutch language to refer to the doctors' collective as the artsenstand, i.e. "a class of physicians". Membership was allotted only to those with a license to practice and who conducted themselves in a manner that could be expected from 'gentlemen', with dignity and prudence.59 As a class, physicians were part of Dutch society, but stood apart from it at the same time. Their conduct was regulated by mores specific to the medical profession.

Hence, ethical guidelines and peer pressure served to regulate the conduct of practitioners. While physicians were subject to the law like anyone else, ethical wisdom in medicine was understood to come with years of experience, i.e. , it required the lived experience of being a doctor to be able to judge what was right and wrong in medical practice (and science) and which measures had to be taken in case of misbehaviour. Right or wrong depended on context and could not be fixed by hard legislation. From this, it followed that the governance of medicine was first and foremost a professional affair. Members of the artsenstand had a duty to hold each other accountable, as only they could really understand what it meant to be a physician. Vice versa, the interference of 'medical outsiders' with the practice of medicine was often treated with suspicion, as laypeople did not possess the lived experience of a physician.

This class ideology translated itself in various safeguards of internal control. First of all, seasoned practitioners had a responsibility to instil a sense of right and wrong on younger generations. They led by example, at the bedside and in classes. Secondly, physicians reminded each other of the ethics of their practice through both the written and spoken word. Although it would take until 1936 in the Netherlands before the NMG published its first booklet on medical ethics, it was common since the founding of the Dutch Journal of Medicine in 1857 for physicians to discuss the ethics of medicine in its pages or even to publish entire lectures on the subject. ${ }^{60}$ Thirdly, from 1905 onwards, the NMG held disciplinary hearings to hold physicians responsible for any misbehaviour (in 1930, these internal organs were augmented by an official medical court in which colleagues and jurists had a seat). Finally, one of the most important safeguards was a physician's professional identity: the moment someone adopted this identity, he no longer just represented himself but the artsenstand as a whole. Since a single physician's misconduct reflected badly upon the entire profession, he carried a weighty responsibility towards his colleagues to constantly be on his best behaviour. Even more, he carried this responsibility to all of society, because if patients would lose faith in the artsenstand due to bad press, they would seek refuge in the arms of quacks, to their own detriment. Consequently, the duty "not to undermine trust in the medical profession" became one of the most reiterated sayings in publications like the Dutch Journal of Medicine in the early twentieth century.

\footnotetext{
${ }^{59}$ For more on the notion of the old gentleman-physician, see: Edward Shorter, Bedside Manners. The Troubled History of Doctors and Patients (New York: Simon and Schuster, 1985).

${ }^{60}$ Mattheus Colenbrander, C. Fehmers \& Theodoor Hammes, Medische Ethiek (Amsterdam: Nederlandsche Maatschappij tot Bevordering der Geneeskunst, 1936); Hector Treub, Medische Fatsoensleer. Drie Colleges (Amsterdam: Scheltema \& Holkema, 1903).
} 
Human experimentation by no means figured prominently in most publications of Dutch physicians on medical ethics. More common were themes like medical confidentiality (crucial) and commercial advertising (objectionable). Still, from the early twentieth century onwards, probably in response to growing antivivisectionist complaints, members of the Dutch medical profession did start to discuss the appropriate stance of members of the Dutch artsenstand towards human experimentation more regularly, as Burger did in 1904. Yet, such considerations did not translate in explicit ethical guidelines for the practice in the early twentieth century. In the 1936 NMG ethics booklet, the topic was wholly neglected even. Its chapters addressed themes like 'the general demeanour towards the public', 'poor care', and 'how to pass on one's practice upon retirement', but not human vivisection. ${ }^{61}$ This held true for most countries. Explicit guidelines-let alone official regulations-for medical tests upon human beings are for the most part a product of the post-1945 period. ${ }^{62}$

Various reasons exist why formal regulations did develop in the second half of the twentieth century for the governance of human experimentation. One, which will be discussed in chapter 2, is the fact that World War II provided an enormous stimulus for the systematic conduct of medical experiments with human beings, leading some historians to conclude that human experimentation before World War II was in comparison nothing more than a "cottage industry". Another, which will be discussed in chapters 3 and 4, is the fact that another type of societal opposition to "modern medicine' surfaced in the 1960 s and 1970 s, which was much more successful in convincing governments that medical research and practice had to be brought under public control than the Dutch antivivisectionists had ever been. First, however, this chapter discusses the cultural impact which World War II and especially the Nazi concentration camp experiments had in this regard. ${ }^{63}$

Today, the notion of 'human experimentation' is closely associated with the atrocities committed in Nazi concentration camps in the name of medical science. Searching it online, for instance, immediately brings up images of SS doctors submitting camp prisoners to gruesome experiments that often ended only in death. Likewise, in present-day textbooks and policy reports on the ethics of human subjects research, they often serve as a self-evident reminder why restrains just have to be imposed by public authorities on human research. This chapter shows, however, that in the immediate post-war era, when the first foundations for the regulation of human experimentation were laid in the Netherlands, Dutch physicians drew on their war experi-

\footnotetext{
${ }^{61}$ Colenbrander, Fehmers \& Hammes, Medische Ethiek.

${ }^{62}$ A notable exception was Germany. Already in 1900, the Prussian government had issued Instructions that advised surgeons and physicians to obtain informed consent. In 1931, the German Reich's Ministry of the Interior sent around Richtlinien to each of the German federal states which strictly condemned non-therapeutic experiments on patients and emphasized the importance of what is now called 'informed consent' for any intervention other than diagnostic or therapeutic ones. At the time, this type of formal state measures were internationally without precedent. See: Elkeles, 'The German Debate on Human Experimentation between 1880 and 1914', pp. 19-34; Nadav, 'The "Death Dance of Lübeck": Julius Moses and the German Guidelines for Human Experimentation, 1930', pp. 129-135.

${ }^{63}$ The experiments in Japanese camps during World War II should not been forgotten. However, in the immediate post-war decade, little was known about these experiments in the Netherlands. Dutch physicians and antivivisectionists solely referred to the "Nazi" or "German" concentration camp experiments in publications. For more information on the Japanese experiments, see: Takashi Tsuchiya, 'The Imperial Japanese Experiments in China', in The Oxford Textbook of Clinical Research Ethics, pp. 31-45.
} 
ences to rally against any form of state involvement with medicine. For them, the war had taught that only an artsenstand could safeguard ethical medicine.

This chapter also shows how this was starkly different for groups who had rallied since the late nineteenth century against the hegemony of the medical profession and its support for experimental medicine. After the war, Dutch antivivisectionists found definitive proof in the Nazi concentration camp experiments of the debilitating effects of 'modern medicine'. It had reached its pinnacle in the horror chambers of the Third Reich. Crucially, it was in the context of the political confrontation between these two camps in 1955, that the Dutch government was first advised to consider governing the practice of human experimentation with a system of ethics by committee.

\section{The Nazi experiments and the Dutch medical profession}

From 9 December 1946 to 20 August 1947, 20 medical doctors and three Nazi officials were brought before the US military court in the Nuremberg Palace of Justice to stand trial for mass murder under the guise of euthanasia and involvement in a series of experiments that were executed on prisoners of the Nazi concentration camps. ${ }^{64}$ This tribunal has become known as the Doctors' Trial, which laid bare the gruesome atrocities committed by the Nazis in the name of medical science. Prisoners had been subjected to lethal sea-water, high-altitude, and freezing experiments; to tests measuring the effects of poisonous bullets, mustard gas, and incendiary bombs; to sterilization experiments which frequently resulted in severe debilitation; to name a few of the experiments. From 1945 to 1947, horrific descriptions of these studies found their way into the pages of Dutch newspapers. ${ }^{65}$ Dutch journalists discussed them in tones of disbelief and horror. The experiments demonstrated the absolute inhumanity of the Nazi regime: how camp prisoners had been brutally tortured, maimed, and killed without so much of a hint of compassion in those responsible for them.

In the Dutch Journal of Medicine, the Nazi concentration camp experiments were condemned as the work of pure evil that were a far cry removed from civilized medical science. To emphasize this, words like 'medical' and 'colleagues' were put between brackets in journal descriptions of the Nazi experiments. ${ }^{66}$ Vice versa, in discussing 'regular human experiments', any connection with the concentration camps was emphatically denied. "We have to get rid as soon as possible of the unpleasant associations linked to experiments due to the criminal actions of many Germans", one physician wrote in Medisch Contact in 1949, "as they may form a hindrance in scientific

\footnotetext{
${ }^{64}$ See: Paul J. Weindling, 'The Nazi Medical Experiments', in The Oxford Textbook of Clinical Research Ethics, pp. 18-30; Ulf Schmidt, 'Medical Ethics and Nazism', in The Cambridge World History, pp. 595-608; Michael R. Marrus, 'The Nuremberg Doctors' Trial in Historical Context', in Bulletin for the History of Medicine Vol.73 (1999), pp. 106-123.

${ }^{65}$ See for instance: 'De nieuwe procesronde in Neurenberg. Experimenten op mensen worden berecht. Gruwelijke details', in Het Vrije Volk Tuesday 10 December 1946, p. 3; 'Het proces tegen de fabeltjes. Medici staan terecht te Neurenberg', in De Tijd Tuesday 10 December 1946, p. 3; 'Kinderen werden gesteriliseerd in Ravensbrück', in De Waarheid Saturday 21 December 1946, front page; 'Gevangenen werden met mosterdgas bewerkt. Gruwelijke bijzonderheden voor het hof te Neurenberg', in De Waarheid Saturday 4 January 1947, front page.

${ }^{66}$ F. Dekking, 'Medische' experimenten in Duitsche concentratiekampen', in Nederlandsch Tijdschrift voor Geneeskunde Vol. 90 (1946), p. 1011; F. Dekking, 'Het proces der Duitse artsen', in Nederlandsch Tijdschrift voor Geneeskunde, Vol. 91 (1947), pp. 1830-1833.
} 
traffic". ${ }^{67}$ Indeed, the Editor of the Dutch Journal of Medicine Joghem van Loghem stressed in 1953, "Those who tackle the permissibility of tests upon humans, need to dissociate the subject from its German past". ${ }^{68}$

Historians generally agree that in the first two decades after World War II, medical professions around the world evaluated the concentration camp experiments as 'Nazi exceptionalism'.69 The Nuremberg Code, for this reason, was virtually ignored by the international medical community in the immediate post-war period..$^{\circ}$ On August 19, 1947, this Code had been promulgated by the four American judges presiding over the Doctors' Trial as part of their verdict. The hope was that such a reminder would in the future prevent horrors in the conduct of human experiments. The Code consisted of ten principles, including the principle of informed consent, the absence of coercion, and the requirement of an appropriate risk-benefit ratio for participating research subjects. It was the first ever official international code of medical ethics and is nowadays considered by many people as "the primary foundational document informing all ethics codes on research with humans" ${ }^{71}$ Yet, in the immediate post-war decades, as ethicist Jay Katz has famously observed, many considered it "a good code for barbarians but an unnecessary code for ordinary physician-scientists”, i.e., Nuremberg would not pertain to the conduct of civilized medical researchers. ${ }^{72}$

Indeed, also in the Netherlands between 1953 and 1955, the existence of the Code was never once acknowledged by the Health Council committee 'tests upon human beings'. Equally, the Nazi concentration camp experiments were brought up only two times. Once, during its first meeting, when the President made clear that there was no need to discuss them.73 Once, when the committee was selecting possibly relevant literature for her reflections on the governance of human experimentation and a dissertation on medicine in the German concentration camps was brought up. ${ }^{74}$ Also this work needed no discussion, the committee decided, as it described Nazi crimes and was therefore irrelevant for the topic under consideration. 75

\footnotetext{
${ }^{67}$ D.K. de Jongh, 'Medische ethiek. Antwoord aan Prof.dr. G.C. Heringa', in Medisch Contact Vol. 4 (1949), pp. 600-604, pp. 602-603.

${ }^{68}$ J.J. van Loghem, 'Geneeskundige proefnemingen bij mensen', in Nederlands Tijdschrift voor Geneeskunde Vol. 97 (1953), pp. 518-520, p. 518. This dissociation of medical science from the Nazi crimes was an active strategy of the prosecution at Nuremberg, which sought to prove that the experiments "revealed nothing which civilized medicine can use". See: Telford Taylor, 'Opening Statement of the Prosecution. December 9, 1946', reprinted in The Nazi Doctors, pp. 67-93, p. 91.

${ }^{69}$ Rothman, Strangers at the Bedside, pp. 62-63; Baker, 'Transcultural Medical Ethics', pp. 319-320; Jenny Hazelgrove, 'The Old Faith and the New Science. The Nuremberg Code and Human Experimentation Ethics in Britain, 1946-73', in Social History of Medicine Vol. 15 (2002), pp. 109-135; Weindling, 'The Origins of Informed Consent, pp. 37-71; Wilson, The making of British bioethics.

${ }^{70}$ A 1998 study into the adoption of the Nuremberg principles by national medical associations in the second half of the twentieth century suggests that the Code remained virtually unknown in most of South America, Europe, and the United States until at least the mid-1960s. See: Gonzalo Herranz, 'The Inclusion of the Ten Principles of Nuremberg in Professional Codes of Ethics: An International Comparison', in Ethics Codes in Medicine, pp. 127-139.

${ }^{71}$ George J. Annas \& Michael A. Grodin, 'The Nuremberg Code', in The Oxford Textbook of Clinical Research Ethics, pp. 136-140, there: p. 136.

${ }^{72}$ Jay Katz, 'The Consent Principle of the Nuremberg Code. Its Significance Then and Now', in The Nazi Doctors, pp. 227-239, p. 228.

${ }^{73}$ NL-HaNA, 2.15.33, 548, Minutes proeven op mensen, 14 december 1953, p. 7.

${ }^{74}$ This dissertation was: Elie Aron Cohen, Het Duitse concentratiekamp. Een medische en psychologische studie (Amsterdam: Uitgeverij H.J. Parijs, 1952).

${ }^{75}$ NL-HaNA, 2.15.33, 548, Minutes proeven op mensen, 11 maart 1954, p. 8.
} 
Still, Dutch physicians worried that the Doctors' Trial had put a slur on the reputation of 'scientific human experimentation'. In the Dutch Journal of Medicine, Van Loghem lamented that "the treatment of the subject [in the Trial] has apparently had the result that, more than before the war, people nourish distrust of the ethics of experimental research" ${ }^{76}$ Not only had the revelations of the Nazi concentration camp experiments scared people, the defence had also dared to produce a list during the Trial with international literature published in the last century to prove that ethical transgressions in medicine were by no means a new phenomenon in the Third Reich. Van Loghem, who was appalled by the comparison of the Nazi crimes to regular medicine, worried that this social unrest still had not died down by 1953.77

This strong dissociation with the concentration camp experiments certainly does not imply that Dutch physicians expressed no concern whatsoever about the conduct of human experimentation in those early years after World War II. Articles like those by Van Loghem, for instance, served to remind readers of the Dutch Journal of Medicine of their moral responsibilities when experimenting on humans. "Every founded consideration of the subject will strengthen the awareness of our responsibility", Van Loghem wrote in $1953 .{ }^{78}$ Yet, he considered the faulty association with the concentration camp experiments to be a knife to the heart for a scientific practice that, with the right safeguards, was essential for the practice of medicine to progress.

For this reason, some Dutch physicians even felt that ethical concerns about medicine should not be debated in public at all. Laypeople might get the wrong impression and call for outside interference with affairs that concerned the artsenstand only. In 1949, for instance, editor of Medisch Contact Gerard Heringa wrote a stern reply to a philosophical paper that was published in his journal questioning the foundations of medical ethics and that dedicated a large segment to the question if therapeutic experiments with humans were permissible and, if so, under what circumstances. "Personally I regard this publication with concern", Heringa reproached, "because I fear it will cause confusion and shake trust in the artsenstand. I do not see much good in the public discussion which is bound to follow". 79 The paper's author was convinced that Heringa exaggerated. "Surely, the layperson intelligent enough to read our articles is capable to set apart the mentality of a Nazi from that of a Dutch physician", he wrote in reply. ${ }^{80}$ Heringa was adamant, however, that the subject had to be treated with the utmost care to prevent measures from being taken that could possibly shake the public's trust in the Dutch medical profession. For that reason, he persuaded an-

\footnotetext{
${ }^{76}$ Van Loghem, 'Geneeskundige proefnemingen bij mensen', p. 518. Emphasis in original.

${ }^{77}$ Ibid., p. 518. During the Doctors' Trial, the defense had offered evidence that also American researchers had conducted dangerous experiments on prisoners during World War II. See: Ulf Schmidt, 'The Nuremberg Doctors' Trial and the Nuremberg Code', in History and Theory of Human Experimentation, pp. 71-116; Jon M. Harkness, 'Nuremberg and the Issue of Wartime Experiments on U.S. Prisoners. The Green Committee', in Journal of the American Medical Association Vol. 276 (1996), pp. 1672-1675. For an example of a Dutch newspaper report, see: 'Amerikaanse artsen nemen proeven op mensen', in De Waarheid, Dinsdag 11 Februari 1947, p. 2.

${ }^{78}$ Van Loghem, 'Geneeskundige proefnemingen bij mensen', p. 520. See also: J.J. van Loghem, 'Geneeskundige proefnemingen bij mensen (II) \& (III)', in Nederlandsch Tijdschrift voor Geneeskunde Vol. 98 (1954), pp. 2266-2267, pp. 3038-3039.

${ }^{79}$ G.C. Heringa, 'Medische Ethiek, Practische Geneeskunde en Wetenschap', in Medisch Contact Vol. 4 (1949), pp. 539-545, p. 540. In response to: D.K. de Jongh, 'Over medische ethiek', in Medisch Contact Vol. 4 (1949), pp. 526-532.

${ }^{80}$ De Jongh, 'Medische ethiek. Antwoord aan Prof.dr. G.C. Heringa', p. 602.
} 
other colleague that year to withdraw a submission on the ethics of clinical research. In "times of turmoil", the subject really was unfit for public discussion. ${ }^{81}$

That public unrest over the Nazi concentration camp experiments might result in outside interference with the practice of medicine, disturbed Dutch physicians. Partly, they framed this concern in a familiar rhetoric of the importance of protecting the artsenstand. But, partly, the memory of the recent occupation of the Netherlands also fuelled a belief among Dutch physicians that their practice had to be defended against any form of political ideology and government bureaucracy.

In 1946, this feeling was articulated with passion in Medisch Contact by the eminent Dutch physician Jean Jacques Brutel de la Rivière. The journal Medisch Contact was not just any magazine and Brutel, as he was mostly called, not just any physician. During the war, a number of Dutch physicians had united themselves in a resistance group called Medisch Contact ('medical contact') which was much celebrated in later years. In May 1945, this group published its first Announcements and in 1946, this publication gained status as one of two official journals of the NMG (the other being the Dutch Journal of Medicine). Brutel had been one of the leaders of Medisch Contact and had towards the end of the war led the 'Large Advisory Committee of Illegality', installed by Queen Wilhelmina to coordinate the activities of all Dutch resistance groups. ${ }^{82}$ In 1945, Brutel became President of the NMG, a position he traded in two years later for the joint Presidency of the Health Council and the Central Committee for Public Health. ${ }^{83}$ He was made an honorary member of the NMG in 1947, and was showered with other honorary titles and metal in the years thereafter (including the American Medal of Freedom that was awarded to 20 Dutch citizens in 1953 for their war efforts). ${ }^{84}$ Also, not entirely unimportant, from 1953 to 1955, Brutel chaired the Health Council committee 'tests upon human beings', a role in which he wrote most parts of the first ever Dutch policy document on human experimentation.

In his 1946 essay in Medisch Contact, Brutel reflected on the position of the Dutch medical profession in a country which he believed was at sea. Born in 1885, he wrote, he had witnessed the effects of urbanization, industrialization, and far-reaching 'pillarization' on Dutch society, and lived through a devastating economic crisis and two World Wars. As a result of these developments, Brutel concluded in 1946, the Netherlands had lost its internal social stability and moral anchors:

\footnotetext{
${ }^{81}$ NL-HaNA, 2.15.33, 549, letter of F. Wibaut to P.A. van Luijt', 11 February 1954.

82 'Dr. J.J. Brutel de la Rivière 60 jaar arts', in Nederlands Tijdschrift voor Geneeskunde, Vol. 116 (1972) , pp. 585-586. See also: G.A. Lindeboom, Dutch medical biography. A biographical Dictionary of Dutch Physicians and Surgeons 1475-1975 (Amsterdam, 1984), pp. 1642-1643; 'Installatie Nationale Advies Commissie. Een stap op den weg naar een nood-parlement', in Veritas, Saturday 21 July 1945, 1. On the Dutch medical resistance, see: The issue 'Artsen en hun oorlog' of Medisch Contact Vol. 64 (2009), Nr. 18, 29 April 2009; Hanna van den Ende, 'Vergeet niet dat je arts bent'. Joodse artsen in Nederland, 1940-1945 (Amsterdam: Boom, 2015).

${ }^{83}$ R.B.M. Rigter, Met Raad en Daad. De geschiedenis van de Gezondheidsraad, 1902-1985 (Rotterdam: Erasmus Publishing, 1992).

84 'Amerikaanse onderscheidingen voor twintig Nederlanders. Medal of Freedom o.a. voor de ministerpresident', in De Tijd, Tuesday 7 April 1953, p. 4.
} 
The notions of 'morality' and 'immorality' currently flow between anchorages lost and new ones yet unfound. Nobody knows exactly what they will mean and how they should be formulated, to help us understand human behaviour in an age of industry and city life. We are standing in between two worlds, one dead and the other barely born. It is our faith to live through a generation of chaos. ${ }^{85}$

As long as Dutch society was in flux, physicians could not trust their milieu exterieur to sustain them with the necessary moral fibre to fulfil their professional duties. Now more than ever, therefore, a strong and independent organization of the Dutch medical profession had become essential for ethical medical practice.

According to the primus inter pares Brutel, the NMG had an essential role to fulfil in this regard. ${ }^{86}$ The medical society had to cultivate a moral tradition among Dutch physicians to prevent abuse by actively spreading knowledge about its medical ethics and to repress abuse with its internal justice system (that, in turn, was likely to have a preventive effect). Brutel was worried, however. In the last half century, the professional function of the NMG had watered down due to a growing influence of health insurance funds and government policy on the organization of medical practice. More and more, physicians in the Netherlands worked in employment rather than as free agents, with the result that they increasingly valued company mores above professional traditions. Slowly but surely, this bureaucratization of medicine would erode the moral standards held high by the artsenstand and replace them with the norms of the state, which were formal and sterile, weak and capricious.

Brutel claimed he had first noticed how the absence of a robust profession negatively affected compliance with communal norms in the Dutch East Indies, where he had practiced medicine from 1916 to 1926 . Yet, it was his war experience which had convinced him that medical practice did not mix with state interference. Twice in his letter, he pointed out that it had been physicians employed by the state who had felt least compelled to join the resistance during the war. Twice, he referred to them as "the weakest link", who lacked the professional identity and awareness of the moral duties which defined the physician. ${ }^{87}$ "Any norms stipulated by the state or the health funds", Brutel wrote in conclusion of his letter, "will inevitably carry a more formal character and will be bound to official rules and regulations. They will lose the character of living norms which have up until now kept patients safe or at least better protected than would have been possible any other way". ${ }^{88}$

Hence, if it was up to Brutel, the government had to stay clear from any interference with the organization of medicine, certainly if it concerned medical ethics. Only the artsenstand could cultivate a moral tradition which would guide and regulate the behaviour of physicians. To this end, the NMG announced plans in 1947 to ensure that the "spiritual unity" that had kept Dutch physicians strong during the war would not be lost. The organization admitted that, in the past, it had sometimes focused too much on material gain. "The complaint, that our Society was too much of a trade un-

\footnotetext{
${ }^{85}$ J.J. Brutel de la Rivière, 'Uitoefening der Geneeskunst in Vrij Beroep tegenover deze Uitoefening in Dienstverband', in Medisch Contact Vol. 2 (1947), pp. 189-197, there: p. 191.

${ }^{86}$ Dutch medical historian Mart van Lieburg refers to Brutel as primus inter pares, in: M.J. van Lieburg, 'Vergeten helden', in Medisch Contact Vol. 64 (2009), pp. 812-815.

${ }^{87}$ Brutel de la Rivière, 'Uitoefening der Geneeskunst in Vrij Beroep', p. 194, p. 197.

${ }^{88}$ Ibid., p. 197.
} 
ion, has been voiced repeatedly, and certainly not by the least of us". ${ }^{89}$ Accordingly, in an attempt to mitigate such concerns, the NMG would establish new departments that would deal with matters of medical ethics. In 1949, when the medical association celebrated its centennial birthday and was awarded the Royal prefix (KoninklijkKNMG), Brutel ended the festivities by calling for a work to be written that would "adapt our existing medical ethics to the radical changes that have taken place in the profession of medicine and in society at large"..$^{\circ}$ That same year, the KNMG installed a Committee Professional Confidentiality, followed up in 1954 by a Committee Medical Ethics, with the task to write a booklet on medical ethics that could be presented ceremoniously to all Dutch medical students upon receiving their degree to symbolize the moral duties they assumed as full-fledged members of the Dutch artsenstand (see also chapter 3). ${ }^{91}$ The organization was confident that such initiatives would serve to cultivate the moral tradition which Brutel was convinced would provide the best safeguard against any professional misconduct by Dutch medical practitioners.

The governance of human experimentation held a central position in this renewed attention of the Dutch artsenstand for the ethics of their profession. Concerns existed among Dutch physicians in the immediate post-war period that the traditional moral standards were shifting for this practice. In many international journals, they argued, experiments that were frowned upon only yesterday, now filled up the pages without much sign of alarm. Towards the end of the 1940s, therefore, a few Dutch physicians started a lobby to bring the ethics of medical experiments on human beings under the attention of their colleagues. Notably, they did so on an international rather than national platform. Apparently, Dutch physicians had become convinced that especially their colleagues in other countries needed an explicit reminder of the ethics of human experimentation. With this, they did not so much have their 'colleagues' in Germany in mind, but their colleagues in countries such as the United States, who seemed to be willing to engage in human experimentation with evermore speed.

The first request for more explicit international attention for the ethics of human experimentation came in 1949. That year, the General Assembly of the KNMG debated whether to adopt the Declaration of Geneva, which had been promulgated by the recently established World Medical Association (WMA) in 1948 to provide physicians around the world with a modern-day adaptation of the Hippocratic oath..$^{22}$ The WMA hoped that, by 'updating' this traditional symbol of the worldwide medical profession, a global medical community could be sustained that could withstand the potentially debilitating effects of national political regimes. 93

\footnotetext{
${ }^{89}$ F.Wibaut, 'Reorganisatie der Maatschappij, betekenis der te stichten secties', in Medisch Contact Vol. 2 (1947), pp. 1-4, p. 1, p. 2.

${ }^{90}$ Heringa, 'Medische ethiek, practische geneeskunde en wetenschap', p. 539.

91 'Medische Ethiek anno 1970. Inleiding van de voorzitter der Maatschappij, Dr. L. van der Drift, ter Algemene Vergadering op 18 april 1970 te Utrecht', in Medisch Contact Vol. 25 (1970), pp. 413-417.

92 A. Frewer, 'Human Rights from the Nuremberg Doctors Trial to the Geneva Declaration', in Medicine, Health Care and Philosophy Vol. 13 (2010), pp. 259-268.

${ }^{93}$ F. Wibaut, 'Notulen vergadering 5 februari 1949', in Medisch Contact, Vol. 4 (1949), pp. 22-27.
} 
The idea was that all members of national medical organizations would take this new 'physician's oath'. However, when the Geneva Declaration was put to vote at the KNMG's annual meeting in 1949, several members of the Dutch medical organization professed they were unimpressed by the principles set forth by it. Not only was this physician's oath phrased as a "typically sentimental American promise", it also failed to acknowledge a central element of modern medicine: the practice of human experimentation. ${ }^{44}$ As representatives of the Alkmaar division argued:

The fact is that more and more tests upon human beings are conducted for the purpose of medical-clinical or other scientific research. [...] The Alkmaar division is of the opinion that our Society needs to raise her voice and combat this evil, against which we need to defend ourselves both morally and practically. 95

The Alkmaar division therefore urged the Central Board of the KNMG to request the WMA to have the Geneva Declaration explicitly mention the role and responsibilities of scientific researchers. Despite this passionate plea, the KNMG's General Assembly voted in favour of the Declaration, albeit with a difference of only four votes. ${ }^{96}$ Undeterred, in 1951, the Alkmaar division tried again. In a letter sent to all local departments of the medical association, it raised the alarm about the increase of studies describing human experiments in international medical journals: "The mentality that speaks from the literature is an indicator that the ethical standards of doctors are in great danger". ${ }^{77}$ Again, the Alkmaar division urged the Central Board to persuade the WMA to issue an official statement about the limits of human experimentation. What was more, it recommended to request editors of medical journals to take these into consideration in their refereeing process. After all, their institutional authority made them ideal safeguards against the conduct of unethical experiments.

The Central Board responded by asking Roel Hamburger, head of the Alkmaar division to co-author a report on the subject that could be sent to the WMA for further consideration. ${ }^{8}$ In 1953, this position paper was discussed by the Committee Medical Ethics of the international medical association. It was the first time that the ethics of human research made the agenda of an international organization. ${ }^{99}$ In 1954, both authors were invited to present their position paper to the WMA's General Assembly in Rome. Also Heringa, Editor of Medisch Contact, was invited to give a talk on the responsibilities of medical journals in the governance of human experimentation. ${ }^{100}$ That year in Rome, the WMA adopted its Principles for those in Research and Experimentation, the predecessor of the organization's 1964 Helsinki Declaration-a set of

\footnotetext{
94 'Kort verslag van de $99^{\text {ste }}$ algemene vergadering', in Medisch Contact, Vol. 4 (1949), pp. 246-266, pp. 253-254.

95 Paraphrased from: Wibaut, 'Notulen vergadering 5 februari 1949', p. 27.

96 'Kort verslag van de $99^{\text {ste }}$ algemene vergadering', p. 254.

${ }^{97}$ R. Hamburger \& H. Beukenhorst, 'De belofte bij het toetreden der Mij.', in Medisch Contact Vol. 6 (1951), pp. 15-16, p. 15.

${ }^{98}$ NL-HaNA, 2.15.33, 549, 'RAPPORT uitgebracht door Dr. R.J. Hamburger [...] inzake experimenten met mensen', 11 April 1953; Ibid., L.A. Hulst, 'Experiments on human beings', 10 April 1953.

${ }^{99}$ L.A. Hulst, 'Van het Hoofdbestuur. De World Medical Association', in Medisch Contact, Vol. 8 (1953), pp. 504-508. See also: Lederer, 'Research Without Borders', pp. 145-164.

${ }^{100}$ G.C. Heringa, 'De verantwoordelijkheid van medische redacties voor de instandhouding der medische ethiek', in Medisch Contact, Vol. 9 (1954), pp. 554-557.
} 
ethical principles for research with human subjects that has since acquired universal status. In Medisch Contact, Heringa lauded the KNMG as the national organization which had succeeded in bringing the ethical concerns over human experimentation to the attention of an international audience of physicians. ${ }^{101}$

In 1955, Hamburger wrote a letter of concern to the Journal of the American Medical Association (JAMA) after reading in its pages about an experiment with humans testing the effects of ultraviolet radiation. "I feel we must searchingly ask ourselves", the Dutch physician penned, "if the margin between experiments such as these and those perpetrated in the German concentration camps, is so very wide". ${ }^{102}$ Hamburger acknowledged that medicine owed much to "the splendid work done in the United States" in recent years. However, this leading position was exactly why "we must expect that this country will also be one of the foremost in upholding the high ethical standards which are essential in the promotion of medical science for the benefit of mankind". In Medisch Contact, this letter was reprinted with a statement that it was thanks to Hamburger that the ethics of human experimentation were since 1954 considered internationally (it was also one of the first times that a Dutch medical journal admitting a resemblance between the Nazi experiments and those of 'civilized physicians'). The artsenstand, the message was, worked hard to ensure that all patients, also in other countries, remained safe in the hands of physicians. Modern medicine presented difficult ethical issues, but the elite of the Dutch medical profession operated at the ethical frontier of these developments. In the Netherlands, everything was done to keep medical ethics in high regard to ensure it remained an effective mechanism of internal control for the artsenstand-both at home and abroad.

\section{The Nazi experiments and the Dutch antivivisectionists}

Not everyone in the Netherlands was equally convinced, however, that the Dutch medical profession really had such honourable intentions in these matters. In 1946, for instance, the Anti-Vivisectie Stichting (Antivivisection Foundation, AVS) vowed to fight the corrupting influences of society with evermore strength:

In the trials against the war criminals in Nuremberg it has become clear to which horrendous vivisection-tests the prisoners and internees in Germany have been exposed. This must be another reason for us to continue our actions with supreme efforts, so that such horrors will forever be brought to a halt. ${ }^{103}$

In 1947, the AVS sent an urgent letter to Minister of Social Affairs Willem Drees, to warn "[his] Excellence that the notorious experiments on human beings in the concentration camps just take up a tiny part of the countless experiments which are frequently conducted upon those of special means in normal times as well”. ${ }^{104}$ It was of

\footnotetext{
${ }^{101}$ G.C. Heringa, 'Prof. Dr. L.A. Hulst. Lid van de Council der W.M.A.', in Medisch Contact Vol. 10 (1955), p. 789

${ }^{102}$ R.J. Hamburger, 'Proeven op mensen', in Medisch Contact, Vol. 10 (1955), pp. 333-334, p. 334.

${ }^{103}$ J.J. Theling, 'Vijftien jaren van strijd tegen de vivisectie', in Meededeelingen Lustrum-Nummer Vol. 15 (1946), pp. 3-4, p. 3.

${ }^{104}$ NL-HaNA, 2.15.37, 2357, letter of the secretary of the Dutch Health Council to the Minister of Social Affairs, 17 July 1947.
} 
vital importance the Dutch government realized that, also in the Netherlands, "it is all which stands defenceless in life from which the scientific experimenter above all recruits his material", whether these were "the suckling in children's clinics, small children in orphanages, small or non-paying patients in hospitals, less wealthy women in childbed, or the tuberculosis patients and insane in sanatoriums". ${ }^{105}$

To substantiate these claims, the AVS presented Drees with nine Dutch research studies "of dubious ethical quality", with the apology that a much longer list could have been compiled had the Foundation's library not been destroyed in the war. ${ }^{106}$ Most of these studies described the experimental use of invasive medical procedures, particularly on young children. A dissertation on digestion-leukopenia from 1923, for instance, recorded how a four month old baby-"the ill and nervous Johanna"-had been subjected to 56 blood tests in a period of two months. ${ }^{107}$ Most of the studies also suffered from a lack of permission by the participating research subjects. Thus, one of the reports on the possible exogenous causes to climate asthma made mention of the fact that most "outpatient material" that had been injected with active substances for experimental purposes had been "completely unaware of what they had been injected with". ${ }^{108}$ This study had produced no satisfactory results, yet had caused severe negative side effects in the participating research subjects: "Once in a while a patient told us spontaneously that he had never felt this terrible in his life". ${ }^{109}$

The AVS also accused the Dutch medical profession of causing serious and sometimes lethal harm to innocent research subjects in their frenzy to conduct dangerous experiments. As evidence, it produced a Dutch study conducted in the late 1920 on the Bacillus Calmette-Guérin (BCG) vaccine, which had been developed in the early twentieth century to prevent tuberculosis. The Dutch researchers, the AVS insisted, had experimented on sick children, meaning that children with an already weakened immune system had deliberately been exposed to additional active bacterial agents. The "young Dina K.", for instance, had been experimentally inoculated with BCG in December 1928, whereafter she had quickly developed an abscess at the injection site in combination with a case of whooping cough. ${ }^{110}$ In the winter of 1929 , the girl had begun suffering from bronchitis, whereafter she had died in early April of acute meningitis. According to the AVS, such studies were comparable to the Lübeck disaster of 1930, when 73 infants had died from contaminated BCG-vaccines. ${ }^{111}$

Notwithstanding these serious accusations, the principal reason why the AVS had decided to write their alarming letter to Drees in 1947 was not to convince the Dutch government to bring the practice of human experimentation in the Netherlands to a halt. Instead, the organization hoped to persuade the Minister of Social Affairs to give his consent to the establishment of a professorial chair in vivisection-free medicine at

\footnotetext{
105 Ibid.

${ }^{106}$ NL-HaNA, 2.15.37, 2357, letter of M. Stuart to the Minister of Social Affairs, 16 September 1947.

${ }^{107}$ NL-HaNA, 2.15.37, 2357, appendix to the letter of Mr. M. Stuart to the Minister of Social Affairs, 16 September 1947, p. 1.

${ }^{108}$ NL-HaNA, 2.15.37, 2357, appendix to the letter of Mr. M. Stuart, pp. 2-3.

${ }^{109}$ Ibid., p. 3.

${ }^{110}$ Ibid., p. 5.

${ }^{111}$ See: Christian Bonah \& Philippe Menut, 'BCG-Vaccination around 1930 - Dangerous Experiment or Established Prevention? Practices and Debates in France and Germany', in Twentieth Century Ethics, pp. 111-128.
} 
one of the Dutch universities. From the 1930s onwards, various Dutch antivivisection groups had raised funds to subsidize an endowed chair in this area. Yet, as professors could only be appointed at state universities by Royal Decree, a Dutch professorship in vivisection-free medicine could not be realized without government permission. ${ }^{112}$ This chair was direly needed, the Dutch antivivisectionists argued, because it would allow students who wished to pursue a career in medicine to decide for themselves which scientific method they believed was convincing: one which tortured defenceless animals and neglected intuitive thinking-i.e. 'regular medicine'-or one that appreciated the complicated nature of disease without needing to resort to abuse and murder-i.e. vivisection-free medicine. Plus, as the existing doctors' monopoly made it illegal in the Netherlands to offer healing services without a medical diploma (and license), the lack of choice in Dutch medical curricula left the AVS forced to conclude that Dutch medicine currently really remained incomplete and dogmatic. ${ }^{113}$

This opinion was carried forward by more social movements than the antivivisectionists in the 1940 s and 1950s. The letter to Drees was co-signed by multiple organizations, such as the Dutch Society for Naturopathy, the Dutch Vegetarian Society, and the Dutch Society for Homoeopathic Healers. In parliament, the orthodox protestant party (SGP) actively lobbied for a chair in vivisection-free medicine as well. ${ }^{114}$ These various parties all had their own reasons for joining the antivivisectionist cause. The Association of Homeopathic Healers made it very clear, for instance, that it supported the AVS only "from a business point of view". ${ }^{115}$ In letters to the Dutch government and the KNMG, the homoeopaths emphasized that they did not believe a true understanding of medications could be realized without animal experiments, but that they hoped that the establishment of a chair in vivisection-free medicine would provide an institutional platform at Dutch universities for the teachings of Hahnemann. The SGP supported vivisection-free medicine because it opposed the vaccination programmes, which the orthodox protestants believed to stand in direct opposition to God's providence. ${ }^{116}$ Regardless of their diverging incentives, these parties defended their cooperation on the basis of a communal anxiety over the technical nature of modern medicine, that "neglected medicine's synthetic element and treated sickness instead of the sick". ${ }^{117}$ All hoped a chair in vivisection-free medicine would dilute "an understanding of medicine that is solely based on the modern sciences of nature". ${ }^{118}$

Even though the SGP was the only political party in Dutch parliament to explicitly support the antivivisectionist cause, its political influence in the immediate post-war period should not underestimated. Between 1945 and 1955, Dutch ministers requested the country's national Health Council at no less than three occasions to investigate complaints made by antivivisectionists. The Dutch Health Council had been founded

\footnotetext{
${ }^{112}$ Although this approval did not compel university faculties actually to establish such a professorial chair, the AVS nonetheless hoped it would give a chair in vivisection-free medicine a push in the right direction.

${ }^{113}$ NL-HaNA, 2.15.37, 2357, letter of M. Stuart to the Minister of Social Affairs, 16 September 1947.

${ }^{114}$ NL-HaNA, 2.15.33, 547, Anti-Vivisectie-Stichting 'Aan de leden van de 1ste en 2de Kamer der Staten Generaal, date unknown.

${ }^{115}$ This letter was published in Medisch Contact: 'Homoeopathie', Vol. 5 (1950), pp. 438-440.

${ }^{116}$ Handelingen Tweede Kamer 1949-1950, 16 December 1949, pp. 1097-1098.

${ }^{117}$ NL-HaNA, 2.15.33, 547, Anti-Vivisectie-Stichting 'Aan de leden van de 1ste en 2de Kamer", p. 1.

${ }^{118}$ Ibid., p. 1.
} 
in 1902 as an independent scientific advisory board to provide the Dutch government with "objective non-political advice on matters that may affect Dutch public health", and by the 1940s, it had become common for the Council President to install ad hoc committees with relevant experts to write solicited and unsolicited reports for Dutch statespersons. ${ }^{119}$ In 1947, Drees requested advice whether it was desirable to realize a chair in vivisection-free medicine. Equally, in 1953, the Dutch government asked the Health Council for advice on the legality of animal and human vivisection, resulting in the instalment of two more ad hoc committees-one of them the committee 'tests upon human beings'. In both instances, antivivisectionist complaints formed the direct cause behind the creation of these committees (see below).

In 1947, Brutel had just been installed as Council President. Although he resigned from his post in 1951, he was reinstated in 1954 after his successor became gravely ill. Hence, the physician who was convinced that only an artsenstand that was free from state interference could keep patients safe was largely responsible for the three Council reports on medical vivisection in the mid-twentieth century. Perhaps for this reason, Brutel's dissertation was one of the studies which the AVS had decided to include in its 1947 list. In 1932, the physician had successfully defended a thesis on allergic skin reactions in non-allergic persons. ${ }^{120}$ According to the AVS, Brutel had injected a variety of substances, including a preparation of the pneumococcus bacterium causing pneumonia and a suspension of spirochetes "which may possibly cause syphilis" into human subjects. ${ }^{121}$ At first, the AVS stated, Brutel had mainly used mental patients, but a large number of positive test results had led him to question if these subjects were suitable for his research studies. Thereafter, the physician had proceeded with patients of women's clinics, most of whom were pregnant.

No records have been preserved which suggest that Brutel was asked to step down as President of the Health Council after the accusations made by the AVS or to refrain from chairing the committee on a chair in vivisection-free medicine. On the contrary, Drees' 1947 request for advice was addressed directly to Brutel, and the physician set out to organize a committee to investigate whether animal experimentation really had a coarsening effect on vivisectors and whether "vivisection-free medicine" was able to develop treatments that were on par with the prophylactics and therapeutics that had been realized with the established experimental methods. ${ }^{122}$

Brutel asked two antivivisectionists to participate in the committee deliberations: a homoeopath and an osteopath who had been proposed by the AVS as suitable representatives of the vivisection-free cause. The majority of seats, however, were taken up by physicians who were convinced that vivisection was indispensable for medicine to progress. The two antivivisectionists did try to convince their committee members of the value of vivisection-free medicine. They argued, for instance, that "the physico-

\footnotetext{
${ }^{119}$ Rigter, Met Raad en Daad; R. Bal, W.E. Bijker \& R.P.J. Hendriks, Paradox van wetenschappelijk gezag: over de maatschappelijke invloed van adviezen van de Gezondheidsraad (Den Haag, 2002).

${ }^{120}$ Jean Jacques Brutel de la Rivière, Over allergische huidreacties bij niet-allergische personen (Proefschrift Universiteit Leiden, Handelsdrukkerij Deventer Dagblad, 1932).

${ }^{121}$ NL-HaNA, 2.15.37, 2357, appendix to the letter of Mr. M. Stuart, p. 6.

${ }^{122}$ NL-HaNA, 2.15.33, 547, brief 'betreffende: leerstoelen vivisectie-vrije geneeskunde', 28 May 1948.
} 
analytical method" of modern science that had come to dominate medical practice fell short of including many essential elements that played a role in health and healing. As the homoeopath expounded during the first committee meeting:

You talk about the necessity of causal thinking. There are many forms of thinking: intuitive thinking, symbolic thinking, technical thinking [...]. Causal thinking is only applicable to the 'reduced human being' - an ontology essential for the physical method to establish its validity [...]. I do not deny that we need the input of the natural sciences, but we should not forget about all that is psychic. ${ }^{123}$

Yet, of course, all the other committee members disagreed. Intuition might provide a starting point for new investigations, they argued, but these always had to be experimentally verified before they could serve in developing new medicines. Hence, vivisection was indispensable for medicine to move forward and help improve the health of the Dutch people. ${ }^{124}$ The two antivivisectionists then objected that the concentration camp experiments proved that vivisection blurred the minds and numbed the senses of physicians. Again, however, the rest of the committee dismissed this objection. If anything, naturopathy, a vivisection-free approach to healing, had been popular in Germany prior to World War II. ${ }^{125}$ Hence, if a connection was to exist between one way of knowing and the Nazi concentration camps experiments, perhaps a finger instead should be pointed in the direction of the holistic sciences.

Unsurprisingly, in 1949, the majority of the committee decided to advise the Dutch government against the establishment of a professorial chair in vivisection-free medicine. Since it was the privilege of the sitting Council President to decide who received an invitation to participate in the ad hoc committees, the outcome of the committee deliberations had been fixed in advance. Brutel let two antivivisectionists participate, but made sure that those in favour of vivisection found themselves in a safe majority of likeminded peers. The antivivisectionists were aware of their disadvantaged position. Once they realized that there was little chance the Health Council would advise the Dutch government to authorize a professorial chair in vivisection-free medicine, they wrote a letter of complaint to Brutel about the way they were treated during the committee meetings. As both were graduates of a Dutch university, possessed an orderly service record, and had always been willing to defend their ideas in the established circles of the Dutch medical profession, why, then, did the other committee members so easily brush aside their statements on the values of vivisection-free medicine? And since none of their ideas had ever been falsified on substantial grounds during committee meetings, the two antivivisectionists could only conclude that this derogatory attitude sprang forth from dogmatism-a limited state of mind they had never expected from "a group of professionals known to have fought heavily for the freedom of thought and speech under the infamous Nazi regime". ${ }^{126}$ The artsenstand, they felt, misused its position of power to further its own interests.

\footnotetext{
${ }^{123}$ NL-HaNA, 2.15.33, 547, Notulen van de vergadering van de commissie, 2 June 1948, p. 3.

${ }^{124}$ NL-HaNA, 2.15.33, 547, J.J. Brutel de la Rivière, 'Concept betreffende: vivisectie', 8 October 1948.

${ }^{125}$ NL-HaNA, 2.15.33, 547, Notulen van de vergadering van de commissie, 2 June 1948, p. 2.

${ }^{126}$ NL-HaNA, 2.15.33, 547, Letter of Gerard Bakker to Jan Jacques Brutel de la Rivière 'betreffende leerstoelen vivisectievrije geneeskunde', 30 November 1948.
} 
True enough, even though the Dutch antivivisectionist movement was able to generate quite some political traction in the immediate post-war period, the typical decision of the Dutch government to request the national Health Council for policy advice in these matters made sure that the elite of the Dutch medical profession kept a firm grip on the outcome of policy deliberations. Still, despite this position of power, this elite was far from confident that the government would not decide to act against the 'solemn scientific advice' of the Health Council. This concern was not without reason. In 1949, when the Health Council advice was debated in Dutch parliament, the SGP demanded an explanation from the government. How was it possible that the establishment of a single professorship was actively obstructed in a country that supposedly stood for freedom of education? ${ }^{127}$ At first, the Minister of Education responsible for answering this question replied that the request could not be honoured because he had realized in conversations with the AVS that the organization did not just wish to add to the existing Dutch medical curricula, but to realize an entirely different system of education. This, the Minister stated, was "practically unrealizable for the time being". ${ }^{128}$ After some debate, however, he agreed that an academic climate should be open to multiple philosophies and promised once more to take the request for a professorial chair in vivisection-free medicine into consideration. ${ }^{129}$

This commitment caused considerable commotion among the ranks of the KNMG. In the pages of Medisch Contact, physicians cried out that antivivisectionists simply denounced all of modern medical science and thus had no right to take part in Dutch academic life. Heringa was sure that the realization of a chair in vivisection-free medicine was "an experiment of massive gruesomeness that far surpassed any human or animal vivisection imaginable". ${ }^{130}$ The KNMG-President posted concerned letters to the Dutch Prime Minister, the Minister of Social Affairs, the State Secretary of Public Health, and the Minister of Education, Arts and Sciences, to warn them that such a chair would not only endanger the general level of scholarship in the Netherlands, but would also cause substantial damage to public health by instilling young impressionable students with grossly flawed doctrines. ${ }^{131}$ Really, they had to understand that the antivivisectionist stance posed a threat to the entire Dutch nation. As a result of this lobby, the Minister of Social Affairs convinced the Minister of Education that, in the interest of Dutch public health, it was best to leave the matter alone..$^{132}$

Throughout the 1950s, various Dutch social groups kept pushing together with the SGP for an alternative to "an understanding of medicine based solely on the modern sciences of nature" at a Dutch university. Every other year, the government received a request for a chair in vivisection-free medicine or homoeopathy. In the Dutch Journal of Medicine and Medisch Contact, proponents of experimental medicine kept on eying such requests with concern. At stake in these heated debates over a single prof-

\footnotetext{
${ }^{127}$ Handelingen Tweede Kamer 1949-1950, 16 December 1949, p. 1099.

${ }^{128}$ Ibid., p. 1100.

${ }^{129}$ See also: J.J. van Loghem, 'De Vivisectievrije Geneeskunde in de Tweede Kamer', in Nederlandsch Tijdschrift voor Geneeskunde Vol. 94 (1950), pp. 18-19.

${ }^{130}$ G.C. Heringa, 'Een leerstoel voor de homoeopathie?', in Medisch Contact, Vol. 5 (1950), pp. 191193, p. 193.

${ }^{131}$ Published as 'Leerstoel voor de homoeopathie?', in Medisch Contact, Vol. 5 (1950), pp. 303-306.

${ }^{132}$ NL-HaNA, 2.15.33, 547, letter of the Minister of Social Affairs A.M. Joekes to the Minister of Education, Arts and Sciences, 'leerstoel homoeopathische geneeskunde', 13 April 1950.
} 
essorial chair was the ideological embedding of 'modern medicine' within the Dutch state. For the proponents of vivisection-free medicine, the experimental tradition in medicine was based on a flawed conception of health and healing. It was a dangerous practice, which meant the government had a duty to intervene in the organization of Dutch medicine, open up universities to other ways of knowing, and, ideally, prohibit all forms of animal and human vivisection. In contrast, those in favour of the experimental tradition in medicine argued that such experiments were an intrinsic part of the modern health care state. Without vivisection there would be no medical progress and, hence, no potential for realizing better futures for Dutch citizens. The government therefore had a duty to support medical experiments and to protect it from undue attacks. As Brutel wrote in a letter accompanying the presentation of the 1954 Health Council advice on the legality of animal vivisection:

We have considered adding a passage about the actions that the Government could take to protect those who work in the field of vivisection [...] Although such recommendations lie outside the mandate of this committee, I would like to point out that the Government has the possibility to critically investigate the defamatory methods used by the AVS.133

This type of reminders, the essays in Dutch medical journals denouncing vivisectionfree medicine, the letters by the KNMG-they all indicate that the Dutch medical profession was by no means certain in the mid-twentieth century that 'modern medicine' was ingrained enough in Dutch society to withstand the accusations which its critics brought forward. Hence, when the Health Council in 1953 received a request to explore the conduct of human experimentation in the Netherlands, the physicians that gathered to consider its permissibility were highly aware of the possible political consequences of their findings. They had to develop a report that suggested how human experiments could be kept within bounds without exposing modern medicine as such to fundamental questions about its legitimate position in Dutch society.

\section{A 'modern approach' to medical ethics}

The affair over vivisection-free medicine in the late 1940 s did not end wholly without success for the Dutch antivivisection movement. In 1949, Drees' successor as Minister of Social Affairs decided to have his civil servants chart how often and under what circumstances animal experiments were conducted in the Netherlands. This report was presented to the Health Council in 1953, with the request to determine whether any further legal measures were necessary to keep this practice under control. That same year, the Health Council was also asked to investigate if the Dutch government needed to take any action in the governance of human experimentation. ${ }^{134}$ Again, the reason behind this request were accusations by the AVS at the address of Dutch physicians, who would prey on the weak members of society to conduct scientific experiments. On Saturday 9 May 1953, specifically, Dutch newspaper Het Vrije Volk report-

\footnotetext{
${ }^{133}$ NL-HaNA, 2.15.33, 546, J.J. Brutel de la Rivière, 'Bericht op schrijven 14 April 1953 No. 5148 , Directie Volksgezondheid, Afd. M.Z.B, Betreffende: vivisectie', pp. 11-12.

${ }^{134}$ Rigter, Met Raad en Daad, p. 209.
} 
ed on a movie and lecture night organized by the AVS to inform the public about vivisections in the Netherlands. "Serious accusation against the Leiden hospital", its bold headline read, "Babies and lunatics used for experiments?". ${ }^{135}$ During the course of the evening, the AVS had produced several dissertations and articles by Dutch physicians to prove its audience what sort of human experiments took place in the Netherlands. One example concerned a study conducted in the Academic Hospital of Leiden to confirm a hypothesis concerning the aetiology of nettle-rash. To test whether the disease was caused by a virus, a physician had dripped 'sterile urine and faeces filtrates' into the noses of babies admitted to the Leiden hospital. ${ }^{136}$

Het Vrije Volk was one of the biggest newspapers of the Netherlands in the 1950s and the article soon reached the State Secretary of Public Health Piet Muntendam, himself a physician, who decided to contact the Health Council for advice. Were these accusations true and, if so, did measures have to be taken to prevent them? Council President Pieter van Luijt decided to answer these questions by installing an ad hoc committee titled 'tests upon human beings', the common terminology for human experimentation in the Netherlands until the 1970s. This committee seated prominent members of the Dutch artsenstand. First, there was Brutel, who acted as chairman for most of the two years it took the committee to produce its final report. Then, there was the internist Cornelis Douwe de Langen, a highly honoured member of the Dutch medical profession and the other co-author of the report which had been sent to the WMA in 1952 on the subject of human experimentation. ${ }^{137}$ There was internist Job Pannekoek, another leader of the Dutch medical resistance in World War II. ${ }^{138}$ The Dutch Superintendent of Public Health Cornelis Banning participated.139 Pharmacologist Samuel Elzevier de Jongh, soon to be rector of Leiden University, participated (also see chapter 2).140 Willem Karel Dicke, director of the Juliana Children's Hospital, took part. ${ }^{141}$ Willem Paul Plate, gynaecologist to the Dutch royal family held a seat. ${ }^{142}$ So on and so on. ${ }^{143}$ No antivivisectionists were invited. No 'medical outsiders'

\footnotetext{
135 'Ernstige beschuldiging tegen Leids ziekenhuis. Baby's en krankzinnigen gebruikt bij proeven?', in Het Vrije Volk, Saturday 9 May 1953, 5.

${ }^{136}$ In 1950, results of this study had been published in the Dutch Journal of Medicine. A.A. Botter, 'Over de aetiologie van de strophulus infantum', in Verhandelingen van het Instituut voor Praeventieve Geneeskunde Vol. 16 (1950). Also: J.R. Prakken, 'A.A. Botter, Over de aetiologie van de strophulus infantum', in Nederlandsch Tijdschrift voor Geneeskunde, Vol. 16 (1950), p. 2766.

${ }^{137}$ See: L. Schalm, 'Prof. Dr. C.D. de Langen 75 jaar', in Nederlands Tijdschrift der Geneeskunde Vol.106 (1962), pp. 1825-1826; N.H. Swellengrebel, 'Levensbericht C.D. de Langen', in: Jaarboek KNAW, 1966-1967, Amsterdam, pp. 353-357; Lindeboom, Dutch medical biography, pp. 1139-1141. ${ }^{138}$ J.B. Scholten, 'J.H. Pannekoek 50 jaar arts', in Nederlands Tijdschrift voor Geneeskunde Vol.123 (1979), pp. 1359-1360; Van Lieburg, 'Vergeten helden'.

${ }^{139}$ Lindeboom, Dutch medical biography, pp. 67-68.

${ }^{140}$ P.J. Gaillard, 'Levensbericht S.E. De Jongh', in Jaarboek Huygens Institute - Royal Netherlands Academy of Arts and Sciences (1976), pp. 200-202; E.L. Noach, 'In memoriam Prof.Dr. S.E. de Jongh', in Nederlands Tijdschrift voor Geneeskunde Vol. 120 (1976), pp. 1226-1228.

${ }^{141}$ F.Th. van Genderen, 'In Memoriam Prof. Dr. W.K. Dicke', in Nederlands Tijdschrift voor Geneeskunde Vol. 106 (1962), p. 1108.

${ }^{142}$ P.G. Hart, 'In memoriam Prof. Dr. W.P. Plate', in Nederlands Tijdschrift voor Geneeskunde Vol. 127 (1983), pp. 1269-1270.

${ }^{143}$ Furthermore installed were professor in bacteriology and serology A.B.F.A. Pondman, professor of internal medicine and physician-director of the Nijmegen Canisius hospital J.A.M.J. Enneking, professor of psychiatry and experimental physiology L. Van der Horst, paediatrician H.P.J. Koenen, lung specialist H.C. Hallo, and medical statistician M.G. Neurdenburg. In the final report, State Secretary Piet Muntendam was listed as a committee member, as was the physician Pieter Adrianus van Luijt,
} 
were asked to hold a seat. Apparently, in the 1950 s still, the governance of human experimentation was a subject which, in the eyes of the Council President, could be considered by members of the Dutch artsenstand alone.

These participants were furthermore expected to consider the subject under investigation solely with their identity as physician. As the Council President proclaimed in his introductory speech during the first committee meeting:

I have the hope that the significantly different sources from which we derive our ethical principles, like religion, philosophy or conscience, will not be brought to the fore during our discussions. What this circle of physicians has in common is medical ethics. While nuances are also possible in this area, I am confident that it is this commonality which will allow us to formulate one definitive advice. ${ }^{144}$

In other words, even though the participating physicians in their personal lives might be members of different religious congregations or have different political tendencies, in the committee 'tests upon human beings' this was considered background noise. Professional ethics was expected to trump personal viewpoints.

Indeed, their professional identity proved crucial for the way in which the committee members approached the question if additional safeguards had to be realized for human experimentation in the Netherlands. For one thing, they shared many of the concerns that had led physicians like Hamburger to address the international medical community in the 1950s. All felt that, judging from research studies that recently had been published in medical journals, it was high time that international guidelines were formulated to keep this practice in check. Certainly in countries like the United States, committee members argued, medical researchers seemed to have little hesitation to subject "prisoners, negroes, and orphans" to all sort of risky procedures that hardly had any benefit for participating research subjects. ${ }^{145}$ But also in the Netherlands it seemed as if every new generation of physicians felt it could go a bit further in experimenting on their patients. As the internist Cornelis Douwe de Langen wrote sternly on the subject in the Dutch Journal of Medicine in 1958:

These days, one can research the circulation of blood with a catheter in one of the compartments of the heart of a sick man, of a healthy human being, or of a patient that suffers from an entirely different illness. One can stick needles in his veins and arteries, without being afraid that emotions will run high or that a medical scandal will develop. ${ }^{146}$

\footnotetext{
President of the Health Council from 1951 to 1954. In 1955, he was replaced by physician Jan Wester. Secretary of the committee was the physician V.M.J. Kettlitz. For biographical information, see: F. Westendorp Boerma, 'Prof. Dr. A. Pondman 70 jaar', in Nederlands Tijdschrift voor Geneeskunde Vol. 104 (1960), pp. 1008-1010; C.L. Majoor, 'In memoriam Prof. Jules A.M.J. Enneking', in Folia Medica Neerlandica Vol. 8 (1965), pp. 163-166; F.C. Stam, 'Prof. Dr. L. van der Horst 50 jaar arts', in Nederlands Tijdschrift voor Geneeskunde Vol. 114 (1970), pp. 785-786; F. Bezemer, 'In memoriam P.A. van Luijt', in Nederlandsch Tijdschrift der Geneeskunde Vol. 98 (1954), pp. 3513-3514; J.R. Prakken, 'Dr. J. Wester 65 jaar', in Nederlands Tijdschrift voor Geneeskunde Vol. 110 (1966), p. 595.

${ }_{145}^{144}$ NL-HaNA, 2.15.33, 548, Minutes proeven op mensen, 14 december 1953, p. 1.

${ }^{145}$ Ibid., p. 2.

${ }^{146}$ C.D. de Langen, 'Proeven op mensen en de verschuiving van te stellen normen', in Nederlands Tijdschrift voor Geneeskunde Vol. 102 (1958), pp. 25-27, p. 27.
} 
It was a concern he and others voiced repeatedly in committee meetings. The artsenstand, all felt, had to put a lid on things before they would get out of hand.

Yet at the same time, the committee was very aware of the immediate cause behind its congregation and sought to use its advisory position to the Dutch government to protect the experimental tradition in medicine. De Langen, outspoken conservative in allowing human experimentation, drummed it into the committee that it had to think long and hard about which ethical provisions for the practice it was willing to defend in public and which were to remain absolutely confidential. ${ }^{147}$ Its final policy report just could not provide grist to the mill of the antivivisectionist cause.

This tension between the desire for internal control and fear for undue outside interference dominated the committee meetings. Its members attempted to formulate safeguards that would prevent unethical behaviour among medical researchers, while simultaneously reaffirm to those in power that human experimentation as such was beyond moral suspicion. It was a balancing act that took various forms. First of all, the committee spent much time on the exact wording of its report. The Health Council would recommend the government that additional measures could be taken to safeguard the ethical conduct of human experimentation in the Netherlands, but with words that would reassure the government that no reasons existed for drastic actions. Thus, words like many [dangerous experiments] were changed into some, terms like often into sometimes. ${ }^{148}$ A sentence that stated "if the doctor uses a patient for a different goal [than the recovery of his health], the doctor violates his position of trust" was deleted when a committee member recalled why the government had asked the Health Council for advice. ${ }^{149}$ Instead, the final report included reassuring segments to take the edge off "comments that patients are used as guinea pigs" in Dutch hospitals, which were "false depictions" that needlessly caused anxiety. ${ }^{150}$

Secondly, the committee made sure to disarm any antivivisectionist claims about the "corrupting effects of modern medicine" by dismissing outright that such statements had any bearing whatsoever on the topic which the Health Council had been asked to advise upon. Thus, its report started by stating firmly:

This committee wishes to stress that the scientific methods [...] have proven their value for science and humanity. They need no defence and the Committee only has to ascertain if their application has in exceptional cases led to irresponsible acts, and in those cases outline the means to combat these excesses. ${ }^{151}$

In other words, by stressing that modern experimental medicine needed 'no defence', the committee took pains to emphasize that neither the epistemic status nor societal position of human experimentation was at stake in its governance. The Health Council only needed to formulate safeguards against a few excesses.

\footnotetext{
${ }^{147}$ NL-HaNA, 2.15.33, 548, Minutes proeven op mensen, 9 februari 1954, p. 7.

${ }^{148}$ NL-HaNA, 2.15.33, 548, Minutes proeven op mensen, 22 september 1955, p. 5.

${ }^{149}$ NL-HaNA, 2.15.33, 548, Minutes proeven op mensen, 27 januari 1955, p. 8.

${ }^{150} \mathrm{~J}$. Wester, 'Advies van de Voorzitter van de Gezondheidsraad, d.d. 10 oktober 1955 uitgebracht aan de Minister van Sociale Zaken en Volksgezondheid betreffende proeven op mensen'. To be found in:

NL-HaNA, 2.15.33, 548 .

${ }^{151}$ Ibid., p. 5.
} 
Third and most importantly, because the practice as such needed no defence, the committee proposed a different ethical framework to regulate the behaviour of medical practitioners. Antivivisectionists often claimed the experimental tradition in medicine violated the traditional medical ethics. The ancient Hippocratic precept primum non nocere, after all, prescribed that physicians above all else had a duty to abstain from causing harm. Thus, in the Council committee on vivisection-free medicine, the two antivivisectionists had argued that the "the official science of healing has come to wander from its original goal" with the use of vivisections in medicine, as "physicians have a duty to help not harm". ${ }^{152}$ Also the participants in the Council committee "tests upon human beings' noticed an incongruence to exist between the Hippocratic oath and human experimentation. They, however, reached the exact opposite conclusion as the antivivisectionists had done: i.e. not the modern experimental tradition was the problem, the traditional ethics of medicine was.

The internist Job Pannekoek was the first to make this link explicit. Modern medicine, he argued, was full of risk. Since the nineteenth century, an array of medications and surgical techniques had been developed that could potentially cause great harms. Nonetheless, the medical profession did use these tools, as they also potentially could do great good. Physicians, in other words, had learned to make risk-benefit analyses (the 'calculus of suffering') to determine whether a medical intervention was justified. Pannekoek invoked the example of narcotics in surgery to underscore his point. Even though patients experienced more negative side effects from "modern narcotics" than from traditional aether narcotics, their use was justified because they allowed for safer surgical interventions. ${ }^{153}$ "Both modern medications and modern medical practice carry risks", Pannekoek stated firmly, "Hippocrates' old theorem can therefore in this modern day and age no longer be maintained in its entirety". ${ }^{154}$

The cardinal question was, however, whether this calculus of suffering also held up when risks were taken by some individuals to benefit the health of others. This, after all, was the ethical problem at stake in most human experimentation. The committee was unsure. Some members appeared to think it did. The paediatrician Willem Karel Dicke, for instance, brushed aside the issue by arguing that modern life itself was full of risk. After all, all sorts of 'modern goods', such as detergents, insecticides, and cars, carried risk. "We live in technical times and we simply need to adapt to them", Dicke proclaimed with fervour, "The existence of risk is not a medical problem. It is a problem of society at large". ${ }^{155}$ Others stated that life in modern society had become more "group-minded" than "individual-minded". ${ }^{156}$ Although no committee member stated it outright, some seemed to think it was justified to expose a few individuals to more than average risk if this could possibly benefit a great many others.

Others disagreed. De Langen, for one, argued a crucial difference to exist between the conscious decision to drive a car (or undergo surgery with narcotics) and unconsciously being experimented upon as a hospital patient. The doctor-patient relationship always had been of an individual nature and had to remain so. Brutel also ap-

\footnotetext{
${ }^{152}$ NL-HaNA, 2.15.33, 547, 'Concept betreffende: vivisectie', 8 oktober 1948, pp. 1-2.

${ }^{153}$ NL-HaNA, 2.15.33, 548, Minutes proeven op mensen, 23 december 1954, p. 7.

${ }^{154}$ NL-HaNA, 2.15.33, 548, Minutes proeven op mensen, 11 maart 1954, p. 2.

${ }^{155}$ NL-HaNA, 2.15.33, 548, Minutes proeven op mensen, 23 december 1954, p. 13.

${ }^{156}$ Ibid., p. 12.
} 
pears to have had his doubts. He felt strongly, at least, that if the committee decided that the profession of medicine should become more group-minded than individualminded, they had a duty to inform the Dutch people about this change. Patients had a right to know if their physicians decided that "the old principle that was once the position of trust between patient and physician has been forsaken".

Eventually, the committee decided that the solution was not so much to formulate ethical imperatives that held up under all circumstances (e.g. 'first, do not harm' or 'the greatest benefit for the greatest number of people'), but to propose professional and institutional safeguards that made it possible to establish on a case-by-case basis whether risks were worth taking. "When experimenting on human beings is absolutely necessary", Brutel concluded (as the committee clearly felt it was), "we need to create conditions that keep each risk as small as possible". ${ }^{157}$ The goal was not to avoid all risk, but to minimize those risks that sometimes just had to be taken. The modern practice of medicine required a modern approach to risk governance.

What were these safeguards then? The first was the formulation of guidelines for tests upon human beings that "carry some risk, extraordinary discomfort or pain with them". These guidelines were strict. They emphasized the need for informed consent and made clear that, even then, "the responsibility of the researcher and not the willingness of the subject is primary". They forbade tests on children, prisoners or "lunatics" with more than average risk, discomfort or pain. The same went for group investigations in homes for children or the elderly. Likewise, tests upon dying individuals were forbidden under all circumstances. The guidelines furthermore advised against tests on patients who suffered from incurable diseases and disapproved of tests which carried substantial risk. These were "not in harmony with the nature and goal of medical science". All tests immediately had to be brought to a halt if a patient asked for it or if unforeseen danger arose. Also, it was not allowed to bother patients with unnecessary tests and "it goes without saying that any not strictly unavoidable physical or mental suffering and danger has to be prevented". ${ }^{158}$

With the exception of tests on dying patients, the presence of risk was decisive for whether the guidelines applied. The committee did not make a categorical distinction between experimental, diagnostic, or therapeutic tests. All, the committee argued, ultimately served to benefit a patient's health. Hence, not the experimental character of a test determined its permissibility, but its risks as opposed to its benefits. According to the committee, its guidelines therefore also applied to diagnostic or therapeutic tests with more than average risk, discomfort, or pain. However, vice versa, if these risks were absent, physicians did not have to take the guidelines into account, regardless of the nature of the intervention. Hence, despite its strong emphasis on the need for informed consent, the final Health Council report also stated:

The position of trust between physician and patient is not violated if the physician, without actually asking permission, performs actions that serve to increase knowledge or his own experience, as long as these actions do not do any damage or delay recovery. 159

\footnotetext{
${ }^{157}$ All quotes in this paragraph: Ibid., pp.12-14.

${ }^{158}$ J. Wester, Advies van de Voorzitter van der Gezondheidsraad d.d. 10 oktober 1955, p. 10.

${ }^{159}$ Ibid., p. 7.
} 
The committee did distinguish, however, between the professional identities of the attending physician and medical researcher. If a physician wanted to do experiments that entailed risks on patients that he was currently treating, he was obliged to "mobilize an advisory committee" before he was allowed to proceed. ${ }^{160}$ The final report was not entirely clear whether this advisory committee actually needed to give permission for the experiment to continue. Nonetheless, it was the first time that some form of local peer review was proposed for the oversight of human experimentation in the Netherlands: substantial risks could best be governed through a process of communal control. Of course, these committees were to consist solely of medical colleagues. ${ }^{161}$ After all, only members of the artsenstand could truly know when a medical-ethical line was crossed and when risks could legitimately be taken.

Lastly, the report recommended the government to consider installing a permanent advisory board, seating "persons who are familiar with the subject of tests upon human beings", which researchers could turn to for advice if needed.162 Too often, the Health Council suggested, human experiments were either redundant or invalid because the experimenter had not kept abreast of current developments in his field or because he had not picked the right research design. ${ }^{163}$ It was advisable, therefore, to realize a national advisory body that could function as an information centre for physicians considering to conduct human experiments. Due to the ongoing specialization of medical science, it could no longer be expected from the average practitioner to have a complete overview of all various subdomains that made use of human experimentation. Hence, it made sense, both ethically and methodologically, to pool expertise to prevent bad science and promote good science. The 1955 Health Council advice 'tests upon human beings' concluded, therefore, with the sort of poetic statement that only policy documents can muster: "For this goal, the Committee proposes to bring a Committee into being". ${ }^{164}$ Together with the suggestion for communal review on the local level, it was the first ever proposal for the governance of human experimentation in the Netherlands through a system of ethics by committee.

Officially, the Council advice 'tests upon human beings' was directed to the national Dutch government. The State Secretary of Public Health, after all, had ordered this policy report in 1953 after the accusations of the AVS in Het Vrije Volk. In practice, however, its recommendations for the governance of human experimentation were all directed at the organization that headed the Dutch medical profession: the KNMG. To make sure that the Dutch medical community would take notice of the guidelines, the Health Council proposed the government to request the KNMG to "push the thoughts contained in the advice on its members" through measures that the organization saw fit. Also, it was a good idea if the WMA was notified of these measures. Furthermore, the government had to request the KNMG to exert its influence on editors of medical

\footnotetext{
${ }^{160}$ Ibid., p. 10.

${ }^{161}$ NL-HaNA, 2.15.33, 548, Minutes proeven op mensen, 5 maart 1955, p. 9.

${ }^{162}$ Wester, Advies van de Voorzitter van der Gezondheidsraad d.d. 10 oktober 1955, p. 11.

${ }^{163}$ Ibid., p. 5, pp. 9-10.

${ }^{164}$ Ibid., p. 11.
} 
journals to make sure that article submissions "that are in conflict with medical ethics" would be refused. ${ }^{165}$ Finally, the government was to ask the KNMG to incorporate the most important elements of the Health Council report in the booklet on the ethics of medicine it was currently preparing (also see chapter 3).

These were recommendations of a group of physicians who believed strongly that a practice like human experimentation could best be governed by an artsenstand. Even though the Health Council was an official advisory body to the Dutch government, the committee 'tests upon human beings' wrote the advice with their colleagues in mind. The guidelines were formulated not as measures for public policy, but as general rules for fellow physicians. All the government had to do was to protect experimental medicine from undue attacks from antivivisectionists. For the rest, the artsenstand would take care of things. The safeguards the Health Council proposed for the governance of human experimentation were all meant as measures of internal control: by members of the medical profession for members of the medical profession.

What is more, the policy report marked a defence of the societal position of human experimentation as much as it sought to formulate safeguards for incidental excesses. The members of the committee 'tests upon human beings' genuinely feared the political influence of antivivisectionists and purposefully downplayed any concerns it had about unethical experiments on human beings in the Netherlands. Trust in the medical profession was essential, they argued, and their report had to reassure both the government and general public that the Dutch artsenstand had things under control. The committee members did so to protect the experimental tradition in medicine, which they believed was the only way to realize progress in medical science and practice. For them, human experimentation was, albeit within bounds, a moral obligation: some risks just had to be taken to realize better cures for current and future patients. What was more, in the eyes of the committee, this held true not only for physicians, but for patients as well. As it was stated in the 1955 Health Council report:

The Committee feels obliged to point out that the patient admitted in the hospital profits significantly from experiences that the physician has gained from past patients. The public knows that hospitals do not only exist to nurse and treat the sick, but also to increase scientific knowledge. 166

In committee meetings, some members had argued that just like physicians, patients had a moral duty to expose themselves to experimentation. Dicke even felt that they were morally indebted to the medical profession, who had brought so much relief to modern society. ${ }^{167}$ Others, however, had remarked that a term like "moral obligation" should not be used in the report, as it would also be read by laypeople. Still, it could not hurt to remind the public that hospitals did not just exist to heal the sick, but also to further medical progress. The entire Dutch nation, the undertone was, had a moral obligation to contribute to medical progress, in whatever way possible.

\footnotetext{
${ }^{165}$ Ibid., p. 12.

${ }^{166}$ Ibid., p. 7.

${ }^{167}$ During committee meetings, only one member remarked that such reasoning reminded him of Nazi Germany. See: NL-HaNA, 2.15.33, 548, Minutes proeven op mensen, 5 april 1955, pp. 7-8.
} 
In the 1960 s and 1970 , in a remarkably short period of time, this belief that an autonomous artsenstand was best capable to govern the conduct of Dutch physicians started to show cracks that many believed were beyond repair. Chapter 3 of this $\mathrm{PhD}$ thesis explores how in a period of only a decade the ideals of men like Brutel about a 'free medical profession' made place for a sense of crisis about the societal position of the artsenstand. The existing medical ethics, even if 'modernized', came to be considered outmoded, while a cadre of medical outsiders united to rally against the societal position of the artsenstand in ways that were much more successful than the antivivisectionists had ever been. Medicine in modern society, the argument became, did not require internal but external control. However, before moving on to this call for more external control, chapter 2 first takes up another proposal for more internal control in the governance of human experimentation that was proposed by elite members of the Dutch medical profession in the late 1960s. By then, the antivivisectionist threat had largely retreated into the background for Dutch proponents of 'the experimental tradition in modern medicine'. Instead, a number of its most vocal advocates had started eying their own medical colleagues with concern. Because most Dutch practitioners, as it turned out, did not keep abreast of new developments in the field or show much interest in things such as research design. Hence, the reform of Dutch medicine was direly needed, this new elite told itself, perhaps even with use of government force. For internal control over medicine could only be realized if the average practitioner was actually made to listen to what the profession's experts had to say. 


\section{- Chapter 2 • a moral need for epistemic filters}

In 1962, the Dutch Journal of Medicine published an article on the ethics and science of clinical trials: experiments done with patients in clinical practice. "The resistance a physician feels against experimenting on his patients is understandable", the author wrote with regards to the ethics of clinical trials. ${ }^{1}$ After all, every patient deserved the best treatments currently available. Yet, due to the recent boom of medical science, it had become increasingly difficult for a physician to decide which treatments really were best. In older times, the body of collected knowledge about healing substancesthe traditional materia medica-had expanded only slowly, which had made it possible for most physicians to gain a comprehensive overview of available medicines and their appropriate use in clinical practice. In recent decades, however, the explosive growth of medical science had made it virtually impossible for the average practitioner to keep track of all new medicines pushed on the market every year. Even worse, as "products of the pharmaceutical industry generally find their way into practice before a sound judgement has been obtained about their value and risks", it was very well possible for physicians to prescribe ineffective drugs to their patients. Especially "peripheral doctors", the author wrote, constantly felt pressured by patients and industry to prescribe the newest wonder drugs available. "In this new situation, thousands of physicians are constantly experimenting", often with high risk and only little reward, as it was hardly possible in most of these cases to speak of sound scientific research. "One can thus state without reservation", the author concluded, "that the conduct of good experimental research is ethically more responsible than the usually ineffective evaluations in practice". ${ }^{2}$ It was high time for reform in Dutch medical research and practice. A moral need existed for proper human experimentation.

This chapter examines two more policy reports that were developed by the Dutch Health Council between 1968 and 1981 on the governance of human experimentation. In this period, an awareness grew among Dutch politicians that the rights of research subjects required additional protection, resulting in various requests for advice to the Health Council to determine whether public policy measures in this area were desirable. In 1971, the national advisory body delivered the first of these two reports, which contained the first fully developed Dutch blueprint for research ethics committees. And in contrast to the Council's report of 1955, the 1971 report now granted the Dutch state a central role in the governance of human experimentation. Public regulation of the practice really was necessary, the advisory body had come to argue-a position it repeated in 1981 when it published a second report containing elaborate suggestions for the oversight of human experimentation with research ethics committees.

\footnotetext{
${ }^{1}$ O. Fokkens, 'Oordeelsvorming in de geneeskunde', in Nederlands Tijdschrift voor Geneeskunde Vol. 106 (1962), pp. 1896-1899.

${ }^{2}$ Ibid. All quotes in this paragraph are from p. 1986.
} 
Who participated in these two Health Council committees? Why did they diverge from their 1955 predecessors who had shied away from any state involvement with the governance of medicine? And, once more, which role did these committees imagine as a result of these reflections for research ethics committees in the oversight of human experimentation? This chapter argues that the development of these reports, including their proposals for an oversight system using research ethics committees, has to be viewed in light of a larger Dutch reform movement in the twentieth century that sought to make medical practice more 'rational' by submitting new and existing medicines to systematic clinical experimentation. Dutch clinicians, this group argued, especially those operating "in the periphery", still prescribed medications to patients without much scientific proof that these actually worked. Driven by ignorance and financial motives, they would try out most medicines that were sent their way by the pharmaceutical industry and, at best, write up incidental case reports of their findings with individual patients. Hence, reform was needed-to bring the uncontrolled proliferation of medicinal substances under control and make sure that all Dutch patients, regardless of who treated them, were beneficiaries of treatments whose efficacy had been proven through controlled clinical trials on enough human patients to yield statistically significant results. "Rational medical practice", in short, demanded systematic human experimentation. This chapter shows that research ethics committees in the Netherlands were imagined in the 1970 s to fulfil a specific governance function in these specific attempts at therapeutic reform.

Section I of this chapter first explains the notion 'therapeutic reform', a term from historian Harry Marks, and makes clear why systematic clinical experimentation (and thus human experimentation) gained significant support in the mid-twentieth century in countries like the United States and Great Britain. Section II subsequently outlines why this international development initially found little support among Dutch physicians, to the great frustration of a group of (mainly) pharmacologists who started to seek out state support in the 1960 s and 1970s to push their ideals of therapeutic reform on Dutch medical practice as well. Finally, sections III and IV show how these attempts at reform were instrumental in the realization of two Health Council reports between 1968 and 1981, and explain why their authors believed that the practice of ethics by committee could help bring about a medical system in the Netherlands built around their specific epistemic ideals of "rational therapeutics".

\section{Therapeutic reform and clinical experimentation}

In his 1997 book The Progress of Experiment, the late Harry Marks traces the history of a "disparate group whom I have labelled 'therapeutic reformers', individuals who sought to use the science of controlled experiments to direct medical practice". ${ }^{3}$ Since this publication, the notion of therapeutic reform has come to be generally used in historical literature to denote attempts to change the organization of medicine by individuals who were convinced that medical practice had to be rationalized by linking the ethos of scientific research to clinical care. In the following pages, this notion is shortly discussed, with specific attention to the ideas of Marks.

${ }^{3}$ Harry M. Marks, The Progress of Experiment. Science and Therapeutic Reform in the United States, 1900-1990 (Cambridge: Cambridge University Press, 1997), p. 4. 
According to Marks, whose work covers American history, this call for more controlled experimentation to steer medical practice first emerged towards the end of the nineteenth century. In the early 180os, pharmacists in France and Germany had isolated the active ingredients of some of the most significant parts of the materia medi$c a$-including morphine, quinine, caffeine, and codeine-that could be manufactured in standardized bulk extracts and sold for commercial purposes. 4 Together with the development of synthetic chemical methods for producing pharmaceuticals after the mid-180os, this development gave rise to what is often called "the modern pharmaceutical industry". 5 The result of this "therapeutic revolution", Marks claims, was that by the end of the nineteenth century "a seemingly interminable series of potent therapeutic agents" had been introduced in the American drug market. ${ }^{6}$

The development of these techniques for isolating and synthesizing pharmaceutical compounds brought optimism to medical practice. A firm belief existed that physicians had more options for successfully healing patients than ever before in history, and that these compounds had been brought about thanks to the development of the experimental tradition in medicine (see chapter 1). The array of pharmaceutical compounds appeared to be "material vindication of medicine's growing faith in laboratory science". ${ }^{7}$ Yet, at the same time, the growing influence of pharmaceutical companies over patient treatment also provoked serious concern among physicians. The nascent drug industry relied heavily on colourful advertisements full of promises of all sorts of wonder drugs that were often targeted directly at patients. ${ }^{8}$ What was more, many pharmaceutical firms put so-called proprietary products on the market: compounds marketed under scientific sounding brand names-often protected by trademarksthat masked their actual chemical composition. Hence, it was often unclear what, if any, therapeutic effects many of these supposed "miracle cures" had, apart from those advertised by the pharmaceutical company selling them. ${ }^{9}$

These developments, Marks writes, left the medical profession's scientific leadership around the turn of the twentieth century with a "novel intellectual and political problem": i.e. "how best to harvest the riches of the laboratory while protecting medicine from the incursions of the market?". ${ }^{10}$ The solution, according to Marks, was found in an intellectual program called "rational therapeutics". Already in the 1870s, American physicians impressed by the experimental programme of the French physiologist Claude Bernard (see chapter 1) had started to insist that progress in clinical practice depended on the realization of a proper experimental tradition in medicine.

\footnotetext{
${ }^{4}$ M. Weatherall, In Search of a Cure. A History of Pharmaceutical Discovery (Oxford: Oxford University Press, 1990).

${ }^{5}$ Jordan Goodman, 'Pharmaceutical Industry', in Medicine in the $20^{\text {th }}$ Century, pp. 141-154.

${ }^{6}$ Marks, The Progress of Experiment, p. 17. Marks borrows the term 'therapeutic revolution' from Charles E. Rosenberg, 'The Therapeutic Revolution. Medicine, Meaning and Social Change in Nineteenth Century America', in Morris J. Vogel \& Charles E. Rosenberg (eds.), The Therapeutic Revolution. Essays in the Social History of American Medicine (Philadelphia: University of Pennsylvania Press, 1979), pp. 3-25.

${ }^{7}$ Marks, The Progress of Experiment, p. 18.

${ }^{8}$ Jackson Lears, Fables of Abundance. A Cultural History of Advertising in America (New York: Basic Books, 1994), pp. 43-46; Peter Temin, Taking your Medicine. Drug Regulation in the United States (Cambridge, Mass.: Harvard University Pres, 1980).

${ }^{9}$ See: Joseph M. Gabriel, Medical Monopoly. Intellectual Property Rights and the Origins of the Modern Pharmaceutical Industry (Chicago: The University of Chicago Press, 2015), pp. 103-106.

${ }^{10}$ Marks, The Progress of Experiment, p. 20.
} 
In particular the laboratory study of drug actions was heralded by these physicians as the engine of future therapeutic progress. ${ }^{11}$ In the early twentieth century, these ideals translated in a programme of 'rational therapeutics' built on two pillars. Firstly, therapeutic agents were only considered a 'rational choice' if their mechanisms of action had been established 'scientifically' by laboratory study and animal vivisection prior to their introduction into clinical practice. Secondly, rational therapeutics required physicians to conduct themselves according to the principles of scientific medicine in their practice: they had to use drugs in accordance with what had been established 'scientifically' about their pharmacological effects, meaning that they were not permitted to prescribe them for ailments other than those for which they actually had been proven to work through laboratory study. Yet, these new epistemic ideals were not accepted by all members of the medical profession, and certainly not by all social groups (see chapter 1). They were part of a specific paradigm that lauded the rise of "modern experimental medicine", whose fruits would be intellectually superior to all other ways of knowing in medical research and practice. Its proponents therefore felt they had to organize a reform movement that would convince the profession at large of the benefits of "rational therapeutics" (or, if colleagues were unwilling to listen, to impose these ideals upon them somewhat more forcefully, see below).

The intellectual programme of rational therapeutics was built on a deep distrust of the pharmaceutical industry. Only an independent science of drug evaluation, headed by the medical profession, would be able to withstand the pressures of big businessor so these reformers believed. But, and this is an important point in Marks' work, in addition to distrust of corporate sponsored research, therapeutic reformers had just as little faith in the capacities of the average physician to rationally use the drugs that were available for treating patients. Drug firms did not only target patients with their advertisements, they also tried to persuade physicians to purchase their goods for an attractive price or with the promise that a particular new product did wonders for the treatment of patients. "Among therapeutic reformers", Marks maintains, "the gullible physician soon vied with the ignorant layman as a symbol of the corrupt state of therapeutics". ${ }^{12}$ With true reformist zeal, they therefore set about to enlighten particularly "the peripheral physician" of the crucial importance of rational therapeutics-an abstract entity encompassing all practitioners that were not part of medicine's scientific elite. ${ }^{13}$ The average practitioner had to be taught how to behave rationally, in order to offer patients the best therapeutic care available and to withstand the pressures of industry. The project of therapeutic reform, in other words, was first and foremost an attempt at internal control over medicine by a self-conceived elite of the (American) medical profession, who believed the periphery had to be managed.

\footnotetext{
${ }^{11}$ See also: John Harley Warner, 'Ideals of Science and Their Discontents in Late Nineteenth-Century American Medicine', in Isis Vol. 82 (1991), pp. 454-478.

${ }_{12}$ Marks, The Progress of Experiment, pp. 19-20. For a similar attitude among elite British 'therapeutic reformers' in the early twentieth century, see: David Cantor, 'The MRC's support for experimental radiology during the interwar years', in Joan Austoker \& Linda Bryder (eds.), Historical perspectives on the role of the MRC (Oxford: Oxford University Press), pp. 181-204.

${ }^{13}$ Marks, The Progress of Experiment, pp. 28-32.
} 
Notably, this distrust of the peripheral clinician did not translate so much in any direct attempts to regulate clinical practice, but in attempts to conduct more and better clinical research. "What binds reformers", Marks states, "is the shared belief that better knowledge about the effects and uses of drugs will lead directly to better therapeutic practice" ${ }^{14}$ If only the scientific standards of drug evaluation could be elevated, pharmacotherapy would follow as a matter of course. This, however, posed a second, albeit related, problem. Although laboratory study reigned as the pinnacle of medical science in the early twentieth century, therapeutic reformers at the time readily accepted that the evaluation of a drug's efficacy ultimately had to take place in clinical practice. Traditionally, this type of evaluation had meant that physicians tried out a new medicine on a few patients and shared their findings by means of case reports. In the eighteenth and nineteenth century, however, distinct numerical approaches to determining clinical efficacy had been developed: from the 1850 os onwards, followers of the French physician Pierre Louis had started to argue that efficacy could only be proven by systematically comparing between groups of patients that had been treated with different procedures (see chapter 1). Only this way was it possible to determine if a new substance offered a welcome addition to the materia medica.

This type of experimentation required gathering observations on large numbers of patients with a given disease under fairly controlled circumstances. Sometimes, this was possible in large hospital wards, but often the number of comparable cases needed to yield satisfactory results exceeded the number of cases available on a single ward in a limited space of time. In the first half of the twentieth century, therefore, therapeutic reformers tried to organize so-called "cooperative clinical studies" which brought together clinicians in various institutional settings to follow the same agreedupon treatment plan in tackling a specific illness. Their individual case files were subsequently collected and compared. Ideally, these trials would make sure that enough patients were treated by enough physicians under comparable conditions to eliminate what therapeutic reformers had come to argue was an important source of bias in clinical experimentation: the clinical judgment of individual physicians. ${ }^{15}$

In practice, however, most trials were a failure. Since no infrastructure existed for their systematic conduct, it was difficult to convince hospital staff and boards to accept the organizational limitations which cooperative studies imposed on their daily practice. Neither was much money available to realize such an infrastructure. In addition, crucial cultural limitations existed that made it hard for such studies to succeed. After all, their set-up required physicians to regiment their behaviour: all participants had to adopt strict social norms to ensure their observations followed an agreed-upon treatment plan that allowed for the comparison of results. "Such sacrifices of intellectual autonomy”, Marks argues, "proved especially difficult for researchers raised in a medical culture that prized individual experience and judgement above all else". ${ }^{16}$ Consequently, cooperative trials in the early twentieth century were often plagued by a lack of uniformity-the exact problem they were meant to resolve.

\footnotetext{
${ }^{14}$ Ibid., p. 3.

${ }^{15}$ Ibid., p. 42-70.

${ }^{16}$ Ibid., p. 53. The idealized cultural identity of a medical researcher in this period was one who possessed a stroke of genius and laboriously worked by himself to bring about medical innovation, not one who anonymously laboured as a worker bee to reach collective results. Think, for instance, of: Sinclair Lewis, Arrowsmith (New York: Grosset and Dunlap, 1925).
} 
This changed in the second half of the twentieth century. Historians generally recognize that the 1940 s ushered in "a new era for [clinical] trials" ${ }^{17}$ One reason is that the desired infrastructure for organizing cooperative trials was realized in this period-in countries like the United States at least-due to the outbreak of World War II. To further the war effort, the United States government in 1941 created the Office of Scientific Research and Development, which was given almost unlimited amounts of funding and resources to coordinate scientific research for militaristic purposes for the duration of the war. ${ }^{18}$ This Office also included a Committee for Medical Research (CMR), which received about 25 million dollars between 1941 and 1947 to plan and oversee medical research studies-an unparalleled amount of money spent on medical research at the time. ${ }^{19}$ Its management was given in the hands of prominent academic physicians who adhered to the ideals of rational therapeutics that had developed in the late nineteenth and early twentieth century. This, Marks argues, offered them an opportunity to put their ideals of therapeutic reform into practice. ${ }^{20}$ The central and militaristic organization of the CMR, combined with the amount of available funds, greatly favoured the execution of controlled clinical trials.

Crucially, this infrastructure was maintained after the end of the war. In 1945, the director of the Office of Scientific Research and Development Vannevar Bush wrote a now famous report titled Science, the Endless Frontier, in which he listed among other things the spectacular advances that medical research would have made during the war. His prime example was penicillin. The antibiotic drug, first discovered in 1928, had been mass produced during World War II with the help from the CMR. "We all know how much the new drug, penicillin, has meant to our grievously wounded men on the grim battlefronts of this war - the countless lives it has saved - the incalculable suffering which its use has prevented", Bush wrote passionately. "Science and the great practical genius of this nation made this achievement possible". ${ }^{21}$ To make sure that also in times of peace the war against disease could be fought, Bush felt that systematic federal funding of medical research was absolutely necessary.

According to historian David Rothman, American Congress responded to this call by reorganizing the existing National Institutes of Health (NIH) along the lines of the CMR. $^{22}$ To this end, incredible sums of money were pumped into the expansion of the NIH in the first post-war decades. Whereas the organization had in 1945 still received

\footnotetext{
${ }^{17}$ Desirée Cox-Maksimov, 'The making of the Clinical Trial in Britain, 1910-1945. Expertise, the State and the Public' (PhD-thesis, University of Cambridge, 1997), p. 270; Martin Edwards, Control and the Therapeutic Trial. Rhetoric and Experimentation in Britain, 1918-1948 (Amsterdam: Rodopi, 2007); Marks, The Progress of Experiment; Löwy, 'The Experimental Body'; Linda Bryder, 'The Medical Research Council and Clinical Trial Methodologies before the 1940s. The Failure to Develop a 'Scientific' Approach', JLL Bulletin: Commentaries on the history of treatment evaluation, retrieved at http://www.jameslindlibrary.org/ on 12 October 2016.

${ }^{18}$ Daniel J. Kevles, The Physicists. The History of a Scientific Community in Modern America (New York: Vintage Books, 1979), pp. 296-301; Jon Agar, Science in the Twentieth Century and Beyond (Cambridge: Polity Press, 2012), pp. 264-268.

${ }^{19}$ Rothman, Strangers at the Bedside, p. 31.

${ }^{20}$ Marks, Progress of Experiment, p. 99.

${ }^{21}$ Vannevar Bush, 'Science. The Endless Frontier. A Report to the President on a Program for Postwar Scientific Research', July 1945.

${ }^{22}$ Rothman, Strangers at the Bedside, p. 53. See also: Alan T. Waterman, 'Introduction', in the 1960 reprint of 'Science. The Endless Frontier', pp. xi-xii. Retrieved from:

https://archive.org/stream/scienceendlessfr00unit\#page/n15/mode/2up on 20 October 2016.
} 
about 700.00o dollars on a yearly basis for medical research studies, this number had by 1965 increased to almost 437 million a year. ${ }^{23}$ In 1970, this had become 1.5 billion dollars. ${ }^{24}$ In addition, the NIH opened a Clinical Research Centre in the 1950s, where healthy individuals were routinely hospitalized to participate in clinical studies under strictly controlled circumstances. ${ }^{25}$ These developments, to use the words of Rothman, turned many of the medical experiments on human subjects that had been conducted prior to World War II into a "cottage industry" by comparison. ${ }^{26}$

A second reason why the 1940 s ushered in a new era for clinical trials is the fact that a new method for conducting these trials was brought to fruition in this decade that would soon come to dominate clinical research: the randomized controlled trial (RCT). In 1948, the British Medical Journal published the outcome of a clinical study on the effects of the antibiotic drug streptomycin on pulmonary tuberculosis that had been conducted from 1946 to 1948 under auspices of the Medical Research Council in Great Britain. ${ }^{27}$ Modelled after statistical theories about randomization developed earlier in the century, participating patients had been randomly allocated between a treatment group and a control group that received only the existing standard treatment (bed rest). All other variables had been kept as constant as possible in the clinic to determine if the variable under investigation (the administration of streptomycin) produced a statistically significant beneficial effect in treating pulmonary tuberculosis. Patients in neither of the two groups had been informed about participating in an experiment, nor did the specialists grading the monthly X-rays or the bacteriologists examining patients' sputum know who belonged to the treatment and who to the control group. To eliminate any potential bias all parties involved had been kept as ignorant as possible. The trial was, as it is now called, "double-blind". ${ }^{28}$

In the second half of the twentieth century, the randomized controlled trial would acquire the status of "gold standard" for rational therapeutics. ${ }^{29}$ In 1998, in an issue of the British Medical Journal commemorating 50 years of RCTs, the journal's Editor even suggested that the method might be the most important development in medicine in the past century or more, "as important a change as that in the renaissance, when medicine began to base itself on experimental evidence rather than on reinterpreting the teachings of the ancients".$^{30}$ Thanks to the RCT, his argument was, medicine had finally been able to move to "a type of medicine where treatment is expected to be based more on firm evidence of benefit than on the treating doctor's opinion". ${ }^{31}$ Instead of an art, clinical practice had at last become a science.

\footnotetext{
${ }^{23}$ Beecher, 'Ethics and Clinical Research', pp. 1354-1360.

${ }^{24}$ Rothman, Strangers at the Bedside, p. 53.

${ }^{25}$ See also: Stark, Behind Closed Doors.

${ }^{26}$ Rothman, Strangers at the Bedside, p. 18.

27 'Streptomycin Treatment of Pulmonary Tuberculosis. A Medical Research Council Investigation', in British Medical Journal 2 (1948b), pp. 769-782; Alan Yoshioka, 'Use of Randomisation in the Medical Research Council's Clinical Trial of Streptomycin in Pulmonary Tuberculosis in the 1940s', in British Medical Journal Vol. 317 (1998), pp. 1120-1223.

${ }^{28} \mathrm{~J}$. Crofton, 'The MRC randomized trial of streptomycin and its legacy. A view from the clinical front line', in Journal of the Royal Society of Medicine Vol. 99 (2006), pp. 531-534.

${ }^{29}$ Marcia Meldrum, 'A Brief History of the Randomized Controlled Trial. From Oranges and Lemons to the Gold Standard', in Hematology/Oncology Clinics of North America Vol. 14 (2000), pp. 745-760.

30 'Fifty years of randomized controlled trials', in British Medical Journal Vol. 317 (1998), p. 1167.

${ }^{31}$ Ibid.
} 
Of course, what counts as medical science has changed through time. The famous nineteenth-century physiologist Claude Bernard would likely have scoffed at the suggestion that medicine had finally become a science due to the invention of the RCT. As he wrote in his 1865 Introduction to the Study of Experimental Medicine: "I do not [...] reject the use of statistics in medicine, but I condemn not trying to get beyond them and believing in statistics as the foundation of medical science"..$^{2}$ Where statistical analysis offers only probabilistic knowledge, the laboratory study of disease causation could offer deterministic proof of the nature of disease and healing processes. 33 Still, in the mid-twentieth century, the RCT was surprisingly quickly accepted in medical literature as truly a superior way of knowing to other types of scientific evidence. Already by the end of the 1950s, the term "gold standard" had taken hold to position the RCT at the top of the hierarchy of evidence in clinical science. 34

Historians who have investigated this paradigm shift offer various reasons for this swift transition that contributed to the conduct of many more clinical experiments in this period. Marks, for instance, explains the quick acceptance of the RCT by pointing to the organizational purposes it fulfilled for therapeutic reformers. The RCT's use of centrally controlled treatment allocations and-if possible-blind assessment of therapeutic outcomes "provided researchers with a mechanism that reduced the investigator's opportunity to change his mind in midstream about the methods of purposes of a study". 35 Within the project of rational therapeutics, in other words, the RCT successfully functioned as a tool of internal control that allowed therapeutic reformers to steer the conduct of individual clinical researchers. Other historians have argued that randomized allocation helped to solve an ethical dilemma of the mid-twentieth century, i.e., which patients would receive a lifesaving drug like streptomycin as long as its industrial production was outnumbered by patients' requests. ${ }^{36}$

Most importantly, perhaps, is the fact that the development of the RCT coincided with the growing state involvement in the governance of medicine around the midtwentieth century. The level of organization that a large-scale RCT requires was made possible in large part because of government support. The British streptomycin trial, for instance, was executed within the structure of the country's National Health Service (NHS) which had been established in 1946 as the world's first single-payer health care system. ${ }^{37}$ The centralized organization of the NHS proved an important vehicle for drawing together patients from various hospital settings as well as for the execution of standardized research protocols. The same was true for the first American

\footnotetext{
${ }^{32}$ See: Timo Bolt, 'A Doctor's Order. The Dutch Case of Evidence-Based Medicine (1970-2015)' (PhD-thesis, Utrecht University, 2015), p. 62. Original citation: Bernard, An Introduction to the Study of Experimental Medicine, p. 138.

${ }^{33}$ See: Matthews, Quantification and the Quest for Medical Certainty.

${ }^{34}$ Meldrum, 'A Brief History of the Randomized Controlled Trial'.

${ }^{35}$ Marks, The Progress of Experiment, p. 128.

${ }^{36}$ Iain Chalmers, 'Statistical Theory Was Not the Reason That Randomization Was Used in the British Medical Research Council's Clinical Trial of Streptomycin for Pulmonary Tuberculosis', in Gérald Jorland, Annick Opinel \& George Weisz (eds.), Body Counts. Medical Quantification in Historical \& Sociological Perspectives (Montreal \& Kingston: McGill-Queen's University Press, 2005), pp. 309334. Also: Benjamin Toth, 'Clinical Trials in British Medicine 1858-1948, with special reference to the development of the randomised controlled trial' (PhD-thesis, University of Bristol, 1998); Edwards, Control and the Therapeutic Trial.

${ }^{37}$ Charles Webster, The National Health Service. A Political History (New Edition) (Oxford: Oxford University Press, 1998).
} 
RCT, that was conducted from 1946 to 1948 under the auspices of the United States Public Health Service (PHS), which provided the funds and infrastructure needed for the collection of comparable results. Together with a number of other RCTs conducted in the early 1950s, these trials provided a proof of principle that large-scale controlled clinical trials, which had been so difficult to organize in the first half of the twentieth century, were in fact possible if the right conditions were realized.

Hence, by the late 1950s, the frustrations that had plagued Marks' therapeutic reformers earlier in the twentieth century were starting to be replaced by opportunities to impose their epistemic ideals of rational therapeutics on the medical profession at large. In nations like the United States and Great Britain at least, the combined availability of funds, infrastructure, and a standardized research method resulted in a significant increase in clinical trials in the immediate post-war decades.

Historians have at times expressed their surprise (and dismay) about the fact that there appears to have been little consideration of the ethics and governance of human experimentation in precisely this crucial period in its history. Rothman, for instance, remarks that while the first two decades after World War II "witnessed an extraordinary expansion of human experimentation in medical research", they were marked at the same time by a remarkable neglect of the rights of research subjects. In a period that the Nazi concentration camp experiments should have been fresh on the minds of clinical researchers, "utilitarian justifications that had flourished under conditions of combat and conscription persisted, and principles of consent and voluntary participation were often disregarded". In the media, the Nuremberg Code received only sporadic attention, while in government "the thrust of public policy was not to check the discretion of the experimenter but to free up the resources that would expand the scope and opportunity for research".$^{8}$ In a Gilded Age of clinical research, Rothman concludes, an astonishingly laissez-faire attitude persisted among medical researchers and practitioners with regards to the ethics of this practice. 39

Rothman is right that fairly little attention existed for the rights of research subjects in the immediate post-war decades. As chapter 3 will make clear, the language of patients' rights would start to take centre stage only from the mid-1960s onwards in international discussions over the governance of human experimentation. That does not mean, however, that the ethics of human experimentation-and clinical research in particular-were not discussed in the 1940s and 1950s. "Historians [who] have puzzled over the relative absence of ethical discussions over medical research in the first twenty years after World War II", Marks remarks delicately in direct response to Rothman's claims, "have been looking in the wrong place". Debates over clinical research in this period were highly ethically charged, even if contributors did not typically emphasize the importance of patient autonomy. "The ethics in question", Marks writes, "was the traditional ethics of therapeutic reformers, who tried to persuade physicians that their beliefs about therapy were unjustified". ${ }^{40}$

\footnotetext{
${ }^{38}$ Rothman, Strangers at the Bedside, p. 51.

${ }^{39}$ Ibid., pp. 51-69. This remark has since been repeated by Robert Baker in Before Bioethics.

${ }^{40}$ Marks, The Progress of Experiment, p. 157.
} 
By the early 1950s, many new drugs came on the market every year, including a stream of antibiotics, hormones, and antipsychotics - all potent drugs with a capacity to cause great harm..$^{41}$ According to Marks, these developments caused a new generation of therapeutic reformers to rally with ever greater intent for the need for controlled trials to evaluate the uses and effects of new and existing medicines. Clinicians who still prescribed 'unproven cures', these reformers maintained, were the ones who played with human lives, who experimented without any hope for trustworthy results, who ultimately conducted themselves unethically. "In treating patients with unproven remedies we are, whether we like it or not, experimenting on human beings", the statistician and "father of the RCT" Austin Bradford Hill wrote in 1954, "and a good experiment well reported may be more ethical and entail less shirking of duty than a poor one"..$^{2}$ In the world of therapeutic reformers, controlled clinical trials were ethically more justifiable than no systematic experimentation at all.

Indeed, as the next parts of this chapter will show, in the 1960s and 1970, the time period that ethical discussions over human experimentation came to be dominated in the United States by concerns over the rights of research subjects, parallel discussions in the Netherlands were just as much influenced by concerns over the apparently dismal state in which Dutch therapeutics found itself-at least according to a group of Dutch pharmacologists and statisticians who hoped to reorganize clinical research in the Netherlands after American and British models. More controlled experiments had to be conducted on human patients in the Netherlands if Dutch therapeutics ever was to become fully rational and relatively safe. A moral need existed in the Netherlands, this group of scholars came to argue, for urgent therapeutic reform.

\section{Dutch attempts at therapeutic reform}

In the mid-1950s, when the Dutch Health Council was asked by the government to write a report on the governance of human experimentation in the Netherlands, there were arguably not that many Dutch clinical researchers in need of ethical constraint. Better put, there were not that many Dutch clinical researchers, although antivivisectionists might counter that all of modern medicine was one big unethical experiment that put innocent creatures in harm's way. Unlike the United States, where medical research became a national industry during World War II, the occupied Netherlands did not develop centrally coordinated clinical research programmes in the war years in the hope of obtaining strategic advantages. Dutch physicians that did manage to conduct research in this period were lauded in later years for their work, which they would have "performed under difficult circumstances during the war". 43

In this period, a number of Dutch physicians did start to lobby for the conduct of more systematic clinical trials in the Netherlands. This group consisted of researchers and practitioners from a variety of backgrounds. Some had been trained as internists, others as statisticians. However, the leading Dutch spokespersons for this movement

\footnotetext{
${ }^{41}$ Hardy \& Tansey, 'Medical Enterprise and Global Response, 1945-2000', pp. 471-487.

${ }^{42}$ Marks, The Progress of Experiment, pp. 157-158; Bradford Hill, quoted in Donald Mainland, 'The Modern Method of the Clinical Trial', in Methods of Medical Research Vol. 6 (1954), p. 157.

${ }^{43}$ W. Lammers, 'Bij het afscheid van Professor Gaarenstroom', in Nederlands Tijdschrift voor Geneeskunde Vol. 109 (1965), p. 1889.
} 
in the mid-twentieth century were pharmacologists. Pharmacology, the study of drug action, had flourished in the Netherlands in the first half of the twentieth century due to financial investments of the Rockefeller Institute and Dutch pharmaceutical industry. 44 Yet, like in most countries, Dutch pharmacological research in this period had mostly proceeded through animal experiments. Although large-scale clinical trials did at times take place, clinical tests usually occurred in the form of sending out samples to clinicians who were asked to report back their findings in case reports, usually with only a handful of patients. ${ }^{45}$ By the early 1950s, Dutch pharmacologists increasingly evaluated this practice as unsatisfactory. Inspired by the recent developments in the United States and Great Britain, they started to advocate the need for systematic clinical experimentation to determine the efficacy of medications. Without comprehensive knowledge of the physiological responses of drugs in actual human patients, they argued, the study of drug action remained incomplete. A new branch therefore had to be added to medicine, i.e. the branch of clinical pharmacology.

An early and prominent Dutch advocate of clinical pharmacology was Frans Nelemans, the first scholar appointed to teach the subject (as a privatdozent) at one of the Dutch universities in $1956 .{ }^{46}$ In his inaugural lecture, Nelemans lauded the progress pharmacology had made in the twentieth century, but also declared that as a result of this "a gap [now] exists between the laboratory and the clinic". While most pharmacologists could no longer call themselves clinicians because they spent all their time in a laboratory, most clinicians no longer understood the study of drug action due to the advancements that pharmacology had made in the last century. According to Nelemans, this was dangerous, especially in an era in which so many new pharmaceuticals found their way to clinical practice each year. Clinicians had to consult pharmacologists about the drugs they could sensibly prescribe, while pharmacologists had to move back into the clinic to study drug action. The field's current dependency on animal experiments made the use of pharmaceuticals in clinical practice at best incomplete, at worst hazardous. 47 In short, clinical pharmacologists were needed to bridge the divide between laboratory and clinic, between science and practice.

\footnotetext{
${ }^{44}$ In the early 1920s, German pharmacologist Rudolf Magnus acquired funds from the Rockefeller Foundation to build a pharmacological laboratory in Utrecht. In 1923, German pharmacologist Ernst Laqueur co-founded the Dutch pharmaceutical company Organon that provided the funds for his famous research into the industrial production of hormones. This influx of finances contributed to the emergence of a well-known generation of Dutch pharmacologists in the mid-twentieth century. See: E.L. Noach, 'The history of pharmacology in the Netherlands', in Trends in Pharmacological Sciences Vol. 11 (1990), pp. 236-239; J.H. Gaarenstroom, 'Het aandeel van Nederland in de vooruitgang der geneeskundige wetenschap van 1900 tot 1950', in Nederlandsch Tijdschrift voor Geneeskunde Vol. 95 (1951), pp. 762-767; Annet Mooij, 'Laqueur, Ernst (1880-1947)', in Biografisch Woordenboek van Nederland. URL:http://resources.huygens.knaw.nl/bwn/BWN/lemmata/bwn6/laqueur [12-11-2013] ; R.H. Vermij, David de Wied. Toponderzoeker in polderland (Utrecht, 2008); H. Timmermans \& D.D. Breimer, 'Levensbericht Everhardus Jacobus Ariëns', in Levensberichten en herdenkingen 2007 (Amsterdam: Koninklijke Nederlandse Akademie van Wetenschappen, 2007), pp. 6-17.

${ }^{45}$ Nelly Oudshoorn, 'Laqueur en Organon. Het Universitaire Laboratorium en de Farmaceutische Industrie in Nederland', in Gewina Vol. 22 (1999), pp. 12-22.

${ }^{46}$ F.A. Nelemans, Klinische Farmacologie (Openbare Les gehouden aan de Rijksuniversiteit te Utrecht op Dinsdag 13 november 1956). The status of privatdozent or privaatdocent was an unsalaried position that used to exist at Dutch universities to teach classes in a subject that did not yet form a part of the standard curriculum of faculties. The position was typically used for new academic subjects.

${ }^{47}$ Also: F.A. Nelemans, 'Klinische farmacologie', in W. Lammers, F.A. Nelemans \& P. Siderius (eds.), Algemene Farmacotherapie. Het Geneesmiddel in Theorie en Praktijk (Leiden, 1961), pp. 19-20, p. 19.
} 
Given the need for a better understanding of drug action in actual human patients, Nelemans envisioned clinical pharmacologists to spent much of their time conducting clinical research studies: more clinical trials needed to be conducted to test the safety and efficacy of new and existing medicinal products. Clinical pharmacologists would do so, Nelemans explained to his audience, by drawing on the latest scientific insights about sound research methods. These, he continued, prescribed that more clinically controlled studies had to be conducted, in which neither the patients nor the clinicians would know which patients were administrated an active medicinal substance and which a placebo for the full duration of the trial period. Furthermore, Nelemans claimed confidently, "a clinical trial is only called reliable these days if the results can be treated statistically". ${ }^{48}$ The first official clinical pharmacologist of the Netherlands, in other words, was a strong advocate of the double-blind RCT.

Nelemans was not the only Dutch pharmacologist who actively started to promote the need for controlled clinical trials in this period. In 1958, for instance, pharmacologist and rector of Leiden University Samuel Elzevier de Jongh (see chapter 1) gave a public speech in honour of the $383^{\text {rd }}$ birthday of Leiden University-a lecture he dedicated to discussing the history and future of pharmacotherapy. This branch of medicine, De Jongh argued, found itself in the midst of "tempestuous times". ${ }^{49}$ Since the nineteenth century, the pharmacologist explained, much progress had been achieved thanks to the discovery of new drugs. Diseases that once caused certain death could now be cured or prevented with pills, sera, and vaccines..$^{\circ 0}$ However, because "it rains rather than drizzles new medications today", an urgent need had developed for their systematic clinical evaluation. ${ }^{11}$ After all, unless the introduction of new drugs into clinical practice would categorically be forbidden (which De Jongh argued was clearly undesirable), every new medicine at some point had to be tried out on patients for the first time: "It does not do to obscure the affair with fine words, the first application in man carries the character of an experiment". ${ }^{2}$ Yet, precisely because experimentation was an indispensable part of clinical practice, De Jongh felt it was ethically more justified to make sure that such tests were systematically conducted in controlled clinical settings than to rely on individual clinicians to write up case reports of incidental investigations with a new drug. Some people, De Jongh argued, claimed the use of control groups was unethical as they withheld possibly effective therapies to patients in need. But these people were mistaken. "The unjust, although well-intended, omission of a control group in the past has had the result that the effectiveness of currently established therapies is strictly still unproven". ${ }^{53}$ For De Jongh, previous member of the Council committee 'tests upon human beings' (see chapter 1), this was a distinct ethical problem. Without controlled clinical trials, patients would routinely be treated with worthless medicines, thereby threatening their recovery. Hence, systematic clinical experimentation was a moral necessity-for the sake of the patient.

\footnotetext{
${ }^{48}$ Nelemans, Klinische Farmacologie, p. 11.

${ }^{49}$ S.E. de Jongh, De Ontwikkeling der Farmacotherapie (Rede ter Herdenking van de $383^{\text {ste }}$ Verjaardag der Rijksuniversiteit te Leiden op 8 februari 1958. Uitgesproken door de Rector Magnificus), p. 4.

${ }^{50}$ Ibid., p. 8.

${ }^{51}$ Ibid., p. 10.

${ }^{52}$ Ibid., p. 10. De Jongh borrowed this line of argumentation from: Gerrit Arie Lindeboom, 'Ethiek in de medische wetenschap', in Universiteit en Hogeschool Vol. 3 (1957), pp. 131-141.

${ }^{53}$ De Jongh, De Ontwikkeling der Farmacotherapie, p. 14.
} 
Six days after De Jongh's commemorative speech, the Dutch pharmacologist Chris Rümke made a similar ethical argument in a public lecture given at the Free University of Amsterdam to inaugurate his appointment as privatdozent in another branch of medicine that was just gaining attention in the Netherlands: medical statistics. ${ }^{54}$ In this lecture, Rümke also stated that experimentation should be considered an indispensable part of clinical practice. Experiments on patients could not be avoided, they could only be kept at a bare minimum. This meant, however, that an "ethical necessity" existed "that efficient use be made of data obtained from experiments on human beings" to ensure that clinical experiments could in fact be kept at a bare minimum. 55 Medical statistics, Rümke argued, could help researchers meet this demand. Clinical trials had to be set up in such a way that with a minimal input of patients a maximum result could be achieved. Like Nelemans, Rümke was convinced this optimization was ideally realized with the conduct of an RCT. Instead of the often "worthless investigations of individual clinicians", systematic clinical trials had to be organized that were built around statistical notions of scientific controls and randomization.

Nelemans, De Jongh and Rümke were therapeutic reformers: they were convinced that more controlled clinical experimentation would ensure better knowledge about clinical drug use, which would in turn contribute to better therapeutic practice. They were also-at times-frustrated elitists. They felt they understood better than the average practitioner which courses of action in clinical research and practice should be considered rational, but they had few means at their disposal, other than the power of persuasion, to make their medical colleagues comply with their epistemic convictions. In short, Dutch therapeutic reformers of the 1950s and 1960s desired internal control to realize their ideals of rational therapeutics, but lacked hard political and economic power to bring these to fruition. In his 1958 lecture, De Jongh lamented the fact that no "communal apparatus" existed in the Netherlands to direct the experimental investigation of new pharmaceutical products. A group consisting of "chemists and physicians, scholars and manufacturers, laboratory workers, and clinicians" did regularly cooperate in attempt to determine the clinical safety and efficacy of all the new medicines that were introduced in Dutch medical practice each year, but this situation was "far from ideal". ${ }^{6}$ Some sort of formal structure had to be realized in the Netherlands for the systematic conduct of controlled clinical trials.

One Dutch research organization was trying to organize such a system for the conduct of coordinated clinical trials in the mid-1950s. This was the Netherlands Organization of Applied Scientific Research (TNO), an independent research organization which had been established in 1932 by the Dutch government to conduct applied sci-

\footnotetext{
${ }^{54}$ Chr. L. Rümke, De taak van de Medische Statistiek (Vrije Universiteit van Amsterdam, 14 februari 1958). Also: A.J. Dunning, 'Afscheid prof.dr. Chr. L. Rümke', in Nederlands Tijdschrift voor Geneeskunde Vol. 136 (1992), pp. 900-901; J.P. Vandenbroucke, 'De opkomst van medische statistiek en epidemiologie in het klinisch wetenschappelijk onderzoek van de afgelopen eeuw', in Nederlands Tijdschrift Voor Geneeskunde Vol. 143 (1999), pp. 2625-2628.

${ }^{55}$ The exact quote is from the English abstract of Rümke's inaugural lecture, reprinted as: Chr. L. Rümke, 'De taak van de medische ethiek' in Statistica Neerlandica Vol. 12 (1958).

${ }^{56}$ De Jongh, De Ontwikkeling der Pharmacotherapie, p. 14.
} 
entific research studies "in service of the public interest". The organization received government funds, but-as an independent body-made its own decisions about what type of research it would fund. By the mid-twentieth century, TNO had become the largest Dutch research organization for applied science.57 In December 1951, Dutch pharmacologist Johan Gaarenstroom, a previous pupil of De Jongh and a former supervisor of Rümke, had just finished an internal memo for TNO on "the possibilities of coordinated research on pharmaceuticals" in the Netherlands..$^{8}$ In this memo, Gaarenstroom concluded that Dutch scientists were "at their wits' end" due to a lack of any infrastructure for clinically testing the safety and efficacy of new drugs. Sometimes, researchers knew "a friendly clinical relation willing to try out a new substance", but this option was scarce. With the help of TNO, therefore, Gaarenstoom hoped to organize systematic clinical trials in the Netherlands after American model.59 The pharmacologist wanted to bring together players from industry, academia, and clinical practice to realize a system for clinical experimentation.

Despite its central position in the Dutch scientific research landscape, TNO was initially sceptical of Gaarenstroom's plans. When his memo was discussed at a board meeting of the organization's Health Department, for instance, most board members openly doubted if "any willingness can be found in the Netherlands for the systematic conduct of clinical research". ${ }^{60}$ In their eyes, a "complete lack of interest" existed for such matters in the country. From others in academia and industry, Gaarenstroom received similar replies. Most were unconvinced that cooperative clinical studies had much chance of success in the Netherlands. Past attempts at cooperation between the parties the pharmacologist had in mind had always failed. Sometimes, joint exploitation had proven impossible due to disputes over the distribution of commercial gain. At other times, the relations between chemists and pharmacologists had proven too strained to cooperate productively. To expect these parties suddenly to be capable to work together after all on systematic drug trials was wishful thinking. ${ }^{61}$

Another difficulty that Gaarenstroom's respondents foresaw was the professional ethos of Dutch clinicians. In 1951, a board member of TNO's Health Department remarked that the reigning Dutch medical ethics made physicians reluctant to participate in clinical trials. ${ }^{62}$ One of these contacts wrote in response to his memo: "I would have thought you knew the Dutch clinician well enough to know this proposal in its current form does not have much chance of success". ${ }^{63}$ In comparing the Dutch situation to the United States, where "the big bosses have access to much more patient material", this contact (probably from the pharmaceutical industry) wrote:

\footnotetext{
${ }^{57}$ Harry Lintzen et al., Tachtig jaar TNO (2012), accessible at: http://www.histech.nl/www/nl/publications/view/tachtig-jaar-tno.

${ }^{58}$ NL-HaNA, TNO, Gezondheidsorganisatie 1949-1980, 2.14.36.06, 608, Nota Dr. J.H. Gaarenstroom betreffende gecoördineerde geneesmiddelen research, 06-12-1951.

${ }^{59}$ See also: T. van Helvoort, 'De publieke functie van universitaire wetenschapsbeoefening. Amerikanisering als leidmotief bij de scheikunde aan de Groningse universiteit', in L.J. Dorsman \& P.J.

Knegtmans, Onderzoek in opdracht. De publieke functie van het universitaire onderzoek in Nederland sedert 1876 (Hilversum, 2007), pp. 67-92.

${ }^{60}$ NL-HaNA, TNO, 2.14.36.06, 608, bestuursnotulen 06-12-1951.

${ }^{61}$ NL-HaNA, TNO, 2.14.36.06, 608, Nota Dr. J.H. Gaardenstroom.

${ }^{62}$ NL-HaNA, TNO, 2.14.36.06, 608, bestuursnotulen 06-12-1951.

${ }^{63}$ NL-HaNA, TNO, 2.14.36.06, 608, Nota Dr. J.H. Gaardenstroom.
} 
I know agreements exist there between industrial firms and certain clinicians that oblige clinicians to test everything for these companies in exchange for significant sums of money. Do you deem this possible in the Netherlands? I don't. The entanglement of research with teaching, the overburdening of clinicians, the small size of this country, the specialization of interests-they make that I have little hope of radical change. Also here, industry will have to find her own way.

For various reasons, in short, the realization of an infrastructure for large-scale clinical trials in the Netherlands was deemed unrealistic by many insiders in the field in the mid-twentieth century. Still, TNO did install a Committee Clinical Drug Research in 1952 to "fill the existing void of clinical research in the Netherlands". ${ }^{4}$ It included prominent Dutch physicians and medical scientists, like the internist Cornelis Douwe de Langen (see chapter 1) and the eminent Dutch pharmacologist Ulbe Gerrit Bijlsma who had held a professorial chair at Utrecht University since 1928 and who had been its rector in the late 1940s. Three of its other members were Rümke, Gaarenstroom, and Nelemans-who was appointed as its chairman in 1956.65

From its inception in 1952 onwards, the Committee Clinical Drug Research sought to stimulate clinical experimentation in the Netherlands by functioning as coordination centre for cooperative clinical studies and by putting funds available for clinical trials in general. ${ }^{66}$ It also sought to communicate "sound judgements" about the efficacy of new and existing medications to Dutch clinicians in the hope this knowledge would rationalize pharmacotherapy in the Netherlands. ${ }^{67}$ It did so by collecting available literature and non-published data in comprehensive overviews, but also by conducting clinical research studies itself. In publications like the Dutch Journal of Medicine and Pharmaceutical Weekly, the Committee informed clinicians and pharmacists of its findings. ${ }^{68}$ In addition, it served as a helpdesk for questions about pharmaceutical products. ${ }^{69}$ The goal was that by 'educating' the average Dutch clinician about the responsible use of drugs, a rational therapeutics would be brought into existence in the Netherlands: i.e. only pharmaceuticals that had been proven effective through "sound research" (meaning they fitted the epistemic standards of the reformers that held a seat in the TNO Committee) would be used in clinical practice, by practitioners who knew how to responsibly prescribe them to patients.

In practice, however, this proved difficult. In part, because the committee only had limited funds at its disposal. In part, because, as TNO made clear in a press release when it decided to dismantle the Committee in 1975, "the research programme of this committee could hardly be built up responsibly due to the great difficulty to acquire representative clinical data, seriously handicapping the reproducibility of results". ${ }^{70}$ Even with a large organization like TNO behind them, in other words, controlled clin-

\footnotetext{
${ }^{64}$ NL-HaNA, TNO, toegang 2.14.36.06, 608, eerste vergadering 19-11-1952.

${ }^{65}$ M.M. Hilfman, 'Mededelingen adviescommissie klinisch geneesmiddelenonderzoek', in Nederlands Tijdschrift voor Geneeskunde Vol. 100 (1956), p. 1671.

${ }^{66}$ NL-HaNA, TNO, 2.14.36.06, 608, eerste vergadering, 19-11-1952.

${ }^{67}$ NL-HaNA, TNO, 2.14.36.06, 608, brief van F.A. Nelemans aan Prof.dr. J.W.H. Mali, 30-10-1959.

${ }^{68}$ NL-HaNA, TNO, 2.14.36.06, 608, eerste vergadering, 19-11-1952.

${ }^{69}$ NL-HaNA, TNO, 2.14.36.06, 608, brief van F.A. Nelemans aan Prof.dr. J.W.H. Mali.

70 'Opheffing Werkgroep Klinisch Geneesmiddelenonderzoek TNO', in Nederlands Tijdschrift voor Geneeskunde Vol. 119 (1975), p. 418.
} 
ical trials had remained difficult to organize in the Netherlands. Dutch clinicians often had been unwilling or unable to cooperate and, even if they did, their results had often differed too much to yield trustworthy results. It appeared as if Gaarenstroom's contacts in the early 1950 s had been right: there was little hope of radical change in the Netherlands regarding the conduct of clinical drug research-and, by implication, of other types of clinical (and thus human) experimentation as well.

Throughout the 1960s, Dutch therapeutic reformers like Nelemans did continue to advocate the importance of controlled clinical trials in the Netherlands. In 1961, Nelemans co-edited the handbook Algemene Farmacotherapie with two fellow pharmacologists that would go through seven editions in the decades thereafter as education material for Dutch students. ${ }^{71}$ In one of the first chapters-on the subject of clinical pharmacology-Nelemans taught: "Even though tests with the double blind technique cannot always be conducted upon patients because of ethical reasons, there are relatively few cases known in which a study without the double blind method has led to truly sound judgements". ${ }^{72}$ In 1963, Nelemans and De Jongh gave speeches at a conference of the Dutch pharmaceutical industry to convince drug manufacturers of the necessity to conduct systematic clinical trials prior to the release of new products. 73 In Dutch newspapers, their talks were reported under headlines such as 'New Medicines Demand Experiments on Humans', 'The Necessity of the Clinical Experiment' and, in one paper with a bit of flair for drama, 'Humans are the Best Laboratory Animals'. ${ }^{74}$ Dutch reformers embarked on a national campaign in the 1960s, in short, to convince the field of the epistemic and ethical superiority of their way of knowing.

In 1970, Nelemans co-authored another booklet titled Therapeutic Evaluation of Medicines. By then, however, his appeal for rational therapeutics had grown considerably more sour. With the publication of this booklet, he and his co-author wrote in the preface, they hoped "to ask attention for one of the most stepmotherly endowed branches of science" and to point out "the pitfalls that one runs into with every therapeutic evaluation and that are responsible for the fact that an intolerable number of therapeutic studies go wrong". "As difficult as it must be to process for many physicians", the two carried on in the introduction, "conclusions about the therapeutic value of a medicine based on observations of the patient who is 'only treated' are almost always useless and often misleading". They sorely hoped, therefore, "that with the publication of this booklet more physicians than is currently the case will delve into the problems that play a role in this [i.e. clinical drug research]".75

\footnotetext{
${ }^{71}$ Lammers, Nelemans \& Siderius, Algemene Farmacotherapie.

${ }^{72}$ F.A. Nelemans, 'Klinische farmacologie', in Ibid., pp. 19-20, p. 20. Italics added.

73 'Veiligheid van Nieuwe Geneesmiddelen', in Medisch Contact 18 (1963), pp. 359-361.

74 'Veilig gebruik nieuwe geneesmiddelen', in Friese Koerier, Saturday 30 November 1963, p. 21; 'Onderzoek nieuw medicijn eist experiment op mens', in De Tijd-Maasbode, Friday 10 May 1963, p. 4; 'Risico's zijn in farmacologie onvermijdelijk', in De Telegraaf, Friday 10 May 1963, p. 3; 'De Mens is het Beste Proefdier', in De Waarheid, Thursday 30 November 1963, p. 4.

${ }^{75}$ F.A. Nelemans \& W.G. Zelvelder, Therapeutische evaluatie van geneesmiddelen (Leiden: Stafleu's Wetenschappelijke Uitgeversmaatschappij, 1970), p. 5, p. 9, p. 5.
} 
With publications such as these, Nelemans tried to both increase and improve the conduct of Dutch clinical drug research in the 1960s. Others attempted so as well, by publishing concerned opinion pieces in Dutch medical journals that warned about the shortcomings of clinical drug research in the country. ${ }^{76}$ Increasingly, however, Dutch therapeutic reformers in this period started to turn to other tools of reform in attempt to realize their ideals of rational therapeutics. Most prominently, instead of the soft power of academic persuasion, the hard power of government force started to surface in their work. "It is neither wrong nor unwise", Nelemans and his co-author surmised delicately in conclusion to their booklet in 1970, "if society, by means of the government, ensures that only drugs which are effective [...] may be put into circulation". 77 Reform would be realized, in the end, not by convincing Dutch clinicians with valid epistemic or ethical arguments, but through state interference.

In his work, Nelemans was careful to present this growing state interference with the organization of Dutch medical practice as an external force: an intervention from outside the system of medicine that he or other therapeutic reformers really had little influence on. In their 1970 booklet, for instance, the two authors presented a future vision for clinical drug research in the Netherlands. The state would increasingly put regulatory criteria in place demanding drug manufacturers to offer clinical evidence to prove the efficacy of their products. The state would increasingly hold clinicians accountable if they did not provide 'optimal pharmacotherapy'. With these measures, the state would increasingly stimulate clinical experimentation. This vision was presented in a dry, matter-of-fact tone. "We leave open whether this development is desirable", the two authors concluded, "we just signal her" ${ }^{78}$ As the next section shows, however, behind the scenes therapeutic reformers like Nelemans had everything to do with the growing state involvement in Dutch pharmacotherapy in the 1960s and 1970s. On various occasions, they lobbied with the Dutch government in these decades to enforce their ideals of rational therapeutics: if medical practitioners would not cooperate willingly, they had to be made to walk in line using state force. In 1971, one of these lobby attempts contained the first Dutch blueprint for the governance of human experimentation using a system of ethics by committee.

\section{State imposed epistemic reform}

In 1958, Dutch parliament passed the Medicines Supply Act to regulate the production and distribution of medicines in the Netherlands.79 It replaced a much older Dutch Law on Pharmacy, dating from 1865, which had regulated the Dutch pharmaceutical drug market for almost a hundred years. ${ }^{80}$ The 1958 law substantially altered

\footnotetext{
${ }^{76}$ See for instance: J.R. Prakken, 'Tekortkomingen van het klinisch geneesmiddelenonderzoek en gevaren van de industriële propaganda', in Nederlands Tijdschrift voor Geneeskunde Vol. 105 (1961), pp.

1569-1571; Fokkens, 'Oordeelsvorming in de geneeskunde'.

${ }^{77}$ Nelemans \& Zelvelder, Therapeutische evaluatie van geneesmiddelen, p. 139.

${ }^{78}$ Ibid., p. 139.

${ }^{79}$ Wet van 28 juli 1958, houdende nieuwe regelen nopens de geneesmiddelenvoorziening en de uitoefening der artsenijbereidkunst (Wet op de geneesmiddelenvoorziening).

${ }^{80}$ Wet regelende de uitoefening der artsenijbereidkunst, 1 Junij 1865; A. Querido, Een eeuw staatstoezicht op de volksgezondheid ('s-Gravenhage, 1965), pp. 19-25; B. Kruithof, 'Wetgeving of Marktordening? Apothekers en Drogisten in het Interbellum', in Gewina 22 (1999), pp. 34-45.
} 
the Dutch regulatory regime of pharmaceuticals. ${ }^{81}$ From then on, so-called 'packaged medicines'-medicines produced industrially and delivered pre-packaged to apothecaries, druggists, and grocers-could be put on a restricted list by a thereto appointed regulatory agency, so they could only be purchased at licensed apothecaries. In addition, wholesale drug manufacturing now required government authorization, while the existing Dutch Pharmaceutical Inspection was empowered to monitor the professional practice of pharmacists much more closely. ${ }^{82}$ In short, from the late 1950 os onwards, the Dutch government had much more hard power than ever before in history to steer the production and distribution of medicines in the Netherlands-and hence, in theory, to direct the conduct of Dutch pharmacotherapy as well.

Still, the 1958 Medicines Supply Act was not meant, in first instance, to stimulate the conduct of 'rational therapeutics' in the Netherlands, at least not as envisioned by reformers like Nelemans. The Act primarily had been designed to ensure good manufacturing practices: to make sure medicines were prepared in hygienic environments and under controlled circumstances, to prevent contamination and to ensure that the dose of active principle in each unit of medicine was fixed and known. ${ }^{83}$ "Criteria for the toxicity and efficacy of drugs", public servants responsible for the execution of the Act recalled in 1988, "were only of secondary importance". 84

Nonetheless, Dutch therapeutic reformers did take the 1958 Medicines Supply Act as an opportunity to realize some of their ideals of rational therapeutics. In 1959, for instance, the TNO Committee Clinical Drug Research discussed the implications of the Act for large-scale clinical research in the Netherlands. Nelemans was adamant it offered distinct possibilities. Most directly, Article 3 of the Act stipulated that a yet to be installed regulatory agency would only register packaged medicines "of which it may reasonably be expected that they possess the advertised effect". The text of the Act did not mention how exactly this agency was to determine if packaged medicines did in fact possess the effects advertised or, more importantly, what standards of efficacy it should insist on. Yet, Nelemans argued, if the right people were appointed to this regulatory agency, Article 3 offered a realistic chance to force drug manufacturers to conduct more controlled clinical trials: "If these methods would be standardized, and if only those medicines that have been tried and tested according to these methods would be accepted, much would have been accomplished already". 85

\footnotetext{
${ }^{81}$ Rein Vos, 'The 'Dutch drugstore' as an attempt to reshape pharmaceutical practice. The conflict between ethical and commercial pharmacy in Dutch cultures of medicines', in M. Gijswijt-Hofstra, G.M. van Heteren \& E.M. Tansey (eds.), Biographies of Remedies. Drugs, Medicines and Contraceptives in Dutch and Anglo-American Healing Cultures (Amsterdam: Rodopi, 2002), pp. 57-74; Toine Pieters, 'Tussen controle op afstand en betrokken begeleiding. Historische trajecten in het staatstoezicht op geneesmiddelen', in Kennis Cahier (Inspectie voor de Gezondheidszorg, 2010), pp. 49-60; C. van den Berg, 'Herinneringen aan de wordingsgeschiedenis van de wet op de geneesmiddelvoorziening', in Tijdschrift voor Sociale Geneeskunde 42 (1964), pp. 12-15.

${ }^{82}$ C.J. Goudsmit, 'De Totstandkoming van de Wet op de Geneesmiddelenvoorziening', in De wet op de geneesmiddelenvoorziening. Beschouwingen, Tekst van de Wet, Uitvoeringsbesluiten ('s-Gravenhage: Koninklijke Nederlandse Maatschappij ter Bevordering der Pharmacie, 1963), pp. 8-12.

${ }^{83}$ C.A. Teijgeler (ed.), Het College ter Beoordeling van Geneesmiddelen. Een Registratie (Bloemendaal, 1988), p. 3. For a historical overview of the rise of standards for 'good manufacturing practices' in the first half of the twentieth century, see: Christoph Gradmann \& Jonathan Simon (eds.), Evaluating and Standardizing Therapeutic Agents, 1890-1950 (Basingstoke: Palgrave Macmillan, 2010).

${ }^{84}$ Teijgeler, Het College ter Beoordeling van Geneesmiddelen, p. 3.

${ }^{85}$ NL-HaNA, TNO, 2.14.36.06, 608, $19^{\mathrm{e}}$ vergadering, 12-06-1959.
} 
Notably, not all members of the Committee Clinical Drug Research agreed this was a good idea. The eminent Bijlsma, in particular, was sceptical about Nelemans' suggestion to make sure this new regulatory agency would only be permitted to "accept medicines that have been investigated in a statistically responsible manner". This epistemic 'tunnel vision', the famous pharmacologist stated, made him feel uncomfortable. For one thing, because such a strict legislative rule would turn patients in many instances into "nothing more than test animals", as the efficacy of not only new but also existing medications would have to be established through controlled clinical trials. And for another, because he doubted whether the type of epistemic singularity advocated by Nelemans should be enforced on medical researchers and practitioners by the state. "In former times, without statistical research", Bijlsma remarked sharply, "medicines were also developed". Sure, it could be useful to demand specific scientific evidence for the efficacy of medicines in instances that obviously worthless drugs were pushed for market access (to keep 'alternative healers' of the drug market, for instance), but to demand from regular researchers that they could only establish the efficacy of drugs with one method bordered on the dogmatic. Indeed, another committee member added, all clinics had their own proven methods for testing the efficacy of drugs for patients. To enforce the standardization of these practices from above was questionable, as it took away physicians' autonomy. Nelemans, however, openly wondered if his colleagues fully understood the difference between the clinical study and clinical use of drugs. Variation might be defended in case of the second, he stated, but could not possibly in case of the first. After all, embracing variety undermined the very idea of conducting large-scale trials to control for any sources of potential bias in clinical experimentation. This was why the Dutch government should enforce the standardization of clinical research methods with legislation. ${ }^{86}$

Despite the fact that the 1958 Medicines Supply Act did not mention which standards this yet to be established regulatory agency had to use in its evaluation of clinical efficacy, Nelemans would soon get a chance to implement his ideas of enforced therapeutic reform on a state level. Initially, the effectuation of the 1958 Act had not been a priority for the Dutch government. Only in 1963, in fact, did it install the regulatory agency that would from then on be responsible for the registration of packaged medicines in the Netherlands: the (Packaged) Medicines Evaluation Board. ${ }^{87}$ It did so after the infamous Thalidomide-disaster of 1961, when it became clear that the over-thecounter drug thalidomide, that had been sold since the late 1950 os as a low-risk medicine against nausea and morning sickness, had in a few years' time caused more than 10.000 infants to be born worldwide with severe teratogenic deformities. ${ }^{88}$ Marketed in the Netherlands under the brand name Softenon, thalidomide had also been prescribed to Dutch pregnant women, although much less in comparison to other countries. ${ }^{89}$ Nonetheless, the disaster caused a big scare in the Netherlands. Newspapers

\footnotetext{
${ }^{86}$ For all, see: Ibid.

${ }^{87}$ In Dutch: Het College ter Beoordeling van (Verpakte) Geneesmiddelen.

${ }^{88}$ For how thalidomide influenced the regulation of pharmaceutical drugs in the twentieth century, see: Jean-Paul Gaudillière \& Volker Hess (eds.), Ways of Regulating Drugs in the $19^{\text {th }}$ and $20^{\text {th }}$ Centuries (Basingstoke: Palgrave Macmillan, 2013); Peter Temin, 'Government Actions in Times of Crisis: Lessons from the History of Drug Regulation', in Journal of Social History 18 (1985), pp. 433-438.

${ }^{89}$ Whereas in Germany approximately 4000 babies with teratogenic deformities were born as a result of thalidomide, this number amounted to 25 in the Netherlands. See: 'Ouders van softenon-kinderen
} 
reported that such disasters could easily occur again, not in the least because the government was hardly prepared for them..$^{\circ}$ In parliament, Minister Veldkamp of Social Affairs and Public Health was urged to finally make haste with the effectuation of the Medicines Supply Act. On television, the Director-General of Public Health Piet Muntendam had to promise that the effectuation of the Act would prevent a disaster like Softenon from ever happening again in the Netherlands. ${ }^{91}$

Because of the thalidomide-tragedy, the Medicines Evaluation Board was granted much leeway in 1963 to develop a regulatory system capable of evaluating the safety of packaged medicines prior to their market release. Two central figures in its set-up were pharmacologists Poppe Siderius, then Chief Medical Officer of the Netherlands, and Willem Lammers, who was employed by the National Institute for Public Health and Environmental Hygiene. The two men knew each other well. They had been coworkers in Groningen under direction of Gaarenstroom and, together with Nelemans, had sat on the editorial board of the handbook Algemene Farmacotherapie of $1961 . .^{22}$ Like Nelemans, who was appointed as a board member to the Medicines Evaluation Board, Siderius and Lammers were convinced of the need to conduct elaborate controlled clinical experiments to evaluate the efficacy of pharmaceutical products. What was more, they agreed with Nelemans that the Medicines Evaluation Board should interpret Article 3 of the Medicines Supply Act to mean that the regulatory agency could demand drug manufacturers to provide proof of the efficacy of their products through the conduct of controlled clinical experimentation.

In 1988, in honour of the $25^{\text {th }}$ anniversary of the Medicines Evaluation Board, the two pharmacologists commemorated this decision under the banner "A Law is Just a Law". The Dutch government had put them in the position to regulate the national pharmaceutical drug market and Siderius and Lammers had taken it as their responsibility to regulate it as they saw fit. "From the beginning onwards, we had to work as trendsetters", Lammers recalled in 1988. "Until then, no formal monitoring of medications existed and suddenly we were there with a system that made all sorts of demands". ${ }^{93}$ One of the first members of the Medicines Evaluation Board, internist Job Pannekoek (a prior member of the Health Council committee 'tests upon human beings') similarly recalled: "At first, it was hard work to substantiate that a sound clinical judgment requires scientifically sound research methods":

I remember I gave a talk in 1956 about the importance of 'clinical trials'. In England, they were already pretty advanced at the time in this way of doing sound medical research. But in the Netherlands, no one was thinking this way. Here, most were still working chiefly subjectively. ${ }^{94}$

geen kans op schadevergoeding', in De Telegraaf, Wednesday 21 February 1968, p. 9; 'Thalidomide eiste ook in Nederland slachtoffers', in Limburgs Dagblad, Thursday 2 January 1969, p. 7.

90 'Wij slikken duizenden pilletjes per dag', in De Waarheid, Thursday 13 September 1962, p. 4

91 'Talloze problemen voor Veldkamp', in Limburgs Dagblad, Thursday 22 November 1962, p. 5;

'Wanneer controle op verpakte geneesmiddelen?', in De Waarheid, Thursday 22 November 1962, p. 3;

M. Cluysenaer \& L. Breeveld, 50 Jaar College ter Beoordeling van Geneesmiddelen (Haarlem, 2013).

${ }^{92}$ Lammers et al., Algemene Farmacotherapie. See also: Vermij, David de Wied.

93 'Wet is Maar Wet', in Het College ter Beoordeling van Geneesmiddelen, p. 3.

${ }^{94}$ Ibid., p. 10. Italics added. 
It was necessary, therefore, Pannekoek argued, that the Medicines Evaluation Board would start to demand that the efficacy of medications could only be proven by "clinical trials with truly double blind investigations from which real evidence can be obtained to establish a significant difference between a group that is treated with a certain drug and a group that is not". "Demanding such an objective criterion of efficacy", he added proudly, "was pretty revolutionary at the time". 95 To ensure the Board also took this 'revolutionary view', Siderius and Lammers had known advocates of the RCT take up a seat in the regulatory agency. "Because of the experiences that we had gained with the publication of our [hand]book", the two explained in 1988, "we were well-informed about the expertise that then existed in the Netherlands". ${ }^{6}$ They knew exactly who to ask to reform the Dutch pharmaceutical drug market.

Hence, even though the 1958 Medicines Supply Act brought more state control to Dutch pharmacotherapy than ever before in history, elite members from the medical profession took the driver's seat in the realization of these oversight mechanisms. As a result, the disciplinary power of a fairly small group of Dutch physicians, who had since long been dissatisfied with the way most of their colleagues practiced medicine, grew significantly. With the hard power provided by the state, Dutch therapeutic reformers acquired a tool in the early 1960s that in theory allowed them to steer the conduct of clinicians in the Netherlands: if only drugs whose efficacy had been proven with 'objective' clinical research methods would be granted market access, all clinical researchers had to start conducting their trials according to the rules prescribed by the RCT, while all clinical practitioners could only prescribe those drugs which had been approved by the Medicines Evaluation Board. This, reformers such as Nelemans hoped, would soon result in the conduct of more clinical trials in the Netherlands. As he wrote in his vision for the future of Dutch clinical drug research in 1970:

On the one hand, it will be allowed to state that every practicing physician has the duty, when an appeal is made on him, to cooperate with studies that serve to determine the value of medicines and to spent part of his working hours [...] in this vein. On the other, society may expect and perhaps even demand from her patient-members that they make themselves available for studies as meant here. 97

The Medicines Evaluation Board, in short, was designed to function as an epistemic filter for clinical drug research in the Netherlands, i.e., it had to use the hard power of the Dutch state to sift out what reformers like Nelemans believed to be good clinical research from bad clinical research. And in doing so, the Evaluation Board would be able to enforce a specific epistemic perspective upon Dutch pharmacological science and medical practice-and upon Dutch society more generally. ${ }^{9}$

\footnotetext{
${ }^{95}$ Ibid., p. 10. Italics added.

${ }^{96}$ Ibid., p. 2.

${ }^{97}$ Nelemans \& Zelvelder, Therapeutische evaluatie van geneesmiddelen, p. 140.

${ }^{98}$ According to Theodore M. Porter, state force was the primary reason why RCTs came to dominate clinical research from the 1970s onwards: "This kind of experimental rigor was not demanded by doctors. Neither did it arise naturally within any particular community of medical researchers. Doctors, of course, learned to accept it, but the impulse for uniform and rigorous standards came mainly from regulatory authorities". In Theodore M. Porter, Trust in Numbers. The Pursuit of Academic Objectivity in
} 
The measures taken by the Medicines Evaluation Board did not immediately result in more controlled clinical trials in the Netherlands. In fact, although few data exist of the frequency with which RCTs (and other clinical trials) were conducted in the 1960s and 1970s, estimates suggest that Dutch clinical research (including the conduct of clinical trials) only significantly started to grow in size towards the end of the 1980s, when the Dutch government started to make systematic investments into the infrastructure needed to coordinate large-scale clinical research studies. 99

Still, from about the mid-1960s onwards, controlled clinical trials, and particularly the RCT, did become more widely known in the Netherlands. In late August 1967, for instance, the matter of "double-blind pharmacological investigations" was discussed for the first time by Dutch parliament. ${ }^{100}$ The immediate cause was the publication of a paper in the Dutch Journal of Medicine earlier that year describing a clinical trial that had been conducted on the treatment of coronary afflictions with oral anticoagulants (thinners that prevent the blood from clotting). The paper was written by Nelemans and had been conducted under auspices of the TNO Committee Clinical Drug Research in such a way, he wrote, that it "comes close to the requirements of an ideal trial": the double-blind RCT.101 Significant results had been found as well. From the thirteen trial patients who had died between 1964 and 1966, eleven had been part of the control group. The statistical likelihood that this difference could be attributed to chance had been calculated to be less than 0.01 percent. Further experiments on the appropriate duration of anticoagulant treatments had established that the death rate in the placebo group was significantly higher than in the treatment group. Within three months, therefore, TNO terminated its second study and recommended that all patients in the Netherlands who had suffered a heart attack should be prescribed a life-long treatment of oral anticoagulants, as this would greatly increase their overall life expectancy. In Dutch newspapers, these results were published in bold and exultant headlines: the scientific experiments of TNO "directly saved lives". ${ }^{102}$

In Dutch parliament, however, the study provoked more critical responses. Member of parliament Henk Vonhoff of the conservative-liberal party VVD, for instance, wished to know from the government whether it was aware that double-blind clinical investigations were conducted in the Netherlands and whether it was true that pa-

Science and Public Life (Princeton: Princeton University Press, 1995). See also: Theodore M. Porter, 'Medical Quantification. Science, Regulation, and the State', in Body Counts, pp. 394-401.

${ }^{99}$ For a clear and detailed overview of these Dutch government investments in the 1980 s, see Chapter 5 'Patient-Related Research in Motion', in Bolt, A Doctor's Order, pp. 187-220.

100 'Vragen van de heer Vonhoff (V.V.D.) inzake "dubbelblinde" farmacologische onderzoeken. (Ingezonden 22 augustus 1967.)', Aanhangsel Tweede Kamer 1967-1968, nummer 119, pp. 241-242.

${ }^{101}$ F.A. Nelemans, 'De Behandeling van Coronaire Aandoeningen met Orale Anticoagulantia', in $\mathrm{Ne}$ derlands Tijdschrift voor Geneeskunde Vol. 111 (1967), p. 510.

102 'Experiment redt negentien levens', in De Tijd, Thursday 5 December 1968, p. 3; 'Na hartinfarct levenslange behandeling', in Het Vrije Volk, Saturday 7 December 1968, p. 2; 'Wetenschappelijk onderzoek redde direct levens', in Het Vrije Volk, Thursday 6 February 1969, p. 2; 'T.N.O.-onderzoek redt leven van 19 patiënten', in Nederlands Dagblad, Tuesday 10 December 1968, p. 2. 
tients participating in these trials usually were not asked for their permission. ${ }^{103}$ In addition, if this was true, did the government not agree that these studies fundamentally violated the dignity of individual human beings? Also, was it true that the Medicines Supply Act encouraged the conduct of double-blind studies in the Netherlands, and did this method truly have such great advantages that they should be accepted as an integral part of Dutch society? Then, if this was correct, was the government not of the opinion that the Dutch state carried a responsibility to monitor the way in which and by whom these studies were conducted in the Netherlands? ${ }^{104}$

The State Secretary of Social Affairs and Health Care Roelof Kruisinga (a physician himself) initially responded in writing to Vonhoff's questions. "Leading experts from around the world", Kruisinga stated confidently, "are of the opinion that double-blind research as a rule should be regarded inevitable". ${ }^{105}$ In this sense, it was true that the Medicines Supply Act demanded the conduct of RCTs, as it stipulated that packaged medicines could only be brought into circulation if they could reasonably be expected to possess the advertised effect. It was not true, however, that such studies were usually carried out without patients' consent. While patients were not allowed to choose if they preferred the treatment or the control group, they were "usually informed that an experimental investigation was taking place", leaving them free to withdraw from the study at any time they wanted. Kruisinga did not agree, therefore, that RCTs fundamentally violated the dignity of individual human beings. ${ }^{106}$

Vonhoff was not satisfied with these answers. Armed with newspaper snippets, he confronted the State Secretary in parliament. Kruisinga might claim that researchers in the Netherlands generally obtained the consent of their research subjects, but "one of the research leaders, dr. Nelemans", had argued publicly on multiple occasions to find informed consent illogical. Only recently, the clinical pharmacologist had been quoted in a Dutch newspaper to say that research subjects could only truly provide informed consent if they were completely aware of the risks they exposed themselves to and that, if this information was available, no need existed to conduct the experiment, since the whole point of a trial was to find out the risks and benefits of a treatment. Nelemans had even stated that since written consent forms often served only to absolve researchers in case experiments went south, the emphasis on informed consent could also be considered unethical. ${ }^{107}$ Vonhoff suspected that a different reason underlay the reluctance to obtain consent: "In Medisch Contact, I at one point find the statement that the manner and persuasion in which a physician prescribes a recipe to his patient has important effects on the healing process and that this placeboeffect needs to be eliminated to get objective results". ${ }^{108}$ In other words, full disclo-

\footnotetext{
${ }^{103}$ Ibid. Also: 'Dr. R.J.H. Kruisinga beantwoordt vragen inzake "dubbelblinde” farmacologische onderzoeken', in Medisch Contact Vol. 22 (1967), pp. 1125-1126; 'Kamervragen over fatale experimenten', in De Telegraaf, Friday 25 August 1967, p. 3.

104 'Vragen van de heer Vonhoff inzake "dubbelblinde" farmacologische onderzoeken', p. 241.

${ }^{105}$ Ibid., p. 242.

${ }^{106}$ Ibid., p. 241.

107 'Vergadering van donderdag 2 november 1967', in Vaste Commissie voor de Volksgezondheid (Zitting 1967-1968), T50-T52, T50. See also: 'Wat hebben ze gezegd', in Limburgs Dagblad, Tuesday 29 August 1967, p. 12; 'Geen proefkonijnen', in Leeuwarder Courant, Saturday 26 August 1967, p. 3; 'Levens van hartpatiënten door fopmedicijn gered. Onderzoek na vragen Kamerlid', in Nieuwsblad van het Noorden, Tuesday 29 August 1967, p. 3.

108 'Vergadering van donderdag 2 november 1967', p. T50.
} 
sure of the experimental procedure would make it hard to meet "the requirements of an ideal trial". Hence, omitting informed consent was not primarily in the interest of patients, but in the interest of eager researchers such as Nelemans.

Other members of parliament voiced concerns as well. Jan Lambers of the Labour Party PvdA (also a physician) agreed with State Secretary Kruisinga that double-blind investigations were needed, but had heard that such experiments were usually only conducted with publicly insured patients, i.e. patients that depended on health funds provided by the state because their income was too low to afford private health insurances. ${ }^{109}$ Again, Kruisinga offered a reassuring reply: "In my experiences in academic hospitals, also class patients are included in this type of research studies". ${ }^{110}$ Nonetheless, he promised to investigate the concerns of the members of Dutch parliament. In particular, he would seek advice about one of the last questions posted by Vonhoff: if the state had a responsibility to monitor the conduct of double-blind pharmacological studies in the Netherlands. To this end, Kruisinga in 1968 submitted a request for advice to the national Health Council. The State Secretary wished to know from the scientific advisory body whether "legislation for clinical drug research and state oversight of such research is needed" and, if so, what such regulations should look like. ${ }^{111}$ To this end, four internists, two pharmacologists, a general practitioner, and a pharmacist met up thirteen times between 1969 and 1971 to write a report for the regulation of clinical drug research in the Netherlands. ${ }^{112}$ One of these pharmacologists was Frans Nelemans, who, in this capacity, helped to draw up the first Dutch blueprint for the governance of human experimentation with research ethics committees.

\section{Research ethics committees as epistemic filters}

Appointed as the chairman of the Council committee 'clinical drug research' was Leiden pharmacologist Erik Noach. Noach was a former student of Samuel de Jongh and had taken over the latter's professorial chair in 1963. ${ }^{113}$ At Leiden University, he had been experimenting with the communal review of clinical research studies since 1965 (also see chapter 5), which made him an excellent candidate in the eyes of the Council President to chair a committee on the regulation of clinical drug research in the Netherlands. In the second half of the twentieth century, Noach would make various important contributions to the organization and governance of medical science in the Netherlands. He was one of the architects of a new curriculum for the biomedical sciences at Leiden University, for instance, and was considered an authority on the appropriate regulation of 'alternative medications' and animal experiments. First and foremost, however, Noach is remembered for his contributions to the Dutch governance of human subjects research. In many ways, in fact, as will become clear, he may be considered the founding father of Dutch research ethics committees.

\footnotetext{
${ }^{109}$ Ibid., p. T50.

${ }^{110}$ Ibid., p. T51.

${ }^{111}$ Gezondheidsraad, Advies inzake klinische farmacologie (Den Haag: Staatsuitgeverij: 1982), p. 111.

${ }^{112}$ NL-HaNA, Gezondheidsraad, 2.15.36, 1476, Rapport inzake klinisch onderzoek van geneesmiddelen, 1971. See also: Gezondheidsraad, Klinische farmacologie, pp. 111-135.

${ }^{113}$ E.L. Noach, Tweeërlei farmacologie. Inaugurele rede Leiden (Amsterdam: N.V. Noord-

Hollandsche Uitgevers Maatschapij, 1964); David de Wied, 'Erik Noach, college en vriend', Geneeskunde en Ethiek in Harmonie, pp. 11-18.
} 
Noach advised the Council President to compose the committee 'clinical drug research' of three types of experts: practitioners of the clinical and pre-clinical sciences, stakeholders in the Dutch pharmaceutical industry, and representatives of the Dutch civil service. Finally, if the Council President found it desirable to seek advice from a "non-medical expert in ethical issues", Noach recommended to invite the Leiden Professor in the Philosophy of Religion and Ethics Herman Heering. ${ }^{114}$ No records have been preserved that indicate that Heering, who would go on to become a prolific author on medical ethics in the 1970 (see chapters 3 and 6) was invited to participate in the committee 'clinical drug research'. Instead, the Council President invited seven physicians and a pharmacist, all established disciplinary insiders to the Dutch field of medicine and health. The men were all appointed in a personal capacity, yet each of them did represent an organization relevant to the practice and politics of Dutch clinical drug research in the late 1960s. The industrial pharmacist worked for Brocades \& Stheeman, one of the largest Dutch pharmaceutical companies at the time. ${ }^{15}$ The first internist sat on the board of the National Specialists Association, the second was employed as a public health officer, the third was a highly-esteemed academic, while the fourth, the internist Louis Stuyt, headed a department of internal medicine at a large hospital (and would go on to become the Dutch Minister of Public Health and Environmental Hygiene in 1971). The general practitioner, in turn, sat on the board of the College for General Practitioners. Finally, there was Frans Nelemans, long-time leader of TNO's Committee Clinical Drug Research, a known advocate of the controlled clinical trial, and, as it happened, the direct reason why the State Secretary of Public Health had requested the Health Council to write this policy report.

Already in his pre-advice, Noach had drafted the framework within the committee was to operate. Deliberations had to start from four premises. First, that "human experimentation to determine the useful, undesirable, and toxic effects of medicines is of the utmost importance" and, following the 1958 Medicines Supply Act, "to a certain extent mandatory by law". Second, that it was essential to follow "rigorous scientific methods" to ensure clinical research "yields optimal information with minimal risks". Third, given these first two premises, that the committee was to keep close ties with the Medicines Evaluation Board. And, finally, that committee members were not to forget that clinical drug research was just one type of human experimentation. Existing "international opinions" in this area, such as the 1964 Helsinki Declaration (see chapter 1) for instance, would have to be consulted. ${ }^{116}$

In laying down these ground rules for any Council deliberation on the governance of clinical drug research, Noach invoked a clear rhetoric of therapeutic reform. As he stated very explicitly in his pre-advice:

The committee will need to develop a description of clinical drug research in such a way that it will encourage the conduct of experimental tests-which are scientifically and ethically correct-as being in the interest of public health and therefore

\footnotetext{
${ }^{114}$ NL-HaNA, Gezondheidsraad, 2.15.36, 1478, letter of E.L. Noach to Health Council President A.J.Ch. Haex, 2 July 1968.

${ }^{115}$ See: T. Rinsema, 'Brocades \& Stheeman. Van Apotheker-Fabrikant tot Farmaceutische Industrie', in Gewina Vol. 22 (1999), pp. 23-33.

${ }^{116}$ NL-HaNA, Gezondheidsraad, 2.15.36, 1478, letter of E.L. Noach to Health Council President A.J.Ch. Haex, 2 July 1968, pp. 2-3.
} 
necessary, while scientifically flawed tests - which on this ground are already ethically deplorable-will be hindered as much as possible. ${ }^{117}$

Noach, in other words, made it clear from the start that any form of state oversight for clinical drug research would have to function as another epistemic filter: i.e. it had to sift out good clinical research from bad clinical research-good here simultaneously referring to methodologically sound and ethically just.

This tight knit between sound clinical research methods and good moral behaviour would continue to form the core of the committee's final advisory report to the Dutch government of 1971. Its opening pages, for instance, contained a telling citation from a 1968 report by the World Health Organization (WHO) on "principles for the clinical evaluation of drugs" (drawn up under leadership of statistician Austin Bradford Hill). "For the investigation of drugs", this citation read, "planned scientific studies in man are always necessary. It is not always recognized that it is unethical to introduce into general use a drug that has been inadequately tested". ${ }^{118}$ Ergo, the WHO-report read on, "The ethical problem is not solely one of human experimentation; it is also one of refraining from human experimentation". ${ }^{119}$ Noach's Council committee 'clinical drug research' firmly supported this assessment: controlled clinical experimentation was ethically necessary and, therefore, its active promotion under the right circumstances a moral good. What was more, as this type of scientific research was likely to increase biomedical knowledge and have a positive pedagogical effect on medical students and practicing physicians, every reason existed for the Dutch government to actively support and promote clinical drug research in the Netherlands. ${ }^{120}$

This did not mean, the Health Council emphasized, that foundational principles of medical ethics did not have to be taken into account in the conduct of human experiments. ${ }^{121}$ However, as the Council report underscored literally multiple times, sound clinical research was both necessary and inevitable (the latter because the Medicines Supply Act 'simply' demanded proof of efficacy). ${ }^{122}$ Hence, like the Council committee 'tests upon human beings' before it in 1955, also the Council committee 'clinical drug research' maintained in 1971 that all that it could sensibly do was to propose policy measures that would minimize risks that just had to be taken in human experiments, and to ensure that no fundamental ethical lines were crossed in the process.

What these policy measures for clinical drug research should look like formed the core of the thirteen committee meetings which took place between 1969 and 1971. Its eight members eventually agreed on four "general guidelines". First, conducting clinical drug research was only permitted for physicians and dentists. Second, while no group of research subjects should a priori be excluded from participation in clinical

\footnotetext{
${ }^{117}$ Ibid., p. 2.

${ }^{118}$ NL-HaNA, Gezondheidsraad, 2.15.36, 1476, Rapport, p. 5.

119 'Principles for the Clinical Evaluation of Drugs', in World Health Organization Technical Report Series No. 403 (Geneva, 1968), p. 6.

${ }^{120}$ NL-HaNA, Gezondheidsraad, 2.15.36, 1476, Rapport, pp. 6-7.

${ }^{121}$ Ibid., p. 5.

${ }^{122}$ Ibid., p. 7.
} 
research, strong caution had to be exercised in conducting experiments with 'special groups', like children or mentally ill patients. Third, as the try-out of drug samples on individual patients "as a rule misses any scientific value", this should only be allowed with registered pharmaceuticals with a known composition. Finally, following the 1964 Helsinki Declaration, the report stated that "in general" the informed consent of research subjects was required. Notably, however, the committee made a distinction between the consent of healthy research subjects and those participating in a clinical trial. In case of the first, informed consent was a necessary requirement. Yet, in case of the second, the Health Council recommended the government to demand only that permission should be acquired "as is common in normal medical treatments". ${ }^{123}$ In other words, clinical researchers had to be permitted to take the consent of patients to undergo a clinical procedure as sufficient information that they were also willing to take part in a clinical trial. Whether or not a researcher was in such instances obliged to inform patients that they possibly could also receive a placebo instead of an active therapeutic agent was left unspecified in the 1971 Council report.

In his 1970 booklet (which appeared in the midst of the committee deliberations), Nelemans had also invoked the Declaration of Helsinki. This international document, he and his co-author explained, was of the utmost importance for the conduct of clinical drug research. Still, researchers really had to interpret it "to the spirit of the letter". After all, the two claimed, if the Declaration was taken literally, pretty much all clinical experiments would become impossible, which "certainly cannot have been the intention of the Declaration". The passage in the Declaration on the requirement of informed consent, for instance, "really has to be understood to mean that no research may ever be conducted if the patient would not have given his permission if he would have been informed of all data available". 124 "It makes more sense", Nelemans and his co-author wrote in closing of the booklet, "to automatically assume the cooperation of a patient (at least as far as it concerns the evaluation of therapeutic and diagnostic procedures), unless there is clear evidence to the contrary". ${ }^{125}$

To be sure, Nelemans did emphasize the need for strict ethical rules in the conduct of clinical research studies. Such experiments were only permitted, he argued, "if they satisfy medical ethics, perhaps most easily described in practice as that the physician would not hesitate to let himself or his family participate [in the trial]". ${ }^{126}$ In addition, the experiment, if successful, would have to yield important new insights and existing pharmacotherapies would need to have objections "which can be overcome completely or partially by the new medicine". ${ }^{127}$ In addition, Nelemans made very clear that also "a scientifically sound trial, no matter how important it is, may never be executed if it sins against medical ethics". ${ }^{128}$ The pharmacologist just was unconvinced that the requirement of informed consent-in case of clinical experiments-added much to these rules. Instead, the medical community had to invest in its professional ethics, institutional safeguards, and other types of communal control. ${ }^{129}$

\footnotetext{
${ }^{123}$ Ibid., p. 12.

${ }^{124}$ Nelemans \& Zelvelder, Therapeutische evaluatie van geneesmiddelen, p. 51.

125 Ibid., p. 142.

${ }^{126}$ Nelemans, Klinische Farmacologie, p. 10.

${ }^{127}$ Ibid., p. 11.

${ }^{128}$ Ibid., p. 11. Italics in original.

${ }^{129}$ Nelemans \& Zelvelder, Therapeutische evaluatie van geneesmiddelen.
} 
The Council committee 'clinical drug research' largely followed Nelemans' logic in its recommendations for policy measures to the Dutch government. Instead of developing suggestions on how best to ensure the freely given informed consent of patients in clinical drug research, the committee proposed a system of oversight "that should better guarantee the safety and wellbeing of research subjects". ${ }^{130}$ This system worked as follows: a physician (or dentist) who wanted to conduct a clinical drug trial would have to make a report about his plans to the Dutch Medical Inspection. He could then start with the execution of his study. However, if the Inspection suspected something to be wrong, it was entitled to bring this study to a halt. If a researcher failed to report his study and this was found out, the Dutch Public Prosecution Service would be entitled to take legal steps and possibly even penal measures.

In its report, the committee formulated two main reasons for this type of oversight of clinical drug research. The first was that "in the interest of science only technically correct investigations, in which a warrant of optimal information acquisition is present, may be conducted". One of the main things the Dutch Medical Inspection had to assess, therefore, was whether the clinical studies that had been reported were methodologically sound. The second was that, "on ethical grounds, it is necessary to establish impartially if the objectives and execution of the study weigh out against the risks taken by research subjects". ${ }^{131}$ If a clinical trial simply duplicated another study, for instance, no new scientific insights would be gained, which the committee deemed to be a wasteful use of resources. Or, if a hospital did not have the right research facilities to properly execute a clinical trial, no valid results could be obtained (and participants could be put in danger), which would be another reason for the Dutch Medical Inspection to bring the clinical study in question to a halt.

To assist the Dutch Medical Inspection in this task, Noach et al. proposed to set-up local review committees in the main Dutch research centres (including medical faculties and academic hospitals). Experts in the field of clinical drug research would take up a seat in these committees to evaluate "the scientific merits of a proposed study as well as on its closely related ethical aspects". ${ }^{132}$ In addition, one overarching national committee had to be installed which could fulfil a variety of functions. For instance, if multiple centres took part in a clinical study (a so-called multicentre trial) the national committee could coordinate the activities of local committees. Also, if the Dutch Medical Inspection or a local committee did not possess the right expertise to meaningfully evaluate a research proposal, the national committee could take on this task. Finally, to gain a comprehensive overview of the field of clinical drug research in the Netherlands and to minimize any unnecessary duplications, the national committee could keep track of all clinical drug trials conducted in the Netherlands and, if possible, even to propose measures to better organize such studies. ${ }^{133}$

Noach et al. compared the functioning of these committees to the practice of refereeing that had since long been popular with academic journals and, somewhat more recently, with grant organizations. ${ }^{134}$ The local committees would be asked primarily

\footnotetext{
${ }^{130}$ NL-HaNA, Gezondheidsraad, 2.15.36, 1476, Rapport, p. 13.

${ }^{131}$ Ibid., p. 13.

132 Ibid., p. 18

${ }^{133}$ Ibid., pp. 20-22.

${ }^{134}$ Ibid., p. 13. For more on the historical practice of 'refereeing' by scientific journals and grant organisations, see: Melinda Baldwin, Making nature. The History of a Scientific Journal (Chicago: The Uni-
} 
to assess the scientific quality of research proposals and the availability of appropriate research facilities. If this was all in order, the study could proceed. If not, suggestions for improvement would have to be made. For instance, researchers might have to include more patients in their study to get statistically significant results or make changes in the way they collected data to eliminate possible confounding variables. In other words, like the Medicines Evaluation Board was imagined to operate as an epistemic filter at the end of the clinical drug research pipeline, these boards were imagined to operate at the beginning of it. In this regard, the Health Council followed the 1968 WHO report, which stated that "investigators should discuss the plans of investigation with other physicians and experienced medical research workers before embarking on the initial investigation of a new drug [...] best done by a local medical or scientific committee rather than by an official control organization". ${ }^{135}$ The more epistemic filters in place, in short, the better the system functioned.

Taken together, this system of review committees was expected to raise the quality of clinical drug research in the Netherlands. "Consultation of this nature is a powerful tool to raise the level of science", the 1971 Council report stated, "which is in the long haul also in the interests of the participants in the study". ${ }^{136}$ In addition, Noach et al. hoped this system would raise the quantity of clinical drug trials in the Netherlands. A main reason why it remained difficult to undertake large-scale controlled clinical trials in the Netherlands, they argued, was the moral reluctance of Dutch clinicians to engage in clinical research. Yet, "the committee cannot shake the impression", the Council report read, "that these restraints are often more founded on emotion than on reason". ${ }^{137}$ Review committees, tasked to carefully evaluate if study protocols lived up to the reigning moral standards of the Dutch medical profession, could take away these doubts. In addition, if critics would unjustly accuse clinical researchers of unethical conduct, these committees could offer appropriate "moral backing". ${ }^{138}$ This way, clinicians no longer stood alone in fulfilling their moral obligation to bring about medical progress, which in turn would help to "contribute to the intensification of clinical drug research in the Netherlands, which has been developed insufficiently in part because of hesitations of physicians on ethical grounds". ${ }^{139}$

In short, between 1969 and 1971, seven Dutch physicians and one pharmacist drew up the first blueprint of the governance of human experimentation in the Netherlands by means of review committees that were to judge clinical research protocols on their scientific and ethical merits. Although Noach et al. at the time did not refer to these committees explicitly as research ethics committees, their system of combining local review committees with one national committee would become the core of all Dutch policy discussions on the subject in subsequent decades, when the governance of hu-

versity of Chicago Press, 2015); Alex Csiszar, The Scientific Journal. Authorship and the Politics of Knowledge in the Nineteenth Century (Chicago: The University of Chicago Press, 2018); Aileen Fyfe, 'Journals and Periodicals', in A Companion to the History of Science, pp. 387-399; Mark Solovey, Shaky Foundations. The Politics-Patronage-Social Science Nexus in Cold War America (New Brunswick: Rutgers University Press, 2013); Robert E. Kohler, Partners in Science. Foundations and Natural Scientists, 1900-1945 (Chicago: The University of Chicago Press, 1991).

135 'Principles for the Clinical Evaluation of Drugs', 31.

${ }^{136}$ NL-HaNA, Gezondheidsraad, 2.15.36, 1476, Rapport, p. 13.

${ }^{137}$ Ibid., p. 12.

${ }^{138}$ NL-HaNA, Gezondheidsraad, 2.15.36, 1478, Discussie nota M25-2, p. 7.

${ }^{139}$ NL-HaNA, Gezondheidsraad, 2.15.36, 1476, Rapport, p. 10. 
man experimentation gradually became a matter of national importance in the Netherlands. Research ethics committees, in their initial conception, were expert committees, intended to promote more systematic and controlled clinical experimentation in the Netherlands and to weed out methodologically good science from bad science in Dutch clinics and research institutions. Noach et al. acknowledged that methodologically good science did not necessarily equate to ethically good science. However, they were convinced that methodologically bad science did equate to ethically bad science. Hence, they imagined review committees to function first and foremost as epistemic filters, which they believed to be an absolute moral requirement for the conduct of all forms of clinical-and other types of human-experimentation.

Noach et al. were also certain that this change in governance had to be realized by state interference. In theory, they argued in the 1971 Council report, voluntary cooperation of researchers with this system of oversight was very well possible. Equivalent to the general practitioner who had grown accustomed to consulting medical specialists, a clinical researcher could be conditioned to consult the appropriate experts in the conduct of clinical drug research. However, these experts remained a scarce good in the Netherlands. Hence "as long as no specialized training in clinical drug research exists [...] the danger remains that voluntary oversight will lead to unacceptable risks, for example because a necessary correction is not made because of the misplaced selfconfidence of a researcher". ${ }^{140}$ As long as clinical research was not up to par in the Netherlands, therefore, the hard power of the government was needed to direct the professional conduct of individual Dutch clinical researchers.

Still, the precise involvement of the government had to be carefully orchestrated. "A straightjacket which is too narrow", the 1971 report read, "will reduce the enthusiasm for conducting clinical drug research [...] which certainly cannot be in the interest of the public health". ${ }^{141}$ After all, "a Government generally exercises more caution than is strictly necessary on ethical or scientific grounds, as she is vulnerable to public opinion, even if the latter is predominantly based on emotional grounds". ${ }^{142}$ The role of the government, therefore, had to be strictly limited to authorizing the Dutch Medical Inspectorate and the conglomerate of review boards to keep watch over the conduct of clinical research in the Netherlands (and demanding from researchers that they reported any clinical studies to these bodies). The actual administration of these legislative measures-i.e. the review of clinical studies-had to remain the prerogative of the Dutch medical profession itself. Or, more precisely, it had to become the prerogative of specific elite members of the Dutch medical profession, who would use the hard power provided by the government to control those peripheral researchers who did not always know what they were doing, but who suffered from "misplaced selfconfidence" and thereby put patients at risk. What the Dutch government had to enable, in short, was more internal control over clinical research in the Netherlands, by a self-appointed elite of the Dutch medical profession.

\footnotetext{
${ }^{140}$ Ibid., p. 14.

${ }^{141}$ Ibid., pp. 14-15.

${ }^{142}$ Ibid., p. 16.
} 
After the Health Council sent a final draft version of the report to the Ministry of Public Health and Environmental Hygiene in December 1971 (before it would be published publically for all to read), nothing happened for almost two years. Only in May 1973 did the Council President receive a reply from the department, with the remark that the government agreed that "national legislation for the protection of those involved in clinical research is desirable", but that questions still existed about the system of oversight proposed by the Health Council. ${ }^{143}$ First, was the Council absolutely certain this system would not "put a break on clinical investigations, which are necessary"? Second, given the scarcity of expertise on clinical drug research in the Netherlands, which experts precisely would take up a seat in these review committees? Was a lack of this expertise, after all, not one of the main reasons why oversight was needed in the first place? Before the government would undertake any steps to prepare legislation for clinical drug research in the Netherlands, therefore, it first wanted the Health Council to think further about the possible implications which these policy measures could have for the development of clinical drug research and clinical pharmacology in the country. ${ }^{144}$ The Dutch government, it seemed, was not in any hurry in the early 1970 s to realize additional oversight for clinical experimentation.

In response to this request, the Council President duly brought another committee into existence which started deliberating in 1974. Noach this time served as a regular committee member, as did eight other physicians, a pharmacist, and a lawyer. Again, this committee set out to write a report on the regulation of clinical drug research in the Netherlands, to make sure it absolutely would not 'put a break on clinical investigations', and to make policy suggestions on how enough expertise could be cultivated in the Netherlands to effectively take on the oversight of clinical drug research. This Council committee 'clinical pharmacology' officially started its work in 1974. In 1976, it was joined by another committee tasked to consider the permissibility of experiments with radioactive material in the Netherlands. ${ }^{145}$ By that time, the Health Council was working on its fourth policy advice on the governance of human experimentation-in a period of only 20 years. Both reports were published in the early 1980 : the report on experiments with radioactive material in 1980, the report on clinical pharmacology (that contained the first official publication of the 1971 Council report 'clinical drug research') in 1981. This was fourteen years after the politician Vonhoff had asked State Secretary Kruisinga if the Dutch state was not responsible to monitor the way in which clinical drug trials were conducted in the Netherlands. ${ }^{146}$

There were various reasons why it took the Health Council this long to finish a report that was only meant to provide some additional reflections on the advice already delivered in 1971. One was simply administrative: the calendars of participants often did not align. Another was the expansion of the committee's tasks to formulate policy measures for the cultivation of expertise in clinical drug research in the Netherlands. Now the committee members, who were all enthusiasts of clinical pharmacology, had the ear of the Ministry, they used the opportunity to develop elaborate plans for the

\footnotetext{
${ }^{143}$ Gezondheidsraad, Advies inzake klinische farmacologie, p. 13.

${ }^{144}$ Ibid., p. 13.

${ }^{145}$ NL-HaNA, Gezondheidsraad, 2.15.36, 3.3.101, Commissie experimenten met radioactieve stoffen op proefpersonen [120].

${ }^{146}$ Gezondheidsraad, Advies inzake normen voor het toedienen van radioactieve stoffen aan vrijwilligers (Den Haag: Staatsuitgeverij: 1981); Gezondheidsraad, Advies inzake klinische Farmacologie.
} 
expansion of the discipline. In name of the public interest, they argued, the number of clinical pharmacologists active in university hospitals had to increase from a meagre six to at least sixteen, but preferably to 25 or even $30 .{ }^{147}$ In addition, the government seriously had to invest in traineeships for clinical pharmacologists and to integrate the discipline in the existing Dutch system of medical specialists.

In developing these plans, the oversight system of review committees to ensure the ethical conduct of clinical drug research (the original reason the Health Council had been asked to further consider the expansion of clinical pharmacology in the Netherlands) increasingly took a backseat. Towards the end of the committee deliberations, in the late 1970s, some committee members even remarked that it would be a waist if their plans for the growth of clinical pharmacology would not be realized because the policy report also contained chapters on the regulation of clinical experimentation in the Netherlands through a system of local review committees.

One committee member who did continue to care intensively about the sections in the report on the functioning of review committees was Erik Noach. In an early stage of the committee deliberations, the majority of the Council committee 'clinical pharmacology' decided to resolve the lack of enough experts to man multiple local review committees by advising the government to install only one national Council for Clinical Research that would evaluate all patient-related research in the Netherlands. Researchers were still obliged to report a study to this Council before starting it, and this Council would still inform the Dutch Medical Inspection if it suspected any wrongdoings. However, in contrast to the 1971 Council report, the 1981 version now came to argue that "this Council is not supposed to act as a scientific advisory body for clinical researchers". ${ }^{148}$ Noach disagreed. The centralization of review procedures, he warned, "will greatly stall the much needed growth of clinical research in the Netherlands". ${ }^{149}$ Given the expectation that researchers would likely await the verdict of the Council for Clinical Research before starting their studies, undesired delays in the conduct of clinical trials could once again be expected. In addition, Noach felt that review committees should evaluate the scientific quality of research protocols. By the late 1970s, in fact, he had even come to argue that clinical trials should only be permitted in the Netherlands after "a review committee has notified a researcher in writing that no scientific or ethical objections exist against the research study". ${ }^{150}$

Noach could not convince the other committee members. The majority maintained that one Council for Clinical Research was the most practical solution for the problem of insufficient available expertise and that, moreover, "the installation of the Council and the duty to report research studies is only meant to stimulate sound research, not to make scientific research dependent on the medical insights of the Council". ${ }^{151}$ The Leiden pharmacologist decided, therefore, to invoke his right as a Council member to write a minority report for the Dutch government in which he set out his alternative plans for the governance of clinical experimentation in the Netherlands by means of

\footnotetext{
${ }^{147}$ Gezondheidsraad, Advies inzake klinische farmacologie, p. 36.

${ }^{148}$ Ibid., p. 57.

${ }^{149}$ Ibid., p. 98.

${ }^{150}$ Ibid., p. 99. E.L. Noach \& P.J.W.M. de Kroon, 'Medische ethiek: patiënten en proeven. De Commissie Medische Ethiek in het Academisch Ziekenhuis en de Faculteit der Geneeskunde te Leiden', in Medisch Contact Vol. 34 (1979), pp. 1575-1583.

${ }^{151}$ Ibid., p. 57. Italics added.
} 
local review committees (which he now explicitly referred to as ethics committees). In his alternative system-which resembled much of the system his Council committee had proposed in 1971-one national Council did function as coordination and supervision office, but local ethics boards formed the backbone in the oversight of clinical research. What was more, the ethical evaluation of research protocols very much included a strict evaluation of their scientific quality.

Noach's diverging opinion slowed down and further weakened a policy report that already for quite some time had started to look like a failure. When the definitive version of the report was finally sent to the Ministry of Public Health and Environmental Hygiene in November 1981, the political winds had changed. By then, ethical discussions over the rights of research subjects, which had dominated public discourse in countries such as the United States and Great Britain since the late 1960s, had finally reached the Netherlands. All of a sudden, a report from a scientific advisory body that emphasized the need for more clinical experimentation and power for elite members of the medical profession appeared incredibly outdated. So much so, in fact, that the Dutch government had decided a few years earlier, in 1978, to request another policy report on the appropriate governance of human experimentation in the Netherlands. Only this time it did not sent this request to the Health Council-an expert advisory body-but to the Central Council for Public Health, an advisory body that seated representatives of various political and civil society organisations. Since 1975, this Council had been tasked to develop policy reports for the realization of patients' rights in the Netherlands (see chapter 3 ) and in 1982, also this Council published a report recommending the oversight of human experimentation using local review committees (see chapter 4). Contrary to the Health Council reports, however, this report did not advocate the moral need for therapeutic reform or more internal control. Instead, it emphasized the rights of research subjects and a need for more democratic oversight mechanisms, i.e., research ethics committees were now argued to be needed to realize more external control over human experimentation. Still, one member of the Central Council for Public Health, the one who in fact wrote most of its 1982 report on the public governance of human experimentation in the Netherlands, was a familiar face. This Council member was Leiden pharmacologist Erik Noach. 



\section{PART II}

\section{EXTERNAL CONTROL}

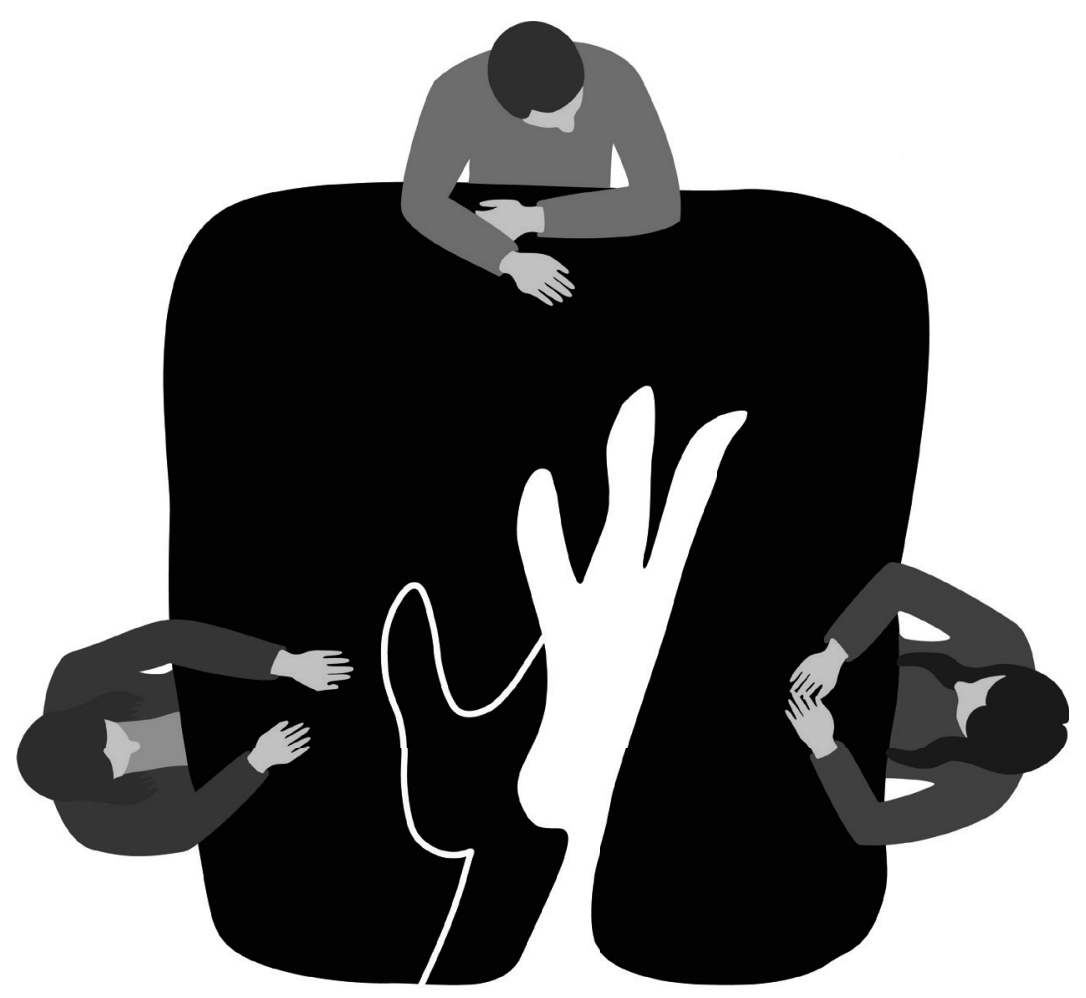





\section{- Chapter $3 \cdot$ medical ethics in a modern society}

In August 1969, the social-democratic Dutch newspaper Het Vrije Volk ran an almost full-page interview with psychiatrist Rudi van den Hoofdakker, better known to large audiences as the poet Rutger Kopland. ${ }^{1}$ The piece was accompanied by a photograph of the psychiatrist. Sitting on a camping chair without a shirt on, legs crossed, he was vigorously arguing a case. Addressing someone outside of the frame, his brows were furrowing, his hands gesticulating. "Artsenstand", the headline read, "a drift anchor that inhibits progress". ${ }^{2}$ The interview was held because the psychiatrist had recently published an article in which he had claimed that the Dutch artsenstand resembled a "stronghold of know-it-alls". ${ }^{3}$ The moment students started medical school, Van den Hoofdakker argued, they learned to don themselves in age-old cloaks of medical ethics, hanging nicely ironed in the closet next to their white coats, just waiting to be put on. They did not have to decide for themselves what was morally right or wrong, they just had to act as members of the artsenstand would. This conservatism, the psychiatrist felt, inhibited social progress. Physicians and patients had to break free from the chains of medical paternalism, in which the child constantly expected the father to solve all problems, while the father was constantly afraid to violate the trust the child put in him. The artsenstand had to descend from its stronghold and discover it did not stand apart from society. Physicians had to learn to "talk, talk, talk" with patients and make decisions with instead of for them. What was needed was an "ethics against ethics": a close examination of why doctors held the moral beliefs they did.4 For like many others around 1970, Van den Hoofdakker had come to believe that the Dutch artsenstand and its ethics tradition had fallen into deep, deep crisis.

Chapters 3 and 4 of this $\mathrm{PhD}$-thesis explore the growing call for external control over Dutch medicine in the 1960 s and 1970s, and the encapsulation of research ethics committees by this movement in the early 1980s. In 1982, the Dutch Central Council for Public Health published a report stating that ethics review was needed to secure the rights of human research subjects in medical experiments. Public oversight of this practice was needed, this report read, because in a modern democratic society "seclusion and mystery have to make way for openness and transparency".5

\footnotetext{
${ }^{1}$ See: Stefaan Evenepoel, Volmaakt onaf. Over de stijl en thematiek in de vroege poëzie van Rutger Kopland (Leuven: Universitaire Pers Leuven, 2000); J. Coetzee, Landscape with Rowers. Poetry from the Netherlands (Princeton: Princeton University Press, 2003).

${ }^{2}$ K. Tamboer, 'Groningse zenuwarts R.H. van den Hoofdakker: "Artsenstand - sleepanker dat vooruitgang afremt", in Het Vrije Volk, Saturday 30 August 1969, p. 5.

${ }^{3}$ R.H. van den Hoofdakker, 'Het bolwerk der beterweters', in Wijsgerig Perspectief op Maatschappij en Samenleving Vol. 9 (1968-1969), pp. 292-301.

${ }^{4}$ R.H. van den Hoofdakker, Het bolwerk van de beterweters. Over de medische ethiek en de status quo (Amsterdam: Kritiese Bibliotheek, 1970), p. 33.

${ }_{5}^{5}$ Centrale Raad voor de Volksgezondheid, Deeladvies inzake medische experimenten, p. 7, p. 15.
} 
The specific events that led the Dutch government to request this report from the Central Council for Public Health, as well as the committee deliberations that preceded its publication in 1982, will be examined further in chapter 4. First, this chapter details the rise of the patients' rights movement in the Netherlands in the 1960s and 1970s. Even though the KNMG had announced after World War II that it would make significant investments in the existing Dutch medical ethics tradition to ensure that the professional identity that had kept Dutch physicians strong in times of war would not wither away (see chapter 1), this optimism crumbled in the decades thereafter. By 1970, the Dutch Journal of Medicine and Medisch Contact were filled with concerns over an apparent crisis of medical ethics that plagued the Netherlands. In national parliament, questions started to be asked about the need to formulate new ethics for Dutch medicine, while an amalgam of social movements started to advocate the need to elevate the position of the patient in the Dutch health care system. Instead of "vertical relations of dependence and subordination", the new mantra became, the Dutch government had to realize "horizontal relations of consultation and participation" in health care. Eventually, towards the end of the 1970s, as the next chapter will show, the notion of 'ethics by committee' became part of this discourse.

Section I of this chapter traces how this sense of crisis about the existing medical ethics tradition arose in the Dutch medical community in the 1960s, a feeling that gradually diluted the idea that the artsenstand still formed a separate class in Dutch society in charge of its own mores. Section II, in turn, maps the initial response of the Dutch government to this crisis, while section III investigates the growing popularity of a patients' rights lingo in Dutch policy circles in the early 1970s. Section IV, finally, details how these developments in 1978 resulted in the installation of the Committee Rights of the Patient by the Central Council for Public Health. This committee, that marked a true attempt at participative decision-making in Dutch health care, wrote the 1982 Central Council report on the governance of human experimentation in the Netherlands. To secure the rights of research subjects, also this report came to argue, the Dutch government had to enforce a system of ethics by committee.

\section{The Dutch crisis of medical ethics}

Ever since World War II, medical ethics had been an important area of focus in the Dutch medical community. In 1947, the (K)NMG announced plans to establish new departments that would invest in the professional ethics of physicians to preserve the "spiritual unity" which had kept Dutch physicians strong during the war. In 1949, at the closing festivities of the centennial birthday of the KNMG, the primus inter pares Jean Jacques Brutel de la Rivière called for the production of a work "that adapts our existing medical ethics to the radical changes that have taken place in the profession of medicine and in society at large". That same year, the association installed a Committee Professional Confidentiality, that was succeeded in 1954 by a Committee Medical Ethics which was to write a new booklet describing Dutch medical ethics (for all developments, see chapter 1). These measures were needed, the KNMG maintained, because in the past the association had functioned too much as a trade union. Change was required if the organized Dutch medical profession hoped to safeguard the future ethical conduct of medical research and practice in the Netherlands. 
In the 1950s, the Dutch medical community seemed to take pride in this renewed attention for medical ethics. The KNMG-journal Medisch Contact, for instance, regularly kept its readers updated of the excellent progress made by the Committee Medical Ethics on the new ethics booklet. Between 1954 and 1958 it regularly printed draft versions of chapters with the request to readers to send in their comments and questions. This collective effort, the idea was, would result in robust ethics guidelines that carried the seal of approval of the majority of the Dutch artsenstand, that could then be expected to uphold them in practice. ${ }^{6}$ Similarly, in the mid-1950s, the KNMG relished the fact that the Dutch had brought the ethics of human experimentation to the attention of the international medical community (see chapter 1). In the Netherlands, its message was, everything was done to keep the ethics of medicine in high regard, to make sure it remained an effective mechanism of internal control.

At the start of the 1960 s, this positive image initially continued to reign supreme. In 1959, the KNMG had finished working on its new ethics booklet.7 Titled Medische Ethiek en gedragsleer (Medical ethics and behavioural rules), it covered all sorts of subjects, like the importance of medical confidentiality, the rights and responsibilities of general practitioners when handing over their practice to colleagues, the appropriate attitude toward the pharmaceutical industry and the general press, the position of Dutch physicians in the national health care system, etcetera. ${ }^{8}$ The plan was that all members of the KNMG would be sent a copy of the ethics booklet, and that all Dutch medical students would from then on be presented with a copy upon their graduation to remind them of the moral duties that this rite of passage bestowed upon them. The Committee Medical Ethics, in the meanwhile, would be reinstated by the KNMG as a permanent advisory board for all matters concerning medical ethics. 9

In their announcement of the new booklet in 1960, the editors of Medisch Contact expressed their excitement over the realization of new ethics for Dutch medical practice. In the past, the editors explained, Dutch physicians had at times mistakenly spoken of ethics-which was a 'heavy word', suggesting deep moral reflection-when they had really meant to talk of etiquette: the customary mores of polite conduct among medical colleagues. The new booklet therefore strictly separated between the two, "so that it is clear that also in the leading circles of the medical society this distinction is appreciated". ${ }^{10}$ With the wealth of material that each of the chapters contained, the editors were convinced it offered Dutch physicians solid handles for the sometimes difficult ethical decisions that awaited them in their practice. ${ }^{11}$

\footnotetext{
${ }^{6}$ Draft chapters were regularly printed in Medisch Contact between 1954 and 1958. For examples, see: 'Het overdoen van de praktijk', in Medisch Contact Vol. 9 (1954), pp. 298-299; 'De pers en de geneeskunde', in Medisch Contact Vol. 10 (1955), pp. 242-245; 'Assistentie, waarneming en associatie', in Medisch Contact Vol. 11 (1956), pp. 16-21; 'Honorarium', in Medisch Contact Vol. 12 (1957), pp. 546-551; 'Het ziekenfondswezen', in Medisch Contact Vol. 13 (1958), pp. 105-108.

${ }^{7} \mathrm{KNMG}$, Medische ethiek en gedragsleer (Amsterdam: Koninklijke Nederlandse Maatschappij tot Bevordering der Geneeskunst, 1959).

${ }^{8}$ One chapter addressed the ethics of medical experiments on human beings and contained the ethical guidelines of the 1955 Council report. For the publication of the draft chapter in Medisch Contact, see: 'Proeven op mensen', in Medisch Contact Vol. 13 91958), pp. 108-109.

9 'Commissies', in Medisch Contact Vol. 13 (1958), p. 335; Dekker, 'De derde druk van het boekje 'Medische Ethiek en Gedragsleer', in Medisch Contact Vol. 15 (1960), p. 160.

10 “"Medische Ethiek” opnieuw gedrukt', in Medisch Contact Vol. 15 (1960), pp. 169-170, p. 169.

${ }^{11}$ Ibid., p. 170.
} 
That same year, the Protestant internist Gerrit Arie Lindeboom published another booklet on medical ethics, Opstellen over medische ethiek (Essays on medical ethics), which contained chapters on subjects like medical confidentiality, human and animal vivisection, but also on subjects like artificial insemination and euthanasia. ${ }^{12}$ The internist had written the essays, he stated in the introduction, to fill the void that existed in Protestant medical circles with regard to counselling on subjects of medical ethics. ${ }^{13}$ In the Dutch Journal of Medicine, Lindeboom's booklet was recommended as a learned and thoughtful publication that was certainly of interest to physicians of other persuasions as well. ${ }^{14}$ Various newspapers also reviewed the booklet positively. ${ }^{15}$ One, which printed a joint review of Lindeboom's essays and the new KNMG booklet, even commented enthusiastically on "the curious fact that, as much as their philosophies of life may differ, physicians have ever since Hippocrates displayed a profound agreement on medical ethics". The publication of these two new ethics booklets was only further proof of the "fortunate fact that physicians in difficult circumstances can rely on a common opinion". ${ }^{16}$ In short, quite some confidence existed in the Netherlands anno 1960 about the capacity of the Dutch artsenstand to regulate the conduct of its physicians through the formulation of solid medical ethics.

Over the course of the 1960 s, however, this image would change radically. In a period of only ten years, the perception in Dutch medical circles of its ethics tradition took a sharp downturn. In 1970, a physician even declared in Medisch Contact that Dutch medical ethics was "in full crisis" ${ }^{17}$ Anyone denying this just had to reread a recent policy report of the KNMG. There, tucked away between a few policy decisions, a paragraph titled 'serious problems' contained the admission that the association's Committee Medical Ethics had been unable to write an updated version of Medische ethiek en gedragsleer. ${ }^{18}$ The Committee could, if this was desired, create another edition containing behavioural rules for physicians, but had "given up hope to compose another Medische Ethiek". ${ }^{19}$ The author in Medisch Contact felt this failure stood testimony to a deep crisis in moral medical authority in the Netherlands that had "become manifest around 1960" and that had brought about a "degeneration in medical thinking”. ${ }^{20}$ Within a single decade, 'the leading circles of Dutch medical society' had lost their once easy connection to that "heavy word": ethics.

\footnotetext{
${ }^{12}$ G.A. Lindeboom, Opstellen over Medische Ethiek (Kampen: J.H. Kok N.V, 1960).

${ }^{13}$ In Catholic circles, discussion of medical ethics was more common. Pope Pius XII, for instance, frequently addressed the subject and spoke on conferences such as those of the World Medical Association. See: Darrel W. Amundsen, 'The Discourses of Roman Catholic Medical Ethics', in Cambridge World History of Medical Ethics, pp. 218-254.

${ }^{14}$ C.L. de Jong, 'G.A. Lindeboom, Opstellen over medische ethiek', in Nederlands Tijdschrift voor Geneeskunde Vol. 104 (1960), p. 1897.

${ }^{15}$ See for instance: 'Leemte in medische opleiding', in Leeuwarder Courant, Tuesday 13 September 1960, p. 2; 'Nieuwe uitgaven', in Nieuwsblad van het Noorden, Thursday 2 June 1960, p. 27; 'Gesprek aan het ziekbed', in Gereformeerd Gezinsblad, Saturday 16 July 1960.

16 'Over medische ethiek. Twee nieuwe uitgaven', in De Tijd-Maasbode, Thursday 19 May 1960, p. 7.

${ }^{17}$ W. Metz, 'Over de crisis in de medische ethiek', in Medisch Contact Vol. 25 (1970), pp. 330-332.

18 'Kort verslag H.B.-vergadering', in Medisch Contact Vol. 21 (1966), pp. 210-211, p. 210; G. Dekker, 'Jaarverslag 1967 der Maatschappij', in Medisch Contact Vol. 23 (1968), pp. 718-723, p. 721.

19 'Inleiding 154ste Algemene Vergadering', in Medisch Contact Vol. 25 (1970), pp. 5-6, p. 5.

${ }^{20}$ Metz, 'Over de crisis in de medische ethiek', p. 330.
} 
What happened to Dutch medical ethics in the 1960s? On 24 March 1961, Medisch Contact printed a review of the new KNMG ethics booklet and Lindeboom's Opstellen by the Utrecht theology and ethics professor Johannes de Graaf that was much less enthusiastic about the two booklets than previous reviews had been. While both publications had clearly been written with good intentions, De Graaf wrote, neither could exactly be called modern: "One senses a certain longing for the good old days of personal relations [...] as if physicians still feel helpless in the industrialized mass society of today". ${ }^{21}$ Both booklets, he felt, envisioned the doctor-patient relationship as a special bond of trust between two individuals who knew one another intimately. Yet, like most of "modern society", the modern health care system was now organized through collective social structures (hospitals, health insurance plans) and a far-reaching division of labour (specialization, teamwork). In effect, doctor and patient had often become strangers to each other and their interactions functional and fleeting. ${ }^{22}$ That did not mean medical ethics no longer mattered in a modern society, De Graaf continued. Quite the opposite, in a world with weak social ties clear moral guidelines for a practice like medicine had become more important than ever. Still, the ethics professor argued, the medical profession would have to find a new way of relating to patients, and to "tune the ethos of the physician in to the modern wavelength". ${ }^{23}$

De Graaf was wary, for instance, of the recurring appeal to the conscience of physicians in the KNMG booklet for dilemmas that it did not have a clear answer to: "As if we may just trust this conscience as long as the physician acts in the spirit of the professional ethics formulated in this book". In ethics, the professor argued, scholars had since long stopped using 'conscience' as a normative authority: it served to recognize feelings of guilt and remorse, but did not provide an "index of moral guidelines". In fact, De Graaf stated, for a work with the words 'medical ethics' in its title, the KNMG booklet had surprisingly few moral guidelines to offer for medical practice. That is, it dealt in detail with a specific subset of ethical problems-those "on which consensus since long exists"-like the need for professional confidentiality or (im)permissibility of commercial advertising. But subjects that most people in recent years had come to associate with medical ethics, such as the permissibility of birth control, artificial insemination, or lobotomy, passed in review only in the chapter 'The physician and religion' with the comment to respect patients' personal viewpoints. Perhaps such an elusive approach was inevitable for any association hoping to represent all physicians in the country, De Graaf remarked delicately, but it did mean the KNMG had little to offer for physicians struggling with truly difficult ethical questions. ${ }^{24}$

A year later, in April 1962, the editors of Medisch Contact responded to De Graaf's critiques with a leading article titled 'Ethical problems for the physician'. Given their enthusiastic reaction to the new KNMG booklet only two years earlier, their reply was surprisingly pliable. While physicians could rest on a longstanding tradition of moral

\footnotetext{
21 'Medische Ethiek', in Medisch Contact Vol. 16 (1961), pp. 190-191, p. 190. For Johannes (Hannes) de Graaf, who was also a pastor as well as the leader of the Pacifist Socialist Party (PSP) in the Netherlands, see: E.D.J. de Jongh, Hannes de Graaf. Een leven van bevrijding (Kampen: Ten Have, 2004).

${ }^{22}$ For a similar analysis in this period, see: I. Boerema, 'De Keerzijde van de Vooruitgang in de Geneeskunde', in W. Peremans et al., Acht voordrachten over de keerzijde van de vooruitgang in de natuur-en geneeskundige wetenschappen ('s-Gravenhage: Martinus Nijhoff, 1962), pp. 39-55.

23 'Medische Ethiek', p. 190.

${ }^{24}$ All quotes in this paragraph: Ibid., p. 191.
} 
contemplation, they wrote, it was true this tradition increasingly seemed to fall short these days. The main cause of this development, the editors argued, was the "dizzying speed in which 'the new sciences' [had] penetrated the terrain of the physician" in the last century (and thus not, as De Graaf had stated, the changing social bonds in Dutch society). In recent years, for example, the medical profession had tried to get to grips with the implications of technologies for respiration and resuscitation developed by electrical engineers in the mid-twentieth century that fundamentally altered the possibilities to preserve life. But before a moral consensus had been reached on this topic already "a new wave of technical skill [was] poured out onto humanity" in the form of artificial insemination, which now offered the possibility also to conceive life. The editors agreed with De Graaf that such developments demanded more reflection than was currently the case, but they understood why this often did not happen:

The consequences of these technical possibilities are so far reaching, that some are hardly willing to think further about them. [...] People want to be undisturbed and live their old lives as much as possible, not just because these new possibilities are incalculable and frightening, but because they do not know how to cope with the type of ethical concerns that these [technologies] bring. ${ }^{25}$

Nonetheless, the editors did feel the KNMG had a leading role to fulfil in this regard and emphasized that debates about these new developments could also be held in the pages of their journal: "The more use is made out of this [...] the more serious we can strive to stay faithful to the tradition that physicians can draw support from their professional ethos in determining their standpoint [on ethical issues]". ${ }^{26}$

This call for more communal reflection was certainly put into effect in the Netherlands in the 1960s. In 1962, already, the KNMG issued a reflection paper on the ethics of artificial insemination and organized a live debate on the topic at its General Assembly. ${ }^{27}$ In the next few years, Medisch Contact published essays on the ethical implications of new medical technologies almost every other week. In these papers, the most frequently asked question was if the old adage in medical ethics to sustain life as much as possible still held true in an era when the possibilities for doing so seemed to grow evermore endless. In 1965, a two day medical conference was held on the theme 'Ethics or Etiquette' with talks like 'The inadequacy of our existing medical ethics' and 'What should the norm of our practice be?'. ${ }^{28}$ In 1966, the KNMG took under consideration if it should start to study medical ethics "scientifically" (it did not specify what it meant with this exactly) and in 1967, it decided that its standing Committee Medi-

\footnotetext{
${ }^{25}$ Red., 'Ethische problemen voor de arts', in Medisch Contact Vol. 17 (1962), pp. 237-238., p. 238.

${ }^{26}$ Ibid., p. 238.

27 'Discussie over: rapport kunstmatige inseminatie', Medisch Contact Vol. 17 (1962), pp. 239-241.

28 'Varia', in Medisch Contact Vol. 20 (1965), p. 278. Around the same time, Medisch Contact frequently started to advertise lectures on the topic of medical ethics and any ongoing problems therewith. See, for instance: M.W. Jongsma, 'Medische ethiek', in Medisch Contact Vol. 21 (1966), pp. 311-316; 'Dr. J.C. Schultsz over Medische Ethiek', in Medisch Contact Vol. 21 (1966), pp. 782-783; 'Voordrachten: internist C.L.C. Nieuwenhuizen, onderwerp "De ethische consequenties van de moderne ontwikkeling in de geneeskunde en biologie"', in Medisch Contact Vol. 22 (1967), p. 377; C.P. Sporken, 'Katholieke moraal en abortus', in Medisch Contact Vol. 22 (1967), pp. 385-389; 'Voordrachten: Dr. H. Hamminga, onderwerp "Enige medisch-ethische problemen"', in Medisch Contact Vol. 22 (1967), p. 469; 'Varia: Het dogma in de medische ethiek', in Medisch Contact Vol. 22 (1967), p. 1163.
} 
cal Ethics was in serious need of rejuvenation. Among other things, it had to critically scrutinize the contents of the KNMG ethics booklet (only eight years old at the time) and, if it believed this to be necessary, completely rewrite them. ${ }^{29}$ In 1968 , the KNMG approached all medical faculties in the country with the request to pay more attention in their curricula to the discussion of medical ethics. ${ }^{30}$

This enthusiastic increase of communal reflection on medical ethics in Dutch medical circles in the 1960s, however, did not quite have the desired effect. The more journals like Medisch Contact discussed the implications of new technologies for the existing Dutch medical ethics tradition, the more it became clear that Dutch doctors often could not "rely on a common opinion in difficult circumstances". In the 1950s, still, this communis opinio had, at least rhetorically, been taken as self-evident. Sure, separate factions existed in the artsenstand that were aligned to the (in)famous 'pillars' that organized social and political life in Dutch society into four main politicodenominational movements in this period (i.e. a Catholic, Protestant, socialist, and liberal pillar). ${ }^{31}$ Yet, according to the elite of the organized Dutch medical profession, these "personal viewpoints" did not conflict with the professional ethos of physicians, which they derived from being members of the artsenstand. Thus, in 1953, during the first meeting of the Health Council committee 'tests upon human beings', the Council President had felt confident to remind the participating physicians that ethical principles based on "religion, philosophy, or conscience" would not be brought to the fore in committee deliberations, as they all had the ethics of medicine in common: professional ethics trumped personal ethics (see chapter 1). However, when the Dutch medical profession in the 1960 s increasingly started discussing ethical issues other than the importance of medical confidentiality or commercial advertising, it became clear that physicians often did not agree on the morally right or wrong thing to do in difficult circumstances. On closer inspection, it turned out, the unitary ethos of the Dutch artsenstand was much less solid than had often proudly been assumed.

These first dents in the professional identity of the Dutch artsenstand were further exacerbated in the mid-1960s by a growing recognition that also patients increasingly seemed to question the moral authority of the physician. In 1966, the psychiatrist Jan Marlet (who was an often cited contributor to Dutch debates on medical ethics at the time) co-authored a book with his two brothers-one a jurist, the other a theologianto examine why, despite a lack of much evidence of medical malpractice among Dutch physicians, the Dutch patient increasingly seemed dissatisfied with his practitioner..$^{2}$

\footnotetext{
29 'Kort verslag H.B.-vergadering', in Medisch Contact Vol. 21 (1966), pp. 210-211, p. 210; G. Dekker, 'Jaarverslag 1967 der Maatschappij', in Medisch Contact Vol. 23 (1968), pp. 718-723, p. 721.

${ }^{30}$ Korte verslagen vergaderingen hoofdbestuur', in Medisch Contact Vol. 23 (1968), pp. 337-338, p. 338; W.B. van der Mijn, 'Het takenpakket der maatschappij', in Vol. 23 (1968), pp. 631-637, p. 632.

${ }^{31}$ Thus, in addition to the official KNMG journals, also Catholic and Protestant medical journals existed, while hospitals and health funds often operated within these frameworks as well. See: Friso Wielenga, Nederland in de twintigste eeuw (Amsterdam: Boom, 2009); Peter van Dam, Staat van verzuiling. Over een Nederlandse mythe (Amsterdam: Wereldbibliotheek, 2011).

${ }^{32}$ J.J.C. Marlet, M.F.J. Marlet \& L.N. Marlet, Schuld en verontschuldiging in de medische praktijk (Roermond: J.J. Romen \& Zonen, 1966).
} 
An important psychological reason, the psychiatrist Marlet asserted, was the growth of medical power in recent years. It had made patients continuously expect more and better care, ironically leaving them less satisfied than when physicians had only been able to offer pastoral care. 33 A cultural reason, the jurist Marlet stated, was the strong levelling of social classes in the Netherlands in recent decades. Anno 1966, the doctor was no longer revered as a true "authority-figure". Instead, patients' "sense of selfworth" had increased: if they did not like their physicians, they no longer hesitated to simply choose a different one. ${ }^{34}$ A key economic reason, the jurist added, was the fact that since the 1940 s many more people had acquired health insurance in the Netherlands. This had caused waiting rooms to flood, leaving much less time for the average physician to spend per patient, who felt neglected because of it. The doctor-patient relationship, the psychiatrist Marlet concluded with some sadness, was likely to turn into an ordinary business arrangement in the Netherlands with two parties-a supplier and a consumer-constantly in search of "best value for money". 35

Around the same time, also authors in Medisch Contact started to comment on the changing attitude of the Dutch patient toward his caregivers. The modern patient, the expression went, had become mondig (assertive, mature): he no longer just accepted the authority of his physician, but made demands on the type of treatments he wished to undergo..$^{36}$ Doctors were no longer respected as "magi", as members of a priestly class who could ease suffering with a touch of their hands, but were taken to be mere technical engineers. ${ }^{37}$ In 1967, the liberal Dutch paper Algemeen Handelsblad caused a national stir with the headline 'The doctor is not God'. ${ }^{8}$ Medical malpractice did occur in the Netherlands, the article stated, but the general public was often wilfully kept ignorant of misbehaviour or mistakes in Dutch medical practice:

The artsenstand uses the term 'trust' as a sacred token necessary for a proper medical treatment. In principle, that is true. The danger exists, however, that it also uses the same term as a shield to keep issues that hurt the medical treatment and therefore the general interest out of the public eye. 39

\footnotetext{
${ }^{33}$ J.J.C. Marlet, 'De in rechten vervolgde arts', in Schuld en verontschuldiging, pp. 57-82.

${ }^{34}$ L.N. Marlet, 'Enige raakpunten tussen de medische praktijk en het leerstuk der aansprakelijkheid', in Schuld en Verontschuldiging, pp. 5-65, p. 7.

${ }^{35}$ Marlet, 'De in rechten vervolgde arts', p. 65. See also: J.M.F. Phaff, 'Toepassing medische psychologie door de huisarts', in Medisch Contact Vol. 18 (1963), pp. 480-483.

${ }^{36}$ Dutch historians Stephen Snelders and Frans Meijsman have investigated the history of 'de mondige patiënt' and have concluded that the supposed emergence of the mature patient in the 1960s is largely a historical myth. Dutch patients, they argue, were well capable of voicing their opinions about the treatments they desired long before the 1960s. See: Stephen Snelders \& Frans Meijsman, De mondige patiënt. Historische kijk op een mythe (Amsterdam: Bert Bakker, 2009).

${ }^{37}$ For a contemporary analysis of the emergence of 'the mature patient', see: A. Querido, 'De mondigheid van de patient: I. Diagnose', in Metamedica Vol. 49 (1970), pp. 205-208.

38 'De dokter is God niet', in Algemeen Handelsblad, Saturday 13 May 1967, Supplement p. 1.

${ }^{39}$ The Algemeen Handelsblad based its claim that medical misconduct did take place in the Netherlands on an empirical article published in the Dutch Journal of Medicine in 1963 that had hardly received any coverage in the general press. The newspaper argued it was the first ever article from within the Dutch artsenstand to admit to the existence of such mistakes. See: P.J. Kuijer, J.F. van Rhede van der Kloot \& J. Logeman, 'Sterfte, medische tekortkomingen en foutenbronnen', in Nederlands Tijdschrift voor Geneeskunde Vol. 107 (1963), pp. 1268-1270.
} 
The artsenstand was an impenetrable stronghold, devoid of much social control, that did not operate in a transparent, and therefore accountable, manner. When patients were aware of any misconduct, for instance, the options for filing complaints were scarce. And when cases made it to court, their proceedings were usually kept a secret. In effect, patients could hardly get their voice heard while physicians could do pretty much whatever they pleased. This would not do. In future years, a more "mature and open relationship" had to be developed between the two parties. ${ }^{40}$

The KNMG tried to account for such complaints in the 1960s. Already in 1958, its board had proposed to include a legal counsel in its disciplinary courts (see chapter 1). At first, this proposal had given rise to fierce opposition among members. 'Outsiders' had no place there, the argument ran, as collegial justice was administered according to "the principles of medical ethics which only slowly mature in each physician through his education, experience, and insights". ${ }^{41}$ In 1964, however, the KNMG did install a committee with five physicians and three jurists for the modernization of its justice system. The report delivered by this study group in 1968 strongly advised openness in the association's juridical proceedings. Verdicts had to be made public, including the identity of the accused, even if complaints had been ruled unfounded. Moreover, jurists most certainly had to take up a seat in the disciplinary courts. These measures were needed, the report read, to allow for a more open dialogue with the Dutch public and to ensure the KNMG "keeps pace with social life". ${ }^{42}$

Such measures, however, did not take away a growing unrest in the Netherlands in the late 1960 s about the uneven dynamic of the doctor-patient relationship. In 1968, Dutch jurists organised a conference on 'The physician and the law'. Physicians often failed to realise, speakers complained, that they were bound to the same laws as everyone else in the Netherlands. 43 According to one speaker, it was just typical how "in the familiar ethics booklet of the KNMG [...] the personal bond of trust between physician and patient is repeatedly emphasized", while their legal relation was, if referenced at all, interpreted mostly as an impoverishment of the vocation. 44 This attitude, where physicians kept on thinking of their profession as an ordained ministry akin to priesthood, agitated 'outsiders'. For society to keep its trust in the medical profession, he warned, it was essential that physicians started to recognize the patient as a "legally equal contract partner" and to resist the temptations of paternalism. This idea that the artsenstand formed a separate class in society, and that doctors were like fathers to their patients, just did not fit life in a modern society anymore.

\footnotetext{
${ }^{40}$ The editors of Medisch Contact responded very angrily to what it called was a 'sensationalist publication' in the Algemeen Handelsblad: 'Massamedia en Medici. Het Handelsblad constateert 'de muur van geheimzinnigheid, die de medische wereld om zich heeft opgebouwd, doorbroken', in Medisch Contact Vol. 22 (1967), pp. 527-528.

${ }^{41}$ See: P.Th. Hugenholtz, 'Wijziging rechtspraak', in Medisch Contact Vol. 13 (1958), p. 785.

${ }^{42}$ G. Dekker, 'Rapport van de commissie herziening rechtspraak. Pre-advies van het hoofdbestuur', in Medisch Contact Vol. 23 (1968), pp. 84-104; W.B. van der Mijn, 'De rechtspraak van de maatschappij', in Medisch Contact Vol. 24 (1969), pp. 1029-1031; 'De 150 ${ }^{\text {ste }}$ Algemene Vergadering der Maatschappij', in Medisch Contact Vol. 23 (1968), pp. 453-463, p. 453.

${ }^{43}$ F.F.X. Cerutti et al., De Geneesheer en het Recht (Deventer: Kluwer, 1968); 'Congres te Nijmegen: De geneesheer en het recht', in Medisch Contact Vol. 23. (1968), pp. 315-317; Red. 'Aesculapius en Themis. Een nuttige ontmoeting', in Medisch Contact Vol. 23 (1968), pp. 313-314.

${ }^{44}$ J. Maeijer, 'Juridische relatie geneesheer en patiënt', in Geneesheer en het Recht, pp. 9-23, p. 9.
} 
This surging criticism on the doctor-patient relationship in the Netherlands in the late 1960 s did not hamper the enthusiastic production of new works of medical ethics in this period. In 1968, a long running Dutch editorial series published the title $R e$ cent medisch ethisch denken I (Recent medical ethical thinking I) that intended to do justice to "the evolution, one might even say revolution, that is unfolding itself in thinking about medical ethics". 45 The chapters were mostly written by physicians, but one was by the Remonstrant theologian Herman Heering and one by the jurist Jaap Rang. Its contents, moreover, were starkly different from the KNMG ethics booklet that had been published a decade earlier, with chapters taking on topics like euthanasia, artificial insemination, and anticonception. In 1970, another edition with chapters on topics like sterilization and sexuality was added to the series. ${ }^{46}$ In 1969 , a journalist published the booklet Medische ethiek vandaag (Medical ethics today) with interviews of "sixteen prominent physicians who are confronted day-in-day-out with the most strange and complex new questions of ethics and religion".47 That same year, a conference was held on 'medical ethics between science and society', Heering brought out a book on (medical) ethics titled Ethiek der voorlopigheid (Provisional ethics), and the Catholic theologian Paul Sporken-who would go on to become the first Dutch professor of medical ethics in 1974 (see chapter 6)-published a book titled Voorlopige diagnose (Provisional diagnosis). ${ }^{48}$

In all these publications, concepts like newness, change, and temporality dominated. "Every era has its own ethics", the conference participants concluded. ${ }^{49}$ The existing Dutch medical ethics, Heering and Sporken maintained, fell short because it was too static: physicians believed the Hippocratic tradition transcended particular times and places, but moral rights and wrong could only be determined within the context of specific situations and were thus subjected to change through time and space (see chapter 6). In these publications, also the position of patients increasingly took centre stage. Sporken, in particular, maintained that a context-dependent ethics should include the patient's perspective, who was after all a crucial participant in medical practice. This was where the old KNMG-booklet went astray. It only dealt with physicians: the responsibilities of general practitioners versus specialists, the relation with other caregivers, etcetera. An ethics of health care, Sporken maintained instead, had to take patients as its starting point. Accordingly, his book was divided into five parts: problems of birth (abortion, reproduction); marriage (anticonception, sexuality); maturity (medication, sterilization); end-of-life (reanimation, euthanasia); and death (death criteria, transplantation). By taking this lifecycle approach, the theologian explained, medical ethics would be able to include patients' voices. By extension, this egalitarian approach would move away from the old idea that only members of the artsenstand knew what was ethically best because of their professional identity.

\footnotetext{
${ }^{45}$ L.H.Th.S. Kortbeek et al.(eds.), Recent Medisch Ethisch Denken - I (De Nederlandse Bibliotheek der Geneeskunde, nr. 40) (Leiden: Stafleu's Wetenschappelijke Uitgeversmaatschappij, 1968), p. 5.

${ }^{46}$ A.G.M. van Melsen et al., Recent Medisch Ethisch Denken - II (De Nederlandse Bibliotheek der Geneeskunde, nr. 60) (Leiden: Stafleu's Wetenschappelijke Uitgeversmaatschappij, 1970).

${ }^{47}$ J.P. Calff, Medische Ethiek Vandaag (Amsterdam: Agon Elsevier, 1969), backflap.

48 'Medische ethiek tussen natuurwetenschap en samenleving', in Wetenschap en Samenleving Vol. 23 (1969), no. 5/6; H.J. Heering, Ethiek der Voorlopigheid (Nijkerk: Callenbach, 1969); C.P. Sporken, Voorlopige diagnose: inleiding tot een medische ethiek (Utrecht: Ambo, 1969).

${ }^{49}$ J.J. Groen, 'Iedere tijd heeft zijn eigen ethiek', in De Groene Amsterdammer, 5 juli 1969, pp. 9-10.
} 
Heering and Sporken and their provisional (medical) ethics were popular among Dutch physicians. Both were regularly invited to publish in Medisch Contact, asked to give lectures, and nominated to participate in advisory bodies like the Health Council. Their works helped ensure that the Dutch discourse on medical ethics was more lively and rich by the end of the 1960 s than it had been since a long time. Yet, at the close of the decade, a feeling that something was sorely amiss with the existing Dutch medical ethics tradition dominated public debate in the Netherlands. If change and temporality dictated ethical thinking, the worry was, and if patients' voices had to be included as well, it was next to impossible to formulate moral guidelines that would transcend the here and now. The idea of a longstanding tradition of medical ethics shared by all members of the artsenstand that functioned as an important tool of internal control over the conduct of practitioners seemed to be evaporating into thin air.

In April 1970, the KNMG held its biannual General Assembly. At this meeting, the President announced the association's standing Committee Medical Ethics would be dissolved. $5^{\circ}$ "The acceleration in the evolution of science and society", the President said in defence of this decision, demanded a more "modern approach" to the study of medical ethics..$^{11}$ In the past, the medical community had often thought that only the opinions of physicians mattered in the moral reflection on medicine, but it now recognized that two groups could be distinguished in society on this terrain: "physicians and others".52 "Medical ethics", the President asserted, "is essentially pluralistic and multiple opinions on one and the same question can be fully accounted for".53 Hence, while the KNMG did feel that 'the circle of physicians' had its own unique perspective on what was morally right and wrong in medical practice, the association would start to "give room to representatives of the non-medical population" in the formulation of new medical ethics. "If this does not happen", the President warned, "the danger exists that the ethos of physicians is alienated from the ethical feelings in the population [...] to the detriment of its trust in the class of physicians". ${ }^{54}$

The KNMG planned, therefore, to establish a new committee with "representatives from the Roman-Catholic medical community, Protestant-Christian medical organization, Remonstrant medical association, and humanistic group Socrates" that would be tasked to modernize the existing behavioural rules for physicians-strictly keeping in mind that the social structures in society had changed radically in recent years and that patients were now increasingly mondig. ${ }^{55}$ In addition, the association would start publishing loose-leaf essays on pressing issues in medical ethics that would preferably be written by experts from fields of law, sociology, psychology, and theology (out-

\footnotetext{
${ }^{50}$ L. van der Drift, 'Medische Ethiek anno 1970', in Medisch Contact Vol. 25 (1970), pp. 413-417.

${ }^{51}$ Ibid., p. 413.

52 Ibid., p. 414.

${ }^{53}$ Ibid., p. 416.

${ }^{54}$ Ibid., p. 415.

${ }^{55}$ For an overview of Catholic and Protestant thinking about medical ethics in the Netherlands anno 1970, see: P. Sporken, 'Vijftig jaar medische ethiek in het Katholiek Artsenblad', in Metamedica Vol. 49 (1970), pp. 395-411; G.A. Lindeboom, 'Medisch-ethische bezinning in Protestantse kring', in Metamedica Vol. 49 (1970), pp. 411-416.
} 
siders, in short). These essays would have to take a "pluralistic approach" and include literature suggestions for further self-study. This way, the KNMG hoped to kill two birds with one stone: (1) ensure that "the ethical aspects of the rapid developments on medical-scientific and technological terrain are brought to the attention of physicians and medical students in a timely manner", and (2) provide an appropriate solution to the growing dissatisfaction in the Netherlands with the societal functioning of physicians. "The times have passed", the KNMG President declared solemnly in conclusion to his speech for the General Assembly, "that we could pretend medical ethics to be a secret doctrine belonging to the professional secrets kept by physicians" ${ }^{6}{ }^{6}$ In modern society, everyone had something to say about medical ethics.

\section{The first steps of political interference}

In 1970, still, the KNMG figured that all it needed to do to defuse this crisis was to invest even more in the formulation of better medical ethics-this time with the input of a whole range of medical outsiders. Yet, around the same time that the President of the association held his speech for the General Assembly, Dutch parliament started to interfere as well in ongoing public discussions over the existing Dutch medical ethics tradition. On Tuesday 3 February 1970, to be exact, in a debate in parliament over the annual budget of the Department of Social Affairs and Public Health, the leader of the Protestant Christian-democratic party Arnold Tilanus used his allotted speaking time to address "the position of the physician in modern society". ${ }^{77}$ According to Tilanus, a growing discomfort could be detected in the Netherlands about this position. Trade unions regularly complained that medical fees were too high; consumer organizations accused medical specialists of treating publicly insured patients less carefully than (the more lucrative) privately insured patients; frequent complaints were made that doctors and nurses refused to work night and weekend shifts; and concerns could be heard about the growing unwillingness of general practitioners to make house calls. All in all, Tilanus said cautiously, the societal functioning of physicians "has become a public phenomenon, about which this House can and should speak". ${ }^{8}$

The examples given by Tilanus were all of a socio-economic nature. Nonetheless, the Protestant politician continued whilst turning to the members of the labour party across the aisle, it would be a mistake to solely attribute the growing discomfort about the social position of physicians to structural inequalities in the financial organisation of the national health care system. No, Tilanus stated, "the causes of the existing discontent between physician and patient lie much deeper".59 To make his case, the politician invoked the booklet Medische macht en medische ethiek (Medical power and Medical Ethics) published a year earlier by Dutch 'zenuwarts' (neuropsychiatrist) Jan Hendrik van den Berg. ${ }^{60}$ In this publication, Van den Berg had, like many others in the late 1960s, argued that new medical ethics had to be developed to account for the growing technical powers of medical practitioners. Unlike many others, however, Van

\footnotetext{
${ }^{56}$ All quotes in this paragraph: 'Medische ethiek anno 1970', p. 417.

${ }^{57}$ Handelingen Tweede Kamer 1969-1970, 3 February 1970, pp. 1939-1998.

${ }^{58}$ Ibid., p. 1952.

${ }^{59}$ Ibid., p. 1954.

${ }^{60}$ J.H. van den Berg, Medische macht en medische ethiek (Nijkerk: Callenbach, 1969). The specialism 'zenuwarts', which understood psychiatric illnesses as nervous disorders, was abolished in 1984.
} 
den Berg had explicitly written his booklet for a lay public and had included multiple confronting images of suffering patients who were alive only because they had been 'saved' by medical technology: a man whose lower body had been surgically removed, a baby with a split spine and hydrocephalus (a 'water head'), etcetera. ${ }^{61}$ In "the era of medical power", the psychiatrist had concluded, the once "holy rule" of medical ethics to preserve life at all costs had to be replaced by a new rule stating the physician only "preserves, spares, and lengthens human life when this makes sense". ${ }^{62}$

Medische macht en medische ethiek, in short, was a plea for allowing passive and sometimes even active euthanasia. As such, it caused great uproar in the Netherlands. It was not the first Dutch essay to make this claim, but it was the first to actively seek out a non-academic audience and to provoke great debate in the mainstream media. ${ }^{63}$ Some commentators expressed sympathy for Van den Berg's ideas. Sporken, for instance, stated publicly that he could "follow most parts of the road that Van den Berg is travelling with him". ${ }^{4}$ Others, however, voiced fundamental concerns. In reformed circles, the booklet was referred to as a "Godless book" and its author a "competitor of God". ${ }_{5}$ But also in left-wing intellectual circles Van den Berg's ideas were compared to the older Nazi doctrines. "Even people with few taboos will shudder when reading this", one author wrote, "and wonder where it is that we are going and whether physicians really have any competence in making this type of decisions". ${ }^{66}$

In Dutch parliament, Tilanus drew on Van der Berg in support of his claim that the growing unrest over 'the societal functioning of the physician' went much deeper than annoyances over the working hours of doctors. The growth of medical power, the politician stated, had brought about new "fundamental questions about the beginning and end of life". And while he did not "want to go as far as Professor Van den Berg in his booklet", Tilanus agreed that "new medical power perhaps requires new medical ethics". This was why he had an official request for the government: to ask the KNMG to bring together "a group of physicians and ethicists to study the problem of medical power and ethics and to submit a report about this". ${ }^{67}$

The responsible State Secretary Roelof Kruisinga (see chapter 2) reacted positively to Tilanus' request. He agreed the societal functioning of physicians had been subject to much debate in recent years-a fact he had been reminded of when reading an article by psychiatrist Rudi van den Hoofdakker in 1969 in which the revered public image of the Dutch artsenstand had been identified as the reason why Dutch physicians

\footnotetext{
${ }^{61}$ The booklet stayed on Dutch bestseller lists until at least the spring of 1970. See: Het meest verkochte boek', in De Telegraaf, Saturday 9 August 1969, p. 7; 'Succes voor 'Help! De dokter verzuipt...', in De Telegraaf, Saturday 27 September 1969, p. XIII; 'Meest verkocht', in De Tijd, Monday 9 March 1970, p. 5. By 1985, Medical Power and Medical Ethics had gone through its $25^{\text {th }}$ reprint.

${ }^{62}$ Van den Berg, Medische macht en medische ethiek, 47. For more on Van der Berg, see: H. Zwart, Boude Bewoordingen. De historische fenomenologie ('metabletica') van Jan Hendrik van den Berg (Kampen: Uitgeverij Klement, 2002).

${ }^{63}$ For similar Dutch essays on euthanasia in this period, see: J.J. Prick, 'Discussie over: de medische ethiek met betrekking tot de nieuwste ontwikkelingen in de geneeskunde', in Medisch Contact Vol. 24 (1969), pp. 83-85; C.J. Goudsmit, 'Discussie over: de medische ethiek met betrekking tot de nieuwste ontwikkelingen in de geneeskunde', in Medisch Contact Vol. 24 (1969), p. 386.

${ }^{64}$ Sporken, 'Medische ethiek als cultuurkritiek', p. 1432.

65 'Macht en ethiek', in Nederlands Dagblad, Thursday 24 February 1972, p. 6.

${ }^{66} \mathrm{C}$. Wennen-Van der Mey, 'Medische ethiek ter discussie', in De Groene Amsterdammer, 4 October 1969 , p. 10.

${ }^{67}$ Handelingen Tweede Kamer 1969-1970, 3 February 1970, p. 1954.
} 
had no answers for the ethical dilemmas generated by new technologies. Their high societal standing, Van den Hoofdakker had argued, had turned physicians into sanctimonious know-it-alls: i.e. 'whatever the doctor says is right'. As students, physicians had never learned to think critically, just to behave as members of the artsenstand would. In effect, they were left helpless in the face of dilemmas for which their ethics booklets did not already provide them with readymade answers.

Also Van den Hoofdakker had explicitly addressed a lay audience. The artsenstand was not solely responsible for the inability of physicians to handle ethical dilemmas, the psychiatrist maintained, for the role of know-it-all was a persona which had been shoved down physicians' throat by Dutch society at large for years:

This isolation, this social inertia, this authoritative role of the parental figure is forced upon us from all sides. [...] Slowly but surely you will be turned into a holy cow. They will ask you: and what do you as a physician think of this? And woe betides you, if you say: Me, being a physician, I do not have an opinion about this. I know just as little about this as you. ${ }^{68}$

Hence, the only way for Dutch society to cope with the ethical dilemmas generated by new medical technologies was to assume responsibility and take the artsenstand out of its social isolation. Medical practice, Van den Hoofdakker stated, was not a neutral activity: it was a social practice perpetuating specific religious and ideological beliefs about what lives were worth living and which identities worth existing. Consequently, medical ethics was not the prerogative of the medical profession alone. On a macro level the formulation of moral rights and wrongs in medicine had to be a public conversation, while in the doctor's office the physician and patient had to learn to "talk, talk, talk" with each other, to explore the insecurities and doubts of both persons and to reach decisions that both parties understood and agreed with.

The words of Van den Hoofdakker spoke to Kruisinga, the State Secretary said in parliament. Across the world, the societal functioning of physicians was changing due to the rapid transformations of societies: "Questions that hardly used to be questions, now bring unrest and demand constant attention from the government". ${ }^{69}$ Hence, the State Secretary agreed with Tilanus that the subject of medical ethics had turned into something about which politicians could and should speak, which was why Kruisinga planned to request the Health Council to develop a report on the societal position of physicians, and the role fulfilled therein by medical ethics.

Tilanus was pleased with this promise of the State Secretary, although he was a bit confused about the sort of policy document that would be written and by whom this would be done exactly. He had understood Kruisinga to say that he would request the Central Council for Public Health to write a policy report, a choice that the Protestant politician found unfortunate. The Central Council had officially been installed in 1958 as a complimentary body to the Health Council and advised the Dutch government on the organization of the national health care system. Relevant players in the arena of Dutch public health held a seat in the Central Council: government representatives,

\footnotetext{
${ }^{68}$ Van den Hoofdakker, Het bolwerk van de beterweters, pp. 48-49.

${ }^{69}$ Handelingen Tweede Kamer 1969-1970, 3 februari 1970, p. 1983.
} 
the health inspectorates, health insurance agents, the KNMG, etcetera. ${ }^{70}$ But this was exactly why Tilanus was confused. Rethinking the societal position of physicians and Dutch medical ethics, the politician put forward, required "qualified scholarship" of "professors of medicine, ethics, and possibly social psychology". This was not the terrain of the Central Council. ${ }^{11}$ Sure, Kruisinga responded, which was why he had said he would contact the Health Council. "I find", he concluded, "this belongs much more with a specific expert committee than with the Central Council". ${ }^{72}$

Merely ten days later, the Health Council brought together a small study group to make preparations for "a big committee that will study medical ethics in its broadest sense". 73 The group mostly consisted of physicians, but Sporken had been invited as well, as had Theo Beemer, a moral theologian from the Catholic University of Nijmegen. A year later, this 'big committee', titled the Committee Medical Ethics, was officially installed with the explicit task "to position the physician and patient within the social order [...] according to the insights that exist and are developed within society, so that the government can found policy on this". ${ }^{74}$ More specifically, it would inform the Dutch government under what circumstances physicians were "ethically allowed to put to use the available medical-technical possibilities" (especially in life and death situations) and if any additional steps had to be taken to codify these moral precepts into criminal law. 75 In his request for advice, Kruisinga had asked the Health Council to have a "versatile group that carries the trust of the KNMG" investigate these questions. ${ }^{76}$ Accordingly, the Committee initially consisted of eight physicians, five jurists, a judge, nurse, sociologist, and moral theologian. Later, in the spring of 1973, Heering, Sporken, and a philosopher joined the committee deliberations as well, to "reinforce the representation from the side of ethics". .77 Most were from diverse religiousideological backgrounds and came from universities across the country.

Still, despite the explicit decision of Kruisinga to ask an expert-group to rethink Dutch medical ethics, some committee members did wonder if their composition really befitted a committee like theirs. During the first meeting, for instance, participating psychiatrist and editor of Medisch Contact J.H. van Meurs brought up if patients were not underrepresented in the Committee. ${ }^{78}$ Similarly, when the Committee prepared to discuss euthanasia in newborn babies in 1973, Heering asked whether mothers should be included in the deliberations, as they were "most closely involved with the issue". ${ }^{79}$ Other members, however, strongly opposed such suggestions. Their work was "of a scientific nature", they objected, and therefore did not include the perspec-

\footnotetext{
${ }^{70}$ Henri Festen, Spanningen in de gezondheidszorg. 25 jaar Centrale Raad voor de Volksgezondheid (Zoetermeer: Nationale Raad voor de Volksgezondheid, 1985).

${ }^{71}$ Handelingen Tweede Kamer 1969-1970, 3 februari 1970, p. 1987.

${ }^{72}$ Ibid., p. 1993. Italics added.

${ }^{73}$ NL-HaNA, 2.15.36, 1374, Minutes 13 February 1970, p. 2.

${ }^{74}$ NL-HaNA, 2.15.36, 1374, Minutes Commissie Medische Ethiek, 20 April 1971, p. 11.

${ }^{75}$ Gezondheidsraad, Interim-advies inzake euthanasie ('s-Gravenhage, 1972), pp. 3-4.

${ }^{76}$ NL-HaNA, 2.15.36, 1374, Minutes Commissie Medische Ethiek, 14 February 1972, p. 10.

${ }^{77}$ NL-HaNA, 2.15.36, 1374, Minutes Commissie Medische Ethiek, 23 January 1973, p. 2.

${ }^{78}$ NL-HaNA, 2.15.36, 1374, Minutes Commissie Medische Ethiek, 20 April 1971, p. 7.

${ }^{79}$ NL-HaNA, 2.15.36, 1374, Minutes Commissie Medische Ethiek, 13 December 1973, p. 2.
} 
tive of interest groups. ${ }^{80}$ And when participating jurist Jaap Rang voiced scepticism over the ability of the Committee to formulate new medical ethics which would carry the support of all people in the Netherlands, vice-chairman and neurosurgeon Boet de Lange replied soothingly that "while this Committee does not represent the Dutch cultural pattern in every detail, it also does not deviate that much from it". In other words, the expert committee really should be able of formulating "a communis opinio that will serve as a benchmark for the Minister to base his policy upon". ${ }^{81}$

What it meant, however, to formulate expert opinions that simultaneously represented "the Dutch cultural pattern" mostly remained unclear. During its first meeting, the Committee decided to take a topical approach to the formulation of new medical ethics and to tackle those problems that received the most attention in the media and politics first. The topic of euthanasia was considered urgent, for instance, and would be the subject of the Committee's first interim-report. Thereafter, the matter of "euthanasia of heavily defected newborns" would be tackled. The Committee made a list of ethical problems it wished to deal with later, including controversial topics like abortion, anticonception, and "test tube babies". The estimate was that most of these topics would take up only limited time, meaning that the Committee would be able to move quickly. The ethics of human experimentation, for example, was something the Committee did not want to spend more than one meeting on. ${ }^{82}$

Reality proved to be more unruly. The development of the first report on euthanasia alone took the Committee already over one and a half year. And when it published this document in the fall of the 1972, the Committee admitted it had been "difficult, yes, even virtually impossible" to formulate ethical norms that would be acceptable to the majority of the Dutch people. ${ }^{83}$ Pointing to recent public upheavals over the permissibility of abortions in the country, the report explained that the Netherlands had become a pluralist society in recent years. "It used to be possible to speak of a communis opinio among the majority of physicians and other groups of the population on this topic", the report read, "but now this same measure provokes contradictory and often strong reactions among various social groups and among doctors themselves". ${ }^{84}$ Hence, although the government had asked the Health Council to formulate ethical norms that could be codified into criminal law, the Committee felt that as long as this plurality of opinions continued to exist among the Dutch people, it would be wrong for any government advisory body to stipulate normative rules. Any state had to avoid acting as "a master of morality", the report concluded, as "the boundaries between democratic and dictatorial governance are, after all, fluid". ${ }^{85}$

The Committee Medical Ethics did, however, have a different proposal. In recent years, the interim-report read, a trend had been noticeable in Dutch society in which the longstanding authority of paternal figures-like "the government, Church, or scientifically formed expert"-had come under attack: "The conviction is gaining ground that every individual has enough self-knowledge to decide for himself what is in his

\footnotetext{
${ }^{80}$ Ibid., p. 2.

${ }^{81}$ NL-HaNA, 2.15.36, 1374, Minutes Commissie Medische Ethiek, 14 February 1972, p. 10.

${ }^{82}$ NL-HaNA, 2.15.36, 1374, Minutes Commissie Medische Ethiek, 14 December 1972, p. 2.

${ }^{83}$ Gezondheidsraad, Interim-advies inzake euthanasie, p. 10.

${ }^{84}$ Ibid., Interim-advies inzake euthanasie, p. 10.

${ }^{85}$ Ibid., p. 6.
} 
own best interest". ${ }^{86}$ Thus, instead of codifying potentially oppressive norms of moral behaviour into criminal law, the Dutch government could better stipulate "wat a patient is entitled to demand from a physician" and "to what extent a physician is entitled to meet such demands". ${ }^{87}$ A modern medical ethics, the Committee felt, should take its starting point in the rights of both patients and physicians.

This frame of rights sort of worked for the interim-report on euthanasia. A patient, the Committee argued, could demand from a physician to act according to the best of his abilities and to respect a patient's wishes (meaning that active involuntary euthanasia was always forbidden). But a patient could never demand from his physician to act against his will (and administer euthanasia), since also a physician had rights. ${ }^{88}$ By delegating the question whether euthanasia was desirable to individual patients and whether it was permitted to individual doctors, the Committee hoped to avoid formulating many normative moral viewpoints itself in its first report. For its second report on euthanasia in newborns, however, this procedural approach to ethical decision-making proved more difficult. Babies, after all, could not know or voice what was in their own best interest. ${ }^{89}$ To solve this problem, some of the participating jurists proposed to build the report around the notion of a 'presumed will'-i.e. "what can be assumed the patient would have wanted if he would be able to form his will as a mentally normal adult human being". ${ }^{\circ}$ Most members, however, found this approach unacceptable. "No physician or ethicist can make head or tail of this juridical fiction", Heering even sneered at one point in dismissal of this suggestion. ${ }^{91}$

This, however, left the Committee Medical Ethics with a serious problem. It would have to formulate normative ethical rules after all, which was precisely what it had tried to avoid with its rights discourse. Over the course of 1973 and 1974, the Committee did try to reach some sort of agreement on the topic, but the more committee members deliberated, the more it became clear they just could not agree on what was ethically permissible in euthanasia in newborns. By the fall of 1974, one member suggested that the second interim-report should perhaps contain the caveat stating that "the report does represent a communis opinio, but the personal opinions of members may deviate on certain points. ${ }^{92}$ Yet, in order to satisfy all those opinions, more and more footnotes and caveats had to be added to the report. The Council Committee Medical Ethics, as it turned out, could not form a benchmark for the government to base policy on, other than establishing that a carefully selected expert group was unable to reach an agreement on ethically sensitive 'medical' interventions.

By the end of 1974, it was clear the Committee would not be asked to develop any further policy reports. During their final meeting, the Committee's chairman reflected on how difficult their work had been. ${ }^{93}$ The committee members had been requested to position the physician and patient in modern Dutch society and to think about the implications of the growing technological powers for Dutch medical ethics. But three

\footnotetext{
${ }^{86}$ Ibid., p. 16.

${ }^{87}$ NL-HaNA, 2.15.36, 1374, Minutes Commissie Medische Ethiek, 20 April 1971, p. 6.

${ }^{88}$ Gezondheidsraad, Interim-advies inzake euthanasie, pp. 24-25.

${ }^{89}$ This report was: Gezondheidsraad, Advies inzake euthanasie bij pasgeborenen (Rijswijk, 1975).

${ }^{90}$ See: NL-HaNA, 2.15.36, 1374, Minutes Commissie Medische Ethiek, 13 June 1974, p. 7.

${ }^{91}$ See: NL-HaNA, 2.15.36, 1374, Minutes Commissie Medische Ethiek, 15 August 1974, p. 8.

${ }^{92}$ NL-HaNA, 2.15.36, 1374, Minutes Commissie Medische Ethiek, 31 October 1974, p. 2.

${ }^{93}$ NL-HaNA, 2.15.36, 1374, Minutes Commissie Medische Ethiek, 28 November 1974.
} 
years of deliberations had only brought them two reports on euthanasia (that would both be heavily contested in the political arena in the years to come). 94 In early 1975, the Committee Medical Ethics was disbanded without much publicity. This 'failure' by no means ended government involvement in the "societal functioning of the physician in modern society". Quite the contrary, the 1970 s would become a defining decade for Dutch political initiatives to-as Van den Hoofdakker had framed it-take the artsenstand out of its social isolation. However, instead of the psychiatrist's proposal to achieve this with his mantra of "talk, talk, talk", suggestions increasingly surfaced in the Netherlands during the 1970 in favour of "law, law, law".

\section{The consolidation of a patients' rights discourse}

In 1972, the Health Council was the first ever advisory body to the Dutch government to propose the frame of patients' rights as a suitable alternative to the traditional conception of the doctor-patient relationship in existing Dutch medical ethics texts. The term "patients' rights" was not new at the time. Already in 1953, for instance, the Dutch Senator (and well-known proponent of social medicine) Arie Querido had coauthored a Declaration of the Rights of the Patient, which was presented that year in Amsterdam to the World Health Organization (WHO). 95 The code had ten principles, such as the right to be seen as a person instead of a complex of organs and symptoms, the right to all possible help in overcoming concerns and anxieties, and the right to full attention to one's socio-cultural background and moral-religious attitudes. Yet, the WHO had not accepted this Declaration in 1953 and neither had patients' rights gained much traction in Dutch political circles in the 1950 os and 1960 s.

Why the patients' rights frame did gain political currency in the 1970s is a question that cannot easily be answered by pointing to a single sufficient cause. An important and obvious context, of course, is the fact that the 1960 s had also in the Netherlands been a decade of social turbulence in which multiple anti-establishment movements emerged. As in other countries, the Dutch counterculture of the Sixties had included a rebellion against traditional modes of authority like the Church, state, and expert. ${ }^{96}$ The medical profession was not exempt from such attacks. Certainly in the late $1960 \mathrm{~s}$ and early 1970s, numerous conflicts erupted in Dutch care facilities over their "paternalistic set-up"-at times resulting in the occupation of buildings by activists (and, in one instance, in widely broadcasted police raids). ${ }^{97}$ Occupiers typically protested the hierarchical organisation of these facilities and demanded that residents could influence their own living conditions and treatment plans. In a democratic and egalitarian society, the argument was, everyone should be able to take charge of their own lives. Similarly, in 1970, a group of Dutch physicians began the movement 'kritiese artsen',

\footnotetext{
${ }^{94}$ Heleen Weyers, Euthanasie. Het proces van rechtsverandering (Amsterdam: AUP, 2004); Kennedy, Een weloverwogen dood.

${ }^{95}$ H.L. 'De rechten van de patiënt', in Katholiek Artsenblad Vol. 47 (1968), pp. 162-164.

${ }^{96}$ Hans Righart, De eindeloze jaren zestig. Geschiedenis van een generatieconflict (Amsterdam: De Arbeiderspers, 1995); James Kennedy, Nieuw Babylon in aanbouw. Nederland in de jaren zestig (Amsterdam: Boom, 1995).

${ }^{97}$ E.H. Tonkens, Het zelfontplooiingsregime. De actualiteit van Dennendal en de jaren zestig (Amsterdam: Bakker, 1999). Also: Commissie van advies inzake het democratisch en doelmatig functioneren van gesubsidieerde instellingen, Discussie-nota, September 1975 (Rijswijk: Secretariaat, 1975), p. 8.
} 
(critical doctors) that identified repressive social structures as the main cause for disease in civilized society. If physicians truly wanted to help their patients, this group argued, they had to overthrow the elitist Dutch health care system. $9^{8}$

Yet, that the discourse of patients' rights would emerge victorious from this turbulent period is not as self-evident as it is sometimes taken to be. In the Netherlands, at least, the most vocal social criticism over the set-up of the Dutch health care system in these years was predominantly a socialist critique: a conviction that skewed socioeconomic structures and institutional hierarchies were to blame for the suffering of patients. Hence, grand plans to right these injustices were not geared so much toward the codification of rights for individual patients (a liberal ideal), but toward the realization of alternative social structures and an improvement of the economic position of historically disenfranchised societal groups. In Dutch parliament, in contrast, the initial response to the presumed crisis of medical ethics predominantly had been conservative. When Tilanus in 1970 called for a reconsideration of Dutch medical ethics, for instance, he emphasized that he wanted the artsenstand to get its house in order before the growing public unrest about the societal functioning of physicians would force the government to step in. For the Protestant politician, governing the ethical conduct of medical practitioners in the Netherlands mostly had to be left to the field itself-as it had been in the past. As he stated in support of his request:

The physician has to integrate in modern society and make himself familiar with the modern thinking of the people. When he fails to do so and when he keeps on resisting modern thinking men and the modern and open society, this society will try to encapsulate him because it cannot miss him. By isolating himself, he provokes socialization. I would regret that. I am an opponent of that.99

Of course, the perception that patients increasingly seemed dissatisfied with mainstream medical practice did play a central role in the emergence of the Dutch crisis of medical ethics during the 1960 s. Still, only few commentators on this crisis in the late 1960 s had proposed a patients' rights frame as the new foundation for medical practice in a modern society. Sporken, for instance, who probably stressed the inclusion of patients' perspectives most strongly out of all commentators in that period, did not write much about patients' rights. His approach was more discursive. The conception of 'what it means to be human' (het mensbegrip) in modern medical science, the theologian frequently stated, had come to differ too much from what it had always meant in social life. Therefore, to resolve the anxieties people experienced about the growing medical powers, these two viewpoints had to be integrated through an ongoing dialectic confrontation with one another. Medical ethics, Sporken maintained, in essence was cultural criticism. ${ }^{100}$ Similarly, Van den Hoofdakker had proclaimed his mantra

\footnotetext{
${ }^{98}$ Duco Hellema, Nederland en de jaren zeventig (Amsterdam: Boom, 2012).

${ }^{99}$ Handelingen Tweede Kamer 1969-1970, 3 February 1970, p. 1952.

${ }^{100}$ See: C.P. Sporken, 'Medische ethiek als cultuurkritiek. Naar aanleiding van revalidatie, levensverlenging en euthanasia', in Medisch Contact, Vol. 24 (1969), pp. 1431-1434. Also: 'Stervensbegeleiding: Medisch-ethische plicht? Door Dr. C.P. Sporken, ethicus, directeur van het Mgr. Bekkers Centrum, Katholieke Universiteit Nijmegen', in Medisch Contact Vol. 25 (1970), pp. 418-424. For a similar understanding of medical ethics, see: W. Metz, 'Wijsgerige heroriëntatie in de medische ethiek', in Algemeen Nederlands Tijdschrift voor Wijsbegeerte en Psychologie Vol. 61 (1969), pp. 1-18.
} 
of "talk, talk, talk" to encourage patients and doctors to express their insecurities and doubts and to explore the socio-cultural implications of medicine-not for patients to start using their newfound voices to claim rights. Only Van den Berg, really, outright stated in the late 1960 s that a new Dutch medical ethics should revolve around patients' rights to decide on their own lives. In Medische Ethiek en Medische Macht, the psychiatrist envisioned a future in which physicians had become instruments for patients who planned their own medical treatments after full disclosure of all available information, if needed with a medical dictionary at hand. ${ }^{101}$ Yet, Van den Berg's work was also the most controversial in the Netherlands in the early 1970 .

So why did the Health Council Committee Medical Ethics land on a patients' rights frame as the foundation for modern Dutch medical ethics? One key reason likely was the early participation of five jurists and a judge in the Committee (compared to only one theologian and sociologist). Already in the first meeting, chairman and jurist Jan de Vreeze had declared that "the relation between the rights and duties of the physician and rights of the patient will be an important point for this Committee". Not all members had immediately agreed. Theologian Beemer, for instance, had proposed to take a broader approach: medical ethics was an application of "the general ethics" of society, which the Committee had to study first to determine what could be considered morally right and wrong in medicine. Physician Gerard Dekker, a previous secretary-treasurer of the KNMG, remarked that the existing medical ethics did not deny patients' rights and that the KNMG these days even made it a point to develop moral guidelines with medical outsiders. So why would a new medical ethics have to revolve around the notion of patients' rights? Because, De Vreeze replied, medical ethics just could no longer be "medico-centric". "In practice", jurist C.J. Goudsmit added, "the ethical viewpoints of physicians sometimes deviate strongly from patients' wishes". ${ }^{102}$ New medical ethics had to take these wishes as their starting point.

The influence of the five jurists on the Committee Medical Ethics was substantial. They prepared discussion papers for committee meetings, participated actively, and often reminded the other members that the reports they were preparing would likely form the basis for government policy. Their findings therefore had to be translatable into administrative and legislative measures. The majority of the Committee accepted this legalistic approach to formulating new medical ethics. ${ }^{103}$ The first interim-report stated, for instance, that an intimate connection existed between the domains of medical ethics and law. The first was an application of general moral principles, while the second derived its precepts from basic human rights, but both could be traced back to generally accepted norms for human interaction. This was why ethical principles, the report read, were over time often encoded in laws and treaties. ${ }^{104}$ Medical ethics, in short, could also be debated with a predominantly juridical approach.

\footnotetext{
${ }^{101}$ Van den Berg, Medische Macht en Medische Ethiek, p. 48.

${ }^{102}$ For all: NL-HaNA, 2.15.36, 1374, Minutes Commissie Medische Ethiek, 20 April 1971, pp. 6-7

${ }^{103}$ Van Meurs retired in 1972 because felt the approach of the Committee failed to "solve any fundamental problems". See: NL-HaNA, 2.15.36, 1374, Minutes Commissie Medische Ethiek, 22 June 1972.

${ }^{104}$ Gezondheidsraad, Interim-advies inzake euthanasie, p. 8, p. 15.
} 
In 1973, after Sporken and Heering joined the Committee, this legalistic approach to medical ethics came to be questioned more frequently in committee meetings. Neither theologian was a big fan of principlism, the ethical theory that moral rights and wrongs can be deduced from general moral principles which remain stable over time (see chapter 6). Their approach to ethics was predominantly situational: moral rights and wrongs always had to be induced from a specific context and required conversation rather than legislation. Although this did not contradict a patients' rights frame (both theologians in fact agreed that patients should be an equal conversation partner to their physicians), neither Sporken nor Heering was convinced it should be understood as a foundation for medical ethics in and of itself. Yet, in Dutch policy circles in the early 1970s, the input of jurists in discussions over the public governance of medical practice weighted stronger than that of ethicists. In part, they were invited to participate more often and in larger numbers because their legal expertise was considered a sine qua non for formulating policy measures that might alter the legal system. Yet, in part, they were also invited to participate more often because they were better organised and politically connected than ethicists in this period. ${ }^{105}$

All jurists participating in the Committee Medical Ethics, for instance, were members of the Dutch Society for Health Law, which had been established in 1968 by the upcoming jurist Henk Leenen. Leenen, who had written his doctoral thesis on "fundamental social rights and health care", had come up with the idea after visiting the first international conference on medical law in Belgium in 1967. All Dutch jurists interested in the regulation of the field of health, he felt, should regularly meet to exchange ideas and build a network. ${ }^{106}$ Notably, only jurists were allowed to become a member of the Society. Health law, Leenen argued, had to be understood as a subcategory of law, not medicine-and health jurists had to use "the definitions and categories of the law", which required professional legal training. Hence, while the jurist considered it valuable that medical students took notice of the field, it had to be clear that the topic could only be studied academically in the faculty of law. Jurists were the experts and health law was their terrain, even if they would cooperate closely with "experts in the field of executive health care" (i.e. with caregivers). ${ }^{107}$

Health law, as envisioned by Leenen, encompassed a variety of terrains. It included environmental legislation (as the environment was potentially a threat for health), but also the development of the welfare state (to ensure that all citizens had access to health care). ${ }^{108}$ Predominantly, however, the academic field of health law in the Netherlands in the 1970 s and 1980 s revolved around the codification of patients' rights. In

\footnotetext{
${ }^{105}$ See: Loes Kater, Disciplines met Dadendrang. Gezondheidsrecht en gezondheidsethiek in het Nederlandse euthanasiedebat 1960-1994 (Amsterdam: Aksant, 2004).

${ }^{106}$ H.J.J. Leenen, Sociale grondrechten en gezondheidszorg (Proefschrift Utrecht, 1966); H.J.J. Leenen, 'Vereniging voor Gezondheidsrecht 25 jaar: geschiedenis van de start', in Tijdschrift voor Gezondheidsrecht Vol 16 (1992), pp. 128-134; H.J.J. Leenen, 'De geschiedenis van de Vereniging voor Gezondheidsrecht', in Tijdschrift voor Gezondheidsrecht Vol. 2 (1978), pp. 184-189. Leenen also founded the Dutch Journal for Health Law and wrote two handbooks on health law He is often regarded as the father of Dutch health law. For more on Leenen, see: J.K.M. Gevers \& J.H. Hubben (eds.), Grenzen aan de zorg, zorgen aan de grens. Liber amicorum voor Prof.dr. H.J.J. Leenen (Alphen aan den Rijn: Samsom H.D. Tjeenk Willink, 1990).

${ }^{107}$ H.J.J. Leenen, 'Gezondheidsrecht. Een poging tot plaatsbepaling', in Tijdschrift voor Sociale Geneeskunde Vol. 46 (1968), pp. 778-785, p. 784.

${ }^{108}$ Ibid. See also: Leenen, Sociale grondrechten en gezondheidszorg.
} 
1973, jurist Jaap Rang was appointed as the first Dutch professor in the field of health law-The title of his oration was 'Patient Law'. ${ }^{109}$ According to Rang, it was "undeniable that the patient is a key figure in both the ethics and morality of medical practice, but when it comes to the translation of this [precept] in terms of legislation, the patient appears to have been lost". ${ }^{110}$ It did not matter whether one checked the first (1929) or last (1972) Dutch handbook on 'the physician and the law'-in neither did the patient even make it as an index-entry. ${ }^{111}$ This had the unfortunate effect, Rang argued, that patients were virtually forced to surrender themselves upon entering the health care system..$^{12}$ Hence, the freshly appointed professor stated, it was high time that the Dutch government took action and started integrating the rights of patients into Dutch health laws. Not as an antithesis to the authority of physicians, but because such laws primarily had to serve "the persons for whom this care is meant". ${ }^{113}$ Solid health laws had to be synonymous with patients' rights. ${ }^{114}$

Both Leenen and Rang participated in the Health Council Committee Medical Ethics and took up a seat in multiple government advisory bodies in the 1970 s and $1980 \mathrm{os}$ concerned with the revision of the Dutch health care system. ${ }^{115}$ They were academics, but they were also practitioners: both actively wished to influence government policy on the terrain of health care. And in the advisory bodies to which they were invited as experts on the terrain of health law, both emphasized again and again that the most crucial change that had to be brought about in the Netherlands was the overthrow of the hierarchical conception of the doctor-patient relationship in the old Dutch medical ethics tradition through the proper codification of patients' rights.

To be sure, not only jurists and ethicists took part in the Health Council Committee Medical Ethics. The majority of seats was reserved for physicians, and the composition of the committee as a whole had to be approved by the KNMG. It would have been very well possible, in other words, for the organized Dutch medical community to steer the committee deliberations in a different direction from the patients' rights frame that De Vreeze had proposed already in the first committee meeting. Yet, the KNMG had a key strategic reason in the early 1970 s for supporting a patients' rights approach to medical ethics: it was scared that the increasing public unrest over medical ethics would otherwise translate in government policy that would curb the thera-

\footnotetext{
${ }^{109}$ J.F. Rang, Patiëntenrecht. (Leiden: Stafleu's Wetenschappelijke Uitgeversmaatschappij, 1973). It should be noted that Leenen had by then had already taken up a professorial chair at the University of Amsterdam, but his appointment officially was to study 'the social backgrounds of health and health care'. See: H.J.J. Leenen, Systeem-denken in de gezondheidszorg (Alphen aan de Rijn: Samson, 1971). ${ }^{110}$ Rang, Patiëntenrecht, p. 11.

${ }^{111}$ Ibid., p. 33. Rang lists: H.H. Eyck \& A.J. Verstegen, Arts en wet. Rechtskundige handleiding voor geneeskundigen (Haarlem: De Erven Bohn, 1929; $2^{\text {de }}$ druk); W. Schuurmans Stekhoven, Jurisprudentia Medica (Groningen: Wolters-Noordhoff, 1972).

${ }^{112}$ Rang, Patiëntenrecht, p. 21.

${ }^{113}$ Ibid., p. 33.

${ }^{114}$ See also: H. Nys, 'Van Leenen tot Legemaate. 40 jaar Nederlands gezondheidsrecht in een twintigtal oraties', in Oratiebundel Gezondheidsrecht. Verzamelde redes 1971-2011 (Den Haag: SDU Uitgevers, 2012).

${ }^{115}$ In 1982, Rang also became the first national Dutch ombudsman: a government official tasked to investigate complaints by citizens against a violation of their rights by the government.
} 
peutic freedom of Dutch physicians. This concern was not without reason. Traditionally, the Dutch government had taken a hands-off approach in its governance of the medical domain. Legislation had mostly served to delimit who was permitted to practice medicine (and who was not), while the actual content of medical practice-which actions were permitted (and which were not)-had largely been left to the field itself. Around 1970, however, the Dutch government started to shift gears on this terrain-a change that did not go unnoticed in the Dutch medical community.

A defining moment in this regard was the decision by State Secretary Kruisinga in 1970 to ask the Health Council if the government had to take steps to codify medicalethical principles into criminal law. The KNMG was anxious about this development. The Committee Medical Ethics, secretary-jurist Wim van der Mijn (and active member of the Dutch Society for Health Law) told the association's General Assembly in 1972, was a first sign the government no longer just sought to regulate the preconditions of medical practice in the Netherlands, but to meddle with its content as well. ${ }^{116}$ Although the KNMG had ensured that enough experts participated in the Committee "who enjoy the confidence of the Association", political developments in the early 1970 made the association fear that the Dutch government might just curb therapeutic freedom altogether. An ominous sign, for instance, was that soon after the installation of the Committee Medical Ethics in 1971, the new government announced that it would establish another "committee to advise on legal safeguards for medical interventions with important psychological, ethical, legal, and social aspects". This plan was proof, Van der Mijn said at the General Assembly of 1972, "that those in political circles are willing to go far under pressure of public opinion. ${ }^{117}$

To determine the official stance of the KNMG on these political developments, the General Assembly of 1972 was organized around the topic of 'the role of the legislature in medical practice'. The association's board itself seemed to accept that medical practice would increasingly be regulated by the Dutch government in years to come. Most physicians realized, the President stated during his introduction, that their societal position had changed in recent years. Although it had been common not so long ago for physicians to "advocate complete independence with regard to their societal functioning", many now accepted that they operated in institutions and networks that were governed by company mores, government regulations, and insurance policies. ${ }^{118}$ In addition, Van der Mijn pointed out in his contribution, the growth of medical powers scared people, making it understandable that "increasingly the desire is expressed for others to have a say and for the legislator to regulate" ${ }^{119}$ Anno 1972, in short, the old political ideal of the artsenstand as a separate class in Dutch society governed by its own mores and internal justice system was apparently no longer considered a realistic or even desirable option by leaders of the organized Dutch medical community. Doctors just no longer worked in solitude, the President stated at the General Assembly, a reality that the medical community had to face head on..$^{120}$

\footnotetext{
${ }^{116}$ W.B. van der Mijn, 'De wetgever en het medisch handelen', in Medisch Contact Vol. 27 (1972), pp. 1165-1171.

${ }^{117}$ Ibid., p. 1166 .

118 'De 160ste Algemene Vergadering der K.N.M.G.', in Medisch Contact Vol. 27 (1972), pp. 11611164 , p. 1162.

${ }^{119}$ Van der Mijn, 'De wetgever en het medisch handelen', p. 1166.

${ }^{120}$ De 160ste Algemene Vergadering der K.N.M.G.', p. 1162.
} 
Still, the association's leadership did continue to have strong reservations about what type of government regulations would come to govern Dutch medical practice in the future. "Modern thinking about individual and authority", Van der Mijn said to the General Assembly, "moves increasingly towards an appeal on everyone's personal responsibility". The patient was now understood to be able to make his own medical decisions, but surely this held for the physician as well: as long as he was a competent practitioner who was willing to account for his actions, no state should seek to regulate his behaviour. Instead, it should aim to cultivate the personal responsibility of both patient and physician. "Certainly when it concerns ethical problems that allow for plural insights", Van der Mijn added, "this appeal to the personal responsibility of the physician will be justified. The legislator then best stands aloof". ${ }^{121}$

That did not mean that it was not advisable for the government to take additional measures for the ways in which patients and physicians reached decisions. The codification of patients' rights, for instance, Van der Mijn pointed out, might not be such a bad thing. After all, despite all this talk of the mondigheid of patients, "most carry their suffering more through hope than knowledge. [...] They miss the expertise for a true dialogue". Hence, particularly in medical interventions in which much was at stake, the legal reassurance of their rights could make patients feel safe again in the hands of their caregivers. Vice versa, Van der Mijn continued, it could offer important support to physicians: "Not every doctor feels happy with the appeal on his expertise, his ethical opinions, his sense of responsibility". ${ }^{122}$ Thus, codifying which rights patients did-and did not-have could help physicians in their interactions with patients and provide clarity about their liability in case things went wrong. Finally, by clearly regulating procedures of medical decision-making in the Netherlands, Van der Mijn suggested, the government could more easily leave alone the actual content of these decisions and thus the therapeutic freedom of physicians. "If this would also be the opinion of the medical world", Van der Mijn promised the General Assembly in closing of his speech, "the legislator will certainly have attention for this". ${ }^{123}$

Not everyone in the Dutch 'medical world' shared this opinion. In 1972, in fact, a substantial group of physicians had actually separated itself from the KNMG because it felt that the medical association had been bargaining away the longstanding Dutch medical ethics tradition in recent years. One year earlier, in 1971, the KNMG had published new guidelines for induced abortions in unwanted pregnancies in the Netherlands. Instead of stipulating univocal ethical norms, the association had stated that the decision to cooperate with such procedures should be left to individual physicians in consultation with a second practitioner after a careful consideration of the relevant factors at play (and that they should always occur in general hospitals or thereto appointed clinics).124 The KNMG, in short, had published largely procedural guidelines for ethical decision-making in abortions. What was more, it had communicated these guidelines to the government stating that it was willing to cooperate with legislative measures in this direction. ${ }^{125}$ In reaction to this development, 2200 Dutch physicians

\footnotetext{
${ }^{121}$ Van der Mijn, 'De wetgever en het medisch handelen', p. 1171.

${ }^{122}$ Ibid., p. 1168.

${ }^{123}$ Ibid., p. 1171.

${ }^{124}$ Van het Hoofdbestuur, 'Officieel: Richtlijnen ten behoeve van de uitvoering van abortus provocatus', in Medisch Contact Vol. 26 (1971), pp. 1025-1027.

125 'Openbare hoorzitting abortus provocatus', in Medisch Contact Vol. 26 (1971), pp. 1031-1032.
} 
had signed a petition pleading the KNMG not to cooperate with the legalization of abortions in the Netherlands. And, in 1972, a group of them had started their own medical association, titled Nederlands Artsenverbond (Dutch Covenant of Doctors), which took 'respect for human life' as its unwavering point of departure. "We feel sold and betrayed as physicians", the dissenters wrote of the KNMG in its first publication in 1973, "by those of whom it may be expected that they, from the virtue of their position, would have been the last ones standing to defend our Hippocratic tradition". ${ }^{126}$ From its establishment onwards, therefore, the Covenant started publishing its own medical ethics journal in an urgent attempt to counteract the "ethical derailment" of the KNMG-and with that of the entire Dutch medical community. ${ }^{127}$

The Covenant was a fairly flourishing medical association in the 1970s and 1980s, with over a thousand members and a journal which appeared about four times a year. Still, by 1983 , the Protestant physician and prominent Covenant-member Gerrit Arie Lindeboom had to admit that the association was largely isolated from the rest of the medical world. ${ }^{128}$ It was treated as a quantité négligeable by the KNMG and shunned by the Dutch Journal of Medicine and Medisch Contact. In effect, it had hardly any influence on mainstream medical-ethical debates. The same held true for Dutch policy circles. The Covenant hoped to maintain a more hierarchical doctor-patient relation in the Netherlands governed by strict ethical norms. ${ }^{129}$ Most politicians and policy officials, however, took the KNMG as the sole representative of the Dutch medical community. And its main representative in these circles, the jurist Wim van der Mijn, stated again and again in this period that the Dutch medical community favoured a patients' rights frame in the regulation of the doctor-patient relationship-provided that the state left alone the therapeutic freedom of Dutch physicians.

In May 1973, another government took office in the Netherlands: the Den Uyl cabinet, a coalition of five political parties that is often remembered as the most left-wing government the Netherlands has ever had. An important policy goal of the Den Uyladministration was to replace "vertical relations of dependence and subordination" in publically financed institutions with "horizontal relations of consultation and participation" ${ }^{130}$ The underlying ideology of this governance ideal was the idea of the mondige burger (assertive citizen) who sought to make his voice heard in Dutch society but who lacked institutional outlets for doing so. By then, also the term mondige patient had become a commonplace in mainstream Dutch newspapers..$^{131}$

\footnotetext{
${ }^{126}$ A.E.M. van der Does de Willebois, 'Kroniek van de artsen actie eerbiediging menselijk leven', in Informatiebulletin van het Nederlands Artsenverbond No. 1 (November 1973), pp. 3-48, p. 4.

${ }^{127}$ K.F. Gunning, 'Eerbiediging menselijk leven. Voorwoord', in Informatiebulletin van het Nederlands Artsenverbond No. 1 (November 1973), p. 2.

${ }^{128}$ G.A. Lindeboom, 'Tegen de stroom in (Tien jaren Nederlands Artsenverbond)', Vita Humana Vol. 10 (1983), pp. 5-30, p. 20.

${ }^{129}$ See, for instance: J.A. van der Does de Willebois, 'Medische ethiek', in Vita Humana Vol. 10 (1983), pp. 3-4; A.E.M. van der Does de Willebois, Het Vaderloze Tijdperk. Een cultuurpsychologische verkenning van de geseculariseerde samenleving (Brugge: Tabor, 1984).

${ }^{130}$ Commissie van advies, Discussie-nota, September 1975, p. 8.

${ }^{131}$ For a few examples, see: 'Dokter kijkt uit naar mondige patiënt', in Limburgs Dagblad, Saturday 2 May 1970, p. 40; 'Heeft zieke recht op volwassen behandeling?', in Leeuwarder Courant, Friday 29
} 
Initially, the term patients' rights had not formed a big part of this discourse. Solutions were mostly sought not in the legal codification of individual rights but in the realization of alternative social structures: citizens had to be made mondig through a levelling of social classes and a public school system. ${ }^{132}$ In May 1975, however, during a debate on the reform of the national health care system, member of parliament Dick Dees-a representative of the conservative-liberal party VVD that did not take part in the Den Uyl-administration-complained that the government hardly had any attention for the realization of patients' rights in the Netherlands, even though "the call for a better description of the rights and duties of the patient, the call for better legal protection is getting louder" in the country.133 In support of this statement, Dees pointed to the recent development of health law as a "new scientific discipline" in the country, the establishment of multiple patient associations in the early 1970s, and the growing body of "excellent publications" on the topic, especially those of "Leiden professor of health law, Prof. Rang". ${ }^{134}$ Dees had decided to file a motion, therefore, requesting the government to conduct a study about the "recalibration of patient law". ${ }^{135}$ His request could count on overwhelming support. On 13 May 1975, the 'motion-Dees' was adopted unanimously by the Dutch House of Representatives. As a member of the Labour Party (then the biggest government party) put it: it was crucial for patients' rights to be codified in the Netherlands "in the shortest time possible". ${ }^{136}$

\section{The establishment of yet another Committee}

Despite such univocal calls for immediate action in Dutch parliament in May 1975, the Den Uyl-administration was in no hurry to implement the motion-Dees. It took the government over a year, for instance, to send a first update to Dutch parliament (after an inquiry by Dees what had happened to his motion) and by then it could only announce that the department of Public Health was making preparations for a committee that would study the subject of patients' rights. ${ }^{137}$ At the department of Public Health, in the meanwhile, responsible State Secretary Jo Hendriks could not make up his mind about what type of committee should take on this project. Initially, he had wanted to establish an independent State Committee that would report directly to the government, but after government officials had made all the necessary preparations for the installation of this committee, he decided he rather wanted the Central Council for Public Health to take the matter into consideration. ${ }^{138}$

January 1971, p. 2; 'Cruijf lichtend voorbeeld van mondige patiënt', in De Tijd, Friday 13 April 1972, front page; 'Patiënten betuttelen ... hoe lang duurt dat nog?', in Het Vrije Volk, Wednesday 7 February 1973, p. 4; 'Arts moet uitleggen wat hij voorschrijft', in Nieuwsblad van het Noorden, Tuesday 24 April 1974, p. 3. H.S. Terburgh, 'Groeiende mondigheid patiënt door overheid weer afgenomen?', in NRC Handelsblad, Saturday 4 October 1975, p. 4.

${ }^{132}$ See: J.B. Ahlers, Meer mensen mondig maken ('s-Gravenhage: Staatsuitgeverij, 1975).

${ }^{133}$ Handelingen Tweede Kamer 1974-1975, 6 May 1975, p. 4257.

${ }^{134}$ Ibid., p. 4257.

${ }^{135}$ Kamerstuk Tweede Kamer 1974-1975 kamerstuknummer 13012 onderstuknummer 11, Structuurnota Gezondheidszorg, Motie van het lid Dees c.s. (voorgesteld 7 mei 1975).

${ }_{136}$ Handelingen Tweede Kamer 1974-1975, 13 May 1975, p. 4241.

${ }_{137}$ Aanhangsel van de Handelingen Tweede Kamer 1975-1976, nr. 1316, p. 2615.

${ }^{138}$ See: NL-HaNA, DG Volksgezondheid, 2.15.65, 1373, Notitie aan de Heer Staatssecretaris, Bijlage bij nota nr. 104.274; See: NL-HaNA, DG Volksgezondheid, 2.15.65, 1373, NOTA 12 november 1976, A.S. nr. 104.587, Betreft: Procedure rond instelling Staatscommissie Patiëntenrecht. 
This did not fall well with the department. The officials preparing this dossier had advised the State Secretary against the involvement of the Central Council. If a State Committee would be installed, they felt, the government could participate in the election procedure and keep close tabs on the approach that would be taken to patients' rights. The Central Council, in contrast, was an independent advisory body that elected its own members, who all had "constituents to represent" (i.e. the health insurance boards, health inspectorates, KNMG, etcetera). ${ }^{139}$ What was more, any policy reports written by sub-committees of the Central Council would first have to pass through the Council's Committee of Delegates and the main Council itself, with ample opportunities for original conclusions to be watered down. Yet, despite these objections, Hendriks had become adamant by early November 1976 that the Central Council for Public Health should take on the study of patients' rights-a decision for which he did not give any justification to the disgruntled government officials (at least not in writing), who could start all over again with their preparations. As a result, the Central Council only received the request to study the realization of patients' rights in October 1977months after the left-wing Den Uyl administration had fallen. ${ }^{140}$

In execution of this request, the President of the Central Council for Public Health physician Henri Festen contacted Leenen and Van der Mijn (then still secretary-jurist to the KNMG) to see if they would lead a Committee Rights of the Patient as respectively its chairman and vice-chairman. ${ }^{141}$ The two health jurists accepted and together set out together to form a team which could tackle the study of patients' rights in the Netherlands. It was another procedure that provoked extensive internal debate and led to considerable delays. In his initial request for advice, State Secretary Hendriks had asked for a versatile committee to be established with "adequate representation from the side of the patient/client or, put differently, the consumer of health care". ${ }^{142}$ Yet in the first plans of Leenen and Van der Mijn, only two patient-representatives on a total of nine committee members had been suggested, with one of these two representing the Dutch Consumer Association. ${ }^{143}$ The other suggested committee members were mostly jurists or health professionals. The Central Council's Committee of Delegates-which had to approve these plans-was the first to express dissatisfaction over this distribution. One delegate felt that a member of the Diabetes Association really should be elected, another that someone from the National Council for Social Welfare should be asked to participate as well. Also, was it not a good idea to invite someone from "the circles of women associations" to ensure the female sex was represented? And perhaps someone from "the group of homophiles" should be included too, given the delicate subject-matter of the Leenen-committee. ${ }^{144}$

\footnotetext{
${ }^{139}$ NL-HaNA, DG Volksgezondheid, 2.15.65, 1375, Verslag van de vierde vergadering van de Werkgroep Patiëntenrecht en kwaliteitsbewaking op 20 oktober 1976, 14.00 uur; NL-HaNA, DG Volksgezondheid, 2.15.65, 1375, Werkgroep Patiëntenrecht en kwaliteitsbewaking, p. II.

${ }^{140}$ NL-HaNA, Centr. Raad Volksgezondheid, 2.27.16, 803, Adviesaanvrage inzake patiëntenrecht, 26 oktober 1977.

${ }^{141}$ NL-HaNA, Centr. Raad Volksgezondheid, 2.27.16, 803, 8006 6, Nota voor het C.v.G.

${ }^{142}$ NL-HaNA, Centr. Raad Volksgezondheid, 2.27.16, 803, Adviesaanvrage inzake patiëntenrecht.

${ }^{143}$ NL-HaNA, Centr. Raad Volksgezondheid, 2.27.16, 803, 8006 6, Nota voor het C.v.G, p. 7.

${ }^{144}$ Ibid., p. 14.
} 
Van der Mijn, who was also a delegate, protested. The upcoming study concerned the rights of patients, he argued, not "the rights of citizens in general". ${ }^{145}$ Still, he was willing to concede that patients were perhaps somewhat underrepresented in the current proposal and that a representative from the women associations and the National Council of Social Welfare could be invited (the Association for Housewives eventually made the final cut). However, when this amended proposal was discussed in the Central Council itself, additional protests could be heard. Complaints were voiced that no dentist or psychiatrist had been included and that still too few seats were reserved for patient-representatives. One Council-member representing the Society for Outpatient Mental Health Care even argued that a committee about patients' rights should consist solely of patient-representatives, as "in the circles of patient/clientorganisations a widespread belief exists that nothing will change if patients' rights are approached from the perspective of caregivers". ${ }^{146}$

Again, Van der Mijn - who was also a Council-member-protested. This type of arguments really exaggerated the situation, he maintained, and "in no way do justice to the serious aim [...] to give sufficient voice to all those who clearly represent the interests of the patient". In addition, "the slightest need" existed "for a report in which the rights of the patient are proclaimed for the umpteenth time, as [...] no one benefits from rights when they cannot be realized in practice". ${ }^{147}$ Most Council members agreed with the KNMG-jurist and gave Leenen and Van der Mijn permission to proceed with the installation of the Committee Rights of the Patient.

In the months thereafter, however, the Council kept on receiving letters of complaint about the composition of the committee. "According to our interpretation", the Association for Patients' Interests wrote in, only "three persons in the committee may act or speak on behalf of the patient [...] in contrast to eight persons who clearly represent the caregivers". ${ }^{148}$ Another letter was sent by the organized paramedical associations with the request that also they would be allowed to "contribute either directly or indirectly to the work of the Committee". ${ }^{149}$ Similar letters followed from organisations representing retirement homes, "parents around residential schools", and volunteer organisations for individuals with psychiatric problems. The chairman of the Association Equal Rights for all Ways of Healing sent in a letter, asking if their input was not desired. After all, the association represented a wide range of healing practices in the Netherlands and had as goal to further the interests of patients both in the alternative healing circuit and more in general. ${ }^{150}$ The trade association Nefarma, in the meanwhile, wrote in to state that it hoped also the pharmaceutical industry would be permitted to offer its insights on the subject of patients' rights. ${ }^{151}$

\footnotetext{
${ }^{145}$ Ibid., p. 14.

${ }^{146}$ NL-HaNA, Centr. Raad Volksgezondheid, 2.27.16, 22, 1002135 , Zakelijk verslag van de $135^{\mathrm{e}}$

Raadsvergadering op maandag 13 maart 1978, pp. 2-10, p. 7.

${ }^{147}$ Ibid., p. 8.

${ }^{148}$ NL-HaNA, Centr. Raad Volksgezondheid, 2.27.16, 803, brief van Drs. G.M.J. Van der HaakTielens, namens Vereniging Patiëntenbelangen aan de Voorzitter van de CRV, 16 oktober 1978.

${ }^{149}$ NL-HaNA, Centr. Raad Volksgezondheid, 2.27.16, 803, brief van T.J. Van Goelst Meijer, sekretaris Gezamenlijk Overleg Beroepsverenigingen in de Gezondheidszorg, 16 oktober 1978.

${ }^{150}$ NL-HaNA, Centr. Raad Volksgezondheid, 2.27.16, 803, brief van J. Brouwer, voorzitter vereniging gelijke rechten voor alle geneeswijzen aan de Voorzitter van de Gezondheidsraad, 13 oktober 1978.

${ }^{151}$ NL-HaNA, Centr. Raad Volksgezondheid, 2.27.16, 803, brief aan de Algemeen Secretaris van de CRV van Dr. Sanders, Nefarma, 17 juli 1978.
} 
In February 1979, when the Committee Rights of the Patient had just got underway, the committee members decided to invite two more patient-representatives, one from a national foundation for health education, the other from the Dutch Disability Council. ${ }^{152}$ By June that year, the Committee of Delegates concluded that also people with learning disabilities needed addition representation in the Committee. ${ }^{153}$ It was a trend indicative of the difficulties the Central Council experienced in honouring the ideal of the mondige patient. Reality was that all sorts of patients existed, many with their own needs and interests, so how did one decide who got to talk? And excluding a specific patient group from a committee on patients' rights was like withholding a suffragist her right to vote. The entire idea of the Committee, many argued, was that patients would finally be treated as mature individuals whose voice would be listened to in health care-so they should most certainly have their say in a committee that got to set an important standard for the ways in which the doctor-patient relationship would be regulated in the Netherlands in the years to come. Any policy measures that the Committee Rights of the Patient would propose, the ideal was, should have been reached through a process of participative decision-making in which the inclusion of patient-representatives would make sure that their perspective was heard and, just as important, that the scales of influence would not unfavourably tip in the direction of the interests of caregivers. After all, vertical relations of dependence and subordination had to make way for horizontal relations of consultation and participation on all governance levels in health care: from the doctor-patient relationship to the conference tables of the Central Council Committee Rights of the Patient.

Between 1980 and 1982, the Committee Rights of the Patient produced five policy reports on the realization of patients' rights in the Netherlands. Four of these reports primarily offered policy proposals for the future regulation of the doctor-patient relationship in the Netherlands. The first outlined the "juridical relation between patient and physician", including legal conditions for informed consent in medical practice. The second offered measures for protecting patients' privacy in health care. The third report detailed mediation processes for handling patients' complaints, and the fourth discussed a number of "core provisions for the regulation of the relationship between patient and doctor" in terms of a legally binding medical contract. ${ }^{154}$

\footnotetext{
${ }^{152}$ NL-HaNA, Centr. Raad Volksgezondheid, 2.27.16, 803, 8006 80, 19 februari 1979; NL-HaNA, Centr. Raad Volksgezondheid, 2.27.16, 803, brief van J.W. Engelkes aan de Stichting Nederlandse Gehandicaptenraad.

${ }^{153}$ NL-HaNA, Centr. Raad Volksgezondheid, 2.27.16, 52, 1004 228, Zakelijk verslag van de $209^{\mathrm{e}}$ C.v.G.-vergadering gehouden op maandag 11 juni 1979, pp. 11-12; NL-HaNA, Centr. Raad Volksgezondheid, 2.27.16, 23, Zakelijk verslag van de $147^{\text {ste }}$ Raadsvergadering gehouden op maandag 13 augustus 1979, p 13.

${ }^{154}$ Centrale Raad voor de Volksgezondheid, Deeladvies betreffende de juridische relatie tussen patiënt en arts, het recht van de patiënt op informatie en het toestemmingsvereiste ('s-Gravenhage: Staatsuitgeverij, 1980); Centrale Raad voor de Volksgezondheid, Deeladvies inzake de bescherming van de privacy van de patiënt ('s-Gravenhage: Staatsuitgeverij, 1981); Centrale Raad voor de Volksgezondheid, Deelsadvies inzake bemiddeling van klachten van patiënten (Rijswijk: Centrale Raad voor de Volksgezondheid, 1982); Centrale Raad voor de Volksgezondheid, Deeladvies inzake kernbepalingen voor der regeling van de relatie tussen patiënt en arts ('s-Gravenhage: Staatsuitgeverij, 1982).
} 
The Committee took pains not to sketch a dichotomy between patients and physicians in these reports. Already in his inaugural address to the Committee, Festen had emphasized that "the development of patients' rights is not about the creation of an antithesis between patient and caregiver". ${ }^{155}$ The Committee had to pay as much attention to the rights of physicians as to the rights of patients and, most importantly, flesh out how the two could be regulated symbiotically. "A unilateral approach from the legal status of the patient", also the Central Council warned, could very well result in "a disruption of the interplay [between patient and doctor], as is already the case in the United States" (apparently an undesirable prospect). ${ }^{156}$ In addition, the Committee did not just want to focus on rights but also on duties-of both physician and patient. The latter, for instance, was obliged to pay his bills. ${ }^{157}$ A number of committee members even felt that once patients had agreed to a treatment they also should be obliged to keep it up. ${ }^{158}$ Also, patients should not be permitted to mislead a caregiver, since this would inhibit their recovery and disadvantage not only their own wellbeing but also that of society in general (as it would suffer the financial costs). As Van der Mijn, a strong proponent of this view, put it during a committee meeting:

There can be no such thing as a free consultation. If one assumes the physician has the duty to advise the patient to the best of his abilities and according to the [current] state of science, it would be disproportionate when the patient would be completely free to ignore this advice. In my view, the patient is certainly obliged either to follow the advice or to say something of it. Perhaps legal consequences should be connected to this (say, in the terms or conditions for funding). ${ }^{159}$

Leenen counteracted this viewpoint of his vice-chairman. Although the jurist agreed that honesty and diligence were clear moral duties of patients, he did not think these could be put in a legal framework. And that was their mission, Leenen emphasized, to outline the future legal relation of doctors and patients in the Netherlands. ${ }^{160}$

It was a narrow frame the Committee Rights of the Patient had set for itself. In his 1977 request for advice, still, State Secretary Hendriks had made explicit that the government did not want the Central Council to focus just on the codification of patients' rights, but to reflect on the general mentality in Dutch health care about the position of patients and to investigate under what conditions the ideal of the mondige patient could be realized in the country. Such conditions, Hendriks had emphasized, "are not just juridical". ${ }^{161}$ However, in their preparations for the instalment of the Committee, Festen, Leenen and Van der Mijn had decided that priority had to be given to "topical sub-problems that currently present clear choke points in the daily practice of health

\footnotetext{
${ }^{155}$ NL-HaNA, Centr. Raad Volksgezondheid, 2.27.16, 803, Installatie Commissie Rechten van de Patient, p. 6. Underscore in original.

${ }^{156}$ NL-HaNA, Centr. Raad Volksgezondheid, 2.27.16, 22, 1002 135, p. 2.

${ }^{157}$ NL-HaNA, Centr. Raad Volksgezondheid, 2.27.16, 24, 1002 152, Zakelijk verslag van de $152^{\text {ste }}$ Raadsvergadering gehouden op maandag 12 mei 1980, p. 15.

${ }^{158}$ NL-HaNA, Centr. Raad Volksgezondheid, 2.27.16, 813, 8006 61, Zakelijk verslag van de $3^{\mathrm{e}}$ vergadering van de Commissie Rechten van de Patiënt gehouden op maandag 20 november 1978, p. 5.

${ }^{159}$ Ibid., p. 5.

${ }^{160}$ Ibid., p. 7.

${ }^{161}$ NL-HaNA, Centr. Raad Volksgezondheid, 2.27.16, 803, Adviesaanvrage inzake patiëntenrecht, 26 oktober 1977.
} 
care" ${ }^{162}$ Thus, the committee would in turn address the patient's right to information, his right to self-determination (to accept or refuse health care), the protection of his personal sphere (his privacy), and the handling of his complaints. ${ }^{163}$ At a later stage, much of this translated into the legal relation between the doctor and patient and the possible regulation of this relation in terms of a medical contract.

This narrow frame also meant that the Committee Rights of the Patient, despite all the various patient-groups participating in the deliberations, often functioned rather like an expert committee. After all, with such strict delimitations, it was unavoidable that juridical expertise was of formative importance to the work done by the Committee. It also meant the Committee almost religiously avoided using the word ethics. As Van der Mijn explained in 1980 during a meeting of the Committee of Delegates in response to a delegate's question whether a paragraph on the duties of a general practitioner should not at least mention some ethical aspects:

Indeed, it used to be that a good physician was identified as he who acts in accordance with the latest scientific and ethical insights. But since pluralistic views with regards to ethics have developed which can exist next to one another, such a moral assessment has become much more difficult. These days, a reference to ethics is omitted. ${ }^{164}$

For the secretary-jurist of the KNMG, the idea that a unitary professional ethos regulated the behaviour of every Dutch physician had become an antiquarian notion anno 1980. Instead, both patient and physician had to look to the legislature for the codification of their principal rights and duties-a legislature that in the future was likely to draw up separate frameworks for ethically sensitive (medical) practices like abortion or euthanasia, but that was to stay clear of legal moralism as it was no master of morality. In the realm of law, it was better to avoid the pitfall of ethics.

In line with this approach, the word ethics was not mentioned a single time in the four policy reports mentioned above. Only in the fifth report of the Committee Rights of the Patient did the e-word pop up again: a policy document proposing government measures for the public oversight of medical experiments with humans in the Netherlands. It was an odd report for the Committee; the only one out of five that dealt with one specific medical (research) practice and that outlined clear norms for its permissibility. It was also a document which, as will become clear, the Central Council had initially not wanted to write, but that nevertheless would go on to become the cornerstone policy report in the 1980 s and 1990 s for the realization of a legal framework for human experimentation in the Netherlands. Chapter 4 explains why the Committee Rights of the Patient had to write this report-and explores why it decided in the early 1980 s to dust off the traditional lingo of ethics to still be of use in the governance of medical science in a modern society full of mature citizens.

\footnotetext{
${ }^{162}$ NL-HaNA, Centr. Raad Volksgezondheid, 2.27.16, 803, 8006 6, Nota voor het C.v.G., p. 4.

${ }^{163}$ Ibid., p. 7.

${ }^{164}$ NL-HaNA, Centr. Raad Volksgezondheid, 2.27.16, 54, 1004 239, Zakelijk verslag van de $239^{\mathrm{e}}$

C.v.G.-vergadering gehouden op donderdag 1 mei 1980, p. 9.
} 



\section{- Chapter 4 • experimenting with human beings}

"Societal developments", the biologist and philosopher Matthijs Visser concluded in an October 1979 issue of Medisch Contact, "have made a consumer, also one of health packages, more mondig and critical. [...] The modern patient wants to know what is done with him or her". ${ }^{1}$ What else is new, the weary reader at the close of the 1970 s might have thought. By then, the notion of the mature patient made an appearance in journals like Medisch Contact almost every other week, with authors (doctors, jurists, philosophers, and others with a claim to a specific type of expertise) stating again and again that the modern patient now increasingly sought to make his voice heard and no longer just accepted the authority of caregivers. Anno 1979, Dutch experts stood in line to profess they now knew the expert's place in health care.

But Visser did have something new to say. Despite all the talk of patients' rights in the Netherlands, he wrote, one key element of this discourse was still wholly neglected: the rights of human research subjects. Hardly any form of public oversight existed for human experimentation in the country, for instance, even though "trust in experts has been shaken quite a bit” recently. True, some policy measures had been proposed in the past years to strengthen the "internal surveillance" of human research studies, including the realization of expert review bodies in Dutch research centres. Yet Visser did not think these were appropriate for the governance of a scientific practice in an open, egalitarian society. "Expert-thinking", he argued, "stands in the way of a satisfactory ethics review of biomedical experiments on humans, as scientific interest usually prevails above ethical interest". To keep the biomedical research establishment in check, therefore, committees consisting mostly of lay members had to be installed in the Netherlands to decide on the permissibility of human experiments. As "only democratic decision-making is acceptable", Visser argued, such committees had to operate as jury trials, allowing ordinary citizens to participate in the governance of science. In the eyes of the biologist-philosopher (and later self-proclaimed bioethicist), the realization of patients' rights would not be complete in the Netherlands if the practice of human experimentation was not brought under external control. ${ }^{2}$

This chapter examines the policy report written by the Central Council Committee Rights of the Patient in the early 1980 s on the governance of 'medical tests upon human beings' in the Netherlands. In 1982, it recommended the Dutch government to demand that experiments with humans could only take place in the country if a thereto installed review committee had first given its permission for doing so. These bodies had to include at least two "society-representatives" to ensure "seclusion and mystery make way for openness and transparency" in a democratic society.

\footnotetext{
${ }^{1}$ M.B.H. Visser, 'Ethische aspecten van medische experimenten op de mens (I) \& (II)', in Medisch Contact Vol. 34 (1979), pp. 1351-1358 \& pp. 1386-1390, p. 1352.

${ }^{2}$ All quotes in this paragraph:, p. 1351, p. 1352, p. 1390.
} 
In the 1980 s and 1990s, this report by the Central Council of Public Health came to function as the cornerstone document for the governance of human experimentation in the Netherlands. In virtually all Dutch policy deliberations on the subject, the report was referred back to as the blueprint for an appropriate governance system for human research studies and, from its publication onwards, the Central Council report was preferred by Dutch politicians over all the Health Council reports that had previously been published on the subject (see chapters 1 and 2). By the end of the century, in fact, it often seemed as if none of the Health Council reports had ever been written at all. In Dutch policy circles, the Central Council report had come to function as the single most authoritative policy document on human experimentation.

But why did the Central Council Committee Rights of the Patient, a working group installed to modernize the doctor-patient relationship in the Netherlands, develop a policy report on the public governance of human experimentation in the early 1980s? And why did someone like the Leiden pharmacologist Erik Noach, who simultaneously participated in the Health Council committee 'clinical pharmacology' (see chapter 2), take up a seat in the Committee Rights of the Patient? Who else participated and why did they recommend that human experiments should be reviewed by committees in which at least two "society-representatives" held a seat? Finally, what type of oversight function did the Central Council imagine for these committees in the governance of human experimentation and how did this conception relate to the policy reports which had previously been published by the Health Council?

To answer these questions, Section I of this chapter first outlines how, in comparison to countries such as the United States and Great Britain, unrest over unethical human experimentation only played a minor role in "the backlash against professional society" in the Netherlands in the 1960 s and early 1970s. Section II subsequently explains how in the late 1970s this unrest suddenly did emerge, resulting in an urgent request of the Dutch government to the Central Council for Public Health to include the topic of human experimentation in the Committee Rights of the Patient. Sections III and IV, finally, study the 1982 Central Council report on the governance of human experimentation and make clear that, contrary to the older Health Council reports, this new report envisioned research ethics committees to function as tools of external control that gave laypeople an opportunity to participate in the governance of medical research. Yet, they also show that, like the older Health Council reports, the Central Council report intended to protect and promote the conduct of human research in the Netherlands. Only this time the project of therapeutic reform went hand in hand with a narrative of egalitarian decision-making in a democratic society.

\section{A discernible absence of Dutch concern}

Historians who have investigated the emergence of the patients' rights movement in other countries in the 1960 s and 1970 - most notably the United States and Great Britain-have often maintained that a series of exposés of unethical human research studies in medicine inaugurated the quickly spreading public distrust in the autonomy of the medical profession in this period. Rothman, for instance, claims in his 1991 Strangers at the Bedside-in which he famously investigates the transformation of the American doctor-patient relationship from the mid-Sixties to the mid-Seventies- 
that "the story opens in the laboratory, not the examining room": i.e. the revelation of a number of human research scandals in the mid-196os first "revealed a stark conflict between clinical investigators and human subjects, between researchers' ambitions and patients' well-being", a perception that almost singlehandedly "undercut an older confidence in the exercise of medical discretion". ${ }^{3}$

The defining moment that caused this pendulum to swing, according to Rothman, was a publication by Harvard anaesthesiologist Henry Beecher in the June 1966 issue of the renowned New England Journal of Medicine. In this article, titled 'Ethics and Clinical Research', Beecher discussed 22 clinical research studies that had been published in recent years in prominent medical journals, which he believed to be ethically questionable. ${ }^{4}$ His list included studies in which known effective treatments had been withheld in favour of placebos; invasive physiological studies with little to no benefit for the participating subjects; studies in which patients deliberately had been infected with disease; studies in which no informed consent had been obtained. This "roll of dishonour" included the now infamous Willowbrook State School study that had been running since the late 1950 s in which clinical researchers infected disabled children with hepatitis to study the period of infectivity of infectious hepatitis. 5 It also included a study conducted at the Jewish Chronic Disease Hospital in 1962, in which elderly patients had been injected with cancer cells without their knowledge. ${ }^{6}$ The study Beecher himself found most shocking was a clinical trial in which penicillin deliberately had been withheld from 109 soldiers with streptococcal infections and which caused two soldiers to develop acute rheumatic fever and one acute nephritis. ${ }^{7}$

Beecher was not the first to raise the alarm about unethical clinical research studies in the United States in the mid-1960s, but, according to Rothman, the significance of his publication was twofold for the emerging patients' rights discourse in this period. First, it argued that unethical research studies were no exception to modern medical science. Beecher pressed his 22 anonymized cases had all recently been published in "excellent journals" and were just a selection from a much larger pool of questionable studies. ${ }^{8}$ Second, it made clear that mainstream medical researchers did not shy away in the post-war era from using human beings as research subjects "who were in one sense or another devalued and marginal [...] retarded, institutionalized, senile, alcoholic, or poor, or [...] military recruits, cannon fodder in a war against disease". ${ }^{9}$ This, despite knowledge of the atrocities that had taken place in World War II in the name of medical science. "The thought that some would have agreed that deliberate infection was all right since the subjects were mental defectives", Beecher said at one point of the Willowbrook State School study, "gives me the Nazi shudders".10

\footnotetext{
${ }^{3}$ Rothman, Strangers at the Bedside, p. 10.

${ }^{4}$ Beecher, 'Ethics and Clinical Research', pp. 1354-1360.

${ }^{5}$ Walter M. Robinson \& Brandon T. Unruh, 'The Hepatitis Experiments at the Willowbrook State School', in The Oxford Textbook of Clinical Research Ethics, pp. 80-85.

${ }^{6}$ John D. Arras, 'The Jewish Chronic Disease Hospital Case', in Ibid., pp. 73-79.

${ }^{7}$ D.S. Jones, C. Grady \& S.E. Lederer, "Ethics and Clinical Research"-The $50^{\text {th }}$ Anniversary of Beecher's Bombshell', in The New England Journal of Medicine Vol. 374 (2016), pp. 2393-2398, p. 2395.

${ }^{8}$ Beecher, 'Ethics and Clinical Research'.

${ }^{9}$ Rothman, Strangers at the Bedside, p. 80.

${ }^{10}$ Jones, Grady \& Lederer, "'Ethics and Clinical Research”, p. 2396. Original source: Henry K. Beecher papers, 1948-1976. Boston: Harvard Medical Library, Francis A. Countway Library of Medicine.
} 
The admission that mainstream American medical researchers regularly conducted experiments on disenfranchised social groups, Rothman states, ensured anno 1966 that Beecher's article "quickly became linked to the rights movements that were gaining strength in the 1960s" ${ }^{11}$ Studies like the ones that took place in Willowbrook and the Jewish Chronic Disease Hospital were seen as evidence that weaker members of society were easily abused by (medical) elites that violated their rights and used them as guinea pigs for their own advancement. In 1972, this perception was further corroborated in the mainstream media by the uncovering of the Tuskegee syphilis study: a study by the U.S. Public Health Service in which the progression of untreated syphilis in impoverished African-American men from Tuskegee (Alabama) had been monitored since 1932, even though penicillin had been available as an effective cure for the disease since the 1940 s and other cures had commonly been used before then. For a period of 40 years, these men had been offered free 'medical care', hot meals and-so as to conduct an autopsy-free burials in return for their participation. Yet, they were never told they suffered from syphilis and that actual cures existed for their illness. As a result, many of the men died, 40 of their wives contracted the disease, and nineteen of their children were born with congenital syphilis. ${ }^{12}$

These and other exposés of unethical human experimentation in the 1960 s and early 1970s, Rothman writes, fostered a great distrust of the discretionary authority of the American medical profession and brought a rights discourse to medicine: i.e. the notion of informed consent first gained prominence in the context of the subjectresearcher relationship in the United States, not the doctor-patient relationship. ${ }^{13}$ In addition, Rothman maintains, research scandals contributed to the realization of new "mechanisms for collective decision-making" in medicine.14 In 1966, the U.S. Surgeon General drew support from Beecher's article for a memo he had sent out to American hospitals and universities a few months earlier, announcing that applications to the U.S. Public Health Service for financial support for clinical research studies from then on had to "provide prior review of the judgement of the principal investigator or program director by a committee of his institutional associates" (i.e. Institutional Review Boards). ${ }^{15}$ In 1974, after the Tuskegee study, this prerequisite was codified into law by the passing of the National Research Act. ${ }^{16}$ This new mechanism of ethics by committee, Rothman argues, would later spread to the governance of regular medical practice as well in the United States. Hence, human research scandals played a key role in the rise of the American patients' rights movement in the 1960s and 1970s, including the call for more public procedures of medical decision-making.

\footnotetext{
${ }^{11}$ Ibid., p. 10.

${ }^{12}$ Jones, Bad Blood. The Tuskegee Syphilis Experiment (New York: Free Press, 1981); Susan M. Reverby, Examining Tuskegee. The Infamous Syphilis Study and its Legacy (Chapel Hill: The University of North Carolina Press, 2009).

${ }^{13}$ Ibid., p. 100. See also: Ruth R. Faden \& Tom L. Beauchamp, A History and Theory of Informed Consent (Oxford: Oxford University Press, 1986).

${ }^{14}$ Rothman, Strangers at the Bedside, p. 10.

${ }^{15}$ Stark, Behind Closed Doors, p. 154. Original source: Memo to the Heads of Institutions Conducting Research with Public Health Service Grants from the Surgeon General, February 8, 1966, folder 2, Ethical, Moral and Legal Aspects, CC, ONIHH, NIH.

${ }^{16}$ Tom. L. Beauchamp, 'The Belmont Report', in The Oxford Textbook of Clinical Research Ethics, pp. 149-155; Joan P. Porter \& Greg Koski, 'Regulations for the Protection of Humans in Research in the United States', in Ibid., pp. 156-167.
} 
A similar case has often been made for the emergence of a patients' rights movement in Great Britain in the 1960s. Since the late 1950s, British medical tutor Maurice Pappworth had started writing concerned letters to medical journals he found to publish reports of questionable human experiments without much hint of any ethical reservations. When journal editors refused to publish Pappworth's letters, however, the medical tutor in 1962 decided to write a piece for a popular British magazine, listing dubious experiments on patients with a call for a "battle to defend the rights of all patients against the whims and ambitions of some doctors" ${ }^{17}$ In early 1963 , historian Duncan Wilson writes, this call led to the establishment of the British Patients Association, a high-profile social movement that in the 1960 s "regularly challenged medical paternalism in letters to newspapers and professional journals" ${ }^{18}$ Pappworth, in the meanwhile, kept on collecting medical research articles mentioning dubious experiments on humans (mostly conducted in Great Britain and the United States) and, in 1967, published over 200 of them in a book titled Human Guinea Pigs. ${ }^{19}$ Again, the physician berated the organized medical profession for its unwillingness or inability to prevent this type of studies from taking place and called for the active involvement of "medical outsiders" to halt these activities. British Parliament had to demand every regional hospital board to install a "consultation committee", seating at least one lay member, to review (clinical) research protocols. "The medical profession", Pappworth wrote, "must no longer be allowed to ignore the problems or assert, as they often do, that this is a matter to be solved by doctors themselves". ${ }^{20}$

Pappworth's call to arms, Wilson emphasizes, did not actually lead to more outsider involvement in or formal regulation of medicine in Great Britain in the late 1960s. When British parliament debated Pappworth's claims in May 1967, for instance, the responsible statespersons rejected any form of government involvement with human experimentation. Similarly, a year later, when the Patients Association demanded a public inquiry into the matter, the Ministry of Health rejected this proposal by stating that ethical questions were "for the profession to consider". ${ }^{21}$ As a result, Wilson argues, the governance of clinical research in Great Britain mostly remained a form of "club regulation" (internal control) for quite some years to come.22 Still, Pappworth's work marked one of the "earliest and strongest critiques of medicine" in Great Britain in the 1960 s and, as such, concerns over human research practices contributed significantly to a larger "backlash against professional society" and a concomitant rise of the patients' rights movement in Great Britain in this period. ${ }^{23}$

\footnotetext{
${ }^{17}$ Wilson, The making of British bioethics, p. 45. Original source: Maurice H. Pappworth, 'Human Guinea Pigs. A Warning', in Twentieth Century Vol. 171 (1962-1963), pp. 66-75, p. 75.

${ }^{18}$ Wilson, The making of British bioethics, p. 45. See also: Hazelgrove, 'The Old Faith and the new Science'; A. Mold, 'Patient Groups and the Construction of the Patient-Consumer in Britain. An Historical Overview', in Journal of Social Policy Vol. 39 (2010), pp. 505-521.

${ }^{19}$ Maurice H. Pappworth, Human Guinea Pigs. Experiments on Man (London: Routledge, 1967).

${ }^{20}$ Ibid., p. ix.

${ }^{21}$ Wilson, The making of British bioethics, p. 48.

${ }^{22}$ In making this claim, Wilson joins scholars like Laura Stark and Adam Hedgecoe to argue that the origins of neither IRBs in the United States nor RECs in Great Britain can be explained simply by pointing to the outbreak of research scandals. See the introductory chapter of this PhD-thesis.

${ }^{23}$ Wilson, The making of British bioethics, p. 44, p. 43.
} 
How was this in the Netherlands? Contrary to the United States and Great Britain, only little public unrest over human experimentation could be detected in the country in the 1960 s and early 1970 s. In the 1950s, still, antivivisectionists had at times made headlines with claims of unethical experiments on vulnerable patients that would be conducted in Dutch hospitals and clinics. In 1953, this even led to the instalment of a Health Council committee to investigate the governance of 'tests upon human beings' (see chapter 1). In the 1960s, however, such claims of experimental misconduct grew smaller rather than larger in the Netherlands. Sporadically, Dutch media did report incidents, but at no time did these result in prolonged public unrest.

In 1966, for instance, newspapers reported that pharmaceutical company PhilipsDuphar had tested anti-flu tablets on residents of an 'insane clinic' in Eindhoven: 250 out of 750 patients (as well as a few staff members) had been given these tablets instead of their yearly anti-flu vaccination to compare for their immunity. ${ }^{24}$ This caused a stir. In the liberal newspaper Algemeen Dagblad, Senator Arie Querido (co-author to the Declaration of the Rights of the Patient of 1953, see chapter 3) strongly condemned the tests: whether or not the pills turned out to be harmless, a principal line had been crossed by conducting experiments on "the mentally disturbed". "Even if it is just sugar water", Querido was quoted to say, "the other end is the gas chamber". ${ }^{25}$ In parliament, the Senator requested the government to forbid all human experimentation in state-supervised facilities in the Netherlands. Despite this uproar, however, the matter was easily settled by an admission of the responsible State Secretary that such practices indeed should not take place in the Netherlands, a reminder he promised to convey to the Superintendent for Mental Health and the KNMG. ${ }^{26}$ Afterwards, Dutch newspapers did not keep the scandal alive for much longer. It was one of the few Dutch human research 'scandals' recorded in the 1960s.

Also foreign research scandals occasionally made Dutch news in this period. Pappworth's Human Guinea Pigs, for instance, received widespread news coverage in the Netherlands in 1967.27 Similarly, when the British physician claimed during a radio interview in 1971 that uninformed and terminally ill patients were commonly used as test animals "not only in America but also in England", he could once again count on a significant amount of Dutch media attention. ${ }^{28}$ In 1972, also the Tuskegee syphilis

\footnotetext{
${ }^{24}$ See: 'Anti-griepmiddel op krankzinnigen beproefd', in De Waarheid, Saturday 17 September 1966, front page; 'Directeur psychiatrische instelling: 'Patiënten geen proefkonijn', in De Waarheid, Tuesday 20 September 1966, p. 2; 'Proeven op verpleegden. Prof. Querido: van toestemming kan geen sprake zijn', in Leeuwarder Courant, Saturday 17 September 1966, p. 7.

${ }_{25}$ 'Nieuw anti-griep preparaat toegepast in psychiatrische inrichting', in Algemeen Dagblad, Monday 19 September 1966, p. 4.

${ }^{26}$ Aanhangsel Eerste Kamer 1966-1967, nr. 19, p. 39.

27 'Boek van specialist veroorzaakt storm. Engelse zieken werden als proefkonijnen gebruikt', in Nieuwsblad van het Noorden, Thursday 18 May 1967, front page; 'Ernstige beschuldigingen Britse arts. Experimenten op onwetende patiënten. Binnenkort vragen in Lagerhuis', in De Waarheid, Thursday 18 May 1967, p. 2; Dr. Maurice Pappworth: In Engeland en VS experimenten op patiënten', in Leeuwarder Courant, Thursday 18 May 1967, front page; 'Opwinding in Engeland. Proeven op mensen in ziekenhuizen. Onderzoek regering gevraagd', in De Tijd, Friday 19 May 1967, p. 9.

28 'Bekende Londense arts onthult: Britse zieken zijn vaak 'proefkonijn', in De Telegraaf, Tuesday 12 October 1971, p. 9; 'Arts beschuldigt: Britse 'fonds'-patiënten als proefkonijnen', in Het Vrije Volk, Monday 11 October 1971, front page; 'Schandaal in Engeland en VS. Fondspatiënten als proefkonijnen. Experimenten met kernstraling', in De Tijd, Monday 11 October 1971, p. 5; 'Britten bang voor rol van proefkonijn', in Limburgsch dagblad, Tuesday 12 October 1971, p. 3; 'Brit blind na experiment in ziekenhuis', in De Telegraaf, Wednesday 13 October 1971, p. 9.
} 
study made headlines (although this was nothing compared to the storm of indignation which the study provoked in the United States). ${ }^{29}$ However, when news of these scandals broke in the Netherlands, they were discussed as foreign problems by Dutch media and did not translate-at least in writing-into any heightened awareness that unethical human experimentation in medicine might present a significant problem for the position of patients 'at home' as well. Similarly, none of these foreign scandals resulted in parliamentary questions or debate in the Netherlands.

Likewise, in the emergence of a crisis of medical ethics in Dutch medical circles in the 1960 s (see chapter 3), concerns over unethical human experimentation in medicine only played a minor role. In the late 1950 s and early 1960s, still, prominent physicians like internist Cornelis Douwe de Langen (see chapter 1), internist Gerrit Arie Lindeboom (see chapter 3), and surgeon Ite Boerema had warned that the number of questionable clinical research studies recorded in international medical journals was increasing rapidly, a development that gave rise to grave concern. $3^{30}$ Boerema, in fact, claimed already in 1961 that these articles were a sign that medical professions were no longer capable of regulating the conduct of 'their' physicians. ${ }^{31}$ Yet, these Dutch commentators had pointed largely to the United States in their concerns over human experimentation: American physicians no longer knew right from wrong, American patients were in danger, American medical ethics was failing. When in the late $1960 \mathrm{~s}$ a similar sense of crisis emerged about Dutch medical ethics, different concerns took centre stage: new technologies raised questions about life and death, while changing social bonds demanded a new approach to the doctor-patient relationship. In medical journals and mainstream media alike, interventions like abortion, artificial insemination, and euthanasia dominated-not human experimentation. ${ }^{2}$

In the early 1970s, Dutch proponents of a patients' rights approach to the governance of medicine did occasionally start to focus their attention on human experimentation. In 1970, for instance, health jurist Jaap Rang (see chapter 3) wrote a lengthy treatise on human experimentation and the Dutch criminal law system for the booklet Recent medisch ethisch denken II in which he discussed a number of questionable medical experiments involving human beings that had taken place recently in France,

\footnotetext{
29 'Onthulling na experiment van 40 jaar. Amerikaanse negers waren proefkonijnen voor syfilisonderzoek', in Leeuwarder Courant, Wednesday 26 July 1972, p. 6; 'Rumoer om experiment met negers', in Nederlands Dagblad, Thursday 27 July 1972, p. 3; 'Syfilislijders als proefkonijn. Medisch schandaal in VS', in De Tijd, Wednesday 26 July 1972, front page; 'Proefkonijnen...', in Limburgsch Dagblad, Thursday 27 july 1972, p. 3. Beecher's accusations seem to have been hardly mentioned in Dutch newspapers at all. The only article this author could find was: 'Patiënten gebruikt als proefkonijnen', in Limburgsch Dagblad, Friday 17 June 1966, p. 3.

${ }^{30}$ De Langen, 'Proeven op mensen en de verschuiving van te stellen normen'; G.A. Lindeboom, Geneeskundige Proeven op mensen. Referaat voor de negendertigste wetenschappelijke samenkomst op 3 juli 1957 (Assen: G.F. Hummelen's Boekhandel en Eletrische Drukkerij N.V., 1957); Boerema, 'De Keerzijde van de Vooruitgang in de Geneeskunde'.

31 'Felle conclusie van Prof. Boerema. Moderne maatschappij wordt 'gekkenhuis'. Ernstig verval medische stand', in De Telegraaf, Saturday 8 April 1961, p. 9; 'Prof.dr. I. Boerema. Menselijke geest groeide niet mee met materiële vooruitgang. Medische ethiek ernstig bedreigd', in Nieuwsblad van het Noorden, Saturday 8 April 1961, p. 6;'Prof. Boerema op natuur- en geneeskundig kongres: Materieelmedische vooruitgang niet met een morele teruggang betalen', in Leeuwarder Courant, Friday 7 April 1961, p. 13.

${ }^{32}$ Likewise, when the government asked the Health Council to reconsider the societal position of the physician in 1970, tests upon human beings was a topic the Committee did not want to spend more than one meeting on (see chapter 3).
} 
Italy and the United States (Rang mentioned Beecher and the Jewish Chronic Disease Hospital study), and emphasized that a research subject's informed consent was also in the Netherlands a sine qua non for the legal permissibility of human research studies (even if this condition was not codified by Dutch law). ${ }^{33}$ A few years later, in June 1975, health jurist Henk Leenen (see chapter 3) wrote two articles for Medisch Contact, in which also he brought up Beecher and the Jewish Chronic Disease Hospital study and emphasized the absolute precondition of a subject's informed consent. ${ }^{34}$ In addition, Leenen recommended the installation of review committees in Dutch hospitals and research centres to decide on the permissibility of medical experiments with humans that reported to a national council in which "at least the professional organizations, hospitals, medical faculties, independent scientific practitioners, and jurists" took up a seat. 35 In the United States, Leenen wrote in defence of this suggestion, a similar oversight system already existed for human experimentation.

In Dutch parliament, Leenen's articles inspired a number of parliament members to ask the government why exactly no regulatory system for human experimentation still existed in the Netherlands. ${ }^{36}$ The responsible State Secretary of Public Health Jo Hendriks replied soothingly. The current disciplinary laws offered medical examiners boards the option to take repressive action if needed, the State Inspectorate for Public Health could keep an eye on things, and pharmaceutical products that were used for experimental use first had to be registered with the country's Medicines Evaluation Board. What was more, "the possibility of being held liable in civil courts for any possible damages in the treatment of patients (resulting from experimentation) will surely prevent irresponsible experiments". ${ }^{37}$ There was no need to worry, in other words. Nonetheless, since the House of Representatives had recently adopted a motion that requested the government to recalibrate Dutch patient law (see chapter 3), Hendriks promised to ensure that the Council that would execute this study would also take the position of patients in experimental treatments into account. $3^{8}$

Indeed, when Hendriks finally contacted the Central Council for Public Health in 1977 to take up the study of patients' rights in the Netherlands, the request for advice contained a sentence stating that also "the position of the patient in medical research and in teaching situations (demonstrations) may deserve consideration", a statement which in itself makes clear that, toward the late 1970s, the governance of human experimentation was still not considered a matter of immediate concern in Dutch political circles. ${ }^{39}$ In any case, it did not make the list of topical choke points drafted by

\footnotetext{
${ }^{33}$ Jacob F. Rang, 'Medisch experiment op de mens en strafrecht', in Recent medisch ethisch denken II, pp. 33-87. See also: C.P. Sporken, 'Ethische reflexies. Experimenten met de mens', in Katholieke Gezondheidszorg Vol. 37 (1968), pp. 190-194.

${ }^{34}$ H.J.J. Leenen, 'Juridische aspecten van medische experimenten op de mens (I) \& (II)', in Medisch Contact Vol. 30 (1975), pp. 746-750 \& pp. 753-767.

${ }^{35}$ Ibid., p. 767.

${ }^{36}$ Aanhangsel van de Handelingen Tweede Kamer 1974-1975, nr. 1690, p. 1307.

${ }^{37}$ Ibid., p. 1307.

${ }^{38}$ None of the politicians present in this exchange seemed to remember that parliament member Henk Vonhoff had already asked the government in 1968 how it sought to guarantee the rights of patients participating in clinical research, which had led the government to request a Health Council report on the regulation of clinical drug research - a report that had still not been published (see chapter 2).

${ }^{39}$ NL-HaNA, Centr. Raad Volksgezondheid, 2.27.16, 803, Adviesaanvrage inzake patiëntenrecht, 26 oktober 1977. Italics added.
} 
Festen, Leenen, and Van der Mijn in early 1978 (see chapter 3), which the Committee Rights of the Patient absolutely had to discuss. Hence, also the author of the two articles which had provoked Dutch parliament to ask questions about the governance of human experimentation in 1975 did not consider the matter so urgent in early 1978 to make it part of a committee on the realization of patients' rights. In the Netherlands, no one really seemed to worry about human experimentation.

\section{The effect of two atypical research scandals}

This all changed in the spring of 1978. On the morning of Thursday 20 April 1978, Dutch newspapers had big news to report: Leiden University would have appointed criminologist Wouter Buikhuisen-an employee of the Ministry of Justice-as Professor of Criminology and Penology and offered him a dowry of 250.00o guilders "from public funds" to conduct scientific research into the "biological characteristics of the delinquent". $4^{\circ}$ With this money, the papers reported, Buikhuisen was planning to hire a neurobiologist, a psycho-physiologist, and an endocrinologist to study the role of the nervous system in criminal behaviour. It was news that led to a great public outcry in the Netherlands. "Views from the nineteenth century threaten to return", one newspaper headlined, "Buikhuisen wants to conduct brain research on prisoners". ${ }^{41}$ Even though the criminologist made a public statement two days later that he had no wish to deny the social determinants of criminal behaviour and that he had no plans whatsoever to start putting electrodes in people's brains (as "innocent measurements of the heart, urine, wrist, and a little blood may already provide many clues about the influence that certain bodily substances have on behaviour"), it was the comparison with the nineteenth-century Italian criminologist Cesare Lombroso and his infamous theory of criminal atavism that stuck in the Dutch media. ${ }^{42}$

In the influential left-wing magazine Vrij Nederland, well-known linguist and literary critic Hugo Brandt Corstius soon started up a weekly column dedicated to tackling Buikhuisen's ideas. 43 In these columns, Corstius repeatedly argued that Buikhuisen was not only a perverted scientist-a Nazi ideologist, in fact-but also an incredi-

\footnotetext{
${ }^{40}$ See, for example: F. Gongrijp, 'Eis van nieuwe hoogleraar in Leiden: Hersenonderzoek bij delinquenten', in De Telegraaf, Thursday 20 April 1978, p. 3; 'Volgens reclasseringsblad KRI: Dr. R. Buikhuisen wil onderzoek biologische kenmerken delinquent', in Leeuwarder Courant, Thursday 20 April 1978, p. 15; 'Dr. Buikhuisen: hersenonderzoek delinquenten', in Het Vrije Volk, Thursday 20 April 1978, p. 9; 'Eis voor aanvaarden hoogleraarschap in Leiden. Criminoloog dr. Buikhuisen wil onderzoek hersenen misdadigers', in Nieuwsblad van het Noorden, Thursday 20 April 1978, p. 3.

41 'Opvattingen uit de negentiende eeuw dreigen terug te keren. Buikhuisen wil hersenonderzoek bij gevangenen', in De Waarheid, Thursday 20 April 1978, front page.

${ }_{42}$ The theory that criminals can be identified through inborn degenerative traits like a sloping forehead or excessively long arms. M.E. Chavennes, 'Criminologie met Buikhuisen: terug om beter te springen', in $N R C$, Saturday 22 April 1978. See also: 'Dr. W. Buikhuisen: 'Geen sprake van hersenonderzoek bij delinquenten', in Nederlands Dagblad, Friday 21 April 1978, p.5. For the comparison with Lombroso, see: K. Wiese, 'Buikhuisen volhardt in gevaarlijke denkfouten', in Nieuwsblad van het Noorden, Tuesday 10 October 1978, p. 4; 'Plannen Buikhuisen oude wijn in nieuwe zakken', in Leeuwarder Courant, Saturday 27 June 1 981; 'Omstreden geleerde vertrekt', in Limburgsch Dagblad, Thursday 2 March 1989, p. 5. See also: W. Dekker, De affaire Buikhuisen: het ontstaan en de achtergronden rondom zijn biosociale onderzoek (Doctoraalscriptie Erasmus Universiteit Rotterdam, 2009).

${ }^{43}$ Fifteen of these were published later that year under the title Buikhuisen, dom én slecht (Buikhuisen, stupid and evil). P. Grijs, Buikhuisen, dom én slecht (Amsterdam: Vrij Nederland, 1978). Hugo Brandt Corstius published his columns under the pseudonym Piet Grijs.
} 
bly stupid one who neither understood basic philosophy of science nor seemed aware of the latest publications in his own field of study. In the national Dutch law journal, in the meanwhile, well-known legal sociologist Kees Schuyt strongly questioned "the scientific merit of the proposed study" and proposed that Buikhuisen should postpose his research until he had managed actually to formulate a sound theoretical model for his biosocial hunches. As they stood, his plans had too many methodological shortcomings to yield any reliable scientific results. ${ }^{44}$ Buikhuisen would confuse statistical concepts of normality with juridical ones, for instance, and ignore the difficulties of correlating physiological characteristics with social and criminal ones. 45 These shortcomings, Schuyt felt, presented a serious moral problem demanding "increased civil vigilance" in the Netherlands-especially among academics:

You could argue that we need not be so afraid of research that cannot yield valid results anyway. But the opposite is true. If someone uses so little philosophy of science in his work, the danger is much greater. Because apparently arguments do not always count and politicians do not know that much about philosophy of science or other philosophies. In the end, philosophy of science is also ethics for researchers, to which they should hold themselves. 46

In addition, Schuyt maintained that the way in which Buikhuisen planned to obtain his data was morally problematic. Would he conduct tests on prisoners, for instance, and, if so, how would he make sure they were in a position to give their free consent? Also, was his plan to use medical data for criminological or juridical ends not in conflict with the reigning medical ethics? And what about the privacy of individuals? Did the Dutch state not have an obligation to protect its citizens from this sort of scientific 'progress'? The answers to these questions concerned society at large, Schuyt argued, and therefore demanded both public and political debate. 47

Indeed, in Dutch parliament Buikhuisen's appointment in Leiden soon became the subject of an emergency debate that was requested by the Dutch communist party. ${ }^{48}$ On 26 April 1978, 131 members of the Dutch House of Representatives came together for an exceptional event in Dutch parliamentary history: in the afternoon of that day,

\footnotetext{
${ }^{44}$ C.J.M. Schuyt, 'Veroordeeld tot criminaliteit? Een wetenschapsfilosofische en ethische reflectie op het voorgenomen onderzoek van Prof.dr. W. Buikhuisen', in Nederlands Juristenblad Vol. 53 (1978), pp. 389-399, p. 395. For Buikhuisen's reply, see: W. Buikhuisen, 'De wetenschapsfilosofische en ethische 'reflexen' van Prof. Schuyt', in Nederlandse Juristenblad Vol. 54 (1978), pp. 477-481. In that same edition, see: J.J.M. van Dijk, 'Weerwoord op het requisitoir van Schuyt', pp. 481-487.

${ }^{45}$ For example, Schuyt wrote, behaviour, "[Buikhuisen] will have to prove why one person with a bulky male body becomes a recidivist and the other an excellent rugby player". See: Schuyt, 'Veroordeeld tot criminaliteit?', p. 393.

${ }^{46}$ C.J.M. Schuyt, 'Reflex of reflectie. Antwoord aan Buikhuisen enVan Dijk', in Nederlands Juristenblad Vol. 53 (1978), pp. 517-526, p. 526. For the reply of Buikhuisen, see: W. Buikhuisen, 'De 'regressies' van Schuyt', in Nederlands Juristenblad Vol. 53 (1978), pp. 526-530.

${ }^{47}$ Schuyt, 'Veroordeeld tot criminaliteit?', pp. 396-397. Schuyt recommended Jay Katz's famous 1972 book Experimentation with human beings as an "excellent guide" for these discussions. The physician and Yale Law School professor Jay Katz played a defining role in the fledgling bioethics movement in the United States in the 1970s and served on the federal inquiry into the Tuskegee Syphilis Study. See: J. Katz, Experimentation with Human Beings (New York: Russell Sage Foundation, 1972).

${ }^{48}$ See: 'Door CPN'er Wolff: Interpellatie over onderzoek dr. Buikhuisen', in Nieuwsblad van het Noorden, Friday 21 April 1978, p. 2; 'Joop Wolff interpelleert', in De Waarheid, Friday 21 April 1978, front page.
} 
both the Minister of Education and Sciences and the Minister of Justice were summoned to parliament to defend the appointment of a single professor at a Dutch university. 49 Political concern varied per party, but most politicians voiced deep concern about Buikhuisen's plans to do biosocial research on criminal behaviour. A member of the Christian-democratic party emphasized it was essential that human kind would not become subordinate to science and technology..$^{\circ}$ Representatives of the smaller progressive parties wanted the government to promise that weak members of society would not be abused by the scientific elites and underscored the similarities between Buikhuisen's plans and the prevailing scientific ideologies in Hitler's Third Reich. ${ }^{11} \mathrm{~A}$ member of the Labour Party, in the meanwhile, claimed that since Buikhuisen's professoriate was supported with public funds, Dutch parliament could hold the government responsible for his actions. So, how did the Ministers plan to supervise Buikhuisen's research and which policy measures were they taking to safeguard the voluntary consent of imprisoned research subjects in the Netherlands?

Also Dick Dees, member of parliament for the conservative-liberal party VVD (see chapter 3), was allotted time to speak. Moving away from Buikhuisen, Dees wished to direct attention toward "questions of a more general nature": the autonomy of Dutch universities, the freedom of scientific research and, crucially, the regulation of human experimentation in the Netherlands. With regard to the first two domains, the liberal politician argued, a government had to practice caution. With regard to the third domain, however, things were different. After all, Dees stated, it was very well conceivable that a researcher, "driven by a desire to solve his problems", might cross the limits of what was tolerable. Yet what was the government now actively doing to protect the rights of research subjects in the Netherlands? There was the Health Council advice from 1955, Dees noted, and questions had been asked in parliament in 1975 about the articles by Leenen. But as far as Dees could see, neither initiative had led to any direct action from the Dutch government. What had happened, for example, to the promises of State Secretary Hendriks in 1975? Could the Minister of Education and the Minister of Justice perhaps clarify what had come of his plan to make human experimentation part of a study into the rights of patients in the Netherlands?52

In his address, Minister of Education and Sciences Arie Pais (a VVD-member) emphasized that this type of broad parliamentary discussion on the relation between science and society was a great initiative. After all, the subject under investigation did not so much concern the appointment of a single professor, but pertained to "the tree of knowledge of good and evil" and the fruits society may reasonably pick from it.53 It was important to recall from time to time that "a societal frame exists for academia" and that scientists could not just hide away in their ivory towers without accounting for their actions to Dutch society. Pais had to agree with party-member Dees, howev-

\footnotetext{
${ }^{49}$ Handelingen Tweede Kamer 1977-1978 26 april 1978, pp. 2199-2218.

${ }^{50}$ Ibid., p. 2208.

${ }^{51}$ Ibid., pp. 2205-2213. Some politicians also lauded Buikhuisen. The representative of the progressive liberal party D66, for instance, called Buikhuisen an excellent researcher and spoke critically of "those so-called structuralists [...] who believe that, when the structure of society changes, criminal behaviour will disappear naturally". A member of the orthodox Calvinist party SGP felt that Buikhuisen's ideas were like a breath of fresh air in an era in which everything had to be caused by societal injustice.

${ }^{52}$ All quotes in this paragraph: Ibid., p. 2207.

${ }^{53}$ Ibid., p. 2214.
} 
er, that a government should practice restraint in interfering with academic freedom. The not so distant past had shown, after all, what could happen if "a state believes it can misuse the practice of science for its own purposes". ${ }^{44}$ He had no intention, therefore, to interfere with the appointment of Buikhuisen in Leiden. Nonetheless, his colleague for the Ministry of Justice, the Christian-democrat Job de Ruiter, could affirm that the Dutch government was willing to promote a study into the realization of legal safeguards for the protection of human research subjects. In fact, as far as he knew, the study mentioned by Hendriks in 1975 had been running for a while now. Hence, De Ruiter would request his colleague from the department of Public Health to give Dutch parliament an update of this ongoing study. .5

The Minister of Justice would soon find out, however, that the Committee Rights of the Patient had not yet gathered even once (see chapter 3) and had no plans to write a report on the governance of human experimentation. Still, Dutch parliament kept on firing questions at him in the months thereafter about the measures he was taking to handle "professor Buikhuisen and his plans". ${ }^{56}$ In October 1978, therefore, De Ruiter announced that he had asked the new State Secretary of Public Health Els Veder Smit to send a pressing request to the Central Council of Public Health to make 'tests upon human beings' a priority in the Committee Rights of the Patient. ${ }^{57}$ In the meanwhile, the Ministry of Justice would issue an interim-arrangement to protect prisoners from undue experimentation, an emergency regulation that went into effect in June 1980 and prevented Buikhuisen from doing his study..$^{8}$ Hence, due to a single criminologist, the Dutch government in 1978 suddenly got serious about the governance of human research-not because he had actually conducted any questionable experiments, but because too many people felt he had questionable ideas.

In December 1978, political pressure mounted even more when a second research scandal came to light. On Wednesday 13 December, national newspaper De Telegraaf reported that the Inspectorate of Mental Welfare in Noord-Brabant was investigating "circulating rumours that 640 mentally retarded patients have been exposed for years to irresponsible and medically unnecessary diagnostic procedures in the context of scientific research". ${ }^{59}$ It based these claims on an article published five days earlier in a regional newspaper which mentioned that in Brabant nursing home Huize Assisiëa facility run by friars-the general practitioner on duty was accused of having carried out all sorts of dubious tests on patients, including craniometry (measurements of the skull) and pneumoencephalography (an invasive procedure in which the cerebrospinal fluid around the brain is drained by a lumbar puncture to provide a more defined

\footnotetext{
${ }^{54}$ Ibid., p. 2215.

${ }^{55}$ Ibid., p. 2218.

${ }^{56}$ Kamerstuk Tweede Kamer 1978-1979, kamerstuknummer 15300-VI, onder-nummer 12, p. 2.

${ }^{57}$ Handelingen Tweede Kamer 1978-1979 18 oktober 1978, p. 584.

${ }^{58}$ Voorschriften omtrent onderzoek voor wetenschappelijke doeleinden ten aanzien van hen die rechtens vrijheidsbeneming ondergaan, 9 juni 1980 (Staatscourant).

${ }^{59} \mathrm{~F}$. Gonggrijp, 'Inrichting in Udenhout in opspraak. Ingrepen op zwakzinnigen in onderzoek', in $D e$ Telegraaf, Wednesday 13 December 1978, p. 6.
} 
structure of the brain on a roentgen scan). ${ }^{60}$ Soon, newspapers also reported that an abdominal surgery and castrations had taken place at the nursing home, all without a clear medical indication and all by the same general practitioner, who lacked the professional qualifications for doing so and who did not have the appropriate equipment needed for these operations at his disposal in Huize Assisië. ${ }^{61}$

In Dutch parliament, politicians put pressure on State Secretary of Public Health Els Veder Smit by firing a series of pressing questions at her. What was true of the rumours surfacing in the Dutch media? What immediate actions was the government taking? When would the investigations of the Inspectorate be finished? Quite a few members of parliament directly linked the events at Huize Assisië to Buikhuisen: they were further proof that the weaker members of Dutch society needed dire protection from the overly eager hands of experimenting scientists. ${ }^{62}$ Veder Smit, however, had few answers to these questions, as she herself was awaiting the Inspectorate's report. This report came in on 30 January 1979. Only a censured version was sent to Dutch parliament, which was obliged to treat it confidentially. ${ }^{63}$

Between 1969 and 1973, the Inspectorate noted, the general practitioner on duty in Huize Assisië had conducted a pneumoencephalography approximately 180 times, at least four times under narcosis. ${ }^{64}$ In addition, between 1965 and 1978, 1447 roentgen photos of the skull had been taken-the majority from pupils, but also a few from volunteers, and 23 from "students from a remote primary school" without permission of their parents. ${ }^{65}$ In seventeen cases, small drill holes in the skull had been detected. Eleven of these could be explained as older lobotomies conducted by a neurosurgeon in a specialized clinic, but for the other six no satisfactory explanation was available. ${ }^{66}$ Also, in 1972 one stomach and two testicular operations had been carried out. None

\footnotetext{
${ }^{60}$ A very clear overview of the initial breaking of the scandal is provided by: D.P. Engberts, 'Het verhaal achter het schandaal. Medische proeven met verstandelijke gehandicapten in een Noord-Brabantse inrichting in de jaren zestig en zeventig', in Geneeskunde en Ethiek in Harmonie, pp. 125-153.

${ }^{61}$ See: 'Nieuwe onthullingen over zwakzinnigeninrichting', in De Telegraaf, Tuesday 19 December 1978, p. 7. 'Zwakzinnigeninrichting proefterrein. Operaties door niet-deskundigen', in De Waarheid, Saturday 16 December 1978, p. 7; 'Rapport: Verboden operaties in zwakzinnigentehuis', in Nieuwsblad van het Noorden, Tuesday 19 December 1978, p. 3; 'Schedelmetende arts voor tuchtcollege', in Het Vrije Volk, Thursday 28 December 1978, p. 5.

${ }^{62}$ Handelingen Tweede Kamer 1978-1979, 21 december 1978, pp. 2534-2537.

${ }^{63}$ This, the Director-General of Public Health wrote to the Inspectorate of Mental Welfare, to avoid punishing the people involved more than necessary beforehand. See: NL-HaNA, Hoofdinsp. Geestelijke Volksgezondheid, 2.27.5035, 638, Nota van de Directeur-Generaal van de Volksgezondheid aan de plv. Geneeskundig Hoofdinspecteur voor de Geestelijke Volksgezondheid, 31 januari 1979. The original report can be found in: NL-HaNA, Hoofdinsp. Geestelijke Volksgezondheid, 2.27.5035, 638, Onderzoek van de klachten over bepaalde medische praktijken in het zwakzinnigeninstituut 'Huize Assisië'. See also: NL-HaNA, Tweede Kamer, 1945-1989, 2.02.28, 11683, Onderzoek in de zwakzinnigeninrichting Huize Assisië te Udenhoudt, 1978-1979.

${ }^{64}$ NL-HaNA, Hoofdinsp. Geestelijke Volksgezondheid, 2.27.5035, 638, Vertrouwelijk Eindrapport betreffende een onderzoek in de zwakzinnigeninrichting Huize Assisië te Udenhout, p. 2. In the document sent to parliament, the incidences from 1969 (49) were excluded. See: NL-HaNA, Tweede Kamer, 1945-1989, 2.02.28, 11683, Tweede Kamer der Staten-Generaal, Zitting 1978-1979, 15470 nr. 2 , Brief van de Staatssecretaris van Volksgezondheid en Milieuhygiëne, bijlage, p. 1.

${ }^{65}$ Ibid., pp. 5-6.

${ }^{66}$ As noted in the second interim-report: NL-HaNA, Hoofdinsp. Geestelijke Volksgezondheid, 2.27.5035, 638, Tweede Interimrapport, p. 5. Other radiographic examinations were also unusually high. In 1978 alone, 270 of these investigations had been conducted, multiple of which "should be characterized as specialist [procedures], including contrast photos of the stomach, bladder, and kidney".
} 
of these had taken place on the basis of a clear medical indication, in "an appropriate and suitable space" or in the presence of an anaesthetist or qualified surgeon. Auxiliary staff had assisted, but they had lacked the proper experience for doing so. ${ }^{67}$ Finally, in the early 1970 s the general practitioner had performed insulin shock therapy (a highly invasive and at the time already outmoded procedure) on three pupils without keeping track of their progress and without prior experience in doing so. No proper medical indication had existed for them. ${ }^{68}$

In the report sent to Dutch parliament, no information was provided as to why the general practitioner had taken all these tests. In one of the two confidential interimreports of the Inspectorate, however, it was noted that a friar who had frequently assisted the general practitioner had during an interview made mention of "pseudoscientific theories" which could only be proven with radiographic measurements of the skull. ${ }^{69}$ In addition, in a medical file of one of the pupils of Huize Assisië, the Inspectorate had found calculations of a so-called "organicity-coefficient", a concept about which the assisting friar had published in Huize Assisië's in-house journal that served to establish the relation between the shape of the skull, the composition of the brain, and human behaviour more generally. ${ }^{70}$ In fact, the scandal would initially have come to light because the friar had enthusiastically tried to get a local newspaper to publish about their ideas-He was proud of their scientific work. ${ }^{71}$

In early January 1979, the assisting friar announced his resignation to go and live at a neighbouring congregate. $7^{2}$ Both the general practitioner and medical-director of Huize Assisië, however, had to appear before a disciplinary court. In September 1980, they were fined 10.000 guilders each-at the time the highest financial punishment possible in the Netherlands. The court could have taken away their license to practice medicine, but had decided against this because no permanent damage had been done to the pupils of Huize Assisië and because the defendants had already suffered great immaterial disadvantages from the widespread media attention which the case had generated. In addition, the court had taken into account that the general practitioner had worked as a missionary physician in Nigeria before he started his appointment at Huize Assisië and was therefore used to "operating independently". ${ }^{73}$

This verdict meant that the general practitioner was allowed to resume his practice at Huize Assisië, an outcome that caused a great public outcry. On Thursday 18 September, Utrecht neurosurgeon Henk Verbiest stated in De Telegraaf that "the verdict of the disciplinary tribunal is utterly unacceptable" and violated "an elementary sense

\footnotetext{
${ }^{67}$ Ibid., pp. 8-10.

${ }^{68}$ Ibid., pp. 10-11. In one case, the Inspectorate noted, a contraindication had even existed.

${ }^{69}$ NL-HaNA, Hoofdinsp. Geestelijke Volksgezondheid, 2.27.5035, 638, Eerste Interimrapport betreffende een onderzoek in de zwakzinnigeninrichting Huize Assisië te Udenhout, p. 6.

${ }^{70}$ Ibid., p. 3.

${ }^{71}$ See: NL-HaNA, Hoofdinsp. Geestelijke Volksgezondheid, 2.27.5035, 638, Verslag van de bijzondere ledenvergadering van de oudervereniging van Huize Assisië, gehouden op 3 februari 1979, p. 4.

${ }^{72}$ NL-HaNA, Hoofdinsp. Geestelijke Volksgezondheid, 2.27.5035, 638, Brief van Verhoeven aan Van Soest, Udenhout 10 januari 1979. See also: See, for example: 'Zwakzinnigeninrichting proefterrein. Operaties door niet-deskundigen', in De Waarheid, Saturday 16 December 1978, p. 7; 'Huisarts en röntgenassistent verdacht. Onderzoek medische experimenten in tehuis', in Leeuwarder courant, Tuesday 19 December 1978 , p. 3.

${ }^{73}$ NL-HaNA, Hoofdinsp. Geestelijke Volksgezondheid, 2.27.5035, 638, Enkele beschouwingen over de uitspraken van het college voor medisch tuchtrecht te Eindhoven in de zaken tegen artsen Huijsmans en Van Dongen.
} 
of justice". ${ }^{74}$ This discontent was reinforced by the fact that the respective rulings had been published as confidential documents. The general public had only been able to take notice of them because of a press release issued by Huize Assisië itself.75 It made Verbiest suspicious. In January 1979, the neurosurgeon had himself been contacted by the Inspectorate for Mental Welfare to investigate the six instances in which drill holes had been found without a satisfactory accompanying explanation. ${ }^{76}$ However, when Verbiest had contacted the Inspectorate with multiple "urgent questions" and a request for further information, he had never heard anything back. This led the neurosurgeon to wonder how the other evidence underlying the disciplinary verdict had been collected. Had the Inspectorate really got down to the bottom of the case or had it tried to sweep more serious offenses under the carpet? In any case, the verdict was proof for Verbiest-and he was quoted as such in De Telegraaf-that the medical disciplinary system no longer functioned properly in the Netherlands. 77

The events at Huize Assisië were not right away linked to the governance of human experimentation in the Netherlands. The general practitioner was portrayed in Dutch media as an out-of-control cowboy who had operated in Assisië as he had grown used to during his time "in the jungle" ${ }^{78}$ Although his behaviour was strongly condemned, he was framed as an exception who was in no way representative for Dutch medicine more generally. In early 1979, however, Huize Assisië became part of a two-piece article in Medisch Contact by biologist-philosopher Matthijs Visser on the governance of clinical experimentation in the Netherlands. What had occurred at Assisië, also Visser affirmed, should be understood as an awful exception. It did not represent the way in which physicians generally conducted experiments with patients in the Netherlands. Still, the biologist continued, that did not mean there was no reason for concern. To prove his point, Visser had collected 45 articles from the Dutch Journal of Medicine to show that also in the Netherlands medical researchers were not careful enough in experimenting on patients. The articles did not always specify if the informed consent of patients had been obtained and if they did, not enough information always had been provided. Worse, some articles mentioned non-therapeutic studies (i.e. studies unlikely to have direct benefit for participating patients) with substantial risk, which made it questionable if they should have been conducted at all.79

To ameliorate this situation, Visser argued, the government had to take charge of the oversight of medical experiments on human beings in the Netherlands. The biologist noted that some forms of 'internal control' had been proposed for the governance of human experimentation in recent years, but these, he maintained, were inadequate for the governance of such a sensitive scientific practice. By virtue of their professional disposition, medical researchers were unable to reach unbiased ethical decisionstheir interest in the progress of scientific research prevented them from "fully appre-

\footnotetext{
${ }^{74}$ F. Gonggrijp, 'Prof. Verbiest verbreekt stilzwijgen in zaak-Assisië. Uitspraken tuchtcollege volledig onaanvaardbaar', in De Telegraaf, Thursday 18 September 1980, p. 6.

${ }^{75}$ NL-HaNA, Hoofdinsp. Geestelijke Volksgezondheid, 2.27.5035, 638, Perscommuniqué H. Assisië.

${ }^{76}$ NL-HaNA, Hoofdinsp. Geestelijke Volksgezondheid, 2.27.5035, 638, Aan de hooggeleerde Prof. H. Verbiest van de Geneeskundig Hoofdinspecteur van de Geestelijke Volksgezondheid, 16 januari 1979.

${ }^{77}$ Gonggrijp, 'Prof. Verbiest verbreekt stilzwijgen'.

${ }^{78}$ Willem Kloppert, 'Dokter Huijsmans werkte in Assisië als in de rimboe', in Het Vrije Volk, Wednesday 20 December 1978, p. 9.

${ }^{79}$ Visser, 'Ethische aspecten van medische experimenten op de mens'.
} 
ciating the rights of the research subject". ${ }^{80}$ Hence, laypeople had to take on this role. People with no affiliation to medical research, after all, were "best able to impartially represent the public opinion on the admissibility of experiments". 81 "If we truly want to democratize health care, including biomedical research, and to protect the right to mental and bodily integrity of all patients and test subjects involved", Visser wrote in conclusion, "some things will have to be regulated by law". ${ }^{82}$ Human experimentation in the Netherlands had to be brought under external control.

In one of the next issues of Medisch Contact, the editor in chief of the Dutch Journal of Medicine responded indignantly to Visser's piece. "It is interesting to note how more and more non-physicians concern themselves with the actions of physicians to check if they are ethical", the editor started off delicately. Really, he very much appreciated the enthusiasm, and all this under the banner of protecting the integrity of the patient. However, the editor continued angrily, as "Dr. Visser violates the integrity of at least 45 Dutch physicians, he is morally obligated to not just leave it at such gratuitous allegations, but to justify himself properly and understandably". ${ }^{83}$ So perhaps the biologist could be so kind to help the Dutch Journal of Medicine out and identify these "sins against ethics" he had detected in its pages. For the "unsuspecting medical reader" just could not find them, although-the editor concluded cynically-this was probably because "physicians are blind to their own mistakes". ${ }^{84}$

Also other physicians and biomedical researchers wrote in. ${ }^{85}$ Most notably, Dirk van Bekkum responded, who was considered an authority on the subject. Trained as a physician and a biochemist, Van Bekkum had been director of the Radiobiological Institute of the Netherlands Organization for Applied Scientific Research (TNO) since 1960. Under his leadership, the institute had made key international contributions in the 1960 s and 1970 s to radiobiology, experimental leukaemia research, bone marrow transplantation, and stem cell research-and by the end of the 1970s, the radiobiologist had gained international renown as a leading medical scientist. ${ }^{86}$ What was more, in 1969, Van Bekkum had established a Foundation for the Biosciences and Society together with Prince Claus of the Netherlands, husband of Queen Beatrix. Their goal was to familiarize a broad audience with new developments in the biomedical sciences and to consider their ethical and social aspects. In this capacity, he had authored multiple short texts in the 1970 on on the ethics of clinical research. ${ }^{87}$

\footnotetext{
${ }^{80}$ Ibid., p. 1351.

${ }^{81}$ Ibid., p. 1387.

${ }^{82}$ Ibid., p. 1390.

${ }^{83}$ L.B.W. Jongkees, 'Ethische aspecten van medische experimenten op de mens', in Medisch Contact Vol. 35 (1980), pp. 80-81.

${ }^{84}$ Ibid., p. 81 .

${ }^{85}$ See, for instance: A.W. Moll van Charante, 'Ethische aspecten van medische experimenten op de mens', in Medisch Contact Vol. 35 (1980), p. 101.

${ }^{86}$ See: B. Löwenberg, 'Dirk Willem van Bekkum. 30 juli 1925-17 juli 2015', in Levensberichten en Herdenkingen 2015 (Koninklijke Nederlandse Akademie van Wetenschappen), pp. 13-22. In 2007, the Dutch Journal of Medicine named Van Bekkum as one of the Dutch biomedical researchers who might have gotten a Nobel prize for their work: 'Wie had de Nobelprijs moeten krijgen?', in Nederlands Tijdschrift voor Geneeskunde Vol. 151 (2007), pp. 73-77.

${ }^{87}$ D.W. van Bekkum, 'Experimenten met mensen', in Ethiek, Cahiers van de Stichting BioWetenschappen en Maatschappij Vol 3, Nr. 2 (Deventer: Van Loghum Slaterus, 1976), p. 25; D. W. van Bekkum, 'Proeven op patiënten: techniek, ethiek', in Kanker, Cahiers van de Stichting BioWetenschappen en Maatschappij Vol 3, Nr. 4 (Deventer: Van Loghum Slaterus, 1976), p. 38.
} 
In his reply to Visser in Medisch Contact, Van Bekkum remarked that as a result of "the emancipation from patient to client" in recent years, people had increasingly started to argue that medical research had to be brought under public control. They were typically people, Van Bekkum noted, with "no personal experience in the field of medical research" who "carry on a theoretical discussion and try to realize regulation with the aid of foreign inspiration and information". ${ }^{8}$ However, these people tended to forget or be oblivious to one crucial thing: contrary to the United States and Great Britain, hardly any medical experiments with humans took place in the Netherlands, as it very much remained an underdeveloped field. The radiobiologist therefore called on all actual medical researchers to start speaking out on the governance of human experimentation and to help realize a workable system of oversight. If not, a danger existed that a field that was only just beginning to blossom in the Netherlands unduly would be nipped in the bud due to overbearing concerns of medical outsiders. This, Van Bekkum warned, would ultimately be to the detriment of Dutch health care itself. The radiobiologist very much was a therapeutic reformer (see chapter 2).

In Dutch parliament, however, Visser's article was received with more enthusiasm. In May 1980, during a parliamentary debate on the possible amendment of the Dutch constitution, the biologist's arguments were used by politicians to advocate the integrity-or inviolability - of the human body to be a fundamental right of Dutch citizens. "Visser shows", one parliament member stated, "that the introduction of new diagnostic and treatment methods has been neglected in the Netherlands, also compared to other countries". ${ }^{89}$ It was a perspective which could count on overwhelming political support in the Netherlands at the close of the 1970s. In 1976, still, the proposal to codify the inviolability of the human body in the Dutch constitution had been repudiated on the grounds that full inviolability was an unrealisable goal and would as such undermine the strength of a constitutional right. $9^{\circ}$ By 1979, however, politicians from across the political spectrum pointed towards Buikhuisen and Huize Assisië to underscore the crucial importance of the constitutional codification of physical inviolability. ${ }^{91}$ On June 25, the amendment was adopted unanimously by the Dutch House of Representatives. ${ }^{22}$ And whatever the Central Council Committee Rights of the Patient was working on, it had to make human experimentation a priority now.

\section{The new function of research ethics committees}

In August 1978, in the aftermath of the Buikhuisen-affair, the Central Council discussed the urgent request of State Secretary Veder-Smit to make the governance of 'medical tests upon human beings' part of the Committee Rights of the Patient. It was not very enthusiastic about the idea. The President of the Health Council, who was a delegate of the Central Council, remarked that his advisory body already had the subject in study (see chapter 2), while a participating jurist argued it was unreasonable to

\footnotetext{
${ }^{88}$ D.W. van Bekkum, 'Medische experimenten en proeven op mensen. De rechten van patiënten in het medisch-wetenschappelijk onderzoek', in Medisch Contact Vol. 35 (1980), pp. 115-118, p. 115.

${ }^{89}$ Handelingen Tweede Kamer 1979-1980, 28 mei 1980, p. 4953.

${ }^{90}$ See: H.A. Edeler, De drinkwaterfluoridering. Tandartsen, staat en volksgezondheid in Nederland 1946-1976 (Houten: Bohn Stafleu van Loghum, 2009).

${ }^{91}$ Handelingen Tweede Kamer OCV/UCV 1978-1979 14 mei 1979, pp. 931-938.

${ }^{92}$ Handelingen Tweede Kamer 1978-1979, 25 juni 1979, p. 5678.
} 
ask Leenen et al. to study the governance of human experimentation in full: a rounded investigation of the topic required them to consider more elements than only the rights of patients in research situations (like, for example, the need for such research in the Netherlands) and the Committee Rights of the Patient had not been installed for this purpose. The delegates strongly recommended the Committee, therefore, only to write a report stating the rights of patients in medical experimentation and to leave its governance for another occasion and advisory body to consider. 93

In January 1979, also Leenen decided that if the Committee Rights of the Patients had to write a report on the subject of 'medical tests upon human beings', a separate working group had to be installed for this task. The topic was too specific and would take the Committee itself too much time and work. ${ }^{94}$ The jurist N. de Jong, a member of the Committee Rights of the Patient, was willing to chair this working group. ${ }^{95} \mathrm{He}$ was joined by four other Committee members: an internist representing the KNMG, a medical inspector, a member of the National Hospital Council, and a representative of a patient organization who had recently published a book on patient law that dealt among other things with the governance of human experimentation. ${ }^{96}$ In addition, a number of people that did not take part in the Committee Rights of the Patient participated. In addition to two nurses, the Utrecht paediatrician Wim Wolters was invited, who was at the time busy organising a conference on "the possibilities and limitations of medical experiments with humans". ${ }^{97}$ The Leiden pharmacologist Erik Noach took part, who had earlier chaired the Health Council 'clinical drug research' and who still participated in the Health Council committee 'clinical pharmacology' (see chapter 2). Finally, two TNO-employees were asked to take up a seat: Theo Gerritsen, a biochemist who had chaired an American IRB in the 1970s and who was currently developing guidelines for human research at TNO (see chapter 5); and Dick van Bekkum, head of its Radiobiological Institute and an authority on clinical research.

Hence, the decision of Leenen to install a separate working group for the development of a policy report on the governance of medical tests upon human beings meant that, contrary to the main Committee Rights of the Patient itself, only one patientrepresentative took part in the deliberations of the working group, which lasted from May 1979 to May 1981. In fact, with the exception of jurist De Jong (who took part in the Committee Rights of the Patient to represent the Dutch Health Insurance Funds), all working group members were health care providers. Yet, if this disproportionate composition might have worried advocates of the Dutch patients' rights movement, the conclusions of the working group in its final report likely surprised them: in 1982, the Central Council recommended a regulatory regime for human experimentation to the Dutch government that was more strict than any of the Health Council reports which had ever been written on the topic. From its first page onwards, the report put the rights and protection of human research subjects centre stage.

\footnotetext{
${ }^{93}$ NL-HaNA, 2.27.16, 51, 1004215 , Minutes of the $215^{\text {th }}$ C.v.G.-meeting, 3 August 1978, p. 9.

${ }^{94}$ NL-HaNA, 2.27.16, 554, 8008 19, Minutes of the working group, 8 May 1979, p. 2.

${ }^{95}$ NL-HaNA, 2.27.16, 549, brief van H.J.J. Leenen aan Johan Engelkens, 2 januari 1979.

${ }^{96}$ NL-HaNA, 2.27.16, 549, 8008 2; M.J. Aghina, Patiëntenrecht. Een kwestie van gewicht (Assen/Amsterdam: Van Gorcum, 1978).

${ }^{97}$ Wolters organized this conference in collaboration with two famous American bioethics institutes: the Kennedy Institute and Hastings Institute. See: W.H.G. Wolters, Medische experimenten met mensen. Mogelijkheden en Grenzen (Utrecht: Bohn, Scheltema \& Holkema, 1980).
} 
First of all, the Central Council report made much more elaborate demands on the informed consent of research subjects than any of the older Health Council reports. In 1971, for instance, the committee 'clinical drug research' had stated that the explicit permission of research subjects was "generally" required: non-therapeutic studies could never take place without subjects' informed consent, yet clinical trials could as long as patients had given permission "as is common in normal medical treatments" (see chapter 2). In 1982, in contrast, the working group 'medical tests upon human beings' stated that no researcher was ever allowed to conduct medical experiments with humans without having first acquired their informed consent. Even more, it emphasized that research subjects were always entitled to revoke their permission and to submit complaints if they felt that they had not been treated properly..$^{8}$ Also, experiments with humans could only take place if a research protocol lived up to "reasonable standards" regarding the objectives and execution of the proposed study, which included the duty for researchers to ensure an experiment had a positive risk/benefitratio with only limited discomfort for subjects (both physically and mental), that it honoured subjects' privacy and personal integrity, and that in case a research subject was also a patient, the refusal to participate would not negatively affect his or her treatment plans. ${ }^{99}$ Finally, individuals who found themselves in "a dependent position" could never participate in experiments, unless these were geared directly toward the "special situation in which these persons find themselves", and then only if these could absolutely not be held without their participation. ${ }^{100}$

Secondly, the 1982 Central Council report underscored emphatically that the practice of human experimentation had to be regulated by law. It referred multiple times to the articles of Rang, Leenen, and Visser on the topic and admitted that "although patient law is now establishing a place for itself in health care, the rights of sick and healthy research subjects in the biomedical and behavioural sciences are still hardly ever discussed". ${ }^{101}$ The working group's justification for the need for public regulation was twofold. One, it argued that the nature of medical experimentation was such that the wellbeing of research subjects could potentially come into conflict with a successful outcome of the research study, meaning that legal warrants were needed to protect the interests of research subjects. Two, it suggested that all biomedical researchers had to be held publicly accountable out of principle. The report cited Visser's article from Medisch Contact multiple times, including statements like "biomedical research cannot escape the ever-increasing call for more societal influence on scientific research" and "the times have passed that a researcher could autonomously define his own field of research". ${ }^{102}$ The report also wrote that "progress of medical science cannot shield itself from social scrutiny and seclusion and mystery have to make way for openness and transparency". ${ }^{103}$ In a modern democratic society, the suggestion was, a practice like human experimentation principally required public control.

\footnotetext{
${ }^{98}$ Centrale Raad voor de Volksgezondheid, Deeladvies inzake medische experimenten, p. 38.

${ }^{99}$ Ibid., pp. 27-31.

${ }^{100}$ Ibid., p. 38. The Central Council included minors, detainees, handicapped individuals, patients, and

the mentally-ill in this category.

${ }^{101}$ Ibid., p. 6.

${ }^{102}$ Ibid., p. 8.

${ }^{103}$ Ibid., p. 15.
} 
Thirdly, following these conclusions, the 1982 Central Council report proposed to restrain the individual autonomy of biomedical researchers much more than any of the Health Council reports had ever done. The latter of these three had suggested that after a researcher had notified a central authority of his resolution to conduct a medical experiment involving human beings he could immediately start with the execution of his study (if this authority suspected something to be wrong, it could then request the Dutch Medical Inspection to halt the study). Instead, the Central Council argued that researchers should only be permitted to start their study if a thereto appointed authority had given its seal of approval. The difference with the older Health Council reports, according to the working group, was that the former were based on a 'yes, if'premise, while its own work was built around a 'no, unless'-principle. ${ }^{104}$ Less Delphic, the working group meant that the decision to start a human research study could not be left to individual researchers. To safeguard "the personal integrity, wellbeing, and rights of the research subject", the 1982 report read, the Dutch government had to ensure that human experimentation could only take place in the Netherlands after a thereto appointed authority had first given its permission for doing so. What was more, this authority also had to be empowered to do follow-up checks to inspect if researchers stuck to the protocols they had submitted for review. If not, it should be authorized to halt studies mid-way. ${ }^{105}$ To protect human research subjects from any wrongdoings, the message was, constant vigilance was required.

This type of oversight, the working group maintained in its 1982 report, could best be realized by establishing "independent local or regional review committees" which would be tasked to assess the permissibility of research protocols "with due regard for prevailing views and norms and this both scientifically and ethically". ${ }^{106}$ These bodies had to be overseen by one national council that would register all approved research protocols (to prevent unnecessary duplications of research studies), document developments in thinking about human experimentation, and direct the local and regional committees to review studies in a more or less uniform manner. In addition, it could check whether the local and regional committees operated as they were supposed to and, if needed, function as an appeal body for research studies that were declined by a local or regional committee. ${ }^{107}$ Finally, this central authority would publish a report about her activities each year that would explain developments on the terrain of medical-biological research "in a manner that is understandable for a larger audience, so that also in this way more openness and transparency is provided". ${ }^{108}$

In itself, of course, this suggestion was nothing new. By 1982, review committees had become a commonplace in at least the United States, Great Britain and Swedenall nations that were important reference cultures for the Netherlands in the governance of biomedical science. ${ }^{109}$ Already in 1975, the World Medical Association (WMA) had amended its Helsinki Declaration (see chapter 1) to state that all human research protocols should be submitted to "a specially appointed independent committee for

\footnotetext{
${ }^{104}$ Ibid., p. 45.

${ }^{105}$ Centrale Raad voor de Volksgezondheid, Deeladvies inzake medische experimenten, pp. 45-46.

${ }^{106}$ Ibid., p. 45.

${ }^{107}$ Ibid., pp. 49-50.

${ }^{108}$ Ibid., p. 50.

${ }^{109}$ See, for instance: Visser, 'Ethische aspecten van medische experimenten op de mens'.
} 
consideration, comment and guidance". ${ }^{110}$ Plus, in the Netherlands itself, authors like Leenen, Rang, Noach, Visser, and even Van Bekkum had recommended the installation of review committees in the 1970s, while the Health Council had already advised the Dutch government three times to regulate medical tests on human beings through some sort of system of ethics by committee (see chapters 1 and 2).

In contrast to the 1955 and 1971 Health Council reports, however, the 1982 Central Council report recommended that such review committees should not only consist of "experts on the terrain of medicine and medical-biological research", but should also include "a number of other experts, including an ethicist or pastor and a jurist, as well as a nurse and at least two laypersons who can function as society-representatives" ${ }^{111}$ The report did not elaborate why 'an ethicist or pastor and a jurist' had to be included. In a working group meeting, however, Noach had argued that including "someone with expertise in ethics" made sense because review committees had to evaluate the ethical permissibility of protocols. Hence, it could be useful to include a member with authority on the subject. According to the pharmacologist, it did not matter whether this member was an ethicist, a theologian, a pastor, or "people who busy themselves with norms of human behaviour"; they just needed some sort of affinity with issues of morality. ${ }^{112}$ The report did explain why the participation of a nurse was a good idea; she could be expected to offer a different viewpoint on issues and, importantly, "her function ensures that she is often better informed of certain situations and has more direct contact with research subjects". ${ }^{113}$ The inclusion of a nurse, in other words, was another important safeguard for the protection of research subjects.

Notably, the role of two "laypersons who can function as society-representatives" was not defended in the policy report, nor had it been questioned in meetings of the working group. When their inclusion was first suggested by Noach, in fact, all members had immediately accepted the idea. ${ }^{114}$ Van Bekkum had even proposed that also representatives of patient organizations could take up a seat. It was the participating patient representative who had advised against this suggestion, as such organizations were not yet organised well enough in the Netherlands to let enough representatives take up a seat in multiple local committees. Plus, Noach had added, it was better if lay people only participated à titre personnel, otherwise all sorts of groups would want to be represented. Committees, he argued, "just need to ask a few people whom they know to have a bit of quality and a certain interest [in the topic]". ${ }^{115}$

The working group did discuss for some time how many laypeople should participate in the review of human research protocols. In discussing Visser's and Van Bekkum's articles in Medisch Contact, Van Bekkum himself stated that he did see something in the installation of review committees consisting almost solely of laypeople. If expert committees first evaluated the scientific quality of study proposals, it was fine if laypeople thereafter evaluated if they also respected the rights of research subjects. This would ensure that laypeople would not be overpowered by experts in committee

\footnotetext{
${ }^{110}$ Robert V. Carlson, Kenneth M. Boyd, \& David J. Webb, 'The revision of the Declaration of Helsinki: past, present and future', in British Journal of Clinical Pharmacology Vol. 57 (2004), pp. 695-713.

${ }^{111}$ Centrale Raad voor de Volksgezondheid, Deeladvies inzake medische experimenten, p. 47.

112 NL-HaNA, 2.27.16, 554, 8008 100, Minutes of the working group, 24 November 1980, p. 7.

${ }_{113}$ Centrale Raad voor de Volksgezondheid, Deeladvies inzake medische experimenten, p. 47.

${ }^{114}$ NL-HaNA, 2.27.16, 554, 8008 78, Minutes of the working group, 23 June 1980.

115 Ibid., p. 8.
} 
discussions and could really make their voice heard. The radiobiologist knew of centres in the United States, he told the other working group members, where they had gained positive experiences with this type of reviewing, so why not give it a try in the Netherlands? Noach, however, argued it was better not to segregate experts and laypeople. They would have to reach verdicts on the permissibility of research proposals together, not separate from one another. The majority of the working group agreed. As it was explained in the 1982 report: "The integration between the world of science and the non-scientific world is best achieved by mixed committees" in which "scientists and laypeople can both influence one another". ${ }^{116}$ In theory, it was another way to realize the ideal of mature citizens. Review committees would help establish "horizontal relations of consultation and participation" in health care (see chapter 3) and function as tools of external control over medical research studies.

Finally, one of the most striking differences between the Central Council report of 1982 and the previous Health Council reports was the frank acknowledgement of the potential dark sides of human experimentation. While the Health Council reports had consistently shied away from mentioning too negative examples of medical tests upon human beings to shield the practice from undue public outrage (see chapters 1 and 2), the Central Council report stated outright in its introduction that human experiments had acquired a bad reputation as a result of the "horrendous abuse of the defenceless prisoners in the German concentration camps in World War II, and the exposé of a few scandals on this terrain in especially the U.S.A." ${ }^{117}$ Noted, the report did not state if this reputation was justified, but it established a connection that functioned in itself as a justification for public control over human experimentation.

Yet, in part, as the next section will show, this break with the Health Council reports in practice served a goal remarkably similar to these reports, namey to protect the conduct of human experimentation from all too critical societal critiques. Noach, in fact, managed something with the Central Council's working group 'medical tests upon human beings' he had not been able to with the Health Council committee 'clinical pharmacology', i.e., to make sure that a blueprint for the governance of human research would not result in undesired delays in clinical research in the Netherlands. The pharmacologist Noach very much remained a therapeutic reformer.

\section{The 'old' function of research ethics committees}

In 1979, the deliberations of the working group had started off on a bit of a rough note. During the first few meetings, the members had debated what type of interventions should exactly be included in the category of 'medical tests upon human beings'. Like the Health Council committees before it, the working group soon concluded that it was not always so easy to distinguish between medical research and practice. When did an intervention constitute an experiment and when was it just a form of advanced care? Did observational studies count as experiments? Should interventions that were already routine in the United States but still hardly ever tried out in the Netherlands be included? And what about the first time a surgeon in training carried out an operation? After a little while, the working group decided to settle on a generic description:

\footnotetext{
${ }^{116}$ Centrale Raad voor de Volksgezondheid, Deeladvies inzake medische experimenten, p. 46.

${ }^{117}$ Ibid., p. 5.
} 
"Investigations consisting of the application of new or insufficiently tested resources and procedures in humans with the goal to determine if new insights can be acquired or if prevailing insights require revision". ${ }^{118}$ Most working group members agreed this definition had to be understood as a guideline rather than a strict juridical category: it would be up to the review committees to decide which activities warranted further investigation. As Noach put it during the working group's first meeting: in practice, medical experiments with human beings were simply recognized as everything which "deviates from regular medical treatment". ${ }^{119}$

Van Bekkum, however, strongly disagreed with this generic description for human experimentation. Absent from the first three meetings of the working group, the radiobiologist sent in pressing notes to express his discontent. Especially the fact that the working group's definition included the conduct of clinical trials frustrated him:

If one wants to classify this work as 'experiments with human beings' one has to realize that therewith all introductions of new treatments and diagnostic methods, that is all innovation in health care, will come to fall under the term 'experiments with human beings'. [...] I do not think it is wise to treat these activities by a working group called medical tests upon human beings, given the very special interpretation that all outsiders and many physicians give to this. ${ }^{120}$

With this 'special interpretation' Van Bekkum meant the recent unrest in the Netherlands over human experimentation. The label 'tests upon human beings', the radiobiologist argued, had come to acquire a negative connotation in the Netherlands in recent years. It now invoked images of the research scandals that had taken place in the United States or worse, of the Nazi concentration camp experiments. ${ }^{121}$ Clinical trials, Van Bekkum pressed, had to be kept away from any association with these atrocious events, otherwise the already fragile field of clinical research would be shut down in the Netherlands. Clinical trials were not even experiments really, the radiobiologist continued, they were a form of "rational therapeutics" in which multiple treatments were compared to determine their efficacy. This was different from pure experimentation and labelling them as such would be detrimental to medical research and practice in the Netherlands. In fact, Van Bekkum wrote in, if the working group decided to proceed in this fashion, he was forced to break his ties with it. ${ }^{122}$

This remark provoked considerable dismay among members of the working group. Noach pressed, however, that it was important to keep Van Bekkum on board, as he belonged to a relatively small group of experts in the Netherlands who had any practical experience with the subject under investigation. During a subsequent meeting at which Van Bekkum was actually present, the radiobiologist explained his frustration: as things stood, he claimed, about 50 percent of all therapeutic and diagnostic inter-

\footnotetext{
${ }^{118}$ Centrale Raad voor de Volksgezondheid, Deeladvies inzake medische experimenten, p. 14. See also: NL-HaNA, 2.27.16, 554, 8008 24, Minutes of the working group, 8 June 1979; NL-HaNA, 2.27.16, 554, 8008 39, Minutes of the working group, 27 August 1979.

${ }^{119}$ NL-HaNA, 2.27.16, 554, 8008 19, Minutes of the working group, 8 May 1979, p. 4.

${ }^{120}$ NL-HaNA, 2.27.16, 549, 8008 22, brief van D.W. van Bekkum aan H.T.M. Linssen, 18 juni 1979, pp. 1-2. Underscore in original.

${ }^{121}$ NL-HaNA, 2.27.16, 554, 8008 45, Minutes of the working group, 22 October 1979, p. 6.

${ }^{122}$ NL-HaNA, 2.27.16, 554, 8008 39, Minutes of the working group, 27 August 1979, p. 2.
} 
ventions in the Netherlands had never been tested on their efficacy; they only persisted out of tradition. ${ }^{123}$ Hence, the systematic conduct of clinical trials was direly needed in the Netherlands to evaluate the merits of all these interventions. Yet for that to happen, it did not help to start connoting rational therapeutics with the contaminated label 'tests upon human beings' and argue it required more public control. Patients in clinical trials did not need additional legal protection, Van Bekkum argued, they typically received "a top treatment by a top team, often with resources that are available nowhere else". ${ }^{124}$ If anything, the radiobiologist scoffed, patients treated by physicians who just meddled about with therapies needed extra protection.

Some working group members objected that Van Bekkum seemed to forget he was a "frontier scientist". His experiences with the conduct of clinical research were likely to be more positive than those in "hospitals and clinics, where all kinds of things happen under the guise of science". The participating medical inspector, in particular, argued that he at times encountered situations upon his control-visits that made him think that "especially those [working] in clinics often have absolutely no realization of what it is they are doing exactly". ${ }^{225}$ The elite scientist Van Bekkum, in other words, might be trusted with the conduct of clinical trials, but the same could not reliably be said of the average physician; the regulation of clinical trials was needed to keep practitioners conducting experiments in the periphery in check.

Noach, however, professed to agree with Van Bekkum that the term 'medical tests upon human beings' had become a bit of a taboo in recent years. In Leiden, he stated, they therefore preferred to speak of "patient-related research" instead of clinical experiments. ${ }^{126}$ Even more, he agreed with the radiobiologist that patients participating in clinical trials were usually surrounded with better safeguards than those who did not. Yet, he continued by turning to Van Bekkum, this was partly because most clinical researchers acknowledged such patients needed additional protection. Hence, the working group's goal should not be to keep clinical trials away from public regulation, but to ensure that all experiments with human beings took place under similar conditions-and to eradicate the negative public image of the practice this way.

In part, the participating patient representative added, this negative public image was the effect of the "high degree of seclusion and mystery in which this sort of activities currently takes place". Most laypeople did not know what to make of the stories they heard about human experimentation, because the practice was often wrapped in a "dense fog". Hence, if the general public was to be made "more research-minded", (which apparently also the patient representative considered desirable), "more openness and insight has to be provided". ${ }^{127}$ Noach agreed. Their group had to make clear that human research was "no unseemly activity" and "be as open as possible to make the Dutch public more familiar with the phenomenon". If the saying "unknown, unloved" held true, people had to be introduced as soon as possible to good human experimentation. ${ }^{128}$ This was an important duty and opportunity the working group had in writing a policy report on the public governance of the practice.

\footnotetext{
${ }^{123}$ NL-HaNA, 2.27.16, 554, 8008 45, Minutes of the working group, 22 October 1979, p. 3.

${ }^{124}$ Ibid., p. 7.

${ }^{125}$ NL-HaNA, 2.27.16, 554, 8008 51, Minutes of the working group, 19 November 1979, p. 2.

${ }^{126}$ NL-HaNA, 2.27.16, 554, 8008 45, Minutes of the working group, 22 October 1979, p. 5.

${ }^{127}$ Ibid., p. 5.

${ }^{128}$ NL-HaNA, 2.27.16, 554, 8008 24, Minutes of the working group, 8 June 1979, p. 11.
} 
The entire working group, including Van Bekkum, could agree with this proposal. Its policy report would state the rights of research subjects in the conduct of 'medical tests upon human beings', including clinical trials, but it would also emphasize that the practice itself, when conducted within bounds, was (a) needed to realize the much desired progress of Dutch health care and (b) nothing to worry about. Thus, while the 1982 Central Council report frankly acknowledged that human experimentation had acquired a bad reputation due to American research scandals and the Nazi concentration camp experiments, it stated simultaneously that good human experimentation should be understood as categorically different from such past wrongdoings. In fact, the report read, since "the words 'medical tests upon human beings' still invoke associations with abuses from the past" and "the working group has wanted to stay away from such negative images, it has preferred to speak in her reflections of experiments with human beings". This new label fitted the contents of the report better anyway, as the preposition upon unjustly suggested an "underlying position" of the research subject in experimentation. A healthy researcher-subject relation, after all, was not a vertical relation of dependence of subordination, but a horizontal relation of consultation and participation. ${ }^{129}$ Experiments took place with human beings.

Also the blueprint in the 1982 Central Council report for the functioning of review committees served to protect and promote what the working group believed was good human experimentation. The report frankly admitted, for instance, that it hoped a positive effect of including laypeople in review committees would be the erosion of the negative public image of human experimentation. More openness would show the general public that "experiments are useful and necessary and take place in compliance with rules and procedures". ${ }^{130}$ To ensure this, it was important for participating laypeople to agree that human experimentation was in fact 'necessary and permitted'. They could not, for instance, reject the practice altogether like the old antivivisectionists had done (see chapter 1). Furthermore, they needed to conduct themselves "in a reasonable manner" to participate in the review of proposals. Not just every layperson was qualified, they had to have "a bit of quality and a certain interest" to be eligible for a committee seat. To ensure that the right 'society-representatives' were elected, therefore, Noach proposed that in practice laypeople would be chosen via a "cooptation procedure", whereby each of the sitting members, i.e. the experts, would be permitted to decide which laypeople were suitable to take part. ${ }^{131}$

In addition, the working group maintained review committees had to seat enough scientific experts to judge the scientific quality of proposals. For studies to be permitted, they had to adhere to "generally accepted scientific principles [...] including both the theoretical and methodological aspects as well as the organization of the study". ${ }^{132}$ Thus, like the Health Council reports before it, the Central Council report proposed

\footnotetext{
${ }^{129}$ Centrale Raad voor de Volksgezondheid, Deeladvies inzake medische experimenten, p. 14. See also: Van Bekkum, 'Medische experimenten en proeven op mensen', pp. 116-117.

${ }^{130}$ Centrale Raad voor de Volksgezondheid, Deeladvies inzake medische experimenten, p. 46.

${ }^{131}$ NL-HaNA, 2.27.16, 554, 8008 100, Minutes of the working group, 4 November 1980, p. 7.

${ }^{132}$ Centrale Raad voor de Volksgezondheid, Deeladvies inzake medische experimenten, p. 27-31.
} 
for review committees to function like epistemic filters: they had to sift out good research studies from bad research studies, with good also referring to methodologically sound (see chapter 2). In meetings, Van Bekkum literally referred to review committees as "filters" with the appropriate "know-how" to judge research design. ${ }^{133}$ Only the Central Council no longer spoke of the maxim 'only good science is ethical science', but of 'only good science is reasonable science'. Sound science, as defined by a specific class of medical researchers, had become a patients' right.

Thirdly, the working group purposefully recommended an oversight system built around multiple local review committees. It argued this would benefit the intensification of clinical research studies in the Netherlands more than a system built around a single national council, as the Health Council had recommended in 1981 (see chapter 2). As a member of the Health Council committee 'clinical pharmacology', Noach had in 1981 already written a minority report on the matter because he feared the installation of a single national Council for Clinical Research would lead to undesirable delays in the conduct of clinical trials in the Netherlands (see chapter 2). In the working group 'medical tests upon human beings', the pharmacologist repeated his concern and found an ally in Van Bekkum. According to both researchers, the swift realization of medical progress in the Netherlands demanded that ethics review would never take more than a few weeks, which implied that enough committees had to be installed in the country to guarantee that all review requests could be handled quickly.

Finally, the working group advocated local review committees because it believed these to hold a more workable mid-way between the public and professional regulation of human experimentation. Particularly Noach and Van Bekkum feared that a national council was likely to enact abstract principles and rigid demarcations in the review of protocols due to its physical distance from actual research situations. According to Van Bekkum, the criteria proposed by the Central Council for determining the permissibility of research studies could never be taken as conditiones sine quibus non, but as benchmarks to decide if a study was reasonable. Were the scientific qualifications of researchers in order? Check. Did the host organisation have proper research facilities? Check. Did the review committee feel enough laboratory and animal experiments had already been conducted? Check. These questions could only be answered by committees familiar with the actual research setting; no national authority could stipulate absolute criteria for them. ${ }^{134}$ In research, Noach explained, "there are always imponderable elements at play" that could not be written down on paper. Hence, as only local authorities could truly know their "pappenheimers" [darlings], only they could emphatically decide whether the research(ers) being reviewed meant to do well-and thus reach informed and, crucially, flexible decisions. ${ }^{135}$

It was in this context that the word 'ethics' once again popped up in the reports of the Committee Rights of the Patient. While the word had not been mentioned a single time in one of the other four reports that were written under the flag of the Committee between 1980 and 1982 (see chapter 3), it was used several times in the 1982 report 'medical experiments with human beings', which spoke of the "ethical and juridical aspects" of human experimentation and the need to ensure the practice violated

${ }^{133}$ NL-HaNA, 2.27.16, 554, 8008 100, Minutes of the working group, 4 November 1980, p. 5.

${ }^{134}$ NL-HaNA, 2.27.16, 554, 8008 86, Minutes of the working group, 15 September 1980, p. 7.

${ }^{135}$ NL-HaNA, 2.27.16, 554, 8008 51, Minutes of the working group, 19 November 1979, p. 11. 
"neither ethical standards nor human rights". ${ }^{136}$ The report nowhere specified what it meant precisely with 'ethical standards', but in an appendix to the report prepared by Noach, the pharmacologist justified this heuristic use of the e-word:

Views of medical-ethical issues have gone through a rapid revolution in recent decades, which does not yet appear to be complete. For this reason, the stipulation of all too strict and detail norms is premature and undesirable..$^{137}$

The recent crisis of medical ethics (see chapter 3), in short, meant that the working group could not specify which ethical norms should precisely govern the conduct of medical experiments with human subjects. However, this crisis was precisely the reason why the word 'ethics' was used in the policy report: i.e. as it was still unclear what would be considered ethical in years to come, the stipulation of all too detailed legal norms might stifle a practice that was still developing. Instead, "a certain standard of norms needs to be developed through experience within each review committee over the course of her existence". Reviewers, Van Bekkum had argued in a working group meeting, continuously had to "align themselves with prevailing views in a particular country [...] which are not static and will change from time to time". Tacit and fluid, such views could not be laid down in sterile legislation-they depended on the context of individual research studies and fell in the category of 'ethics'. ${ }^{138}$

Hence, all in all, despite the fact that the 1982 Central Council report drew explicitly on articles like those by Visser to frame its policy recommendations, its blueprint for the oversight of human experimentation differed crucially. Where Visser favoured the participation of laypeople to institutionalize a healthy form of public distrust in medical researchers, the working group hoped their participation would restore public trust in the medical research establishment. Similarly, where Visser felt reviewers should operate as distant judges to reach impartial decisions, the working group stated that a close proximity to and intimate familiarity with research studies was needed to reach objective decisions. And where advocates of the patients' rights movement typically emphasized the importance of univocal legal rules for human experimentation, the working group preferred to speak of fluid ethical standards and the need to decide on a case-by-case basis if studies were permitted. Although the working group agreed, in short, that medical experiments with humans demanded external control to protect participating research subjects, it hoped much more than critical thinkers such as Visser that this control would safeguard the practice itself as well. According to therapeutic reformers like Noach and Van Bekkum, a moral need still very much existed in the Netherlands for proper human experimentation.

After the working group finished its deliberations in May 1981, its report first had to be discussed by, consecutively, the Committee Rights of the Patient, the Council's Committee of Delegates, and the Central Council itself, before it could be released for

\footnotetext{
${ }^{136}$ Centrale Raad voor de Volksgezondheid, Deeladvies inzake medische experimenten, p. 42.

${ }^{137}$ Ibid., Bijlage IV, Proeve van werkwijze van een toetsingscommissie, p. 6.

${ }^{138}$ NL-HaNA, 2.27.16, 554, 8008 103, Minutes of the working group, 26 January 1981.
} 
publication (a true Matryoshka-effect of the famous Dutch polder model). Although the report was accepted fairly easily by the Committee Rights of the Patient itself, it ran into difficulties when it was discussed in the Committee of Delegates and Central Council. In the Committee of Delegates, the new President of the Central Council Jo Hendriks (the old State Secretary of Public Health) noted that even though the report presented an important and solid piece of work, hesitation had befallen him with regard to "the aspects of the subject which have to do with ethics". As the report dealt with an "extremely sensitive matter", it felt out of order to freely use the word ethics while "the ethical discipline as such" had not been represented in the working group. Before the report was ready to be published, therefore, Hendriks first wanted to contact a number of ethicists and ask them what they thought of the document's "ethical merits". Multiple delegates agreed. Certainly because the report also mentioned past research scandals, it would be wise to ask individuals who concerned themselves with ethics and religion to check if they could live with its contents.

Delegate Wim van der Mijn, the jurist representing the KNMG who served as the vice-chairman of the Committee Rights of the Patient (see chapter 3), objected. The report was in line with "prevailing views on medical ethics", he argued, and his constituency, the Dutch medical profession, had no problem with the concept-document. Besides, the working group had been asked to explore the juridical difficulties of experimenting with human subjects-not its ethical aspects-and this had been done. Every Council report had ethical aspects, so why make a problem out of this one? In the opinion of the jurist, Hendriks really attributed "a weight to ethicists above their significance". Another delegate wondered if the Council President not rather wanted advice on how the report could be read. Hence, did Hendriks not mean public relations officers instead of ethicists? Hendriks was adamant, however, that ethicists had to take another look at the report. The Committee of Delegates decided, therefore, to send the document to five authors who had published on the subject of (medical) ethics in recent years to check if they could agree with its contents. ${ }^{139}$

The responses of these authors varied, but they generally concurred that the report did not contain any statements that flagrantly violated any ethical norms and values. Most importantly, their responses satisfied Hendriks, which meant that the report could now be discussed in the Central Council itself. There, however, additional objections mounted. One member in particular, a representative of a Dutch patient organization, confessed to have shivered when reading the report, as it emphasized so strongly the absolute necessity of experimenting on humans while speaking only in veiled ethical terms about interactions between researcher and subject. In his opinion as a "medical outsider", the report came across as suspiciously "medical": i.e. its recommendations had been written from a technical perspective, whereas it should have been written from the perspective of patients' rights. ${ }^{140}$ What was more, he was unimpressed with the composition of the oversight committees that the report proposed. Physicians dominated, while only a few seats had been reserved for those who would see it as their primary aim to secure the interests of patients.

\footnotetext{
${ }^{139}$ All quotes in the last two paragraphs: NL-HaNA, 2.27.16, 51, 1004259 , Minutes of the $259^{\text {th }}$ C.v.G.-meeting, 5 February 1982, pp. 3-6.

${ }^{140}$ For the responses, see: NL-HaNA, 2.27.16, 811, 8008139 until 8008 145. For the meeting, see: NLHaNA, 2.27.16, 24, 1002 165, Minutes of the $259^{\text {th }}$ Central Council meeting, 4 February 1979, pp. 4-6.
} 
Both Leenen and Noach, who were present for comments, assured the hesitant Council members that the experience they already had with reviewing research protocols taught them that there was no need to worry about these things. In practice, reviewers always worked things out in an open and congenial manner, whereby ample attention was paid to the rights and interests of research subjects. ${ }^{141}$ Leenen admitted that also he found the use of the term ethics somewhat vague in the report, but this, the jurist argued, was unavoidable. Ethical norms changed from time to time, so it did not make sense to try and nail them down in a policy report. He could guarantee, however, that the norms used in the report rested on a "widespread and international consensus", such as the Declaration of Helsinki. ${ }^{142}$ If the Council insisted, however, Leenen was willing to tone down those parts of the report that came across as overly enthusiastic about the conduct of human experimentation. ${ }^{143}$

With that admission and a few changes, the Central Council report 'medical experiments with human beings' was finally authorized for publication in March 1982. In the 1980 s and 1990s, it became the blueprint for the governance of human research studies in Dutch political circles. Nonetheless, as will become clear from the next two chapters, it would take another sixteen years for the Dutch government to effectuate a law for the conduct of 'medical experiments with human beings' in the Netherlands. In effect, when Dutch parliament in 1997 for the first time got to debate a legislative proposal based on the 1982 Central Council report, it was discussing a system of ethics by committee that had already congealed around the ideas of those who had started to push in the 1980 os for more expert control over human research. In fact, when members of parliament once again brought up the need for more democratic control, the Dutch government increasingly found solace in a new type of expert to resolve the tension between these two modes of governance: the ethicist. For while Van der Mijn, a strong advocate of the Dutch patients' rights movement, had still argued in the early 1980 s that it was foolish to attribute a weight to ethicists above their significance, this new expert on the block in the late twentieth century came to fulfil a key function in the public governance of human research studies in the Netherlands.

\footnotetext{
${ }^{141}$ NL-HaNA, 2.27.16, 24, 1002 165, Minutes of the $259^{\text {th }}$ Central Council meeting, 4 February 1979, p. 10.

${ }_{142}^{142}$ Ibid., p. 5.

${ }^{143}$ Ibid., p. 11.
} 



\section{PART III}

\section{EXPERT CONTROL}

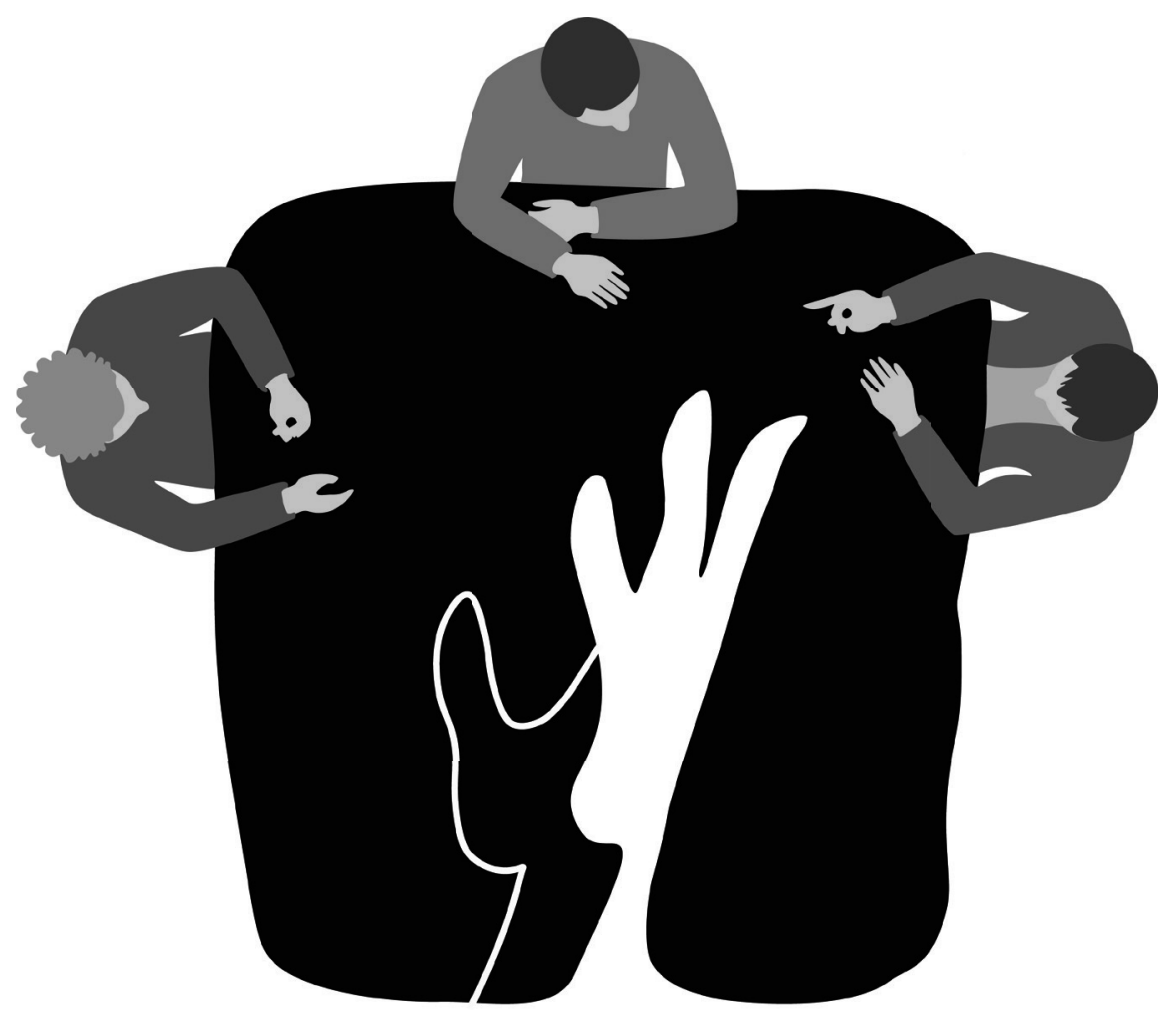





\section{- Chapter 5 • public governance in a pluralist society}

Around half past eight in the evening of Tuesday 3 September 1997, the Dutch House of Representatives began its official deliberations on 'the medical research involving human subjects bill', a legal proposal that had been in the works ever since 1982. Ad Lansink, representative of the Christian Democratic Appeal, was the first member of parliament to shine his light on the long-awaited bill. "Mr. Speaker!", the Christiandemocrat began formally, "the fight against disease and the care for the sick and disabled remains both a task and a mission, also for science and technology". Progress in these fields was absolutely necessary if society was ever going to end the suffering of patients. Still, Lansink continued solemnly, not everything which had sprung forth from science and technology in the past years could be labelled as progress, of which a growing number of questionable human research studies served as ringing reminders. Now more than ever, the Christian politician emphasized therefore, "society and the government have a duty to ascertain whether all research is permitted when held up to the norms and values that should bind a pluralist society". ${ }^{1}$

Lansink was not too sure, however, whether the incumbent Dutch government, an administration made up solely of secular parties, shared the same concern. The review bodies described in the bill, for instance, were not expected to include a single layperson, and did not in any way have "to take the ethical and religious plurality of society into account". ${ }^{2}$ Similar concerns were put forward by the other confessional parties in Dutch parliament. For these committees would not only check if researchers respected the rights of patients in 'regular' experiments, they potentially also had to decide on the permissibility of more contentious studies, such as experiments with embryos and foetal material or those that fiddled with genes. Really, Lansink pressed, how could "a committee that does not have to account to anyone" decide on studies about which no ethical consensus existed in Dutch society?3 What sort of public function did research ethics committees fulfil in a democratic society?

This chapter examines the realization of the Dutch Medical Research Involving Human Subjects Act (WMO), which has regulated the conduct of (medical) research with humans in the Netherlands since 1998. In the early 1980s, after the subsequent publication of the 1981 Health Council report 'clinical pharmacology' (see chapter 2) and the 1982 Central Council report 'medical experiments with human beings' (see chapter 4), the expectation was that the Dutch government would make haste with legislation for the conduct of human research in the Netherlands. As Dutch ethicist Heleen Dupuis aptly put it in 1982: "The matter of ethics committees, as expressed in the report of the Central Council for Public Health, is pretty much one of the only

\footnotetext{
${ }^{1}$ Handelingen Tweede Kamer 1996-1997, 3 September 1997, p. 103-7289.

${ }^{2}$ Ibid., p. 103-7287. Also: Tweede Kamer, 22588, Nr. 10, Eindverslag, p. 29.

${ }^{3}$ Handelingen Tweede Kamer 1996-1997, 3 September 1997, p. 103-7310.
} 
things about which a reasonable consensus exists in our country". ${ }^{4}$ Yet, the realization of an actual legal framework would take another sixteen years. Although none of the four statespersons responsible for the WMO ever publicly questioned the urgency of a legislative framework, successive Dutch governments found reasons for most of the 1980 s and 1990 s to postpone its parliamentary discussion.

This chapter maps this political inertia and argues it has to be understood in light of changing political winds in the 1980 s and 1990s that oscillated between two governance ideals: a proactive and a reactive oversight system for human research, that each hinged on a different conception of the role of the government in regulating the conduct of its citizens. This inertia did not prevent a plethora of Dutch research ethics committees to spring up in the late twentieth century. Spurred on by international developments, hospital boards and other consortiums realized numerous review bodies in this period to oversee medical experiments with humans. Yet, it did ensure that the government had little influence on how these committees came to organize themselves. In effect, when Dutch parliament in 1997 could for the first time debate the oversight mechanisms that should ideally govern human experimentation in a democratic society, it was debating a practice that had congealed in the 1980 s around the ideals of forerunners who pushed for the expert control of human experimentation to guarantee uniform and independent review procedures. This did not prevent Dutch parliament members from demanding more democratic oversight of human research studies to ensure widely supported ethics review decisions in a pluralist society. It did mean, however, that political ideals of democratic governance in the Netherlands had to be balanced against a reality of expert review bodies.

To trace these developments, section I of this chapter first studies the governmental preparations for the WMO up until its parliamentary treatment in 1997. Section II charts the actual realization of Dutch research ethics committees in the 1980s, while section III looks at mounting criticisms on this development towards the end of this decade. Section IV analyses the parliamentary debates on the WMO, and investigates the tension that members of Dutch parliament experienced between the democratic and expert oversight of human research practices in a pluralist society. This tension, the Dutch government eventually came to argue, could be resolved by granting one sort of expert a key role in the public governance of human research by means of the practice of ethics by committee. This expert was the professional ethicist.

\section{Political 'vigour' in the Dutch polders}

In April 1982, one month after the publication of the Central Council report 'medical experiments with human beings' (see chapter 4), Dutch parliament unanimously adopted a motion stating that with the publication of this report, a large enough consensus now existed in the Netherlands in favour of taking legal measures for the regulation of human research studies. ${ }^{5}$ It was time the government started preparing a bill on the topic. This task was taken up by State Secretary of Welfare, Health and Culture Joop van der Reijden (member of the Christian-democratic party), who could report

\footnotetext{
${ }^{4}$ NL-HaNA, 2.15.36, 1708, 125-390, Beraadsgroep Gezondheidsethiek, 9 September 1982, p. 21.

${ }^{5}$ Handelingen Tweede Kamer 1981-1982, 20 april 1982, p. 3027; Tweede Kamer 1981-1982, Kamerstuk 16771, nr. 9, Motie van het lid Wessel-Tuinstra C.S.
} 
about a year later that his department was preparing a bill in line with the 1982 Central Council report. This meant, he explained to parliament, that he would not follow the recommendations of the 1981 Health Council report (see chapter 2):

The Health Council emphasises the importance of scientific research. However, while recognizing this importance, I prefer a regime that puts more emphasis on the legal position of the research subject. My thoughts are therefore more aligned with the scheme the Central Council has developed for this regulation. ${ }^{6}$

Thus, Van der Reijden planned to develop a proactive oversight system for medical experiments with humans in the Netherlands: experiments would only be permitted after a research ethics committee had given its approval. ${ }^{7}$ Notably, however, the State Secretary did not plan to fully adopt the Central Council blueprint. While his plans mentioned the inclusion of "experts in medicine, medical-biological or pharmacological research, ethics, law, and nursing", they omitted the participation of "representatives of society", which had been one of the central tenets of the 1982 report to ensure that "seclusion and mystery make way for openness and transparency" in a democratic society (see chapter 4). Van der Reijden offered no justification for this omission. ${ }^{8}$ After the report had been published, however, the Council had received multiple letters warning against the inclusion of laypeople in the oversight of scientific research. As the renowned pharmacologist Everhardus Ariëns wrote to the Council President in 1984: "I have doubts about the suggested participation of 'society-representatives'. Who will appoint these?". What if a proponent of alternative medicine would take up a seat and oppose any form of pharmacotherapy? What if a layperson with a confessional background would take part to reject any form of intervention medicine? Really, Ariëns-who was an active therapeutic reformer-wrote, only "relevant experts" should be allowed to participate, who could be "expected to reach a consensus based on open argumentations". 9 In Dutch parliament, Van der Reijden adopted this line of reasoning. In the absence of enough experts, the State Secretary explained, "unsound research is approved and sound research hampered". ${ }^{10}$ Ethics boards had to function as epistemic filters, leaving little room for the inclusion of laypeople. ${ }^{11}$

In 1984, still, Van der Reijden was optimistic that his 'human experimentation bill' would be ready to be submitted before the end of the political year. Nonetheless, to ensure the safety of research subjects as much as possible before a final law would be passed, he decided to already make the installation of an 'independent medical review committee' an official admission requirement for hospitals wishing to participate in the Dutch health insurance funds. To be sure, this policy measure only required hospitals to install a review committee, not for medical researchers actually to pay it a

\footnotetext{
${ }^{6}$ Tweede Kamer 1982-1983, Kamerstuk 16771, nr. 14, Brief van de Staatssecretaris van Welzijn, Volksgezondheid en Cultuur, p. 40.

${ }^{7}$ Handelingen Tweede Kamer OCV/UCV 1983-1984, 14 mei 1984, p. 94-18.

${ }^{8}$ Tweede Kamer 1982-1983, Kamerstuk 16771, nr. 14, p. 43.

${ }^{9}$ NL-HaNA, 2.27.31, 1065, Codenummer 4063, Nr. 739, Brief van E.J. Ariëns aan J.P.M. Hendriks, 7 September 1984. For Everhardus Ariëns, see: 'Levensbericht Everhardus Jacobus Ariëns', pp. 6-17.

${ }^{10}$ Handelingen Tweede Kamer 1983-1984, 9 February 1983, p. 2154. See also: J.W. Bins, 'Experimenten met mensen. Een verdwenen advies', in Medisch Contact Vol. 38 (1983), pp. 97-98.

${ }^{11}$ Handelingen Tweede Kamer 1983-1984, 10 February 1983, p. 2261.
} 
visit-let alone ask for its permission. Yet Van der Reijden hoped that hospital boards would stimulate their functioning by working the magic of 'corporate liability', i.e., in case things went south, hospital insurance would only pay up if researchers had first been given permission for their studies by an in-house review board.

The initiative indicates the determination of the Christian-democrat in the early 1980 s swiftly to realize better oversight mechanisms for human research studies in the Netherlands. In 1985, however, his expeditious plans were brought to a halt by a change in political winds that came blowing from the very government he was a part of. In the mid-1980s, like in many other countries in this period, initiatives to reduce government spending and regulations came to dominate Dutch politics. In 1982, the Christian-democrat Ruud Lubbers-often called the Dutch Margaret Thatcher-had won the elections with the slogan 'more market, less government'. He held the post of Dutch prime minister until 1994, a period of twelve years which were dominated by attempts to reduce the "mania for organization" by public organisations. His administration claimed this held particularly for the Dutch health care system, which would be an overwhelming bureaucracy with little leeway for professionals to act efficiently and in the interest of patients. Rather than top-down state regulations, therefore, the Lubbers-governments nurtured the bottom-up powers of the market-a neoliberal politics that went hand in hand with initiatives of privatization and deregulation. ${ }^{12}$ This framework proved to be an ill fit for a human experimentation bill that proposed to greatly restrict the professional autonomy of researchers by the installation of multiple local review committees. In 1985, therefore, the Ministers of Justice and Interior Affairs decided to veto Van der Reijden's plans on the grounds that it did not fit the Dutch government's attempts to reduce government regulations. ${ }^{13}$

In 1986, therefore, Van Der Reijden set out to write a second Dutch human experimentation bill that agreed more with the recommendations of the 1981 Health Council report. Researchers would be obliged to notify a national authority of their plans to conduct experiments with humans, but they would not have to await its permission to proceed with their studies. ${ }^{14}$ Before the State Secretary got well underway, however, his four year term in office ended. In July 1986, the Christian-democrat was succeeded by a familiar face: the conservative-liberal politician Dick Dees, who served as the State Secretary of Welfare, Health and Culture in the second Lubbers-cabinet until 1989. Dees had been an early political advocate of the codification of patients' rights in the Netherlands and had pressed the Dutch government ever since the Buikhuisenaffair to make haste with a definitive law for human experimentation (see chapters 3 and 4). What was more, just months before starting his term as State Secretary, the conservative-liberal politician had co-signed a parliamentary motion demanding the government that it would submit a 'human experimentation bill' as soon as possible. ${ }^{15}$ Dees, in short, could be expected to make a priority out of a legislative proposal for the governance of human research studies in the Netherlands.

\footnotetext{
${ }^{12}$ Roland Bertens, Gezondheid tussen staat en markt. De opkomst van het marktdenken in het Nederlandse zorgstelsel, 1974-1987 (Masterthesis Health Law, Universiteit van Amsterdam, 2015).

${ }^{13}$ Tweede Kamer 1984-1985, Kamerstuk 18600-XVI, nr. 24, Verslag van een mondeling overleg; Tweede Kamer 1985-1986, Handelingen 29 januari 1986, p. 2872; J.C. van Es, 'Experimenten met mensen en wetgeving', in Medisch Contact Vol. 40 (1985), p. 1115.

${ }^{14}$ Tweede Kamer 1985-1986, Handelingen 21 november 1985, p. 1688.

${ }^{15}$ Tweede Kamer 1985-1986, Kamerstuk 19200-XVI, nr. 89, Gewijzigde motie van het lid Terpstra c.s.
} 
Sure enough, by the end of 1987, his department had prepared another bill which did meet Lubbers' deregulation requirements. ${ }^{16}$ Research ethics committees would oversee the conduct of human research in the Netherlands, but these would only operate reactively, i.e., researchers were could engage in studies as long as they registered these with a national authority, and the State Inspectorate would only intervene if wrongdoings were suspected. ${ }^{17}$ After this renewed vigour, however, things slowed down once more, as Dutch legislative tradition demanded that the bill was first discussed by a number of advisory bodies before it was sent to parliament. Hence, the bill first travelled from the Council of Ministers to the National Council for Public Health, and from an interdepartmental juridical committee to the Dutch Council of State, the country's highest advisory body. Dees lamented these holdups, but had few means to influence them. The realization of a definitive law had to wait. ${ }^{18}$

By the time the Council of State was ready to issue its advice on Dees' human experimentation bill, three years had passed and Dees had been succeeded by labour politician Hans Simons, State Secretary of Welfare, Health and Culture in the third Lubbers-government. To make matters worse, the Council of State was, to put things mildly, not too enthusiastic in its appraisal of the new human experimentation bill. In addition to "some editorial comments", the Council had no less than twenty points of improvement to raise. While not all of these were of equal weight, some went right to the heart of the bill. For one thing, as if the matter had not been debated enough in the past fifteen years, the Council of State advised the government to replace the reactive mode of oversight in the bill with a proactive one, i.e., human experiments should only be legally allowed if a review committee had first given its permission for doing so. ${ }^{19}$ In addition, the Council of State objected to the bill's caveat that research studies were not allowed to "conflict with generally accepted ethical standards":

The Council considers the criterion set out in these provisions to be unclear for the researcher and unmanageable for the prosecuting authorities and criminal courts. After all, it is not the task of the criminal court to determine which ethical norms that have not been translated into juridical norms may be regarded generally acceptable. ${ }^{20}$

The biggest issue the Council of State had with Dees' bill, however, was that it allowed for non-therapeutic research studies to be conducted with individuals who lacked the legal capacity to consent. Indeed, Dees had left this option open for "research which entails little to no burden for the people involved and which may benefit the health of the group to which they belong, as long as the results of this study cannot be obtained by means of experiments with persons that do have legal capacity". ${ }^{21}$ According to the

\footnotetext{
${ }^{16}$ Tweede Kamer OCV/UCV 1988-1989, Handelingen 27 februari 1989, p. 33-18.

${ }^{17}$ Tweede Kamer 1991-1992, Kamerstuk 22588-A, Advies Raad van State, Nader rapport, p. 6.

${ }^{18}$ Tweede Kamer OCV/UCV 1988-1989, Handelingen 27 februari 1989, p. 33-18.

${ }^{19}$ Tweede Kamer 1991-1992, Kamerstuk 22588-A, p. 6.

${ }^{20}$ Ibid., p. 4.

${ }^{21}$ Ibid., p. 2.
} 
Council of State, however, this caveat was in direct violation of Article 7 of the 1976 International Covenant on Civil and Political Rights that prohibits any medical and scientific experimentation without the prior and in freedom given consent of research subjects-a clause which had been adopted to prevent any future recurrence of the atrocities committed under the flag of scientific research in the Nazi concentration camps in World War II, and that had been ratified by the Netherlands in 1978. ${ }^{22}$ The same went, the Council of State suspected, for the European Convention of Human Rights of 1950. While the Convention itself does not explicitly address the conduct of human research studies, the European Commission had ruled in 1983 that "medical treatment of an experimental character and without the consent of the person involved may under certain circumstances be regarded as prohibited by Article 3" which forbids inhumane or degrading treatments or punishments. ${ }^{23}$

It took Simons over one and a half years to respond to the objections raised by the Council of State. Surprisingly, despite the bill's muddled history when it came to desired oversight systems, he took no issue with the Council's protest against a reactive surveillance mode. In fact, the State Secretary now once more proposed a proactive system to counteract the Council's charge that the bill contained vague ethical standards. A proactive system made the prior permission by a review committee a defining criterion for criminal prosecution, which was a crystal-clear juridical norm. ${ }^{24}$ What was more, as review committees were only quasi-judicial bodies, they did not have to follow the same judicial rules of evidence as criminal courts had to, meaning that they could draw on ethical norms in the review of human research studies.

Simons was more reluctant, however, to concede to the Council's criticism about allowing non-therapeutic experiments with legally incapacitated individuals. Yes, the International Covenant on Civil and Political Rights prohibited such research studies, but, as the Council of State itself made clear, this Article had been informed by the Nazi concentration camp experiments, which were certainly not the experiments the Dutch department of Welfare, Health and Culture had in mind. It wished to allow for, say, experiments with patients suffering from Alzheimer's disease, to aid a better understanding of the nervous system of such patients, and to conduct EEG-tests on children under the age of ten. ${ }^{25}$ Simons was therefore only willing to meet the Council of State halfway. He would adapt Dees' bill to state that only those experiments with legally incapacitated individuals that directly benefited those belonging to the same legal category were permitted, and then only those studies which could absolutely not be performed without them. In addition, the bill would demand that this type of studies was only permitted if they contained minimal risks and objections and that they could only be reviewed by one national committee to guarantee "the greatest possible care and expertise" ${ }^{26}$ With such extra precautions in place, however, Simons did wish to allow for non-therapeutic experiments with legally incapacitated individuals, and in 1991, he once again felt ready to pilot a third version of the Dutch human experimentation bill through the national House of Representatives.

\footnotetext{
${ }^{22}$ Ibid., p. 1.

${ }^{23}$ Ibid., p. 3. See also: ECHR, Xv. Denmark, (no. 9974/82), Commission decision of 2 March 1983, D. \& R. 32, p. 282.

${ }^{24}$ Tweede Kamer 1991-1992, Kamerstuk 22588-A, p. 4.

${ }^{25}$ Ibid., pp. 2-3.

${ }^{26}$ Ibid., p. 3.
} 
Unfortunately for Simons, when Dutch members of parliament could for the first time submit written comments on this latest version of the human experimentation bill, it became clear that members from across the political spectrum struggled with precisely this element of the legislative proposal. ${ }^{27}$ It did not help in this regard, that no consensus existed on the issue among influential Dutch commentators on the bill. Proponents could count on the support of ethicist Inez de Beaufort, who had successfully defended a dissertation on medical experiments with human beings in 1985 and who warned that fully excluding legally incapacitated people from medical research would make any scientific breakthroughs impossible that could help treat disorders from which only these individuals suffered. ${ }^{28} \mathrm{~A}$ similar argument was put forward by the health lawyer Evert-Ben van Veen, who was an oft-cited authority on human experiments and who supported Simons in his reading of the International Covenant on Civil and Political Rights. ${ }^{29}$ Opponents, however, could count on the support of jurists Lucas Bergkamp and Henk Leenen (see chapter 3), who argued that non-therapeutic experiments with the legally incapacitated did violate Article 7 of the International Covenant on Civil and Political Rights. ${ }^{30}$ Although one could think up many examples of low-risk experiments that could potentially benefit these groups, the fact remained that others would decide if they were willing to contribute to scientific progress without any direct benefit in return. Crossing this line was like opening a can of worms: innocent studies would be stretched to match others that were also fairly innocent, which would serve as precedent for studies that were surely also reasonably innocent. Be warned, Leenen wrote, "exceptions often devour the rule". ${ }^{31}$

The fact that someone of Leenen's calibre opposed the human experimentation bill carried weight among members of Dutch parliament. ${ }^{22}$ And because they more generally found it difficult to decide which way was best ("we have not yet found the philosophers' stone", the liberal party wrote in 1992), they decided mid-1993 to organize another expert hearing on the topic.33 Parliamentarians wanted to know what type of non-therapeutic experiments with the legally incapacitated were typically conducted in the Netherlands and if these were really necessary from a medical point of view. 34 Although the members did not yet give any verdict, it appeared a realistic possibility

\footnotetext{
${ }^{27}$ Tweede Kamer 1992-1993, Kamerstuk 22588, nr. 5, Voorlopig verslag, pp. 32-42.

${ }^{28}$ I. de Beaufort, 'Niet-therapeutisch wetenschappelijk onderzoek met wils-onbekwame personen', in Nederlands Tijdschrift voor Geneeskunde Vol. 133 (1989), pp. 737-740.

${ }^{29}$ Van Veen had also served as the secretary to the National Council committee on medical experimentation to have evaluated Dees' legislative bill in the late 1980s and was politically regarded as an expert on the subject. See: Evert-Ben van Veen, 'Het betrekken van incompetenten in experimenten - een commentaar op enige commentaren', in Tijdschrift voor Gezondheidsrecht Vol. 13 (1989), pp. 536551; Evert-Ben van Veen, 'Het betrekken van incompetenten bij experimenten', in Tijdschrift voor Gezondheidsrecht Vol. 14 (1990), pp. 33-35.

${ }^{30}$ L. Bergkamp, 'Een voorstel voor een Wet op de medische experimenten: enkele kanttekeningen', in Tijdschrift voor Gezondheidsrecht Vol. 13 (1989), pp. 190-204; H.J.J. Leenen, 'Niet-therapeutische experimenten met incompetenten', in Nederlands Juristenblad Vol. 64 (1989), pp. 1501-1504; L. Bergkamp, 'Het betrekken van incompetenten bij experimenten', in Nederlands Tijdschrift voor Gezondheidsrecht Vol. 14 (1990), pp. 19-26; H.J.J. Leenen, 'Het betrekken van incompetenten bij experimenten', in Nederlands Tijdschrift voor Gezondheidsrecht Vol. 14 (1990), pp. 29-32.

${ }^{31}$ Leenen, 'Niet-therapeutische experimenten met incompetenten'.

32 Tweede Kamer 1992-1993, Kamerstuk 22588, nr. 5, p. 38.

${ }^{33}$ Tweede Kamer 1992-1993, Kamerstuk 22588, nr. 5, p. 39; Tweede Kamer 1993-1994, Kamerstuk 22588, nr. 6, Brief van de Minister van Welzijn, Volksgezondheid en Cultuur.

${ }^{34}$ Tweede Kamer 1995-1996, Kamerstuk 22588, nr. 7, Memorie van antwoord, p. 39.
} 
that Dutch parliament would come to forbid all non-therapeutic research with legally incapacitated individuals in the Netherlands. Alarmed by this prospect, no less than 12 biomedical associations sent a joint letter to the Dutch government in late 1993 to explain the "paramount importance that it remains possible in the Netherlands to conduct excellent and acceptable non-therapeutic research with the legally incapacitated". 35 It was signed both by politically influential associations such as the KNMG, the Royal Dutch Academy of the Sciences (KNAW), and the Netherlands Organisation for Scientific Research (NWO), and by associations which united medical practitioners who often treated legally incapacitated patients..$^{6}$

Due to the commotion, the department of Welfare, Health and Culture decided it once again needed more advice on the matter. In May 1994, it therefore installed an ad-hoc committee consisting of three physicians, an epidemiologist, an ethicist, and a jurist to write up a policy advice. 37 One year later, this committee concluded it should be possible to engage in low-risk non-therapeutic experiments with legally incapacitated individuals if a thereto installed committee had first given its approval. It recommended, however, to replace the terminology of 'medical experiments' in the legislative proposal with 'medico-scientific research'. For one thing, because the scope of the bill covered both observational and interventional research studies, while only the latter were usually denoted as experiments in the Dutch language. For another, because the use of "the term [experiment] seems to evoke negative associations in the average citizen". $3^{8}$ Hence, like the Central Council before it, also this committee proposed a rebranding of human experimentation to neutralize what it suspected might be a leading cause in the hesitant public opinion about non-therapeutic studies with legally incapacitated people: a tarnished public image (see chapter 4). With this latest addition in place, the Dutch government in 1995 once more felt confident to submit the newly baptised 'legislative proposal on medico-scientific research with humans' to the national House of Representatives. Yet, due to another change in government and standard parliamentary delays, the first oral treatment of the bill did not take place before September 1997. By then, a definitive law for regulating human research in the Netherlands had been in the making for already more than fifteen years.

\footnotetext{
${ }^{35}$ R.J.M. Dillmann \& W.R. Kastelein, 'Niet-therapeutisch wetenschappelijk onderzoek met wilsonbekwame patiënten; een gezamenlijk standpunt van Nederlandse medisch-wetenschappelijke organisaties', in Nederlands Tijdschrift voor Geneeskunde Vol. 138 (1994), pp. 1676-1680.

${ }^{36}$ Ibid., p. 1676. Listed were: the Dutch Society for Paediatrics, the Dutch Society for Nursing Home Physicians, the Dutch Society for Psychiatry, the Dutch Society for Gerontology, the Dutch Society for Physicians in Mental Health Care, Dutch Society for Epidemiology, Dutch Society for Neurology, Society Academic Hospitals and Dutch Society for Medical-Ethical Review Committees. Together, they presented an overview of the type of research studies they believed should be legally permitted and how these could best be assessed by local review committees. They also provided a list with examples of scientific studies which would be brought to a halt if a full ban would go into effect. This included research into respiratory problems in new-borns, into risks of playing sports for children with Down-syndrome, and into reasons for the poor recovery of comatose patients.

${ }^{37}$ Tweede Kamer 1993-1994, Kamerstuk 22588, nr. 6.

${ }^{38}$ Advies inzake regeling van medisch-wetenschappelijk onderzoek met minderjarigen en meerderjarige wilsonbekwamen [uitgebracht door de Commissie medische experimenten met wilsonbekwamen] (Rijswijk: Ministerie van Volksgezondheid, Welzijn en Sport, 1995), p. 21.
} 
The slow trajectory of the Dutch human experimentation bill during the 1980 s and 1990 gave rise to many concerns and frustrations in the Netherlands. In the sixteen years that passed between the publication of the Central Council report in 1982 and the effectuation of the WMO in 1998, members of Dutch parliament filed numerous motions in attempt to pressure the government into making haste with its legislative plans for human experimentation. ${ }^{39}$ In 1989, one member even warned in parliament that the lack of proper legislation had made the Netherlands "a true paradise for conducting experiments" for researchers from countries like the United States in which human research acts had existed for quite some time now. This, the concerned parliament member charged, was "utterly reprehensible from an ethical and patient protection point of view". ${ }^{40}$ Dutch patients were turning into guinea pigs for the worldwide research community while their own government stood idly by.

In Medisch Contact, similar concerns could be heard from time to time as well. In 1986, for example, health jurist Henriette Roscam Abbing pondered cynically what would come in the Netherlands of the regulation of more controversial biomedical research fields, like recombinant DNA technology, if the Dutch government could not even enact a human research act, a law about which an overwhelming consensus existed that it actually should be there. If the government did not hurry up its legislative process, she warned, the Netherlands would soon turn into "a 'free state' for experiments [...] which are refused elsewhere". ${ }^{41}$ Similarly, in 1987, a group of general practitioners warned that "the Netherlands is (becoming) an international testing ground for all sorts of experimental research". ${ }^{42}$ In recent years, they claimed, Dutch general practitioners had started receiving more and more requests from international pharmaceutical companies to enrol their patients in clinical trials in return for financial rewards or lucrative gifts like a computer. ${ }^{43}$ Deputy Superintendent of Public Health Herman van Geuns confirmed these claims in Medisch Contact: in the past few years, the Dutch State Inspectorate had received multiple complaints from general practitioners about advances of 'Big Pharma', which would be drawn to Dutch general practice because of its lack of systematic oversight. 44 Although the State Inspectorate tried to fill this lacuna the best it could, Van Geuns wrote half apologetically-half angrily, "it can only effectively perform this task, if a legal basis exists for it". 45

In the late 1980 s and 1990s, more of these concerns were voiced in Dutch parliament, academic journals, and the general press. If the Dutch government failed to act soon, their repeated message was, something was bound to go seriously wrong in the ethical conduct of human research studies in the Netherlands. Without the realiza-

\footnotetext{
${ }^{39}$ Tweede Kamer 1981-1982, Kamerstuk 16771, nr. 9; Tweede Kamer 1985-1986, Kamerstuk 19200XVI, nr. 89; Tweede Kamer 1991-1992, Kamerstuk 21264, nr. 17, Motie van het lid Kohnstamm.

${ }^{40}$ Tweede Kamer OCV/UCV 1988-1989, Handelingen 27 februari 1989, p. 33-6.

${ }^{41}$ H.D.C. Roscam Abbing, 'Genetische experimenten met mensen. Wetgever quo vadis?', in Medisch Contact Vol. 41 (1986), pp. 533-535.

${ }^{42}$ Emmy G. Scholten, 'Wetenschappelijk onderzoek huisartspraktijken', in Medisch Contact Vol. 42 (1987), p. 1188.

${ }^{43}$ J.W. van Ree \& B. Bottema, 'Wetenschappelijk onderzoek huisartspraktijken', in Medisch Contact Vol. 42 (1987), p. 953.

${ }^{44}$ H.A. van Geuns, 'Uit de Geneeskundige Hoofdinspectie: Medische experimenten in de huisartspraktijk', in Medisch Contact Vol. 42 (1987), p. 694.

${ }^{45}$ H.A. van Geuns, 'Het Staatstoezicht en medische experimenten met mensen', in Medisch Contact Vol. 40 (1985), pp. 801-802, p. 802.
} 
tion of a proper legal basis for the governance of these studies, their proper oversight was simply impossible. However, if any foreign researcher after reading such articles would have descended upon the Netherlands in the expectation that (s)he would be able to conduct all sorts of medical experiments with humans in the country without encountering some sort of review board, (s)he would have been in for a rude awakening. For a wealth of oversight bodies for human experimentation did spring up in the Netherlands in the 1980s-So many, in fact, that by the end of the decade, traditional enthusiasts of the research ethics committee had started to argue that legislation was needed to bring the practice of ethics by committee itself under control.

\section{Developments on the ground}

In 1976, the first official 'research ethics committee' of the Netherlands was inaugurated at Leiden University, titled the Committee Medical Ethics (CME). The Leiden CME was installed to provide institutional advice on various issues of ethical concern, but its foremost task was the ethics review of research protocols of medical experiments with human subjects that were executed under auspices of the Leiden medical faculty and university hospital. This local review board, which would become the prototype for almost all other Dutch research ethics committees in the 1980s and 1990s, was the brainchild of a medical scientist who had held a professorial chair in pharmacology at Leiden since 1963 and who by 1976 had become quite the national authority on the governance of human research with review committees. The founder and first chairman of the Leiden CME was the pharmacologist Erik Noach.

Noach had actually already been involved in early experiments with the communal ethics review of clinical research studies at Leiden university since 1965. In early June of that year, the board of the Leiden medical faculty had received a letter from geneticist and scientific director of its Institute for Radio Pathology and Radiation Protection Frits Sobels with the following request:

Given the medical-ethical issues which the leadership of the Institute of Radio Pathology and Radiation Protection faces when it comes to making observations in human research subjects, I would appreciate it when you would install a faculty committee that may provide advice in such cases. It seems to me that it might be useful in general if a permanent faculty committee will be created for medicalethical problems which are related to research on human subjects. 46

The faculty board had responded by requesting Sobels to write a report on the possible installation of such a committee, a task which he set out to fulfil with Leiden internist Jaap de Graeff and the newly appointed professor in pharmacology at Leiden university Erik Noach. In December 1965, Noach presented this report in front of the board of the medical faculty and recommended the installation of a "permanent fac-

\footnotetext{
${ }^{46}$ The early history of the Leiden committee medical ethics is described in detail by Prof.mr.dr. Dick Engberts, the current vice-chairman of the committee (2016) in: D.P. Engberts, 'De vroege Jaren. Ontstaan en werkzaamheid van een medisch-ethische (toetsings)commissie in Leiden in de Jaren zestig van de vorige eeuw', in Dilemma's getoetst, pp. 9-28. This article is based on Noach's personal archive and the archive of the Leiden Committee Medical Ethics. Sobel's letter is quoted on page 9.
} 
ulty committee" that could help formulate standards for the conduct of human experiments and help decide in specific cases if researchers acted in accordance with these norms. ${ }^{47}$ Notably, the board did not follow this advice; no official ethics committee was installed in Leiden in 1965 . Yet, in the period thereafter, it did occasionally start to send human research protocols to the three physicians with the request to evaluate their permissibility, making their activities one of the first forms of ethics by committee in the oversight of human experimentation in the Netherlands.

It is not entirely clear why the board of the Leiden medical faculty at times started to send human research protocols for evaluation to the triumvirate Sobels, De Graeff, and Noach in the late 1960 s. At first, they were only asked to advise on the permissibility of ultimum refugium experiments (i.e. experimental interventions that serve as a last resort to safe a patient). From July 1967 onwards, however, the men were also occasionally asked to review protocols for the execution of a randomized controlled trial. $4^{8}$ A letter posted in 1967 by the Leiden medical faculty's board of trustees to the U.S. Department of Health, Education and Welfare offers one reason why this development took place. This letter, that was written in the context of a grant-application, served to reassure the United States government of the following:

[...] In 1965, the Faculty of Medicine at the University of Leiden instituted a committee to investigate all proposed experimental procedures involving humans which are to be undertaken by the members of the faculty. 49

This was quite an exaggeration, as Sobels, De Graeff, and Noach by no means evaluated all or even most human research protocols in Leiden. Yet in 1966, in the midst of the public outrage over the many questionable clinical experiments with human subjects that would regularly take place in United States hospitals, the U.S. Public Health Service (PHS) had made "prior review of the judgment of the principal investigator or program director by a committee of his institutional associates" an official eligibility requirement for those who wished to receive PHS-grants (see chapter 4). Soon thereafter, this policy was also adopted by the U.S. Food and Drug Administration (FDA) and the U.S. Department of Health, Education and Welfare..$^{\circ}$ In theory, these policies mandated that also Dutch researchers hoping to receive grant money from the PHS (or Dutch companies wishing to market their products on the United States consumer market) needed to have their human research studies monitored by 'a committee of his institutional associates', which explains the reassuring letter of the Leiden medical faculty to the U.S. Department of Health, Education and Welfare: it ensured the access of its researchers to American money. In reality, however, only Leiden had some sort of review board in the late 1960 s and even this committee appears to have disbanded for unknown reasons after a few years of semi-active duty. ${ }^{11}$

\footnotetext{
${ }^{47}$ See also: J. Bennebroek Gravenhorst, 'Medisch-ethische toetsing van wetenschappelijk onderzoek in Nederland', in Geneeskunde en Ethiek in Harmonie, pp. 97-105, p. 98.

${ }^{48}$ Ibid., p. 19.

${ }^{49}$ Ibid., p. 15.

${ }^{50}$ A detailed overview of this development is provided in Stark, Behind Closed Doors. The quote from the PHS's 1966 decree is derived from page 154.

${ }^{51}$ Engberts, 'De vroege jaren', p. 22.
} 
It was in November 1973 that the board of the Leiden medical faculty received another request from one of its physicians to install a research ethics committee. The reason underlying this request, this physician wrote, was that medical research internationally seemed to be subjected increasingly to ethical demands. Publications, for instance, "are [now] sometimes made dependent on the existence of a written verdict of an ethics committee". Hence, it would be helpful if the Leiden medical faculty was willing to install a review committee that "can operate as official conscience and warranting agency" ${ }^{52}$ Again, the faculty council commissioned Noach for a response. The pharmacologist wrote back to state that Sobels, De Graeff, and he were no longer active because they had expected the government to take over after publication of the Health Council advice 'clinical drug research' in 1971 (see chapter 2), in which he and his team had recommended the formal regulation of human research in the Netherlands. However, as it appeared that the Dutch government was in no hurry to realize any public oversight mechanisms for the practice (see chapter 2), Noach agreed that it would be a good idea for the Leiden medical faculty to reactivate its dormant ethics committee.53 In June 1976, this advice resulted in the official instalment of the Leiden CME, often taken to be the oldest Dutch research ethics committee.

In 1979, Noach proudly reported in Medisch Contact that his CME had received more than 60 requests for advice over the past three years, most of which had been handled within six weeks. 54 Things were going well, the pharmacologist wrote. Even though the CME could officially only review protocols which researchers had actually decided to submit, it inhabited quite a powerful position within the academic hospital and medical faculty, as both institutions had agreed only to be held liable for research studies that the CME had authorized. This 'threat', the expectation was, would incite most researchers to first pay the CME a visit before starting a study. Noach emphasized, however, that Leiden researchers did not have to fear the CME. Protocols were always evaluated in consultation with the applicants, and procedures were specifically designed to pose only a minimal burden. Researchers really had to think of the CME as a collegial form of peer review and not as a meddlesome form of oversight-Noach et al. were no police men. ${ }^{55}$ Still, ethics review was needed, the pharmacologist wrote, because "the regularly resurfacing view that particularly in teaching hospitals patients would be used as 'guinea pigs' can only be combatted with a clearly coordinated policy that does not need to shun publicity, particularly with regards to ethical issues". ${ }^{6}$ Ethics boards had to help restore the public's trust in medical research.

The Leiden CME was not the only research ethics committee active in the Netherlands at the end of the 1970s. In 1973, a committee had been established at the Free University of Amsterdam which gave advice about clinical pharmacological research as well as about euthanasia and abortion cases. 57 In 1977, a survey conducted at TNO

\footnotetext{
${ }^{52}$ Ibid., p. 22.

${ }^{53}$ Ibid., p. 23.

${ }^{54}$ Noach \& De Kroon, 'Medische ethiek: patiënten en proeven', pp. 1575-1583.

${ }^{55}$ See also: P.J.W.M. de Kroon, 'De begintijd van de Leidse Commissie voor Medische Ethiek', in Geneeskunde en Ethiek in Harmonie, pp. 93-95.

${ }^{56}$ Noach \& De Kroon, 'Medische ethiek: patiënten en proeven', p. 1581.

${ }^{57}$ Lucas Bergkamp, 'American IRBs and Dutch Research Ethics Committees: How They Compare', in IRB: Ethics \& Human Research Vol. 10 (1988), pp. 1-6. In this article, Bergkamp dates the instalment of the Medical Ethical Committee of the Free University of Amsterdam to 1970. In 1977, however,
} 
by the biochemist Theo Gerritsen (see chapter 4) on the existence of review committees in the Netherlands brought back that a 'committee research subjects' had recently been installed at the university of Rotterdam and that small informal review groups were now active at the universities of Nijmegen and Utrecht as well. Gerritsen, however, was sceptical about the actual functioning of these committees. "With the exception of Leiden", the biochemist wrote down in an internal TNO-memo in 1977, "the situation with regards to monitoring the use of human subjects is so miserable at the Dutch teaching hospitals and medical faculties that it does not appear sensible to trust the judgment of these self-styled local committees". ${ }^{8}$ By the end of the 1970s, in short, the practice of ethics by committee to oversee the conduct of human research studies was still hardly a familiar phenomenon in the Netherlands.

This changed spectacularly in the 1980s. In June 1981, the University of Groningen proudly announced in Medisch Contact that "after Leiden now also Groningen has its CME".59 In 1985, Noach could report that approximately 20 ethics boards were now active in the Netherlands. ${ }^{60}$ Merely one year later, jurist Lucas Bergkamp already counted 63 research ethics committees in the country. In a few years' time, Bergkamp predicted, their total would likely amount to more than a hundred. ${ }^{61}$ Sure enough, by 1989 their grand total was estimated to lie around 150 committees. ${ }^{62}$

Commentators in the 1980 s at times puzzled about the sudden exponential growth of Dutch research ethics committees in the absence of legislation mandating the ethics review of human experiments in the Netherlands. Nonetheless, various likely reasons exist to explain why they shot up like mushrooms in this period. First of all, the fact that State Secretary Van der Reijden in 1984 made research ethics committees an admission requirement for Dutch health insurance funds undoubtedly played a role in their explosive growth rate after the mid-1980s. Secondly, the history of the Leiden CME indicates that changing grant and publishing policies likely had an effect as well. Indeed, when Bergkamp in 1986 asked 25 Dutch research ethics committees why they had been established in the early 1980s, grant and publishing policies scored high on their lists. ${ }^{63}$ By then, especially Anglo-Saxon funding agencies and journals had made written approval of an ethics committee a requirement to be able to apply for funding or to submit an article involving the conduct of human research studies.

TNO received a letter from the Free University of Amsterdam about the activities of this committee, stating it had only been active for four years (thus going back to 1973). See: NL-HaNA, 2.14.36.06, 481, brief van Chr. L. Rümke aan TNO, 01-04-1977.

${ }^{58}$ NL-HaNA, 2.14.36.06, 481, brief van T. Gerritsen aan H.G. van Brummen, 20-04-1977. In Groningen, a research ethics committee existed on paper, which was inactive in practice.

59 'Medisch Ethische Commissie', in Medisch Contact Vol. 36 (1981), p. 776.

${ }^{60}$ E.L. Noach, 'De functie van ethische commissies bij medische experimenten met mensen', in $\mathrm{Me}$ disch Contact Vol. 40 (1985), pp. 872-874.

${ }^{61}$ L. Bergkamp, Medisch Ethische Commissies en het Toezicht op Experimenten met Mensen. Verslag van de eerste fase van een onderzoek naar de structuur en het functioneren van medisch ethische commissies (Universiteit van Amsterdam: Instituut voor Sociale Geneeskunde, 1986), p. 204, p. 14.

${ }^{62}$ E.J. Boer, 'Medisch-ethische commissies, taak en functie bij wetenschappelijk onderzoek', in Nederlands Tijdschrift voor Geneeskunde Vol. 133 (1989), pp. 1659-1664.

${ }^{63}$ Bergkamp, Medisch Ethische Commissies [...] Verslag van de eerste fase, pp. 28-29, p. 31. 
Also in the Netherlands this policy had started to gain ground in the early 1980 s. In respectively 1978 and 1980, both the Dutch Foundation for Fundamental Medical Research (FUNGO-ZWO) and TNO had adopted the same set of guidelines stipulating that all grant applications for experiments with humans directed at their address had to be accompanied by a positive verdict from a "committee research subjects". ${ }^{64}$ FUNGO and TNO stated to base this policy on the 1975 revision of the Declaration of Helsinki, which demanded that all human research protocols from then on had to be submitted to "a specially appointed independent committee for consideration, comment and guidance". ${ }^{65}$ Hence, rather than awaiting whatever decision the Dutch government might eventually make in the regulation of human research studies, the then two most influential public financers of medical research in the Netherlands decided to go along with international trends in the governance of the practice. If the national government would not act up to protect Dutch research subjects, the suggestion was, the Dutch scientific community and its funders would act themselves.

In Medisch Contact, the initiative of FUNGO and TNO was interpreted a tat more cynically by biologist and philosopher Matthijs Visser (see chapter 4) as an attempt to "prevent outside interference by putting one's house in order". ${ }^{66}$ Indeed, when going through the archive of the TNO-committee that prepared these guidelines, one comes away feeling somewhat ambivalent about why these were issued precisely in 1980. As far as can be judged, the committee certainly appears to have had the interests of research subjects in mind when devising these guidelines. For one thing, Leenen served as a committee member, who was notorious for his fierce defence of patients' rights, and also chairman Gerritsen seems to have been an enthusiast for realizing research ethics committees in the Netherlands that would strongly curb the conduct of clinical research studies in favour of the protection of Dutch research subjects. Early drafts of the TNO guidelines testify to these concerns. Section 6 of the draft guidelines, for example, stipulated that experiments with human beings were only ever allowed if no coercion had been exercised on research subjects and that experiments with people in a dependent relation-like employees and soldiers-should therefore be discouraged. In addition, the Section contained a substantial list of people who should never be permitted to serve as research subjects, including children, 'imbeciles', 'the mentally disturbed', comatose patients, dying people, prisoners, and patients suffering from a disease other than the one studied in the experiment itself. ${ }^{67}$

When these guidelines were discussed by the Executive Committee of TNO in February 1978 , however, it became clear that not everyone in the upper echelons of the applied science organization was equally enthusiastic about the fact that an organisation like TNO would formulate such strict guidelines. One board member, in particular, stated outright to have fundamental objections to the draft guidelines: "Human research will be seriously hampered on non-scientific grounds, on grounds of sensi-

\footnotetext{
${ }^{64}$ NL-HaNA, 2.14.36.06, 481, brief van TNO aan de directies van Academische Ziekenhuizen en besturen van Medische Faculteiten in Nederland, 1 april 1980. See also: M.B.H. Visser, 'Nieuwe richtlijnen voor biomedisch onderzoek', in Medisch Contact Vol. 36 (1981), pp. 23-24.

${ }^{65}$ Carlson, Boyd \& Webb, 'The revision of the Declaration of Helsinki'.

${ }^{66}$ M.B.H. Visser, 'Medische experimenten. Van experimenten op mensen naar experimenten met mensen', in Medisch Contact Vol. 37 (1982), pp. 711-713.

${ }^{67}$ NL-HaNA, 2.14.36.06, 481, 77 H 05165, Voorlopige richtlijnen voor onderzoekingen met proefpersonen" verricht in het kader van de stichting FUNGO en de Gezondheidsorganisatie TNO, 12-10-1977.
} 
tive social repression, if Section 6 is accepted". ${ }^{68}$ Although it was important to protect research subjects, this board member continued, it was equally essential to protect biomedical research studies from overly rigid regulations: "It would be disastrous for human research if universal guidelines are imposed, as these make very important research impossible through their formal and literal application, and this on pseudoethical grounds". ${ }^{69}$ One apparently only had to look at the United States for this fear to be confirmed. There, research was made impossible "on grounds that are little scientific and apparently ethical". Really, it would be "unacceptable if human research is substantially curtailed under the guise of medical ethics".70

Gerritsen tried to reassure the Executive Committee that he in essence agreed with such objections, which was why the guidelines had already been "phrased sufficiently relativistic": the key was that local research ethics committees could decide on a caseby-case basis whether a research study was ethically acceptable or not, allowing them to make flexible decisions..$^{71}$ Nonetheless, this admission could not assure the TNOboard members that the guidelines were ready to be published. They internally had to be discussed more first. In the months thereafter, Section 6 was effectively watered down to state that experiments could "as a rule" not be conducted with special groups or coercion and that, if researchers wanted to make an exception to this rule, they had to provide persuasive motives for it. ${ }^{22}$ While this addition saved Section 6 from elimination, it also gave researchers enough freedom to deviate from it whenever they felt this was needed for their work to progress. In an internal memo, Gerritsen concluded that the guidelines had become a compromise between those who feared that ethical rules would sound the death knell for all Dutch clinical research and those who were concerned that not enough was done to guarantee the rights of Dutch patients. At a time that international pressure was mounting, they served to protect the conduct of human research as much as they served to protect research subjects. ${ }^{73}$

Still, even if the precise reasons of TNO (and FUNGO) for honouring the Declaration of Helsinki might have been more ambiguous than they were publicly made out to be, the fact that the two of the biggest sponsors of medical research in the Netherlands came to demand that all human research studies funded through their channels had to be reviewed by ethics boards likely became a significant driver in the installation of research ethics committees in the Netherlands in the 1980s. As ethicist Maurice de Wachter wrote of this financial incentive in Medisch Contact in 1978: "Recently, one can recognize a trend of financial sponsors explicitly demanding safeguards [for human experiments] as a condition for funding". "What morality itself could not effectuate", the ethicist concluded both cynically and expectantly of this development, "probably thus will be achieved with some pressure on the purses". ${ }^{74}$

\footnotetext{
${ }^{68}$ NL-HaNA, 2.14.36.06, 481, 78 H 02411, Gedeelte van de notulen van de vergadering van het dagelijks bestuur van de gezondheidsorganisatie TNO van 15 februari 1978, p. 3.

${ }^{69}$ Ibid., p. 1.

${ }^{70}$ Ibid., p. 2.

${ }^{71}$ Ibid., p. 2.

${ }^{72}$ NL-HaNA, 2.14.36.06, 481, 78 H 10984, Brief aan de leden van de Commissie Medische Ethiek Proefpersonen van Dr. Th. Gerritsen, 16 juni 1978, Bijlage: herziene richtlijnen.

${ }^{73}$ NL-HaNA, 2.14.36.06, 481, Notitie aan de leden van het dbGO van Dr. Th. Gerritsen, 3 november 1978, Betreft: voorlopige richtlijnen voor onderzoekingen met proefpersonen.

${ }^{74}$ M.A.M. de Wachter, 'Toestemming van proefpersonen', in Medisch Contact Vol. 33 (1978), pp. 925-928, p. 925.
} 
Other sort of financial incentives probably had a similar effect. In 1981, for example, the FDA reached an agreement with the U.S. Department of Health, Education and Welfare which mandated institutional review for all FDA-regulated activities involving human research subjects. 75 From then onwards, clinical research studies that involved medicines, vaccines, medical devices or other products regulated by the FDA could not commence until an Institutional Review Board had given its permission. Although these regulations were not directly applicable to studies conducted outside of the United States-as "standards of protection for human subjects may vary from country to country, and the United States should not impose its standards on other countries"-it is very well possible that also pharmaceutical companies conducting human research studies in the Netherlands decided to comply with these conditions to sell their products on the lucrative American consumer market. ${ }^{6}$ Similarly, in the 1980s, the European Economic Community (EEC) started to develop harmonization requirements for products traded within its member states. In 1990, it published the position paper 'Good clinical practice for trials of medicinal products in the European Community' that stipulated the need for prior ethics review of human research protocols. 77 Even though this document only had the status of a 'compelling recommendation', it is likely that also this policy contributed significantly to the explosive rise of Dutch research ethics committees in the late twentieth century. ${ }^{78}$

As a result of these developments, a dense and at times impermeable forest of research ethics committees had sprung up in the Netherlands towards the end of the 1980s. These committees operated under various guises-interchangeably called institutional review boards, medical ethics committees, independent review councils, or ethics committees-with hardly any rules for their composition. Anyone, really, could claim the existence of a Dutch research ethics committee in the late 1980s. People did. In 1987, for instance, a few months after Deputy Superintendent of Public Health Van Geuns had warned in Medisch Contact that insufficient oversight mechanisms for human research studies existed in Dutch general practice clinics, the journal published a letter by two members of an unnamed Dutch research ethics committee huffing angrily that "the State Inspectorate apparently is not aware of the fact that an objective review option most certainly does exist”. Did he not know the Foundation

\footnotetext{
${ }^{75}$ John C. Petricciani, 'An Overview of FDA, IRBs and Regulations', in IRB: Ethics \& Human Research Vol. 3 (1981) No. 10, pp. 1-3.

${ }^{76}$ Food and Drug Administration, Protection of Human Subjects; Informed Consent. 21 CRF Parts 50, $71,171,180,310,312,314,320,330,361,430,431,601,630,812,813,1003,1010$ [Docket No. 78N0400], January 27, 1981. Retrieved from the World Wide Web on Thursday 18 February 2016 : http://www.fda.gov/ScienceResearch/SpecialTopics/RunningClinicalTrials/ucm113818.htm.

${ }^{77}$ H.D.C. Roscam Abbing, 'EG-aanbevelingen inzake experimenten met geneesmiddelen bij mensen', in Nederlands Tijdschrift voor Geneeskunde Vol. 134 (1990), pp. 2124-2125.

${ }^{78}$ Problem with these conjectures is that no one in the 1980s seems to have known exactly how many human research studies were conducted in the Netherlands or by whom, let alone whether these were all subjected to prior ethical review. In a 1986 survey, Lucas Bergkamp did approach 51 pharmaceutical companies for information about their review practices. However, he only received a reply from 30 of them, including seventeen which merely sent a letter to decline participation in Bergkamp's study. See: Bergkamp, Medisch Ethische Commissies [...] Verslag van de eerste fase, p. 144.
} 
'Independent Review Board' was active in the Netherlands outside of hospital walls? And that it had been brought into existence by 'the research community' to "advocate the importance of assessing the ethical and legal acceptability of extramural experimental research in an impartial manner, irrespective of any institution and without any commercial intention?". ${ }^{79}$ Well, clearly Van Geuns did not. From which one may either conclude that the Dutch Deputy Superintendent of Public Health was not that well informed about the concerns he chose to write about in Medisch Contact or that the actual practice and system of ethics review in the Netherlands had become a bit inscrutable, to say the least. As a result, even though research ethics committees had been envisioned to restore a much needed public trust in the Dutch medical research establishment at the start of the 1980s, they themselves were increasingly turning into an object of distrust in the Netherlands towards the end of it.

\section{Distrust, frustration, and the call for uniformity}

In itself, of course, distrust of research ethics committees was not altogether new in the Netherlands in the late 1980 s. Also in the late 1970 s and early 1980 s the functioning of these bodies had occasionally been criticized in the Netherlands. In 1980, for instance, one year after Noach had proudly suggested in Medisch Contact that his CME was already widely accepted in Leiden, the Dutch medical journal received a rather biting letter from the Leiden surgeon M. A. van Dongen suggesting otherwise. Printed as 'Experiments on humans', its first lines read as follows:

After years of silence about Him, there he is, God, the Father, with his watchful eye also in the Academic Hospital of Leiden. Finally in the hospital 'for advanced medicine' of the Praesidium Libertatis, while the confessional universities are arduously trying to get rid of Him. His name: CME. ${ }^{80}$

Leiden, the oldest university of the Netherlands, had carried the slogan 'bulwark of freedom' (Libertatis praesidium) ever since the late nineteenth century to emphasize its status as an independent university where scientific study could progress free from undue ideological and religious influences. Anno 1980, however, Leiden had also become the first Dutch university to install an in-house committee authorized to determine whether its researchers behaved ethically-a development which clearly did not sit well with all members of the old Praesidium Libertatis. ${ }^{81}$

The event that provoked this disgruntled letter was specific, yet revealing for later discussions on the public governance of ethically controversial human research practices. In December 1979, newspaper De Telegraaf had reported that a Leiden internist had taken blood samples from foetuses aborted in the fifth month of pregnancy for a study he was conducting into 'normal levels of coagulation' in foetuses of that age. ${ }^{82}$ This news caused a public outcry in the Netherlands. Although it was uncertain if the

\footnotetext{
${ }^{79}$ Emmy G. Scholten \& L.H.B.M. van Benthem, 'Medische experimenten in de huisartspraktijk', in Medisch Contact Vol. 42 (1987), p. 953.

${ }^{80}$ Van Dongen, 'Experimenten op mensen', p. 170.

${ }^{81}$ For the background o

${ }^{82}$ Frits Gonggrijp, 'Commissies gepasseerd: Bloemenhove liet experimenten toe na late abortus', in $D e$ Telegraaf, Friday 21 December 1979, p. 7.
} 
foetuses had still shown signs of life-like muscular movement or a heartbeat-when the tests had been taken, leading Dutch newspapers soon reported that experiments were conducted on "live-aborted children" in the Netherlands. ${ }^{83}$ In the evening of Tuesday January 8, Dutch physician Karel Gunning, chairman of the Dutch Doctors Covenant (see chapter 3) and the World Federation of Doctors Who Respect Human Life, compared the status of foetuses in such experiments on national radio to the historical status of slaves and concentration camp prisoners: "The point is-to justify these tests, you have to assume they are not human [...] That they have no soul and feel no pain [...]". ${ }^{84}$ Gunning therefore called on all listeners of the Evangelical Broadcasting to start writing letters to Prime Minister Van Agt to show him that Dutch people would not stand for such atrocious acts. After the broadcast, multiple Dutch families sat down to write emotional letters to Van Agt and Queen Juliana, pleading them to please bring these ungodly practices to an immediate halt. ${ }^{85}$

De Telegraaf pointed out that the experiments had been brought to light when the internist had tried to submit a research report to the British Journal of Haematology for publication. The journal had responded positively, but had requested the internist to procure some sort of evidence that his study had been conducted in accordance with the reigning Dutch standards for the ethical assessment of clinical experiments. To clear this hurdle, the Leiden internist had knocked on the door of Noach's CME. "A bit naïve that he did not already do so before he began [his research]", Noach was quoted to say in De Telegraaf. Nonetheless, his team would take on an after-the-fact ethics review of the blood tests taken at the abortion clinic. ${ }^{86}$

This comment had apparently gotten Van Dongen, who was also secretary to the Dutch Doctors Covenant, worked up. How could it be, the surgeon charged rhetorically in Medisch Contact, that in an era in which even the KNMG admitted it could no longer "adopt in writing generally accepted rules of conduct", a select group of people could be anointed to tell right from wrong within the walls of an academic hospital? Why was it that in an age when traditional moral authority was withering away, a new 'God' could be inaugurated to do an 'after-the-fact ethics review' of experiments with aborted foetuses? And what sort of qualifications did these reviewers have that allowed them to make such grand decisions? "Are we jubilant when first a philosopher is added to the little club of moderators?", Van Dongen wrote angrily, "Are we then later put at ease when the philosopher turns out to be an ethicist?" Really, what sort of expertise did these professionals possess to help them solve ethical dilemmas that the Netherlands at large no longer had a univocal answer to?87

In the late 1990s, these pressing questions by Van Dongen were raised again in the parliamentary debates on the WMO, specifically in discussions over the permissibility of experiments with legally incapacitated individuals: what authority and expertise did research ethics committees possess to sensibly decide on the ethical permissibility of research studies about which no reasonable consensus existed in the Netherlands?

\footnotetext{
${ }^{83}$ See, for example: 'Bloemenhove experimenteerde al op levend-geaborteerde kinderen', in Nederlands Dagblad, Saturday 22 December 1979, p. 2.

${ }^{84}$ NL-HaNA, 2.15.65, 2456, 8-1-1980, EO, Tijdsein, N1, 20.50 uur. Dr. Gunning (Voorzitter Nederlands Artsenverbond) over medische proeven op levend geaborteerde kinderen, pp. 1-2.

${ }^{85}$ These letters can be found in: NL-HaNA, 2.15.65, 2456.

${ }^{86}$ Gonggrijp, 'Commissies gepasseerd'.

${ }^{87}$ Van Dongen, 'Experimenten op mensen', p. 170.
} 
Yet, in the early 1980 s, the criticism voiced by Van Dongen, which basically discarded the entire notion of ethics by committee, did not do much to dampen the burgeoning enthusiasm for research ethics committees in the Netherlands. ${ }^{88}$ Quite the opposite, despite the fact that their rise marked a historically unprecedented incursion on the professional autonomy of Dutch researchers, only few felt the need to publicly criticize the establishment of more and more research ethics committees in the 1980s. By the early 1990s, still, those looking for biting comments on the functioning of Dutch research ethics committees by members of the Dutch medical research establishment could really only refer to a single article: a two-page commentary by the Flemish physician Jan Vandenbroucke that was published in 1990 in the Dutch Journal of Medicine. ${ }^{89}$ In all its singularity, however, this article made significant waves, in no small part because Vandenbroucke was a prominent and respected member of the Dutch medical research establishment. Appointed in 1987 at Leiden University as a professor of clinical epidemiology, the Flemish physician had quickly risen to prominence in the Netherlands as a prolific advocate of the upcoming evidence-based medicine movement and astute commentator on the Dutch health care system..$^{\circ}$ And around 1990, he would increasingly position himself as an ardent critic of the Dutch patients' rights movement and the detrimental effect he believed this movement to have on the conduct of medical research studies in the Netherlands.

In his 1990 article, provocatively titled 'Medical ethics and health law: obstacles for a further increase of medical knowledge?', Vandenbroucke strongly criticized the functioning of research ethics committees in the Netherlands. In the last few decades, the epidemiologist claimed, more and more uniform rules and procedures had been introduced for the governance of medical research and practice in the name of medical ethics, health law, and patient autonomy. The informed consent of patients was now required for every little intervention and observation (even if these did not harm patients in the slightest) and research ethics committees now perused research protocols to see if they complied with a predetermined set of standards. This had the effect, Vandenbroucke stated, that the conduct of biomedical research was becoming impossible in the Netherlands. Frozen vials of blood serum, for instance, could only be used in the country for the exact reason they had been stored, which was often later diagnostic use. This meant that unless their legal owner (i.e. the patient) gave permission otherwise, it was forbidden to use these samples for research purposes, even if they were used anonymously. This had the implication that retrospective epidemiological

\footnotetext{
${ }^{88}$ The Dutch government responded to the outcry of foetal experimentation by separating the more controversial experiments with 'humans' (those with human foetuses and embryos) from the regulation of 'standard' human experiments: a separate law would be drawn for these practices, which was realized in 2002: Wet van 20 juni 2002, houdende regels inzake handelingen met geslachtscellen en embryo's (Embryowet). Paragraph 5 of this law lays down rules for experimental research with foetuses. ${ }^{89}$ J.P. Vandenbroucke, 'Medische ethiek en gezondheidsrecht; hinderpalen voor de verdere toename van kennis in de geneeskunde?', in Nederlands Tijdschrift voor Geneeskunde Vol. 134 (1990), pp. 5-6. ${ }^{90}$ Upon his retirement in 2015, Vandenbroucke was made Knight in the Order of the Netherlands Lion and lauded as "one of the greatest and most influential scientists to have worked in the Dutch hospital sector". See: http://gemeente.leiden.nl/nieuwsitem/artikel/koninklijke-onderscheiding-voor-professordr-jp-vandenbroucke/. Downloaded from the World Wide Web on Tuesday February 23, 2016.
} 
studies into, say, the spread of HIV could not be executed in the Netherlands (a conclusion he got published in a leading Dutch newspaper under the headline stating 'In the Netherlands the individual outweighs the fight against AIDS'). ${ }^{91}$ And, yet, Vandenbroucke continued exasperated, ethicists and jurists now started to demand even more uniformity and stricter compliance with the rules they thought up, especially in the governance of human research. An era of "new Marxism" had begun in the medical sciences, in which national policies regimented scientists at the peril of innovative research approaches that were essential for all sciences to progress. ${ }^{22}$

The epidemiologist borrowed this conclusion from a famous 1975 editorial by internist Franz Ingelfinger in the Annals of Internal Medicine, titled 'The Unethical in Medical Ethics'. Despite “an appropriate imposition of stricter ethical guidelines in medical research and practice” in the late 1960s and early 1970s, Ingelfinger had written in this editorial, genuine ethical concerns were now increasingly trivialized by the realization of juridical procedures that mainly served to avoid risk and litigation. ${ }^{93}$ In the United States, the "interminable regulations in the futile pursuit of covering all contingencies" already bordered on the absurd, while one had to wonder if this "bureaucracy of ethics" made the conduct of human experimentation more ethical. After all, eventually these rules and procedures were likely to have the opposite effect of what institutional ethics review had originally meant to achieve. For in every bureaucracy, Ingelfinger claimed, it was almost inevitable that "the force of the basic ethic is weakened, [that] the details become more important than their essence, [that] the letter of the law takes precedence over its spirit". ${ }^{94}$

In 1975, Ingelfinger had held a new cadre of experts responsible for this supposed bureaucratization of medical ethics: jurists and ethicists, professional practitioners of the emerging field of bioethics in the United States. In 1990, Vandenbroucke did the same. Practitioners from the newly established disciplines of health law and ethics in the Netherlands, the epidemiologist argued, constantly clamoured with the constitution and principles of autonomy in hand that "no one may be obliged to contribute to the wellbeing of others, not even if they are not in the least affected". 95 These "outsiders" now even argued that "only good research may pass as ethical research", a proposition that proved their flawed understanding of scientific practice:

This position assumes it is possible for them (or others) to determine what methodologically correct research is, and that it can be known in advance that methodologically correct research will result in correct results and that methodologically less good research will automatically result in errors. This [stance] fails to take the actual dynamics of medico-scientific research into account. ${ }^{96}$

\footnotetext{
${ }^{91}$ J.P. Vandenbroucke, 'In Nederland weegt individu zwaarder dan Aidsbestrijding', in NRC Handelsblad, Friday 31 May 1991. See also: J.P. Vandenbroucke, 'Het Centraal Bureau voor de Statistiek: de begraafplaats van onze doodsoorzaken', in Nederlands Tijdschrift voor Geneeskunde Vol. 133 (1989), pp. 2112-2114.

${ }^{92}$ A term borrowed from M. Perutz, 'The New Marxism', in New Scientist Vol. 123 (1989), pp. $72-73$.

${ }^{93}$ Franz J. Ingelfinger, 'The Unethical in Medical Ethics', in Annals of Internal Medicine Vol. 83 (1975), pp. 264-269.

${ }_{94}$ All quotes in this paragraph: Ibid., p. 267.

${ }^{95}$ Vandenbroucke, 'Medische ethiek en gezondheidsrecht', p. 5.

${ }^{96}$ Ibid., p. 6.
} 
Actual practitioners of the biomedical sciences, of course, would never come up with such a nonsensical demand. Hence, Vandenbroucke suggested austerely in closing of his article, rather than guarding the borders of medicine, jurists and ethicists might want to guard the borders of their own disciplines a bit more closely. For their enthusiasm was turning into an unethical threat to the progress of medicine.

Unsurprisingly, Vandenbroucke's comments were received somewhat scornfully by prominent ethicists and jurists in the Netherlands. Leiden ethicist Heleen Dupuis, for instance, complained that "the statements of Vandenbroucke testify to a lack of taste and are completely incongruent with actual practice". ${ }^{97}$ Even if research ethics committees slowed down the execution of study protocols, she argued, they certainly did not prevent whole scores of studies from being executed by acting as obtuse defenders of principles of autonomy. Also the secretary to the Leiden CME, the ethicist and jurist Dick Engberts, stated in a reply to Vandenbroucke's piece that the epidemiologist's remarks were improvident, untrue, and at times outright offensive: "By talking like this, you bring the integrity of colleagues into disrepute". ${ }^{8}$ In the Dutch Journal of Medicine, in the meanwhile, Leenen accused Vandenbroucke of sheer ignorance. The epidemiologist not only came across uninformed about recent developments in health law and ethics, the jurist wrote angrily, he also put words in the mouths of jurists and ethicists that did not belong there. Equally austerely, therefore, Leenen advised Vandenbroucke "to stay within the borders of his own discipline and to first acquire knowledge of other disciplines if he wants to judge them". 99

Criticism also came, albeit in lesser numbers, from Dutch medical practitioners. In Medisch Contact, for one, Editor Cor Spreeuwenberg rebuked Vandenbroucke's "unsophisticated attitude" as outright xenophobia. ${ }^{100}$ The epidemiologist was simply one of those practitioners who rejected all perspectives on medical practice and research that had not been put forward by medical colleagues. Vandenbroucke himself, however, wrote back that he had personally received many positive comments on his article, an indication that his contribution "has formed a rendition of a large latent discontent within the medical profession" ${ }^{101}$ He was willing to admit that his critics offered a "useful counterweight" to his concerns, but he could not shake the impression that they did seem a bit too eager to dismiss his criticism as mere "isolated belching". A whole cadre of eminent scientists, after all, had warned against the bureaucratization of ethics since the 1970s. Hence, instead of brushing aside his complaints as erroneous and perverse, jurists and ethicists might want to try to understand why such isolated monodies sounded oddly in tune upon closer inspection.

As previous chapters have shown, jurists and ethicists only played a modest part in the emergence of the practice of ethics by committee in the Netherlands. The demand

\footnotetext{
${ }^{97}$ Sylvia van Leeuwen, 'Medische Ethiek', in Cicero, 24 november 1989.

${ }^{98}$ See also: B. Baak, 'Zelfbeschikkingsrecht: hinderpaal of ideaal', in Beweging.

${ }^{99}$ H.J.J. Leenen, 'Commentaar', in Nederlands Tijdschrift voor Geneeskunde Vol. 134 (1990), p. 926.

${ }^{100}$ C. Spreeuwenberg, 'Staan patiëntenwetten de gezondheid in de weg?' in Medisch Contact Vol. 46 (1991), p. 1019. See also: C. Spreeuwenberg, 'Een handboek tegen xenofobie', in Medisch Contact Vol. 46 (1991), p. 423.

${ }^{101}$ J.P. Vandenbroucke, 'Reactie', in Nederlands Tijdschrift voor Geneeskunde vol. 124 (1990), p. 928.
} 
that human research protocols should first be reviewed on their scientific and ethical merits had come from biomedical researchers themselves, who imagined these review bodies to function primarily as a form of internal control over the conduct of clinical research in the Netherlands. Vandenbroucke was not wrong, however, that especially jurists and ethicists had started arguing in the late 1980s that more uniformity had to be realized in the functioning of Dutch research ethics committees. Between 1986 and 1988, for instance, the jurist Lucas Bergkamp had researched the daily functioning of Dutch research ethics committees and concluded that review standards differed both between and within the committees under investigation. ${ }^{102}$ In two 300-page reports, Bergkamp had analysed all rulings of 1986 from 22 research ethics committees active in Dutch academic and general hospitals, and had asked them to review three protocols in which he purposefully had included a number of "methodological, ethical and informed consent-problems". ${ }^{103}$ From this information, Bergkamp concluded that not all committees reviewed the methodological quality of protocols; that most had different rules for the required competence of researchers; and that they showed little consistency in their evaluation of informed consent procedures. The jurist located the cause for this "variation and inconsistency" in the large number of ethics committees active in the Netherlands, which would make it impossible to "avoid big differences in composition, procedures, and especially employed standards of evaluation”. ${ }^{104}$ This, Bergkamp claimed, was "one of the most important problems which the review system by medical ethics committees currently has to cope with". ${ }^{105}$

Taken by itself, this comment might explain some of the frustration expressed by a researcher like Vandenbroucke about the manner in which jurists or ethicists would approach the governance of human experimentation. For although Bergkamp listed multiple examples of dubious protocols that were approved without too much difficulty by the committees under investigation, his conclusions did not so much emphasize the fact that the current review system might sustain unethical experimentation, but that the research ethics committees did not follow uniform procedures. Likewise, although the jurist did emphasize in his reports that "inconsistency between committees is not necessarily undesirable nor does consistency in itself imply a good judgement", later statements by him did sound bureaucratic at times. ${ }^{106}$ In a conference report on "the task and function of medical ethics committees in scientific research", for instance, Bergkamp was quoted to favour standardized review procedures because "It remains difficult to accept that a protocol is not approved in, say, Leiden but that the same study can take place in Amsterdam". ${ }^{107}$ If this type of uniformity truly was the most important reason why a national oversight system for human experimentation had to be realized in the Netherlands, it becomes understandable why Vandenbroucke would voice frustration about the role that jurists (and ethicists) would play in discussions over the governance of the biomedical sciences.

\footnotetext{
${ }^{102}$ Bergkamp, Medisch Ethische Commissies [...] verslag van de eerste fase; [...] verslag van de tweede fase.

${ }^{103}$ L. Bergkamp, 'Variatie en inconsistentie in de beoordeling van experimenten door medisch ethische commissies', in Nederlands Tijdschrift voor Geneeskunde Vol. 133 (1989), pp. 446-449.

${ }^{104}$ Boer, 'Medisch-ethische commissies', p. 1659.

${ }^{105}$ Ibid., p. 1660.

${ }^{106}$ Bergkamp, Medisch Ethische Commissies [...] verslag van de tweede fase, p. 20

${ }^{107}$ Boer, 'Medisch-ethische commissies', p. 1660.
} 
Yet Bergkamp and fellow thinkers had better reasons for insisting on uniformity in the review of human research studies than some sort of zealous bureaucratic desire for standardized procedures. Already in 1985, the Dutch ethicist Inez de Beaufort had called for "supervision, coordination, and a certain degree of uniformity" in the jumble of research ethics committees she saw springing up in the Netherlands. ${ }^{108}$ She did so in the last few pages of her PhD-thesis, in which she emphasized the need for flexible review procedures and acknowledged that existing research ethics committees did not always manage to strike the right balance between legitimate criticism and meddlesome interference (she herself was a member and advisor of three such committees). ${ }^{109}$ Nevertheless, De Beaufort did feel it was important to develop more uniform review procedures in the Netherlands. In part, she argued, this was needed to avoid frustration and delays in the conduct of especially large-scale clinical trials: "Those in a review committee who have been confronted with protocols for multi-centre trials are likely to have experienced that one committee sometimes judges differently than fellow committees". ${ }^{110}$ Such discrepancies, De Beaufort argued, were understandably frustrating for researchers, who could then collect data at one hospital but not at another, even though they had twice submitted the same research protocol. In part, this was needed to avoid frustration among ethics reviewers themselves. For one thing, because unexplainable differences between review boards undermined trust in the overall system, which had to be avoided. For another, because in those instances that one committee passed a protocol while another might consider rejecting it, researchers could put pressure on the second committee "with the argument that her 'difficult attitude' blocks a collaboration with other institutions, while another committee, note well, has already given a positive advise". ${ }^{111}$ Hence, better coordination and cooperation was likely to leave both researchers and reviewers less frustrated.

In 1986, Bergkamp added 'the danger of shopping' to this list of reasons why variation between review committees should be avoided: researchers could very well go round the existing committees until they had found one willing to give any research protocol its blessing. ${ }^{112}$ In the absence of legislation making demands on the constitution and operation of research ethics committees, it was not altogether unlikely that such a committee could indeed be found. Only uniform review procedures could offer adequate protection to human research subjects-without some form of national coordination and registration it remained unclear what standards reviewers used in evaluating research protocols, which studies they on average let pass, and whether the risks and benefits of participating in research studies were distributed somewhat evenly among potential research subjects. Hence, variation became a matter of great concern for the jurist- "one of the most important problems which the review system by medical ethics committees currently has to cope with"-and the call for uniform procedures something he would repeatedly emphasize until the Dutch government eventually enacted a law for human experimentation in 1998.

\footnotetext{
${ }^{108}$ De Beaufort, Ethiek en experimenten met mensen, p. 187.

${ }^{109}$ p. 185.

${ }^{110}$ Ibid., p. 187.

${ }^{111}$ Ibid., p. 187.

${ }^{112}$ Bergkamp, Medisch Ethische Commissies [...] verslag van de eerste fase, p. 166. See also: L. Bergkamp, Het proefdier mens. De normering en regulering van medische experimenten met mensen (Alphen aan de Rijn: Samsom Uitgeverij, 1988).
} 
In the prolonged absence of any government action in the 1980 s and 1990s, various self-regulating attempts were undertaken to realize coherence between the review procedures of Dutch research ethics committees. Already in 1983, Noach and Dupuis started organizing a postgraduate course at Leiden about the 'ethics review of medical experiments with human beings', with all those active or interested in reviewing human research protocols invited to attend via Medisch Contact. ${ }^{113}$ In 1984, an Institute for Health Ethics was established in Maastricht, which similarly started to offer training courses for members of ethics committees, teaching them the ins-and-outs of reviewing protocols: what they should pay attention to, which standards they should uphold, and what sort of issues they could expect to encounter (also see chapter 6). In 1987, the Dutch Hospital Council and KNMG even founded a 'national station of support' with information and support for anyone involved in reviewing 'experimental human and patient-related research'. ${ }^{114}$ And in 1991, the two organizations joined forces with an informal partnership of Dutch research ethics committees that had existed since 1982 to found the Dutch Society for Medical Ethics Review Committees (NVMETC), which was to bring together experts of ethics review, to influence national developments in this area, to advance cooperation between local committees, and to foster reliable and professional review procedures. ${ }^{115}$

What thus more or less took place in the Netherlands in the 1980s was a process of attempted professionalization of a trade that had barely existed a decade before. The competent ethics reviewer adhered to a communal set of standards and practices, sat in on training sessions to refresh his or her reviewing skills, and was a member of a national Society that oversaw the conduct of its members. They were attempts to get a grip on the quickly expanding mass of research ethics committees in the Netherlands and to acquire some sense of control over all sorts of independently operating reviewers. In this process, much emphasis was put on the importance of expertise. Ethics committees were in need of professionals who knew what they were talking about and who were equipped to take on the growing number of protocols that were submitted for review every year. Unwanted variation, the ideal was, could be combatted by implementing nationwide standards that would be applied uniformly by qualified reviewers. Once they were properly trained, it would matter no longer whether a protocol was submitted in Leiden or Groningen: uniform protocols would guarantee that the outcome of all reviews would be sufficiently similar if not the same.

This notion of the expert-reviewer did not sit well with the inclusion of laypeople in research ethics committees as had been envisioned by the Central Council in 1982. As one of the participants at the 1989 conference on "the task and function of medical ethics committees in scientific research" pointed out: "We must prevent that all and sundry can take up a seat in such a committee and join in on conversations they don't

\footnotetext{
${ }^{113}$ See: 'Ethische beoordeling van medische experimenten met mensen'. Boerhaave-cursus van het PAOG', in Medisch Contact Vol. 38 (1983), p. 12.

114 'Landelijk steunpunt experimenteel mens/patiëntgebonden onderzoek', in Medisch Contact Vol. 42 (1987), p. 606.

115 'Nieuwe vereniging wil deskundigheid leden van medisch-ethische commissies vergroten', in $\mathrm{Me}$ disch Contact Vol. 46 (1991), 1409-1410.
} 
understand". ${ }^{116}$ In this regard, advocates of uniform review procedures could be happy that Van der Reijden had decided in 1983 to ignore a rather vital section of an advice commissioned to strengthen the position of research subjects in the Netherlands. Still, for these advocates of 'proper expertise', reason for concern was on the horizon. In the 1990s, due to commotion over non-therapeutic experiments with legally incapacitated individuals, multiple political parties would start to advocate that the various beliefs present in Dutch society about contentious ethical issues should be fairly represented in the research ethics committees that the bill spoke about. For what sort of ethics did these committees really prescribe and promote? And what sort of expertise did these reviewers possess to help them solve ethical dilemmas about which no reasonable consensus existed in the Netherlands? Should laypeople not participate to voice the precarious position in which vulnerable subjects often found themselves, especially those unable to give their consent? And what about the representation of specific religious and ideological points of view? After all, was it not true that liberal reviewers were more likely to align themselves with the views of the medical research establishment than Christian or socialist reviewers would be?

It was this tension between expert and democratic oversight that remained to be resolved when Dutch parliament in 1997 could finally debate the long-awaited Dutch human research bill, diligently prepared in the previous decades by State Secretaries Van der Reijden, Dees and Simons. By that time, however, the baton had been passed to the final maestro of the WMO: the social-liberal politician Els Borst-Eilers, Minister of Health, Sport and Welfare under both administrations of Prime Minister Wim Kok (then leader of the Dutch labour party)-the first Dutch governments since 1918 that did not include a single party of markedly Christian persuasion.

\section{The fulcrum function of the ethical expert}

Today, Els Borst-Eilers (often called Els Borst) is remembered as one of the most influential Dutch politicians of the late twentieth century, particularly in the areas of health care and medical research, with her signature validating more than a hundred Dutch laws. ${ }^{117}$ Most famously, she was responsible as Minister of Health for the passing of the Termination of Life on Request and Assisted Suicide (Review Procedures) Act of 2001, more commonly known in the Netherlands as 'the euthanasia law'-an event that at the time made headlines and waves the world over. ${ }^{118}$ In 2002, after her term as Minister, she was made Officer of the Order of Orange Nassau and, in 2012, she was granted the honorary title Minister of State, a lifelong title that is only rarely awarded in the Netherlands and only to politicians of exceptional merit, who may use it to advise the Dutch Sovereign on delicate political matters. ${ }^{119}$

\footnotetext{
${ }^{116}$ Boer, 'Medisch-ethische commissies', pp. 1662-1663. Italics added.

${ }^{117}$ Mark Kranenburg, 'Haar rust was haar wapen. Necrologie Elst Borst (1932-2014)', in NRC Handelsblad, 11 February 2014.

${ }^{118}$ Wet van 12 april 2001, houdende toetsing van levensbeëindiging op verzoek en hulp bij zelfdoding en wijziging van het Wetboek van Strafrecht en van de Wet op de lijkbezorging (Wet toetsing levensbeëindiging op verzoek en hulp bij zelfdoding).

119 J.W.M. Engels, 'Constitutionele observaties bij de minister van Staat', in C. van Baalen et al. (eds.), De Republiek van Oranje, 1813-2013. Jaarboek Parlementaire Geschiedenis 2013 (Amsterdam: Boom, 2013).
} 
Prior to her political career, Borst had already compiled an impressive resume as a medical doctor and manager. After having obtained her medical degree in 1958, she received her doctoral title in 1972 on the genesis and prevention of rhesus immunization. By then, she had already come to lead the Utrecht Blood bank and, in 1976, she took up the position of medical director at the Utrecht academic hospital, one of the largest hospitals of the Netherlands. ${ }^{120}$ She left this position in 1986 to take on the vice-presidency of the Dutch Health Council, a function that she combined from 1992 onwards with a professorship on 'evaluation-research of clinical actions' in Amsterdam. During her term as Minister, she became a fellow of the Royal College of Physicians of Edinburgh and a member of the American Institute (now National Academy) of Medicine.121 After her death in 2014, the many eulogies commemorating her life without exception lauded her efforts, both as physician and politician, to help resolve many of the complex medical ethics dilemmas that had dominated Dutch public discourse since the 1970s. "Few have made such a great contribution to the debate about medical ethics in the Netherlands", the website of Medisch Contact read in 2014. ${ }^{122}$ In these tributes, the euthanasia law served as the prime example of her influence. Yet, as Minister of Health, Borst played a decisive part in many other ethics dossiers as well. One of these was the governance of human experimentation.

Already during her time as medical director, Borst had concerned herself with the governance of human experimentation. In 1983, for instance, she was asked to speak about the "ethics review of medical experiments with human beings" at the first postgraduate course on the topic that was organized by Noach and Dupuis. In her lecture, Borst lauded the institutional functioning of review committees, which she believed to "fit [...] the current era of the mondige patient critical of governments and modern clinical medicine". ${ }^{123}$ What was more, when she became vice-president of the Health Council in 1986, Borst served as a chairwoman to the Council's Standing Committee Health Ethics and Core Committee Ethics Medical Research (KEMO), that was established in 1989 by government request to provide policy advice on "ethical, legal and juridical questions of a general nature" relating to "socially relevant" developments in medical research. ${ }^{124}$ The KEMO typically advised the government on research studies that could count on much public attention, such as experiments with foetal material and studies involving somatic cell therapy. From the early 1990 on onwards, this advisory body, and thus also Borst, occasionally even took over reviewing such protocols from local ethics boards (which the latter did not always appreciate). ${ }^{125}$

\footnotetext{
${ }^{120}$ Nele Beyens \& Timo Bolt, “A Medical Doctor in Politics’, Els Borst-Eilers and the Rise of Evidence-Based Healthcare in the Netherlands', in Low Countries Historical Review Vol. 132-1 (2017), pp. 16-37.

${ }^{121}$ Louise J. Gunning-Schepers, 'In memoriam. Els Borst (1932-2014), in Nederlands Tijdschrift voor Geneeskunde Vol. 159 (2014), p. B1026.

${ }^{122}$ Evert Pronk, 'Els Borst: arts, minister, euthanasievoorvechtster' (2014, February 11), Retrieved from http://www.medischcontact.nl/actueel/nieuws/nieuwsbericht/141980/els-borst-arts-ministereuthanasievoorvechtster.htm on Tuesday 8 March 2016.

${ }^{123}$ E. Borst-Eilers, 'Review commissie, fouten, ongevallen en near accidents (FONA) commissie en 'medical audit', in Ethische beoordeling van medische experimenten met mensen (Leiden: Rijksuniversiteit, Faculteit der Geneeskunde, 1983), pp. 137-139, p. 139.

${ }^{124}$ Tweede Kamer 1989-1990, Kamerstuk 20620, nr. 16, Grenzen van de zorg. Brief van de Staatssecretaris van Welzijn, Volksgezondheid en Cultuur, p. 2.

${ }^{125}$ Gezondheidsraad, Kerncommissie Ethiek Medisch Onderzoek (KEMO) 1993-1999 (Den Haag: Gezondheidsraad, 2004; publicatie no 2004/K01).
} 
Hence, when Borst became Minister of Health, Welfare and Sport in August 1994, she already had quite some experience under her belt to put to good use in one of the longest running political dossiers bequeathed to her: the realization of the Dutch human experimentation bill. Borst held this ministry until 2002, as part of the two consecutive governments led by labour party politician Wim Kok, usually referred to as the Purple Coalitions due to their union of the Dutch labour party PvdA (red) and the conservative-liberal party VVD (blue). Borst was a member of the third party which completed these cabinets: the progressive social-liberal party D66. ${ }^{126}$ None of these parties had a religious grounding, which made 'Purple I' the first Dutch government since the introduction of proportional representation in 1918 in which no confessional parties participated. This had its effect, particularly in regulations that were considered "morally contentious". Before Kok's two terms had come to an end, prostitution had been legalized in the Netherlands, as had same-sex marriage and euthanasia. The latter especially divided the secular and confessional parties in Dutch parliament like few other dossiers had ever had, with Borst not infrequently cast in the role of irreverent statesperson. In 2001, she even faced a motion of no-confidence signed by all three Christian factions in the Dutch House of Representatives because she had been recorded by a leading Dutch newspaper in an interview about the successful completion of her euthanasia bill to have clenched her fist, smiled, and said "It is finished"-the same last words Jesus spoke on the cross, as recorded in the Bible. ${ }^{127}$ This rift ran so deep that, when the Christian-Union politician Arie Slob spent a few days in the headquarters of D66 in 2012, he asked "half-jokingly, but also seriously" for the portrait of Borst to be turned facing the wall whilst he was there. ${ }^{128}$

In the parliamentary discussions over the Dutch human experimentation bill emotions did not run as high. Yet, also there a divide existed at times between the secular coalition parties and Christian opposition parties. Principal dissent manifested itself, in particular, over the permissibility of non-therapeutic experiments with legally incapacitated individuals. As the Christian-democrats wrote to explain their rejection of this particular section of the human experimentation bill in 1996: "Every human being, created in the image of God, has an intrinsic value, which cannot be reduced to his health or intellectual capacities nor to the importance he has for a third party or society as a whole". ${ }^{129}$ Already in 1992, when their own leader Lubbers had still been Prime Minister, the Christian-democrats had issued similar objections to the human experimentation bill of the liberal State Secretary Simons. ${ }^{130}$ And when they were put in the opposition benches in 1994, their restrictive stance only grew stronger. Similarly, much more than the secular parties, Christian parties pushed for democratic representation in advisory councils like the KEMO because they feared that experiments

\footnotetext{
${ }^{126}$ Menno van der Land, Tussen ideaal en illusie. De geschiedenis van D66, 1966-2003 (Den Haag: Sdu Uitgevers, 2003).

${ }^{127}$ Margriet Oostveen, 'Ik kan me goed voorstellen dat artsen stervenshulp niet melden', in NRC Handelsblad, 14 April 2001; Tweede Kamer 2000-2001, Kamerstuknummer 27681, nr. 1, Motie van het lid De Hoop Scheffer C.S.

${ }^{128}$ A. de Jong, 'Slob (CU): Altijd verbinding zoeken', in Reformatorisch Dagblad, 1 September 2012. Retrieved from http://www.refdag.nl/nieuws/politiek/slob_cu altijd_verbinding zoeken_1_671287, on Wednesday 9 March 2016.

${ }^{129}$ Tweede Kamer 1995-1996, Kamerstuk 22588, nr. 10, p. 19.

${ }^{130}$ Tweede Kamer 1992-1993, Kamerstuk 22588, nr. 5, pp. 32-34.
} 
with foetuses and embryos would be approved more easily if nobody from the pro-life movement could have its say. ${ }^{131}$ Particularly during the 1990 , 'the importance of ethical pluralism in a democratic state' became an oft-heard statement by Christian parties in debates over regulations pertaining to medical ethics.

Borst was in favour of non-therapeutic experiments with legally incapacitated individuals and, like her predecessors, wished to make haste with the enactment of the human experimentation bill. Before she could do so, however, she had to await the report of the ad-hoc committee that had been installed in the last months of the third Lubbers-administration to advise on the permissibility of research with legally incapacitated individuals, which meant she could only begin to pilot the human experimentation bill through Dutch parliament in 1995. And when she did, she started off with such a political misstep that the governance of human research once more became a subject of heated debate in the Netherlands. In the evening of 3 October 1995, Borst confirmed on national television that she was planning to adopt the conclusions of the aforementioned ad-hoc committee: i.e. permitting research with legally incapacitated individuals if stringent conditions had been met. She defended this decision with the same example of finding a cure for Alzheimer's disease that Simons had used in his response to the Council of State in 1992. However, she did so in a manner that caused great consternation. As she was quoted in the Dutch media the next day: "According to Borst, the testing of a pill against Alzheimer's disease is only possible on demented elderly people. In the interest of medical research, she finds it conceivable that drugs in the future will be tried out on these patients". ${ }^{132}$

Dutch members of parliament could not point out quick enough that this certainly was not what they had in mind when considering non-therapeutic experiments with legally incapacitated people. In a leading Dutch newspaper, the Christian-democrats were quoted to have "great difficulty with the plans of Borst" and that she "now really is starting to overstep the boundaries" (the article did not specify which boundaries exactly).133 Leenen went on record to label Borst's example 'unfortunate' and the Alzheimer's Foundation reported to have received "a flood of calls from worried relatives of Alzheimer's patients" since the television broadcast of October 3.134 "Who decides that only drugs will be applied that are meant to do something about this dementia? As a layperson, you cannot keep a check on this", a concerned wife of an Alzheimer's patient was recorded to say. Two geriatricians wrote in to explain that the type of research mentioned by Borst was important for the patients they typically treated and that the human experimentation bill in its current form certainly was no permit for researchers to do as they please; the norms laid down in the proposal were really very strict. The geriatricians blamed Borst for suggesting otherwise and voiced strong concerns about the damage she might have done: "Since the statement of Minister Borst on October 3, it seems that a majority of politicians and the public are turning against the possibility of experiments with the legally incapacitated". ${ }^{135}$

\footnotetext{
${ }^{131}$ See, for example: Handelingen Tweede Kamer 1989-1990, 30 januari 1990, p. 33-1720.

132 'Borst: proef op wilsonbekwamen soms toestaan', in NRC Handelsblad, 4 October 1995.

133 Ibid.

${ }^{134}$ Koen Greven \& Joke Mat, 'Overleg met familie verzacht angst voor medisch experiment', in NRC Handelsblad, 5 October 1995.

${ }^{135}$ W.H.L. Hoefnagels \& M.G.M. Olde Rikkert, 'Van ongebreideld medisch onderzoek op wilsonbekwamen is helemaal geen sprake', in NRC Handelsblad, 17 October 2015.
} 
Borst's misstep was not so big that it resulted in the sort of moratorium feared by the two geriatricians. And in the official presentation of her plans in January 1996, she had already learned to phrase her plans differently. She now emphasized that the WMO would codify a strict 'no, unless'-approach in the regulation of non-therapeutic research with legally incapacitated individuals. All such studies were forbidden by law, unless a realistic possibility existed that the research subject involved could at one point benefit from the research results; unless they were 'group-bound' (meaning that the research could only be conducted with members of the same legal category as the research subject); and unless they only had negligible and minimal risks. In addition, informed consent always had to be obtained from the subject's legal guardian and the study immediately had to be brought to a halt if a subject showed any unusual form of resistance. ${ }^{136}$ Similarly, to illustrate the sort of studies she did wish to allow for, Borst now pointed to the neonatal heel prick (Guthrie test), a procedure by which a few blood drops are taken from new-borns to screen for genetic disorders (that had been developed thanks to decades of collecting blood samples from infants without much of a therapeutic goal). It was a frame that could count on a better reception in Dutch media. "Borst says: prohibit experiments with the legally incapacitated", headlines now read, "Only in exceptional cases will it be possible to do medical research with the demented elderly, small children, or mentally disabled" ${ }^{137}$

Despite this shift of frame, however, the turmoil over Borst's remark ensured that the oral treatment of the human experimentation bill in Dutch parliament started off with substantial discontent among Dutch politicians. In their final written comments on the bill, the Christian-democrats stressed their "regret that the first signee [Borst] deemed it necessary in October of last year to ventilate her personal position on research with the legally incapacitated in general, and dementia patients in particular, ahead of any official government standpoint". ${ }^{138}$ With her rash statements, the Minister of Health had caused "unrest in society", which was very unfortunate. How could Borst guarantee that researchers would always operate in the best interest of research subjects when the latter had few to no means, either legally or mentally, to make their objections heard? And, importantly, how could laypeople keep an eye on this if they had no access to the review committees outlined in the WMO-bill?

Indeed, the fact that the human experimentation bill did not dictate any laypeople to take part in the ethics review of human research studies became another point of contention in the public indignation over Borst's misstep. In its 1996 form, the legislative proposal provided for a two-tier system with a limited number of local research ethics committees that were to be recognized and managed by one central committee. Article 12 and 14, respectively, laid down that the central committee had to consist "in any case of one or more physicians and of persons who have expertise in the field of pharmacology, nursing, the behavioural sciences, law, the methodology of scientific research, and ethics"-and that it could recognize only those local committees which "in any case consist of one or more physicians and of persons who have expertise in the field of law, the methodology of scientific research, and ethics". ${ }^{139}$ Hence, Borst

\footnotetext{
${ }^{136}$ Tweede Kamer 1995-1996, Kamerstuk 22588, nr. 7, pp. 42-43.

137 'Borst: verbied experimenten op wilsonbekwamen', in NRC Handelsblad, 13 januari 1996.

${ }^{138}$ Tweede Kamer 1995-1996, Kamerstuk 22588, nr. 10, p. 17.

${ }^{139}$ Tweede Kamer 1995-1996, Kamerstuk 22588, nr. 9, p. 5, p. 6.
} 
had decided to carry on the line taken by her predecessors and discard the suggestion in the 1982 Central Council report to include "society-representatives" in the ethical review of human research studies. ${ }^{140}$ One was only eligible for a seat in a research ethics committee if one could lay claim to a specific sort of expertise, not if one represented an interest group to the research study under review.

Most parties in the Dutch House of Representatives-including those that participated in the Purple Coalition-objected to this exclusion. The labour party argued it robbed the bill of its social basis; one of the reformed parties brought up that laypeople possessed their own useful 'lay expertise'; the green party argued that the position of the research subject needed strengthening in negotiations over the ethical permissibility of experiments; while the conservative-liberal party felt that a representative of a patient organisation had to take part to ensure the interests of this group. ${ }^{141}$ The orthodox Protestant party, in turn, stated that lay-representation was "needed to take the diversity of ethical views in society into account in the composition of the [local] committees and the central committee", a concern which was voiced by the reformed parties and Christian-democrats as well (collectively, these four confessional parties took up about 25 percent of the Dutch House of Representatives). ${ }^{142}$

In her reply to these objections, Borst admitted that she did not see much use for the participation of laypersons. First of all, if they participated solely on the basis of not being an expert, they hardly would have anything meaningful to contribute. Anyone taking part in the review of scientific research, Borst felt, could only ever contribute in a meaningful way if they had a big enough understanding of the protocol under investigation. In order to do so, however, reviewers needed so much expertise that it was questionable whether they really were laypeople anymore. ${ }^{143}$ Secondly, if laypeople participated to represent interest groups like patients or research subjects, they would undermine "the independent assessment of a research protocol" and increase the danger that "personal or commercial interests influence the assessment of protocols". ${ }^{144}$ Thirdly, Borst considered it redundant to let laypeople participate to ensure that "opinions from outside medical circles are expressed" or that "reviewers do not start to identify with researchers". The need to counteract the dominance of researchers in committees, she argued, was already fulfilled by the contribution of "experts on the terrain of law, research methodology, and ethics". ${ }^{145}$ Finally, reviewing protocols had to be done by experts to guarantee uniform and independent ethical judgements. Only this, Borst argued, could result in objective judgements. In short, the Minister of Health was inclined to dismiss the whole issue of lay-representation.

Dutch parliament members were not so easily persuaded, however, especially not because they knew the matter could count on a large majority in the House of Representatives. During the first oral treatment of the bill, therefore, they used their right of amendment to propose that the WMO should mandate at least one representative

\footnotetext{
${ }^{140}$ Her version of the human experimentation bill was identical, in this regard, to that of Simons, her direct predecessor. See: Tweede Kamer 1991-1992, Kamerstuknummer 22588, nr. 1, pp. 5-6, p. 6.

${ }^{141}$ Tweede Kamer 1995-1996, Kamerstuk 22588, nr. 7, pp. 52-53.

${ }^{142}$ Tweede Kamer 1992-1993, Kamerstuk 22588, nr. 5, p. 49, p. 51. See also: Tweede Kamer 19951996, Kamerstuk 22588, nr. 10, p. 29, p. 37.

${ }^{143}$ Tweede Kamer 1995-1996, Kamerstuk 22588, nr. 7, p. 53.

${ }^{144}$ Ibid., p. 53.

${ }^{145}$ Ibid., p. 55.
} 
of the Dutch consumer-/patient organization to be added to both the local committees and central committee. ${ }^{146}$ These representatives did have a specific type of expertise, they argued, as they were experts in being patients and research subjects, which was an essential piece of the jigsaw puzzle that made up the ethics review of human research studies. Borst was not convinced, as she felt a nurse also possessed this type of expertise, but she was willing to meet Dutch parliament halfway. She would not change the human experimentation bill to include a lay-representative, but she would add the stipulation that, in addition to the experts already mentioned in Articles 12 and 14, all committees had to appoint one person to "specifically review the scientific research from the perspective of research subjects". ${ }^{147}$ This could be a nurse, patientrepresentative, or someone else-as long as they took part to watch over the position of research subjects, not to represent a specific interest group.

This did not, of course, solve the objection raised by the Christian parties that the committees should fairly represent the diverse ethical and ideological viewpoints present in Dutch society. But Borst had a different solution for this. In reply to questions posed by the Christian parties she pointed to the requirement of Article 12 and 14 that someone 'with expertise in the field of ethics' should take up a seat in the various research ethics committees. "From this person it should be expected", she stated, "that he in particular will make visible which visions and arguments exist with regard to a specific subject in our pluralistic society". ${ }^{148}$ The ethicist was thus responsible for collecting the various moral viewpoints which could exist in the Netherlands on an issue relating to human experimentation and to put these forward during committee deliberations. Not all members of parliament were immediately convinced. "It is a bit unclear why an ethicist should have a seat in the committees", reformed politician André Rouvoet remarked, "if he only serves to clarify what attitudes exist in society with regard to a particular subject". "Why should an ethicist do this and not a social scientist, for example?", Rouvoet continued, "It seems to me, that if you ask an ethicist, he brings along his own opinion". ${ }^{149}$ Other confessional parliamentarians raised similar points. "You have ethicists in all sorts of shapes and sizes", another reformed politician remarked, "That does not detract from their scientific quality, but it says preciously little about how representative they are". ${ }^{150}$

In part, the Christian political parties pressed this hard on the position of ethicists in research ethics committees, because the Dutch House of Representatives was simultaneously having a similar discussion on the composition of the ethics committees that would be installed in the Netherlands if Borst's euthanasia law was to go into effect. The idea was that these committees would also include an ethicist, something about which particularly the Christian parties were sceptical, as most felt that euthanasia could under no circumstances be considered ethical. So it mattered quite a bit what sort of ethicist would be asked to take up a seat in these ethics committees. In these related debates, Borst said of the role of the ethicist:

\footnotetext{
${ }^{146}$ Tweede Kamer 1996-1997, Kamerstuk 22588, nr. 19.

${ }^{147}$ Handelingen Tweede Kamer 1996-1997, 3 September 1997, p. 104-7330; Tweede Kamer 1996-

1997, Kamerstuk 22588, nr. 23.

${ }^{148}$ Tweede Kamer 1995-1996, Kamerstuk 22588, nr. 7, p. 62.

${ }^{149}$ Handelingen 3 September 1997, p. 103-7308..

${ }^{150}$ Handelingen Tweede Kamer 1996-1997, 9 September 1997, p. 105-7417.
} 
A good ethicist is trained in careful reasoning and clear analysis [...]. That is his contribution. If you have a strong personal opinion which prevents you from ever considering pros and cons, you should not take up a seat in such a committee. And otherwise you must at times also be sure to take away from your own feelings and personal beliefs and just make an objective judgment. ${ }^{151}$

Hence, Borst thus envisioned ethical experts to contribute to ethics committees in the role of analyst, able to weigh the opinions of others in a careful and objective manner and to offer insightful analytical terms and reasoning schemes. As such, they made committee deliberations more rational (logical) and therewith more reasonable (fair, sensible). In addition, by smartly drawing on her previous life as vice-President of the Health Council (in which she had often participated in committee deliberations on ethically charged medical issues), Borst maintained that 'a good ethicist' could bring together different types of experts with different types of temperaments:

During my time at the Health Council, I have always benefited greatly from the presence of ethicists in committees. They were the people who, when it comes to thinking lucidly [...] were often the strongest committee members. A jurist argues very carefully and formally, while a doctor often argues with quite a lot of emotion. In those instances, an ethicist was clearly the neutralizing factor. ${ }^{152}$

Borst's ethicists, in other words, helped to make deliberations more humane without becoming overly emotional, and excelled in navigating difficult discussions through troubled waters. They did not have strong moral opinions themselves, but mediated the opinions of others, allowing people with conflicting viewpoints to reach harmonious decisions. Ethicists were, in short, ideal moderators.

This conception of the ethicist's contribution in euthanasia committees could have easily been transported to their role in research ethics committees. Borst never did so, however, for reasons that remain unclear. The sobering truth may well be that her department never really thought through the position of the ethicist until pushed for it in parliament, with the euthanasia debates taking place just after those on the human experimentation bill. Indeed, in the 1980 s and early 1990s, the participation of ethicists in research ethics committees mostly had been accepted to be self-evident in Dutch policy circles. Both the 1981 Health Council advice and the 1982 Central Council reports had recommended the inclusion of ethicists in local review boards without much explanation (even though the Central Council did speak interchangeably of the need for either an ethicist or a pastor). And although it was not the case that all ethics committees established in the Netherlands in the 1980s seated an ethicist, the suggestion that the review of human research protocols might also take place without involving ethicists was never actively questioned in Dutch parliament in these years, nor did any of the statespersons responsible for the human experimentation bill ever justify why it stipulated the requirement of ethical expertise. ${ }^{153}$

\footnotetext{
${ }^{151}$ Eerste Kamer 1997-1998, Handelingen 21 April 1998, p. 28-1475.

152 Ibid., p. 28-1475.

${ }^{153}$ See also: Kater, Disciplines met dadendrang.
} 
Dutch statespersons at times did, however, use the inclusion of ethicists strategically. In 1992, for instance, Simons used the requirement of ethical expertise to counter requests from parliament about lay-representation. The latter was not needed, he argued, as "it may be especially expected from the ethicist to take an approach from the perspective of research subject protection". ${ }^{154}$ When this met loud protests in parliament, however, as ethical expertise was argued to differ from lay-representation, Simon just as easily dropped this professional function of ethicists from subsequent memorandums and parliamentary discussions. ${ }^{155}$ Borst, likewise, at times maintained that 'a good ethicist' was defined by the ability to "just make an objective judgement", while she at other times stressed that ethicists had varying ideological-religious backgrounds that influenced the way in which they reviewed research protocols. She did so, for instance, in the solution she devised to pacify the continuing unrest in Dutch parliament over non-therapeutic research with legally incapacitated individuals. The WMO, she promised, would require that such studies could only take place if permission had first been acquired by the central committee, which would include "ethicists from diverse ideological and religious backgrounds". ${ }^{156}$ Hence, when it came to the evaluation of more contentious human research studies, it suddenly was desirable to base one's judgement of the socio-cultural background one represented-the sort of membership that Borst had explicitly rejected in discussions over the participation of laypeople in local ethics committees. And while she stated emphatically at other occasions that a good ethicist 'takes away from his own feelings and personal beliefs', personal beliefs now served as an important eligibility requirement for ethicists to participate in the central committee for medical research.

Borst thus imagined multiple democratic functions for ethicists to fulfil in the public governance of human research studies in the Netherlands. On the local level, they would make sure to present the various moral viewpoints existent in Dutch society to the other committee members, so that also minority opinions would not be neglected in the review of 'regular' experiments with human beings. On the national level, however, they would ensure that the outlook on life typical of the group they represented was heard to counterbalance it against the views of the other ethicists selected to take up a seat in the central committee. Nonetheless, as they were after all experts, they were expected to do all this in a uniform, independent, and objective manner. Ethicists did not represent interest groups, but presented the viewpoints of various social groups. In doing so, they acted as the fulcrum that balanced democratic with expert control, an apparently ideal solution for the public governance of a scientific practice in a pluralist society without the actual participation of the unruly "all and sundry", as Bergkamp et al. had started to fear towards the end of the 1980 s.

On 25 February 1998, the Dutch Medical Research Involving Human Subjects Act went into effect, signed by "Beatrix, by the grace of God, Queen of the Netherlands, Princess of Orange-Nassau, etc. etc. etc.”, Els Borst-Eilers, Minister of Health, Wel-

${ }^{154}$ Tweede Kamer 1991-1992, Kamerstuk 22588, nr. 3, p. 30.

${ }^{155}$ Tweede Kamer 1992-1993, Kamerstuk 22588, nr. 5, p. 63.

${ }^{156}$ Tweede Kamer 1996-1997, Handelingen 4 september 1997, p. 104-7328. 
fare and Sport, and Winnie Sorgdrager, Minister of Justice. ${ }^{157}$ After forty-five years of policy reports, 'medical tests upon human beings' were finally regulated by law in the Netherlands. Anno 2017, 23 Dutch research ethics committees (METCs) are active in the country, overseen by a single Central Commission on Research Involving Human Subjects (CCMO), which also acts as administrative body for appeals and objections of researchers and reviews protocols about which local committees have no authority (as stipulated by the WMO and 2002 Dutch Embryo Act). If a human research study includes an 'advanced therapy medicinal product' (e.g. gene therapies or genetically modified organisms), the protocol must be reviewed by the CCMO. If it is of an interventional and non-therapeutic nature and involves legally incapacitated individuals, the protocol must be reviewed by the CCMO. If it concerns research with embryos, human gametes or foetuses (with the exception of non-invasive observational studies with human foetuses), it must be reviewed by the CCMO. If it involves human research studies with unregistered vaccines or substances that fall under the Opium Act which are used to treat opium addictions, it must be reviewed by the CCMO. If it involves "xenotransplantation with living cells of animal origin", it must be reviewed by the CCMO. In short, an elaborate web of regulations has by now been put in place to regulate all sorts of 'human' experiments in the Netherlands.

This development has not been met with universal enthusiasm, of which the 1990 article by Jan Vandenbroucke probably remains the best known example. However, not just doctors and researchers have faced the growing bulwark of Dutch research ethics governance with apprehension. In 2001, for instance, in a Festschrift in honour of Noach's $80^{\text {th }}$ birthday, the ethicist Heleen Dupuis lashed out in no uncertain terms against the manner in which the WMO was executed in the Netherlands in the early 200os. Citing letters from the CCMO to local research ethics committees threatening to take away their licence to review protocols if they did not carry out the regulations laid down in the WMO in a 'uniform manner', Dupuis wrote bitterly:

Moral pathos has disappeared, to be replaced by managerial arrogance and a mania for organization. The patient, who started all this, has disappeared from view, the review committees are threatened with punishment like naughty children if they do not follow (by the CCMO formulated) procedures. ${ }^{158}$

By overly emphasizing rules and regulations, the Dutch governance of human experimentation had become a "bureaucratic straightjacket", according to Dupuis. ${ }^{159}$ Ironically, with these scornful remarks, she sounded remarkably similar to the American internist Franz Ingelfinger, who had so lamented the growing bureaucracy of ethics in the 1970 and who had blamed ethicists like Dupuis for this. Indeed, one can wonder why the Dutch ethicist was this unhappy with the WMO. Had her profession, after all, not acquired a key function in the public governance of human experiments thanks to the WMO, through which she could perhaps even revive moral pathos?

\footnotetext{
${ }^{157}$ Wet van 26 februari 1998, houdende regelen inzake medisch-wetenschappelijk onderzoek met mensen (Wet medisch-wetenschappelijk onderzoek met mensen).

${ }^{158}$ H.M. Dupuis, 'Ethische aspecten van experimenten met mensen', in Geneeskunde en Ethiek in Harmonie, pp. 155-163, p. 161.

${ }^{159}$ Ibid., p. 159.
} 
Not quite so much, as Dupuis probably knew very well. For while Borst had been generous in her rhetorical depiction of the role of ethicists in research ethics committees, she had been considerably less lavish in her demarcation of the precise ethical framework they were allowed to use in the evaluation of human research protocols. When the green party, for example, inquired in parliamentary debates if the WMO could help to make sure that public funds were no longer spent on "controversial or socially undesirable research", Borst replied immediately that these were not the sort of ethical considerations which the WMO provided for. ${ }^{160}$ The ethics review of human research studies had to be limited strictly to determining "the permissibility of medical research from a scientific point of view and from the perspective of the protection of research subjects". ${ }^{161}$ Hence, the only two measuring rods for ethical permissibility that Dutch research ethics committees were supposed to take into account were: (1) the scientific quality of a study protocol, as 'only good science is ethical science', and (2) the rights and safety of human research subjects. Ethical concerns that were more system-oriented-that took the social desirability of medical research into accountremained safely beyond the purview of research ethics committees.

This held for both the local committees and the CCMO. Although the latter was to fairly represent the various viewpoints on 'human' research studies in a pluralist society, it was not allowed to decide what sort of research studies were morally permissible. If, for instance, a study with xenotransplantation was evaluated by the CCMO, the latter was not allowed to halt it on grounds other than its methodological quality and the protection of research subjects. The decision whether this sort of research is in itself 'socially desirable' had to remain the sole prerogative of Dutch parliament. To ensure this regulation would be observed, Borst laid down in the WMO that all meetings of the CCMO had to take place in the presence of a policy official from the Ministry of Health, Welfare and Sport, who immediately had to notify the statesperson in charge if something of this nature was at stake. The latter would subsequently inform the Dutch House of Representatives, which since 1997, also thanks to Borst, had the legal possibility to halt those treatments and technologies that it deemed "undesirable given the social, ethical or juridical aspects" potentially connected to them. ${ }^{162}$ Borst pictured this policy official to act as "the linking pin between government and independent expertise" in a similar manner as she had imagined the ethicist to function as the fulcrum between expert oversight and democratic control. ${ }^{163}$

Also from the disappointed voice that spoke from the pages of Noach's Festschrift in 2001, one gets a sneaking feeling that Borst's generous depictions of the watchful civil servant and mediating ethicist served a rhetorical purpose more than anything else. Heleen Dupuis was no insignificant commentator. She had been the first ethicist ever to take up a seat in a Dutch ethics board (i.e. the Leiden CME). She had been one of the first scholars who had started to identify as 'health ethicist' in the 1970s, which would go on to become the Dutch variant of the Anglo-Saxon bioethics movement (see chapter 6). She had grown into the doyen of that discipline in the 1980s, and she

\footnotetext{
${ }^{160}$ Tweede Kamer 1992-1993, Kamerstuk 22588, nr. 5, pp. 7-8.

${ }^{161}$ Tweede Kamer 1995-1996, Kamerstuk 22588, nr. 7, p. 9.

${ }^{162}$ Wet van 24 oktober 1997, houdende regels betreffende bijzondere verrichtingen op het gebied van de gezondheidszorg (Wet op bijzondere medische verrichtingen), art. 3.1.

${ }^{163}$ Handelingen Tweede Kamer, 4 september 1997, p. 104-7327.
} 
became the single most famous public face of Dutch medical ethics in the late twentieth century. ${ }^{164}$ In this role, she was both lauded and despised. Many colleagues considered her a pioneer. As her former supervisor Herman Heering (see chapter 3) stated in 1999: "She is the first ethicist who has fully integrated in the medical faculty, the one who may guide medical thinking". ${ }^{165}$ Particularly Dutch philosophers, however, considered Dupuis a prime example of how ethicists should not put their expertise to use. In the 1980 s and 1990s, these scholars had started to voice frequent complaints that Dupuis and her health ethics movement only served to keep the medical research establishment safely in their seats of power. Hence, that Dupuis of all people chose to subtitle her contribution to Noach's Festschrift 'From moral pathos to bureaucratic straightjacket', indicates that not all was well in the Dutch governance of human experimentation after the enactment of the WMO in 1998-and that the public function of ethical experts in the governance of contentious issues in the domains of science, technology, and health is not as self-evident as Borst had made it out to be. The next and final chapter of this $\mathrm{PhD}$-thesis investigates these suppositions.

\footnotetext{
${ }^{164}$ Plus, at the time of publication of Noach's Festschrift, Dupuis had just taken up a seat in the Dutch Senate as member of the biggest liberal party of the Netherlands-a position she held until 2015.

${ }^{165}$ Joke Mat, 'Ethica buiten de ivoren toren nu zelf ter discussie', in NRC Webpagina's 1 maart 1999. See: http://retro.nrc.nl/W2/Nieuws/1999/03/01/Vp/03.html. Downloaded from the World Wide Web on Tuesday July 11, 2017.
} 


\title{
- Chapter 6 . the governing function of ethical experts
}

\begin{abstract}
Allegedly, members of the conservative-liberal party VVD in the early 1990 os called their chairperson, Senator Dian van Leeuwen-Schut, 'Stalin of the Koninginnegracht', due to her ability to rule the party with an iron grip. Van Leeuwen-Schut was known for taking decisive measures and having clear-cut opinions. If she felt strongly about something, she was not one to mince her words. In the afternoon of Tuesday 6 April 1993, in a debate with State Secretary Simons on the annual budget of the Ministry of Welfare, Health and Culture, Van Leeuwen-Schut showed this firm side. "Mr. Speaker!", she stated after a heated debate on government spending in the health care sector (the liberal Senator did not think the government was doing a good job), "I now get around to another point that concerns me, which is the role and position of medical ethicists in health care". ${ }^{1}$ Today, Van Leeuwen-Schot began, "ethicists increasingly start to fulfil the role of policy officials at the Ministry of Welfare, Health and Culture and to master the 'officialese': i.e. [the ability] to draw up regulations and formulate a few ad hoc rules". This, she declared by citing the Dutch philosopher Gerard de Vries, was "extremely annoying": "they show us how we ought to speak about good and evil" and "strive for consensus as the outcome of ethical debates, as if formulating an opinion that is shared by everyone would the goal of the ethicist". The liberal Senator felt this development to be "patronizing and condescending" and, importantly, not quite the fault of ethical experts themselves: "They are also asked to do so by policymakers to reduce their uncertainties". ${ }^{2}$ Hence, if it was up to Senator van Leeuwen-Schot, the government would immediately roll back the role of ethicists in Dutch policy circles. One, because "ethical theories cannot take the place of political debate" and two, because "ethicists are intellectuals and not policymakers". 3
\end{abstract}

This chapter examines the rise of health ethics as a new field of study in the Netherlands in the second half of the twentieth century and, in particular, the debates that ensued in the late 1980 s about the function which this field would fulfil in the public governance of ethically contentious medical (research) practices. As explained in the introduction to this $\mathrm{PhD}$-thesis, the field is often argued to have emerged in the $1960 \mathrm{~s}$ to hold the once autonomous class of physicians, the artsenstand, publicly accountable. In a secular world, the mantra of this accountability movement would have been, all reasonable people should have access to the norms governing medicine, not just a selected group of anointed professionals. As a part of this origin story, the emergence of research ethics committees has often been framed as an early success of the health ethics movement. The two would have arisen as two peas in a pod-as twin responses to growing societal critiques on the medical profession in this period.

\footnotetext{
${ }^{1}$ Handelingen Eerste Kamer 1992-1993, 6 April 1993, p. 24.1081.

${ }^{2}$ Ibid., p. 24.1082. Italics added.

${ }^{3}$ Ibid., p. 24.1123 .
} 
As previous chapters have shown, however, this origin story cannot be maintained for the Netherlands, nor can it, as others have shown, for either the United States or Great Britain. 4 Instead of an effort to democratize the oversight of human experimentation, the emergence of the first Dutch research ethics committees has to be understood as an attempt by a self-appointed elite of the Dutch biomedical research establishment to gain more control over the actions of peripheral practitioners and to increase both the quality and quantity of human research studies. For a long time, this monumental change in governance was only marginally connected to the simultaneous rise of a new discipline or political movement of critical outsiders. Still, as chapter 5 has also alluded to, from the late 1980 s onwards, critical commentators on this change in governance did start to attribute the rise of research ethics committees to the health ethics movement arising alongside of it. According to physician Jan Vandenbroucke (see chapter 5), this new "bureaucracy of ethics" had been brought about by jurists and ethicists who obsessed over rules and procedures, but who hardly ever practiced medicine themselves. Consequently, the old ideal of the republic of (medical) science-governance by members of the medical profession for members of the medical profession-would have been replaced by a model of "new Marxism" with an alien group of Commissars in charge: i.e. a group of ethical experts.

This chapter investigates these claims and shows the relation between the rise of health ethics and research ethics committees actually should be understood the other way around: in the late twentieth century the practice of ethics by committee, originally designed as a tool of internal control over medical research, became a battleground for Dutch ethicists to flesh out their professional identity and public position in a democratic society. To do so, section I of this chapter first traces the emergence of Dutch health ethics as a new field of study in the 1970 s and 1980s. Sections II and III, in turn, detail the growing criticism on the identity and function of 'health ethicists' in the Netherlands in the late 1980s, with special attention for the way in which research ethics committees were used by both advocates and critics of the health ethics movement to substantiate their claims on the sort of function these experts would fulfil in the modern Dutch health care system. Section IV, finally, examines how the Dutch political use for ethical expertise in the 1990s disciplined the ethics discipline in the late twentieth century and revisits how this reflects on the current public governance of human experimentation in the Netherlands.

\section{The rise of a (new) group of ethical experts}

In the 1970 and 1980 s a new sub- or interdiscipline emerged in the Netherlands: a field of study with its own professorial chairs, journals, textbook, and research institutes that collectively came to be known as 'health ethics'. Not everyone commenting on this development in the late twentieth century agreed this new term did justice to the movement that was emerging under the flag of 'health ethics' in this period; some preferred to call it biomedical or bio-ethics, others persisted that it should continue to

\footnotetext{
${ }^{4}$ See the introductory chapter to this $\mathrm{PhD}$-thesis for a more detailed discussion of this counter narrative for the United States and Great Britain. See chapter 2 for the Netherlands. Main references are: Stark, Behind Closed Doors; Schrag, Ethical Imperialism; Hedgecoe, "AA form of Practical Machinery"; Wilson, The making of British bioethics.
} 
use the older term medical ethics. 5 Yet, most agreed by the end of the century that the term had gained general currency in the Netherlands to refer to a new field of study that closely resembled the international bioethics movement.

The emergence of health ethics in these decades is often explained as the 'breaking of the bulwark' of the artsenstand by a group of critical outsiders convinced that the monopoly of the old medical profession on medical ethics had to be broken. ${ }^{6}$ Medical ethics, the health ethicist Heleen Dupuis wrote in the 1988 Dutch Handboek gezondheidsethiek (Textbook health ethics), used to be "ethics of and for the profession". Yet thanks to the rise of the mondige patient and a "storming of the gates of 'the Bulwark of the know-it-alls' by the ethicist and jurist" in the 1960s, "medical ethics has [now] become everyone's business". 7 This narrative of origin is partly true. Health ethics did emerge in the Netherlands as an alternative to an older medical ethics tradition that predominantly had addressed the role and responsibility of physicians. Likewise, ethicists and jurists did play a considerable part in the formation of this new paradigm, although the contribution of caregivers, policy officials, and other contributors should not be underestimated (for both, see chapter 3). However, to understand the rise of health ethics solely as an emancipatory movement from 'the medical bulwark' ignores that this development was closely related to the rise of ethics itself as a standalone academic discipline in the second half of the twentieth century, which did not necessarily aim to democratize older ethics traditions (medical or otherwise), but to find a new way to speak with expert authority on difficult ethical issues.

How so? Until roughly the 1960 s in the Netherlands, ethics, as an academic field of study, had largely been the terrain of theologians, who, if they taught classes in ethics at all, usually had done so in terms of moral theology. ${ }^{8}$ It depended on the theologian what type of ethics would be taught. Orthodox theology professors, for instance, were only permitted to teach the zeden (mores) strictly according to the Scripture. ${ }^{9}$ A Modern Theologist like Izaäk Jan de Bussy, however, a professor of 'ethics and philosophy of religion' at the Municipal University of Amsterdam from 1892 to 1916, taught students that no objective foundation existed for moral judgements and that moral beliefs therefore had to be studied as the product of their historical and social context

\footnotetext{
${ }^{5}$ See: De Beaufort, Medische experimenten met mensen; Hans Achterhuis, 'Schaarste en moraal', in Intermediair Vol. 25 (1989), pp. 41-43, p. 41; Henk ten Have, Een hippocratische erfenis. Ethiek in de medische praktijk (Lochem: Uitgeversmaatschappij De Tijdstroom, 1990); Ten Have, Ter Meulen \& Van Leeuwen, Medisch Ethiek.

${ }^{6}$ Jaspers, 'Controversial issues'; Kater, Disciplines met dadendrang; M. Hilhorst, 'Klimaatverandering in de medische ethiek', in B. Musschenga et al., Ethiek in Nederland. Van 1900 tot 1970 en daarna (Budel: Damon, 2010), pp. 181-205; M. Hilhorst, 'Medische ethiek: onnodige misverstanden', in Tijdschrift voor Beleid, Politiek en Maatschappij Vol. 26 (1999), pp. 292-300. For a discussion of international literature on this topic, see the introduction of this $\mathrm{PhD}$-thesis.

${ }^{7}$ M. Dupuis, 'Ontwikkelingen in de medische ethiek. Van artsencode naar ethiek in de gezondheidszorg', in I.D. de Beaufort \& H.M. Dupuis (red.), Handboek Gezondheidsethiek (Assen/Maastricht: Van Gorcum, 1988), pp. 21-28, p. 25.

${ }^{8}$ See: H.A. Krop, 'De babylonische ballingschap der ethiek. C.W. Opzoomer (1821-1892) en Spinoza', in M. Verkerk (ed.), Filosofie, ethiek en praktijk. Liber amicorum voor Koo van der Wal (Rotterdam, 2000), pp. 43-54; H.A. Krop, 'Laat de universiteit meer dan een vakschool zijn. Het pleidooi voor de Centrale Interfaculteit', in L.J. Dorsman \& P.J. Knegtmans (eds.), Universitaire Vormingsidealen. De Nederlandse universiteiten sedert 1876 (Hilversum: Verloren, 2006), pp. 39-53.

${ }^{9}$ Frits de Lange, 'Tweeërlei ethiek. Of: hoe de gereformeerde ethiek zichzelf overbodig maakte', in Ethiek in Nederland, pp. 77-104.
} 
(De Bussy was a follower of sociologists like Durkheim, Lévy-Bruhl and Simmel). ${ }^{10}$ At Catholic seminaries and Catholic University of Nijmegen (1923), in turn, priests-to-be were trained to argue concrete cases with 'reasonable moral arguments' and to study the proper relationship between Church codes and national law (knowledge and skills they needed to take confessions from their future parishioners). ${ }^{11}$

To be sure, ethics was occasionally taught by professors of other disciplines as well in this period. From 1815 to 1876 , for instance, Dutch students who hoped to enter a theology faculty had needed to obtain a testimonial in "wijsgerige zedekunde" (moral philosophy) from the faculty of letters and philosophy, a class usually taught by a professor in speculative philosophy. However, after the Dutch government revoked this requirement in 1876 , the number of students in the Netherlands studying moral philosophy underwent a sharp decline, leaving it to the individual interests of professors to include ethics in their philosophy classes. Thus, from 1890 to 1928, experimental psychologist Gerardus Heymans did teach ethics classes at the Groningen philosophy faculty to explain why "moral people" were more likely to get married than "immoral people" (an 'observation' which would explain the moral growth of the human species as a whole). ${ }^{12}$ Heymans was an exception, however. By and large until the 1960s, ethics professors were only appointed at theology faculties in the Netherlands, while the term ethicist was mostly reserved for Church authorities (not academics).

This changed radically in the late twentieth century. First, between 1967 and 1973, three Dutch philosophy faculties realized chairs in 'philosophical ethics'. ${ }^{13}$ At Utrecht University, in the meanwhile, the chair of Johannes de Graaf (see chapter 3) in 'ethics and the encyclopaedia of theology' at the theology faculty was changed to one in 'Ethics, including philosophical ethics and the encyclopaedia of theology' at the theology and philosophy faculty. ${ }^{14}$ In the decades thereafter, all other Dutch universities realized ethics chairs at their philosophy faculties as well, with most establishing additional chairs in applied ethics at other faculties. Ethics professors also continued to be appointed at theology faculties. Many of these, however, increasingly started to argue that ethics had to be studied autonomously from theology and debated "with ethical not theological arguments" (see below). ${ }^{15}$ In the 1970 and 1980s, this amalgam of scholars began to communicate with each other in newly founded ethics societies and journals, and increasingly identified as ethicists. While the field was now considered more closely related to philosophy than theology, most practitioners argued that the field had to be understood as an interdiscipline that was defined by its object of study (ethics) and tackled with a specific body of literature and skill-set. Thus, in the 1990s, when academics were pressured by the Dutch government to organise themselves in national research schools, ethicists realized a Research School Ethics that stood separate from the Research School Philosophy and the School for Theology and Religion. ${ }^{16}$ Ethics, the message was, was now an academic field in its own right.

\footnotetext{
${ }^{10}$ Henri Krop \& Koo van der Wal, 'Een eeuw wijsgerige ethiek in Nederland', in Ibid., pp. 105-140.

${ }^{11}$ Frans Vosman \& Carlo Leget, 'Rooms-katholieke moraaltheologie in Nederland', in Ibid., pp. 13-40.

${ }^{12}$ See: Krop \& Van der Wal, 'Een eeuw wijsgerige ethiek in Nederland', pp. 120-124.

${ }^{13}$ Bert Musschenga, 'Nederlandse ethiek na 1970. De wending naar de praktijk, het beleid en het internationale forum', in Ethiek in Nederland, pp. 146-147.

${ }^{14}$ See: Krop, 'Laat de universiteit meer dan een vakschool zijn', p. 49.

${ }^{15}$ Musschenga, 'Nederlandse ethiek na 1970, p. 148.

${ }^{16}$ Ibid., p. 158.
} 
In a 2010 article on the rise of philosophical ethics in Dutch academia in the 1960s and 1970s, historians of philosophy Henri Krop and Koo van der Wal argue that this development was closely related to the broader societal activism of this period. Where philosophers in the early twentieth century had, if they took on ethical topics at all, mainly limited themselves to meta-ethical inquiries into the epistemic status of moral judgements and intuitions, philosophers of the 1960s felt compelled to engage with real-life moral problems. Due to the advent of the Cold War, polluting effects of pesticides, and growing world food shortages (to name just a few problems), more theoretical philosophical approaches increasingly came to be considered irrelevant and disdainful. If philosophy wished to make a real difference in the world, it had to be willing to take on 'actual moral problems'. ${ }^{17}$ According to ethicist Bert Musschenga, similar concerns held for theologians who started to identify as ethicists in the 1960 and 1970s. Hence, Musschenga maintains, the emergence of a Dutch ethics discipline had its roots in the "turn to practical reality" in these decades. Spurred on by stormy developments in medical science and technology, Dutch theologians became willing to take on ethically contentious issues with a case-oriented approach. Instead of locating moral truths in the Bible or other religious texts, they started to evaluate ethical cases by taking their particular context and participants into account. ${ }^{18}$

In both these origin accounts, the threat of techno-scientific advancement played a formative role in the rise of a Dutch ethics discipline after the mid-twentieth century. And, indeed, when reading publications both of philosophers (e.g. Lolle Nauta) and theologians (e.g. Herman Heering) of the late 1960s and early 1970s, their preoccupation with the dark sides of science and technology stands out. ${ }^{19}$ Yet, in most of these texts, especially those written by theologians, a second reason for the need for ethical reflection can be detected as well. In Heering's 1969 Ethiek der voorlopigheid (Provisional ethics), for instance, which was soon to become a standard text in the fledgling Dutch ethics movement, the Remonstrant theologian wrote right after emphasizing the need to investigate if "everything that is technologically possible should also occur"): “The government by-God's-grace has been replaced with a democratic order in which everyone is supposed to bear co-responsibility. The entire sacred confirmation of morality is broken, orders and judgements are disputed and reviewed". ${ }^{20}$ Likewise, in his 1969 booklet on medical ethics, Catholic theologian Paul Sporken wrote: "Ever increasing is the group of believers, who wish to have a say in ethical statements and who no longer accept these are imposed from above, isolated from communal opinions". ${ }^{21}$ Thus, ethical reflection also had become urgent anno 1969 because traditional moral truths were increasingly questioned in a secularizing society.

Sporken, in particular, was convinced that this growing plurality of voices in Dutch society demanded a more secular approach to formulating new (medical) ethics. The Church had to learn to accept, the Catholic scholar wrote, that:

\footnotetext{
${ }^{17}$ Krop and Van der Wal, "Een eeuw wijsgerige ethiek in Nederland'. To make their point, Krop and Van der Wal refer to the famous article: Toulmin, 'How Medicine Saved the Life of Ethics'.

${ }^{18}$ Musschenga, 'Nederlandse ethiek na 1970'.

${ }^{19}$ L.W. Nauta, Argumenten voor een kritische ethiek (Amsterdam: Van Gennep, 1971); Heering, Ethiek der voorlopigheid.

${ }^{20}$ Heering, Ethiek der voorlopigheid, p. 10.

${ }^{21}$ Sporken, Voorlopige diagnose, p. 16
} 
Understanding the ethical demands of humanity is not a monopoly of the Christian community of faith. [...] A Christian ethics only deserves the name in so far that it is willing and open to listen to the revelation and salvation of God wherever it can be heard, where true humanity can be found". ${ }^{22}$

In fact, even though Christian ethics was open to all people, it was best not even to use the adjective Christian anymore, as it might put off a more secular readership. "It is explicitly not my intention", Sporken hastened to write, "to sell this Introduction to medical ethics as theological ethics or moral theology". ${ }^{23}$ An ethicist was at work here, not a theologian. Also Heering, who did invoke the term theological ethics, favoured an approach to ethical reflection that took place in dialogue with others. Moral truths were not to be located in Biblical commandments, but in human beings themselves. ${ }^{24}$ That did not mean, however, that the two theologians-or ethicists-felt that everyone stood on an equal footing in ethical deliberations. Ethicists did have a certain type of expertise. They could function, for instance, Sporken explained in a 1970 talk held for the General Assembly of the KNMG, "as a luminary [voordenker] when it comes to thinking together". Ethicists' intention was not to claim jurisdiction over medical ethics, the theologian added reassuringly, but they could light the way in getting a grip on the difficult ethical problems caused by techno-scientific advancement: "The ethicist may offer a helping hand to physicians from his profession". ${ }^{25}$

To solidify this professional identity of the fledgling Dutch ethics movement, Heering in 1970 sent an invitation to all ethics teachers at Dutch universities and colleges for a meeting on Saturday 7 March in Utrecht. In 1964, Heering had been closely involved in the establishment of the Societas Ethica, an international and interdenominational ethics society, and now wished to install a Dutch ethics society as well. "Because more and more is asked of ethics", Heering wrote in his letter, "this contact and deliberation is increasingly wanted and needed". ${ }^{26}$ All ethics teachers were therefore invited to talk about "the place of ethics (philosophical ethics and moral theology)" in Dutch universities, about the appropriate "division of labour" between ethicists, and about the "joint study and discussion of foundational as well as practical ethics questions". In addition, Heering hoped to discuss how Dutch ethicists could ensure that they were consulted by the government when 'legal articles with clear moral aspects' were drafted. ${ }^{27}$ At the meeting, Heering again emphasized the need for ethicists (i.e. not theologians) to meet regularly: "Developments in academia and society force us to. Ethics can no longer be practiced in isolation. Scholarly ethics is now confronted more than ever with concrete issues". ${ }^{28}$ Those present agreed. On 7 March 1970, the Dutch Society of Ethicists was founded, with the theologian (and now also or even primarily ethicist) Herman Heering as its first chairman.

\footnotetext{
${ }^{22}$ Ibid., Voorlopige diagnose, pp. 21-22.

${ }^{23}$ Ibid., p. 25.

${ }^{24}$ Heering favoured a situation ethics. See: Joseph Fletcher, Situation Ethics. The New Morality (Philadelphia: Westminster Press, 1966).

${ }^{25}$ Paul Sporken, 'Medisch-ethische vragen in verband met anesthesie', in Medisch Contact Vol. 25

(1970), pp. 669-673, p. 669. Italics added.

${ }^{26}$ Bert Musschenga, 'Voorwoord', in Ethiek in Nederland, pp. 7-9, p. 7.

${ }^{27}$ Ibid., p. 7.

${ }^{28}$ Ibid., p. 8. See also: Musschenga, 'De Nederlandse ethiek na 1970'.
} 
At this and other occasions, Dutch theologians like Heering busied a strong rhetoric of public demand: the swift changes in Dutch society necessitated the organisation of ethicists; called for their involvement in policy and legislative proposals; demanded that they would secure a better position in Dutch academia. Heering et al. did (or could) not invoke many actual public cries to substantiate this apparent need for ethicists, but they seemed sure nonetheless that they could fulfil a key role in the binding of society in a time in which traditional authority was waning while moral problems were quickly growing in size due to the ever growing complexity of modern life. And, to be fair, they also increasingly began to be called upon to fulfil this role in the early 1970s. Especially in Dutch medical circles, theologians like Heering and Sporken became welcome guests in this period to help tackle the crisis of medical ethics that had developed in the Dutch medical profession after the mid-1960s (see chapter 3). They were invited to publish in journals like Medisch Contact, asked to speak at general assemblies of the KNMG, and nominated to participate in expert advisory bodies like the Health Council. In 1970, the KNMG even announced that it would start inviting experts from the disciplines of law, sociology, psychology, and theology to write essays on medical ethics that it regularly wished to send to its members (see chapter 3). Hence, at least the upper echelons of the Dutch medical profession appeared quite willing in the early 1970 s to have a new type of experts function as "luminaries" in the adaption of medical ethics to life in the modern Dutch society.

In 1974, Sporken was appointed at the medical faculty of the State University of Limburg (later Maastricht University) as the first Dutch professor of medical ethics. ${ }^{29}$ In 1977, he introduced the term 'health ethics' in his book Ethiek en gezondheidszorg (Ethics and health care). The old medical ethics, the theologian-cum-ethicist argued, had been designed to govern the individual doctor-patient relationship. Yet, the modern health care system had become a complex network of caregivers who all depended on one another to provide good care. In addition, health and disease had acquired important social layers: all patients and caregivers were now embedded in tight knitted social structures and formed by their environment. Hence, a new ethics of health care had to be developed that no longer just focused on the responsibilities of doctors, but "that describes and analyses health care in all her various aspects including the ethical norms that exist or are imagined therein, that clarifies the images of man and society that lie at the root of these norms, and that critically assesses this underlying vision on its humanitarian character".$^{\circ}$ In doing so, ethicists could help ensure that medicine remained a human(e) practice in an era dominated by science.

In 1977, also the Dutch Health Council introduced the term 'health ethics'. In 1975, it had quietly disbanded its Committee Medical Ethics after it had proven difficult to formulate an overarching ethics framework for "medical practice in a modern society" (see chapter 3). Yet, in 1977, the Council President nonetheless decided to install a Standing Committee Health Ethics that could "signal questions and developments in

\footnotetext{
${ }^{29}$ Paul Schotmans, 'In Memoriam Prof. Dr. Paul Sporken', in Ethische Perspectieven Vol. 2 (1992), pp. 13-16, p. 13.

${ }^{30}$ C.P. Sporken, Ethiek en gezondheidszorg $4^{\text {th }}$ edition (Baarn: Amboboeken: 1979) p. 62.
} 
health ethics that should be studied by ad hoc committees", and "coordinate how various Council committees approach health ethics facets". ${ }^{31}$ This new name, committee member Henk Leenen (see chapter 3) stated approvingly at the first meeting, allowed them to include the social dimension of health care and to discuss the responsibilities of the government in providing citizens with good health care instead of only the doctor-patient relationship (which the jurist referred to as medical ethics). ${ }^{32}$ Initially, the Standing Committee seated four physicians, two jurists, and two ethicists-lecturer in theologian ethics Theo Beemer and the upcoming ethicist Heleen Dupuis, who had recently finished her $\mathrm{PhD}$-thesis with Heering on the notion of mondigheid as a basic ethical principle of modern society. ${ }^{33}$ A little while later, Sporken joined the committee as well. The interdisciplinary composition was considered crucial for the workings of the committee. ${ }^{34}$ Yet, the ethicists were attributed a leading role. As its secretary (a physician) stated in 1981, without their input discussions were likely to "break down due to dilettantism, casuistry, and side-tracking”. 35 The ethical experts had to ensure that ethical deliberations took place systematically and methodically.

In 1984, an independent Institute for Health Ethics was established in Maastricht. In 1979, a Dutch conference had been organized on the ethics of human experimentation with the help of two renowned American bioethics institutes. ${ }^{6}$ At this meeting, the director of one of these centres, the Dutch-born obstetrician André Hellegers, had held a passionate speech about the need to realize a similar institute in the Netherlands as well. ${ }^{37}$ With some help of the State University of Limburg, this led in 1984 to the Institute for Health Ethics. The Institute, its founders believed, would function as a "palace of light" in the Netherlands, "a place where the light can shine on questions on life and health" that would help the Dutch people "to see what they are doing with their lives, world, and future", in the expectation that "people who are able to see will not be blind to the light". ${ }^{8}$ More practically, it wished to offer training courses and write reports on issues relating to health ethics. Thus, in 1984, the Institute started to train members of research ethics committees how to justly evaluate human research proposals. That same year, it was asked by the Health Council to write "a thesis that describes the philosophical background of the terms 'value of human life' and 'quality of life', and that gives a definition practical enough to be useful to answer requests for

\footnotetext{
${ }^{31}$ NL-HaNA, 2.15.36, 1692, Letter of A.J.Ch. Haex to Prof.dr. H.J.J. Leenen, 28 March 1977, p. 2.

${ }^{32}$ NL-HaNA, 2.15.36, 1705, 125-19, Minutes of the first meeting of the Standing Committee Health Ethics, 1 December 1977, p. 7.

${ }^{33}$ NL-HaNA, 2.15.36, 1692, Letter of A.J.Ch. Haex to all Standing Committee members, 18 July 1977; H. Terborgh-Dupuis, Medische Ethiek in Perspectief. Een onderzoek naar normen en argumentaties in de (medische) ethiek (Leiden: Stafleu, 1976).

${ }^{34}$ NL-HaNA, 2.15.36, 1692, 125-6, C.M. Voermans-Neleman \& H.J. De Roy van Zuydewijn, 'De Beraadsgroep Gezondheidsethiek', 24 November 1977.

${ }^{35}$ NL-HaNA, 2.15.36, 1707, 125-294, Minutes of the Comm. Health Ethics, 8 and 9 May 1981, p. 67.

${ }^{36}$ The Kennedy Institute and Hastings Center. See: Wolters, Medische experimenten met mensen.

${ }^{37}$ NL-HaNA, 2.21.340, 321, Toespraak door de Voorzitter L.B.J. Stuyt. The term bioethics as it is used today was coined by Hellegers in 1971. Hellegers, who was born in Venlo in 1926 and raised in Flemish Belgium, fled to England when World War II broke out. In 1953, he migrated to the United States. See: John Collins Harvey, 'André Hellegers, the Kennedy Institute, and the Development of Bioethics. The American-European Connection', in Jeremy R. Garrett, Fabrice Jotterand \& D. Christopher Ralston (eds.), The Development of Bioethics in the United States (Dordrecht: Springer, 2013), pp. 37-54.

${ }^{38}$ NL-HaNA, 2.21.340, 321, Het instituut voor gezondheidsethiek, voordrachten gehouden bij de plechtige ingebruikneming van het Instituutsgebouw door L.B.J. Stuyt en M.A.M. de Wachter, p. 8.
} 
advice". ${ }^{39}$ The Institute's conception of ethical expertise, which was interspersed with Enlightenment rhetoric, was similar to the conception formulated by Sporken in the early 1970s: in a society in which traditional moral authorities were no longer accepted, ethicists could function as luminaries in thinking about ethics. Its staff, the Institute's chairman (and former Minister of Health) Louis Stuyt stated in 1986, had been chosen to "form a selection of our "secular pluralist society"- a term he took from the book The Foundations of Bioethics from the philosopher Tristram Engelhardt, which famously states that "in a secular pluralist society, health care policy requires a moral lingua franca, a general moral perspective that transcends particular moral and religious commitments". ${ }^{40}$ The ethicists working at the Institute for Health Ethics, Stuyt explained, would labour to provide this moral lingua franca..$^{41}$

Other expert institutes followed in the late 1980 s and early 1990s. In 1988, a Centre for Bioethics and Health Law was established at Utrecht University and, in 1993, a Dutch Society for Bioethics was inaugurated. $4^{2}$ In the same years, a number of Dutch journals dedicated to health and bio-ethics were founded as well, of which the most prominent was the Tijdschrift voor geneeskunde en ethiek (Journal for medicine and ethics) that saw the light in 1991.43 In 1986, Heleen Dupuis was appointed as professor medical ethics at the medical faculty of Leiden University. In 1991, Inez de Beaufort, who had defended a PhD-thesis on the ethics of medical experiments with humans in 1985 (see chapter 5), was inaugurated as professor of health ethics at Rotterdam University. In the years thereafter, most other Dutch universities realized chairs in medical ethics or health ethics at their medical faculties as well.44

With this growing professional success, health ethics was increasingly recognized as a mature field of study in the Netherlands, although it continued to be understood by most of its practitioners as a subfield of the general academic practice of ethics. As Inez de Beaufort wrote in 1985: "What is biomedical or health ethics? Put shortly: it is the application of 'normal' ethics, the philosophical reflection on norms and values, on moral problems in and around health ethics".45 From this it followed, De Beaufort wrote, that physicians could not lay jurisdictional claims on health ethics on the basis of their profession. Their practical experience in seeing patients was valuable, but did not make them "mini-philosophers". ${ }^{46}$ In 1988, the ethicist repeated this message in the Handboek gezondheidsethiek (Textbook health ethics) that she and Dupuis had edited together. Forty authors had contributed to the Handboek, of which seventeen identified as ethicist (many of whom had originally studied theology), six were jurists, nine were physicians, and eight had other disciplinary identities (including psychology and economy). 47 This versatile approach was chosen because it corresponded to

\footnotetext{
${ }^{39}$ NL-HaNA, 2.21.340, 321, Toespraak door de Voorzitter Dr. L.B.J. Stuyt, p. 5; NL-HaNA, 2.15.36, 1704, Letter of L.B.J. Stuyt to M. de Wachter, 17 July 1984.

${ }^{40}$ H. Tristram Engelhardt Jr., The Foundations of Bioethics (Oxford: Oxford University Press, 1986). The quote is from: H. Tristram Engelhardt Jr. \& Lisa M. Rasmussen, 'Secular Humanism', in Encyclopedia of Life Sciences, doi: 10.1002/9780470015902.a0005890, p. 1.

${ }^{41}$ NL-HaNA, 2.21.340, 321, Het instituut voor gezondheidsethiek, p. 4.

${ }^{42}$ Musschenga, 'Nederlandse ethiek na 1970', p. 156.

43 'Lectori Salutem', in Tijdschrift voor geneeskunde en ethiek Vol. 1 (1991), pp. 1-2.

${ }^{44}$ Musschenga, 'Nederlandse ethiek na 1970', p. 150.

${ }^{45}$ De Beaufort, Ethiek en medische experimenten met mensen, p. 6.

${ }^{46}$ Ibid., p. 11.

47 'Bijdragende auteurs', in Handboek Gezondheidsethiek, pp. v-vii.
} 
the "daily reality of health care", the two ethicists explained. Nonetheless, it had to be clear that professional ethicists took the lead in moral thinking. As De Beaufort and Dupuis also wrote in the introduction of the Handboek:

Well, people could now say, everyone is thus actually an ethicist? Of course almost all human beings are morally thinking and acting beings. And ethics should not be an esoteric chunk of knowledge that is only available to a handful of 'experts' who have mastered a secret language. Yet, to call everyone with a moral 'private practice' an 'ethicist' would be the same thing to call everyone who manages a household wallet an 'economist' and everyone who regularly flicks through a medical family-encyclopaedia a 'medical practitioner'. 48

According to the two editors, ethics was a profession with a specific skillset. Ethicists, they argued, (1) offered terminological clarity, (2) mapped moral problems, and (3) applied normative theories to these problems to propose solutions. What was more, when done successfully, ethicists were able of tackling the growth of moral problems in modern society. "The starting point of this book", the preface stated, is that "Ethics can help, and certainly indicate in concrete terms what direction has to be taken to address and solve a problem". ${ }^{49}$ Hence, the Handboek "not only provides insight into the most important moral problems in health care by giving an overview of them, but also assists in how to tackle them". ${ }^{\circ 0}$ By 1988, in other words, two of the most prominent Dutch (health) ethicists had growing confident enough of the status of their field to assert it was indispensable for a morally healthy health care system. Not consulting ethicists, it seemed, increasingly had to be considered unprofessional.

\section{Storming the bulwark of the ethical know-it-alls}

By the late 1980s, health ethics was snowballing in the Netherlands: institutes and professorships were being established; journals and textbooks were realized; scholars who identified as professional health ethicists were turning into widely known public commentators on all sorts of technological and scientific innovations. Heleen Dupuis, in particular, gained national fame in this period as an expert commentator on ethical problems in health care and the biomedical sciences. Whether it concerned the public discussion of euthanasia, aids, genetics, physical examinations, or the care of the elderly, Dupuis was interviewed and quoted by media from across the ideological spectrum..$^{11}$ The ethicist did not shy away from giving clear opinions on these issues. "It is criminal to endlessly prolong the life of hopeless coma patients", one paper would cite

\footnotetext{
${ }^{48}$ H.M. Dupuis \& I.D. de Beaufort, 'Ethiek - wat is het en wat kan men er mee', in Handboek Gezondheidsethiek, pp. 7-20, p. 18.

${ }^{49}$ Dupuis \& De Beaufort, 'Ethiek - wat is het en wat kan men er mee', p. 7.

${ }^{50}$ De redactie, 'Voorwoord', in Handboek Gezondheidsethiek, pp. 1-2, p. 1.

${ }^{51}$ See, for instance: 'Reageerbuisbaby: hoe ver mag je gaan?', in Limburgsch Dagblad, Saturday 13 March 1982, p. 19; 'Professor Heleen Dupuis: "Medische beoordeling kan tot massale discriminatie leiden', in De Telegraaf, Saturday 6 February 1988, p. T25; 'Welke mensen willen we? Ethiek van biomedisch onderzoek', in NRC Handelsblad, Tuesday 25 May 1988, Wetenschapskatern, front page; 'Medische ethici: Discussie over genetische kennis nog in pril stadium', in De Waarheid, 20 December 1988, p. 8; 'Prof. Dupuis: dood te negatief gewaardeerd', in Nederlands Dagblad, Saturday 1 November 1986, p. 2; "“Verplicht inenten", in Het Vrije Volk, Monday 1 February 1988, p. 3.
} 
Dupuis. $5^{2}$ "Aids-test may also be held without the permission of the patient", another would quote her.53 "Triple abortion [in a woman expecting quintuplets] was humane and prudent”, a third would reference Dupuis.54 She was frequently invited to speak on television, served as the chairperson to the Dutch Society for Voluntary Euthanasia (NVVE), and participated in many a government advisory body. .55

In the same period that health ethics truly started blossoming as an academic discipline, however, criticism also started to grow in the Netherlands on the intellectual aspirations and societal function of health ethics. At times, these critiques came from medical professionals, as it did in 1990 when epidemiologist Jan Vandenbroucke argued in the Dutch Journal in Medicine that the health ethics field was an obstacle for the increase of medical knowledge in the Netherlands-a commentary he stated many medical colleagues off the record agreed with (see chapter 5). Yet, the most scathing on the record criticism of health ethics in the Netherlands in the late 1980s came not from caregivers or medical researchers, but from philosophers, who vehemently disagreed with the intellectual claims and institutional functioning of health ethicists. The role these ethicists envisioned themselves to fulfil in a so-called "secular pluralist society", these philosophers started to argue, was detrimental not only to the academic study of ethics, but to the democratic functioning of society as a whole.

The core of these philosophical critiques was directed at a specific approach to bioor health ethics that had grown popular in the late 1980 s and that facetiously came to be called 'the Georgetown mantra', after the place where it was first proposed in the 1970s. This mantra, also called principlism, is an approach to ethics which revolves around four principles: autonomy, beneficence, non-maleficence, and justice. These principles, its advocates argue, are compatible with most religious, cultural, intellectual, and other outlooks on life and can therefore function as the moral lingua franca of a pluralist society. ${ }^{6}$ In the Netherlands, this approach became known in the $1980 \mathrm{os}$ as 'an ethics of minimum morality'. Every person, the theologian-cum-ethicist Harry Kuitert explained in the 1988 Handboek Gezondheidsethiek, has their own 'comprehensive moral system' that originates from and is nurtured by their social background and personal experiences. ${ }^{57}$ Yet, in order to peacefully coexist with those who adhere to a different moral system, actions of people should be able to be justified by "a minimum morality that [...] posits those basic principles on which coexistence is based as inevitable obligations". ${ }^{8}$ While such basic principles were general, in applying them

\footnotetext{
52 'Heleen Dupuis (44), Medisch Ethica. "Misdadig om leven van uitzichtloze comapatiënt eindeloos te rekken"', in De Telegraaf, Saturday 30 December 1989, p. TA-3.

53 'Ethicus: aidstest kan ook zonder fiat van patient', in $N R C$, Saturday 15 August 1987, p. 3.

${ }^{54}$ Prof. H. Dupuis tegen kunstgrepen op onvruchtbare vrouwen. "Deze drievoudige abortus was humaan en verstandig", in Het Vrije Volk, Thursday 26 June 1986, p. 5.

${ }^{55}$ For her role as chairperson of the NVVE, see: Nieuwe voorzitter NVVE: Wettelijke regeling van euthanasie wellicht als mosterd na de maaltijd', in Leeuwarder courant, Monday 5 April 1982, p. 4.

${ }^{56}$ These principles were originally developed in: Tom L. Beauchamp \& James F. Childress, Principles of Biomedical Ethics (New York: Oxford University Press, 1979).

${ }^{57}$ H.M. Kuitert, 'Morele consensus: mogelijkheden en grenzen', in Handboek Gezondheidsethiek, pp. 29-40, p. 31. In Dutch, the terms, 'smalle en brede moraal' were also used to denote this distinction.

${ }^{58}$ Ibid., pp. 31-32.
} 
to particular cases they became guiding notions to find ethical solutions that should be acceptable to all members of a pluralist society. Thus, in her $1985 \mathrm{PhD}$-thesis, De Beaufort proposed such a normative framework for medical experiments on humans with the Georgetown-mantra. “These are abstract principles”, De Beaufort explained, "but they become more concrete owing to the fact that people can base reasons on them to justify their decisions".59 Subsequently, she defended the need for informed consent (autonomy), appropriate safeguards (non-maleficence), experiments (beneficence), etcetera, with the four principles. This approach allowed governments to take action, De Beaufort claimed, but left 'broad moral beliefs' to people's individual conscience. In so doing, principlism could bind a pluralist society together without unduly infringing upon the wide variety of moral beliefs existent in it.

One of the first explicit critiques on this approach in the Netherlands was voiced at the 1987 winter's meeting of the Dutch Society of Ethicists by philosopher and theologian Paul van Tongeren, who was at the time a professor of 'philosophy in relation to the Catholic tradition' at Leiden University (in 1990, he took up a position of professor in moral philosophy at the Catholic University of Nijmegen). According to Van Tongeren, moral philosophy essentially was a form of hermeneutics: an "art of interpreting or explaining what announces itself as meaningful to us, but that for whatever reason is distant, so that it has to be transposed and explained". The academic study of ethics thus consisted of "bridging this distance, so the meanings we suspect or just faintly discern [to exist] may occur in full form to us again". ${ }^{60}$ This, however, the Leiden professor argued, was everything that the applied ethics tradition that had grown dominant in recent years was not. Ethicists who used the Georgetown-mantra hardly investigated "that what can be heard" in moral instances: they just assumed they already knew what was being said in order to apply their supposedly universal principles. In doing so, Van Tongeren felt, applied ethicists failed to truly understand what was as stake in such instances, making them likely to repeat the very conditions that had initially brought forth these problems in their solutions for them.

A year later, another Dutch philosopher drew a similar conclusion in his (scathing) review of the recently published Handboek gezondheidsethiek. This philosopher was Hans Achterhuis, known nationally as the author of the 1979 bestseller De markt van welzijn en geluk (The market of wellbeing and happiness) in which he argued that the growth of the welfare services in the post war era had led to an enormous dependence on them. ${ }^{61}$ The textbook, Achterhuis argued in his review, constituted a "specific language game in which terms like mondigheid, self-determination, and choice take centre stage". ${ }^{62}$ Although this language game was presented as a moral lingua franca, in reality it was a highly liberal discourse that displaced other ways of thinking and talking about health care, such as more historically and sociologically informed critiques of the modern health care system by critical thinkers like Ivan Illich and Michel Foucault. The authors of the Handboek simply accepted, for instance, that a core ethical

\footnotetext{
${ }^{59}$ De Beaufort, Ethiek en medische experimenten met mensen, p. 7.

${ }^{60}$ P. van Tongeren, 'Ethiek en praktijk', in Filosofie en praktijk Vol. 9 (1988), pp. 113-127, p. 114.

61 "The welfare worker produces the needs of his clients", Achterhuis famously stated after CroatianAustrian philosopher Ivan Illich, and contributed to the medicalization of society, often to iatrogenic effect. Hans Achterhuis, De markt van welzijn en geluk. Een kritiek van de andragogie (Baarn: Ambo, 1979); Ivan Illich, Medical Nemesis. The expropriation of health (London: Calder and Boyars, 1975).

${ }^{62}$ Achterhuis, 'Schaarste en moraal', p. 41.
} 
problem of the modern health care system was the 'scarcity' of medical goods or the costs of health care for society as a whole, without analysing what a term like scarcity means and what function it fulfils in modern capitalist societies. ${ }^{63}$ In other words, like Van Tongeren, Achterhuis accused health ethicists of reproducing the problems they believed to solve by ignoring the fundamental question how some issues and not others come to be socially recognized as ethical problems. Health ethics, the philosopher concluded, could hardly be called a reflexive academic field of study.

The critiques of Van Tongeren and Achterhuis marked the beginning of a storm of denunciations of the field of health ethics by Dutch philosophers in the late 1980s. In 1990, for instance, physician and philosopher Henk ten Have dedicated his full inaugural lecture as 'professor of philosophy related to the Catholic outlook on life' at the State University of Limburg to the misconceptions on which he believed Dutch health ethics was based. ${ }^{64}$ Health ethicists like Dupuis, Ten Have observed, were becoming increasingly popular in the media and government advisory bodies. "Apparently our society has a need for such spokespersons, who offer orientation, directions, a sense of security for confusing and difficult situations that we do not know what to make of ourselves". Still, the philosopher asked, "what really happens to ethics when she lets herself get seduced to fulfil this role?". ${ }^{65}$ Ethics then became a form of moral engineering, a term Ten Have borrowed from American bioethicist Arthur Caplan. ${ }^{66}$ Like engineers, health ethicists would try to surgically dissect and fix moral problems by simplifying moral choices and designing standardized pathways for them. Like engineers, they would be preoccupied with spectacular technological problems and have a desire for homogeneity to streamline ethical decision-making in health care.67 "However complex a case may be, however difficult the decision is to deal with", Ten Have claimed, "the ethicist aims to offer certainty and solutions" by appealing to principles that could easily be translated into policies, rules, and regulations. ${ }^{68}$

But what problems did this approach solve, really? In a book, Ten Have recounted something that had struck him when taking a bioethics course in the United States in the 1980s. "At the same moment an elaborate plea was being held in the course room for the prime importance of individual freedom and respect for autonomy, outside in the public park a few dozen beggars could be discerned who possessed nothing more than a plastic bag or grocery trolley". 69 Why, the philosopher asked, did bioethicists write article after article about the importance of informed consent, while they could hardly be heard about the relation between economic inequality and life expectancy? The reason was, Ten Have felt, because bioethics had created a profile for itself in the 1960 s as a modern 'neutral' alternative to older religious perspectives on medicine. In

\footnotetext{
${ }^{63}$ See also: Hans Achterhuis, Het rijk van de schaarste. Van Thomas Hobbes tot Michel Foucault (Baarn: Ambo, 1988).

${ }^{64}$ Henk ten Have, Ethiek tussen alliantie en dissidentie (Maastricht: Rijksuniversiteit Limburg, 1990); Ten Have, Een hippocratische erfenis; Henk ten Have \& Gerrit Kimsma, Geneeskunde tussen droom en drama. Voortplanting, ethiek en vooruitgang (Kampen: Kok Agora, 1987).

${ }^{65}$ Ten Have, Een hippocratische erfenis, Preface.

${ }^{66}$ See: Arthur Caplan, 'Applying Morality to Advances in Biomedicine: Can and should this be Done?', in W.B. Bondeson, H. Tristram Engelhardt, S.F. Spicker \& J.M. White (eds.), New Knowledge in the Biomedical Sciences (Springer: Dordrecht, 1982), pp. 155-168.

${ }^{67}$ Ten Have, Ethiek tussen Alliantie en Dissidentie, p. 18.

${ }^{68}$ Ten Have, Een hippocratische erfenis, p. 20.

${ }^{69}$ Ibid., pp. 24-25.
} 
this quest for a more secular ethics, principles like autonomy and non-maleficence had been presented as the only sensible "moral Esperanto" of a pluralist society. Consequently, only specific types of issues came to be understood as moral problems (i.e. issues concerned with the position of the individual patient in health care) while others were neglected or designated as 'political': a matter of weighing interests or counting heads (true ethical problems, in contrast, preceded the political process and could be resolved by arguing reasonably). In this same vein, ethicists could present themselves as neutral mediators; the ones who spoke the moral lingua franca of a pluralist society and who could broker a consensus in an otherwise chaotic world. ${ }^{70}$

The grievance of these philosophers with health ethics in part concerned the feeble justification of its intellectual claims. On what epistemic foundations did principles of autonomy and non-maleficence rest? What tools did ethicists possess to consistently and unambiguously apply them to individual cases? And did these principles not just function as catch-all terms, abstract enough to make any moral argument one wanted to? The Georgetown mantra, in short, would function as the emperor's new clothes, with doctors and policymakers as the emperor, ethicists as the shrewd weavers, and philosophers, of course, as the only child sane or daring enough to point out the emperor was in fact naked. To a large extent, however, the grievance of philosophers like Van Tongeren, Achterhuis, and Ten Have also lay with the governance role they believed health ethicists to fulfil in health care and the way in which their dominance in public discourse would push other societal perspectives on the moral permissibility of new sciences and technologies to the margins of the political spectrum.

In 1993, this view was articulated by the philosopher Hub Zwart (a student of Paul van Tongeren) in a PhD-thesis that detailed how health ethicists sought to reach "ethical consensus in a pluralistic society" ${ }^{71}$ Health ethicists, Zwart maintained, typically acknowledged that their claims rested on a feeble intellectual foundation. Their point was not that an ethics of minimum morality produced truth claims, but that it could rest on a reasonable consensus among participants of moral deliberations, which was all that could realistically be expected in a pluralist society. Health ethicists thus advocated a predominantly procedural approach to ethics. As long as people were guaranteed their right to speak and willing to utilize this right in a reasonable manner, i.e. by participating in conversations, sustaining their opinions with arguments, and listening to others, the minimum morality needed for peaceful coexistence would eventually surface in moral deliberations. The deliberation process itself was primary, not its outcome. ${ }^{72}$ However, Zwart argued, while this doctrine was presented as a neutral procedure, it was in reality an attempt to pass off liberal ethics as the only ethic suitable for a pluralist society. By constantly using the threat that all other ethical perspectives might result in conflict and warfare, adepts of ethics of minimum morality effectively labelled these perspectives as threats to peaceful coexistence. ${ }^{73}$ Despite their lip service to pluralism, in other words, advocates of the Georgetown-mantra dismissed

\footnotetext{
${ }^{70}$ Ibid., p. 88.

${ }^{71}$ Hub Zwart, Ethische consensus in een pluralistische samenleving. De gezondheidsethiek als casus (Amsterdam: Thesis Publishers, 1993).

${ }^{72}$ A typical example of this view, Zwart argued, was: H.M. Dupuis, Goed te leven. Reflecties op de moraal (Baarn: Ten Have, 1980).

${ }^{73}$ See also: Hub Zwart, 'De Intolerantie van een Pluralistische Ethiek. De Engelhardt/Callahancontroverse', in Filosofie en Praktijk Vol. 12 (1991), pp. 113-124.
} 
the riches of a pluralist society. "The liberal perspective [on moral discussion]", Zwart wrote, is "de jure broadminded, but de facto restricted".74 Ethicists' supposed ability to 'broker consensus' was in practice an instrument of social control.75

Notably, the example that most of these philosophers used to illuminate their criticism on the health ethics discourse was the ethics and governance of human experimentation. In his 1987 lecture, for instance, Van Tongeren used the example to elucidate his point on the need for hermeneutic ethics. Ethicists, the philosopher argued, should not explain the permissibility of human experimentation in terms of informed consent and the realization of appropriate safeguards. They had to explore more fundamental questions as to why a society would invest in a practice like human experimentation and how this activity relates to "what we really are after in life": what sort of function do human experiments fulfil in our lives and how does this function relate to our convictions of what it means to live a good life? As such, ethicists could help to shape people's moral sensibilities about a practice like human experimentation and make them reflect on whether it should be an accepted and integral part of the society they hoped to live in. Ethicists could not, Van Tongeren continued emphatically, decide in concrete cases of human experimentation whether or not these were ethically permissible on the basis of a limited number of abstract principles.

Similarly, in his denunciation of the role of ethical engineer, Ten Have invoked the example of the Dutch jurist Lucas Bergkamp who had stated in 1989 that variation and inconsistency in research ethics committees were the most important problems that the governance of human experimentation in the Netherlands had to deal with (see chapter 5). This longing for streamlined decision-making procedures and a concomitant "homogenization of all differences", Ten Have argued, was typical for the health ethics movement. While ethics committees could in his opinion not just adopt any ethical norm they wanted to, "strict uniformity and the more or less mandatory imposition of external standards is fatal for all moral deliberation on the desirability and acceptability of [research] proposals". If this was the case, "no reason exists anymore to speak of medical-ethics committees" (they were just juridical committees). ${ }^{76}$ Hence, what ethicists should do was not to participate in research ethics committees as engineers who could help to ensure streamlined decision-making processes, but to "help make the normative dimension of health care practices explicit", including the elements that might not be considered morally problematic yet by the participants in committee deliberations. Their expertise did not consist of making issues manageable, but "to help shape a moral community that better understands itself" through an exploration of the norms, values, and perceptions of life that underlie the practice of human experimentation (Ten Have very much agreed with and actively recommended Van Tongeren's hermeneutic approach to ethics). 77

\footnotetext{
${ }^{74}$ Zwart, Ethische consensus in een pluralistische samenleving, p. 350.

${ }^{75}$ See also: Paul van Tongeren, 'De smalle moraal: pluralisme of uniformiteit?', in Algemeen Nederlands Tijdschrift voor de Wijsbegeerte Vol. 80 (1988), pp. 92-102.

${ }^{76}$ Ten Have, een hippocratische erfenis, p. 88. Italics in original.

${ }^{77}$ Ibid., p. 93.
} 
If ethicists did not take up this more hermeneutic role in the research ethics committees they participated in, Ten Have warned, the danger existed that their membership would allow biomedical researchers to shirk their ethical responsibility. A professor in obstetrics, for instance, had recently stated that an experiment with a new abortion pill did not present any ethical problems, because it had been approved by an ethics committee..$^{8}$ This, Ten Have maintained, was a clear example of how a procedural approach to ethics became an obstacle for substantial reflection on difficult cases: "Once procedures are agreed-upon, they obtain, in accordance with the model of law, an alibi-function. Ethics as a process of continuous reflection on medical action is therewith halted". 79 Ten Have strongly disagreed with Vandenbroucke, therefore, that health ethics formed an obstacle to medical innovation. Quite the contrary, health ethicists' endorsement of a procedural approach to ethics by and large facilitated the growth of the biomedical enterprise. After all, as long as human experiments could be justified with the Georgetown-mantra, they were given a green light in the health ethics discourse. In effect, reflections that might consider their place in medicine or society were effectively relegated to the realm of 'broad moral beliefs', meaning they were beyond the purview of the minimum morality of a pluralist society and could thus not be taken into account in the deliberations of research ethics committees. ${ }^{80}$ As such, Ten Have concluded, health ethicists made sure that the machineries of the biomedical research establishment kept operating smoothly.

Another scholar who expressed this point of view in the early 1990 s was Gerard de Vries, a Dutch philosopher of science and technology who published a series of pieces in this period on the governing function of health ethics in the Netherlands. ${ }^{81}$ According to De Vries, health ethicists liked to think of themselves as bearers of Enlightenment who had come to bring reason and resolution: "The ethicist sets himself up as a spokesperson for rationality and promises to show us the way. [...] What once announced itself as a tragedy turns out to be a [mere] conflict for which a rational solution exists". ${ }^{2}$ De Vries, to put it mildly, was sceptical of this ability. For one thing, he argued, the preferred analytical categories of health ethicists (i.e. autonomy, beneficence, etcetera) were deeply inadequate to make sense of, let alone disentangle, the complex network that constituted the late modern biomedical landscape: the categorical distinction between wilful humans and lifeless technologies, the narrow frame of rights and duties, the fiction of autonomous patients - they all fell painfully short to make sense of the jumble of structures and practices that had come to determine the biomedical enterprise in the twentieth century. Really, "how is it possible", De Vries charged cynically, "that ethicists have succeeded, in spite of the inadequate tools they deliver, to build a blossoming practice for themselves?". ${ }^{83}$

\footnotetext{
${ }^{78}$ Ten Have \& Kimsma, Geneeskunde tussen droom en drama, pp. 86-87.

${ }^{79}$ Ibid., p. 87.

${ }^{80}$ Ten Have, Een hippocratische erfenis; Ten Have \& Kimsma, Geneeskunde tussen droom en drama. See also: See: Achterhuis, 'Schaarste en moraal', p. 43.

${ }^{81}$ Gerard de Vries \& Sara van Epenhuysen, 'Niet de handelingen maar het stuk: ethiek en het experimenten met mensen', in De Gids Vol. 154 (1991), pp. 861-870; G.H. de Vries, 'Medische technologie en morele twijfel', in M.J. Cohen \& G.H. de Vries, Redes gehouden op de $16^{e}$ Dies Natalis van de Rijksuniversiteit Limburg, 10 januari 1992 (Maastricht: Rijksuniversiteit Limburg), pp. 5-13; Gerard de Vries, Gerede Twijfel. Over de rol van de medische ethiek in Nederland (Amsterdam: De Balie, 1993).

${ }^{82}$ De Vries, Gerede Twijfel, p. 17.

${ }^{83}$ Ibid., p. 29.
} 
To answer his own question, also De Vries brought up the ethics and governance of human experimentation in the late twentieth century. In the early twentieth century still, De Vries argued, fairly innocent medical experiments with human beings had frequently caused an outcry, not just among vocal critics of the artsenstand, but also among members of the artsenstand itself. The dominant medical ethics tradition was just not compatible with it, since the Hippocratic adage primum non nocere did not permit experimental interventions that were not in the interest of individual patients. Since World War II, however, this tradition had increasingly been adapted to form a framework in which medical experiments with human beings could explicitly be justified. Medical ethics was made compatible with, and thereby normalized, the conduct of human experiments. Sure, after the growing social criticism in the 1960s, 'outsiders' had been increasingly allowed to participate in the evaluation of medical experiments with humans. Yet, their participation was contingent on their acceptance of the new medical ethics: they had to admit that, in principle, such experiments were permitted and necessary. They had to be reasonable, after all.

According to De Vries, the functioning of research ethics committees proved how "routines have come into existence [in health care] that meet the classic requirements of modern, bureaucratic organisations, formulated by the sociologist Weber: competencies are strictly regulated, intercourse takes place in writing, judgement is in principle impersonal". This bureaucratic framework had great advantages for all involved, it gave legal protection to researchers, to research participants, to those who financed research studies, to hospital administrations, etcetera. It even "provides ethics with a well-functioning memory", with new cases being able to be compared to older ones, with research ethics committees being able to compare notes. Yet, it also ensured, De Vries remarked sarcastically, that ethicists (and other reviewers) did not even have to think anymore. They only had to follow procedure. "If the forms are not filled in correctly", the dictum now was, "the medical ethicist cannot do his job". ${ }^{4}$

Hence, the philosopher concluded, Dutch health ethics was not successful because its norms and skills provided a rational check on the activities of caregivers and biomedical researchers. It was successful, because it had adapted its norms and skills to fit the bureaucratization of medicine in the twentieth century. It provided the status quo with the necessary legitimization of dominant activities like human experimentation without having to open up the debate to more critical voices. Health ethicists, in short, had become indispensable greasers for technoscientific machineries. In doing so, De Vries warned, they undermined the democratic decision-making processes of Dutch society. Under the flag of ethics, moral issues were increasingly depoliticized: manoeuvred outside of the political arena to be 'solved' technocratically by a group of anointed ethical experts. ${ }^{85}$ Already in 1987 , Van Tongeren had raised a similar point in his lecture for the Dutch Society of Ethicists. If moral problems had become difficult to solve in a pluralist society, he had argued, the solution was not to defuse them by having a group of ethical experts draw up some sort of minimum morality: "I see no other possibility than that rules are drawn up in the political and legal arenas, realizing that they are ethically provisional or inevitably without ethical legitimization". "Such rules", Van Tongeren had pressed, "are achieved by counting heads or reaching

\footnotetext{
${ }^{84}$ Ibid., p. 34.

${ }^{85}$ Ibid., p. 37.
} 
compromises". 86 They could not be found in the toolbox of ethical experts, who had to know better than to try and "give a political compromise the pretence of ethical legitimization". ${ }^{87}$ Ethicists were just no problem-solving engineers.

\section{The determined rebuttal of 'the ethical engineers'}

Not surprisingly, prominent representatives of the Dutch health ethics movement did not quite agree with the critical assessments of these philosophers of their field of study. In 1991, for instance, Heleen Dupuis wrote a review of Ten Have's book for the Dutch Journal of Medicine in which she insisted that the newly appointed philosophy professor must have completely lost sight of reality. His portrayal of health ethics, she argued, was so off the mark that it could not even be called a caricature; he had just gotten it wrong in every possible way. ${ }^{88}$ She also scorched the alternative approach to health or medical ethics proposed by Ten Have (see above). Firstly, the role of ethicist as envisioned by Ten Have was described so inadequately that it was completely useless. And, secondly, his description of ethicists as critical thinkers was just a summary of what they did already. "One wonders in what world Ten Have lives", Dupuis ended her review, "that he dares to present something that already exists and has since long become standard practice as his discovery and as something new".

In 1991, the ethicist Frans Jacobs, who had obtained his PhD in 1985 on the topic of how a liberal ethics is the only ethics that meets the demands of a pluralist society, responded to the criticism of Paul van Tongeren on the applied ethics tradition in the Netherlands. ${ }^{89}$ Jacobs started off by admitting that the appearance of many ethicists in the media in recent years resembled a role that vicars had used to fulfil, i.e., the act of "passing normative judgements from an authoritative position" (Jacobs specifically invoked 'Mrs. Dupuis' as an example)..$^{\circ 0}$ This was annoying, he conceded, and not a role that ethicists could legitimately fulfil. Yet, the haughty dismissal of Van Tongeren of the applied ethics tradition was equally annoying. And not just that, it was possibly dangerous as well. Van Tongeren's notion of hermeneutic ethics assumed that if ethicists just listened carefully they could hear what was 'authentically' being said, even if the average person could not discern these distant whispers. Adopting this position, Jacobs charged, was also acting like a priest, only one that was paternalistic and possibly intolerant of outlooks on life that a hermeneuticist believed to be "inauthentic". An ethics of minimum morality, Jacobs countered instead, was not formulated out of some sort of intellectual laziness, but to accommodate for moral beliefs that differed from those of the dominant cultural group in a society. This was an incredibly difficult assignment, yet one essential to develop an ethical framework for peaceful coexistence that did not subsume to intolerance. For Van Tongeren to simply brush this aside was to threaten the possibility for peaceful coexistence.

\footnotetext{
${ }^{86}$ Van Tongeren, 'Ethiek en Praktijk', p. 126.

${ }^{87}$ Ibid., p. 126.

${ }^{88}$ H.M. Dupuis, 'Recensie van H. ten Have, Een hippocratische erfenis', in Nederlands Tijdschrift voor Geneeskunde Vol. 135 (1991), p. 1333.

${ }^{89}$ Frans Jacobs, 'Praktische ethiek: onpraktisch en onfilosofisch?', in Filosofie en Praktijk Vol. 12 (1991), p. 18-30; F.C.L.M. Jacobs, Ten overstaan van allen. Universalisering in de ethiek. Proefschrift Universiteit van Amsterdam (Enschede: Quick Service, 1985).

${ }^{90}$ Jacobs, 'Praktische ethiek', p. 23.
} 
Now more than ever, Jacobs continued, society was in need of such a framework. Pollution, nuclear energy, the arms race-they were all examples of the life threatening consequences of technoscientific advancement. These potentially volatile circumstances demanded moral guidance, guidance that could no longer be offered by Christianity in a secularizing society. Applied ethics, Jacobs maintained therefore, found its right to exist in this demand. Society simply needed scholars who could ask meaningful questions and guide moral thinking about these developments. Dupuis and De Beaufort strongly agreed with this perception of the added value of (health) ethics. Already in her 1985 dissertation, De Beaufort had stated that she firmly believed that ethics, as an academic discipline, should serve to formulate answers to the urgent and complex moral questions that society currently faced. "In this she finds her ultimate justification", De Beaufort contended, "otherwise she is just an academic pastime". ${ }^{91}$ In their 1988 textbook, Dupuis and De Beaufort repeated this point. While armchair philosophers might keep their hands clean by sitting in their ivory towers and savouring their intellectual analyses, applied ethicists made an actual difference in the world by getting their hands dirty in taking on real-life moral problems.

In 1992, the applied ethicist Frans Brom offered another fiery defence of the active involvement of ethicists in the resolution of real-life moral problems. Brom worked at the Utrecht Centre for Bio-ethics and Health Law, but was contracted by the Ministry of Agriculture, Nature and Food Quality to participate in the development of policies for advanced sciences and technologies. Based on his experience, he had become convinced that ethicists had an important contribution to make in the realization of policies that were both morally and socially acceptable. They provided conceptual clarity, pointed out elements that were not yet considered problematic by policymakers, and brought up ethical viewpoints they believed were unjustly ignored. Ethicists were no engineers, Brom argued, they did not replace genuine moral deliberations with technocratic solutions, but acted as mediators to ensure that participants in these deliberations correctly understood one another. ${ }^{22}$ Scholars who assumed that the political solutions of ethical dilemmas could only ever be reached by weighing interests were wrong. By carefully examining the moral presuppositions of these dilemmas, ethicists allowed policymakers to "pursue better, because more rational, policies". ${ }^{93}$ That they might subsequently be used to politically legitimize these policies was not their fault. If anything, ethicists willing to take a seat at the policy table could correct those who unjustly sought to surround policy with an academic aura. After all, the ideas of armchair scholars could just as easily be used by policymakers, making it all too easy to duck responsibility by shouting that any involvement in policy made academics complicit with it.94 In order to speak truth to power, intellectuals actually had to speak to those in power, which was not done from a tall ivory tower.

\footnotetext{
${ }^{91}$ De Beaufort, Ethiek en medische experimenten met mensen, p. 11.

${ }^{92}$ Frans W.A. Brom, 'Ethiek in de praktijk van het overheidsbeleid', in Filosofie en Praktijk Vol. 13 (1992), pp. 79-87.

${ }^{93}$ F.W.A. Brom, B.J. van den Bergh \& A.K. Huibers, 'Wie is er bang voor de ethiek', in Brom, Van den Bergh \& Huibers, Beleid en ethiek (Assen: Van Gorcum, 1993), pp. 5-18, p. 18.

${ }^{94}$ Brom, 'Ethiek in de praktijk van het overheidsbeleid', p. 85.
} 
The core message of all these rebuttals was that professional ethicists did have an important public function to fulfil in a pluralist democracy and that, given the many ethical problems that society faced, their refusal to contribute to the solution of these problems was unwarranted and irresponsible. Philosopher or ethicist, neither had the luxury to rummage around the halls of academia and twiddle their thumbs as long as a societal need existed for their reasoned input. "A world threatened with extinction clings to the life buoy of applied ethics", Jacobs wrote in 1991, "which is thereby saved from extinction caused by irrelevance and sterility". ${ }^{95}$ Yet, an important part of the critiques of philosophers like De Vries and Ten Have was not just the public functioning of ethicists, but the feeble foundations of their moral claims. Even if the ethical problems faced by modern societies were substantial, why would the judgements of ethicists be more relevant than those of the average citizen?

The most systematic answer to this question was offered in 1991 by the upcoming ethicist Theo van Willigenburg in his PhD-thesis Inside the Ethical Expert, which he wrote as a fellow of the Utrecht Centre for Bio-ethics and Health Law. ${ }^{96}$ In 1996, he would become a medical ethics professor at the University of Amsterdam and in 1999 an ethics professor at the philosophy faculty in Rotterdam, where he served as dean as well (before being dismissed in 2005). ${ }^{97}$ Yet, in the early 1990s, he was already one of the most visible faces in the applied ethics field in the Netherlands. In his 1991 thesis, Van Willigenburg explicitly rejected the Georgetown-approach to the analysis and possible solution of moral cases. The idea that moral judgements about real-life ethical problems could be reached by applying moral rules or principles, the ethicist argued, was logically problematic. After all, before an ethicist could know which principles to apply, (s)he first had to qualify the case as being of a certain moral 'kind', e.g., a problem in which the autonomy of individuals was at stake or in which the principle of beneficence might apply. As only the principles themselves could provide this sort of indication, principlism basically was a form of circular reasoning. 98

Rather than dismissing applied ethics, however, Van Willigenburg proposed what he called a case-oriented approach to moral reasoning about particular cases. When people encountered situations that they experienced to be morally problematic, the ethicist wrote, this uneasiness often was not invoked by recognizing that the situation violated a general principle, but by a moral intuition; a direct and immediate reaction to a particular event. "Moral intuitions make us recognize (at least some of) the moral dimensions of a case", Van Willigenburg stated, "and thus interpret a case as being of a certain kind". ${ }^{99}$ This 'intuiting' was nothing else than interpreting an issue according to specific moral patterns that organized how people perceived the world around them. Moral glasses that made them see certain things and not others. These patterns could differ per community and individual and, importantly, change or dissolve upon careful reflection. Yet, according to Van Willigenburg, "satisfying interpretative grids" could be found for specific moral problems by collecting enough real and hypothetical

\footnotetext{
${ }^{95}$ Jacobs, 'Praktische ethiek', p. 22.

${ }^{96}$ Theo van Willigenburg, Inside the Ethical Expert. Problem Solving in Applied Ethics (Kampen: Kok Pharos Publishing House, 1991).

${ }^{97}$ For more, see: 'Ik roep walging op. Interview met Theo van Willigenburg', in Trouw, Saturday 11 October 2014.

${ }^{98}$ Van Willigenburg, Inside the Ethical Expert, pp. 41-67.

${ }^{99}$ Ibid., p. 101.
} 
cases to allow for their comparison and by generating patterns from them to allow for the satisfactory 'intuiting' of future cases. ${ }^{100}$ Hence, rather than a deductive approach to applied ethics (i.e. principlism), Van Willigenburg proposed an inductive approach involving the production and application of 'statistical regularities'.

Notably, like the Dutch philosophers who had started to criticize the applied ethics tradition in the late 1980s, also Van Willigenburg appealed to the recent ethics and governance of human experimentation to explain his perspective on moral reasoning, only to make the exact opposite point as these philosophers had done. The current functioning of research ethics committees, the ethicist argued, provided an excellent example of the way in which systematic inductive moral reasoning worked. One reason was the "broad consensus among all parties concerned (hospital administrations, physicians, patients organisations, medical researchers and pharmaceutical industry) about the moral issues at stake in human experimentation". While these parties could disagree among the value of importance of some issues, Van Willigenburg argued, all underscored authoritative international codes and declarations stating the core principles of human experimentation, meaning that these documents already offered an important interpretative grid for intuiting the moral permissibility of cases of human experimentation. ${ }^{101} \mathrm{~A}$ second reason was that research ethics committees had extensive experience in the moral evaluation of practical cases. Contrary to what some believed, Van Willigenburg stated, the moral reasoning process in these committees did not proceed deductively through an application of moral principles. Instead, committees typically deliberated by invoking cases they had previously dealt with, revisiting the arguments and concerns that had been put forward in those instances. Principles played a role, e.g., by setting the parameters within which discussions took place, but "Fine-graded assessment in moral thinking is performed by a process of comparison of the problem case to other real and hypothetical cases". ${ }^{102}$ This modus operandi of research ethics committees, Van Willigenburg explained, was a perfect institutionalized example of how moral reasoning worked in practice.

To be sure, the robustness of this approach to moral reasoning depended on the number and variety of cases uploaded into the collective memory of a research ethics committee. Imagine, Van Willigenburg wrote, that an expert system (a computer system emulating the decision-making abilities of human experts) was able to mimic this process of going back and forth between past and present cases by building an extensive catalogue of older cases and generating a set of morally relevant dimensions from them (Van Willigenburg imagined a fourteen-dimensional grid that included, among other things, the scientific relevance of experiments, the quality of subjects' consent, the likeness of risks, etcetera). As long as enough old cases were fed to the expert system, it had to be able to generate an algorithm for qualifying and weighing the moral dimensions of new cases and reach fine-graded decisions about them (until, due to technological advancement or changing socio-cultural ideas, a moral consensus could no longer be assumed to exist about human experimentation, which would require a recalibration of the morally relevant dimensions of this practice). ${ }^{103}$

\footnotetext{
${ }^{100}$ Ibid., p. 122.

${ }^{101}$ Ibid., p. 114, p. 113.

102 Ibid., p. 111.

${ }^{103}$ Ibid., p. 122.
} 
Although Van Willigenburg emphasized that his imagined expert system only had heuristic value, his thought experiment served to explain how the moral reasoning processes of research ethics committees could function if their so-called 'hard disk' was filled with enough past cases and if they possessed the 'software' needed to extract the morally relevant dimensions of older cases to qualify and weigh new ones. This, Van Willigenburg argued, was basically what ethical experts did. Moral thinking essentially was "a pattern-driven multi-dimensional process". To some extent, every person was capable of doing this. Yet, due to the fact that professional ethicists could busy themselves full-time with moral issues, the patterns at their disposal tended to be larger and more fine-graded. "The large repertoire of interpretative patterns stored as part of the expertise of the ethical practitioner" Van Willigenburg stated, made him or her more "sensitive to the new (type of) problem, which means that (s)he is able to respond more promptly and accurately to the important cues in the case". ${ }^{104}$ This expert ability did not mean ethicists' judgements were objectively better than those of laypeople. An objective yardstick to measure the accuracy of ethical judgements did not exist. Still, the conclusions of professional ethicists went beyond mere opinions or beliefs. First, because their 'hard drive' was filled with a wide knowledge of past cases (in addition to a sufficient understanding of ethical theories and principles). Second, because their 'software'-their skills in moral reasoning-allowed them to extract the morally relevant dimensions of past cases and explain in a consistent manner how these applied to new cases. "Depending upon the quality of the reasoning process underlying a moral conclusion", Van Willigenburg concluded from this, "one is justified in holding that one does not just 'believe', but that one 'knows". ${ }^{105}$ This knowing was what distinguished the ethical expert from laypersons.

For Van Willigenburg, the ability to combine knowledge of past cases with the skill of consistently going back and forth between new and older cases was the main and perhaps only expertise that ethicists really had. Ethical expertise, Van Willigenburg wrote in response to Ten Have, consisted not of "a kind of 'Greenpeace-like' activism [...] against the dominant 'technocratic' ideology in modern medicine". ${ }^{106}$ Ethicists' contribution was intellectual, not political. Thus, if ethicists were asked to take part in a research ethics committee, their role was not "to put into the pillory the "pernicious power' of the pharmaceutical industry" but to assist in thinking through the research proposal under examination with their knowledge of past cases and ability to argue them consistently. ${ }^{107}$ Similarly, if they were asked to think along with scientists about the permissibility of specific animal experiments, their task was not to start a crusade against all research involving animals. "Ethical practitioners need to be critical", Van Willigenburg pressed, "not as activists or reformers, but as experts who take their discipline seriously as a discipline of reason". ${ }^{108}$ Doing so was not selling out, it was the only role that ethical experts could sensibly fulfil.

\footnotetext{
${ }^{104}$ Ibid., p. 150 , p. 139. Italics in original.

105 Ibid., p. 149.

${ }^{106}$ Ibid., p. 35.

${ }^{107}$ Ibid., p. 36.

${ }^{108}$ Ibid., p. 39. Italics added.
} 
In the early 1990s, these two diverging views on the ability and function of 'ethical experts' were increasingly experienced as a true 'factional struggle' over the identity of the Dutch ethics profession. In 1993, at a conference organised by the Utrecht Centre for Bio-ethics and Health Law, Van Willigenburg and Van Tongeren again crossed swords on the contribution ethicists could really make to "the manner in which moral issues are addressed by policymakers, [...], physicians, and other caregivers". ${ }^{109}$ Van Willigenburg opened the debate by stating that he had decided to appropriate the title 'ethical engineer'. In recent years, he argued, the term engineer had frequently been thrown at applied ethicists to demean their activities. Like plumbers, applied ethicists would be in the business of mindlessly repairing leakages without investigating what might be their cause. Besides being an unjustly negative portrayal of plumbers, Van Willigenburg argued, this also incorrectly described what 'ethical engineers' did. Ethical engineering meant nothing else than to take a careful step-by-step approach to considering the many aspects of moral problems and to put these into thought and word in an orderly manner to enable well-considered ethical decisions to be made. It meant coaching participants in moral deliberations to make valid arguments and "ensure a necessary argumentative hygiene" in the decision-making process. ${ }^{110}$ Hence, an ethical engineer was "someone with their own specific expertise in making concrete moral problems manageable by systematically reflecting upon them". ${ }^{111}$

Critics of this approach, Van Willigenburg continued, argued the ethical engineer was not critical enough; that (s)he did not ask fundamental philosophical questions. Apparently, the ethicist stated cynically, moral questions about the care for the elderly could only be answered by pondering about human existence and what it means to be old. "I find such an approach wicked", Van Willigenburg countered, "It tries to find answers with far-reaching reflection on a philosophical-theoretical level, while we live in a time in which it is very naïve to assume that philosophy (as metaphysics or a philosophy of life) can still give answers to 'fundamental' issues as 'how we should look at existence"'. ${ }^{112}$ Such thinkers, he continued, wanted to tackle a dilemma like whether traffic victims may be used as organ donors by exploring how this question in and of itself betrays a mechanical vision on life. They wanted to make all sorts of historical connections and think up cultural criticisms. Yet, in doing so, they never got around to answering the actual question. Perhaps, Van Willigenburg suggested delicately, it was time for these critics to get out of their comfy armchairs and, instead of reading another book, take up an internship in a hospital or government office to help investigate dilemmas as people experienced them and struggled with in reality. Perhaps it was time for these critics to start making a difference in the world.

Van Tongeren's response was equally forbidding. Van Willigenburg's perspective on ethics, the philosopher felt, bespoke an "almost shocking anti-intellectualism" ${ }^{113}$ The applied ethicist's dismissal of asking overly difficult questions and reading books could only be a "commercial mask" to win over "no-nonsense managers" to hire ethicists, Van Tongeren surmised, for it had little to do anymore with any actual academ-

\footnotetext{
${ }^{109}$ T. van Willigenburg, 'Inleiding', in Beleid en ethiek, pp. 187-188, p. 187.

${ }^{110}$ T. van Willigenburg, 'Ik ben een ethisch ingenieur!', in Ibid., pp. 189-204, p. 189.

${ }^{111}$ Ibid., p. 200.

112 Ibid., p. 191.

${ }^{113}$ P. van Tongeren, 'De ethicus versus de ingenieur', in Ibid., pp. 205-211, p. 207.
} 
ic study. The questions Van Willigenburg discarded as wicked and naïve, those were philosophical investigations: questions that made people reflect on life to understand how certain modes of thinking organized their existence and to consider whether alternative modes of existence were desirable and possible. Van Tongeren had no principle objection to the type of engineering that the applied ethicist was so enthusiastic about. Yet, he continued, "Whatever it is that Van Willigenburg is doing, it is not philosophy anymore. And, as far as ethics is a philosophical discipline, it cannot be ethics anymore either". ${ }^{114}$ Instead, it was some sort of organisational management that philosophy should stay far from. For, if the engineer would become the core identity of ethicists and when (not if) this fad had run its course in a few years' time, "the baby will be thrown out with the bathwater". ${ }^{115}$ In the long run, Van Tongeren warned, the sort of ethics promoted by scholars like Van Willigenburg was sure to bring about the demise of moral philosophy as an academic discipline.

This struggle over the professional identity and political function of Dutch (health) ethics was by no means resolved at conferences in the early $1990{ }^{116}$ For most of the decade, the hermeneutic perspective kept on being denoted as the Nijmegen school of ethics (after the institutional affiliations of Van Tongeren, Zwart, and later also Ten Have), while the applied ethics perspective was referred to as the Utrecht school (after its Centre for Bio-ethics and Health Law). In 1994, when national research schools started to emerge in the Netherlands (see above), the Nijmegen group joined the Research School Philosophy, while the Utrecht group joined the Research School Ethics. To be sure, other academic approaches to health ethics circulated as well in the Netherlands in this period. Scholars like De Vries, for instance, who identified neither with the hermeneutic nor with the applied ethics perspective, joined the Research School of Science, Technology and Modern Culture, which brought together scholars in the area of Science, Technology and Society studies. ${ }^{117}$ And from the mid-1990s onwards, the ethics of care became quite popular in the Netherlands-a normative approach to ethics that opposed the dominance of notions like autonomy and non-maleficence in the Dutch health ethics discourse and instead introduced terms like dependence, vulnerability, and mutual responsibility. ${ }^{118}$ Still, by 1997 , the scholarly dispute between the 'Nijmegen' and 'Utrecht' ethicists continued to be understood as one of the most dominant fracture lines in the Dutch academic practice of ethics. ${ }^{119}$

Hence, when viewed solely from the angle of academic debate, the factional struggle between these two schools of thought reached a standstill in the Netherlands in the late twentieth century. Members of neither camp could convince their opponents

\footnotetext{
${ }^{114}$ Ibid., p. 207.

${ }^{115}$ Ibid., p. 211.

${ }^{116}$ Other gatherings and publications include: H.J. Achterhuis (ed.), Deugt de ethiek? Medische, milieuen bedrijfsethiek tussen trend en traditie (Baarn: Gooi en Sticht, 1993); J.A.M. van Boxtel, J. Gruppelaar, H.J. Achterhuis \& J. Vorstenbosch (eds.), Techniek, voorlopigheid en verlegenheid. Ethiek en technologisch aspectenonderzoek (Den Haag: NOTA, 1993).

${ }^{117}$ Musschenga, 'Nederlandse ethiek na 1970', p. 158.

${ }^{118}$ For prominent Dutch representatives of this perspective, see: H.M. Manschot \& M. Verkerk (eds.), Ethiek in de zorg (Amsterdam: Boom, 1994); M. Verkerk, 'Zorgethiek: naar een geografie van verantwoordelijkheid', in H. Manschot \& H. van Dartel (eds.), In gesprek over goede zorg (Meppel: Boom, 2005), pp. 177-184.

${ }^{119}$ J.S. Reinders, 'Weg uit de ivoren toren? Kanttekeningen bij de tussentijdse evaluatie van het Centrum voor Ethiek KUN', in Tijdschrift voor Geneeskunde en Ethiek Vol. 7 (1997), pp. 90-92, p. 90.
} 
of the intellectual soundness and practical merits of their point of view. When viewed from a broader political and institutional perspective, however, one of the two schools made more headway than the other in the 1990s. For although this was an academic debate, it was heavily influenced by the growing political involvement with the ethics of science, medicine, and health in this decade. In fact, as the last section of this chapter shows, like the rise of research ethics committees in the 1970 s and 1980 s favoured a particular way of knowing in the biomedical sciences (see chapter 2), the expanding regulatory role of the Dutch state in ethically contentious medical (research) practices in the 1990 favoured a certain conception of ethical expertise, especially in the public governance of a practice like human experimentation.

\section{The Dutch political use for ethical experts}

In 1988, a Dutch government policy report on 'the limits of care' included a short, but intriguing statement: "Ethics", page 15 announced matter-of-factly, "is in". ${ }^{120}$ The report was part of a series of policy documents in the 1980 s on the organisation of the Dutch health care system and listed five types of boundaries that the incumbent government, the second Lubbers cabinet, had to deal with in the upcoming years. ${ }^{121}$ The second of these was the "boundary between what may and what may not be considered ethically permissible". ${ }^{122}$ Because the individual increasingly occupied a central place in Dutch society, page 15 read, and because technological advancement increasingly made all sorts of health interventions possible, "the interest for medical ethics, or better put health ethics, is growing". "Ethical reflection [...] on what is good and evil, on what is permitted and what is unacceptable [...] can rejoice in growing public and political attention". ${ }^{123}$ Ethics, in the Netherlands, was en vogue.

Page 15 also noted a second development that had taken place in the last few decades. Despite the individualization of Dutch society, "it is increasingly becoming clear that it is a task for all of us, and then particularly for the government, to weigh the interests of groups of patients against each other when necessary". ${ }^{124}$ The Dutch state, it seemed, was increasingly called upon to take a hands-on approach in the governance of ethically contentious issues in the fields of science, technology, and health. In the past, the 1988 report explained, the government had often refrained from taking a stance in this type of ethical issues, thereby endlessly postponing the development of public policies for them. But while "this sometimes seems morally defensible, it can also lead to ill-fated compromises or more seriously to indecisiveness, hidden selections, or veiled priorities". ${ }^{125}$ The second Lubbers cabinet was determined, therefore, to take a more active stance in the governance of health ethics.

\footnotetext{
${ }^{120}$ Grenzen van de zorg. Regeringsstandpunt inzake het Advies van de Ziekenfondsraad, de Nationale Raad voor de Volksgezondheid en de Gezondheidsraad ('s-Gravenhage: Tweede kamer der StatenGeneraal, Vergaderjaar 1987-1988, 20 620, nrs. 1-2 [1988]), p. 15.

${ }^{121}$ Given the growing diagnostic and therapeutic possibilities, ageing population, and increasing expenditures for health care, these reports all asked, what had to be considered the 'boundaries' of health care - not just in economic, but also in a socio-political and ethical respect. For a detailed description of these reports, see: Bolt, A Doctor's Order, pp. 315-320.

122 Grenzen van de zorg, p. 4.

${ }^{123}$ Ibid., p. 15.

${ }^{124}$ Ibid., p. 15.

${ }^{125}$ Ibid., p. 15.
} 
Already in January 1988, Minister Elco Brinkman (of the Christian-democratic party CDA) and State Secretary Dick Dees (of the conservative-liberal party VVD, see chapters 4 and 5) of the Ministry of Welfare, Health and Culture had sent a memo to Dutch parliament with "an inventory of medical-ethical themes" and discussion of the role of the government in dealing with them. ${ }^{126}$ More and more often, the two statesmen explained, the question was asked whether the far-reaching technical possibilities in medical science did justice to the interests of individuals in health care, and to the interests of society more generally. Protecting these interests was an important duty for a government-Hence, the memo. Yet, Brinkman and Dees had not included any concrete policy measures in their letter. The time, the two wrote, 'was not yet ripe for it'. Instead, the government had "to closely follow the advancing medical technology" and "to introduce legislation and regulation" only when needed, thereby keeping in mind that enough room was left to the "self-regulating activities of the profession". Also the second Lubbers administration was, after all, a government operating under the motto "more market, less government" (see chapter 5).127

This conclusion had provoked a disappointed response in Dutch parliament, also among the parties supporting the government. A member of the Christian-democratic party, for instance, strongly disagreed that the time was not yet ripe for government policy and declared that he did not believe in 'the self-regulating activities of the profession'. A member of the conservative-liberals, in turn, pressed the government to start developing policy on this terrain. A member of the orthodox-Protestant party, in the meanwhile, stated the memo proved the absolute impotence of the government in dealing with medical ethics. Unanimously, Dutch parliament pressed the two statesmen to "provide guidelines and set borders", an issue they kept on addressing in the months thereafter. ${ }^{128}$ In 1989 , the Christian-democrats again raised the concern that the government was not doing enough on the terrain of health ethics. Issues of ethical concern in health care were now only discussed in local ethics committees, they complained, and often only reactively, when problems had already exacerbated and were in need of immediate resolution. "We call this laundering after the fact", the Christian-democrats argued, "It is practicing ethics on an incidental basis". Instead of "being a slave to such developments", government and parliament had to take responsibility and start anticipating them. "Medical technology should not determine ethics, it should be the other way around". ${ }^{129}$ A few months later, a representative of the conservative-liberals voiced the same concern: "Scientific developments are now going so fast that politics is constantly behind the times". A permanent state committee had to be established, therefore, to "keep a finger on the pulse" of such developments and to allow the government to react immediately when necessary. ${ }^{130}$

\footnotetext{
${ }^{126}$ Kamerstuk Tweede Kamer 1987-1988, kamerstuk 20200 XVI, ondernummer 97, Brief van de minister en van de Staatssecretaris van Welzijn, Volksgezondheid en Cultuur, pp. 2-4.

${ }^{127}$ Ibid., p. 2.

${ }^{128}$ Kamerstuk Tweede Kamer 1987-1988, kamerstuk 20200 XVI, ondernummer 173, Verslag van een Mondeling Overleg, 1 June 1988, pp. 2-3, p. 6, p. 7.

${ }^{129}$ Handelingen Tweede Kamer, Vaste Commissie voor de volksgezondheid, 23 January 1989, p. 27.7.

${ }^{130}$ Handelingen Tweede Kamer, Vaste Commissies voor justitie en voor de volksgezondheid, 17 April 1989, p. 445.26; Handelingen Eerste Kamer, 21 March 1989, p. 23.890, p. 23.892. Later that year, in the government policy statement of the third Lubbers cabinet (a coalition between the Christiandemocrats and Labour Party) this expressed need for immediate public action on the terrain of medical
} 
In all these political initiatives, the need for government interference with ethically contentious issues in the field of medicine, health, and science was justified along two familiar lines. One, the speed and ferocity with which new technological and scientific developments announced themselves in the late modern era demanded government attention, as these presented large and, importantly, unprecedented ethical problems to society. Two, in a pluralist and increasingly secular democracy, older authorities and institutional structures for handling such problems-such as the Church, professions, or the famous pillars that would have organized Dutch society along ideological-religious lines until at least the 1960 s (see chapter 3)-could no longer offer solutions that were accepted by the majority of the Dutch population. ${ }^{131}$ Instead, citizens now looked to the state to settle ethical conflicts with official regulations, a role which consecutive Dutch governments increasingly felt compelled to take up in the $1980 \mathrm{os}$ and 1990s, despite the growing popularity of liberal and market-based approaches to the governance of health care, the sciences, and other sectors. ${ }^{132}$

The million-dollar question was, however, how the government could take up this role. In 1988, Brinkman and Dees had proposed to let experts fulfil a substantial role in informing parliament and public about developments in medicine and ethics, and only to realize regulations when this was absolutely needed. In doing so, the two had envisioned a leading role for the Health Council's Standing Committee Health Ethics (see above). As this Committee "concerns itself with continuous reflection on the ethical and juridical aspects of medical developments", Brinkman and Dees argued, it could conduct crucial 'pre-work' in the ethical thinking about medicine and health. ${ }^{133}$ The government would then only take an official position on how to handle ethically contentious issues after these reports had been debated in parliament. ${ }^{134}$ Dutch parliament, however, had not responded too enthusiastically to this proposal of the two statesmen. If the Health Council was to take on this role, the Christian-democrats had stated in the House of Representatives, the Standing Committee Health Ethics really had to include laypeople in its midst. ${ }^{135}$ After all, a committee consisting only of experts could not draw up reports on ethical dilemmas that included the opinions of all people in Dutch society. Similarly, two of the Protestant parties that took up a seat in the Senate had expressed concern that the expert composition of the Health Council did not do justice to the various religious-ideological viewpoints present in Dutch society. ${ }^{136}$ The conservative-liberals, in turn, had objected that the power to make ethical decisions should ultimately befall politicians, not experts. ${ }^{137}$

\footnotetext{
ethics became official government policy. See: Handelingen Tweede Kamer, 27 November 1989, p. 14-318; Kamerstuk Tweede Kamer 1987-1988, kamerstuk 21 545, ondernummer 2 Nota, p. 32.

${ }^{131}$ Wielenga, Nederland in de twintigste eeuw; Van Dam, Staat van verzuiling.

${ }^{132}$ Sjoerd Keulen, Monumenten van beleid. De wisselwerking tussen Nederlands rijksoverheidsbeleid, sociale wetenschappen en politieke cultuur, 1945-2002 (Hilversum: Uitgeverij Verloren, 2014); KeesJan van Klaveren, Het onafhankelijkheidsyndroom. Een cultuurgeschiedenis van het naoorlogse Nederlandse zorgstelsel (Amsterdam: Wereldbibliotheek, 2016).

${ }^{133}$ Kamerstuk Tweede Kamer 1987-1988, kamerstuk 20200 XVI, ondernummer 97, p. 2.

${ }^{134}$ Handelingen Eerste Kamer, 22 March 1989, p. 24.912.

${ }^{135}$ Kamerstuk Tweede Kamer 1987-1988, kamerstuk 20200 XVI, ondernummer 173, p. 2.

${ }^{136}$ Handelingen Eerste Kamer, 22 March 1989, pp. 24.921-24.922.

${ }^{137}$ Handelingen Tweede Kamer, Vaste Commissies voor justitie en de volksgezondheid, 17 April 1989, p. 45.43 .
} 
The concern that an expert body like the Health Council might hamper democratic decision-making processes about ethical issues was voiced repeatedly in the Netherlands in the late 1980 s and early 1990s. In 1990, for instance, sociologist Pim Fortuyn (who would later become one of the most famous politicians the Netherlands has ever known) pointed out in a policy report on the functioning of government advisory bodies that the Health Council in recent years increasingly had started to include ethical opinions in its reports-something it did not have a mandate for. "The Council should limit itself to preparing scientifically-funded opinions", Fortuyn argued, "and refrain from taking a stand on political, social, and ethical issues". ${ }^{138}$ Similar concerns were voiced in Dutch parliament. In 1991, during a parliamentary debate about "the ethical aspects of scientific and technological research", the Christian-democrats criticized the function of the Health Council in political dealings with issues of ethical concern. The dominant role of the advisory body in coming up with policy solutions for medical ethics dilemmas, the government party stated, had the effect that the initial framing of these issues took place by elite groups behind closed doors, generating a small circuit of insiders who frequently participated in the same committees and who were prone to propose similar solutions each time, to the detriment of a broader social and political debate. ${ }^{139}$ The Labour Party, since 1989 a coalition partner of the Christiandemocrats, agreed. Citing Achterhuis and Van Tongeren, its representative pondered in parliament: "How do we prevent that discussions are only held by 'experts'? With experts, I think first of all of so-called ethicists". ${ }^{140}$ The problem with these experts, this representative felt, was that they typically had a "narrow understanding of ethics" that was too easily used to justify new technological developments and explain away societal concerns. "I think we should prevent ethics committees to function in such a way that they legitimize research just because a few people have looked at it". "As Achterhuis says, these committees too often function as a problematic buffer between the controversial practices of scientists and societal critiques". ${ }^{141}$

Such sceptical views on the public functioning of ethics (advisory) committees and ethical experts were popular among Dutch politicians in the early 1990s. Achterhuis and Van Tongeren were invoked in parliamentary debates, as were Ten Have and De Vries. ${ }^{142}$ The government indeed had to prevent that ethics was used as "a greaser to get society to accept [scientific] insights", Minister of Education, Culture, and Sciences Jo Ritzen promised parliament in 1991. Scientific studies always had to be "socially and humanly relevant" and possible ethical concerns had to be carefully considered in a broad societal setting before a study could be executed, not when its outcomes were forced upon society as a fait accompli. ${ }^{143}$ To do so, the influence of 'average citizens' had to be increased in favour of the technocratic opinions of ethical experts. Hence, if

\footnotetext{
${ }^{138}$ W.S.P. Fortuyn, Ordening door Ontvlechting. Een advies over de adviesstructuur in de gezondheidszorg (Rijswijk: Ministerie van WVC, 1990), p. 24.

${ }^{139}$ Handelingen Tweede Kamer, Vaste Commissie voor het wetenschapsbeleid, 4 November 1991, p. 6.2 .

${ }^{140}$ Ibid., p. 6.6.

${ }^{141}$ Ibid., p. 6.7.

${ }^{142}$ Handelingen Tweede Kamer, Vaste Commissie voor de volksgezondheid, 23 January 1989, p. 27.7; Handelingen Eerste Kamer 1992-1993, 6 April 1993, p. 24.1081.

${ }^{143}$ Handelingen Tweede Kamer, Vaste Commissie voor het wetenschapsbeleid, 4 November 1991, p. 6.14 .
} 
philosophers like Achterhuis had one influence on Dutch politics in the early 1990s, it was that any form of political interference of ethicists with 'policy and ethics' came to be eyed with suspicion (not just a specific academic approach to ethics). As the conservative-liberal Senator Dian van Leeuwen-Schut worded it sharply in 1993 by citing De Vries: "Ethicists are intellectuals, not policymakers. Political decisions have to be made in the political arena. [...] It cannot be the case that ethicists tell policymakers already at the start of the ride what decisions have to be reached". ${ }^{144}$

These critical views on the role of ethical expertise in democratic decision-making, however, were not shared by all Dutch politicians and policymakers, especially not as the decade progressed. In 1991, for instance, the physician and soon to be Minister of Health Els Borst (see chapter 5), wrote an article for the Tijdschrift voor geneeskunde en ethiek in which she voiced a rather different point of view. Borst, who was at the time vice-President of the Dutch Health Council, strongly disagreed that the advisory body should refrain from including ethical opinions in its policy reports. Of course, she wrote, a scientific advisory body like the Health Council could never have the last word on ethically contentious issues. This had to be left to elected officials. The problem was, however, that "many debates in the Netherlands about the ethical aspects of gene therapy, embryo research, and prenatal diagnostics are neither here nor there because participants do not have the right facts". Thus, the input of experts was needed, as "ignorance and intense emotions just are no good ingredients to reach a meaningful moral consensus". This did not just hold for the technical side of new biomedical developments: "For good debates in- and outside of parliament [...] some preliminary work in the field of health ethics (and law) is indispensable as well". Ethical experts, Borst maintained in repetition of the Handboek gezondheidsethiek, were capable of raising the level of debate by offering terminological clarity and mapping moral problems. In doing so, they created "the possibility for well-informed societal discussions and a proper consideration by government and parliament”. ${ }^{145}$

In 1993, a similar viewpoint was articulated by J.H.W. Kits Nieuwenkamp, senior policy official at the Ministry of Welfare, Public Health and Culture, in an article on the treatment of ethical issues in Dutch policy circles. "Ethics", Nieuwenkamp wrote, "is not just practiced by ethicists, but by everyone who concerns himself with this sort of issues. Ethics is thus also practiced by policy officials and politicians". Nonetheless, she added quickly, "The ethics practiced by these individuals, who are usually laypeople, would soon get bogged down if they would not be assisted by professional ethicists, who have the tools needed to investigate moral issues in a way that systematic reflection truly takes place and that substantiated policy choices become possible". ${ }^{146}$ At the Ministry of Welfare, Health and Culture, this insight was increasingly realized. The State Secretary, for instance, had started to organize meetings in which policy

\footnotetext{
${ }^{144}$ Handelingen Eerste Kamer 1992-1993, 6 April 1993, p. 24.1107.

${ }^{145}$ All quotes in this paragraph: E. Borst-Eilers, 'Geneeskunde, ethiek en de Gezondheidsraad (Gast aan het woord)', in Tijdschrift voor geneeskunde en ethiek Vol. 1 (1991), pp. 48-49, p. 49.

${ }^{146}$ J.H.W. Kits Nieuwenkamp, 'Wat kan de ethiek voor het beleid betekenen? De rol van de ethiek en van ethici bij het beleid?', in Beleid en ethiek, pp. 34-42, p. 37.
} 
officials discussed ethical issues under leadership of professional ethicists. In addition, they were stimulated to stay in close contact with ethicists at seminars, in hallways of conferences, and in government advisory bodies. A new idea, she continued, was to also start hiring ethicists at Ministries. She knew that the ethicist Frans Brom already worked as consultant at the Ministry of Agriculture, Nature and Food Quality to help develop public policies (see above) and, if it was up to her, her own Ministry would follow suit. "The ethicist", Nieuwenkamp concluded enthusiastically by citing Van Willigenburg, "facilitates the policymaker, as it were". ${ }^{147}$

That year, also State Secretary Hans Simons of the Ministry of Welfare, Health and Culture (see chapter 5) suggested that, despite the present unpopularity of ethicists in Dutch political circles, good reasons existed nonetheless to include them in the policymaking process. As Simons said in his reply to the demand by Van Leeuwen-Schut that the role of ethicists in policy circles immediately had to be rolled back:

In itself, this [demand] is correct, but a surprising development has occurred. In the domain of government control we aspire to a smaller role for the government and for good reasons. [...] Yet, in the domain of issues of medical ethics we are witnessing an opposite trend. As medical technologies and their implications grow, a sharper need crops up for legislation in the domain of medical ethics. ${ }^{148}$

While this response in no way directly addressed the concern of Van Leeuwen-Schut, it provides a clue as to why statespersons would be interested in including ethicists in policymaking. In a time that the government was increasingly called upon to resolve ethical issues, the input of those who concerned themselves professionally with such issues became an alluring route to explore for politicians, even if this went against the grain of popular opinion. This, at least, was the suspicion of Labour Senator Joop van den Berg, who remarked in a 1993 article on the 'Place and task of parliament in ethical discussions', that the Dutch political system as it had developed in the twentieth century just was not equipped to deal with difficult ethical issues. "In the age of pillarization [...] a culture of decision-making developed with an interest in restricting the political agenda. [...] To ensure its stability and acceptance, the political arena did best to abstain from highly charged normative issues". ${ }^{149}$ Thus, in a time that Dutch society, including its political system, had been segregated along religious-ideological 'pillars', ethical issues that ran across these pillars had preferably not been discussed in parliament, while in instances that it really could not avoid dealing with them, experts had been called in to prepare a position that the government could adopt. This approach had allowed politicians to defend decisions by deferring to expert opinions rather than ideological arguments and to thereby depoliticize the treatment of ethical issues. Despite the recent de-pillorization of Dutch society, Van den Berg argued, this pacifying approach to policymaking had remained popular in the country. Dutch politicians just did not know how to handle ethical issues any other way. ${ }^{150}$

\footnotetext{
${ }^{147}$ Ibid., p. 37.

${ }^{148}$ Handelingen Eerste Kamer 1992-1993, 6 April 1993, p. 24.1131.

149 J.Th.J. van den Berg, 'Plaats en taak van het parlement bij ethische discussies', in Techniek, voorlopigheid en verlegenheid, pp. 129-136, p. 131. Italics added.

${ }_{150}$ Also: L. Sterrenberg, 'Ethisch aspectenonderzoek: dans met beleid', in Beleid en ethiek, pp. 26-33.
} 
Indeed, despite the critical attitude towards ethical experts of Dutch politicians in the early 1990s, four Dutch Ministries were found willing in this period to co-finance a "stimulation programme for policy-relevant ethical research" with the Netherlands Organisation for Scientific Research (NWO), that had academics help develop policies for 'the many large and unprecedented ethical problems' that Dutch society faced in an era of swift technoscientific advancement. ${ }^{151}$ With a budget of over nine million guilders, this programme subsidized 67 'ethics and policy projects' in the 1990s, giving a swath of young scholars the opportunity to obtain a PhD in ethics. ${ }^{152}$ Although it offered room for both fundamental and applied ethics studies, the latter proved much more popular, as these were more likely to engage with concrete policy questions. ${ }^{153}$ According to ethicist Musschenga, one of the directors of the stimulation programme, this measure had the effect that especially the applied ethics field grew in the Netherlands in the 1990s, in contrast to the hermeneutic approach to ethics.154

After 1994, this trend was reinforced with the coming to power of the 'Purple Coalition', the first Dutch government since 1918 in which no confessional party took part (see chapter 5). In the early 1990s, most political parties in Dutch parliament had, at one point or another, cautioned for the inclusion of ethicists in policymaking processes. Most often, however, this criticism had been voiced by confessional parties, which were concerned that a reliance on ethical expertise favoured liberal-progressive viewpoints on the permissibility of practices like IVF, euthanasia, or the use of legally incapacitated people as research subjects. The participation of laypeople, they hoped, would make sure that all religious-ideological viewpoints in Dutch society were represented in government advisory committees and ethics committees. The Purple Coalition, however, brought together three secular parties-the social-democratic Labour Party, the conservative-liberal VVD, and the progressive social-liberal D66 (see chapter 5)-and favoured 'a managerial approach' to government, i.e., rather than developing public policies with a specific ideology in mind, the government had to take a business-like approach to steering societal processes. Policy decisions had to follow from a pragmatic consideration of the situation at hand, not from pushing specific

\footnotetext{
${ }^{151}$ These departments were the Ministry of Health, Welfare and Sports, the Ministry of Education, Cultural Affairs and Science, the Ministry of Housing, Spatial Planning and the Environment, and the Ministry of Agriculture, Nature Management and Fisheries.

${ }^{152}$ Musschenga, 'Nederlandse ethiek na 1970', pp. 159-160. In the early 2000s, this programme was extended in slightly augmented form with four million euros to subsidize another 20 ethics projects. ${ }^{153}$ Ibid., p. 160. To see how (public) research funding had historically favoured certain ways of knowing in the sciences and humanities, see: Steven Shapin, The Scientific Life. A Moral History of a Late Modern Vocation (Chicago: The University of Chicago Press, 2008); Kohler, Partners in Science; Solovey, Shaky Foundations; D. Braun, 'The role of funding agencies in the cognitive development of science', in Research Policy Vol. 27 (1998), pp. 807-821.

${ }^{154}$ This went especially for studies submitted to one of the "areas of special attention" in the stimulation programme: that of Ethics and Health. Reason was that the Medical Sciences-section of NWO had at first declined to participate, because most ethicists that would apply for funds lacked practical experience in health care. Rather than investing large sums of money in ethics research conducted by "medical outsiders", it reasoned, NWO would do better to reach out to caregivers to ask them which moral issues they encountered in their practice. To get Medical Sciences on board, NWO asked a committee under leadership of Els Borst to rewrite the elements of those stimulation programme concerned with health ethics, which recommended to have all requests for funding on the terrain of Ethics and Health include a substantial empirical section in their proposals: ethical analyses had to be combined with knowledge and perspectives available in the field of health care itself. See: Ibid., p. 159.
} 
political interests. ${ }^{155}$ This approach was epitomized in particular by D66, a party that had been established in the 1960 s as a pragmatic alternative to religious-ideological approaches to politics. Public policy, the party maintained, should be problem-based (i.e. follow from a consideration of specific problems) and had to be justified with reasonable rather than religious-ideological arguments. While it defended a direct approach to democratic decision-making, this conviction went hand in hand with a belief in the enlightening impact of education: as long as citizens were well-informed, they could be expected to make reasonable choices when called upon to do so. ${ }^{156} \mathrm{Ex}-$ perts fulfilled a key role in this philosophy. Rather than representing the interests of specific groups, they would be trained to 'objectively' analyse problems and 'neutrally' present public policies to those responsible for them: i.e. politicians.

One of the most iconic members of D66 in the 1990s was the physician Els Borst, who served as Minister of Health, Welfare and Sport for almost eight years under the Purple Coalition (see chapter 5). Borst, as the previous chapter has argued, was not a big fan of the participation of laypeople in the development of health care policy. The very definition of laypeople, she maintained, was that they lacked the expertise necessary to engage meaningfully with complex issues. Plus, in a pluralist and individualized society, they could hardly be said to represent specific social groups. Experts, in contrast, did have an important contribution to make. After all, without their input "ignorance and intense emotions would rule" in the political arena when deliberating difficult ethical issues. Hence, in her role as Minister of Health, Borst was only willing to admit that the pluralistic moral viewpoints present in Dutch society would be fairly presented by ethical experts in the various oversight committees that she planned to realize for the public governance of various medical (research) practices. The participation of laypeople, as was repeatedly requested by confessional parties in parliament in this period, was decidedly rejected by Borst (see chapter 5 ).

In this approach to the governance of ethically contentious issues, Borst favoured a particular conception of ethical expertise. "A good ethicist is trained in careful reasoning and clear analysis", she would state in parliamentary debates over the contribution of ethicists to (research) ethics committees, "It is a certain way of thinking""If you have a strong personal opinion which prevents you from ever considering pros and cons, you should not take up a seat in such committees" (see chapter 5). ${ }^{157}$ Borst's understanding of ethicists was similar to that of Van Willigenburg. Like the ethicist, she located ethical expertise in the ability to take a step-by-step approach to moral problems, to order these carefully and to enable well-considered ethical decisions to

\footnotetext{
${ }^{155}$ Jouke de Vries, Paars en de managementstaat. Het eerste kabinet-Kok (1994-1998) (Apeldoorn: Garant, 2002); Klaartje Peters, Een doodgewoon kabinet. Acht jaar Paars, 1994-2002 (Amsterdam: Boom, 2015); Keulen, Monumenten van Beleid. The Purple Coalition has gone down in history as a typical example of Third Way politics, the fusion of social-democratic and liberal styles of government that was internationally popular in the 1990s. See: Anthony Giddens, The Third Way. The Renewal of Social Democracy (Cambridge: Polity Press, 1998); Anthony Giddens, The Third Way and its Critics (Cambridge: Policy Press, 2000); Mark Kranenburg, 'The political branch of het polder model', in NRC Handelsblad, 1 July 1999; Oscar Garschagen, 'Koks poldermodel maakt indruk op Clinton', in De Volkskrant, 23 June 1997; Thijs Niemantverdriet, De vechtpartij. De PvdA van Kok tot Samsom (Amsterdam: Athanaeum Boekhandel, 2014).

${ }^{156}$ Van der Land, Tussen ideaal en illusie; Paul Lucardie, Nederland stromenland. Een geschiedenis van de politieke stromingen (Assen: Koninklijke van Gorcum, 2002), pp. 83-87.

${ }^{157}$ Handelingen Eerste Kamer 1997-1998, 21 April 1998, p. 28.1475.
} 
be made. 'Good ethicists', Borst said in parliament, could guide moral deliberations. Similarly, like Van Willigenburg, Borst emphasized that ethicists could not act as activists or reformers, but only as experts in the discipline of reason, able "to take away from their feelings and personal beliefs to just make an objective judgement". ${ }^{158}$ Ethicists did not have strong moral opinions themselves, but mediated those of othersenabling a proper consideration of ethical issues by those responsible for moral decisions (see chapter 5). They were luminaries in ethical thinking, capable to transcend particular moral and religious commitments and to bring these together. Ethicists, in short, spoke the moral lingua franca needed in a pluralist society.

As the previous chapter explained, Borst also advocated this approach to ethics in political debates over the constellation of euthanasia committees. In discussions over the installation of animal experimentation committees, she voiced a similar opinion. Since the passing of these various pieces of legislation in the late 1990s, the inclusion of appropriate ethical expertise has been an official requirement for the accreditation of all these review bodies. What is more, since 2014, the Central Committee on Research Involving Human Subjects demands that ethicists may only participate in research ethics committees if they hold a degree in theology, philosophy, humanism, or ethics; have "demonstrable knowledge of health ethics, proven by a dissertation and relevant recent publications in peer reviewed journals"; and have at least three years of work experience in health ethics in the five years leading up to taking up a committee seat. ${ }^{159}$ Today, 23 of these accredited committees seating at least one ethicist are active in the Netherlands. In addition, five euthanasia committees exist and about 25 animal research committees are active throughout the country. ${ }^{160}$

Hence, since the late 1990s, Dutch law guarantees professional ethicists a spot in the public governance of a number of ethically contentious medical (research) practices-a feat quite exceptional for a humanities discipline. This not only ensures that the expertise of ethicists is brought to bear in discussing difficult ethical cases, it also provides an incentive for medical (research) centres to hire ethicists to support their medical and scientific staff. At the same time, however, these legal requirements also favour a specific type of ethical expertise. Although none mention what type of ethical expertise is suitable for participating in ethics committees, their practical functioning is, at least in theory, a better fit for the applied ethicist than the hermeneutic philosopher. The ethical evaluation of human research protocols, for instance, focuses on the protection of research subjects within the confines of the Dutch law. Hence, committees are in principle not permitted to reject studies because they would unjustly profit Big Pharma or harm the environment (see chapter 5). ${ }^{161}$ As Van Willigenburg put it in 1991: "The task that the ethical consultant takes up sometimes excludes certain forms of criticism". ${ }^{162}$ Yet, this was precisely why scholars like Van Tongeren and Ten Have had been convinced that ethicists should not take up a seat in ethics committees. For

\footnotetext{
${ }^{158}$ Ibid., p. 28.1475.

${ }^{159}$ See: 'CCMO Deskundigheidseisen leden METC's', in Staatscourant, Nr. 6804, 12 February 2016.

${ }^{160}$ Jan Vorstenbosch, 'Dierethiek in Nederland', in Ethiek in Nederland, pp. 251-276, p. 262.

${ }^{161}$ Similarly, committee members evaluating animal studies cannot a priori reject any form of animal experimentation. They have to accept that, in principle, such experiments are permitted and necessary, See: Tsjalling Swierstra, 'De commissie Biotechnologie bij Dieren: toets of glijmiddel?', in J. Swart, R. Tramper \& M. Jonker (eds.), Afwegen, hoe doe je dat? (Budel: Damon, 2009), pp. 154-164.

${ }^{162}$ Van Willigenburg, Inside the Ethical Expert, p. 36.
} 
ethicists unwilling to accept the role of consultant, in other words, not much of a role is left in these various public review bodies. In that sense, De Vries was right in 1993, that rather than that health ethics disciplined the medical discipline in the twentieth century, the bureaucratization of medicine and growing interference of public authorities in this period has contributed to the disciplining the ethics discipline.

In the last decades, the practice of ethics by committee, in which individual cases of specific medical (research) practices are ethically evaluated by a group of carefully selected experts according to a predetermined set of norms and rules, has continued to be treated as a typical implication of the health or bio-ethics movement of the late twentieth century, both in the Netherlands and internationally, and both by scientific researchers and humanities scholars. When scientists make themselves heard, it frequently is to complain that ethicists needlessly halt scientific progress with their obsession over rigid principles and 'red tape', as Vandenbroucke did in 1991. ${ }^{163}$ Humanities scholars, on the other hand, have continued to state that health or bio-ethics predominantly functions as a greaser for technoscientific machineries. Today, this type of criticism voiced by philosophers in the late 1980 s also has become popular among historians who claim that research ethics committees are an obvious example of how professional bioethics shields the old research establishment from more critical societal voices (see the introductory chapter to this PhD-thesis). ${ }^{164}$

One can wonder, however, to what extent this finger pointing is grounded in reality. For one thing, as previous chapters have shown, it royally overplays the involvement of (bio)ethicists in the realization of oversight mechanisms for human experimentation. While they arose around the same time, the two have very distinct narratives of origin that were, at least in the Netherlands, only knitted together toward the end of the twentieth century. For another, it attributes much more power to ethicists than they have ever had in the governance of human experimentation, certainly in the Netherlands. Hence, even if they ended up acting like Commissars in the oversight of human research studies, they remain just one voice among a larger group of experts of which the vast majority still comes from the biomedical sciences. Plus, as chapter 5 also alluded to, by the early 200os, Heleen Dupuis, famous doyen of the Dutch health ethics movement, was just as frustrated about the way in which the WMO forced local research ethics committees into "bureaucratic straightjackets" as her critics had been. The WMO would have replaced moral pathos by "managerial arrogance and a mania for organisation". While she meant something different with this than De Vries had done when he claimed that the bureaucratization of medicine had produced ethicists who did not have to think anymore, both shared an uneasiness over the standardization of ethical discourse and decision-making in the practice of ethics by committee, a frustration they shared in turn with researchers like Vandenbroucke.

\footnotetext{
${ }^{163}$ Internationally, one of the most recent incarnations of this viewpoint has been put forward by famous cognitive psychologist Steven Pinker in a 2015 article in the Boston Globe. See: Steven Pinker, 'The moral imperative for bioethics', in Boston Globe, 1 August 2015.

${ }^{164}$ The quote is from: Cooter, 'Inside the Whale', p. 662.
} 
Most importantly, however, the narrow focus on professional health ethics ignores the role played by the Dutch government in bringing about this "ethics bureaucracy" in the governance of human experimentation. In 1982, the Central Council for Public Health had proposed to speak of the ethical evaluation of protocols because the stipulation of too detailed legal norms could stifle a practice that was continuously developing. It was perfectly fine to include laypeople in this process, as long as they acted 'reasonable' and were accompanied by experts with a thorough understanding of the protocols under examination (see chapter 4). However, over the course of the 1980s, voices sprang up in the Netherlands to state that detailed juridical rules were needed to ensure uniform decision-making procedures. If the government wanted to exercise public control over human research, it had to make very clear what was and was not permitted. Without exception, all Dutch administrations in the late twentieth century favoured this type of expert approach to the practice of ethics by committee. Whereas professionals could be expected to consistently assess protocols according to agreedupon rules, laypeople-the unruly "all and sundry"-would infuse unpredictable and thus uncontrollable elements into the review process (see chapter 5).

In adopting this policy perspective, the Dutch government never gave a substantial defence of why ethicists should be included in the evaluation of human research protocols. Only in the late 1990s, when it became clear that Dutch parliament would not pass the WMO without an assurance that the plurality of viewpoints in Dutch society would be brought to bear in the evaluation of protocols, were ethicists brought onto the stage as 'obvious mediators' between expert and democratic forms of governance. In claiming this, the Dutch government made eager use of a specific approach to ethical reflection that had become popular in the 1970s and 1980s, and actively furthered one way of knowing in the ethics discipline above others. Still, it has to be pointed out that despite this 'advantageous professional push', the Dutch government more than anything else has payed lip service to the applied ethics tradition with regulations like the WMO. Under this law, ethicists who take up a seat in Dutch research ethics committees remain, even if they want to, hardly able to fulfil the once imagined role of "luminaries" who speak the moral lingua franca of a pluralist society. For only their physical presence was ensured in 1998-by a government that had a specific use for ethicists in a time when Dutch citizens increasingly looked to the state to resolve ethical issues, and that wanted to claim democratic control over human experimentation without actually needing to have society participate in its governance. 



\section{- Conclusion •}

In the evening of July 22, 1964, famous American comedy writer Allan Sherman performed his new song parody of Prokofiev's Peter and the Wolf for a buoyant audience in Boston's Tanglewood Music Center. The parody, that was live broadcasted, relates the story of the young composer Peter, who has just finished creating a beautiful new melody, but who, as a resident of communist Russia, needs to have it approved by the Commissars of music prior to its release. The Commissars, who of course all lack Peter's talent, demand his song to sound more like existing tunes: Tchaikovsky's Swan Lake, Beethoven's Fifth, Brahms' Lullaby. After a while, Peter slinks off, battered and disillusioned, with a song stamped 'not approved' and time in the Clink to rethink his sins. Luckily, all turns out well in the end, as a savvy recording company owner hears Peter whistling his song, recognizes its potential, and, thence, "In spite of the number one Chief Commissar, Peter [became] bigger than Ringo Starr".

Since 1964, Peter and the Commissar has gained fame as a celebration of American individualism and free-market capitalism that reigned supreme during the Cold War. It offers, of course, a stylized repudiation of the Soviet Union's political order. Yet, as Sherman also rhymes, "Now the Commissar in this story is Russia, but that is just for purposes of discussion. One finds this type no matter where one lives, we call them junior executives". For the thing is, the comedy writer points out:

\section{[...] These people on committees, they sit there all day}

And they each put in a colour, and it comes out grey

Grey is a nice colour, but not if you have ever seen

Orange or red or yellow or blue or green

And we have all heard the saying, which is true as well as witty

That a camel is a horse designed by a committee. ${ }^{1}$

Today, the saying [design] by committee has gained general usage in the English language to refer to a defective trait of bureaucratic decision-making: a lack of vision and originality that would stifle innovation. In the sciences, certainly, this practice of 'new Marxism' has often been argued to inhibit any form of 'true progress'.

After World War II, the Netherlands was one of the first nations in which the practice of ethics by committee was proposed as a sensible governance tool for the oversight of research studies with human subjects-or, to use the correct historical term, "tests upon human beings". In the future, the national Dutch Health Council wrote to the government in 1955, medical tests which entailed more than average risk would have to be reviewed first by an advisory committee seating physicians to determine if such interventions were permitted. Still, research ethics committees only sprang up

\footnotetext{
${ }^{1}$ Allan Sherman, 'Peter and the Commissar', on Peter and the Commissar (LP, Mono, Dyn). Camden, N.J.: RCA Red Seal Record (July 22, 1964).
} 
in the 1980 s in the Netherlands and a Dutch law regulating the practice was not realized until 1998-more than 40 years after that first policy report had appeared and well after most other Western countries had put similar regulations in place. This 'lag' was not for lack of trying. After 1955, government advisory bodies published numerous reports on the topic and after the 1970s Dutch parliament regularly pressured the government to make haste with proper legislation. This had the effect that policy deliberations on the governance of human experimentation by means of research ethics committees spanned about half a century in the Netherlands, revealing clear shifts in collective thinking about the position of medical science in Dutch society.

\section{The changing historical function of ethics by committee}

As it turns out, research ethics committees originally were imagined in the Netherlands to capture and steer two transformations taking place in this period: the changing role of science in "modern medicine", and the changing position of medicine and medical science in "modern Dutch society" (with the adjective modern functioning as a prominent actor's category to signal that times had changed and that different governance solutions therefore had to be provided for the proper regulation of a scientific practice like human experimentation). Chapters 1 and 2 examine this first shift. In the 1950s, pressured by ongoing antivivisectionist complaints about the corrupting effects of the 'experimental tradition in modern medicine', a group of Dutch elite physicians came to argue that human experimentation was an integral part of medicine, and the realization of medical progress via experimentation a moral obligation for all Dutch citizens. Of course, tests could only take place if strict conditions had been satisfied, but a certain amount of risk just could not be avoided. According to this group, the practice of ethics by committee could keep such necessary risks at a minimum. In the 1960 s and 1970s, another group of Dutch elite physicians started to claim that, in order for medicine to progress in the country, more and better human research studies had to be conducted. Again, such experiments had to satisfy basic ethical rules to be permitted, but ethics committees were imagined to function primarily as epistemic filters: mechanisms capable of sifting out methodologically good from bad research, that could simultaneously alleviate what they stated to be misguided concerns among the average Dutch physician about the permissibility of such studies.

These attempts to accommodate for and stimulate the changing position of science in Dutch medicine went hand in hand with the formulation of a governance ideal that advocated more internal control over medical research and practice, i.e., the elite of the profession had to keep the average practitioner in check to ensure they acted in accordance with the principles of 'modern medicine'. The best experts had to participate in committees that would function as beacons for the periphery to turn to and, if needed, operate as a form of border control to safeguard the proper conduct of human research studies. For an important part, this governance ideal was proposed to gain the upper hand in a long-time epistemic struggle over the appropriate place of the experimental tradition in 'modern medicine and society'. In the 1950s, the Health Council proposed more elite control to restore public trust in the artsenstand and protect its experimental tradition from what it argued were undue attacks from critical outside forces like the antivivisectionists. In the 1960 s and 1970s, elite control was 
increasingly deemed necessary to keep the 'unruly periphery' of the profession itself in check. In this process, attention shifted from keeping disruptive forces out of medicine to regulating the conduct of practitioners within the discipline, which had the effect that a different role started to be formulated for the Dutch state in governing medicine. Whereas elite physicians like Jean Jacques Brutel de la Rivière had maintained in the immediate post-war era that the profession should be free from all state intervention, a new generation of experts like Frans Nelemans started to claim in the 1960 s that the Dutch medical elite should utilize the hard power of the state to realize their epistemic ideals of 'rational therapeutics'. Still, both generations were convinced that an intimate understanding of and familiarity with the rules of 'modern medical science' were required to make informed ethical judgements in medicine. Hence, any control mechanism for human experimentation, whether put in place by the state or not, always had to be wielded by members of the profession itself.

Towards the end of the 1970s, an alternative governance ideal was formulated for human experimentation to accommodate for a second transformation taking place in these decades: the changing position of medicine and medical science in Dutch society. Chapters 3 and 4 examine this second shift. In the 1960s, a crisis had sprung up in the artsenstand about whether its existing ethics tradition still fitted "life in modern society", that was dominated by technological inventions, by an increase of scale in organisations, and by changing social bonds more broadly. When this crisis connected in the late 1960 s to a larger rebellion against traditional authority, multiple groups came to argue that 'medicine in modern society' required new modes of governance. For patients to direct their own lives, vertical relations of dependence and subordination had to be replaced by horizontal relations of consultation and participation. In the late 1970s, the practice of ethics by committee was enveloped by this movement and reframed as a necessary form of external control over medical research. Professional identity was argued to result in groupthink: as physicians were only trained to act as members of the artsenstand would, they were unable to fairly assess the conduct of colleagues. Ethics committees, therefore, had to consist predominantly of laypeople, who by virtue of not belonging to the biomedical in-group, were much better suited to objectively assess the permissibility of human experiments.

To be sure, this perception of research ethics committees, which was quite popular among social activists in the late 1970s, was never really picked up upon in relevant Dutch policy circles. Behind the closed doors of government advisory bodies, therapeutic reformers like Erik Noach and Dick van Bekkum, who had since long advocated more internal control over human research studies in the Netherlands, successfully pushed for an oversight system led by experts. A few laypeople could participate as society-representatives, but they had to accept that human experimentation in principle was necessary and permitted, and conduct themselves 'in a reasonable manner'. Plus, they ideally would be chosen via a co-optation procedure, meaning that the experts who already held a committee seat would decide which laypeople were suitable to take part. Still, in the Dutch public domain, two distinct governance ideals for research ethics committees had come to vie for affection in the early 1980s: one emphasizing the need for more expert control and one emphasizing the need for more control by those whose identity consisted primarily of not being experts. 
Chapter 5 shows how this conflict was resolved in the Netherlands in the 1980 s and 1990s, a period that research ethics committees began to spring up in greater numbers in the country. So-called society-representatives hardly ever participated in these committees and influential commentators on the governance of human experimentation (often lawyers and ethicists) increasingly came to argue that the participation of laypeople was potentially dangerous: the influx of the unruly "all and sundry" made it hard for review boards to operate consistently, which would be required to guarantee fair and objective decision-making. In Dutch parliament, the participation of laypeople remained more popular, especially among confessional parties which feared that the dominance of experts would marginalize those viewpoints they held dear. Consequently, public control was increasingly argued necessary not to counterbalance the groupthink of the medical in-group, but to ensure that the plurality of viewpoints in a democracy was fairly represented in committees overseeing contentious medical research practices. In the late 1990s, Minister of Health Els Borst rhetorically resolved this dilemma by postulating professional ethicists as ideal mediators between expert and democratic modes of governance. In moral deliberations, these experts would be capable of neutrally presenting all ideological-religious opinions in a pluralist society, thereby enabling "well-rounded and objective decisions" to be made.

\section{The accompanying change in the locus of ethical authority}

As part of this twofold transformation, two related changes took place in the way in which 'ethics' was understood to function in the Dutch governance of medicine. First, the locus of attributed ethical authority changed. In the 1950s, still, the old vocational identity of the artsenstand had reigned supreme in Dutch discussions of medical ethics. Medical-ethical expertise, the argument went, was mostly tacit and only acquired via full immersion in the discipline. Only members of the in-group possessed a honed moral compass to sense what was ethically just in medical situations. ${ }^{2}$ From this selfprofessed epistemic ideal, it followed that the governance of medicine was also first and foremost a professional affair. As only the lived experience of a physician meant that one understood the ethically right thing to do in medicine, the input of outsiders was potentially dangerous. In the 1960 s and 1970s, this ideal of exclusive professional objectivity came under attack from various anti-establishment movements. By virtue of being a thinking subject, everyone would have access to (medical) ethics. The professional identity of physicians, in fact, would be an obstacle for grasping the ethically right thing to do in medicine. In this context, the outsider's perspective of laypeople came to be thought of as more objective than that of the medical in-group.

In the 1980 s and 1990s, as chapter 6 shows, new epistemic ideals were formulated that aimed to do away with all perspectival views on morality. In a pluralist democracy, a general moral perspective that transcended all cultural identities had to be formulated for the public governance of ethically contentious issues to prevent violent conflict. Inclusive deliberation procedures were imagined to result in explicit or even propositional ethical statements: general rules accessible to all members of a democratic society that in turn could be applied to individual cases to determine what was

\footnotetext{
${ }^{2}$ Michael Polanyi, The Tacit Dimension (New York: Doubleday, 1967); Harry Collins \& Robert Evans, Rethinking Expertise (Chicago: University of Chicago Press, 2007).
} 
ethically just. The idea became popular that more objective moral decisions could be reached by 'an escape from perspective'. This moral lingua franca (or 'view from nowhere', as the philosopher Thomas Nagel once put it) would ensure more impersonal and therefore more objective decision-making in a pluralist society. ${ }^{3}$

Ironically, on the back of this new epistemic ideal, the locus of attributed ethical authority again changed in the Netherlands in the 1980 s and 1990s-at least in policy circles concerned with the governance of medical research involving humans. Even if a moral lingua franca could be formulated for a pluralist society, a growing consortium of public commentators and policymakers came to argue, some could be expected to master this language better than others. A new notion of 'disciplinary objectivity' arose, in which the ethical viewpoints of professional ethicists were taken to be more trustworthy than those of laypeople. Even though elected officials were said to remain responsible for ethical decisions at the level of government, they could be expected to make more rational decisions with the help of ethical luminaries.

\section{The accompanying adaptation of the Dutch ethics discourse}

Often, this first change in the way ethics was understood to function in the Dutch governance of medicine is explained by and justified with the changing societal role of medicine and medical science in the second half of the twentieth century. In an age of growing medical powers and egalitarian social structures, the once uncontrolled freedom of physicians to do as they please really had to be reeled in. Yet, around roughly the same time, a second change in the function of ethics in governing medical science was realized that seemingly had the opposite effect. After World War II, the existing Dutch medical ethics discourse was actively adapted to accommodate for and stimulate the conduct of human experimentation. Traditional medical ethics, with its emphasis on primum non nocere and primacy of the personal bond between doctor and patient was argued to no longer suit modern medicine. Therapeutic reformers started a lobby to convince physicians that their concerns to have patients participate in controlled trials were often unfounded and at times even unethical. To enable a rational therapeutics to emerge, after all, everybody-doctor and patient alike-had to participate in experimental investigations. Hence, even if the professional powers of individual researchers might need reeling in, the freedom of the profession as a whole to conduct more research studies had to expand. A moral need existed for human experimentation, which meant that ethics had to be formulated that enabled researchers to take some risks with individuals to benefit society as a whole.

Perhaps surprisingly, the popularity of this utilitarian logic in Dutch policy circles was hardly hampered by the emergence of a patients' rights frame in the 1960 s and 1970s. Although this new framework brought about a more critical assessment of the individual researcher-subject relationship, it did little for a more critical assessment of the societal position of biomedical research as a whole (despite the hopes of more 'radical commentators' like Rudi van den Hoofdakker). Generally speaking, in policy dealings with medical ethics in the Netherlands in this period, state interference was directed toward regulating the procedures by which patients and physicians should

\footnotetext{
${ }^{3}$ Thomas Nagel, The View From Nowhere (Oxford: Oxford University Press, 1986).
} 
make difficult ethical decisions and left alone the actual content of such decisions. In political debates over the permissibility over scientific research, also in case of human experimentation, the same logic was used. Even when undesirable research studies were proposed, as in the case of criminologist Wouter Buikhuisen in 1978, the Dutch government maintained that an open society should guarantee 'freedom of inquiry'. Similarly, in parliamentary discussions on the public governance of human experimentation in the late 1990s, Minister of Health Els Borst decided that participants in research ethics committees were not permitted to question the societal position of the pharmaceutical industry or the negative environmental effects of studies. Reviewers could only consider the permissibility of proposals from a patients rights' perspective. In instances such as these, science was formulated to constitute a societal good that should proceed free from political interference as much as possible. A government could only set the basic parameters in which a scientific practice like human experimentation could take place, not meddle with its actual content.

\section{The disciplining effects of ethics by committee}

Still, it is far from the truth to state that the Dutch government in the second half of the twentieth century acted in an epistemically neutral manner toward the conduct of human experimentation in medicine. In the 1950s, it helped to protect experimental medicine from social critics like the antivivisectionists who claimed that all of modern medicine constituted an unethical experiment by supporting the view that the experimental tradition in and of itself was sound and that only excesses had to be prevented (for which the patients' rights regime later proved suitable). In the 1970s, it initially refused to support research ethics committees as these might hamper experimental studies; and in the 1980s and 1990s, it lent its support to the idea that research ethics committees should function as filters which can halt proposals that do not live up to agreed-upon standards of methodological quality. In effect of these policies, a specific type of human experimentation had by the end of the century become much more ingrained in Dutch society than it had ever been, with a government actively promoting certain ways of peering into the world and not others. Indeed, since the effectuation of the WMO in 1998, epistemic perspectives that do not fall in line with the dominant paradigms of good science can legally be halted in the Netherlands on grounds that it is unethical to submit human research subjects to studies that, due to a flawed research design, will never yield valid results. In combination with the demand that all reviewers have to agree that human research is in and of itself necessary and permitted (i.e. they cannot reject it altogether), the Dutch practice of ethics by committee purposefully has been made to function as a mechanism of exclusion for more radical perspectives on the value and validity of human experimentation.

It is important to point out that this function of the practice of ethics by committee is not the result of some hushed up Machiavellian power play on behalf of a medical in-group who hoped to protect a scientific practice of which it secretly knew it could not stand the light of day. That ethics committees should function as epistemic filters was publicly and repeatedly defended by multiple generations of self-appointed therapeutic reformers who were convinced that only this way the Dutch state would be able to protect citizens from dubious research activities. Sure, reformers such as $\mathrm{Ne}-$ 
lemans strategically used their multiple professional identities to realize these ideals, i.e., pushing the government to further one way of knowing in their role as policy advisor, while presenting this growing state interference as an abstract external force in their academic work. ${ }^{4}$ When called upon, however, reformers usually were quite willing to defend why they believed it was good for the state to provide leading experts in the field with hard power to steer the conduct of the average practitioner.

In this same vein, it also has to be made explicit that despite the frequent rhetorical positioning of science as a republic of equals in which "freedom of inquiry" remains one of the highest goods, this political ideal hardly does justice to some of the most dominant control mechanisms through which the late modern science system has been designed to function. ${ }^{5}$ While it has become somewhat popular today among scientists to complain that 'ethics by committee' has brought a form of New Marxism to the once free republic of science, the practice was invented not so long ago by their very own predecessors to enable scientific progress. Because for these therapeutic reformers, the crisis they believed modern medicine was facing was not primarily one of individual researchers who failed to abide to clear ethical rules, but one of scientific knowledge and how it could be generated and used in medicine. ${ }^{6}$ To prevent medical science from descending into chaos or being corrupted by undue influences, a number of gatekeepers just had to police the borders of the field. ${ }^{7}$ Hence, that committees strictly had to peruse research designs was not an unintended consequence of design by committee in a bureaucracy full of red tape, it was a built-in mechanism to enforce a specific epistemic perspective in Dutch clinical research and practice.

Chapter 6 has argued that the disciplining effect which these developments had on the fledgling Dutch ethics discipline in the late twentieth century was an unintended outcome of the realization of public oversight mechanisms for human research studies in the country. While the applied ethics tradition by the late 1990 s had acquired more political traction in the Netherlands than ethicists advocating a hermeneutic or constructivist approach, the practice of ethics by committee as instituted by the WMO in 1998 was never intended to prioritize a specific epistemic perspective in the Dutch ethics discipline. It was just that the politicians responsible for the WMO had particular use for the expertise promoted by applied ethics in a time that citizens increasingly looked to the state to handle contentious issues in the governance of science, technology, and health-i.e. that ethics was en vogue-while they did not want to admit to undue political influence on these terrains. The notion that ethicists were capable of

\footnotetext{
${ }^{4}$ For an interesting collection of papers that emphasizes the varying roles that experts can perform in different arenas, see: Joris Vandendriessche, Evert Peeters \& Kaat Wils, Scientists' Expertise as Performance. Between State and Society, 1860-1960 (London: Pickering \& Chatto, 2015).

${ }_{5}^{5}$ Michael Polanyi, 'The Republic of Science. Its Political and Economic Theory', in Minerva Vol. 1 (1962), pp. 54-73; Steve Fuller, The Governance of Science. Ideology and the Future of the Open Society (Buckingham: Open University Press, 2000).

${ }^{6}$ See also: Christian Bonah, "Experimental Rage': The Development of Medical Ethics and the Genesis of Scientific Facts. Ludwig Fleck: An Answer to the Crisis of Modern Medicine in Interwar Germany', in Social History of Medicine Vol. 15 (2002), pp. 187-207.

${ }^{7}$ For the notion of 'elite scientists' acting as gatekeepers in order to shape a discipline's contents, see: Imogen Clarke, 'The Gatekeepers of Modern Physics. Periodicals and Peer Review in 1920s Britain', in Isis Vol. 106 (2014), pp. 70-93; Alex Csiszar, 'Broken Pieces of Fact. The Scientific Periodical and the Politics of Search in Nineteenth-Century France and Britain' [Ph.D. Dissertation, Harvard University, 2010); Csiszar, The Scientific Journal; Baldwin, Making Nature.
} 
formulating a general moral perspective transcending particular viewpoints appealed to politicians like Els Borst, who were pressured to ensure that all ethical opinions in a pluralist society were fairly represented in the review of protocols but who saw little use for the participation of laypeople or 'society-representatives' in the public governance of science: ethics review was to proceed in an orderly manner and had to be protected from the disorderly input of the unruly 'all and sundry'.

\section{'Objective judgements' and appropriate political control}

This leaves the question on what sort of input and participants the judgements of research ethics committees today are supposed to rest in the Netherlands. In 1998, to convince Dutch parliament of her vision for the practice of ethics by committee, Borst stated confidently that an orderly review system could be realized as long as reviewers "just make an objective judgement". This statement harbours the belief that objective decision-making about ethical issues in the sciences is not only possible, but may even proceed scientifically itself. As long as certain experts are brought in and certain methods are followed, objective judgements surely can be reached. Yet, historians of science know objectivity to be a fickle concept, that has not always dominated conversations of how knowledge is acquired or judgement is passed, and that, even since it has, has been subject to change through time and space. ${ }^{8}$ In the history of ethics review described in this $\mathrm{PhD}$-thesis, this is no different. In every instance that ethics by committee was proposed as a suitable tool for the oversight of human experiments in the Netherlands, objectivity played a crucial role-in that only those considered capable of passing an objective judgement on the permissibility of protocols could participate in their review. But what it meant to pass an objective judgement, and who could reasonably be expected to pass it, shifted substantially in the latter half of the twentieth century, with strong implications for the forms of oversight that were felt appropriate for human research. Hence, in tracing the historical evolvement of these objectivities, it becomes possible to identify the various subject positions that in the second half of the twentieth century have been imagined capable of standing guard over human research in the Netherlands, and identify the changing ways in which the Dutch political order has sought to control this practice in this period. 9

Originally, in the 1950s, when the practice of ethics "by committee" was first proposed in the Netherlands, the communal review of risky medical tests upon humans was meant to alleviate two concerns about the ability of individual physicians to objectively assess the permissibility of these studies. The first was a moral concern: due to a growing pressure for physicians to advance their careers with scientific research, the temptations to engage in tests that did not primarily benefit the wellbeing of their patients were becoming too strong. The individual physician came to be thought of as too involved to be able to impartially-and thus objectively-determine if risky interventions could be justified. The second was an epistemic concern: due to the growing

\footnotetext{
${ }^{8}$ For the by now classic study in the history of science on the historically evolving notion of objectivity, see: Lorraine Daston \& Peter Galison, Objectivity (New York: Zone Books, 2007).

9 The notion of 'subject positions' is used here as it is typically understood in discourse analysis: i.e. subjects are created within discourses that name and categorize people into hierarchies and enable them to make sense of and participate in the world in certain ways - and not others. See: Foucault, The Order of Things.
} 
specialization of medical knowledge, it had to be doubted whether the average physician was still capable of conducting studies that would truly bring about medical progress, which, under the banner 'only good science is ethical science', was understood to be a moral concern as well. The peripheral members of the profession increasingly had to be considered incapable to accurately -and thus objectively-assess the scientific value of research studies. Together, this layered mistrust in the objective capacities of individual medical researchers led to formulating the need to install committees that would seat experts who were not directly involved in the study under review, but who were still competent enough to determine its scientific worth.

That these expert reviewers had to be impartial with regard to the study under consideration did not mean at the time that they also had to be socially or physically distant from research settings. Erik Noach, in fact, in all his thinking about research ethics committees in the 1960 s and 1970s, repeatedly emphasized that it was essential for reviewers to be intimately familiar with the local context in which an experiment was conducted. Only this closeness allowed them to truly assess if a researcher had the right motives for conducting a study and if the right facilities were in place for the study to proceed responsibly. Only immersion, in short, enabled an informed-and thus objective-assessment of the permissibility of an experiment.

In the 1980s, however, with the mushrooming of research ethics committees in the Netherlands, this notion came under pressure. Increasingly, individual groups of reviewers came to be eyed with suspicion. After all, how could someone who was physically distant from the research setting ascertain if local committees were actually impartial and accurate in reviewing protocols? "Variation and inconsistency", the jurist Lucas Bergkamp worded this suspicion in 1989, were the biggest problems which the Dutch system of ethics by committee had to deal with. Only standardized procedures would be able to squash these individual idiosyncrasies, and only this would ensure a consistent-and thus objective-assessment of research protocols.

Initially, these new objectivities were primarily intended to overcome drawbacks of the growth of the medical science system in the twentieth century, i.e., the increase of scale had undermined older rules of trust in determining if an individual researcher or local group of reviewers was impartial and accurate. Unfamiliarity demanded new ways to assess the ability to be objective and thus new modes to govern the conduct of researchers and reviewers. Communal structures and procedures would enable this strengthening of internal control..$^{\circ}$ Yet, in this same period, key changes took place in the broader societal appraisal of the Dutch medical science system as well, and soon the practice of ethics by committee became imbued with another register of objectivities that served to assert external control over medical research.

\footnotetext{
${ }^{10}$ As Theodore Porter and Lorraine Daston have argued for the rise of accounting traditions in nineteenth century knowledge production: "Certain forms of quantification have come to be allied with objectivity not because they necessarily mirror reality more accurately, but because they serve the ideal of communicability, especially across barriers of distance and distrust'. Lorraine Daston, 'Objectivity and the Escape from Perspective', in Social Studies of Science Vol. 22 (1992), pp. 597-618, p. 609; Theodore M. Porter, 'Quantification and the Accounting Ideal in Science', in Social Studies of Science Vol. 22 (1992), pp. 633-652; Theodore M. Porter, 'Objectivity as Standardization. The Rhetoric of Impersonality in Measurement Statistics and Cost Benefit Analysis', in Allan Megill (ed.), Rethinking Objectivity, special issues of Annals of Scholarschip Vol. 8 (1991), parts 3-4, and Vol. 9 (1992), parts 1-2, pp. 197-238. Also: Shapin, The Scientific Life; Steven Shapin, A Social History of Truth. Civility and Science in Seventeenth-Century England (Chicago: The University of Chicago Press, 1994).
} 
In the 1950 , still, only members of an artsenstand free from state interference had been argued capable of reaching uncorrupted-and thus objective-judgements about the permissibility of medical tests upon humans. By the 1970s, however, the trained judgement of the medical in-group had come to be suspected to muddy rather than to clarify the vision of physicians. Hence, medical outsiders came to be considered more uncorrupted-and thus more objective. In effect, ethics by committee was reimagined as a public control mechanism which had to be yielded by ordinary citizens to realize truly participatory decision-making structures in health care.

Yet, also this notion of objectivity did not last. In the 1980s, laypeople themselves became an object of distrust, not only because they would not understand enough of science to pass informed judgements upon it, but also because they represented just one of the many opinions present in a pluralist society, making participation of a few of them circumspect. Hence, the assessment of protocols had to become devoid of all perspectives; aperspectival as it were-and thereby more objective. ${ }^{11}$

In Dutch policy circles in the late twentieth century, this political desire to realize aperspectival review procedures for the conduct of human experimentation was wed to the earlier notion that consistent review procedures were needed to ensure objective decision-making in the practice of ethics by committee. As long as reviewers were capable of parting with their own personal beliefs to place themselves in the point of view required by the review process-i.e. "to just make an objective judgement" - they would succeed in consistently applying the carefully designed procedures for the adequate assessment of protocols, which would in turn enable a full escape from perspective. Put differently, regardless of the colours put in by the people on committees, the end result would turn out grey-which was exactly what was needed to ascertain that decision-making about ethical issues proceeded impartially. If reviewers just followed procedures, no social group or moral perspective would unduly profit from the public governance of human experimentation in a pluralist democracy.

This conception of objective ethical decision-making permitted the Dutch government in the late twentieth century to kill two birds with one stone. On the one hand, it enabled the state to assert that it did not leave medical researchers to their own devices-an autonomy they had proven incapable of handling, was irresponsible with regard to the amount of power they held, and did not fit a democratic order anyway. Physicians and scientists would have to learn to accept that they did not only have to justify their actions to colleagues and perhaps patients, but to the general Dutch public (by means of the government) as well. Medicine and science were a part of society and could thus be subjected to public scrutiny. Yet, at the same time, the suggestion that this scrutiny would proceed 'objectively' enabled the Dutch government to assert that it infringed neither upon personal beliefs in a pluralist society nor upon the freedom of inquiry that befitted an open society. After all, any state had to avoid acting as a "master of morality", as the boundaries between democratic and dictatorial governance were notoriously fluid. Hence, ethics review was not about bringing researchers under full societal control, only about holding them publicly accountable. ${ }^{12}$ Research-

\footnotetext{
${ }^{11}$ The term 'asperspectival' is derived from: Daston, 'Objectivity and the Escape from Perspective'.

${ }^{12}$ For more on the rise of public accountability cultures in academia and health care in the late twentieth century, see: Strathern, Audit Cultures; Nikolas Rose \& Peter Miller, Governing the Present. Ad-
} 
ers would have to submit protocols to publicly authorized review bodies, yet the decision if these could be executed would not result from unruly deliberations but from a fair application of uniform procedures by appointed administrators. The government itself, in fact, was to refrain from any further interference in the practice. Decisions were made only by neutral-and thus objective-reviewers.

\section{The political use for experts in democratic societies}

It is a conception of the public governance of human research studies that relies on a crafty understanding of the subject position of experts in the practice of ethics by committee. Just as in Van Willigenburg's imagined computer system, the reliance on standard protocols serves to negate judgements of individual experts, with all of their circumspect qualities. Yet, in order to attain the level of consistency required by the review procedure, only those with extensive training, i.e. experts, are considered capable of ensuring that the correct judgements are in fact reached. According to historian of science Theodore Porter, this dependence on standardized procedures administrated by trained bureaucrats has become a typical feature of large-scale liberal democracies in the late twentieth century. According to Porter, in political cultures in which politicians are themselves constantly pressured to account for their actions, those in charge tend to justify policies with an appeal to "the rule of rule" rather than to explicit moral arguments. Referring to rules and procedures allows one to deflect claims of arbitrariness and bias and is a perfect way of "making decisions without seeming to decide". This perception is reinforced by the fact that only those skilled in the application of rules may legitimately exercise this judgement. Trained bureaucrats know better than to let personal beliefs speak through in the evaluation of protocols. They are in the business of following procedure, meaning that any other bureaucrat, as long as they are properly trained, can be expected to reach the same conclusion. This combination of procedural with expert decision-making, Porter argues, has become "especially compelling to bureaucratic officials who lack the mandate of a popular election, or divine right" in modern democracies. It is the sort of objectivity that "lends authority to officials who have very little of their own". ${ }^{13}$

Of course, the legal rules by which human research is regulated in the Netherlands have been subject to extensive consideration in Dutch parliament, who has ultimately used its legislative powers to pass the WMO. Hence, the contemporary governance of human experimentation in the Netherlands is the result of a careful democratic process, in which Dutch citizens by means of their government set the terms under which the practice may take place. Experts only administrate these rules and may do so only in government approved ways. Still, looking back on the Dutch history of governing human experimentation, the extent to which politicians have relied on expert advice to decide what policies are best is striking. Whether it was one of the Health Council committees of the 1950 s and 1970s, the Central Council committee of the early 1980s, or the ad-hoc committee on research with the legally incapacitated in the mid-1990s, all permitted experts to set the frame in which human research would be debated in

ministering Economic, Social and Personal Life (Cambridge: Polity Press, 2008); Harry Oosterhuis \& Frank Huisman (eds.), Health and Citizenship (New York: Routledge, 2014).

${ }^{13}$ Porter, Trust in Numbers, p. 8. 
parliament and what type of policies could be considered suitable for its regulation. What is more, in all these years, the responsible Dutch statespersons not only seemed perfectly happy with this expert-driven approach to the definition of public problems, they actively appeared to invoke expert authority when challenged to take up a normative stance on the permissibility of human research studies, thereby allowing them to depoliticize the issues at hand. This or that policy decision did not just follow from the opinion of politicians, it had been officially advised by experts.

One politician who particularly favoured this approach to policymaking was Minister of Health Els Borst, responsible for the eventual effectuation of the WMO. According to the former medical director and vice-President of the Health Council, the input of experts was needed in public policy as 'ignorance and intense emotions' (which she believed followed from a lack of expert input) prevented reaching meaningful consensus about medicine and health. For those familiar with the history of Dutch politics, a certain irony may be noted in this faith in experts. Today, Els Borst remains one of the most iconic faces of the liberal-progressive party D66 that was established in the 1960 s with the aim to democratize the existing Dutch political order, which would be dominated by the 'closed castes' of the pillorized Dutch society. It was time, D66 felt, that citizens of a modern nation got to speak for themselves. Yet, by the 1990s, D66politicians like Els Borst were happy to assign the authority to speak to another elite, i.e. experts, who only two decades earlier had been framed as one of those traditional authorities that egalitarian societies had to rally against. Previous chapters have suggested that this reliance on experts by politicians might well be a Dutch phenomenon that, with a history of coalition governments, is known for its compromise-based and related expertocratic approach to government. Hence, the role of experts may differ from countries such as the United States which have a two-party system comprised of representatives that have local constituents to satisfy. More research with attention to national context is needed in this regard, not just in the domain of ethics review, but in the general realization of public control mechanisms in the late twentieth century that have intended to hold physicians and scientists to account. ${ }^{14}$

In the Netherlands, this demand for accountability in the conduct of research with human subjects eventually has resulted in a carefully constructed public bureaucracy of ethics that is dominated by the rule of expert consensus and built around two (and only two) premises: for protocols to be permitted they (1) have to be methodologically sound, and (2) contain sufficient safeguards to protect the rights and safety of participating research subjects. Subsequently, if the right procedures have been consistently followed and the correct rules justly applied, judgements are considered objective. In those instances, no undue perspectives are taken to have corrupted the review process, implicating that the decision has democratic approval even if no actual democratic process was involved in evaluating the protocol. Only trained administrators authorized to act on behalf of the government can participate in passing these judgements. Nonetheless, just to be sure, ethical experts have been elevated to function as fulcrums between expert and democratic governance modes for human experimentation. That is, in theory-when the practice is debated in parliament.

\footnotetext{
${ }^{14}$ Further research studies comparing 'discourses of accountability' in governing medicine and health care in the late twentieth century across Europe and the United States are currently developed by Prof.dr. Frank Huisman of Utrecht University and Prof.dr. Nancy Tomes of Stony Brook University.
} 
In the past as well in the present, the at times inflexible and inefficient elements of this bureaucracy have been blamed on the (bio)ethics profession that arose alongside of the practice of ethics by committee in the latter half of the twentieth century. Motivated by a false sense of moral righteousness, these 'Commissars' would have brought about a tangle of red tape in the governance of the medical sciences, frustrating scientific innovation. Yet, simultaneously, and just as loudly, (bio)ethicists have been accused of functioning as a lubricant for the medical research establishment that allows those in charge to push through any scientific innovation without too much societal resistance. Of course, it is crucial for any discipline to exercise reflexivity with regard to its professional functioning, and thus also to critically consider its role in certain forms of governance in favour of others. In the Netherlands as well as in other countries, this reflection does take place from time to time, to which this $\mathrm{PhD}$-thesis has attempted to contribute some much needed historical reflection on the political functioning of Dutch ethicists that goes beyond the idea that professional ethics emerged in the 1960 s and 1970 s "to break the bulwark of the know-it-alls". ${ }^{15}$

Still, for those who want to criticize ethics by committee as a frustrating example of design by committee that either stifles or shields scientific innovation, it seems more prudent to point to the manoeuvring of a specific political order in the late twentieth century than to the mythical dominance of a new ethics discipline that, at least in the Netherlands, has never inhabited more than a few positions of power. This political order wished to assert that it properly dealt with contentious issues in the domains of science, technology, and health-without having to admit to undue interference with the freedom of inquiry of scientists in an open society, and without actually having to include a plurality of societal voices in deciding what is just in these domains. Ethics by committee, then, became nothing but a managerial tool for holding researchers to account that could surely be wielded objectively-permitting science to progress and citizens to sleep sound. That is, of course, those epistemic perspectives that are found to fit the moulds of "authoritative science", and those citizens "reasonable enough" to understand that these moulds are both necessary and permitted.

\footnotetext{
${ }^{15}$ For a fairly recent reflection by Dutch ethicists on their professional and political functioning, see: Mariëtte van der Hoven, Lieke van der Scheer \& Dick Willems (eds.), Ethiek in discussie. Praktijkvoorbeelden van ethische expertise (Assen: Van Gorcum, 2010).
} 



\title{
- Sources and Literature •
}

\author{
National Archive (NL-HaNA), The Hague
}

2.02.28

Tweede Kamer (1945-1999)

11683 15470-2 Onderzoek in de zwakzinnigeninrichting Huize Assisië te Udenhout (1978-1979)

\subsubsection{TNO / Gezondheidsorganisatie (1948-1980)}

$481 \quad$ XH 049 Commissie Ethiek proefdieren

608 Commissie klinisch geneesmiddelenonderzoek

\subsubsection{Gezondheidsraad (1920-1956)}

546 Commissie inzake vivisectie: Stukken betreffende het adviseren aan de minister inzake de wenselijkheid van een wettelijke regeling van de vivisectie (1953-1955)

547 Commissie van Advies inzake het instellen van leerstoelen voor vivisectievrije geneeskunde en voor homeopathie: Stukken betreffende het adviseren aan de minister inzake het instellen van leerstoelen voor vivisectie-vrije geneeskunde en voor homeopathie (1947-1953)

548 Commissie inzake proeven op mensen: Notulen van de vergaderingen (1953-1955)

549 Commissie inzake proeven op mensen: Stukken betreffende het adviseren aan de minister inzake proeven op mensen (1953-1956)

2.15.36 Gezondheidsraad (1957-1990)

\footnotetext{
1374 Commissie medische ethiek: Agenda's en notulen

1476 Commissie klinisch onderzoek van geneesmiddelen: Rapport inzake klinisch onderzoek van geneesmiddelen (1971)

1478 Commissie klinisch onderzoek van geneesmiddelen: Algemene correspondentie (1968-1974): Deel II

1692 Commissie beraadsgroep gezondheidsethiek: Algemene correspondentie (1976-1977)

1704 Commissie beraadsgroep gezondheidsethiek: Algemene correspondentie (1984-1985)

1705 Commissie beraadsgroep gezondheidsethiek: Agenda's en notulen (1977-1979)

1707 Commissie beraadsgroep gezondheidsethiek: Agenda's en notulen (1981)

1708 Commissie beraadsgroep gezondheidsethiek: Agenda's en notulen (1982-1983)
} 
3.3.101 Commissie experimenten met radioactieve stoffen op proefpersonen

3.3.65 Commissie klinische farmacologie

2.15•37

2.15.65

2.21.340

SZ / Volksgezondheid (1918-1950)

2357 Stukken betreffende het onderzoek naar beschuldigingen van het verrichten van vivisectie op mensen in ziekenhuizen (1947)

\section{DG Volksgezondheid (1946-1982)}

1373 Het in- en samenstellen van de Staatscommissie Patiëntenrecht, met bijlagen (1975-1977)

1375 Agenda's en notulen van de vergaderingen van de Werkgroep Patiëntenrecht en Kwaliteitsbewaking, met bijlagen (1976)

2456 Kamervragen inzake op geaborteerde foetussen uitgevoerde medische experimenten, waaronder onderzoek in de Bloemenhovekliniek te Heemstede op foetussen van vijf maanden (1980)

\section{Stuyt, L.B.J. (1951-2000)}

$321 \quad$ Stukken betreffende de oprichting en openstelling van een Instituut voor Gezondheidsethiek aan de universiteit van Maastricht (1984-1986)

\section{Centr. Raad Volksgezondheid (1958-1982)}

22

23

24

51

52

Vergaderingen van de Raad: Agenda's en notulen van de raadsvergaderingen (vergaderingen $134 \mathrm{t} / \mathrm{m} \mathrm{141,1978)}$

Vergaderingen van de Raad: Agenda's en notulen van de raadsvergaderingen (vergaderingen $142 \mathrm{t} / \mathrm{m} \mathrm{149,1979)}$

Vergaderingen van de Raad: Agenda's en notulen van de raadsvergaderingen (vergaderingen $150 \mathrm{t} / \mathrm{m} \mathrm{155,1980)}$

Vergaderingen van het Comité van Gedelegeerden: Agenda's en notulen van vergaderingen van het Comité van Gedelegeerden (vergaderingen $210 \mathrm{t} / \mathrm{m} \mathrm{219,1978)}$

Vergaderingen van het Comité van Gedelegeerden: Agenda's en notulen van vergaderingen van het Comité van Gedelegeerden (vergaderingen $220 \mathrm{t} / \mathrm{m}$ 230, 1979, deel 1)

Vergaderingen van het Comité van Gedelegeerden: Agenda's en notulen van vergaderingen van het Comité van Gedelegeerden (vergaderingen 231 t/m 234, 1979, deel 2) 803-811: Patiëntenrecht: stukken betreffende het adviseren aan de minister inzake patiëntenrecht (1977-1982)

549-533: Medische proeven op mensen: Stukken betreffende het adviseren aan de minister inzake medische proeven op mensen (1978-1982)

554: Medische proeven op mensen: Agenda's en notulen van de vergaderingen van de Werkgroep medische proeven op mensen (1979-1981) 
2.3.28 1065: Medische experimenten: Stukken betreffende het adviseren aan de Staatssecretaris inzake een wettelijke regeling voor experimenten met geneesmiddelen (1984-1985)

2.3.28 1066-1068: Stukken betreffende het adviseren aan de Minister inzake een wetsontwerp 'Regelen inzake medische experimenten, met het advies 'Medische experimenten' (1988) (1984-1992)

2.3.28 1069: Agenda's, notulen en stukken betreffende de samenstelling, taak en werkwijze van de Commissie Medische Experimenten later Commissie Regelen inzake Medische Experimenten (1988)

\subsubsection{Hoofdinsp. Geestelijke Volksgezondheid (1962-1994)}

638 Onderzoek van de klachten voer bepaalde medische praktijken in het zwakzinnigeninstituut 'Huize Assisië' in Udenhout

\section{Government publications}

Parliamentary documents, accessed via www.statengeneraaldigitaal.nl (until 1995) and www.overheid.nl (after 1995):

- Verslag der Handelingen van de Tweede Kamer der Staten Generaal (Handelingen Tweede Kamer)

- Verslag der Handelingen van de Eerste Kamer der Staten Generaal (Handelingen Eerste Kamer)

- Kamerstukken en Aanhangsels van Kamerstukken van de Tweede Kamer en Eerste Kamer der Staten Generaal (Kamerstukken en Aanhangsels)

Dutch laws:

- Wet regelende de uitoefening der artsenijbereidkunst, 1 Junij 1865

- Wet van 28 juli 1958, houdende nieuwe regelen nopens de geneesmiddelenvoorziening en de uitoefening der artsenijbereidkunst (Wet op de geneesmiddelenvoorziening)

- Wet van 24 oktober 1997, houdende regels betreffende bijzondere verrichtingen op het gebied van de gezondheidszorg (Wet op bijzondere medische verrichtingen)

- Wet van 26 februari 1998, houdende regelen inzake medisch-wetenschappelijk onderzoek met mensen (Wet medisch-wetenschappelijk onderzoek met mensen)

- Wet van 12 april 2001, houdende toetsing van levensbeëindiging op verzoek en hulp bij zelfdoding en wijziging van het Wetboek van Strafrecht en van de Wet op de lijkbezorging (Wet toetsing levensbeëindiging op verzoek en hulp bij zelfdoding) 


\section{Newspapers}

Mostly consulted via the newspaper database 'Delpher' of the Dutch Royal Library (Koninklijke Bibliotheek), accessed via www.delpher.nl/nl/kranten.

- Algemeen Dagblad

- De Telegraaf

- De Tijd

- De Tijd-Maasbode

- De Waarheid

- Friese Koerier

- Gereformeerd Gezinsblad

- Het Vrije Volk
- Leeuwarder Courant

- Limburgs Dagblad

- Nederlands Dagblad

- Nieuwsblad van het Noorden

- NRC Handelsblad

- Reformatorisch Dagblad

- Trouw

- Volkskrant

\section{Internet sources}

Bryder L., 'The Medical Research Council and Clinical Trial Methodologies before the 1940s. The Failure to Develop a 'Scientific' Approach', JLL Bulletin: Commentaries on the history of treatment evaluation, retrieved from http://www.jameslindlibrary.org/ on 12 October 2016.

Food and Drug Administration, Protection of Human Subjects; Informed Consent. 21 CRF Parts 5o, 71, 171, 180, 310, 312, 314, 320, 330, 361, 430, 431, 601, 630, 812, 813, 1003, 1010 [Docket No. 78N-0400], January 27, 1981. Retrieved from http://www.fda.gov/ScienceResearch/SpecialTopics/RunningClinicalTrials/ucm113818.ht m on 18 February 2016.

Lintzen H. et al., Tachtig jaar TNO (2012), accessible at: http://www.histech.nl/www/nl/publications/view/tachtig-jaar-tno.

Mooij A., 'Laqueur, Ernst (1880-1947)', in Biografisch Woordenboek van Nederland. URL:http://resources.huygens.knaw.nl/bwn/BWN/lemmata/bwn6/laqueur [12-11-2013].

Pronk E., 'Els Borst: arts, minister, euthanasievoorvechtster' (2014, February 11), retrieved from http://www.medischcontact.nl/actueel/nieuws/nieuwsbericht/141980/els-borst-artsminister-euthanasievoorvechtster.htm on 8 March 2016.

Waterman A.T., 'Introduction', in the 1960 reprint of Science. The Endless Frontier, pp. xi-xii. Retrieved from https://archive.org/stream/scienceendlessfroounit\#page/n15/mode/2up on 20 October 2016.

\section{Audio sources}

Sherman A., 'Peter and the Commissar', on Peter and the Commissar (LP, Mono, Dyn). Camden, N.J.: RCA Red Seal Record (July 22, 1964). 


\section{Published sources}

Advies inzake regeling van medisch-wetenschappelijk onderzoek met minderjarigen en meerderjarige wilsonbekwamen [uitgebracht door de Commissie medische experimenten met wilsonbekwamen] (Rijswijk: Ministerie van Volksgezondheid, Welzijn en Sport, 1995).

'Assistentie, waarneming en associatie', in Medisch Contact Vol. 11 (1956), pp. 16-21.

'Commissies', in Medisch Contact Vol. 13 (1958), p. 335.

'Congres te Nijmegen: De geneesheer en het recht', in Medisch Contact Vol. 23. (1968), pp. 315-317.

'De 150 ${ }^{\text {ste }}$ Algemene Vergadering der Maatschappij', in Medisch Contact Vol. 23 (1968), pp. 453-463.

'De 160ste Algemene Vergadering der K.N.M.G.', in Medisch Contact Vol. 27 (1972), pp. 11611164.

'De pers en de geneeskunde', in Medisch Contact Vol. 10 (1955), pp. 242-245.

'Discussie over: rapport kunstmatige inseminatie', Medisch Contact Vol. 17 (1962), pp. 239241.

'Dr. J.C. Schultsz over Medische Ethiek', in Medisch Contact Vol. 21 (1966), pp. 782-783.

'Dr. R.J.H. Kruisinga beantwoordt vragen inzake "dubbelblinde” farmacologische onderzoeken', in Medisch Contact Vol. 22 (1967), pp. 1125-1126.

'Ethische beoordeling van medische experimenten met mensen'. Boerhaave-cursus van het PAOG', in Medisch Contact Vol. 38 (1983), p. 12.

'Fifty years of randomized controlled trials', in British Medical Journal Vol. 317 (1998), p. 1167.

'Het overdoen van de praktijk', in Medisch Contact Vol. 9 (1954), pp. 298-299.

'Het ziekenfondswezen', in Medisch Contact Vol. 13 (1958), pp. 105-108.

'Homoeopathie', Vol. 5 (1950), pp. 438-440.

'Honorarium', in Medisch Contact Vol. 12 (1957), pp. 546-551.

'Inleiding 154ste Algemene Vergadering', in Medisch Contact Vol. 25 (1970), pp. 5-6.

'Kort verslag H.B.-vergadering', in Medisch Contact Vol. 21 (1966), pp. 210-211.

'Kort verslag van de $99^{\text {ste }}$ algemene vergadering', in Medisch Contact, Vol. 4 (1949), pp. 246266.

'Korte verslagen vergaderingen hoofdbestuur', in Medisch Contact Vol. 23 (1968), pp. 337338.

'Landelijk steunpunt experimenteel mens/patiëntgebonden onderzoek', in Medisch Contact Vol. 42 (1987), p. 606.

'Lectori Salutem', in Tijdschrift voor geneeskunde en ethiek Vol. 1 (1991), pp. 1-2.

'Leerstoel voor de homoeopathie?', in Medisch Contact, Vol. 5 (1950), pp. 303-306.

'Medische Ethiek', in Medisch Contact Vol. 16 (1961), pp. 190-191.

'Medische Ethiek anno 1970. Inleiding van de voorzitter der Maatschappij, Dr. L. van der Drift, ter Algemene Vergadering op 18 april 1970 te Utrecht', in Medisch Contact Vol. 25 (1970), pp. 413-417.

“'Medische Ethiek” opnieuw gedrukt', in Medisch Contact Vol. 15 (1960), pp. 169-170.

'Medische ethiek tussen natuurwetenschap en samenleving', in Wetenschap en Samenleving Vol. 23 (1969), no. 5/6.

'Nieuwe vereniging wil deskundigheid leden van medisch-ethische commissies vergroten', in Medisch Contact Vol. 46 (1991), 1409-1410. 
'Openbare hoorzitting abortus provocatus', in Medisch Contact Vol. 26 (1971), pp. 1031-1032. 'Opheffing Werkgroep Klinisch Geneesmiddelenonderzoek TNO', in Nederlands Tijdschrift voor Geneeskunde Vol. 119 (1975), p. 418.

'Principles for the Clinical Evaluation of Drugs', in World Health Organization Technical Report Series No. 403 (Geneva, 1968), p. 6.

'Proeven op mensen', in Medisch Contact Vol. 13 91958), pp. 108-109.

'Stervensbegeleiding: Medisch-ethische plicht? Door Dr. C.P. Sporken, ethicus, directeur van het Mgr. Bekkers Centrum, Katholieke Universiteit Nijmegen', in Medisch Contact Vol. 25 (1970), pp. 418-424.

'Streptomycin Treatment of Pulmonary Tuberculosis. A Medical Research Council Investigation', in British Medical Journal 2 (1948b), pp. 769-782.

'Varia', in Medisch Contact Vol. 20 (1965), p. 27.

'Varia: Het dogma in de medische ethiek', in Medisch Contact Vol. 22 (1967), p. 1163.

'Veiligheid van Nieuwe Geneesmiddelen', in Medisch Contact 18 (1963), pp. 359-361.

'Voordrachten: internist C.L.C. Nieuwenhuizen, onderwerp "De ethische consequenties van de moderne ontwikkeling in de geneeskunde en biologie”', in Medisch Contact Vol. 22 (1967), p. 377.

'Wie had de Nobelprijs moeten krijgen?', in Nederlands Tijdschrift voor Geneeskunde Vol. 151 (2007), pp. 73-77.

Abbott L. \& Grady C., 'A systematic review of the empirical literature evaluating IRBs: what we know and what we still need to learn', in Journal of Empirical Research on Human Research Ethics Vol. 6 (2011), pp. 3-19.

Ackerknecht E.H., Medicine at the Paris Hospital, 1794-1848 (Baltimore: John Hopkins University Press, 1967)

Achterhuis H., De markt van welzijn en geluk. Een kritiek van de andragogie (Baarn: Ambo, 1979).

Achterhuis H., Het rijk van de schaarste. Van Thomas Hobbes tot Michel Foucault (Baarn: Ambo, 1988).

Achterhuis H., 'Schaarste en moraal', in Intermediair Vol. 25 (1989), pp. 41-43.

Achterhuis H.J. (ed.), Deugt de ethiek? Medische, milieu- en bedrijfsethiek tussen trend en traditie (Baarn: Gooi en Sticht, 1993).

Agar J., Science in the Twentieth Century and Beyond (Cambridge: Polity Press, 2012).

Aghina M.J., Patiëntenrecht. Een kwestie van gewicht (Assen/Amsterdam: Van Gorcum, 1978).

Ahlers J.B., Meer mensen mondig maken ('s-Gravenhage: Staatsuitgeverij, 1975).

Amundsen D.W., 'The Discourses of Roman Catholic Medical Ethics', in Cambridge World History of Medical Ethics, pp. 218-254.

Annas G.J. \& Grodin M.A. (eds.), The Nazi Doctors and the Nuremberg Code. Human Rights in Human Experimentation (Oxford, 1992).

Annas G.J. \& Grodin M.A., 'The Nuremberg Code', in The Oxford Textbook of Clinical Research Ethics, pp. 136-140.

Altman L., Who Goes First. The Story of Self-Experimentation in Medicine (New York: Random House, 1986).

Arras J.D., 'The Jewish Chronic Disease Hospital Case', in The Oxford Textbook of Clinical Research Ethics, pp. 73-79. 
Austoker J. \& Bryder L. (eds.), Historical perspectives on the role of the MRC (Oxford: Oxford University Press), pp. 181-204.

Baker R.B., 'Transcultural Medical Ethics and Human Rights', in Ethics Codes in Medicine, pp. 312-331.

Baker R.B., 'From Metaethicist to Bioethicist', in Cambridge Quarterly of Health Ethics Vol. 11 (2002), pp. 369-379.

Baker R.B. \& McCullough L.B. (eds.) The Cambridge World History of Medical Ethics (Cambridge: Cambridge University Press, 2009).

Baker R.B., Before Bioethics. A History of American Medical Ethics from the Colonial Period to the Bioethics Revolution (Oxford: Oxford University Press, 2013).

Bal R., Bijker W.E. \& Hendriks R.P.J., Paradox van wetenschappelijk gezag: over de maatschappelijke invloed van adviezen van de Gezondheidsraad (Den Haag, 2002).

Baldwin M., Making nature. The History of a Scientific Journal (Chicago: The University of Chicago Press, 2015).

Beauchamp T.L., 'The Belmont Report', in The Oxford Textbook of Clinical Research Ethics, pp. 149-155.

Beauchamp T.L. \& Childress J.F., Principles of Biomedical Ethics (New York: Oxford University Press, 1979).

Beaufort I. de, Ethiek en medische experimenten met mensen (Assen: Van Gorcum, 1985).

Beaufort I. de, 'Niet-therapeutisch wetenschappelijk onderzoek met wils-onbekwame personen', in Nederlands Tijdschrift voor Geneeskunde Vol. 133 (1989), pp. 737-740.

Beaufort I. de \& Dupuis H.M. (red.), Handboek Gezondheidsethiek (Assen/Maastricht: Van Gorcum, 1988), pp. 21-28.

Beecher H.K., 'Ethics and Clinical Research', in New England Journal of Medicine Vol. 74 (1966), pp. 1354-1360.

Bekkum D.W. van, 'Experimenten met mensen', in Ethiek, Cahiers van de Stichting BioWetenschappen en Maatschappij Vol 3, Nr. 2 (Deventer: Van Loghum Slaterus, 1976), p. 25 .

Bekkum D.W. van, 'Proeven op patiënten: techniek, ethiek', in Kanker, Cahiers van de Stichting Bio-Wetenschappen en Maatschappij Vol 3, Nr. 4 (Deventer: Van Loghum Slaterus, 1976), p. 38.

Bekkum D.W. van, 'Medische experimenten en proeven op mensen. De rechten van patiënten in het medisch-wetenschappelijk onderzoek', in Medisch Contact Vol. 35 (1980), pp. 115118.

Bennebroek Gravenhorst J., 'Medisch-ethische toetsing van wetenschappelijk onderzoek in Nederland', in Geneeskunde en Ethiek in Harmonie, pp. 97-105.

Berg C. van den, 'Herinneringen aan de wordingsgeschiedenis van de wet op de geneesmiddelvoorziening', in Tijdschrift voor Sociale Geneeskunde 42 (1964), pp. 12-15.

Berg J.H. van den, Medische macht en medische ethiek (Nijkerk: Callenbach, 1969).

Berg J.Th.J. van den, 'Plaats en taak van het parlement bij ethische discussies', in Techniek, voorlopigheid en verlegenheid, pp. 129-136.

Bergkamp L., Medisch Ethische Commissies en het Toezicht op Experimenten met Mensen. Verslag van de eerste fase van een onderzoek naar de structuur en het functioneren van medisch ethische commissies (Universiteit van Amsterdam: Instituut voor Sociale Geneeskunde, 1986). 
Bergkamp L., Medisch Ethische Commissies en het Toezicht op Experimenten met Mensen. Verslag van de tweede fase van een onderzoek naar de structuur en het functioneren van medisch ethische commissies (Universiteit van Amsterdam: Instituut voor Sociale Geneeskunde, 1988).

Bergkamp L., Het proefdier mens. De normering en regulering van medische experimenten met mensen (Alphen aan de Rijn: Samsom Uitgeverij, 1988).

Bergkamp L., 'American IRBs and Dutch Research Ethics Committees: How They Compare', in IRB: Ethics \& Human Research Vol. 10 (1988), pp. 1-6.

Bergkamp L., 'Een voorstel voor een Wet op de medische experimenten: enkele kanttekeningen', in Tijdschrift voor Gezondheidsrecht Vol. 13 (1989), pp. 190-204.

Bergkamp L., 'Variatie en inconsistentie in de beoordeling van experimenten door medisch ethische commissies', in Nederlands Tijdschrift voor Geneeskunde Vol. 133 (1989), pp. 446-449.

Bergkamp L., 'Het betrekken van incompetenten bij experimenten', in Nederlands Tijdschrift voor Gezondheidsrecht Vol. 14 (1990), pp. 19-26.

Bernard C., An Introduction to the Study of Experimental Medicine (1865; trans. 1927; reprint, New York: Dover, 1957).

Bertens R., Gezondheid tussen staat en markt. De opkomst van het marktdenken in het Nederlandse zorgstelsel, 1974-1987 (Masterthesis Health Law, Universiteit van Amsterdam, 2015).

Bertucci P., 'Shocking Subjects. Human Experiments and the Material Culture of Medical Electricity in Eighteenth-Century England', in The Uses of Humans, pp. 111-138.

Beukers H., 'Een nieuwe werkplaats in de geneeskunde. De opkomst van laboratoria in de geneeskundige faculteiten', in Tïjdschrift voor de Geschiedenis van de Geneeskunde, Natuurkunde, Wiskunde en Techniek Vol. 9 (1986), pp. 266-277.

Bevir M., Governance. A Very Short Introduction (Oxford: Oxford University Press, 2012).

Beyens N. \& Bolt T., "A Medical Doctor in Politics', Els Borst-Eilers and the Rise of EvidenceBased Healthcare in the Netherlands', in Low Countries Historical Review Vol. 132-1 (2017), pp. 16-37.

Bezemer F., 'In memoriam P.A. van Luijt', in Nederlandsch Tijdschrift der Geneeskunde Vol. 98 (1954), pp. 3513-3514.

Bins J.W., 'Experimenten met mensen. Een verdwenen advies', in Medisch Contact Vol. 38 (1983), pp. 97-98.

Boer E.J., 'Medisch-ethische commissies, taak en functie bij wetenschappelijk onderzoek', in Nederlands Tijdschrift voor Geneeskunde Vol. 133 (1989), pp. 1659-1664.

Boerema I., 'De Keerzijde van de Vooruitgang in de Geneeskunde', in W. Peremans et al., Acht voordrachten over de keerzijde van de vooruitgang in de natuur- en geneeskundige wetenschappen ('s-Gravenhage: Martinus Nijhoff, 1962), pp. 39-55.

Bolt T., 'A Doctor's Order. The Dutch Case of Evidence-Based Medicine (1970-2015)' (PhDthesis, Utrecht University, 2015).

Bonah C., "Experimental Rage': The Development of Medical Ethics and the Genesis of Scientific Facts. Ludwig Fleck: An Answer to the Crisis of Modern Medicine in Interwar Germany', in Social History of Medicine Vol. 15 (2002), pp. 187-207.

Bonah C. \& Menut P., 'BCG-Vaccination around 1930 - Dangerous Experiment or Established Prevention? Practices and Debates in France and Germany', in Twentieth Century Ethics, pp. 111-128. 
Borst-Eilers E., 'Review commissie, fouten, ongevallen en near accidents (FONA) commissie en 'medical audit", in Ethische beoordeling van medische experimenten met mensen (Leiden: Rijksuniversiteit, Faculteit der Geneeskunde, 1983), pp. 137-139.

Borst-Eilers E., 'Geneeskunde, ethiek en de Gezondheidsraad (Gast aan het woord)', in Tijdschrift voor geneeskunde en ethiek Vol. 1 (1991), pp. 48-49.

Bosk C.L., 'Review: Strangers at the Bedside: A History of Law and Bioethicss Transformed Medical Decision Making by David J. Rothman', in Contemporary Sociology Vol. 20 (1991), pp. 831-833.

Bosk C.L. \& De Vries R., 'Bureaucracies of Mass Deception. Institutional Review Boards and the Ethics of Ethnographic Research', in Annals of the American Academy of Political and Social Sciences Vol. 595 (2004), pp. 249-263.

Botter A.A., 'Over de aetiologie van de strophulus infantum', in Verhandelingen van het Instituut voor Praeventieve Geneeskunde Vol. 16 (1950).

Bovens M., 'Public Accountability', in Ewan Ferlie, Laurence E. Lynn Jr. \& Christopher Pollitt (eds.), The Oxford Handbook of Public Management (Oxford: Oxford University Press, 2007), pp. 182-208.

Boxtel J.A.M. van, Gruppelaar J., Achterhuis H.J. \& Vorstenbosch J. (eds.), Techniek, voorlopigheid en verlegenheid. Ethiek en technologisch aspectenonderzoek (Den Haag: NOTA, 1993).

Brants M.A., 'Proefnemingen op menschen', in Nederlandsch Tijdschrift voor Geneeskunde (1904), Part, pp. 520-522.

Braun D., 'The role of funding agencies in the cognitive development of science', in Research Policy Vol. 27 (1998), pp. 807-821.

Brieger G.H., 'Human Experimentation. I. History', in Encyclopedia of Bioethics, pp. 684692.

Brom F.W.A., 'Ethiek in de praktijk van het overheidsbeleid', in Filosofie en Praktijk Vol. 13 (1992), pp. 79-87.

Brom F.W.A., Bergh B.J. van den \& Huibers A.K., 'Wie is er bang voor de ethiek', in Beleid en ethiek, pp. 5-18.

Brom F.W.A., Bergh B.J. van den \& Huibers A.K., Beleid en ethiek (Assen: Van Gorcum, 1993).

Brutel de la Rivière J.J., Over allergische huidreacties bij niet-allergische personen (Proefschrift Universiteit Leiden, Handelsdrukkerij Deventer Dagblad, 1932).

Brutel de la Rivière J.J., 'Uitoefening der Geneeskunst in Vrij Beroep tegenover deze Uitoefening in Dienstverband', in Medisch Contact Vol. 2 (1947), pp. 189-197.

Buikhuisen W., 'De wetenschapsfilosofische en ethische 'reflexen' van Prof. Schuyt', in Nederlandse Juristenblad Vol. 54 (1978), pp. 477-481.

Buikhuisen W., 'De 'regressies' van Schuyt', in Nederlands Juristenblad Vol. 53 (1978), pp. 526-530.

Burger H., 'Proefnemingen op menschen', in Nederlandsch Tijdschrift voor Geneeskunde (1904), Part I, pp. 317-320.

Burger H., 'Nog eens proefnemingen op menschen', in Nederlandsch Tijdschrift voor Geneeskunde (1904), Part I, pp. 379-380.

Burger H., 'De bewijsvoering van Dr. Burger', in Nederlandsch Tijdschrift voor Geneeskunde (1904), Part I, pp. 466-467. 
Burger H., 'Proefnemingen op menschen', in Nederlandsch Tijdschrift voor Geneeskunde (1904), Part I, pp. 522-524.

Bush V., 'Science. The Endless Frontier. A Report to the President on a Program for Postwar Scientific Research', July 1945.

Bynum W.F., 'Reflections on the History of Human Experimentation', in The Use of Human Beings in Research, pp. 29-46.

Bynum W.F. et al., The Western Medical Tradition, 180o-20oo (Cambridge: Cambridge University Press, 2006).

Calff J.P., Medische Ethiek Vandaag (Amsterdam: Agon Elsevier, 1969).

Callon M., 'Elements of a sociology of translation: Domestication of the Scallops and the Fishermen of St. Brieuc Bay', in J. Law (ed.), Power, Action and Belief. A New Sociology of Knowledge (London: Routledge, 1986), pp. 196-223.

Cantor D., 'The MRC's support for experimental radiology during the interwar years', in Historical perspectives on the role of the MRC, pp. 181-204.

Caplan A., 'Applying Morality to Advances in Biomedicine: Can and should this be Done?', in W.B. Bondeson, H. Tristram Engelhardt, S.F. Spicker \& J.M. White (eds.), New Knowledge in the Biomedical Sciences (Springer: Dordrecht, 1982), pp. 155-168.

Carlson R.V., Boyd K.M., \& Webb D.J., 'The revision of the Declaration of Helsinki: past, present and future', in British Journal of Clinical Pharmacology Vol. 57 (2004), pp. 695-713.

Centrale Raad voor de Volksgezondheid, Deeladvies betreffende de juridische relatie tussen patiënt en arts, het recht van de patiënt op informatie en het toestemmingsvereiste ('sGravenhage: Staatsuitgeverij, 1980).

Centrale Raad voor de Volksgezondheid, Deeladvies inzake de bescherming van de privacy van de patiënt ('s-Gravenhage: Staatsuitgeverij, 1981).

Centrale Raad voor de Volksgezondheid, Deelsadvies inzake bemiddeling van klachten van patiënten (Rijswijk: Centrale Raad voor de Volksgezondheid, 1982).

Centrale Raad voor de Volksgezondheid, Deeladvies inzake kernbepalingen voor der regeling van de relatie tussen patiënt en arts ('s-Gravenhage: Staatsuitgeverij, 1982).

Centrale Raad voor de Volksgezondheid, Deeladvies inzake medische experimenten ('sGravenhage: Staatsuitgeverij, 1982).

Cerutti F.F.X. et al., De Geneesheer en het Recht (Deventer: Kluwer, 1968).

Chalmers I., 'Statistical Theory Was Not the Reason That Randomization Was Used in the British Medical Research Council's Clinical Trial of Streptomycin for Pulmonary Tuberculosis', in Body Counts, pp. 309-334.

Clarke I., 'The Gatekeepers of Modern Physics. Periodicals and Peer Review in 1920s Britain', in Isis Vol. 106 (2014), pp. 70-93.

Cluysenaer M. \& Breeveld L., 50 Jaar College ter Beoordeling van Geneesmiddelen (Haarlem, 2013).

Coetzee J., Landscape with Rowers. Poetry from the Netherlands (Princeton: Princeton University Press, 2003).

Cohen E.A., Het Duitse concentratiekamp. Een medische en psychologische studie (Amsterdam: Uitgeverij H.J. Parijs, 1952).

Colenbrander M., Fehmers C. \& Hammes T., Medische Ethiek (Amsterdam: Nederlandsche Maatschappij tot Bevordering der Geneeskunst, 1936).

Collins Harvey J., 'André Hellegers, the Kennedy Institute, and the Development of Bioethics. The American-European Connection', in Jeremy R. Garrett, Fabrice Jotterand \& D. Chris- 
topher Ralston (eds.), The Development of Bioethics in the United States (Dordrecht: Springer, 2013), pp. 37-54.

Collins H. \& Evans R., Rethinking Expertise (Chicago: University of Chicago Press, 2007).

Commissie van advies inzake het democratisch en doelmatig functioneren van gesubsidieerde instellingen, Discussie-nota, September 1975 (Rijswijk: Secretariaat, 1975).

Cook H.J., 'Practical Medicine and the British Armed Forces after the "Glorious Revolution"', in Medical History Vol. 34 (1990), pp. 1-26.

Cooter R., 'The Resistible Rise of Medical Ethics', in Social History of Medicine Vol. 8 (1995), pp. 275-288.

Cooter R., 'The Ethical Body', in Medicine in the Twentieth Century, pp. 451-467.

Cooter R., 'Inside the Whale: Bioethics in History and Discourse', in Social History of Medicine Vol. 23 (2010), pp. 662-673.

Cooter R., 'Medicine and Modernity', in The Oxford Handbook of the History of Medicine, pp. 100-116.

Cox-Maksimov D., 'The making of the Clinical Trial in Britain, 1910-1945. Expertise, the State and the Public' (PhD-thesis, University of Cambridge, 1997).

Crofton J., 'The MRC randomized trial of streptomycin and its legacy. A view from the clinical front line', in Journal of the Royal Society of Medicine Vol. 99 (2006), pp. 531-534.

Csiszar A., 'Broken Pieces of Fact. The Scientific Periodical and the Politics of Search in Nineteenth-Century France and Britain' [Ph.D. Dissertation, Harvard University, 2010).

Csiszar A., The Scientific Journal. Authorship and the Politics of Knowledge in the Nineteenth Century (Chicago: The University of Chicago Press, 2018).

Cunningham A.R. \& Williams P. (eds.), The Laboratory Revolution in Medicine (Cambridge: Cambridge University Press, 1992).

Dam P. van, Staat van verzuiling. Over een Nederlandse mythe (Amsterdam: Wereldbibliotheek, 2011).

Daston L., 'Objectivity and the Escape from Perspective', in Social Studies of Science Vol. 22 (1992), pp. 597-618, p. 609.

Daston L. \& Galison P., Objectivity (New York: Zone Books, 2007).

Daston L. \& Vidal F., The Moral Authority of Nature (Chicago: The University of Chicago Press, 2003).

Dekking F., 'Medische' experimenten in Duitsche concentratiekampen', in Nederlandsch Tijdschrift voor Geneeskunde Vol. 90 (1946), p. 1011.

Dekking F., 'Het proces der Duitse artsen', in Nederlandsch Tijdschrift voor Geneeskunde, Vol. 91 (1947), pp. 1830-1833.

Dekker, 'De derde druk van het boekje 'Medische Ethiek en Gedragsleer', in Medisch Contact Vol. 15 (1960), p. 160.

Dekker G., 'Rapport van de commissie herziening rechtspraak. Pre-advies van het hoofdbestuur', in Medisch Contact Vol. 23 (1968), pp. 84-104.

Dekker G., 'Jaarverslag 1967 der Maatschappij', in Medisch Contact Vol. 23 (1968), pp. 718723.

Dekker W., De affaire Buikhuisen: het ontstaan en de achtergronden rondom zijn biosociale onderzoek (Doctoraalscriptie Erasmus Universiteit Rotterdam, 2009).

Dijk J.J.M. van, 'Weerwoord op het requisitoir van Schuyt', in Nederlandse Juristenblad Vol. 54 (1978), pp. 481-487. 
Dillmann R.J.M. \& Kastelein W.R., 'Niet-therapeutisch wetenschappelijk onderzoek met wilsonbekwame patiënten; een gezamenlijk standpunt van Nederlandse medischwetenschappelijke organisaties', in Nederlands Tijdschrift voor Geneeskunde Vol. 138 (1994), pp. 1676-1680.

Does de Willebois A.E.M. van der, 'Kroniek van de artsen actie eerbiediging menselijk leven', in Informatiebulletin van het Nederlands Artsenverbond No. 1 (November 1973), pp. 3-48. Does de Willebois A.E.M. van der, Het Vaderloze Tijdperk. Een cultuur-psychologische verkenning van de geseculariseerde samenleving (Brugge: Tabor, 1984).

Does de Willebois J.A. van der, 'Medische ethiek', in Vita Humana Vol. 10 (1983), pp. 3-4. Dongen M.A. van der, 'Experimenten op Mensen', in Medisch Contact Vol. 35 (1980), p. 170.

Dorsman L.J. \& Knegtmans P.J., Onderzoek in opdracht. De publieke functie van het universitaire onderzoek in Nederland sedert 1876 (Hilversum, 2007).

Drift L. van der, 'Medische Ethiek anno 1970', in Medisch Contact Vol. 25 (1970), pp. 413-417. Dunning A.J., 'Afscheid prof.dr. Chr. L. Rümke', in Nederlands Tijdschrift voor Geneeskunde Vol. 136 (1992), pp. 900-901.

Dupuis H.M., Goed te leven. Reflecties op de moraal (Baarn: Ten Have, 1980).

Dupuis H.M., 'Ontwikkelingen in de medische ethiek. Van artsencode naar ethiek in de gezondheidszorg', in Handboek Gezondheidsethiek, pp. 21-28.

Dupuis H.M., 'Ethische aspecten van experimenten met mensen', in Geneeskunde en Ethiek in Harmonie, pp. 155-163.

Dupuis H.M., 'Recensie van H. ten Have, Een hippocratische erfenis', in Nederlands Tijdschrift voor Geneeskunde Vol. 135 (1991), p. 1333.

Dupuis H.M. \& Beaufort I.D. de, 'Ethiek - wat is het en wat kan men er mee', in Handboek Gezondheidsethiek, pp. 7-20.

Dyck E. \& Stewart L. (eds.), The Uses of Humans in Experiment. Perspectives from the $17^{\text {th }}$ to the $2 O^{\text {th }}$ Century (Leiden: Brill Rodopi, 2016).

Edeler H.A., De drinkwaterfluoridering. Tandartsen, staat en volksgezondheid in Nederland 1946-1976 (Houten: Bohn Stafleu van Loghum, 2009).

Edwards M., Control and the Therapeutic Trial. Rhetoric and Experimentation in Britain, 1918-1948 (Amsterdam: Rodopi, 2007).

Eijnatten J. van, 'Beyond Diversity. The Steady State of Reference Cultures', in International Journal for History, Culture and Modernity Vol. 3 (2015), pp. 1-8.

Elkeles B., 'The German Debate on Human Experimentation between 1880 and 1914', in Twentieth Century Ethics of Human Subjects Research, pp. 19-33.

Emanuel E.J. et al. (eds.), The Oxford Textbook of Clinical Research Ethics (Oxford: Oxford University Press, 2008).

Ende H. van den, 'Vergeet niet dat je arts bent'. Joodse artsen in Nederland, 1940-1945 (Amsterdam: Boom, 2015).

Engberts D.P., 'De vroege Jaren. Ontstaan en werkzaamheid van een medisch-ethische (toetsings)commissie in Leiden in de Jaren zestig van de vorige eeuw', in Dilemma's getoetst, pp. 9-28.

Engberts D.P., 'Het verhaal achter het schandaal. Medische proeven met verstandelijke gehandicapten in een Noord-Brabantse inrichting in de jaren zestig en zeventig', in Geneeskunde en Ethiek in Harmonie, pp. 125-153.

Engberts D.P., Reidsma Y.M. \& Wintzen A.R. (eds.), Dilemma's getoetst. Liber Amicorum voor prof.dr. H.M. Dupuis en prof.dr. P.Vermeij (Leiden: UFB Universiteit Leiden, 2003). 
Engels J.W.M., 'Constitutionele observaties bij de minister van Staat', in C. van Baalen et al. (eds.), De Republiek van Oranje, 1813-2013. Jaarboek Parlementaire Geschiedenis 2013 (Amsterdam: Boom, 2013).

Es J.C. van, 'Experimenten met mensen en wetgeving', in Medisch Contact Vol. 40 (1985), p. 1115 .

Evans J.H., 'A Sociological Account of the Growth of Principalism', in Hastings Center Report Vol. 30 (2000), p. 31-38.

Evans J.H., The History and Future of Bioethics. A Sociological Review (Oxford: Oxford University Press, 2012).

Evenepoel S., Volmaakt onaf. Over de stijl en thematiek in de vroege poëzie van Rutger Kopland (Leuven: Universitaire Pers Leuven, 2000).

Eyck H.H. \& Verstegen A.J., Arts en wet. Rechtskundige handleiding voor geneeskundigen (Haarlem: De Erven Bohn, 1929; $2^{\text {de }}$ druk).

Faden R.R. \& Beauchamp T.L., A History and Theory of Informed Consent (Oxford: Oxford University Press, 1986).

Festen H., 125 jaar geneeskunst en maatschappij (Utrecht: Koninklijke Nederlandsche Maatschappij tot Bevordering der Geneeskunst, 1974).

Festen H., Spanningen in de gezondheidszorg. 25 jaar Centrale Raad voor de Volksgezondheid (Zoetermeer: Nationale Raad voor de Volksgezondheid, 1985).

Fissell M.E., 'The Medical Marketplace, the Patient, and the Absence of Medical Ethics in Early Modern Europe and North America', in The Cambridge World History of Medical Ethics, pp. 533-539.

Fitzgerald M.H., 'Punctuated Equilibrium, Moral Panics and the Ethics Review Process', in Journal of Academic Ethics Vol. 2 (2005), pp. 315-338.

Fletcher J., Situation Ethics. The New Morality (Philadelphia: Westminster Press, 1966).

Fokkens O., 'Oordeelsvorming in de geneeskunde', in Nederlands Tijdschrift voor Geneeskunde Vol. 106 (1962), pp. 1896-1899.

Fortuyn W.S.P., Ordening door Ontvlechting. Een advies over de adviesstructuur in de gezondheidszorg (Rijswijk: Ministerie van WVC, 1990).

Foucault M., The Order of Things. An archaeology of the human sciences (New York: Routledge, 1970).

Foucault M., The Birth of the Clinic. Trans.: A.M. Sheridan-Smith (London: Tavistock Publications, 1973).

French R.D., Antivivisection and Medical Science in Victorian Society (Princeton: Princeton University Press, 1975).

Frewer A., 'Human Rights from the Nuremberg Doctors Trial to the Geneva Declaration', in Medicine, Health Care and Philosophy Vol. 13 (2010), pp. 259-268.

Frewer A. \& Schmidt U. (eds.), History and Theory of Human Experimentation. The Declaration of Helsinki and Modern Medical Ethics (Frankfurt, 2007).

Fuller S., The Governance of Science. Ideology and the Future of the Open Society (Buckingham: Open University Press, 2000).

Fyfe A., 'Journals and Periodicals', in Bernard Lightman (eds.), A Companion to the History of Science (West Sussex: Wiley Blackwell, 2016), pp. 387-399.

Gaarenstroom J.H., 'Het aandeel van Nederland in de vooruitgang der geneeskundige wetenschap van 1900 tot 1950', in Nederlandsch Tijdschrift voor Geneeskunde Vol. 95 (1951), pp. $762-767$. 
Gabriel J.M., Medical Monopoly. Intellectual Property Rights and the Origins of the Modern Pharmaceutical Industry (Chicago: The University of Chicago Press, 2015).

Gaillard P.J., 'Levensbericht S.E. De Jongh', in Jaarboek Huygens Institute - Royal Netherlands Academy of Arts and Sciences (1976), pp. 200-202.

Gaudillière J.-P. \& Hess V. (eds.), Ways of Regulating Drugs in the $19^{\text {th }}$ and $20^{\text {th }}$ Centuries (Basingstoke: Palgrave Macmillan, 2013).

Geison G.L., 'Pasteur's Work on Rabies. Reexamining the Ethical Issues', in Hastings Center Report Vol. 8 (1978), pp. 26-33.Genderen F.Th. van, 'In Memoriam Prof. Dr. W.K. Dicke', in Nederlands Tijdschrift voor Geneeskunde Vol. 106 (1962), p. 1108.

Gevers J.K.M. \& Hubben J.H. (eds.), Grenzen aan de zorg, zorgen aan de grens. Liber amicorum voor Prof.dr. H.J.J. Leenen (Alphen aan den Rijn: Samsom H.D. Tjeenk Willink, 1990).

Geuns H.A. van, 'Uit de Geneeskundige Hoofdinspectie: Medische experimenten in de huisartspraktijk', in Medisch Contact Vol. 42 (1987), p. 694.

Geuns H.A. van, 'Het Staatstoezicht en medische experimenten met mensen', in Medisch Contact Vol. 40 (1985), pp. 801-802.

Gezondheidsraad, Interim-advies inzake euthanasie ('s-Gravenhage, 1972).

Gezondheidsraad, Advies inzake euthanasie bij pasgeborenen (Rijswijk, 1975).

Gezondheidsraad, Advies inzake normen voor het toedienen van radioactieve stoffen aan vrijwilligers (Den Haag: Staatsuitgeverij: 1981).

Gezondheidsraad, Advies inzake klinische farmacologie (Den Haag: Staatsuitgeverij: 1982).

Gezondheidsraad, Kerncommissie Ethiek Medisch Onderzoek (KEMO) 1993-1999 (Den Haag: Gezondheidsraad, 2004; publicatie no 2004/Ko1).

Giddens A., The Third Way. The Renewal of Social Democracy (Cambridge: Polity Press, 1998).

Giddens A., The Third Way and its Critics (Cambridge: Policy Press, 2000).

Gieryn T.F., Cultural Boundaries of Science. Credibility on the line (London: The University of Chicago Press, 1999).

Gijswijt-Hofstra M., Heteren G.M. van \& Tansey E.M. (eds.), Biographies of Remedies. Drugs, Medicines and Contraceptives in Dutch and Anglo-American Healing Cultures (Amsterdam: Rodopi, 2002).

Goodman J., 'Pharmaceutical Industry', in Medicine in the $20^{\text {th }}$ Century, pp. 141-154.

Goudsmit C.J., 'De Totstandkoming van de Wet op de Geneesmiddelenvoorziening', in De wet op de geneesmiddelenvoorziening. Beschouwingen, Tekst van de Wet, Uitvoeringsbesluiten ('s-Gravenhage: Koninklijke Nederlandse Maatschappij ter Bevordering der Pharmacie, 1963), pp. 8-12.

Goudsmit C.J., 'Discussie over: de medische ethiek met betrekking tot de nieuwste ontwikkelingen in de geneeskunde', in Medisch Contact Vol. 24 (1969), p. 386.

Gradmann C. \& Simon J. (eds.), Evaluating and Standardizing Therapeutic Agents, 189o1950 (Basingstoke: Palgrave Macmillan, 2010).

Gray B.H., Human Subjects in Medical Experimentation. A Sociological Study of the Conduct and Regulation of Clinical Research (New York: Wiley-Interscience, 1975).

Griffiths J., Bood A. \& Weyers H., Euthanasia and Law in the Netherlands (Amsterdam: Amsterdam University Press, 1998).

Grijs P., Buikhuisen, dom én slecht (Amsterdam: Vrij Nederland, 1978). 
Groen J.J., 'Iedere tijd heeft zijn eigen ethiek', in De Groene Amsterdammer, 5 juli 1969, pp. 9-10.

Guerrini A., Experimenting with Humans and Animals. From Galen to Animal Rights (Baltimore: The John Hopkins University Press, 2003).

Guerrini A., 'The Human Experimental Subject', in A Companion to the History of Science, pp. 126-138.

Gunning K.F., 'Eerbiediging menselijk leven. Voorwoord', in Informatiebulletin van het Nederlands Artsenverbond No. 1 (November 1973), p. 2.

Gunning-Schepers L.J., 'In memoriam. Els Borst (1932-2014), in Nederlands Tijdschrift voor Geneeskunde Vol. 159 (2014), p. B1026.

Gusfield J.R., The Culture of Public Problems: Drinking-Driving and the Symbolic Order (London, 1981).

Haggerty K.D., 'Ethics Creep: Governing Social Science Research in the Name of Ethics', in Qualitative Sociology Vol. 27 (2004), pp. 391-414.

Halpern S., Lesser Harms. The Morality of Risk in Medical Research (Chicago: The University of Chicago Press, 2004).

Hamburger R. \& Beukenhorst H., 'De belofte bij het toetreden der Mij.', in Medisch Contact Vol. 6 (1951), pp. 15-16.

Hamburger R.J., 'Proeven op mensen', in Medisch Contact, Vol. 10 (1955), pp. 333-334.

Hardy A. \& Tansey E.M., 'Medical Enterprise and Global Response, 1945-200o', in W.F. Bynum et al. (eds.), The Western Medical Tradition. 180o-20oo (Cambridge: Cambridge University Press, 2006), pp. 405-534.

Harkness J.M., 'Nuremberg and the Issue of Wartime Experiments on U.S. Prisoners. The Green Committee', in Journal of the American Medical Association Vol. 276 (1996), pp. 1672-1675.

Hart P.G., 'In memoriam Prof. Dr. W.P. Plate', in Nederlands Tijdschrift voor Geneeskunde Vol. 127 (1983), pp. 1269-1270.

Have H. ten, Een hippocratische erfenis. Ethiek in de medische praktijk (Lochem: Uitgeversmaatschappij De Tijdstroom, 1990).

Have H. ten, Ethiek tussen alliantie en dissidentie (Maastricht: Rijksuniversiteit Limburg, 1990).

Have H. \& Kimsma G., Geneeskunde tussen droom en drama. Voortplanting, ethiek en vooruitgang (Kampen: Kok Agora, 1987).

Have H.A.M.J. ten, Meulen R.H.J. ter \& Leeuwen E. van, Medisch Ethiek (Houten: Bohn Stafleu van Loghum, 2003).

Hazelgrove J., 'The Old Faith and the New Science. The Nuremberg Code and Human Experimentation Ethics in Britain, 1946-73', in Social History of Medicine Vol. 15 (2002), pp. 109-135.

Hazelgrove J., 'British Research Ethics after the Second World War. The Controversy at the British Postgraduate Medical School, Hammersmith Hospital', in Twentieth Century Ethics of Human Subjects Research, pp. 181-197.

Hedgecoe A., 'Research Ethics Review and the Sociological Research Relationship', in Sociology Vol. 42 (2008), pp. 873-886.

Hedgecoe A., Carvalho F., Lobmayer P. \& Raka F., 'Research Ethics Committees in Europe. Implementing the Directive, Respecting Diversity', in Journal of Medical Ethics Vol. 32 (2006), pp. 483-486. 
Hedgecoe A., “'A form of Practical Machinery”. The Origins of Research Ethics Committees in the UK, 1967-1972', in Medical History Vol. 53 (2009), pp. 331-350.

Hedgecoe A., 'Trust and Regulatory Organizations. The Role of Local Knowledge and Facework in Research Ethics Review', in Social Studies of Science Vol. 44 (2012), pp. 59-81.

Hedgecoe A., 'Reputational Risk. Academic Freedom and Research Ethics Review', in Sociology (2015), http://dx.doi.org/10.1177/0038038515590756.

Heering H.J., Ethiek der Voorlopigheid (Nijkerk: Callenbach, 1969).

Hellema D., Nederland en de jaren zeventig (Amsterdam: Boom, 2012).

Helvoort T. van, 'De publieke functie van universitaire wetenschapsbeoefening. Amerikanisering als leidmotief bij de scheikunde aan de Groningse universiteit', in Onderzoek in opdracht, pp. 67-92.

Heringa G.C., 'Medische Ethiek, Practische Geneeskunde en Wetenschap', in Medisch Contact Vol. 4 (1949), pp. 539-545.

Heringa G.C., 'Een leerstoel voor de homoeopathie?', in Medisch Contact, Vol. 5 (1950), pp. 191-193, p. 193

Heringa G.C., 'Prof. Dr. L.A. Hulst. Lid van de Council der W.M.A.', in Medisch Contact Vol. 10 (1955), p. 789.

Heringa G.C., 'De verantwoordelijkheid van medische redacties voor de instandhouding der medische ethiek', in Medisch Contact, Vol. 9 (1954), pp. 554-557.

Herranz G., 'The Inclusion of the Ten Principles of Nuremberg in Professional Codes of Ethics: An International Comparison', in Ethics Codes in Medicine, pp. 127-139.

Hilfman M.M., 'Mededelingen adviescommissie klinisch geneesmiddelenonderzoek', in $\mathrm{Ne}$ derlands Tijdschrift voor Geneeskunde Vol. 100 (1956), p. 1671.

Hilhorst M., 'Medische ethiek: onnodige misverstanden', in Tijdschrift voor Beleid, Politiek en Maatschappij Vol. 26 (1999), pp. 292-300.

Hilhorst M., 'Klimaatverandering in de medische ethiek', in Ethiek in Nederland, pp. 181-205.

Hoofdakker R.H. van den, 'Het bolwerk der beterweters', in Wijsgerig Perspectief op Maatschappij en Samenleving Vol. 9 (1968-1969), pp. 292-301.

Hoofdakker R.H. van den, Het bolwerk van de beterweters. Over de medische ethiek en de status quo (Amsterdam: Kritiese Bibliotheek, 1970), p. 33.

Hoonaard W.C. van den, The Seduction of Ethics. Transforming the Social Sciences (Toronto: University of Toronto Press, 2011).

Horstman K. \& Vries G. de, 'Experimenten met mensen. De constitutie van een medischwetenschappelijke praktijk en een ethisch probleem (Nederland, 1870-1915)', in Kennis en Methode Vol. 1 (1989), pp. 62-83.

Houwaart E.S., De hygiënisten. Artsen, staat en volksgezondheid in Nederland, 1840-189o (Groningen: Historische Uitgeverij Groningen, 1991).

Hoven M. van der, Scheer L. van der \& Willems D. (eds.), Ethiek in discussie. Praktijkvoorbeelden van ethische expertise (Assen: Van Gorcum, 2010).

Hugenholtz P.Th., 'Wijziging rechtspraak', in Medisch Contact Vol. 13 (1958), p. 785.

Huisman F. \& Velde H. te, 'Op zoek naar nieuwe vormen in wetenschap en politiek. De 'medische' kleine geloven', in De Negentiende Eeuw Vol. 25 (2001), pp. 129-136.

Hulst L.A., 'Van het Hoofdbestuur. De World Medical Association', in Medisch Contact, Vol. 8 (1953), pp. 504-508.

Illich I., Medical Nemesis. The expropriation of health (London: Calder and Boyars, 1975). 
Ingelfinger F.J.,'The Unethical in Medical Ethics’, in Annals of Internal Medicine Vol. 83 (1975), pp. 264-269.

Jackson M. (ed.), The Oxford Handbook of the History of Medicine (Oxford: Oxford University Press, 2011).

Jacobs F.C.L.M., Ten overstaan van allen. Universalisering in de ethiek. Proefschrift Universiteit van Amsterdam (Enschede: Quick Service, 1985).

Jacobs F.C.L.M., 'Praktische ethiek: onpraktisch en onfilosofisch?', in Filosofie en Praktijk Vol. 12 (1991), p. 18-30.

Jaeger J., 'An Ethnographic Analysis of Institutional Review Board Decision-Making', Ph.D. diss., University of Pennsylvania (2006).

Jasanoff S., The Fifth Branch. Science Advisers as Policymakers (Cambridge: Harvard University Press, 1990).

Jasanoff S., Designs on Nature. Science and Democracy in Europe and the United States (Princeton: Princeton University Press, 2005).

Jaspers P., 'Controversial Issues in the History of Dutch Research Ethics Governance', in The Journal of Policy History Vol. 23 (2011), pp. 74- 93.

Jaspers P., Houtepen R. \& Horstman K., 'Ethical review: Standardizing procedures and local shaping of ethical review practices', in Social Science \& Medicine Vol. 98 (2013), pp. 311318.

Jones D.S., Grady C. \& Lederer S.E., "Ethics and Clinical Research"-The $5^{\text {th }}$ Anniversary of Beecher's Bombshell', in The New England Journal of Medicine Vol. 374 (2016), pp. 23932398.

Jones J., Bad Blood. The Tuskegee Syphilis Experiment (New York: Free Press, 1981).

Jong C.L. de, 'G.A. Lindeboom, Opstellen over medische ethiek', in Nederlands Tijdschrift voor Geneeskunde Vol. 104 (1960), p. 1897.

Jongh D.K. de, 'Over medische ethiek', in Medisch Contact Vol. 4 (1949), pp. 526-532.

Jongh D.K. de, 'Medische ethiek. Antwoord aan Prof.dr. G.C. Heringa', in Medisch Contact Vol. 4 (1949), pp. 600-604.

Jongh E.D.J. de, Hannes de Graaf. Een leven van bevrijding (Kampen: Ten Have, 2004).

Jongkees L.B.W., 'Ethische aspecten van medische experimenten op de mens', in Medisch Contact Vol. 35 (1980), pp. 80-81.

Jonsen A.R., The Birth of Bioethics (Oxford: Oxford University Press, 1998).

Jongsma M.W., 'Medische ethiek', in Medisch Contact Vol. 21 (1966), pp. 311-316.

Jorland G., Opinel A. \& Weisz G. (eds.), Body Counts. Medical Quantification in Historical \& Sociological Perspectives (Montreal \& Kingston: McGill-Queen's University Press, 2005).

Kater L., Disciplines met Dadendrang. Gezondheidsrecht en gezondheidsethiek in het Nederlandse euthanasiedebat 1960-1994 (Amsterdam: Aksant, 2004).

Katz J., Experimentation with Human Beings (New York: Russell Sage Foundation, 1972).

Katz J., 'The Consent Principle of the Nuremberg Code. Its Significance Then and Now', in The Nazi Doctors, pp. 227-239.

Kennedy J., Nieuw Babylon in aanbouw. Nederland in de jaren zestig (Amsterdam: Boom, 1995).

Kennedy J., Een weloverwogen dood. Euthanasie in Nederland (Amsterdam: Uitgeverij Bert Bakker, 2002). 
Keulen S., Monumenten van beleid. De wisselwerking tussen Nederlands rijksoverheidsbeleid, sociale wetenschappen en politieke cultuur, 1945-2002 (Hilversum: Uitgeverij Verloren, 2014).

Kevles D.J., The Physicists. The History of a Scientific Community in Modern America (New York: Vintage Books, 1979).

Kindermann J.C., 'Proefnemingen op menschen', in Nederlandsch Tijdschrift voor Geneeskunde (1904), Part I, pp. 414-415.

Kits Nieuwenkamp J.H.W., 'Wat kan de ethiek voor het beleid betekenen? De rol van de ethiek en van ethici bij het beleid?', in Beleid en ethiek, pp. 34-42.

Klaveren K.-J. van, Het onafhankelijkheidsyndroom. Een cultuurgeschiedenis van het naoorlogse Nederlandse zorgstelsel (Amsterdam: Wereldbibliotheek, 2016).

Klein A., Verlangen naar verbetering. 375 jaar academische geneeskunde in Utrecht (Amsterdam: Boom, 2010).

Klitzman R.L., The Ethics Police? The Struggle to Make Human Research Safe (Oxford: Oxford University Press, 2015).

Kluveld A., Reis door de hel der onschuldigen. De expressieve politiek van de Nederlandse anti-vivisectionisten, 1890-1940 (Amsterdam: Amsterdam University Press, 2000).

Kluveld A., 'Felix Ortt. De kleine geloven als brug tussen wetenschap en geloof', in De Negentiende Eeuw Vol. 25 (2001), pp. 137-146.

KNMG, Medische ethiek en gedragsleer (Amsterdam: Koninklijke Nederlandse Maatschappij tot Bevordering der Geneeskunst, 1959).

Kohler R.E., Partners in Science. Foundations and Natural Scientists, 1900-1945 (Chicago: The University of Chicago Press, 1991).

Kortbeek L.H.Th.S. et al.(eds.), Recent Medisch Ethisch Denken - I (De Nederlandse Bibliotheek der Geneeskunde, nr. 40) (Leiden: Stafleu's Wetenschappelijke Uitgeversmaatschappij, 1968).

Koster W., 'Nog eens proefnemingen op menschen', in Nederlandsch Tijdschrift voor Geneeskunde (1904), Part I, pp. 378-379.

Koster W., 'De bewijsvoering van Dr. Burger', in Nederlandsch Tijdschrift voor Geneeskunde (1904), Part I, pp. 463-465.

Krabbendam H. \& Napel H.-M.T.D. ten, Regulating Morality. A Comparison of the Role of the States in Mastering the Mores in the Netherlands and the United States (Apeldoorn: 2000).

Kroon P.J.W.M. de, 'De begintijd van de Leidse Commissie voor Medische Ethiek', in Geneeskunde en Ethiek in Harmonie, pp. 93-95.

Krop H.A., 'De babylonische ballingschap der ethiek. C.W. Opzoomer (1821-1892) en Spinoza', in M. Verkerk (ed.), Filosofie, ethiek en praktijk. Liber amicorum voor Koo van der Wal (Rotterdam, 2000), pp. 43-54.

Krop H.A., 'Laat de universiteit meer dan een vakschool zijn. Het pleidooi voor de Centrale Interfaculteit', in L.J. Dorsman \& P.J. Knegtmans (eds.), Universitaire Vormingsidealen. De Nederlandse universiteiten sedert 1876 (Hilversum: Verloren, 2006), pp. 39-53.

Krop H. \& Wal K. van der, 'Een eeuw wijsgerige ethiek in Nederland', in Ethiek in Nederland, pp. 105-140.

Kruithof B., 'Wetgeving of Marktordening? Apothekers en Drogisten in het Interbellum', in Gewina 22 (1999), pp. 34-45. 
Kuhn T.S., The Structure of Scientific Revolutions (4th ed.) (Chicago: University of Chicago Press, 1962/2012).

Kuijer P.J., Rhede van der Kloot J.F. van \& Logeman J., 'Sterfte, medische tekortkomingen en foutenbronnen', in Nederlands Tijdschrift voor Geneeskunde Vol. 107 (1963), pp. 12681270.

Kuitert H.M., 'Morele consensus: mogelijkheden en grenzen', in Handboek Gezondheidsethiek, pp. 29-40.

L.H., 'De rechten van de patiënt', in Katholiek Artsenblad Vol. 47 (1968), pp. 162-164.

Lammers W., 'Bij het afscheid van Professor Gaarenstroom', in Nederlands Tijdschrift voor Geneeskunde Vol. 109 (1965), p. 1889.

Lammers W., Nelemans F.A. \& Siderius P. (eds.), Algemene Farmacotherapie. Het Geneesmiddel in Theorie en Praktijk (Leiden, 1961).

Land M. van der, Tussen ideaal en illusie. De geschiedenis van D66, 1966-20o3 (Den Haag: Sdu Uitgevers, 2003).

Lange F. de, 'Tweeërlei ethiek. Of: hoe de gereformeerde ethiek zichzelf overbodig maakte', in Ethiek in Nederland, pp. 77-104.

Langen C.D. de, 'Proeven op mensen en de verschuiving van te stellen normen', in Nederlands Tijdschrift voor Geneeskunde Vol. 102 (1958), pp. 25-27.

Latour B., Reassembling the Social. An Introduction to Actor-Network-Theory (Oxford: Oxford University Press, 2005).

Lawrence C. \& Shapin S. (eds.), Science Incarnate. Historical Embodiments of Natural Knowledge (Chicago: University Of Chicago Press, 1998).

Lears J., Fables of Abundance. A Cultural History of Advertising in America (New York: Basic Books, 1994).

Lederer S.E., Subjected to Science. Human Experimentation in America Before the Second World War (Baltimore: The John Hopkins University Press, 1995).

Lederer S.E., 'Research Without Borders: The Origins of the Declaration of Helsinki', in History and Theory of Human Experimentation, pp. 145-164.

Lederer S.E., 'The Ethics of Experimenting on Human Beings', in The Cambridge World History of Medical Ethics, pp. 558-565.

Leenen H.J.J., Sociale grondrechten en gezondheidszorg (Proefschrift Utrecht, 1966).

Leenen H.J.J., 'Gezondheidsrecht. Een poging tot plaatsbepaling', in Tijdschrift voor Sociale Geneeskunde Vol. 46 (1968), pp. 778-785.

Leenen H.J.J., Systeem-denken in de gezondheidszorg (Alphen aan de Rijn: Samson, 1971).

Leenen H.J.J., 'Juridische aspecten van medische experimenten op de mens (I) \& (II)', in Medisch Contact Vol. 30 (1975), pp. 746-750 \& pp. 753-767.

Leenen H.J.J., 'De geschiedenis van de Vereniging voor Gezondheidsrecht', in Tijdschrift voor Gezondheidsrecht Vol. 2 (1978), pp. 184-189.

Leenen H.J.J., 'Niet-therapeutische experimenten met incompetenten', in Nederlands Juristenblad Vol. 64 (1989), pp. 1501-1504.

Leenen H.J.J., 'Het betrekken van incompetenten bij experimenten', in Nederlands Tijdschrift voor Gezondheidsrecht Vol. 14 (1990), pp. 29-32.

Leenen H.J.J., 'Commentaar', in Nederlands Tijdschrift voor Geneeskunde Vol. 134 (1990), p. 926.

Leenen H.J.J., 'Vereniging voor Gezondheidsrecht 25 jaar: geschiedenis van de start', in Tijdschrift voor Gezondheidsrecht Vol 16 (1992), pp. 128-134. 
Leeuwen S. van, 'Medische Ethiek', in Cicero, 24 november 1989.

Le Fanu J., The Rise and Fall of Modern Medicine (New York: Basic Books, 2012).

Lewis S., Arrowsmith (New York: Grosset and Dunlap, 1925).

Lieburg M.J. van, 'De tweede geneeskundige stand (1818-1865). Een bijdrage tot de geschiedenis van het medisch beroep in Nederland', Tïjdschrift voor Geschiedenis Vol. 96 (1983), pp. 433-453.

Lieburg M.J. van, 'De ontwikkeling van het klinisch-diagnostisch laboratorium in Nederland tot omstreeks 1925', in Tijdschrift voor de Geschiedenis van de Geneeskunde, Natuurkunde, Wiskunde en Techniek Vol. 9 (1986), pp. 278-318.

Lieburg M.J. van, 'Vergeten helden', in Medisch Contact Vol. 64 (2009), pp. 812-815.

Lightman B. (ed.), A Companion to the History of Science (West Sussex: John Wiley \& Sons Ltd, 2016).

Lindeboom G.A., Geneeskundige Proeven op mensen. Referaat voor de negendertigste wetenschappelijke samenkomst op 3 juli 1957 (Assen: G.F. Hummelen's Boekhandel en Eletrische Drukkerij N.V., 1957).

Lindeboom G.A., Opstellen over Medische Ethiek (Kampen: J.H. Kok N.V, 1960).

Lindeboom G.A., 'Medisch-ethische bezinning in Protestantse kring', in Metamedica Vol. 49 (1970), pp. 411-416.

Lindeboom G.A., 'Tegen de stroom in (Tien jaren Nederlands Artsenverbond)', Vita Humana Vol. 10 (1983), pp. 5-30.

Lindeboom G.A., Dutch medical biography. A biographical Dictionary of Dutch Physicians and Surgeons 1475-1975 (Amsterdam, 1984).

Loghem J.J. van, 'De Vivisectievrije Geneeskunde in de Tweede Kamer', in Nederlandsch Tijdschrift voor Geneeskunde Vol. 94 (1950), pp. 18-19.

Loghem J.J. van, 'Geneeskundige proefnemingen bij mensen', in Nederlands Tijdschrift voor Geneeskunde Vol. 97 (1953), pp. 518-520, p. 518.

Loghem J.J. van, 'Geneeskundige proefnemingen bij mensen (II) \& (III)', in Nederlandsch Tijdschrift voor Geneeskunde Vol. 98 (1954), pp. 2266-2267, pp. 3038-3039.

Löwenberg B., 'Dirk Willem van Bekkum. 30 juli 1925-17 juli 2015', in Levensberichten en Herdenkingen 2015 (Koninklijke Nederlandse Akademie van Wetenschappen), pp. 13-22.

Löwy I., 'The Experimental Body', in Medicine in the $20^{\text {th }}$ Century, pp. 435-449.

Lucardie P., Nederland stromenland. Een geschiedenis van de politieke stromingen (Assen: Koninklijke van Gorcum, 2002).

Maehle A.-H., Drugs on Trial. Experimental Pharmacology and Therapeutic Innovation in the Eighteenth Century (Amsterdam: Rodopi, 1999).

Maehle A.-H. \& Tröhler U., 'Animal Experimentation from Antiquity to the End of the Eighteenth Century. Attitudes and Arguments', in Vivisection in Historical Perspective, pp. 1447 .

Maeijer J., 'Juridische relatie geneesheer en patiënt', in Geneesheer en het Recht, pp. 9-23.

Mainland D., 'The Modern Method of the Clinical Trial', in Methods of Medical Research Vol. 6 (1954), p. 157.

Majoor C.L., 'In memoriam Prof. Jules A.M.J. Enneking', in Folia Medica Neerlandica Vol. 8 (1965), pp. 163-166.

Manschot H.M. \& Verkerk M. (eds.), Ethiek in de zorg (Amsterdam: Boom, 1994).

Marks H.M., The Progress of Experiment. Science and Therapeutic Reform in the United States, 1900-199o (Cambridge: Cambridge University Press, 1997). 
Marlet J.J.C., Marlet M.F.J. \& Marlet L.N., Schuld en verontschuldiging in de medische praktijk (Roermond: J.J. Romen \& Zonen, 1966).

Marrus M.R., 'The Nuremberg Doctors' Trial in Historical Context', in Bulletin for the History of Medicine Vol.73 (1999), pp. 106-123.

Meldrum M., 'A Brief History of the Randomized Controlled Trial. From Oranges and Lemons to the Gold Standard', in Hematology/Oncology Clinics of North America Vol. 14 (2000), pp. 745-760.

Melsen A.G.M. van et al., Recent Medisch Ethisch Denken - II (De Nederlandse Bibliotheek der Geneeskunde, nr. 6o) (Leiden: Stafleu's Wetenschappelijke Uitgeversmaatschappij, 1970).

Metz W., 'Wijsgerige heroriëntatie in de medische ethiek', in Algemeen Nederlands Tijdschrift voor Wijsbegeerte en Psychologie Vol. 61 (1969), pp. 1-18.

Metz W., 'Over de crisis in de medische ethiek', in Medisch Contact Vol. 25 (1970), pp. 330332.

Mijn W.B. van der, 'Het takenpakket der maatschappij', in Vol. 23 (1968), pp. 631-637.

Mijn W.B. van der, 'De rechtspraak van de maatschappij', in Medisch Contact Vol. 24 (1969), pp. 1029-1031.

Mijn W.B. van der, 'De wetgever en het medisch handelen', in Medisch Contact Vol. 27 (1972), pp. 1165-1171.

Mold A., 'Patient Groups and the Construction of the Patient-Consumer in Britain. An Historical Overview', in Journal of Social Policy Vol. 39 (2010), pp. 505-521.

Moll van Charante A.W., 'Ethische aspecten van medische experimenten op de mens', in $\mathrm{Me}$ disch Contact Vol. 35 (1980), p. 101.

Mooij A., De polsslag van de stad. 35o jaar academische geneeskunde in Amsterdam (Amsterdam: Uitgeverij De Arbeiderspers, 1999).

Mooij A., 'Roddels, Ruzie, Achterklap. Veranderende omgangsvormen in de medische beroepsgroep', in Gewina Vol. 21 (1998), pp. 30-37.

Moore P., Blood and Justice. The seventeenth-century Parisian doctor who made blood transfusion history (London: John Wiley, 2003).

Moran M., The British Regulatory State. High Modernism and Hyper-Innovation (Oxford: Oxford University Press, 2003).

Musschenga B., 'Voorwoord', in Ethiek in Nederland, pp. 7-9.

Musschenga B., 'Nederlandse ethiek na 1970. De wending naar de praktijk, het beleid en het internationale forum', in Ethiek in Nederland, pp. 146-147.

Musschenga B. et al., Ethiek in Nederland. Van 1900 tot 1970 en daarna (Budel: Damon, 2010).

Nadav D.S., 'The "Death Dance of Lübeck": Julius Moses and the German Guidelines for Human Experimentation, 1930', in Twentieth Century Ethics of Human Subjects Research, pp. 129-135.

Nagel T., The View From Nowhere (Oxford: Oxford University Press, 1986).

Nauta L.W., Argumenten voor een kritische ethiek (Amsterdam: Van Gennep, 1971).

Nelemans F.A., Klinische Farmacologie (Openbare Les gehouden aan de Rijksuniversiteit te Utrecht op Dinsdag 13 november 1956).

Nelemans F.A., 'Klinische farmacologie', in Algemene Farmacotherapie, pp. 19-20.

Nelemans F.A., 'De Behandeling van Coronaire Aandoeningen met Orale Anticoagulantia', in Nederlands Tijdschrift voor Geneeskunde Vol. 111 (1967), p. 510. 
Nelemans F.A. \& Zelvelder W.G., Therapeutische evaluatie van geneesmiddelen (Leiden: Stafleu's Wetenschappelijke Uitgeversmaatschappij, 1970).

Niemantverdriet T., De vechtpartij. De PvdA van Kok tot Samsom (Amsterdam: Athanaeum Boekhandel, 2014).

Noach E.L., Tweeërlei farmacologie. Inaugurele rede Leiden (Amsterdam: N.V. NoordHollandsche Uitgevers Maatschapij, 1964).

Noach E.L., 'In memoriam Prof.Dr. S.E. de Jongh', in Nederlands Tijdschrift voor Geneeskunde Vol. 120 (1976), pp. 1226-1228.

Noach E.L., 'De functie van ethische commissies bij medische experimenten met mensen', in Medisch Contact Vol. 40 (1985), pp. 872-874.

Noach E.L., 'The history of pharmacology in the Netherlands', in Trends in Pharmacological Sciences Vol. 11 (1990), pp. 236-239.

Noach E.L., "Verschuivende normen in de Medische Ethiek", Lecture HOVO Courses 1989-99, University of Leiden.

Noach E.L. \& Kroon P.J.W.M. de, 'Medische ethiek: patiënten en proeven. De Commissie Medische Ethiek in het Academisch Ziekenhuis en de Faculteit der Geneeskunde te Leiden', in Medisch Contact Vol. 34 (1979), pp. 1575-1583.

Numbers R.L., 'William Beaumont and the Ethics of Human Experimentation', in Journal of the History of Biology Vol. 12 (1979), pp. 113-135.

Nye, Jr. J.S., 'Soft Power', in Foreign Policy No. 80, Twentieth Anniversary (Autumn, 1990), pp. 159-171.

Nye, Jr. J.S., Soft Power. The Means to Success in World Politics (New York: 2004).

Nys H., 'Van Leenen tot Legemaate. 40 jaar Nederlands gezondheidsrecht in een twintigtal oraties', in Oratiebundel Gezondheidsrecht. Verzamelde redes 1971-2011 (Den Haag: SDU Uitgevers, 2012).

Olesko K.M., 'Science Pedagogy as a Category of Historical Analysis: Past, Present, and Future', in Science \& Education Vol. 15 (2006), pp. 863-880.

Oosterhuis H. \& Huisman F. (eds.), Health and Citizenship (New York: Routledge, 2014).

Otterspeer W., The Bastion of Liberty. Leiden University Today and Yesterday (Leiden: Leiden University Press, 2008).

Oudshoorn N., 'Laqueur en Organon. Het Universitaire Laboratorium en de Farmaceutische Industrie in Nederland', in Gewina Vol. 22 (1999), pp. 12-22.

Pappworth M.H., 'Human Guinea Pigs: A Warning', in Twentieth Century Vol. 171 (19621963), pp. 66-75.

Pappworth M.H., Human Guinea Pigs. Experiments on Man (London: Routledge \& Kegal Paul, 1967).

Perkin H., The Rise of Professional Society. England since 1800 (London: Routledge, 1990).

Pernick M.S., 'The Calculus of Suffering in Nineteenth-Century Surgery', in The Hastings Center Report Vol. 13 (1983), pp. 26-36.

Pernick M.S., A Calculus of Suffering. Pain, Professionalism, and Anesthesia in Nineteenth Century America (New York: Columbia University Press, 1985).

Perutz M., 'The New Marxism', in New Scientist Vol. 123 (1989), pp. 72-73.

Peters K., Een doodgewoon kabinet. Acht jaar Paars, 1994-2002 (Amsterdam: Boom, 2015).

Petricciani J.C., 'An Overview of FDA, IRBs and Regulations', in IRB: Ethics \& Human Research Vol. 3 (1981) No. 10, pp. 1-3. 
Phaff J.M.F., 'Toepassing medische psychologie door de huisarts', in Medisch Contact Vol. 18 (1963), pp. 480-483.

Pickstone J.V., 'Production, Community and Consumption. The Political Economy of Twentieth-Century Medicine', in Medicine in the Twentieth Century, pp. 1-19.

Pickstone J.V. \& Cooter R. (eds.), Medicine in the Twentieth Century (Amsterdam: Harwood Academic Press, 2000).

Pieters T., 'Tussen controle op afstand en betrokken begeleiding. Historische trajecten in het staatstoezicht op geneesmiddelen', in Kennis Cahier (Inspectie voor de Gezondheidszorg, 2010), pp. 49-60.

Polanyi M., 'The Republic of Science. Its Political and Economic Theory', in Minerva Vol. 1 (1962), pp. 54-73.

Polanyi M., The Tacit Dimension (New York: Doubleday, 1967).

Porter J.P. \& Koski G., 'Regulations for the Protection of Humans in Research in the United States', in The Oxford Textbook of Clinical Research Ethics, pp. 156-167.

Porter T.M., The Rise of Statistical Thinking, 1820-190o (Princeton: Princeton University Press, 1986).

Porter T.M., 'Quantification and the Accounting Ideal in Science', in Social Studies of Science Vol. 22 (1992), pp. 633-652.

Porter T.M., 'Objectivity as Standardization. The Rhetoric of Impersonality in Measurement Statistics and Cost Benefit Analysis', in Allan Megill (ed.), Rethinking Objectivity, special issues of Annals of Scholarschip Vol. 8 (1991), parts 3-4, and Vol. 9 (1992), parts 1-2, pp. 197-238.

Porter T.M., Trust in Numbers. The Pursuit of Academic Objectivity in Science and Public Life (Princeton: Princeton University Press, 1995).

Porter T.M., 'Medical Quantification. Science, Regulation, and the State', in Body Counts, pp. 394-401.

Powers M., The Audit Society. Rituals of Verification (Oxford: Oxford University Press, 1997).

Prakken J.R., 'A.A. Botter, Over de aetiologie van de strophulus infantum', in Nederlandsch Tijdschrift voor Geneeskunde, Vol. 16 (1950), p. 2766.

Prakken J.R., 'Tekortkomingen van het klinisch geneesmiddelenonderzoek en gevaren van de industriële propaganda', in Nederlands Tïjschrift voor Geneeskunde Vol. 105 (1961), pp. 1569-1571.

Prakken J.R., 'Dr. J. Wester 65 jaar', in Nederlands Tijdschrift voor Geneeskunde Vol. 110 (1966), p. 595 .

Prick J.J., 'Discussie over: de medische ethiek met betrekking tot de nieuwste ontwikkelingen in de geneeskunde', in Medisch Contact Vol. 24 (1969), pp. 83-85.

Querido A., Een eeuw staatstoezicht op de volksgezondheid ('s-Gravenhage, 1965), pp. 19-25.

Querido A., 'De mondigheid van de patient: I. Diagnose', in Metamedica Vol. 49 (1970), pp. 205-208.

Rang J.F., 'Medisch experiment op de mens en strafrecht', in Recent medisch ethisch denken II, pp. 33-87.

Rang J.F., Patiëntenrecht. (Leiden: Stafleu's Wetenschappelijke Uitgeversmaatschappij, 1973).

Red., 'Ethische problemen voor de arts', in Medisch Contact Vol. 17 (1962), pp. 237-238.

Red., 'Aesculapius en Themis. Een nuttige ontmoeting', in Medisch Contact Vol. 23 (1968), pp. 313-314. 
Ree J.W. van \& Bottema B., 'Wetenschappelijk onderzoek huisartspraktijken', in Medisch Contact Vol. 42 (1987), p. 953.

Reich W.T. (ed.), Encyclopedia of Bioethics Vol. 2 (New York: The Free Press, 1978).

Reinders J.S., 'Weg uit de ivoren toren? Kanttekeningen bij de tussentijdse evaluatie van het Centrum voor Ethiek KUN', in Tijdschrift voor Geneeskunde en Ethiek Vol. 7 (1997), pp. 90-92.

Reubi D., 'The Will to Modernize. A Genealogy of Biomedical Research Ethics in Singapore', in International Political Sociology Vol. 4 (2010), pp. 142-158.

Reverby S.M., Examining Tuskegee. The Infamous Syphilis Study and its Legacy (Chapel Hill: The University of North Carolina Press, 2009).

Righart H., De eindeloze jaren zestig. Geschiedenis van een generatieconflict (Amsterdam: De Arbeiderspers, 1995).

Rigter R.B.M., Met Raad en Daad. De geschiedenis van de Gezondheidsraad, 1902-1985 (Rotterdam: Erasmus Publishing, 1992).

Rinsema T., 'Brocades \& Stheeman. Van Apotheker-Fabrikant tot Farmaceutische Industrie', in Gewina Vol. 22 (1999), pp. 23-33.

Risse G.B., Mending Bodies, Saving Souls. A History of Hospitals (Oxford: Oxford University Press, 1999).

Robinson W.M. \& Unruh B.T., 'The Hepatitis Experiments at the Willowbrook State School', in The Oxford Textbook of Clinical Research Ethics, pp. 80-85.

Roelcke V. \& Maio G. (eds.), Twentieth Century Ethics of Human Subjects Research. Historical Perspectives on Values, Practices, and Regulations (Stuttgart: Franz Steiner Verlag, 2004).

Romein J., Op het breukvlak van twee eeuwen 2nd Ed. (Amsterdam: Em. Querido's Uitgeverij, 1976).

Roscam Abbing H.D.C., 'Genetische experimenten met mensen. Wetgever quo vadis?', in $\mathrm{Me}$ disch Contact Vol. 41 (1986), pp. 533-535.

Roscam Abbing H.D.C., 'EG-aanbevelingen inzake experimenten met geneesmiddelen bij mensen', in Nederlands Tijdschrift voor Geneeskunde Vol. 134 (1990), pp. 2124-2125.

Rose N., The Politics of Life Itself (Princeton: Princeton University Press, 2007).

Rose N. \& Miller P., Governing the Present. Administering Economic, Social and Personal Life (Cambridge: Polity Press, 2008).

Rosenberg C.E., 'The Therapeutic Revolution. Medicine, Meaning and Social Change in Nineteenth Century America', in The Therapeutic Revolution. Essays in the Social History of American Medicine, pp. 3-25.

Rosenberg C.E., The Care of Strangers. The Rise of America's Hospital System (New York: Basic Books, 1987).

Rosenberg C.E., 'The Tyranny of Diagnosis. Specific Entities and Individual Experience', in Milbank Quarterly Vol. 8 o (2002), pp. 267-260.

Rosser Matthews J., Quantification and the Quest for Medical Certainty (Princeton: Princeton University Press, 1995).

Rothman D.J., Strangers at the Bedside. A History of How Law and Bioethics Transformed Medical Decision Making (3 ${ }^{\text {rd }}$ ed.) (New Brunswick: AldineTransaction, 1991/2003).

Rümke Chr. L., De taak van de Medische Statistiek (Vrije Universiteit van Amsterdam, 14 februari 1958).

Rümke Chr. L., 'De taak van de medische ethiek' in Statistica Neerlandica Vol. 12 (1958). 
Rupke N.A. (ed.), Vivisection in Historical Perspective (London: Croom Helm, 1987).

Rusnock A., 'The Weight of Evidence and the Burden of Authority. Case Histories, Medical Statistics and Smallpox Inoculation', in Clio Medica Vol. 29 (1995), pp. 289-315.

Schaffer S., 'Self Evidence', in Critical Inquiry Vol. 18 (1992), pp. 327-362.

Schaffer S., 'Regeneration. The Body of Natural Philosophers in Restoration England', in Science Incarnate, pp. 83-120.

Schalm L., 'Prof. Dr. C.D. de Langen 75 jaar', in Nederlands Tijdschrift der Geneeskunde Vol.106 (1962), pp. 1825-1826.

Schiebinger L., 'Human Experimentation in the Eighteenth Century. Natural Boundaries and Valid Testing', in The Moral Authority of Nature, pp. 384-408.

Schiebinger L., 'Medical Experimentation and Race in the Eighteenth-century Atlantic World', in Social History of Medicine Vol. 26 (2013), pp. 364-382.

Schmidt U., 'The Nuremberg Doctors' Trial and the Nuremberg Code', in History and Theory of Human Experimentation, pp. 71-116.

Schmidt U., 'Medical Ethics and Nazism', in The Cambridge World History, pp. 595-608.

Scholten E.G., 'Wetenschappelijk onderzoek huisartspraktijken', in Medisch Contact Vol. 42 (1987), p. 1188 .

Scholten E.G. \& Benthem L.H.B.M. van, 'Medische experimenten in de huisartspraktijk', in Medisch Contact Vol. 42 (1987), p. 953.

Scholten J.B., 'J.H. Pannekoek 50 jaar arts', in Nederlands Tijdschrift voor Geneeskunde Vol.123 (1979), pp. 1359-1360.

Schotmans P., 'In Memoriam Prof. Dr. Paul Sporken', in Ethische Perspectieven Vol. 2 (1992), pp. 13-16.

Schrag Z.M., Ethical Imperialism. Institutional Review Boards and the Social Sciences, 19652009 (Baltimore: John Hopkins University Press, 2010).

Schrag Z.M., 'Review: Behind Closed Doors: IRBs and the Making of Ethical Research by Laura Stark', in American Journal of Sociology Vol. 118 (2012), pp. 494-496.

Schuurmans Stekhoven W., Jurisprudentia Medica (Groningen: Wolters-Noordhoff, 1972).

Schuyt C.J.M., 'Veroordeeld tot criminaliteit? Een wetenschapsfilosofische en ethische reflectie op het voorgenomen onderzoek van Prof.dr. W. Buikhuisen', in Nederlands Juristenblad Vol. 53 (1978), pp. 389-399.

Schuyt C.J.M., 'Reflex of reflectie. Antwoord aan Buikhuisen enVan Dijk', in Nederlands Juristenblad Vol. 53 (1978), pp. 517-526.

Shapin S., A Social History of Truth. Civility and Science in Seventeenth-Century England (Chicago: The University of Chicago Press, 1994).

Shapin S., The Scientific Life. A Moral History of a Late Modern Vocation (Chicago: The University of Chicago Press, 2008).

Shore C. \& Wright S., 'Governing by numbers. Audit culture, rankings and the new world order', in Social Anthropology Vol. 23 (2015), pp. 22-28.

Shorter E., Bedside Manners. The Troubled History of Doctors and Patients (New York: Simon and Schuster, 1985).

Singer P., 'Introduction', in Peter Singer (ed.), Applied Ethics (Oxford: Oxford University Press, 1986), pp. 1-9.

Snelders S. \& Meijsman F., De mondige patiënt. Historische kijk op een mythe (Amsterdam: Bert Bakker, 2009). 
Solovey M., Shaky Foundations. The Politics-Patronage-Social Science Nexus in Cold War America (New Brunswick: Rutgers University Press, 2013).

Spicker S.F. et al. (eds.), The Use of Human Beings in Research. With Special Reference to Clinical Trials (Dordrecht: Kluwer Academic Publishers, 1988).

Sporken C.P., 'Katholieke moraal en abortus', in Medisch Contact Vol. 22 (1967), pp. 385-389.

Sporken C.P., 'Ethische reflexies. Experimenten met de mens', in Katholieke Gezondheidszorg Vol. 37 (1968), pp. 190-194.

Sporken C.P., Voorlopige diagnose: inleiding tot een medische ethiek (Utrecht: Ambo, 1969).

Sporken C.P., 'Medische ethiek als cultuurkritiek. Naar aanleiding van revalidatie, levensverlenging en euthanasia', in Medisch Contact, Vol. 24 (1969), pp. 1431-1434.

Sporken C.P., 'Vijftig jaar medische ethiek in het Katholiek Artsenblad', in Metamedica Vol. 49 (1970), pp. 395-411.

Sporken C.P., 'Medisch-ethische vragen in verband met anesthesie', in Medisch Contact Vol. 25 (1970), pp. 669-673.

Sporken C.P., Ethiek en gezondheidszorg $4^{\text {th }}$ edition (Baarn: Amboboeken: 1979) p. 62.

Spreeuwenberg C., 'Een handboek tegen xenofobie', in Medisch Contact Vol. 46 (1991), p. 423.

Spreeuwenberg C., 'Staan patiëntenwetten de gezondheid in de weg?' in Medisch Contact Vol. 46 (1991), p. 1019.

Stam F.C., 'Prof. Dr. L. van der Horst 50 jaar arts', in Nederlands Tijdschrift voor Geneeskunde Vol. 114 (1970), pp. 785-786.

Stark L.J.M., 'Morality in Science. How Research is Evaluated in the Age of Human Subjects Regulation', PhD Thesis, Princeton University, 2006.

Stark L., Behind Closed Doors. IRBs and the Making of Ethical Research (Chicago: University of Chicago Press, 2012).

Sterrenberg L., 'Ethisch aspectenonderzoek: dans met beleid', in Beleid en ethiek, pp. 26-33.

Stevens M.L.T., Bioethics in America: Origins and Cultural Politics (Baltimore: John Hopkins University Press, 2000).

Stewart L., 'Pneumatic Chemistry, Self-Experimentation and the Burden of Revolution, 17801805', in The Uses of Humans, pp. 139-169.

Strathern M. (eds.), Audit Cultures. Anthropological studies in accountability, ethics and the academy (London: Routledge, 2000).

Swellengrebel N.H., 'Levensbericht C.D. de Langen', in: Jaarboek KNAW, 1966-1967, Amsterdam, pp. 353-357.

Swierstra T., 'De commissie Biotechnologie bij Dieren: toets of glijmiddel?', in J. Swart, R. Tramper \& M. Jonker (eds.), Afwegen, hoe doe je dat? (Budel: Damon, 2009), pp. 154-164.

Taylor T., 'Opening Statement of the Prosecution. December 9, 1946', reprinted in The Nazi Doctors, pp. 67-93.

Teijgeler C.A. (ed.), Het College ter Beoordeling van Geneesmiddelen. Een Registratie (Bloemendaal, 1988).

Temin P., Taking your Medicine. Drug Regulation in the United States (Cambridge, Mass.: Harvard University Pres, 1980).

Temin P., 'Government Actions in Times of Crisis: Lessons from the History of Drug Regulation', in Journal of Social History 18 (1985), pp. 433-438.

Terborgh-Dupuis H., Medische Ethiek in Perspectief. Een onderzoek naar normen en argumentaties in de (medische) ethiek (Leiden: Stafleu, 1976). 
Theling J.J., 'Vijftien jaren van strijd tegen de vivisectie', in Meededeelingen LustrumNummer Vol. 15 (1946), pp. 3-4.

Timmermans H. \& Breimer D.D., 'Levensbericht Everhardus Jacobus Ariëns', in Levensberichten en herdenkingen 2007 (Amsterdam: Koninklijke Nederlandse Akademie van Wetenschappen, 2007), pp. 6-17.

Tongeren P. van, 'Ethiek en Praktijk', in Filosofie en Praktijk Vol. 9 (1988), pp. 113-127.

Tongeren P. van, 'De smalle moraal: pluralisme of uniformiteit?', in Algemeen Nederlands Tijdschrift voor de Wijsbegeerte Vol. 80 (1988), pp. 92-102.

Tongeren P. van, 'De ethicus versus de ingenieur', in Beleid en ethiek, pp. 205-211.

Tonkens E.H., Het zelfontplooïngsregime. De actualiteit van Dennendal en de jaren zestig (Amsterdam: Bakker, 1999).

Toth B., 'Clinical Trials in British Medicine 1858-1948, with special reference to the development of the randomised controlled trial' (PhD-thesis, University of Bristol, 1998).

Toulmin S., 'How Medicine Saved the Life of Ethics', in Perspectives in Biology and Medicine Vol. 25 (1982), pp. 726-750.

Treub H., Medische Fatsoensleer. Drie Colleges (Amsterdam: Scheltema \& Holkema, 1903).

Tristram Engelhardt Jr., H., The Foundations of Bioethics (Oxford: Oxford University Press, 1986).

Tristram Engelhardt Jr., H. \& Rasmussen L.M., 'Secular Humanism', in Encyclopedia of Life Sciences, doi: 10.1002/9780470015902.a0005890.

Tröhler U., "To Improve the Evidence of Medicine". Arithmetic Observation in Clinical Medicine in the Eighteenth and Early Nineteenth Century', in History and Philosophy of the Life Sciences, Vol. 10 Supplement (1988), pp. 31-40.

Tröhler U., 'The Long Road of Moral Concern: Doctors' Ethos and Statute Law Relating to Human Research in Europe', in History and Theory of Human Experimentation, pp. 2754 .

Tröhler U. \& Reiter-Theil S. (eds.), Ethics Codes in Medicine. Foundations and achievements of codification since 1947 (Aldershot, 1998).

Tsuchiya T., 'The Imperial Japanese Experiments in China', in The Oxford Textbook of Clinical Research Ethics, pp. 31-45.

Vandenbroucke J.P., 'Het Centraal Bureau voor de Statistiek: de begraafplaats van onze doodsoorzaken', in Nederlands Tijdschrift voor Geneeskunde Vol. 133 (1989), pp. 21122114 .

Vandenbroucke J.P., 'Medische ethiek en gezondheidsrecht; hinderpalen voor de verdere toename van kennis in de geneeskunde?', in Nederlands Tijdschrift voor Geneeskunde Vol. 134 (1990), pp. 5-6.

Vandenbroucke J.P., 'Reactie', in Nederlands Tijdschrift voor Geneeskunde vol. 124 (1990), p. 928.

Vandenbroucke J.P., 'De opkomst van medische statistiek en epidemiologie in het klinisch wetenschappelijk onderzoek van de afgelopen eeuw', in Nederlands Tijdschrift Voor Geneeskunde Vol. 143 (1999), pp. 2625-2628.

Vandendriessche J., Peeters E. \& Wils K., Scientists' Expertise as Performance. Between State and Society, 1860-196o (London: Pickering \& Chatto, 2015).

Veatch R.M., 'The Birth of Bioethics; Autobiographical Reflections of a Patient Person', in Cambridge Quarterly of Health Ethics Vol. 11 (2002), pp. 344-352. 
Veen E.-B. van, 'Het betrekken van incompetenten in experimenten - een commentaar op enige commentaren', in Tijdschrift voor Gezondheidsrecht Vol. 13 (1989), pp. 536-551.

Veen E.-B. van, 'Het betrekken van incompetenten bij experimenten', in Tijdschrift voor Gezondheidsrecht Vol. 14 (1990), pp. 33-35.

Verkerk M., 'Zorgethiek: naar een geografie van verantwoordelijkheid', in H. Manschot \& H. van Dartel (eds.), In gesprek over goede zorg (Meppel: Boom, 2005), pp. 177-184.

Vermij R.H., David de Wied. Toponderzoeker in polderland (Utrecht, 2008).

Vicedo M., 'Introduction: The Secret Lives of Textbooks', in Isis Vol. 103 (2012), pp. 83-87.

Visser M.B.H., 'Ethische aspecten van medische experimenten op de mens (I) \& (II)', in $\mathrm{Me}$ disch Contact Vol. 34 (1979), pp. 1351-1358 \& pp. 1386-1390.

Visser M.B.H., 'Nieuwe richtlijnen voor biomedisch onderzoek', in Medisch Contact Vol. 36 (1981), pp. 23-24.

Vogel M.J. \& Rosenberg C.E. (eds.), The Therapeutic Revolution. Essays in the Social History of American Medicine (Philadelphia: University of Pennsylvania Press, 1979).

Vos R., 'The 'Dutch drugstore' as an attempt to reshape pharmaceutical practice. The conflict between ethical and commercial pharmacy in Dutch cultures of medicines', in Biographies of Remedies, pp. 57-74.

Vosman F. \& Leget C., 'Rooms-katholieke moraaltheologie in Nederland', in Ethiek in Nederland, pp. 13-40.

Vries G.H. de, 'Medische technologie en morele twijfel', in M.J. Cohen \& G.H. de Vries, Redes gehouden op de $16^{e}$ Dies Natalis van de Rijksuniversiteit Limburg, 1o januari 1992 (Maastricht: Rijksuniversiteit Limburg), pp. 5-13.

Vries G.H. de, Gerede Twijfel. Over de rol van de medische ethiek in Nederland (Amsterdam: De Balie, 1993).

Vries G.H. de \& Epenhuysen S. van, 'Niet de handelingen maar het stuk: ethiek en het experimenten met mensen', in De Gids Vol. 154 (1991), pp. 861-870.

Vries J. de, Paars en de managementstaat. Het eerste kabinet-Kok (1994-1998) (Apeldoorn: Garant, 2002).

Wachter M.A.M. de, 'Toestemming van proefpersonen', in Medisch Contact Vol. 33 (1978), pp. 925-928.

Warner J.H., 'Ideals of Science and Their Discontents in Late Nineteenth-Century American Medicine', in Isis Vol. 82 (1991), pp. 454-478.

Warner J.H., The Therapeutic Perspective. Medical Practice, Knowledge, and Identity in America, 1820-1885 (Princeton: Princeton University Press, 1997).

Warner J.H., Against the Spirit of System. The French Impulse in Nineteenth-Century American Medicine (Princeton: Princeton University Press, 1998).

Wear A., 'The Discourses of Practitioners in Sixteenth- and Seventeenth Century Europe', in The Cambridge World History of Medical Ethics, pp. 379-390.

Weatherall M., In Search of a Cure. A History of Pharmaceutical Discovery (Oxford: Oxford University Press, 1990).

Webster C., The National Health Service. A Political History (New Edition) (Oxford: Oxford University Press, 1998).

Weindling P.J., 'The Origins of Informed Consent: The International Scientific Commission on Medical War Crimes, and the Nuremberg Code', in Bulletin of the History of Medicine Vol.75, No.1 (Spring, 2001), pp. 37-71. 
Weindling P.J., 'The Nazi Medical Experiments', in The Oxford Textbook of Clinical Research Ethics, pp. 18-30.

Wennen-Van der Mey C., 'Medische ethiek ter discussie', in De Groene Amsterdammer, 4 October 1969, p. 10.

Westendorp Boerma F., 'Prof. Dr. A. Pondman 70 jaar', in Nederlands Tijdschrift voor Geneeskunde Vol. 104 (1960), pp. 1008-1010.

Weyers H., Euthanasie. Het proces van rechtsverandering (Amsterdam: AUP, 2004).

Wibaut F., 'Reorganisatie der Maatschappij, betekenis der te stichten secties', in Medisch Contact Vol. 2 (1947), pp. 1-4.

Wibaut F., 'Notulen vergadering 5 februari 1949', in Medisch Contact, Vol. 4 (1949), pp. $22-$ 27.

Wied D. de, 'Erik Noach, college en vriend', Geneeskunde en Ethiek in Harmonie, pp. 11-18.

Wielenga F., Nederland in de twintigste eeuw (Amsterdam: Boom, 2009).

Willigenburg T. van, Inside the Ethical Expert. Problem Solving in Applied Ethics (Kampen:

Kok Pharos Publishing House, 1991).

Willigenburg T. van, 'Inleiding', in Beleid en ethiek, pp. 187-188.

Willigenburg T. van, 'Ik ben een ethisch ingenieur!', in Beleid en ethiek, pp. 189-204.

Wilson D., 'What Can History Do for Bioethics', in Bioethics Vol. 27 (2013), pp. 215-223.

Wilson D., The making of British bioethics (Manchester: Manchester University Press, 2014).

Wolff F.A. (ed.), Geneeskunde en Ethiek in Harmonie. Liber Amicorum voor Prof.Dr E.L.

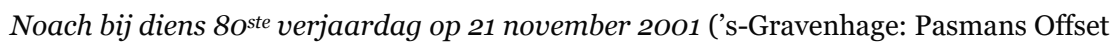
Drukkerij BV, 2001).

Wolters W.H.G., Medische experimenten met mensen. Mogelijkheden en Grenzen (Utrecht: Bohn, Scheltema \& Holkema, 1980).

Yoshioka A., 'Use of Randomisation in the Medical Research Council's Clinical Trial of Streptomycin in Pulmonary Tuberculosis in the 1940s', in British Medical Journal Vol. 317 (1998), pp. 1120-1223.

Zwart H., 'De Intolerantie van een Pluralistische Ethiek. De Engelhardt/Callahancontroverse', in Filosofie en Praktijk Vol. 12 (1991), pp. 113-124.

Zwart H., Ethische consensus in een pluralistische samenleving. De gezondheidsethiek als casus (Amsterdam: Thesis Publishers, 1993).

Zwart H., Boude Bewoordingen. De historische fenomenologie ('metabletica') van Jan Hendrik van den Berg (Kampen: Uitgeverij Klement, 2002). 



\section{- Dutch Summary •}

Dit proefschrift beschrijft de opkomst van systematische ethische toetsing van medische experimenten met mensen in Nederland in de tweede helft van de twintigste eeuw en analyseert deze ontwikkeling tegen de achtergrond van de veranderende maatschappelijke positie van de geneeskunde en medische wetenschap in deze periode. Sinds 1998 is het illegaal in Nederland om medisch-wetenschappelijk onderzoek met menselijke proefpersonen te verrichten zonder dat toestemming is verkregen van zogeheten medisch-ethische toetsingscommissies, internationaal bekend als research ethics committees. Met deze ontwikkeling volgde Nederland een internationale trend: in de tweede helft van de twintigste eeuw werd in veel Westerse landen toestemming van research ethics committees verplicht voor medisch-wetenschappelijk onderzoek met mensen. Deze ontwikkeling was en is echter niet onomstreden. Of het wetenschappelijk beroep op deze wijze 'gedisciplineerd' mag worden en wie precies door de overheid in staat mag worden gesteld om ethische oordelen te vellen over de toelaatbaarheid van wetenschappelijke experimenten blijven onderwerpen van debat onder wetenschappers, beleidsmakers en een breder maatschappelijk publiek.

Geschiedenis vervult een belangrijke functie in deze debatten. De vermeende noodzaak van systematische ethische toetsing wordt bijvoorbeeld vaak verdedigd met historische argumenten. Schandalen en machtsmisbruik uit het verleden zouden uitwijzen dat medische wetenschappers nu eenmaal sociale controle behoeven. Daarnaast zou systematische ethische toetsing passen bij een bredere democratiseringsbeweging in de jaren zestig en zeventig die de professionele autonomie van deskundigen aan banden heeft gelegd ten behoeve van het patiëntrecht en democratische controlemechanismen in de geneeskunde. Geschiedenis wordt echter ook ingezet om te beweren dat systematische ethische toetsing eerder een vijgenbladfunctie vervult in de hedendaagse wetenschap: de routinematig opererende commissies zouden zijn ingesteld in de tweede helft van de twintigste eeuw als een verdedigingslinie tegenover meer radicale kritiek op het maatschappelijk functioneren van de geneeskunde en wetenschap. Deze instrumentele rol van geschiedenis maakt zorgvuldig historisch onderzoek belangrijk. Afhankelijk van het geboden historische kader zal het hedendaagse functioneren van systematische ethische toetsing namelijk anders begrepen worden.

De geschiedenis van systematische ethische toetsing biedt daarnaast ook belangrijke inzichten in de veranderende maatschappelijke rol en positie van de geneeskunde en medische wetenschap in de tweede helft van de twintigste eeuw. Het uitvoeren van medische experimenten met mensen is al zo oud als de geneeskunde zelf. Toch wordt pas sinds de jaren zestig en zeventig van de twintigste eeuw de noodzaak gevoeld om deze praktijk te onderwerpen aan geformaliseerde vormen van gemeenschappelijke controle. Dit proefschrift stelt daarom de vragen waarom het verlangen naar systematische ethische toetsing van medische experimenten met mensen opkwam in Nederland na 1950; op welke wijze deze nieuwe praktijk vorm moest geven aan het verlangen om de geneeskunde en medische wetenschap in goede banen te leiden; wat dit "in goede banen leiden" door de jaren heen precies ging betekenen en voor wie; en welke culturele noties over de rol en positie van de geneeskunde en medische wetenschap in de Nederlandse maatschappij ten grondslag lagen aan deze veranderingen. 
Hoofdstuk 1 toont aan dat de eerste blauwdruk in Nederland voor de systematische ethische toetsing van medisch-wetenschappelijk onderzoek met mensen (of, zoals het toen nog genoemd werd, medische proeven op mensen) in 1955 ontworpen werd door de Nederlandse Gezondheidsraad. In 1953 was dit adviesorgaan ingeschakeld door de toenmalige Staatssecretaris van Volksgezondheid om een rapport te schrijven over de toelaatbaarheid van proeven op mensen in Nederland, in een reactie op aanhoudende beschuldigingen van de nationale antivivisectiebeweging dat sociaal zwakkere patiënten in Nederland regelmatig als proefdieren gebruikt werden. De Gezondheidsraadcommissie die werd samengesteld om dit rapport te schrijven, bestond exclusief uit eminente Nederlandse artsen. Deze groep concludeerde in 1955 dat misstanden op dit gebied inderdaad wel eens voorkwamen en dat maatregelen nodig waren om zulks in de toekomst te voorkomen. Nieuwe ethische richtlijnen en systematische gemeenschappelijke toetsing van deze regels werden hiervoor de oplossing geacht. Echter, de verzamelde artsen benadrukten ook dat proeven op mensen absoluut noodzakelijk waren voor de voortgang van de geneeskunde. De Nederlandse staat had daarom een plicht deze wetenschappelijke praktijk te beschermen tegen onheuse beschuldigingen als die van de antivivisectionisten. Het nemen van enig risico met individuele patiënten moest bovendien aanvaard worden als onvermijdelijk en als een morele plicht voor zowel artsen als patiënten. Tot slot waren de artsen ervan overtuigd dat de overheid zich noch mocht bemoeien met het stellen van inhoudelijke eisen aan de geneeskunde noch met de systematische toetsing van ethische regels. De Tweede Wereldoorlog had immers uitgewezen dat een staat zich verre moest houden van enige bemoeienis met het medische beroep en dat sociale controle op de geneeskunde om die reden slechts intern uitgeoefend mocht worden: door artsen, voor artsen.

Hoofdstuk 2 legt uit waarom de Nederlandse Gezondheidsraad begin jaren zeventig de nationale overheid nogmaals adviseerde om het doen van medische experimenten met mensen te onderwerpen aan systematische ethische toetsing. De aanleiding voor dit rapport waren Tweede Kamervragen uit 1968 waarin de groeiende populariteit van een nieuwe vorm van medisch experimenteren aan de kaak werd gesteld: i.e. gerandomiseerde klinische proeven waarbij de helft van de deelnemende patiënten in plaats van een geneesmiddel een placebo toegediend kreeg (waar zij niet altijd van op de hoogte waren). De Gezondheidsraadcommissie die verantwoordelijk was voor dit rapport bestond voornamelijk uit farmacologen en internisten, die gezamenlijk van mening waren dat conflicterende belangen bij dit soort onderzoeken systematische ethische toetsing noodzakelijk maakte. Echter, de commissie benadrukte ook dat een dergelijk systeem goede klinische wetenschap diende te beschermen en te bevorderen in Nederland. Het grootste ethische probleem op dit gebied, zo beargumenteerden de bijeengebrachte farmacologen en internisten, was niet de veiligheid van deelnemende 'proefpersonen', maar een gebrek aan methodologisch verantwoorde klinische experimenten. In Nederland kwamen elk jaar medicijnen op de markt waarvan de effectiviteit niet voldoende bewezen was volgens de regels van de moderne klinische wetenschap, wat betekende dat scharen van patiënten behandeld werden met medicaties waarvan niet duidelijk was of ze de genezing daadwerkelijk bevorderden. Deze irrationaliteit was het echte ethische probleem en systematische ethische toetsing van klinische experimenten met mensen diende er dan ook vooral om voor dit probleem een oplossing te bieden. Ethische toetsingscommissies moesten daarom bestaan uit des- 
kundigen op het gebied van de klinische wetenschap (farmacologen, statistici en internisten), die tot taak hadden om de kwaliteit van klinisch onderzoek te controleren en te bevorderen en om zorgen weg te nemen bij artsen die uit ethisch conservatisme weigerden mee te werken aan gerandomiseerde klinische proeven. Op deze wijze zou systematische ethische toetsing klinisch onderzoek zowel verbeteren als intensiveren in Nederland. De Gezondheidsraad beval de overheid aan dit soort toetsing wettelijk verplicht te stellen, maar benadrukte ook dat haar rol beperkt diende worden tot het machtigen van deskundigen voor deze inspectietaak. Meer overheidsbemoeienis kon immers wetenschappelijke vooruitgang belemmeren en was daarom af te raden. Sociale controle op de geneeskunde bleef een taak van artsen, voor artsen.

Omdat de Nederlandse overheid begin jaren zeventig weinig heil zag in het verder reguleren van de klinische wetenschap werd het Gezondheidsraadrapport pas gepubliceerd in 1981. Hoofdstuk 3 legt uit dat tegen die tijd echter het culturele klimaat in Nederland met betrekking tot sociale controle op de geneeskunde en wetenschap was veranderd. Waar in de eerste decennia na de Tweede Wereldoorlog veel vertrouwen had bestaan in het zelfregulerend karakter van de medische professie, ontstond rond 1960 een gevoel van crisis onder Nederlandse artsen over de houdbaarheid van hun beroepsethiek. Ingrijpende technologische innovaties wierpen nieuwe vragen op omtrent leven en dood, de spectaculaire groei van het medisch bedrijf maakte dat artsen collega's steeds minder goed kenden, en veranderende maatschappelijke verhoudingen zorgden ervoor dat patiënten steeds meer eisen leken te stellen aan het medisch handelen. Deze zorgen maakten de medische ethiek in de jaren zestig tot een populair onderwerp van debat, zowel binnen als buiten de medische professie.

Deze ontwikkelingen hadden tot gevolg dat de Nederlandse overheid in 1970 vroeg aan de Gezondheidsraad om nieuwe medische ethiek te formuleren die paste bij 'het leven in de moderne samenleving'. De daartoe ingestelde Gezondheidsraadcommissie Medische Ethiek besloot uit te gaan van het patiëntrecht. In de toekomst zouden de rechten en plichten van patiënten en artsen het fundament worden van de medische ethiek. Hoofdstuk 3 betoogt dat deze keuze niet vanzelfsprekend was. In de 'crisis in de medische ethiek' van de jaren 1960 had een meer radicale sociale kritiek over de moderne samenleving en haar vervreemdende maatschappelijke structuren namelijk de boventoon gevoerd. De Gezondheidsraadcommissie Medische Ethiek werd echter gedomineerd door juristen die sterk inzetten op het patiëntrecht en door artsen die in een dergelijke benadering een verdedigingsmechanisme zagen tegen al te grote overheidsbemoeienis met het therapeutisch handelen. In de jaren zeventig werd het patientrecht steeds populairder in Nederland, wat in 1978 resulteerde in de instelling van een grote Commissie Rechten van de Patiënt bij de Centrale Raad voor de Volksgezondheid. De commissie bestond uit juristen, artsen, ambtenaren en vertegenwoordigers van patiëntenorganisaties. De bedoeling was dat zij tezamen recht zouden doen aan de idealen van de participatieve democratie: in de Nederlandse gezondheidszorg zouden verticale relaties van afhankelijkheid en ondergeschiktheid voortaan vervangen worden door horizontale relaties van consultatie en participatie.

Hoofstuk 4 maakt duidelijk hoe, in tegenstelling tot landen als de Verenigde Staten en Groot-Brittannië, onrust over twijfelachtige experimenten met mensen in Nederland geen rol van betekenis speelde in deze maatschappelijke omwenteling. Pas eind jaren zeventig ontstond vrij plotseling breed aandacht voor de ethische problematiek 
van proeven op mensen. Twee incidenten vormden de aanleiding voor deze aandacht: de aankondiging dat een Nederlandse criminoloog onderzoek wilde gaan doen naar de biologische oorzaken van criminaliteit en de ontdekking dat een huisarts al jaren twijfelachtige mensproeven deed in een verzorgingstehuis voor mensen met een verstandelijke beperking. In reactie op deze schandalen drong de Nederlandse overheid erop aan bij de Commissie Rechten van de Patiënt dat het ook een advies schreef over de regulering van proeven op mensen. Invloedrijke publieke commentatoren betoogden dat ethische toetsingscommissies in de toekomst hadden te bestaan uit 'medische buitenstaanders' die maatschappelijke controle uitoefenden op de medische wetenschap. Zulke externe controle was noodzakelijk omdat artsen en wetenschappers onmogelijk objectief het eigen handelen zouden kunnen beoordelen. De werkgroep die werd ingesteld om deze problematiek te bestuderen was het eens met deze zienswijze. Ze benadrukte in haar rapport uit 1982 dat ethische toetsing van medische wetenschap noodzakelijk was in een moderne samenleving om openheid en transparantie te kunnen garanderen. Het patiëntrecht moest bevorderd worden en leken moesten deelnemen aan ethische toetsingscommissies als vertegenwoordigers van de samenleving ter bevordering van 'horizontale relaties van participatie en consultatie' in de wetenschap. Experimenten deed men met mensen, niet op mensen.

Hoofdstuk 4 besluit met de opmerking dat een verschil bestond tussen de manier waarop de werkgroep zich voor de schermen hardmaakte voor het patiëntrecht en achter de schermen betoogde dat goede wetenschap in Nederland beschermd en bevorderd moest worden. Het patiëntrecht mocht de medische wetenschap niet wezenlijk beknotten en systematische ethische toetsing diende ook om het publiek vertrouwen in experimenten met mensen te herstellen. Bovendien zouden alleen leken die redelijk genoeg waren om te erkennen dat dit soort onderzoek belangrijk en noodzakelijk was, deel mogen nemen aan toetsingscommissies. Zittende deskundigen mochten daarom kiezen welke leken konden deelnemen als maatschappijvertegenwoordigers. Niettemin bestond begin jaren tachtig onder Nederlandse politici veel sympathie voor het ideaal van externe controle en het voorstel van de Commissie Rechten van de Patiënt verkreeg dan ook de voorkeur boven eerdere voorstellen voor meer interne controle van de Gezondheidsraad. In 1983 besloot de Nederlandse overheid om het voorstel van de Commissie Rechten van de Patiënt uit te voeren.

Hoofdstuk 5 legt uit hoe dit voorstel medio jaren tachtig onder vuur kwam te liggen ten gevolge van de opkomst van een neoliberaal klimaat dat huiverig stond tegenover meer overheidsregulatie, wat leidde tot veel vertraging in de realisatie van een Nederlands wetsvoorstel voor medische experimenten met mensen. Onder druk van internationale tijdschriften en onderzoekfinanciers kwamen in deze periode toch veel ethische toetsingscommissies tot stand in Nederland. Er bestond echter weinig duidelijkheid over wie precies deelnamen in dit soort commissies en of beoordelaars in staat en bereid waren serieuze ethische oordelen te vellen. De samenstelling en het functioneren van ethische toetsingscommissies werden hierdoor eind jaren tachtig onderwerp van zorg in Nederland. Gebrek aan uniformiteit en consistentie zou het belangrijkste probleem zijn in het systematisch ethisch toetsen van experimenten met mensen en alleen standaardisering van deze praktijk zou dit probleem op kunnen lossen. Maatschappelijke controle door leken werd steeds vaker van de hand gewezen ten gunste van deskundige controle door goed getrainde professionals. 
Pas in 1997 besprak de Tweede Kamer voor het eerst een wetsvoorstel ter regulering van medisch-wetenschappelijk onderzoek met mensen in Nederland. Systematische ethische toetsing door daartoe ingestelde toetsingscommissies vormde de ruggengraat van dit voorstel, maar de zittende overheid-het tweede kabinet Paars-had besloten alleen deskundigen te laten deelnemen in commissies. Met name de confessionele partijen in het parlement (die geen van alle deelnamen aan de regering) uitten grote zorgen over het feit dat leken buiten de ethische toetsing van experimenten met mensen werden gehouden. Wetenschappers, zo betoogden zij, hadden vaker dan gemiddeld liberale opvattingen over de toelaatbaarheid van experimenten, ook die waar maatschappelijk weinig consensus over bestond, zoals onderzoek met foetussen, embryo's of wilsonbekwame mensen. De participatie van leken was nodig om te verzekeren dat ook alternatieve opvattingen uit de pluriforme Nederlandse samenleving gehoor zouden vinden in de toetsingscommissies. De Minister van Volksgezondheid Els Borst zag weinig heil in lekendeelname. Als voormalig medisch directeur en vicevoorzitter van de Gezondheidsraad was ze van mening dat alleen deskundige toetsing zou leiden tot uniforme en onafhankelijke ethische oordelen over de toelaatbaarheid van wetenschappelijk onderzoek. Ze merkte echter op in parlementaire debatten dat het wetsvoorstel voorzag in de deelname van ethici in de verschillende toetsingscommissies, wier expertise bestond uit het objectief inzichtelijk maken van de meningen en argumenten die konden bestaan in een pluriforme samenleving over specifieke ethische dilemma's. Deze professionals, zo betoogde Borst, vormden daarmee het ideale scharnierpunt tussen deskundige en democratische toetsing.

Hoofdstuk 6 onderwerpt deze uitspraken van de Minister van Volksgezondheid aan nadere inspectie. De professionele en politieke functie van ethici was niet onomstreden in Nederland aan het eind van de twintigste eeuw. De discipline was pas ontstaan in de jaren zestig en zeventig en discussie was blijven bestaan over wat nu precies de identiteit en rol was van een ethicus, met name onder leden van de beroepsgroep zelf. Critici betoogden dat deskundigheid in het vellen van ethische oordelen epistemologisch onmogelijk was en dat ethici om die reden geen professionele rol konden vervullen in het uitdenken en uitvoeren van beleid ter oplossing van ethisch gevoelige kwesties. Voorstanders betoogden dat ethici wel bijzondere deskundigheid hadden op dit gebied en met zorgvuldige analyses van ethische dilemma's juist in staat waren overheidsbeleid rationeler en beter te maken. De systematische toetsing van wetenschappelijk onderzoek met mensen speelde een belangrijke rol in deze methodestrijd. De participatie van ethici in toetsingscommissies was voor tegenstanders een typisch voorbeeld van de rol die ethici niet moesten vervullen: ze hadden professioneel niks toe te voegen aan het toepassen van regels op specifieke onderzoeksvoorstellen, maar verleenden met hun participatie wel morele legitimiteit aan de overheid en medische wetenschap. Voor voorstanders was de manier waarop toetsingscommissies functioneerden een mooi voorbeeld van hoe systematische ethische analyses onder begeleiding van ethisch deskundigen een praktijk moreel beter konden maken.

De opkomst van ethische toetsingscommissies in de tweede helft van de twintigste eeuw wordt vaak toegeschreven aan de gelijktijdige opkomst van de ethiek discipline in deze periode. Deze 'buitenstaanders' zouden politici en een breder maatschappelijk publiek ervan overtuigd hebben dat de medische wetenschap onderworpen diende te worden aan regels en procedures die voortvloeiden uit deze nieuwe discipline. Dit 
proefschrift toont echter aan dat ethici in Nederland lange tijd een marginale rol vervulden in de realisatie en promotie van systematische ethische toetsing van medischwetenschappelijk onderzoek met mensen. Pas eind jaren tachtig kregen zij een meer centrale rol in deze praktijk. Hoofdstuk 6 betoogt dat het veranderende politieke klimaat in Nederland aan het einde van de twintigste eeuw hier een belangrijke functie in vervulde. Politici merkten in deze periode dat burgers steeds vaker van de staat verlangden dat zij ethische problemen oploste. Morele vraagstukken werden niet langer toevertrouwd aan geestelijk leiders, professionele elites of andere "morele deskundigen"; de overheid werd verondersteld formele regels en procedures te bepalen. Politici constateerden echter ook dat het Nederlandse parlementaire bestel geen robuuste traditie kende voor democratische afhandeling van zulke vraagstukken. Ten tijde van de verzuiling was een cultuur van besluitvorming ontwikkeld die belang had bij beperking van de politieke agenda en die liever wegbleef bij sterk normatief geladen kwesties. Ook na de ontzuiling was deze cultuur van depolitisering dominant gebleven. Hoofdstuk 6 laat zien dat bewindslieden als Els Borst aan het einde van de twintigste eeuw inderdaad liever een beroep deden op deskundigen om overheidsbeleid voor ethisch gevoelige kwesties op te stellen en uit te voeren dan dat zij dit overlieten aan leken of maatschappijvertegenwoordigers. Dit zorgde ervoor dat met name ethici die zich comfortabel voelden in een dergelijke politieke rol in de jaren negentig konden rekenen op overheidssubsidies en beleidsinvloed. Zo had het verplicht stellen van systematische ethische toetsing van medisch-wetenschappelijk onderzoek eerder invloed op de ethiek discipline in Nederland dan andersom.

Gezamenlijk laten de hoofdstukken in dit proefschrift zien dat de opkomst van systematische ethische toetsing van medisch-wetenschappelijk onderzoek in Nederland tot doel had om twee transformaties in de tweede helft van de twintigste eeuw te realiseren en in goede banen te leiden: (1) de veranderende rol van de wetenschap in de geneeskunde en (2) de veranderende positie van de geneeskunde en medische wetenschap in de Nederlandse maatschappij. Het idee van systematische ethische toetsing kwam op in de jaren vijftig en zestig om een bepaalde epistemologische traditie in de medische wetenschap te beschermen en bevorderen in Nederland. In de jaren zeventig werden medisch-ethische toetsingscommissies steeds vaker voorgesteld als organen die maatschappelijke controle op de medische wetenschap dienden te realiseren. Uiteindelijk besloot de Nederlandse overheid dat ethische toetsingscommissies vooral dienden te fungeren als administratieve organen die de toelaatbaarheid van wetenschappelijk onderzoek met mensen hadden te toetsen aan door de overheid opgestelde rechtsregels en procedures. Deze transitie ging samen met een veranderend begrip van objectiviteit en morele autoriteit in de Nederlandse medische ethiek. Waar tot de jaren zestig uitsluitend artsen in staat werden geacht objectieve morele oordelen te kunnen vellen over de toelaatbaarheid van medische proeven op mensen, en in de jaren zeventig betoogd werd dat juist 'medische buitenstaanders' objectiever konden oordelen over de toelaatbaarheid van wetenschappelijke studies, ging in de jaren tachtig en negentig het idee heersen dat objectieve ethische oordelen slechts door uniforme procedures en getrainde bureaucraten bereikt konden worden.

Ondanks de toenemende nadruk op de maatschappelijke controle van wetenschap in de tweede helft van de twintigste eeuw bleef de ethische toetsing van medischwetenschappelijk onderzoek in Nederland dus voornamelijk een zaak van deskundi- 
gen, al veranderende het type expert dat in staat werd geacht objectieve ethische oordelen te vellen wel. Deze politieke functie van deskundigen stond de Nederlandse overheid toe te beweren dat dat ze publieke controle uitoefende op de medische wetenschap zonder dat ze directe inmenging met ethisch gevoelige kwesties op dit terrein hoefde toe te geven; een vorm van depolitisering die retorisch zowel paste bij het ideaal van een pluralistische samenleving als het ideaal van vrije wetenschapsbeoefening in een open maatschappij. Dit proefschrift toont echter aan dat de keuzes van de Nederlandse overheid in de regulering van medisch-wetenschappelijk onderzoek met mensen wel degelijk specifieke normatieve praktijken in de geneeskunde en medische wetenschap bevorderd hebben. De wijze waarop systematische ethische toetsing van medische proeven op mensen uiteindelijk vorm heeft gekregen in Nederland, maakt dat deze praktijk tegenwoordig meer dan ooit geaccepteerd wordt als een integraal onderdeel van de geneeskunde en dat deskundigen met specifieke epistemologische ideeën over hoe de effectiviteit van geneeskundige interventies bewezen dient te worden meer macht hebben om deze op te leggen aan de beroepsgroep en Nederlandse samenleving. Ook bevordert dit systeem bepaalde vormen van ethiekbeoefening aan de Nederlandse universiteiten en onderzoekscentra en houdt ze meer 'radicale' maatschappelijke kritiek op de toelaatbaarheid van medisch-wetenschappelijk onderzoek met mensen op deze wijze vaak effectief buiten de deur.

Met de bovenstaande conclusies draagt dit proefschrift bij aan een aantal recente studies die vraagtekens stellen bij het lange tijd dominante historische narratief dat research ethics committees opkwamen in de tweede helft van de twintigste eeuw om de medische wetenschap in te dammen en meer democratische controle uit te oefenen op het handelen van artsen en wetenschappers. Daarnaast biedt dit proefschrift nieuwe inzichten in de radicaal veranderende wijzen waarop artsen en wetenschappers in de tweede helft van de twintigste eeuw verantwoording hebben moeten afleggen voor hun professionele handelen; welke veranderende culturele opvattingen over de juiste maatschappelijke positie van de geneeskunde en medische wetenschap hieraan ten grondslag hebben gelegen; wat voor invloed dit heeft gehad op de organisatie en praktijk van het medisch-wetenschappelijk bedrijf; en tot slot, wat de regulatieve rol van de (medische) ethiek is geweest in deze ontwikkelingen. 



\section{- Valorisation Addendum •}

This appendix considers the "knowledge valorisation" of this PhD-thesis. In 2015, I had an interesting experience as a participant in a panel of the History of Science Society organized by the Joint Caucus on Socially Engaged Philosophers and Historians of Science in San Francisco. The other panellists came from the United States, Australia, Mexico, and Taiwan. I started my contribution by talking about the emphasis in the Netherlands on 'knowledge valorisation' and how this informed my work. Already after a minute or so, however, an audience member raised her hand to ask if I could explain what I precisely meant with this strange word "valorisation". The term, it turns out, was hardly familiar to American academics. Indeed, judging from online word searches, 'valorisation' still seems to be a term that is used predominantly in the Netherlands to denote "the process of creating value from knowledge suitable and/or available for social and/or economic use and by making knowledge suitable for translation into competitive products, services, processes and new commercial activities" (the definition of the Dutch National Valorisation Committee in 2011).

As a historian of science, it is worthwhile to point out that this Dutch emphasis on knowledge valorisation (and therefore also this valorisation addendum) rests upon a specific understanding of the social role and position of scholarship that is historically neither self-evident nor uncontested. For while scholars in most historical periods have either claimed or been asked to justify why their work is important, the recent Dutch emphasis on societal use comes forth out of specific government policies that were designed in the early twenty-first century to optimize 'the return on investment' of public research funds. After all, although it is frequently emphasized by politicians and policymakers that valorisation should be understood as "making one's research relevant to society" (a statement so general that it is hard to disagree with), the economic origins of the term shine through in the definition provided by the Dutch National Valorisation Committee, i.e., scholars in receipt of public funds and resources should specify the yields their research will deliver. And the more specific the product can be defined, the better the valorisation has succeeded.

The other panellists asked me in 2015 if it was not sufficient to explain that the funds invested in my PhD-trajectory served to develop my academic skills, which I would need later in my career to teach and produce further knowledge. I have talked about this argument with numerous Dutch academics since. Although most are sympathetic towards it, almost all doubt whether it will be accepted in a valorisation addendum as the sole reason for granting a PhD-scholarship. Of course, it is important for any scholar (PhD-scholar or not) to consider the relevance of their research. Yet, I do feel it is equally important to point out that the definition of valorisation used by the National Valorisation Committee and the requirement to let PhD-candidates defend their work in such terms are indicative of a worrisome trend in the Netherlands in which $\mathrm{PhD}$-trajectories are increasingly commodified as ready-to-wear projects that may yield a predefined set of deliverables ('high impact publications', 'large data sets', 'competitive products', 'commercial activities'), rather than that they are understood as modest stepping stones towards durable academic careers. 
Having said this, this PhD-thesis has argued that careful historical research of the reasons behind the emergence of research ethics committees is needed because history fulfils an important role in the present-day governance of human experimentation. The past is used to offer up moral signposts that are to nudge research and reviewers in certain directions and to stay clear of others; it is used to justify the existence of strict oversight regimes for human subject research; and it is brought to bear to frame the political function that research ethics today fulfil in the public oversight of human research studies. Hence, careful historical research is an important check on the current system of research ethics governance, to ensure that certain historical events and their political implications are not misunderstood-or worse, misused by calculating political actors to push through the policy measures they desire. For this reason, my research results are of interest to all those concerned with the contemporary governance of human subjects research, and particularly to those in policy.

In addition, this $\mathrm{PhD}$-thesis addresses practitioners of health care and the biomedical sciences. Especially among members of these groups, it has become popular to complain that the practice of ethics by committee was forced on them in the second half of the twentieth century by 'zealous medical outsiders' who brought a bureaucracy of ethics into existence that is itself unethical. Yet, this PhD-thesis shows that, at least in the Netherlands, the practice was invented by quintessential medical insiders to force the therapeutic progress they desired on Dutch health care. Hence, that ethics committees strictly had to peruse research designs was not an unintended consequence of design by committee in a bureaucracy with red tape; it was a built-in mechanism to enforce a specific epistemic perspective on Dutch clinical research and practice. This forgotten function of the practice of ethics by committee is of interest to the larger science community as well. Although regulative institutions like research ethics committees are not often subject to elaborate scrutiny by science scholars, they have become obligatory passage points in the present-day infrastructure of science: locus of control that scientists first have to pass through before they can conduct research with human beings. Careful scrutiny of such institutions is needed to understand better how they have come to distribute prestige and power in international science systems in the late twentieth century, and have thus become crucial apparatus for deciding what and who counts as authoritative in the sciences today.

Finally, this PhD-thesis contributes to both public and political debates about how democratic societies wish to handle ethically contentious issues in science, technology, and health. It does so in two ways. First, by exploring the changing ways in which the governance of medical experiments with human beings has been dealt with in the Netherlands in the second half of the twentieth century, its chapters offer up multiple alternative vistas for governing human experimentation that may function as touchstones and points of reflection for the contemporary governance of ethically contentious issues in science, technology, and health. Second, this PhD-thesis recovers what went into the configuration of ethics by committee as it did in the Netherlands, and makes explicit which cultural conceptions of the role of medicine and medical science in society underlie this governance practice. In doing so, it shows that the Dutch government has typically sought to handle ethically contentious issues in science, technology, and health in the late twentieth century with an expertocratic approach both to the definition and to the resolution of public problems in these fields. 
Professional ethicists, this $\mathrm{PhD}$-thesis argues, came to fulfil a specific political function for the Dutch government in the late twentieth century in its quest to depoliticise ethically contentious issues in science, technology, and health. Particularly the latter chapters of this PhD-thesis may therefore be used by ethics practitioners as well in reflection of their professional and political roles in certain forms of governance in favour of others. In the Netherlands as well as in other countries, such reflection does take place from time to time, to which this $\mathrm{PhD}$-thesis contributes some much needed historical reflection on the professional and political functioning of ethicists that goes beyond the idea that the discipline emerged in the second half of the twentieth century purely to hold physicians and (biomedical) researchers to account.

These findings have been disseminated at academic conferences, including talks at conferences of the European Association for the History of Medicine and Health and the Society for the Social History of Medicine. In addition, I have given multiple lectures on the subject for large student audiences at both humanities and medical faculties, and I have given multiple talks at associations for medical professionals, including a lecture for an audience of over 200 physicians at the Nederlandse Internistendagen (Dutch Days for Internists). In 2016, I spoke at a public event in the Rode Hoed in Amsterdam on the topic of 'victims of medicine', and in 2018, my PhD-thesis will form the starting point of a two-day workshop on the governance of medicine and science in the late modern period that will include both international experts on this topic and relevant Dutch stakeholders, including medical practitioners, policymakers, and professional ethicists. My PhD-thesis has resulted in several publications as well, including peer-reviewed articles in Studium, the journal of the Belgian-Dutch Society for the History of Science and Universities, and the Dutch Journal of Medicine, which is delivered weekly to the majority of Dutch physicians in the Netherlands. In the past years, I have also written multiple blog posts on the topic of my PhD-thesis for Shells \& Pebbles, a popular online forum for the history of the sciences.

Finally, in 2016, I initiated and contributed to the first ever Isis Viewpoint on The History Manifesto and its implications for the history of science. In 2014, this highly influential manifest of authors Jo Guldi and David Armitage warned that history as a discipline was marginalising itself in politics and society (or, to invoke a Dutch word, could hardly boost any 'knowledge valorisation' anymore). The Editor of Isis H. Floris Cohen and I invited thirteen historians of science from all over the world to consider what-if any-implications The History Manifesto should have for professional historians of science, and asked Guldi and Armitage to comment upon their thoughts. In 2018, it remains the most downloaded collection of papers that has been published in Isis. While this Viewpoint is not directly a product of my PhD-grant, my development as an academic during my $\mathrm{PhD}$-trajectory greatly influenced it. It is perhaps the piece of 'knowledge valorisation' that I am most proud of. For although I am critical of the idea that academics find their worth in "making knowledge suitable for translation into competitive products, services, processes and new commercial activities", I do believe it is highly important for academics to critically reflect on their professional roles and responsibilities. If this counts as a form of 'knowledge valorisation' as well, my work in the past years hopefully may be found as "relevant to society". 



\section{- Curriculum Vitae •}

Noortje Jacobs was born in Gemert, the Netherlands, on 20 February 1987 to Riek van Eerdt and Frits Jacobs. After graduating from secondary school in 2005, she obtained a liberal arts Bachelor's Degree summa cum laude at University College Maastricht in 2008. As part of her education, she spent a semester abroad at the University of California, Berkeley. At UCM, she won the yearly academic debate of 2007 and was invited back to give the 2009 Alumni Speech at the College's graduation ceremony. In 2008, she was awarded the Best Thesis Award of the university's Humanities Faculty. In 2012, Noortje obtained her Research Master's Degree cum laude from the Descartes Centre for the History and Philosophy of the Sciences and the Humanities of Utrecht University, for which she spent a semester abroad at the University of Oxford, specializing in the history of modern science, medicine, and medical ethics. Her RMA-thesis on the Dutch reception of the 1947 Nuremberg Code was awarded the 2012 Pieter van Foreest science award for academic talent in the medical humanities and the 2013 Descartes-Huygens award for theses written in Belgium and the Netherlands in the field of the history of the sciences and universities.

In 2012, Noortje obtained a PhD-grant in the Sustainable Humanities Programme from the Netherlands Organisation for Scientific Research. She wrote her PhD-thesis on the changing governance of human experimentation in the Netherlands after World War II, which she defends on June 20, 2018 at Maastricht University. During her PhD-trajectory, she was a visiting scholar at Utrecht University and Manchester University, and an editorial assistant at Isis Journal, published by The University of Chicago Press. In 2013, she was awarded the Historia Medicinae award for the best presentation of a PhD-candidate at the biennial conference of the European Association for the History of Medicine and Health in Lisbon.

As of August 2017, Noortje is employed as a teacher and a researcher by the History Department of the Erasmus Medical Centre in Rotterdam. She is a board member of the European Association of the History of Medicine and Health and of Gewina, the Belgian-Dutch Society for the History of Science and Universities. Her current work concerns the influence of research funding on knowledge production in the late modern period and the use of academic ethics in public policy. 
